\title{
Sean $\mathfrak{S} \mathfrak{a} \mathfrak{H} \mathfrak{l}^{\prime} \mathfrak{b}$
}

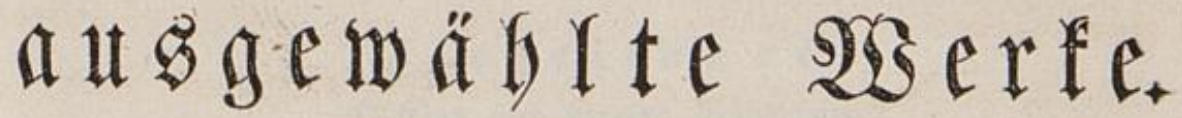

צં

\section{Berlin,}

Dru ư unb જerlag von (5). Reimer.

1848. 


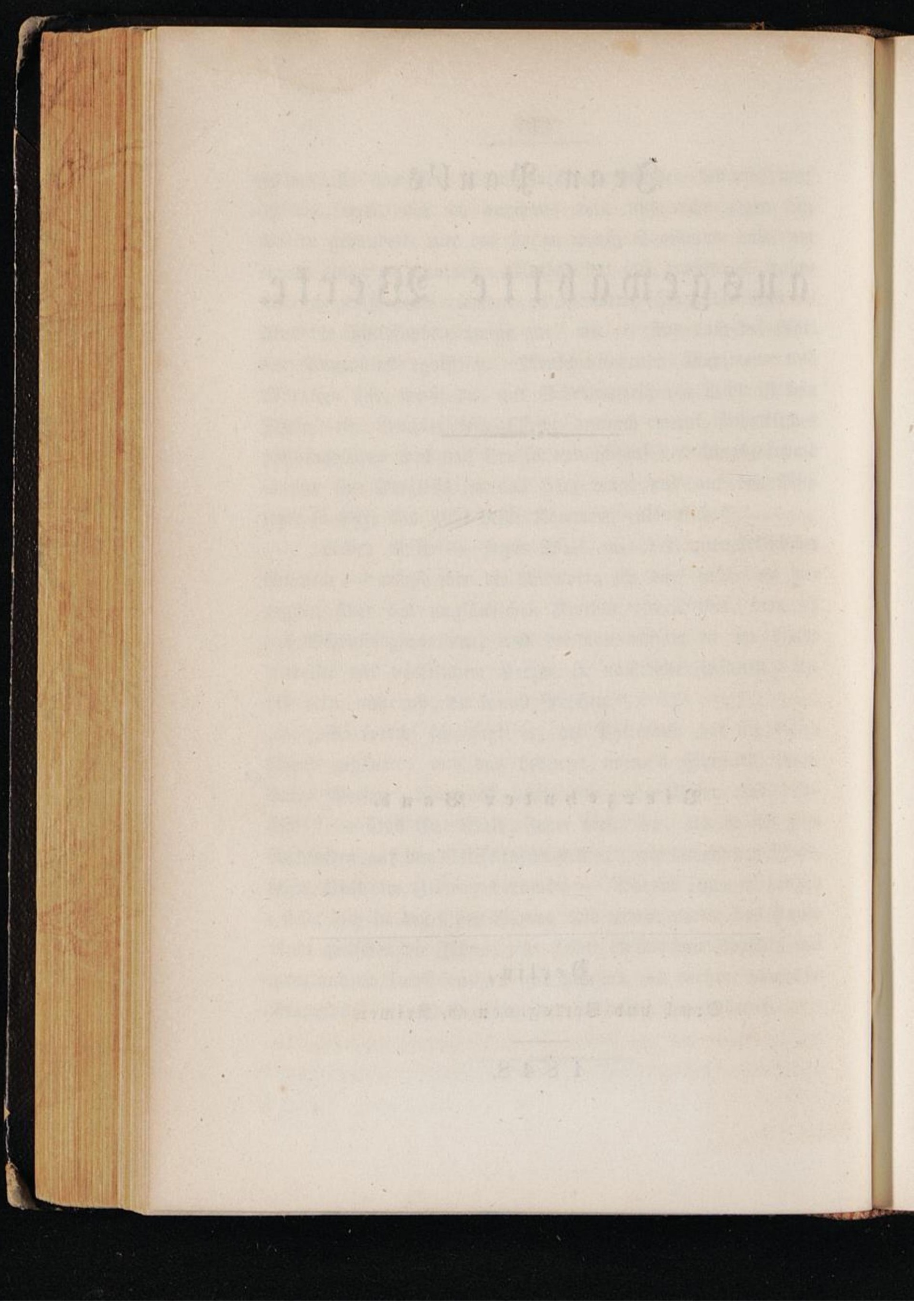




\title{
Tinhalt Des vierzehnten Şandes.
}

\author{
$\mathfrak{F} \mathfrak{l} \mathfrak{e} \mathfrak{g} \mathfrak{e} \mathfrak{l} \mathfrak{j} \mathfrak{a} \mathfrak{h} \mathfrak{r} \mathfrak{e}$.
}

Drittes und viertes Bänbd)en.

Drittes Bändden.

Nro. 33. Stralglimmer. Die Brüber - WBina . Se 3

Nro. 34. Infruftirte Rletten. Ropirfunte . . . . 12

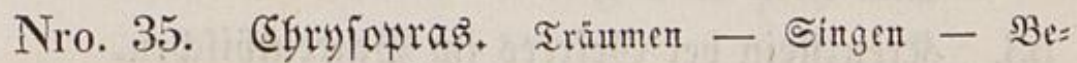
ten - Träuneก . . . . . . . . 15

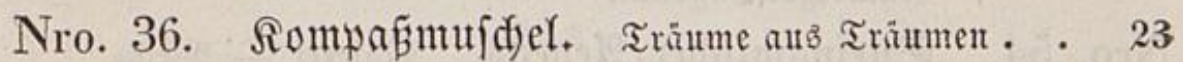

Nro. 37. Eine auserlejene Siabintetsorüje. Neucs Teftament. . . . . . . . . . 31

Nro. 38. Marienglab. Raphaela . . . . . . 38

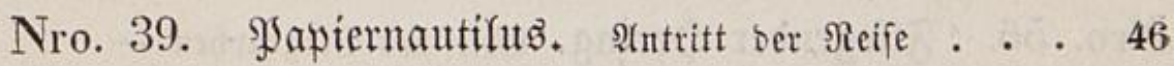

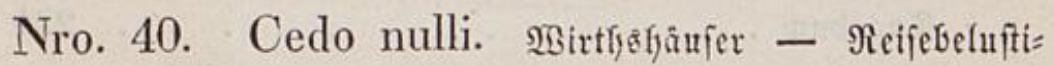
gungen . . . . . . . . . . . 52

Nro. 41. Tröbelifunecfe. Der Bettel=ভtab . . . . 64

Nro. 42. Sdilleripaty. Daв \&eben . . . . . . 68

Nro. 43. Sgolirter Bernfteinftengel. Sdianfwielerber Masfenterr - ber Ëiertanz - bie Ëin= faulferin . . . . . . . . . . . 76

Nro. 44. Rakzenguld aus Sadjen. 2(benteuer . . 81

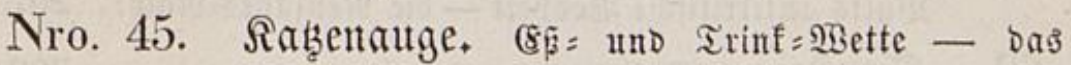
Măbdyen . . . . . . . . . . . . . 89

Nro. 46. EDbler (5rrunat. Der frifde Tag . . . 97

Nro. 47. Titantum. Sarthaụe ber \$gantafie - Bon= mots . . . . . . . . . . . . . 106 
Tro. 48. Gtralfies. Seite

Nro. 48. Stralftes. Die Ropenhöfer গacht . . . . 115

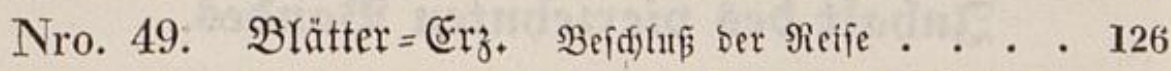

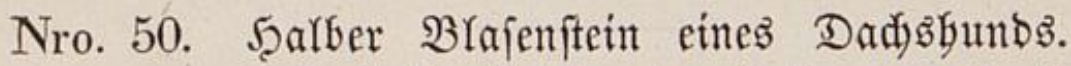

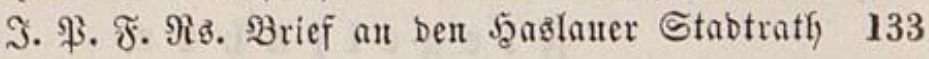

\section{Biertes $\mathfrak{B}$ änd (d)}

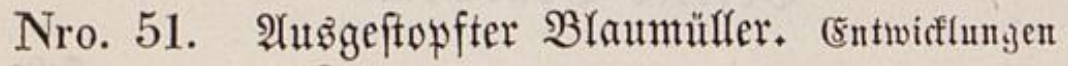
ber Reife und des Notariatz . . . . . . 149

Nro. 52. Auggeftopfter Friegenfduäpper. Bornery= mes sebent............ . . 163

Nro. 53. Rreuzftein bet (5iefrees im $\mathfrak{B}$ atreutbifden. (5läubiger=\$agoftür . . . . . . . . 178

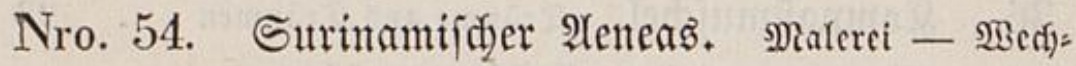
felbrief - Jehbebrief . . . . . . . . 184

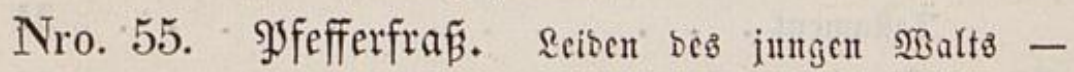
Einquartirung . . . . . . . . . . . 209

Nro. 56. Fliegender \$̧ering. Brief des Biographen Tagebu(f) . . . . . . . . . . . . . 224 Rad)trag zu Nro. 56. Der fliegende Spering 231

Nro. 57. Regenpfeifer. Doppel $=$ \&eben . . . . 235

Nro. 5S. . Siftfuttel. Errinterungen . . . . . 250

Nro. 59. Rotenfdnedfe. Rorreftur - NBina . . 268

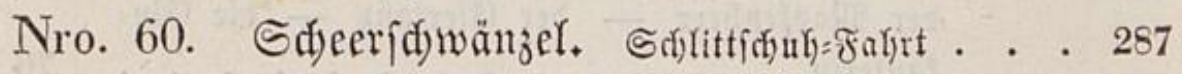

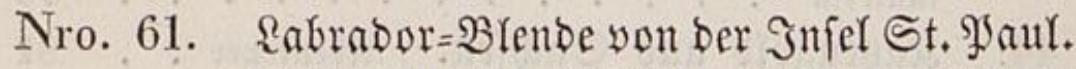

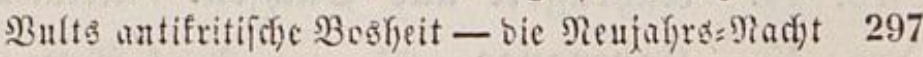

Nro. 62. Sauftein. Einlcitungen . . . . . . 309

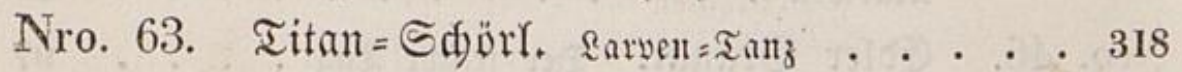

Nro. 64. Mondmild yom Sillatusberg. Briẹ Radtwandler - Iraum . . . . . . . . 331 
$\mathscr{J} \mathfrak{l} \mathfrak{e} \mathfrak{g} \mathfrak{e} \mathfrak{l} \mathfrak{j} \mathfrak{a} \mathfrak{h} \mathfrak{r} \mathfrak{e}$

$$
\text { E } i \text { the } \mathfrak{B} i \mathfrak{o g} \mathfrak{x} \mathfrak{p} \mathfrak{b} i_{e}
$$

bon

$\mathfrak{S} \mathfrak{e} \mathfrak{a} \mathfrak{n} \quad \mathfrak{P} \mathfrak{a} \mathfrak{u} \mathfrak{l}$

Drittes $\mathfrak{B}$ ändden. 


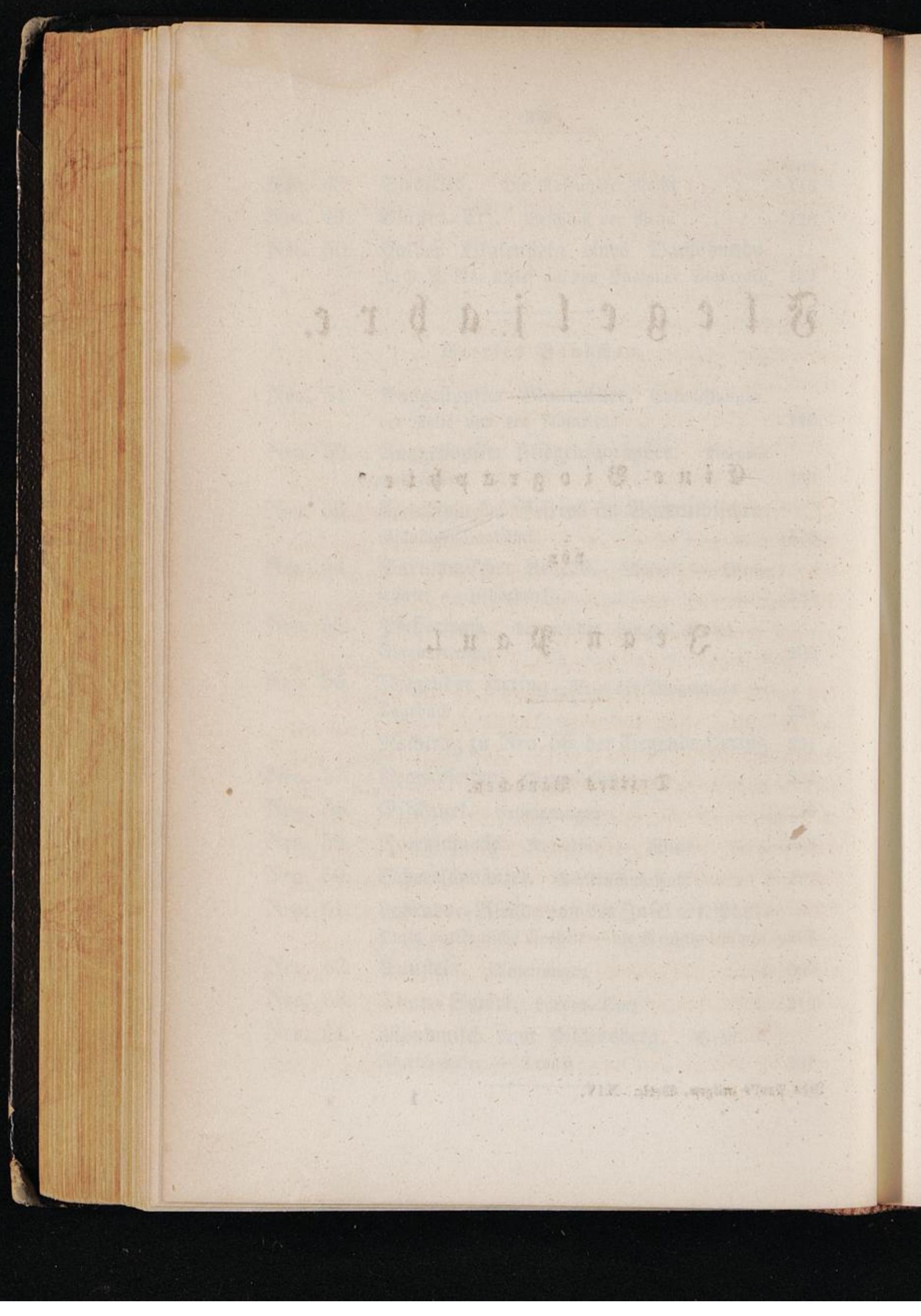


No. 33. $\subseteq \mathfrak{S} \mathfrak{x} \mathfrak{a} \mathfrak{l} \mathfrak{g} \mathfrak{l} \mathfrak{i} \mathfrak{m} \mathfrak{m} \mathfrak{e} \mathfrak{r}$.

D i e $B$ r ü b e - in a.

Selige, beilige rage, weld)e auf die Berjöhnunggftunde der Menjefen folgen! Die Riebe ift wieder blöbe und jungfräu= ridj, Der (5ieliebte nelt und verflärt, Das serz feiert peinent Mai und die Auferfíndenen vom Sdyladytfelde begreifen Den vorigen verge

Sdyladyten beitern Den bezognen 5̧immel auf; beide Brü=

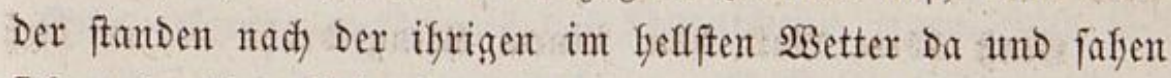
fitd) und afleg fdön beleudytet. Waalt, Der nidyts war alg Rieben und (sieben, wuste jebst gar nidht, wie er beibes nody zärter, nod) wärmer gegent feinen Bruber jern fönte; Denn

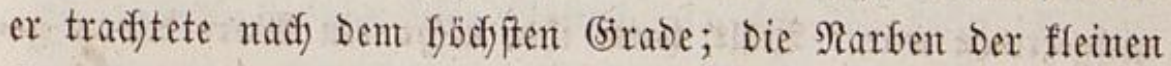
(B)emif̄engbifle Grannten ifn nod) ein wentig und bie Thränen Des jonft Dürren $\Re u l t s$ fratt' er in jeiner Geele aufgebobent. Bult ftand felber als ein Menfidy mit neuen Melodien aus Dent franon Der Rtebe Da. Db er Dieje gleidy mefr Durdy Tha=

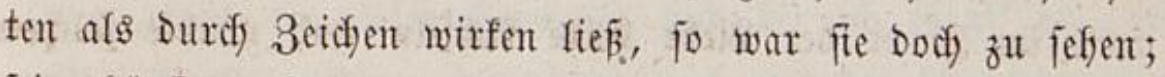

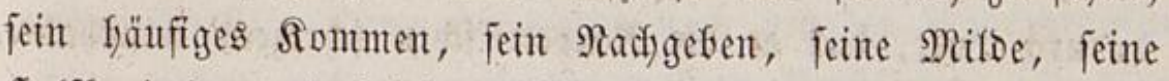

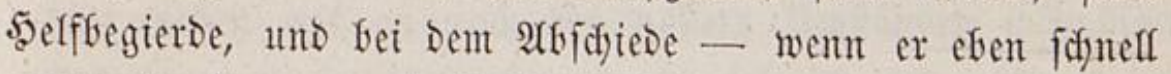
genug bie Treppe und Unftdotbarfeit ermijdjen fonnte - oft 


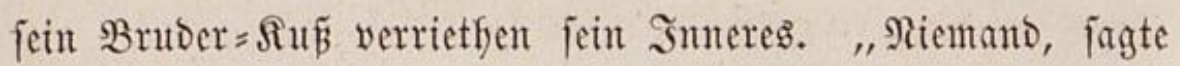
einft $\mathfrak{B a l t}$ zu ifm, famn rüfrender ausjefen als bu, werut Du eben bie Milbe in Deine Feueraugen fringft; fo famen mir immer bie Sparter vor, went fie mit iffen fröten auf

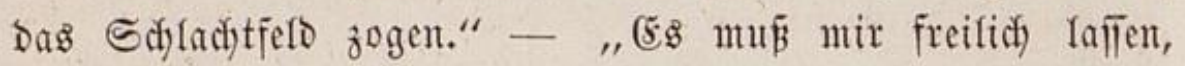
fagte er, als went ein Seefund Mama jagt*), ja idf mödfte es faft einen reifen pianen Sturmwind nennen. Âtber ernift=

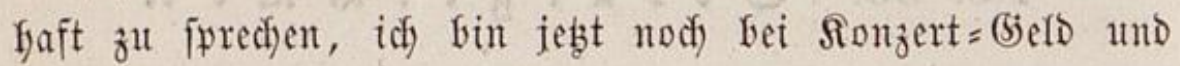

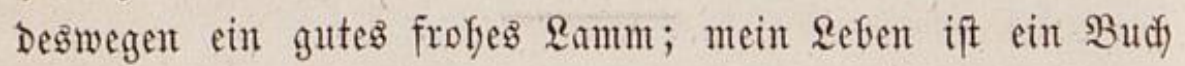
voll gejdlagnen (5oldes, bie blätter fint fo weidy und fo bes weglich), freifich) (5old = Blättçyen audd), mein Sinto!"

2Balt nafym joldje Reben gar nidyt übel. Soweit indé̄ nudi) Bult Das Rieben trieb - Da er fich für Den nädyjten und fachenden. Thron = (Erbent Des abgegangenen freunt $=$ (5ra= fens anjefen fonnte - jo merfte er Dod), Daj er Darin jei=

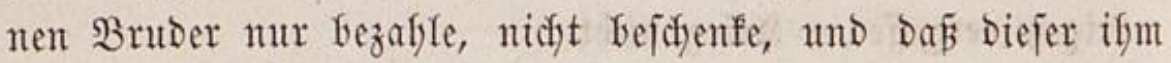
ftets um einen warmen $\mathfrak{I} a g$ yoraus war.

Einft hörte $\mathfrak{B u l t}$ won feinem filingeldraft - er fię eine ganze Mäbdyen = \$enfion fo - bie ganze lyeftige Sdyub= rede wieder, womit ber fanfte $2_{3}$ alt gerabe in Der Rebes= Sauje für ifn gegen feine $\mathfrak{A n t i p a t g e t i f e r ~ a n ~ R e u p e t e r s ~}$ Iafel

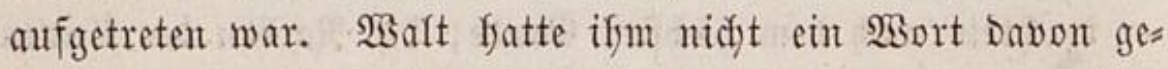
fagt - wiewol aus Riebe nidft blos gegen Den Bruder, fons Dern aud gegen afle $\mathfrak{B}_{\text {elt, }}$ fo wie er aus Doppelter Riebe Das Rabelide Teftament, Das Den Brutber eit wenig beleibigen formte, zut zeigen verweigerte. Bult brülfte ifm beint Ein=

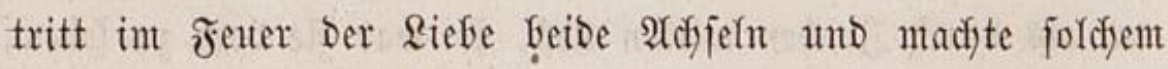

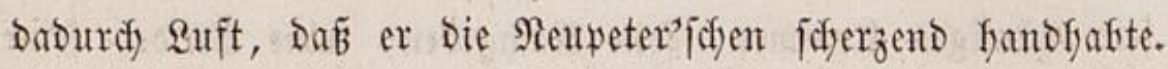

*) Madf Bedfftein Iernt er \$3orte \$apa 26. murmeln 
Aber ex traf bie falfice 3eit, wo 2 Balt an Sowwelpowwer

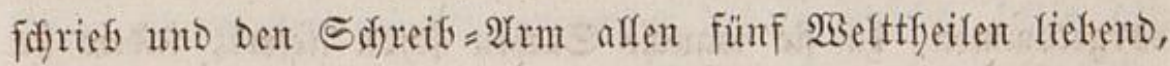
füfrend bot uno wo er fo fefre an Den verlonten Sirotfiar Dachte, weil ex eben im Buch freubenfefte fintenter und ge= funoner Seelen beging. Mit eigner welymütfiger Jrente fofrieb er jebt Daran unter Dem Betrautern Des abgeftorbenen Freundes, jo wie jonft mit Sdjmerzen unter Dem Nadjiagen nad) ifym; unt wunderte fid über Dent Unterfodied.

Der fojone Begeifterungs = Mittag bei Reupeter, auf wel= dfen ifn Buft Durd) feinen Danf zurücffüfrte, ftellte ifm Den (5rafen zu nabe wieder an bie Bruft; er befamnte es Dem Brutber ganz offen, wie ifm Der ferne mit feinem auggeleer $=$ ten Dajeyn und mit Der verlonten $2 B$ ina immer in Dem Ropfe liege und jo fojwer auf ber Bruft - wie er ifje einjam in

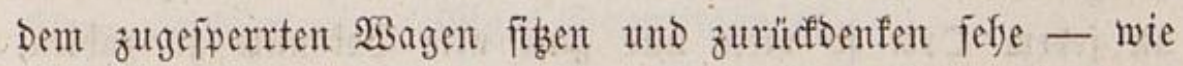
if) ein foldyer aus feittem şinmel in einen Räfig getriebente ADler erbarme und wie Darum feine Marter bitterer auf Der Eroe gefunden werde, als Das Bewustiern, einem edlen (Seift irgent eine zugefülyrt zu baben. ,D $\mathbb{B}$ ult, tröfte mich nur

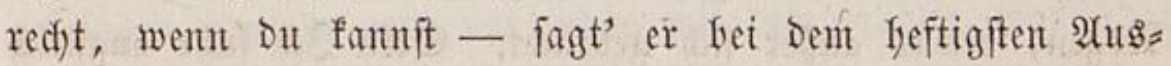

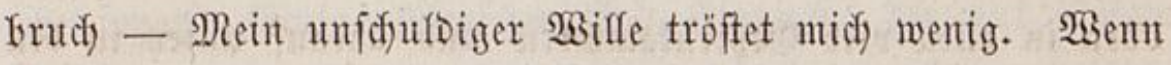
Du zufällig, ofne böfe âtgfidyt, ia in Der Geften viefmefyr, Durdy einen Der 50 ölle entflognen శutfen ein Rranfenfyaus, ober ein unjautoiges Sdyweizeroorf, ober ein 5aus voll (bies fangner angezüntoet fjätteft, uno du jälefi bie Flammen uno Darauf Die (jerippe: adf) Bott, wer hälfe Dir?"

"Mir Die falte Bermunft und Dir id) (jagt' er, aber ofne (Srolf). Denn idf werbe midf bei Der Mäbdyentenfion bart neben mir an nad) Den näfern Umitänden erfundigen.

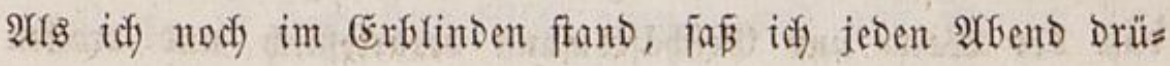




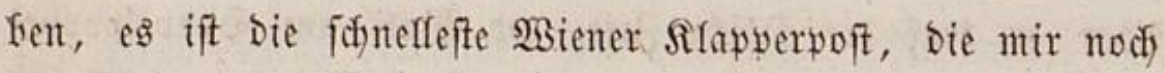
vorgefomment, Da fie manthe Sadjen fidjon liefert, indem fie nod) gefdehen. - Der (5raf wiro nidjt wie Du Durd) Bufälle

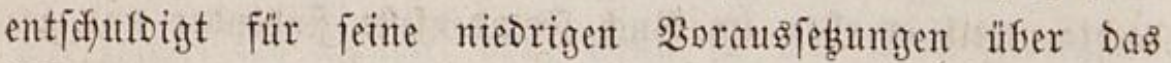
Sejen und Hebergeben Des Briefs; er madft' es ganz nadf Art Der (5ropen uno Der gaffijojen Iragifer, Die, um etwas zu erflären, Yieber bie größte Sinnde als ene fleine annef)men,

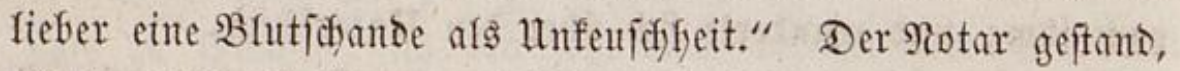
Rlotfars Berfündigung erleidftere Die Raft Der jeinigen; blieb aber bet feinem (jefüffl. In Der (5efellfod)aft fann man einent Memict)en leidfter Gerabfeben als fintauf; bee 2 Balt umgefefrt. Bult ging und veriprady bald wieber zu fomment.

Eines গachmittags fünfte Flitte, Deflen Tanzaal Die ganze Staot war, in $\mathfrak{W a l t s}$ Stübdjen. (Fr war gewofnt, an jebem Orte fo viele uno gute alte Befannte zu zählen, als Einwohner barin waren; Dafer follug er ben zur $\mathfrak{B}$ olfs: menge geförigen Rotar ofne Umftände zur ₹reundes = Nenge. Diejer glaubte gern, er fomme feinetwegen, und wurbe burdf

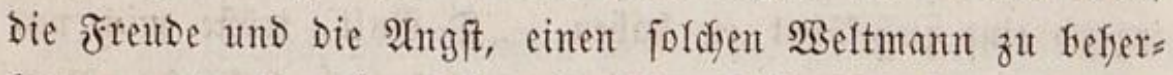
bergen, ctwag aufer fid) gebradyt. Sein Sdi futgr ängftlid oben in aflen vier Gefyirnfamment und Darauf unten in Den Geiden 5erffammern wie eine Maus umfer, um Darin eit

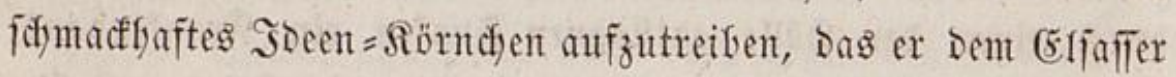
zutragen uno vorlegen fömute zum Smbí̄. (Er fanto wenig,

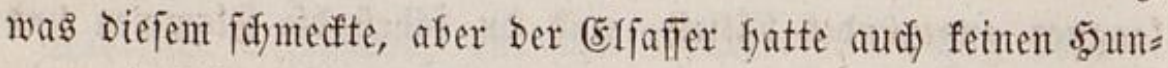
ger und feine Bäfne. Gelefrte Studirftuben= Sañen, weldhe

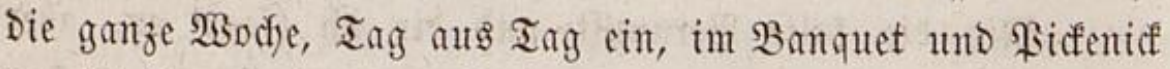
Der feinften, reizentifen Soeen und Bjeridyte aus alfen $\mathfrak{B}_{\text {eft }}$

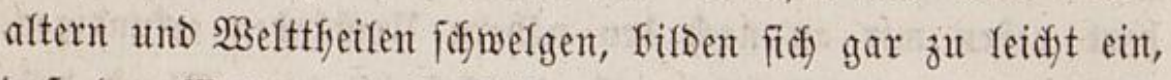

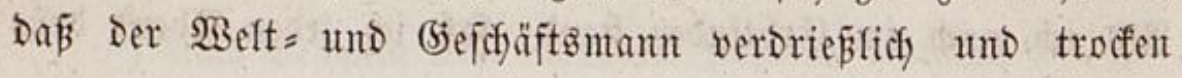


bei ifnen werde, went fie ifne nidft immer feip und fett mit

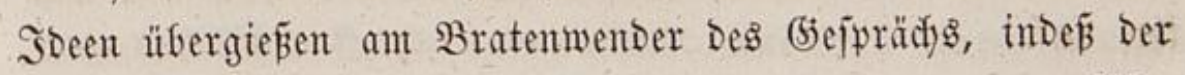

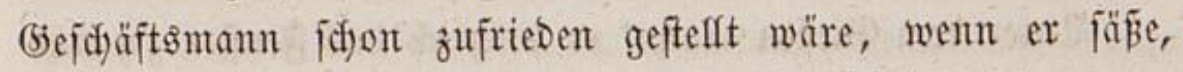
und Der $\mathfrak{B e l t m a n n , ~ w e n t ~ e r ~ a m ~ J e n f f e r ~ f t a ̈ n d e , ~ o b e r ~ v e r = ~}$

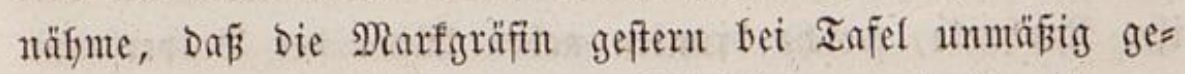

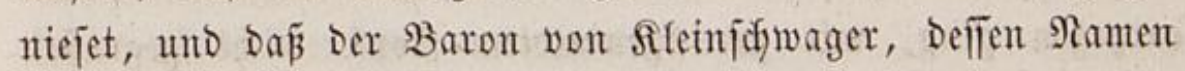
er gar nie gefjürt, Diefen Morgen flos Durdypafitit, ofjne an= zufualten. (Bjelefyrten fann bas fodwerlid) zu oft vorgeftellt werben; fie ziefen fonft immer einen Broviant= $\mathfrak{B a g e n t}$ fïr bie (jefellfognft mit mefreren ober wenigern (bedanfen nach)

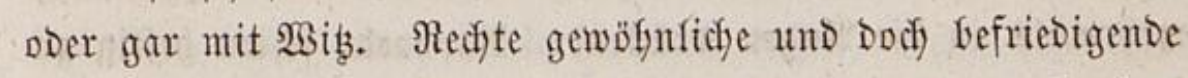
Unterfraltuntg if affgemein unter Den Menfihen Die, Daß einer Das fagt, was ber andere fofon weí, worauf biejer aber

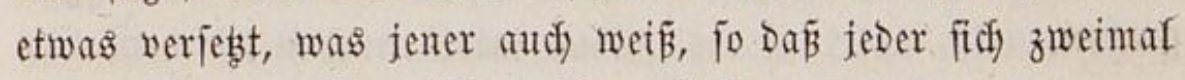
fört, gleidfjam cin geiftiger Doppeltgänger.

Mit Flitten, Der fo feer an Renlien war, als Gottwalt an \$erjonalien, fonnte Diejer wentig anfangen. Indé jprad, fang uno tanzte Der Elfafler fo gut es ging, trat oft ans Fenfter und oft ans $\mathfrak{B}$ üdjerbrett und fudfe Darüber etwas flt jagen, weil er gern vor jebem mit Dem praflite, was jeder eben war. Einige Menfoden find Rlaviere, Die nur einfan zu fpielen find, mandse find Flügel, Die in ein Ronzert gefyö= ren; Flitte fonnte nur vor vielen reden, und blieb im Duett faft zu Dumm.

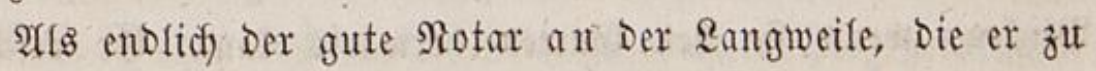
madjen glaubte, felber eine fanto - Dem im (bejpräd), wie in Pharav, ift erwiefen Der (5eminn (bes Bergnügens wie Des (5etDes) nie gröper als Der (Einfas von betDen: fo ftu= Dirte er am Elfafier fyeimlich) Den Franzojen (Denn Eljā́,

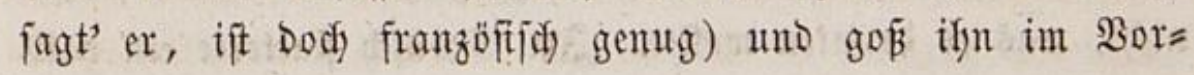




\section{8}

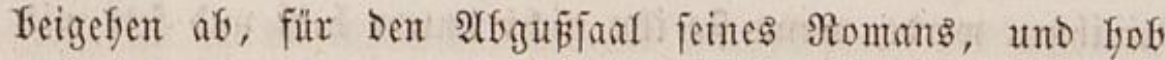
ify auf.

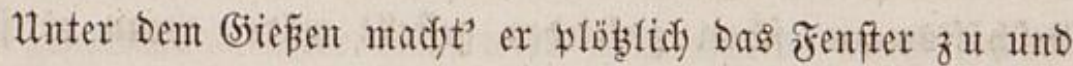
eine Berbeugung in Den Giarten Durdis (5ias finaus, weil ifn Raphaela, welche Druntent neben Sista Der Besperjome entgegen ging, mit zurüdfgewanotem Siopfe leicgt gegrüß̄et fratte. - Da flog flitte berbei. Rapfacla Drefte fids, blicfte fojnell nod cinmal um unto erfante nu biefen. TBina ging langfam und wie fofwere Sdymerzen tragent Darneben, Den

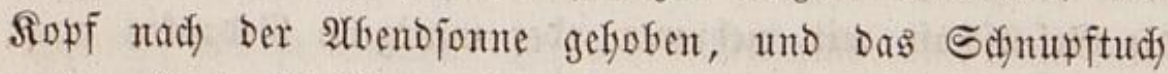

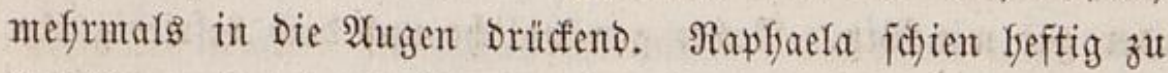
foredjen uno einzubringen uno orbentlich an jeber nebligen Rebens = Stefle verborgnen tiefen Thyänen = Sueffen nad)zu= grabert.

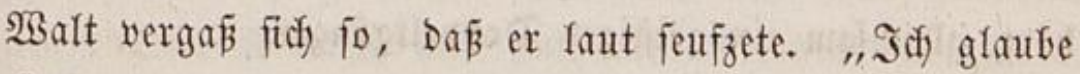

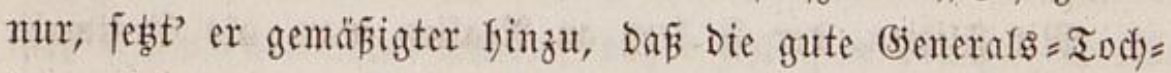
ter weint." — "Drunten? fragte Flitte falt. So ift's in Berzweiflung über Den eingebüß̈ten (5rafen; Denn fie fant feinen $\mathfrak{B}$ erluft nicht überleben. (Ein andermal! - à revoir, ami!" Eo flog er in Den (sarten finab.

23 alt febste fich nieber, ftübste Den fiopf auf Die 5amb, bie feine alugen zudefte, und fatte cinen langen reinen Sdjmerz. (Er war nidjt im Stant, Das rieblidje 2Ungeficht Des fdjönen Mäbdjens oder Defien Reiden zu befyordjen mit SBliffen, went fie Den (barten Gerwärts fam. (Er erichraf vor Der erften Stunde, wo er bei ifrem Bater fopiren unt

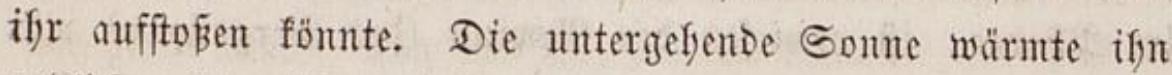

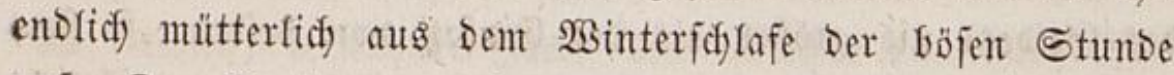
auf. Der (5artent war leer; er ging fimunter. (5r wufifte nidjt, wab er brunten wollte. Sm (5efüfid) flatterte cin balf 
zerriffenes feines Brief=\$apierblatt. (Er nafm es, es war yon weiflicher band und entfielt eine aus einem fremben Briefe fopirte Stelle, wie er aus Den jogenanuten Bänje=

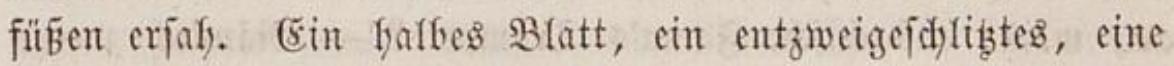
Ropie eines zweiten Briefes - einen erften bätt' er nie gele= fent - fount' er wol anjeljen und lejen:

" "- Blumen entzwei. (5ifautb' es mir. D wie leidyt Itno frof veridfmerzt man eignen Sifmerz! Wie fo fdwer Den fremben, Den man, wiewol fifuldos und gezwungen, lyer=

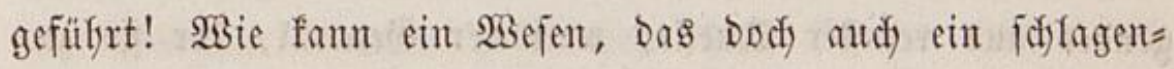
Des 5̧erz flat, ganze Bölfer weinen lafien, went fdyon Der erffe Unglüflidje, Den man madjen müffen, fo welse thut? Berbirg und verid)weige aber meine Rlage gewiīentfaft, Da= mit fie nidjt meinen Bater quäle, Der jo leidyt aflę erfäfrt! Dod) Du thuft es ofnefin. Indeffen fefft mein (sutidulur fo feft als je; nur will idy ifn bezalflen burdy Sifmerzent. Id) foun jebt nichts thun als leiben uno befler werden, idy gefje fäufiger in Die Sirdje, idh fojreibe öfter an meine Nut= ter, idf bin gefälliger gegen meinen Bater, gegen jede Men=

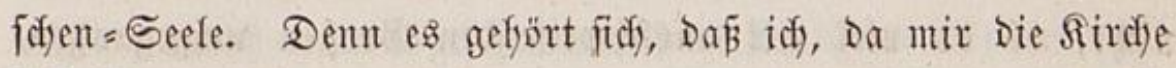
befieflt, Freuden zu nefmen, es anderswo cinforinge, wo fie es erfaulst, einige zu vermefrent. Meine fraben längit aufges fyört uno frülyer als idf $\mathfrak{g}$ hn werloren. - $D$ jei Du glüsflid), meine liebe Raphaela!" - Daraus famnft Du felyen, Sdyounfe,

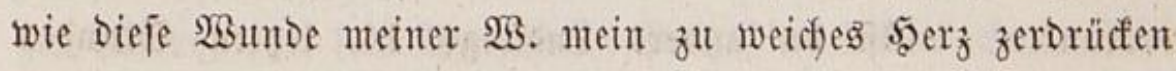

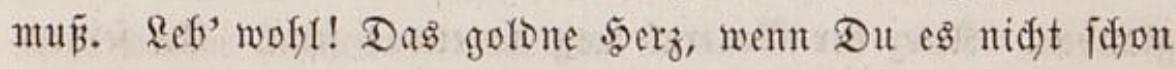
beim Sdymist befteflet haft, muв Durchaus Drei \&oth wiegen. Den sajentrecter uno Dag $\mathfrak{A}$ rmbano fyat meine Mutter be= fommen. Deine Rapfaela." 
Waalt wurbe unter Dem 2 ejen aus feinem reniter na= mentlid) gerufen von Bult mit Den freutigften Mienen; er Ias es unterwegs gar aus. "Du fennft, fing jener luftig an, meine enffadjifiche Fama's Trompete? - Nämlidy meine fumäifhe Sibylle Der Bergangentyeit? Das heiß̧et meine

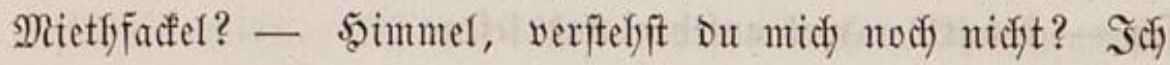
meine meine fifforifide Dftupla uno 8 partes orationis (Dent fo viele Mäbdhen fint's)? 3 um 5̧enfer, bie Sdynapwaife? Die Penfion nämfidy! Sont Diejer mut erfafyr' idf eben fol= gendes aus reinfter Sulflfe, weil Der (bieneral, Der fie zu=

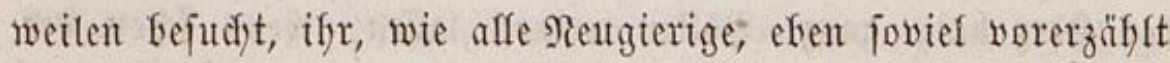
als abfordst.

(5enau genommen ift's Die Dogareina und Direftrice Der

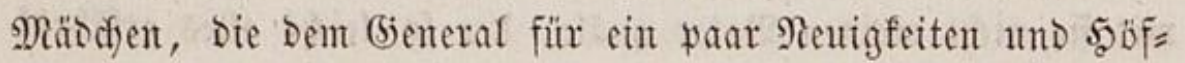
Iidjefeiten gerade fo viel Tobderjeefen opfert, als mir referi=

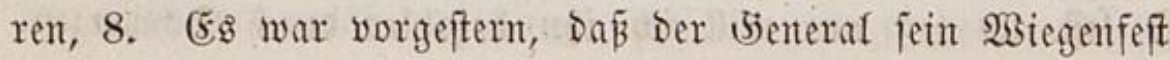
beging, und nadi feiner Sitte Das h. Afendmafy vor feinem Mittaggmafil nafm uno Darauf Der Seelen $=2$ (rzenei viel nad)=

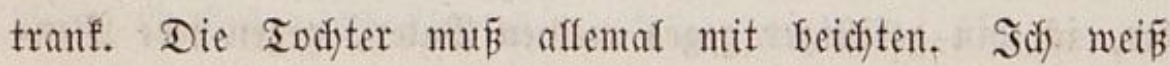

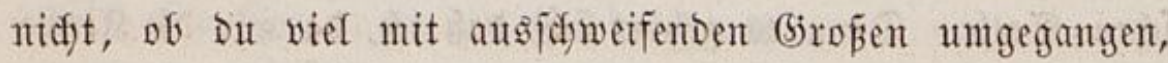
zu weldyen Mündye am leidyteften fagen wie ful sumben: faites la belle, für weldye Der Dhrenbeidft = Stuffl Das $\mathfrak{A}$ : $=$

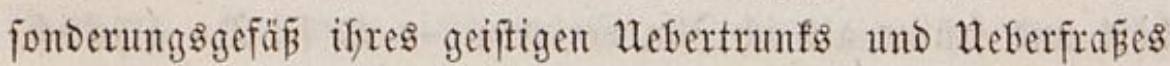
ift, unto weldye, wie Der Norden, ifre Befefjung Den Meibern verbanfen, willft du anders subowigg 14. Yek̨ten Stundent glauben. Surz Der Bienteral mag io etwas fern. Tht jeinem

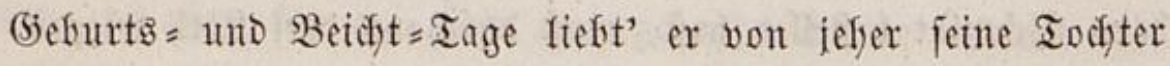
ganz befonders, weil er eine $\mathfrak{A r t}$ Iaufwafler - um zwei entlegne Safromente Durdi friufifigfeiten zu vereinen - Dent

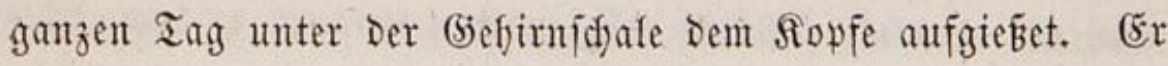


Gat überbaupt bas (5)ute, Dấ er aufridstig gut gegen fie ift;

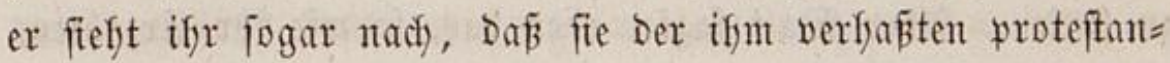

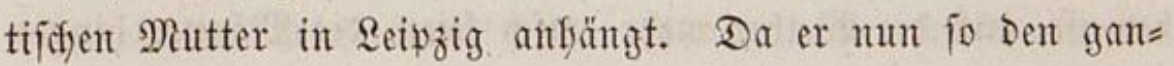
zen Iag mit feiner Beidyt = uno Bater = Todfter beifanment

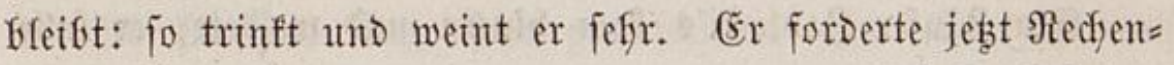
(d)aft won ihr, warum fie nodi) fo trauerte, daj fie faft ben (5rafen mefr zu lieben fojiene als ifren (5ott und Die f). Rirdje uno ifren Bater. Sie antwortete fyeftig: "Das fei es am wentgiften; jogar Dem Rirchenrathe (5) fanz, Der bfters mit ifrr über ben feif. (sifauten geiprodyen, fabe fie mur göflid) zu= gehört; Den (5rafen aber nidft mefrer geliebt als jeden gutent Menifyen." 3ablocfi fragte erftaunt, warum fie ifm, bei iffrer

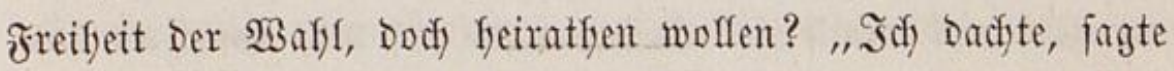

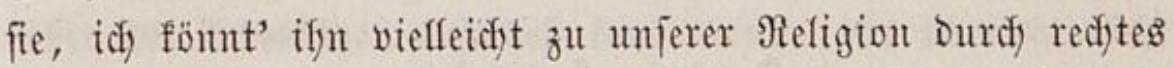
2ufopfern bringen." $\mathfrak{B a l t ! ~ e i n e n ~} \mathfrak{B f i l o j o p h e n ~ b e f e b r e n ! ~ I a u f t ~}$ und tonjuritt fieber cine Perücfe! -

Der Bieneral lädyelte und weinte zugleidf vor \&uft, lief aber immer mefrr auf Das weidye zarte $\mathfrak{B e j e n}$ Sturm, ftieg ins offne 5erz uno holte fich Das zweite (5efreimmin. Sie Goffte nämfich iffer abgeidfiedenent proteftantifonen Mutter (uno wol Dem verichuldeten Bater) zu 3eiten ein Rowffifien aus Dem reichen Efyebette zuzuwerfen; geftand es aber ofne Meta= phern. Da founte fidf Der trunfene $\mathfrak{B}$ ater nicht entfaltent,

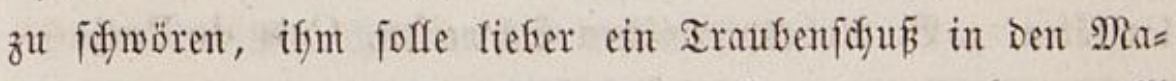

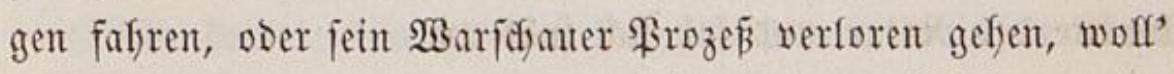
er je einem foldyen jeelentreuten finde etwas abjolagen oder auforingen. Hito fo weiter! Bift Du getröftet?" -

Walt fofwieg; Bult bat ifn um Das zerrifiene Blatt in feiner 5and. (Ex las es frof und fand Darin feinen Beridft befiegelt, uto madjte feinen Swai über Rapfaelens weiblidje 


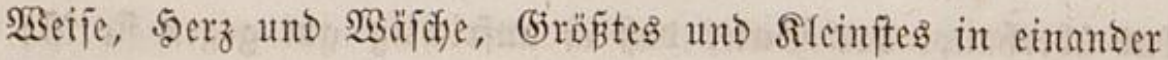

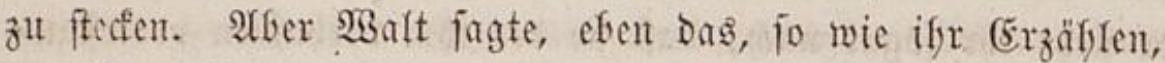

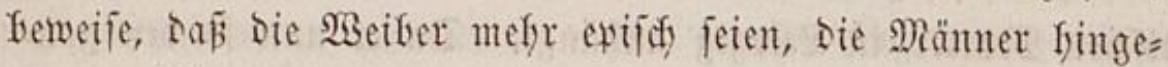
gen Itrifich.

Ein Säufer Babloct's fan finein und meldete, er folle

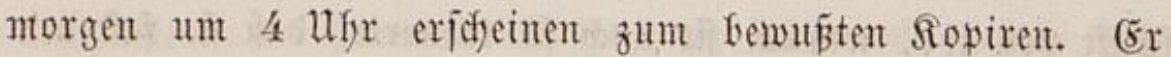
verbarg müfjam Den ganzen $\mathfrak{A b e n d}$ Die Stärfe jeiner Beme= gungent.

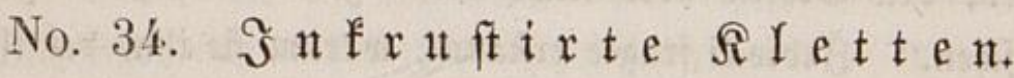

R D bixft un

Um 4 ufr erfiden SBalt vor Dem (5eneral, Der, wie ge=

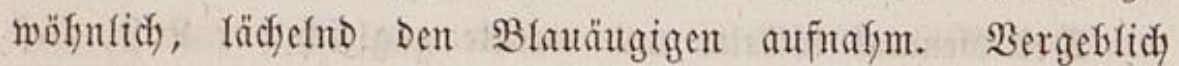
batte er vor einer Erimnerung an Den Brief ober einer $(5 \mathrm{r}=$ fdeinung Der Berfafferin gezagt. 3ablodi gab ifm Die na= mentofen ober nur taufnamigen Briefe auf Dem fod ön geäber= ten Gefretaix fammt Gdyreibbeferlen und ging Dawon. Mit to jelfr auggefud)ten (EnD= Rettern ober Final= Sd)weifen, als

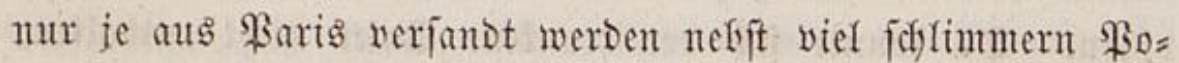
laritäten, z. B. Robegpierrifiden Sdyweifen, Culs de Paris fopirte Der Notar uno faf fid frät um.

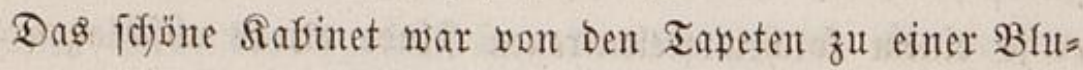
menfaube gemalt, aber volf Bhumenoüfte, Die aus einer waf)= ren famen, uno volf grüner Dämmerung. Die Saloufies (5itter waren vorgezogen, für ifn ein grüner Sdfleier eines blentenden Iagg; jogar im Winter grünte ifn Diejeg Blätter= 
Sfefet Der vertrocfneten bunten Beit wie ein 3auber an. "In

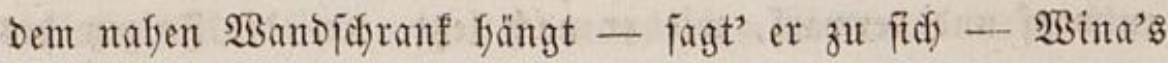
Gimmelbraues Rleid, Denf' idf." Wie auf einer fanftwallendent

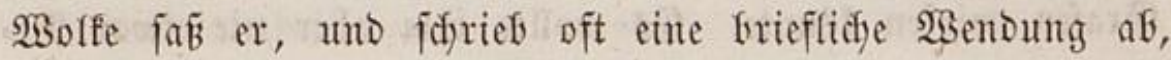

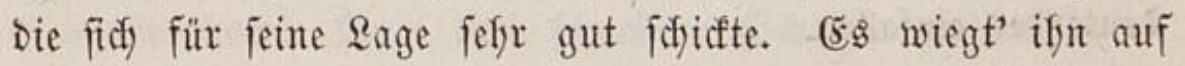

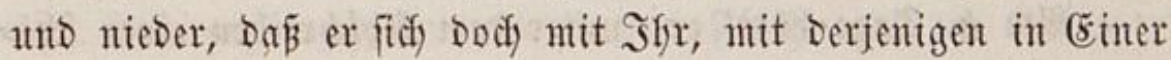
Bimmer $=$ Estene, unter Einem Dache befand, mit welcher er Das Trauerbmo Derjelben Edjmerzen trug und Die ifm nadh Dem Untergang Der Frembiduafts = Some als filler Riebes: 5esperus fortidimmerte.

(Er fopirte mit gejpibaten Ofren, weil er (nicht ofme affe

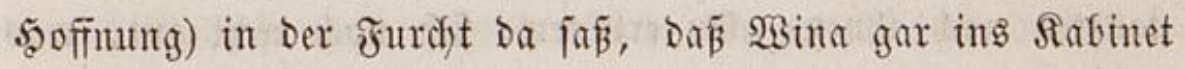
Hutb an einen ober Den andern Gefretair fliege, Den fözzernen oder Den lefentigen. Intoé fam nichts. (Ex überlegte fefri, ob er nidyt in Den 23 andfofyranf einfredjen und Das fimmel= Glaue Rleid alo Den Glauent Aetfer Der fernen Sonte leidft anrüfren follte mit 5 and ooer mit $\mathfrak{M}$ uno - als Der Bseneral

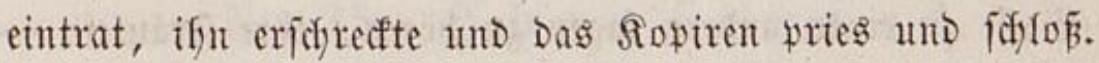

So glüaflidf ging bie Sdyreibfunto und bie (befafrr, SBina zu jeffen, vorubber, und er wanfte heim mit einem Sopfe, Der fith ein wentig im serzen vollgetrunfent batte.

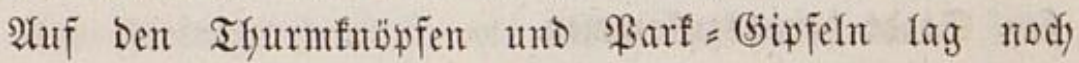

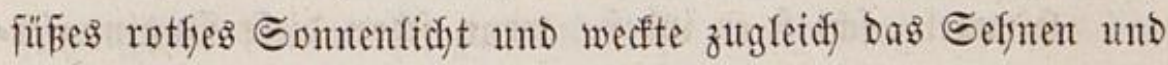

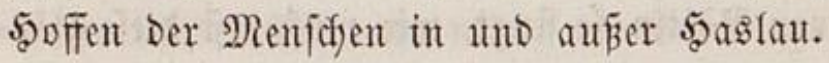

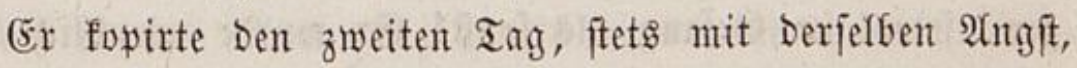
Dẩ $\mathfrak{B}$ Bina bie Thüre aufmadje. Der britte aber - wo wie= Der nidfts fam - madyte ifn, wie jeden Frieger bie Beit, fo mutfig uno fo zum Mann am vierten, Daß er in Der Ifyat

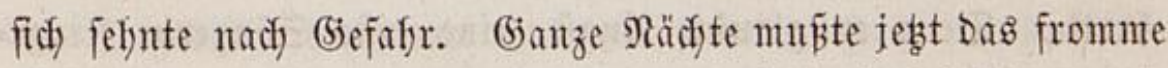
Mäbdjen vor feiner Seele fteffen - er Fatte Dabei feinen ewi= 
gen Früfling - blos weil er einen Plan nady Dem andern entwarf und verwarf, wie er nod) jeb̧t, um die folgen bes vffnen Briefs zu vergüten, etwan Durdi) Die Sanfte für Den (brafen wirfen fönte. (5s wollte iffm aber nie etwas $\mathfrak{B} e=$ Deutendes einfallen.

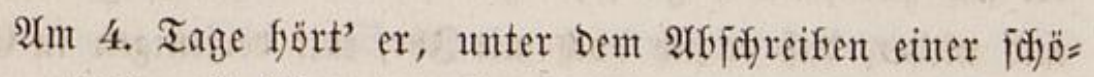
nen erotifuen (beftifulazion im Briefe, cine weiblidye Sing= ftimme, Die, of wol ats Dem britten 3immer, Dod elen fo gut ans Dem britten simmel fommen fonnte. (Er) fopirte feurig weiter; aber eine Sonnenftadt nady Der andern erbaue= ten in ifym Dieje Drpheuts = Töne und Die Jelfen Des Lebens tanzten nad) iffnen. (Er erinnerte fich nod) redft gut, was

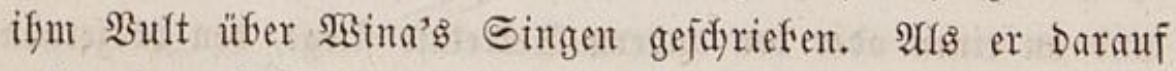
unter bem Seimgeljen biejelfe Stimme fortfingent vor fid mit einer Sdyadftel unter Dem 2 (rm auf Der Treppe faf unt auf jeder Staffel erftaunte und nadjoadjte: fo madyt' es ibm Das idjlecfytefte Bergnügen von Der $\mathfrak{B e l t}$, Dieje Stimme auf Der (ja)̄e zu ciner andern fagen zu fyören, ifye fräulein Denn es war Die \$ubjutgfer - fomme erft nädfifen Freitag

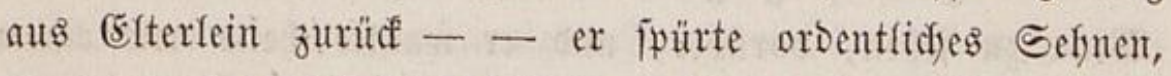
einmal in feinem (jeburtsörtlein fo jeyn uno aus Der fo hei= Ben Strot herauszufomment.

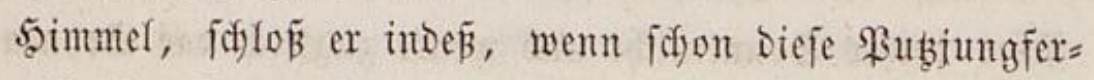
Raryatise Der fernen (söttin jo fingt, wie muß erif Dieje glän= zen, fowol im befang als fonft! (Ex murbe unendida begies

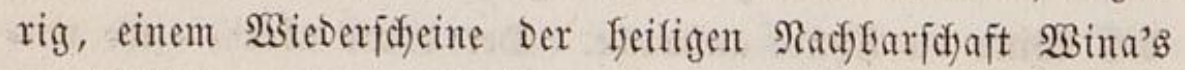
ins (jeficht zu jefyen, überfyaupt einer $\mathfrak{B}_{\mathrm{e}}$ jon, Deren göttfichen (beift Der Töne er finter ifrr gefend anbetete, furz Der Sou= frette. Denn er glaubte längft, eine erfte Sängerin fei ge= wín nidyt bie lebste Monatsheilige ober eine Sirene; uno eine 


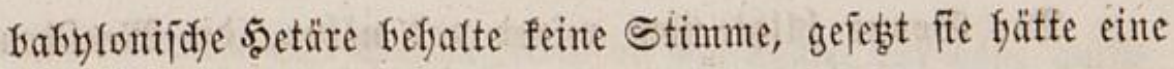
beje|Ten; eine Neinung, die gutmütfige Weltleute mefr jeiner

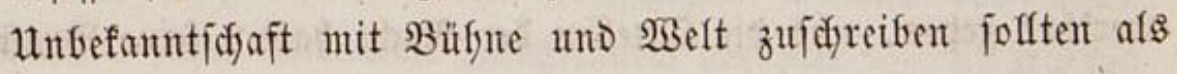
jeiner Dummfyeit.

(Ex modyte faum brei idneffere Sdjritte getfon baben, um ifyr vorzufommen: als er brei flütje und ein Siotfyort vernafym. (Er brefte fid heftig um, mit Der glänzenden Droents=

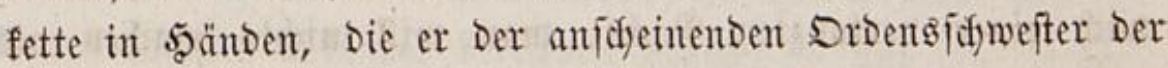
Sflavimuten Der Tugent you Sing=salfe gerifien; und in einer Dunfefn $\mathfrak{A} f(e)$ Der Stadt fieß̄ er Thränen fallen, Darüber Dẩ eine foldhe raube Seele eine Singfinme befibe, und Dá̃ fié

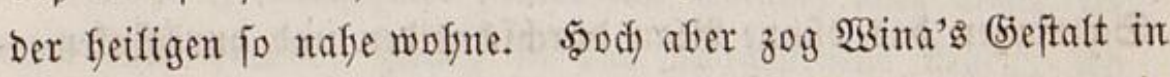

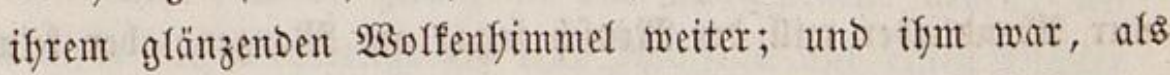
fönne nur ein Iod ifn, wie zut (5ott, fo zur (söttin fringent.

No. 33 . (5) $\mathfrak{x}$ y $\{\mathfrak{o p} \mathfrak{x} \mathfrak{a}$ :

$$
\text { Trüumen - Singen - Beten - Trâumen. }
$$

21m Freitage Darau, wo $\mathfrak{B i n a}$ wiederfommen follte, fprang er, ofye an fie zu Denfent, fo innig= vergnügt aus Dem Bette in Den $\mathfrak{T a g}$, als wär’s ein Brauttag. (Ér wuß̄te feirten

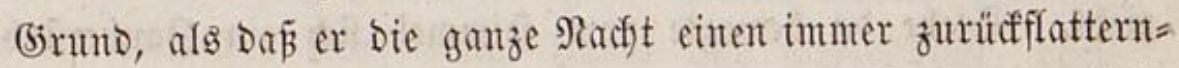

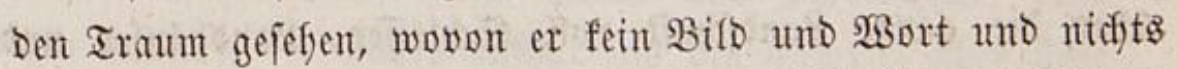
befhaltent, als einige anonyme Sefigfeit. WWie Şimmelsblumen werben oft Iräume Durdh Die Menjofemtudft getragen, und am Tageglidyt bezeidnet nur ein frember frïflingsobuft die Spuren Der veriffumbentert. 
Die Sonne blibte ifym reiner uno näfer, bie Nenfodent faff er wie Durd) einen Traum ber Irunfenfeit foüner und wertfer gefen, und Die Sueflen Der Radyt batten feine Bruft mit fo viel Riebe vollgegolien, Dẩ er nidjt wußste, wohin er fie leiten jollte.

3u Bapter fudft' er fie anfangs zu fringen, aber fein Streffvers und fein Rapitel gelang. (5r fratte einten Tag wie nad) einer vertanzten Nadyt, man wifl nidjts madjen als födjftens Träume, uno aud nidjts anderes baben - affes foll fanft fern, fogar bie sreube — fie foll nidjt mit $2 B$ ind $=$

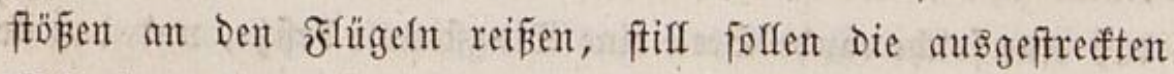
Sdywingen Das Dün $\mathfrak{B}$ (au Durdjichneiden und Durdfinfen nur Abendieder wifl ber Menid, fogar an Morgen, aber fein einzziges firteggfted, unto eit Fllor, aber ein helfgefürbter, he= ziefft und Dämpft Die Trommel Des Eroen = Tobens.

$2 B$ alt fonnte nichts anders madjen - "mur heute feit Snftrument, Das gebe (5jott!" wünịchte er - als cinen Spa=

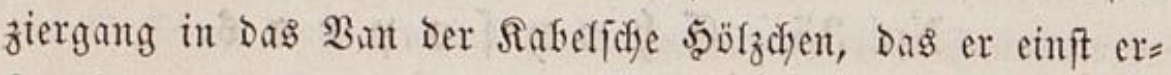
ben fant, uno wo er Den entfrembeten (5rafen zum erftermale auf Der Erò gejeflen. $\mathfrak{t m}$ ifh flogen, gingen, ftanden Träume

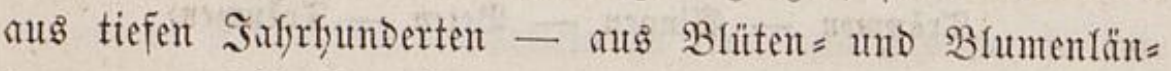
Dern - aus Rnabenzeiten - ja ein Träumedfen fá uno fang

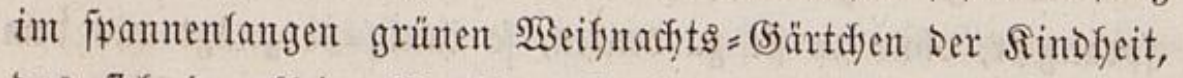
Das fid Der fleine Menfid) auf vier Räbern am Faben nard)=

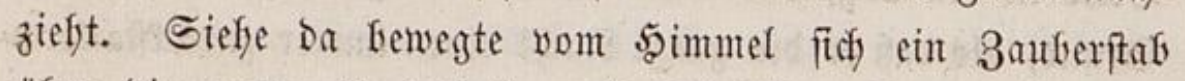

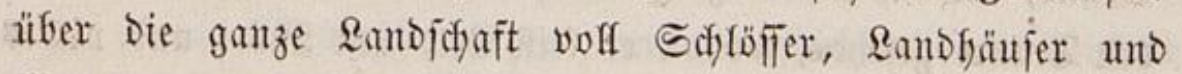

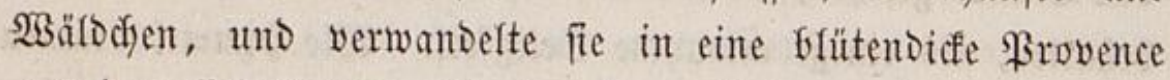
aus Dem Mittelalter. Sn Der Ferne faf er mefrere $\mathfrak{B r o v e n}=$ zalen aus Drivenwäldern fommen - fie fangen heitere Rieber

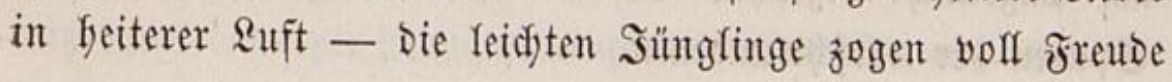


und voll Siebe mit Saitenjpiefen in bie Thäler nor fobje gold = bebefte Burgen auf fernen Bergipiben - aus Den engen Fenftern fafen ritterliche Sungfrauten ferunter ... fie mutroen Gerabgelocft und ließ̄en in Den Âten 8elte aufippamen, um mit Den Provenzalen ein $\mathfrak{B o r t}$ zut reden (wie in jenen Beiten und Rändern, wo bie Erove nodh ein leidytes Euftager Der Didftfunt war, und Der Troubadour, ia Der (5onteur fich in Damen böbfiten Standes verfieben Durfte) - und ein ewiger Früfling fang auf ber (Erbe und im şimmel, Das Leben war ein weidyer Tanz in Blumen.

"Süße Freubentfäler finter Den Bergen, fang $\mathfrak{B a l t}$, idy mödyte aud finüber ziefen in Das morgenrothe Reben, wo Die Riebe nidyts verlangt als eine Sungfrau und einen Didjter - idf) mödte brüben in webender grüflinggluft mit einer Raute zwifichen Den Belten mitgeffen, und Die ftifle Riebe fingen und idfnelf auffören, went $\mathfrak{B i n a}$ vorbeiginge."

Darauf fefrte $\mathfrak{B a l t}$ in fein Ränmerdyen zurüd, fand aber, mit feiner geograpfijojen und fiftorifonen ßrovence in

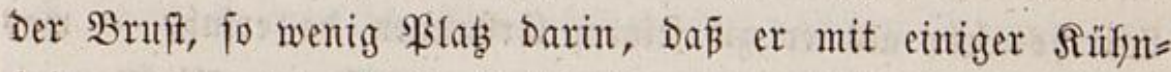

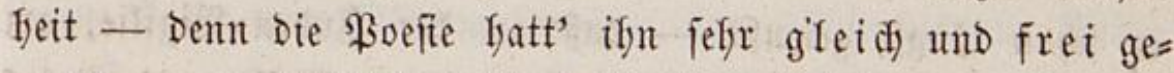
madyt - in Reupeters Rarf finabjpazierte, wo er Floren, mit Früdyten wie eine Fomona bejofyert, in Den $23 u r f$ fam und Die 5and gab. Dem Didfter glärzet bie ganze $\mathfrak{W}_{\mathrm{selt}}$ Dodh aber cine herzoglidfe, fönigliche firone matter als ein fdyöner weiblicher fopf unter frone uno serzogghut, ober als ein anterer, Der nidfts auffat als Den simmel niber fich); er ift beffeiden, went ex einer Fürftin, uno aufgeridytet, went er einer 5ुirtin bie 5and gift; mur zu Den $\mathfrak{B a t e r n ~ b e i b e r ~}$ läjpet er fich oft gar nidft berab.

Sn einter Latbe fant er ein Strumpfbant. (Ein itafiforer Sean Yaul's auşgew. Werfe. XIV. 
Bers - Dent Raphaela verfanto weliat, ofwol er nidft unt ifr Rame war Darauf geftifft. Da er an Diejem geiftigent

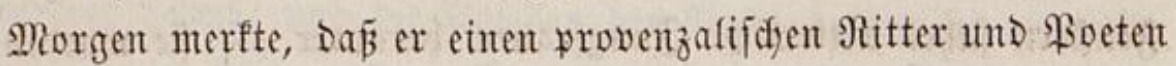

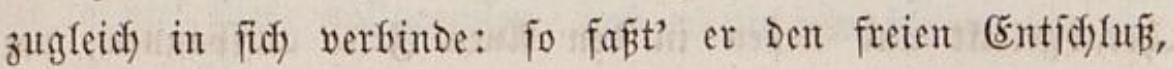
Das Strumpfband - Dent er fielt's für cin Âtmband felber Raphaten, Die er frieflefend foleidfen fah), mit einigent bedeutenden 2 Borten zu überreidfen. (Er legte Das Band weidy vorn auf bie flache \$and wie auf einen Präjentirtefler

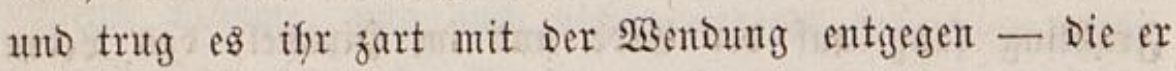
aus viefen andern liber weltlidfen $\mathfrak{A r m}$ und $\mathfrak{A}$ rm aus Den

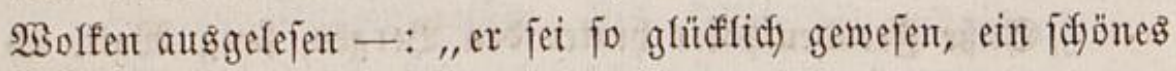
Banto Der Riebe zu funden, eine Sefme an 2 mors Bogen,

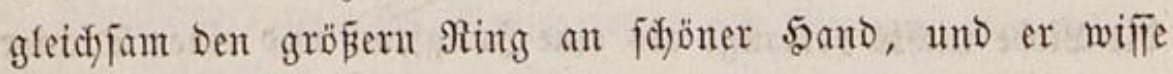
nicht, wer glücflicfer fei, Der fo iffn abzüge ober ber ifn an=

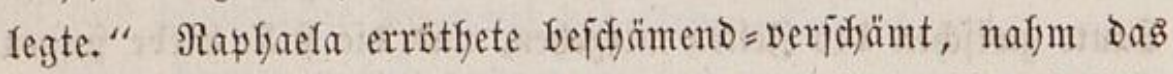
Bant, ftecft' es fdinell ein und ging ftumm fort; $\mathfrak{B}$ alt Dadfte: faif ein gar zu zartes (semulty!

(5r frachte nod) viel yon feiner Morgenfrente an bie Mirtbistafel; als er zu feinem Eritaumen da erfufr - wab

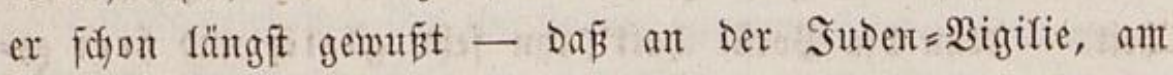
Freitag, Die Ratholifent fafteten. (Er legte Mefier und (sabel neben Den Teffer fyin. Seinen Biffen - unt wär' er aus Dem

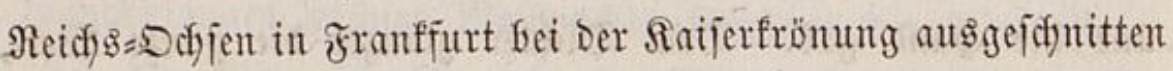
gewejen - hätt' er nod) an bie Bunge heben fömen. "So h

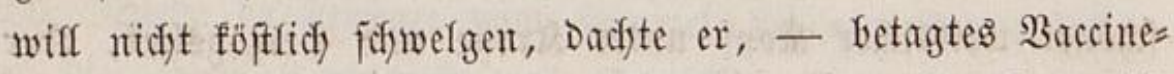
fleijic) war aufgeiebst - in Der Stunde, wo eine jo wohl=

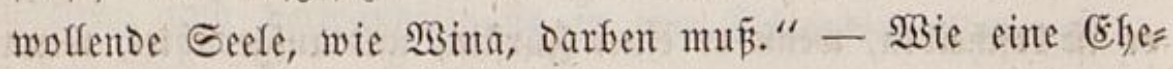
frau, hatte er bei Der (5ileid)gültigfeit gegen eigene $(\widetilde{E} \tilde{B}=$ (Ent= befrungen cin weinendes (Erbarmen über frembe. (Er Dadfte nad) und fand es immer bärter, Daj bie Firdye aud Nonnent 


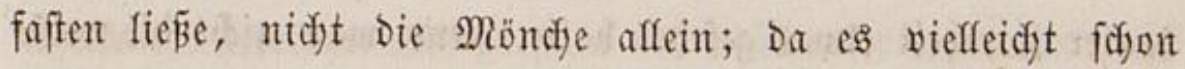
genug wäre, went nur Exibbuben, Epieler, Mörber nidjtg rechts zut effen hätten.

Er ging in Die Sopirftube zum (jeneral, nicht nur mit

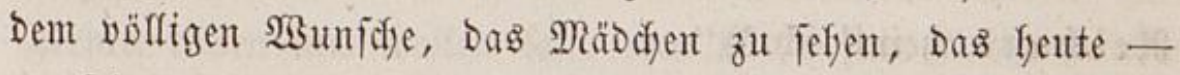
an feinem romantijchen Iage - cine Märtyrin gewejen, fon=

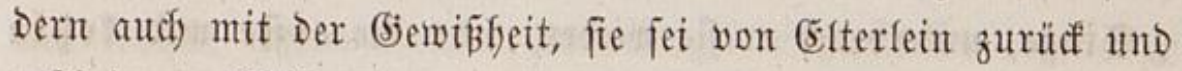
erjocheine. Wäfrento er mit unjägfichem Bergnügen cinen

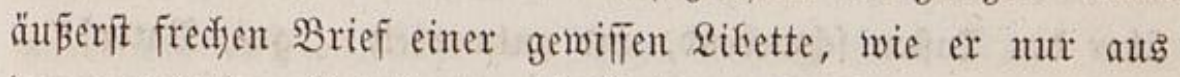
Der moralijoch Eutetia*) voll (Epifurs = Ställe fommen fant, ins Reine fojrieb - Denn er jajmedte in Diejen Frentent= fefdien mur Den Afbentomalf(swein Der geiftigen Riebe und fei= nen gefdwefelten - jo brang aus Den halboffnen Bimmen fein Raut in fein Rabinet, Den er nicht zu einer $\mathfrak{A n f f u ̈ n d i g u n g}$ einer Eridjeinung zitternd madyte. Wie in weiten bichten Waldungen ferne lange Töne fier und Dort romantific) Durdid)= flingen: io fament ifm einzelne afforbe auf Dem fortepiano - Rufe Des Gienerals - Antworten an $\mathfrak{B}$ - Ana vor - Eno= Iidy Gört' er wirflidy WBina felber im nädffen 3 immer mit iffrem Bater yom Singen fwredyen. Err glüfte bis zur Stim finauf, uno bücfte Den unrufigen Ropf faft bis an bie Feder nieder. Sie hatte jenten innigften, herzfichften, mefyr aus Der Bruft als Sieble heraufgefyolten Epradjton, Den $\mathfrak{B e i b e r}$ und Sdfweizer viel bäufiger angeben, als anore Rente.

Sndem Der (Seneral eintrat und Balt flammento fort: fopirent wollte: Gatt' er Das Unglücf, Dấ Das Mäbdfen Sing= noten aus Dem Siabinette fliegent wegholte, ofne Dá er vor

*) Diejen, Ramen Rothitabt trug fonft Paris in unbilblicher Bez̧iehung. 
Iauter 3artfeit etwå gejefen fratte, wenn man nidyt bie weipe Sdjleppe zut hod anjollagen will. Bald Darauf furg im. zwei= ten Bimmer ifyre Singftimme an - "D nein Dod, rief Der

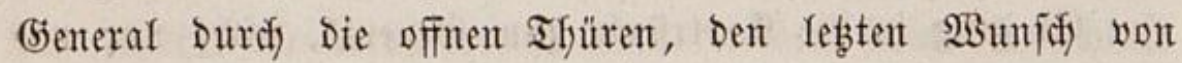
Reidfard meint' idj. * " "

Sie brad ab, und fing ben begefrten 23 unja an. "Singe, unterbrady er fie wieder, mur die erfte und rebzte Strophe ofne bie emmunanten." Sie fielt innen, mit fingern über Den Taften fdwetent, uno antwortete: "gut, Bater!“

Die Berje Yeiñen:

SBann, o Edjiffal, wann wirb enblidy

Nir mein Yeţter গুBund gewährt:

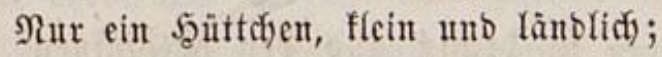

Nur ein fleiner eigner Şeerb;

uno ein Freuno, bewährt uno weije,

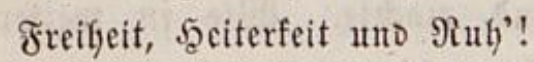

श(d) unb Sie, bas feufis' id) leife,

3ur (Sefä́lyrtin Sie bazu.

Bieles wünfdit' id fonft vergebents;

Sebुo nur zum leb̧tenma!

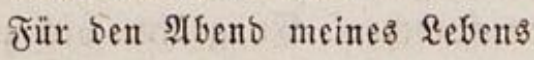

Srgentwo ein Friebens = Thal;

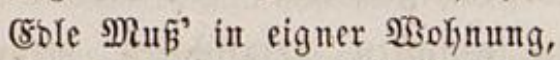

Uno ein 2 Beib yoll 3ärtlichfeit,

Dab, ber Treute zux Belohnung,

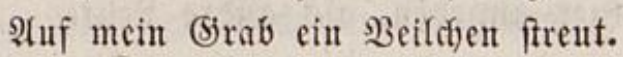

Bina begam, ifre jübe Spradje zerjojmolz in Den nodh

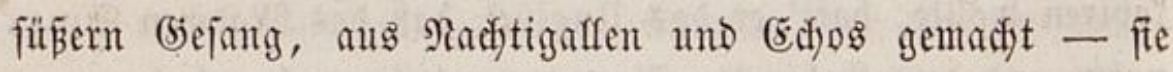

*) ๔. 10. in Reidjarbs Rieber $=$ Sammlung, worin mandje bas 10te mal belier flingen, als bas erftemal, uno Didfter unto Rompenift meiftens iffr gegenjeitiges ercho fint. 


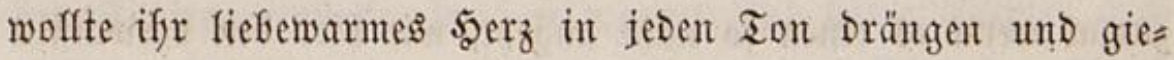
Ben, gleidfjam in einen tönenden Seufzer; -- Den Notar um= fing Der lang geträumte Seelenflang mit Der baerrlid feit Der (Segenwart jo, Dá̉ ifn das Geranrollende Meer, Das er von Fernen rolfen und waflen fah), mut mit fyofen frutfen nafm mind Dectte. Der Beneral fal unter Dent Singen Die Ropie Des frechen leţten Briefes mit einiger wibiger beiterfeit auf Dem (Sefidfte Durch) und fragte lädyelnd: wie gefällt Jfhnen Die wilde Ribette? - „Wie Der jebsige (5e antg, fo wafre, jo innig und fo tief gefüly)" veriebte (5ottwalt. - "Das glaub' id audf)" fagte Zablocfi mit einem ironifoden Mienen=(5) Lanz, Den

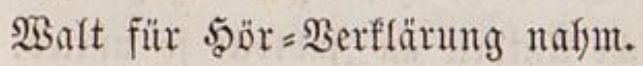

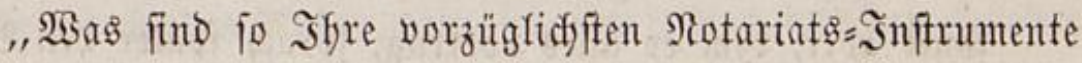
Fisfer gewejen?" fragte Der (5eneral. Waalt gab viele furz

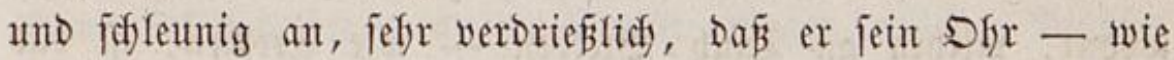
fein Reben - zwijgen bejang uno Proja theilen follte.

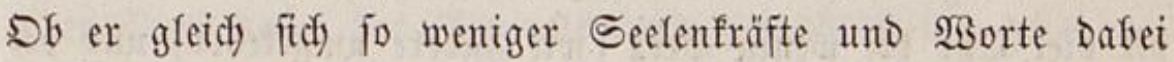
bebiente, als er mur fonte: fo war für 3ablocfi bodi fein

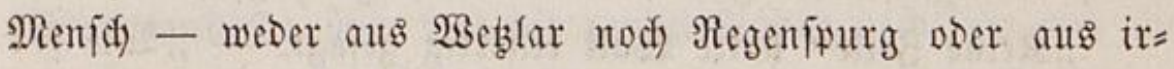
gent einem fdfriftftellerifofen bureau des longitudes et des

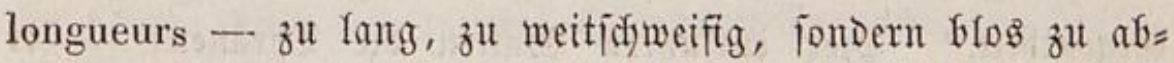

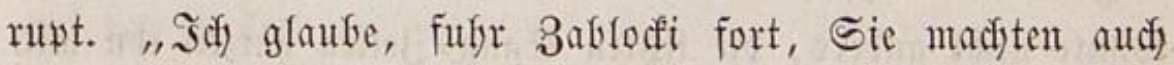
einige Sadfen für Den (Srafen von Silothar?"

"Reine Beife" verjęzte $\mathfrak{B a l t}$ zul eiffertig; er war völlig

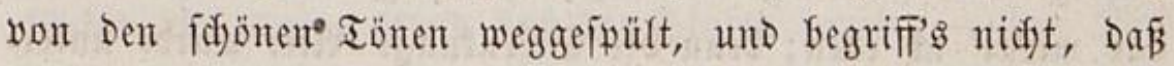
Der (jeneral, Der felfer biefe föbnen \&aute vorgejdyrieben, fie iiber whatte verfjören wollte. ,D (5ott, wie fanu ein Menfid) nidft im harmonifden Strome unterfinfen, fontern Daraus nod) etwas vorftecfen, bejonders die 3unge? Sít Das möglid, 
zumal went es einen fo nafe angeft, wie fiev ben berwaiften

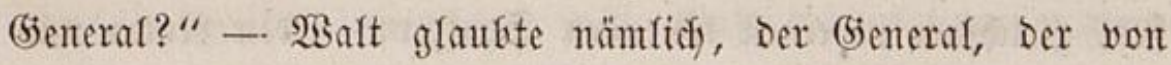
Der frau und audf won Der Iugent gefdiedent war, babe foldye uno äfunlidye Beilent wie

Seţo mur zum Yețtenmat

รür ben शibento meines \&ebens - -

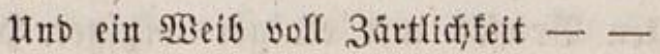

Glos als Nadjtigalfent $=$ Darfeflungen eigener Seclen $=$ Ritagen fingen laffer. (5s fonnte ifn weit mebr rüfren - zumal da es audl) viel reiner war - went er Ion=Sprïdye auf frembe

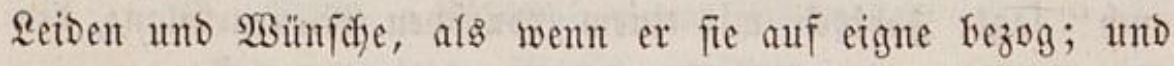
Darum war ifm Der vergeblidfe Intheil an Zablocfi fo unlieb.

Bult afer, Dem er affes vortrug, prad) fpäter Den $\mathfrak{B e l t =}$

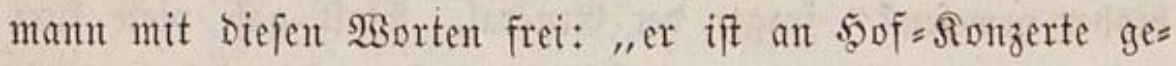
wöfnt, mithin an $\mathfrak{I}$ aub $=$ Bleifen - wie Eremen, ift bas

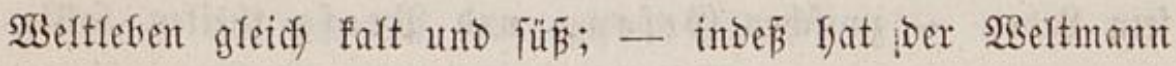
oft viel Shr bet wenig serz (wie andere umgefefret) und be= fordft wenigftens bie form Der Ionfunft ganz gut."

"Reine Beife" Gatte $\mathfrak{B a l t}$ eilfertig gejagt. — "WSie jo? veriebste Zaflocti. Mein (beridytshalter jagte mir gerabe Das Gegentheil." Şier entfubren $\mathfrak{B a l t e n}$ Die Thränen; - er fonnte nidjt anders, Die leķten Sang = 3eifen batten ifn mit=

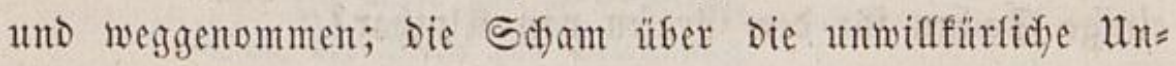
ridytigfeit trug weniger bei: "wafhrfaftig - verfebst' er Dag meint' id eben; Dem Die Gdjenfungg = 2ૈfte wurbe unter= Grodsen - Die erften Beifen fodrieb idf natürfidy." Der (Seneral idfrief Die Berwirmung Des gerilfiteften (Befichts nidft Der foünern Stimme zh, fondern feiner eignen - brad) gut=

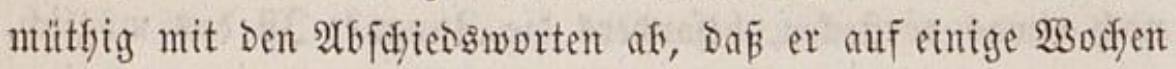


Das Ropiren einftelfe, weil er morgen mit jeiner Iodjter nady Leipzig auf Die Mefle reife. 5̧ier fjörte Das Singen auf und

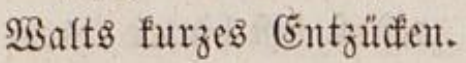

No. 36 . $\mathfrak{\Re} \mathfrak{o} \mathfrak{m} \mathfrak{p} \mathfrak{a} \mathfrak{m} \mathfrak{t}\{\mathfrak{f} \in \mathfrak{f}$.

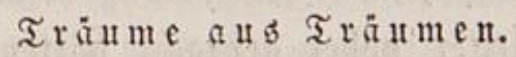

2uf Der fyellen (5anje war Dem aus bem Zabloctifichen Sauje wanfenden Notar, als jei ifhm etwas aub Den 5ändent gezogen, etwa ein ganzer bremender (5friftbaum oder eine 5aimmelaleiter, Die er an bie Sonte anlegen wollent. Hlöbzlidy (al) er - ofne z̆ faffen, wie - sie böfe $\mathfrak{A}$ fter = Sängerin ober \$utbjungfer Des Benerals und vor iffr $\mathfrak{B}$ Bina geffen, it Die fatholijaje Rirdje. Sebstere madjt' er ofne Umitänte zut Simultanfirdye und trit ber zarten Nonne nad), um von ifre Die 3eile: "want, o Sthicfial, wann wirb enolicf)" fortingen fu fyören; Dent fein imteres Shr fyörte fie nod) ganz Deutlid auf Der (5inje.

Sint Tempel fand or fie futeent und getogent auf Dett

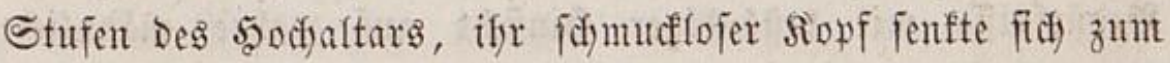

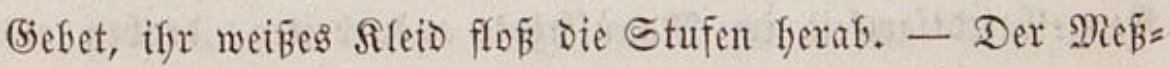
priefter in wunderficher fletoung und Bebienung madjte

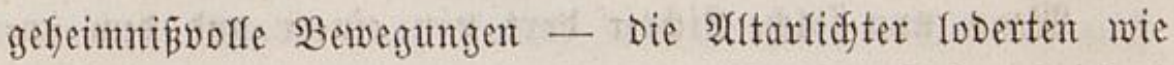

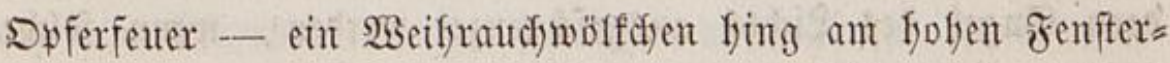
fogen - uno bie untergefente Sonne bficfte nodh glüfent Durdh bie oberften bunten Sdjeifen findurif uno erfeudftete 


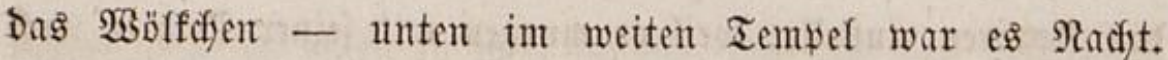

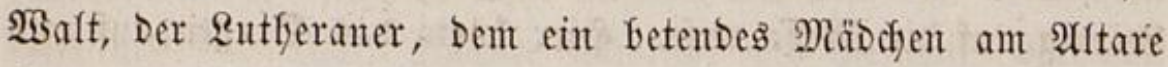
eine neue fimmlijofe (Erjocheinung war, zerfló faft finter iffem

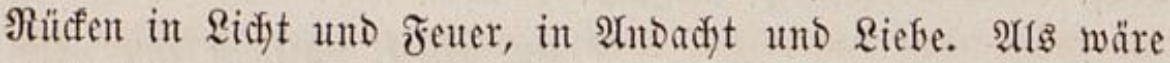
Die feilige Sungfrau aus Dem beflammten Altarblatte, worauf fie gen Sommel ftieg, ferabgezogen auf Die Stufen, um nod einmal auf Der (Erde zu beten, jo feifig=ichön faf) er Das Mäbchen liegen. (Er fielt es für Sünde, fünf Sdyritte weit vorzutreten und Der Beterit gerabe ins fromme Angefidft zut fefen, obgleidh bieje fünf Sdyritte ifn fünf golone Sproffen auf Der simmelaleiter höfer gebrad)t bätten. 3uleb̧t zwang ifn fein (sewifien, gar felfer - wiewol er proteftantifich Dadjte - finter Den ftiflen (jebeten einige eigne leidyte zu

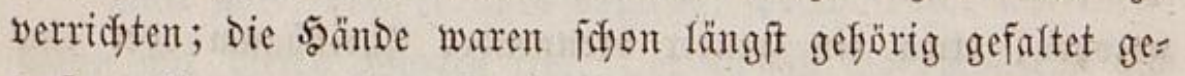
wejen, elj) er mut Darauf gebadjt, etwas Dazul zu betent.

(58 if aber fut glauben, Daß in Der $2 B e l t$ finter Den Stenten, die gewík ifre eignen, gantz fonberbaren Begriffe

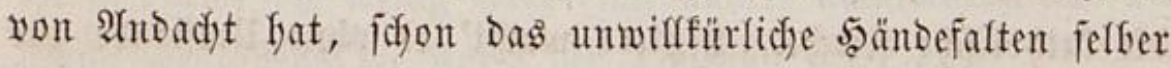
für ein gutes (jebet gegolten, wie Denn mandyer riefige 5ando=

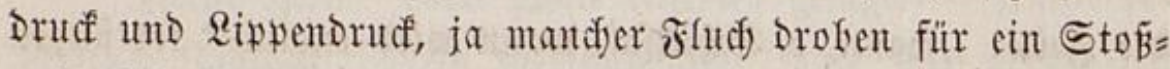

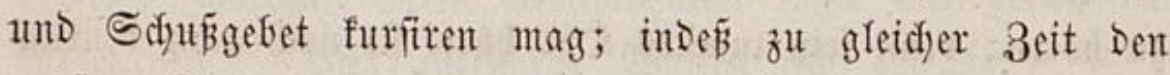
größ̈ten Rirdfenfichtern Gienieden Die Gicbete, Die fie für Den Drucf uno Berlag ofne afle Selfft=Rüfficdten blos für fremoe Bebürfnitīe mit beftändiger ફinficht auf wafre mämlidje Sanzelferebtjamfeit im Namuftipte ausarbeiten, broben als Gaare Flüdje angefdrieben werden.

Wenn mu foldje Ridjter bort von einem und bem an=

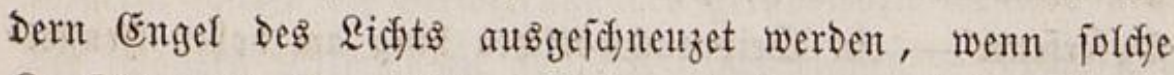
Ronfiftorialvögel zu völligen (5algenvögeln gerupft im simmel fliegen: io Dürfen verfannte. Siafgenvögel biejer $\mathfrak{A}$ rt in iffen 
theologifiden Sournalen, falls fie broben weldye fodreiben, mit

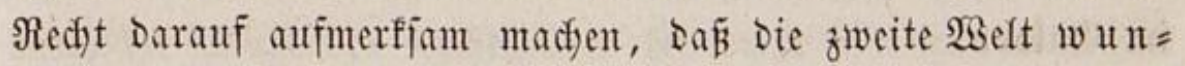
Derlidye secilige habe, und nody mandye $\mathfrak{A}$ uffërung brauthe, bis fie fo weit vorrïfe, Dan fie Gjebete auf Dem Theater und (5iebete auf bem Sofreibepult, nad) (sinem liturgijonen Sty)= liftifum, fo zu jagent, abgeflut(j), gleid) gut aufnefyme.

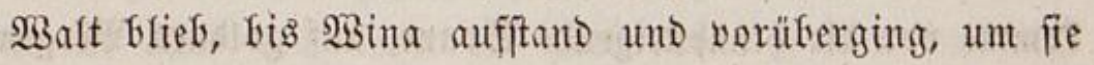
anzulefen. (Er fonnt' es aber nadhber gar nidft begreifen, Dẩ er, als fie in Der größ̈ten Räfe war, unmifleürlid) wie frampffaft bie A̛gen zugeorücft; ,uno was half's mir viel,

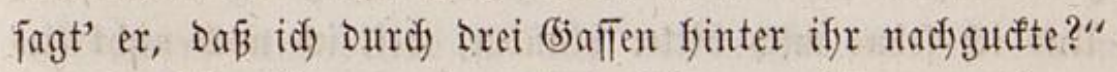

(Er fofweifte aus Der Stabt finaus. (ङs war if)m, als wem zwei cinander entgegen wefjente Stürme eine Roje mit= ten im Soimmel fodwebent erfielten. Drauken ftand ein lan=

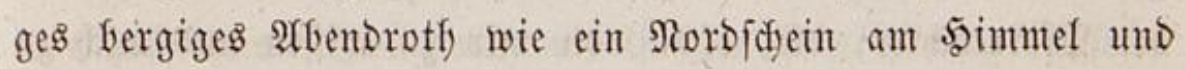

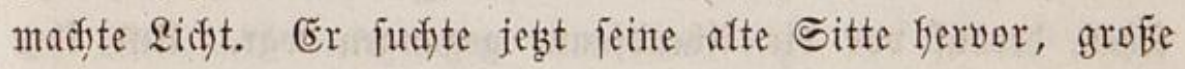
Erregungen $-z$. B. went er irgento einen $\mathfrak{B}$ irtuojen gejefen, und wär's auf Dem Tamzjeile gewejen - baburd zu näf)ren

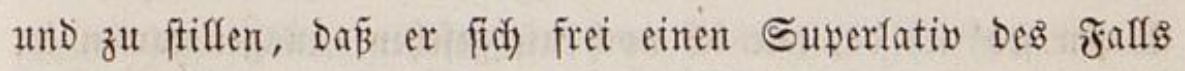
austräumte, wo er bie Sache nodh Millionenmal weiter trieb. (5r magte Dreift Den ferrlichften Traum über $\mathfrak{B}$ inta und fich.

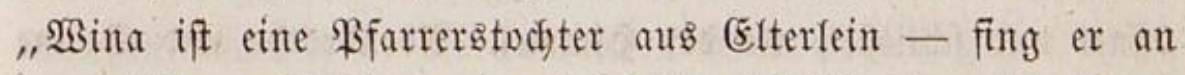
- zufällig reî́ id Durd) mit Suite; id bin etwa cin Mart= graf, ober (5roffferzog, nämliç) Der (Erbprinz Davon - nod) jung (bod) idf) bin's jeşt audf), fo fildofdoun, fefre lang, mit

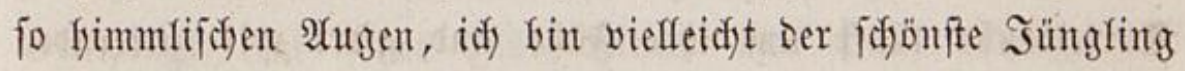
in meinem sande, ganz äfnlidi) Dem (brafen - Sie fab midy vor Dem $\mathfrak{B}$ farrfauje vorbei fprengen auf meinem $\mathfrak{A}$ raber; Da

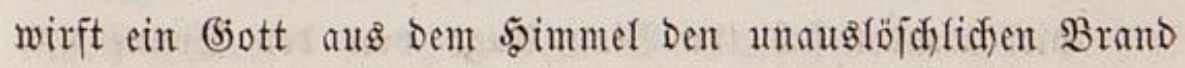
Der Riebe in ifre arme zarte Bruft, als er Das 3cidjen, einen 
(Erbprinzen auf eintem $\mathfrak{A}$ raber, erblifft. Sth fal) fie aber nidft im Sialopy.

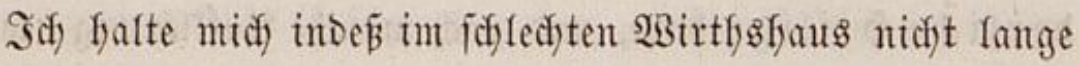
auf, jonbern befteige ofne Suite Den nafen 5immelsberg,

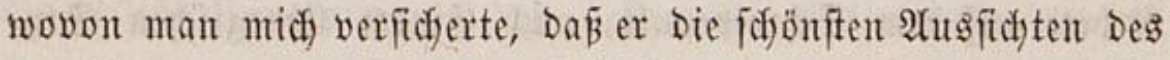

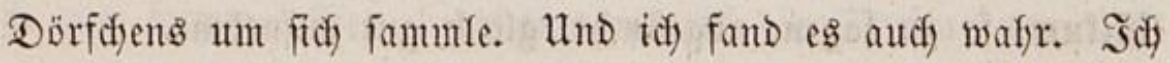
fomme vor Die finabiteigende Somte, auf goldnen Bergen Der

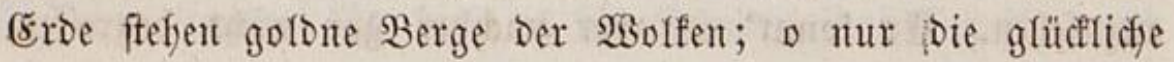
Sonte Darf finter bie feligen (jebirge getyen, weldhe bas alte ewig verfangte rofentothe Riebestfial Des Serzens umichließer - Uno idf jefne midh bitter fyinüber, weil id nod, nidyt lies ben Durfte als \$rinz, und träume mir Szenen. Da fajlägt eine Radjtigall finter mir fo heī́, als ž̉ge fie iffren Ion gewaltjam aus meiner Bruft; fie fibst auf Der linfen Sofjulter

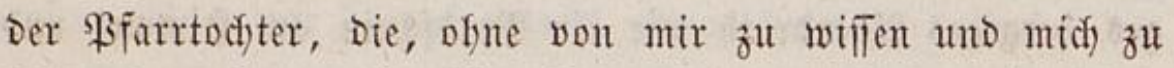

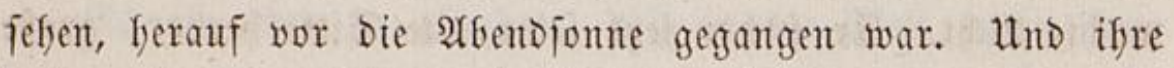
beiben $\mathfrak{A}$ ugen weinen und fie weiß nidft warum, Denn fie

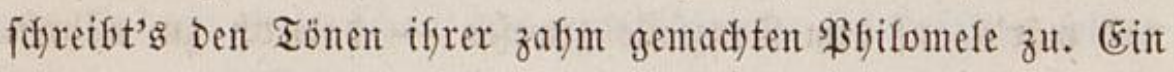
Wejen fef' id Da, wie id) nodh nie gejeffen, ausgenommen int fionzert - Dody es iff eben $\mathfrak{B i n a}$ - e ene Menichen = B(ume

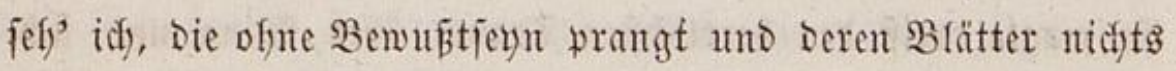

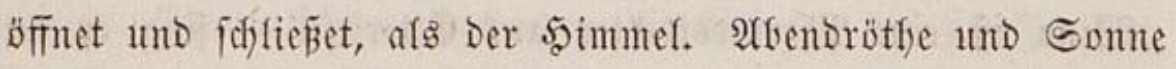

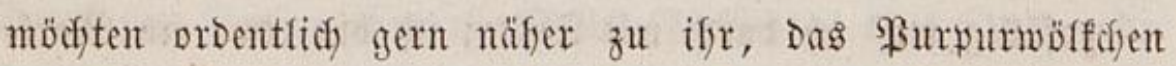

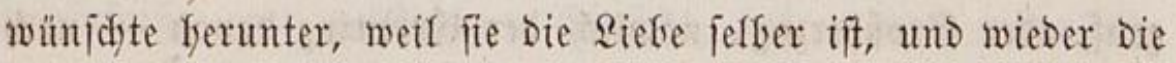
siebe felfer fucht, fie ziefjt afles seben an fid) beran. (sine Turteltaube läuft um ifre ₹üüe und girrt mit zitternden

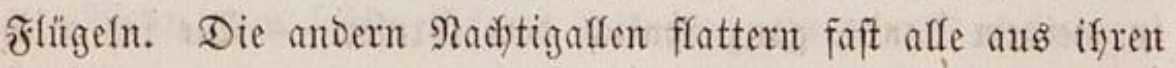
Büfchen und fingen um bie fingende ferum.

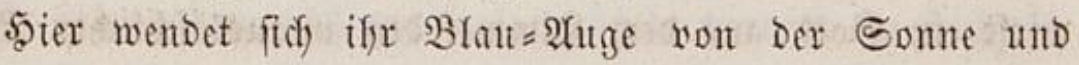

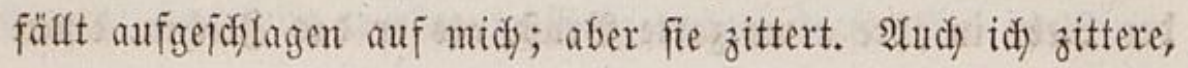


aber bor Freude, und aud ifrentwegen. Sd gefye jut ifrr

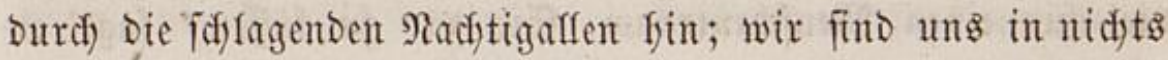
gleidf) als in ber Sdhönbeit, Dentu meine Riebe ift nod) beifer als ifre. Sie büft ify saaupt und weint und bebt, und idy glaube nidyt, Dab allein mein boher Stand fie fo cridyütert.

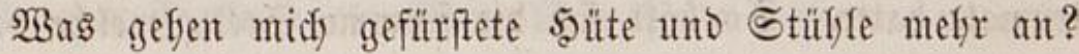

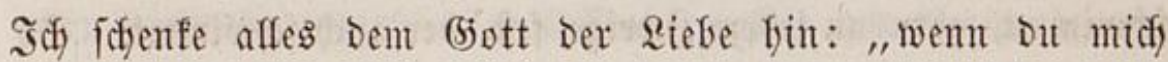

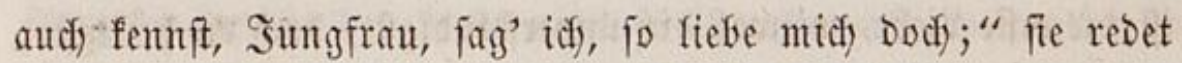
nidyt, aber ifre Radytigall fliegt auf meine Sdfulter und fingt. "Siefy!" fag' idf efrerbietig uno mefor nidyt; uno nefyme ifre rechte Saand und Drüafe fie nit beiben Sänden feit an mein Soerz. Sie wiff fie aber mit Der finfen folent und Iosmadyen; aber idy faffe und orüfe num audy Die Rinfe. So bleiben wir, id) ferb fie unaufförlich an, und fie blicft zumeilen auf, of

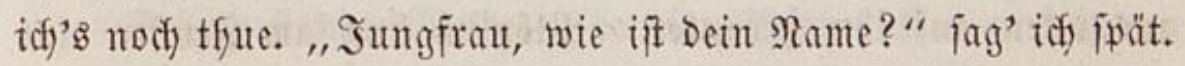

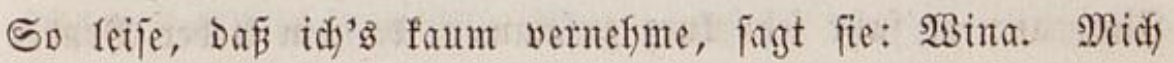
Durd)zittert Der Raut wie eine ferne alte Bruber= Stimme.

"Wina bebeutet Giegerin" antwort' idy. Sie brülft, glaub' idh, fdyad meine Santo; Die Riebe lyat fie erfoben über \$farrer = und über \$rinzenftand. So blit' idy fie unauf= förlidy an, uno fie midh zuweilen - Die rufenten Radutigallen

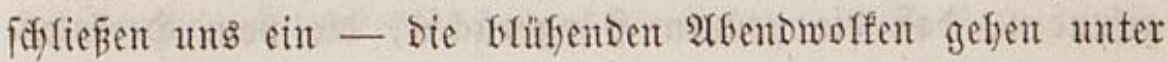
- Der lädefnde $\mathfrak{A}$ fendftern geft unter - Der Sternenlyimmel

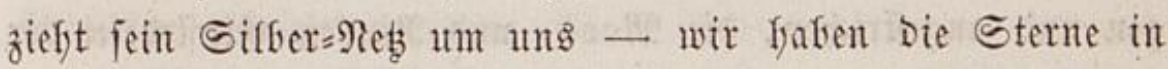
Der Sgand und in ser Bruft, und fofweigen und lieben. Da fängt eine ferne Flöte finter Dem simmelsberge an, uno jagt affes laut, was ung fomerzt nut freuts: „es ift mein guter Bruber, fag' idj, und im Dorfe wobnen meine Yieben (Extern." - Şier fam $\mathfrak{B a l t}$ zu fidd); er farl umfer,

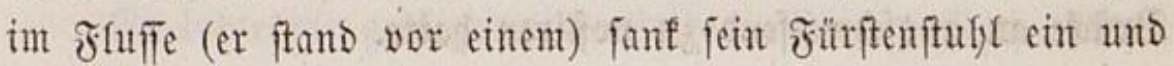




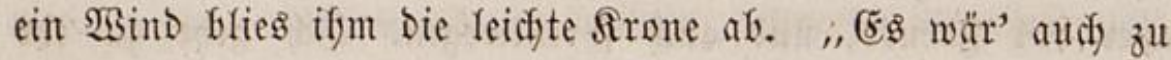
viel für einen Menjofentraum, Sie gar zu fülien" jagt" er

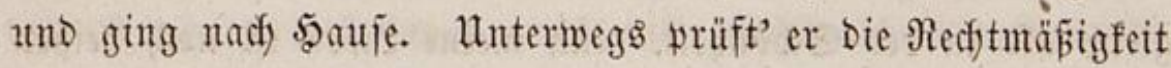
Des Traums und fieft ifn jo Stüaf für Stüif an Den mora=

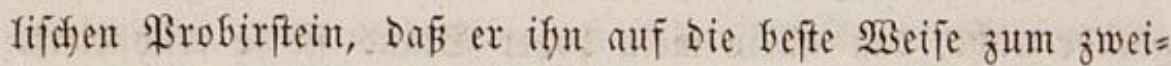
tenmale fatte. So bält fidi Die fromme Scele, weldye bantge fdrwimmt, gern an jebem Bweige feit, ber aud fdjwinmt. So ift bie erfte Riebe, wiewol bie unverftändigite, bod) bie beilitgite; ifre Binde ift fwar biffer und breiter - bem fie gefft üfer Augen, Dfren und $\mathfrak{R u n d}$ zugleid - aber ifre Sdyungfe= Dern fint länger uno weiker, als irgento einer antoen Riebe.

Bor Reupeters baupe unten jafy er fang fo feinem fen= fter auf, feine Befle fam ifm orientlich fremb vor und er fidf, atmo es mar iffm, als müne ber Rotar jede Mimute oben her= ausgucfen auf ifn Geruter. Blöblid) fing am genfter eine Flöte an; er fufre fefyr furz zujammen, da fein liefer Bruber

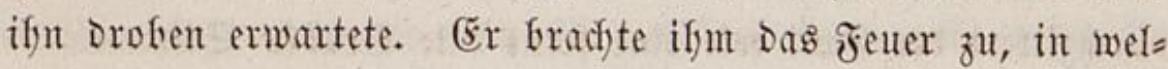
d)es $\mathfrak{B S}_{\text {inta }}$ ifre milbes Del gegollen. Bult war ganz fiebreidy und freunolids; Denu er fratte unterbelfen im Doppel= Romant

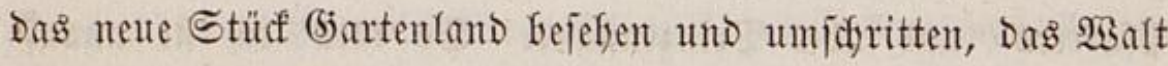
bigfer Daran fertig gemadift uno gemauert - uno fyatte ba

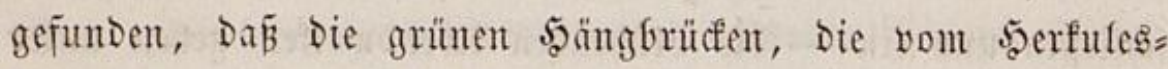
Tempel ber freundidyaft wegfüfrten, jefre fojön gut gefos gen und angeftridyen, Die Moos $=$ uno Rinden $=$ Einfiedelei Der erften $2 i e b e$ aber, bie fidf jelfer nod) für einjam und ein= berzig fält, vortrefflidy, nämlid, ftifl und ounfel uno roman= tifich angelegt worden, fo Daj mun nidfts weiter mefre feflte

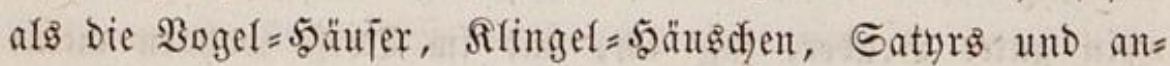
Dere Garten = (5ötter, Die Bult feines Drts uno Amts von Der

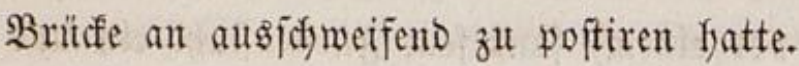


Er pries gewaltig, wiewol feute Das Lob Den Rotar we= niger entzüufte als erweichte. "Brüberlein, jagt' er, fennt” idf Didf und Die Madyt Der Sumft nidyt fo gut, fo fofwurs' id), Du wäreft fidjon auf Dem eleftrifofen Siolir = Sdyemel Der erften Riebe geftanden, uno bätteft geblibst; fo wafyr uno fübjod fteft jeber Funfe Da." Demn Bult batte bisfer, ungeadjet ober viefmefrr wegen aller Dffentyerzigfeit Des Brubers, Das

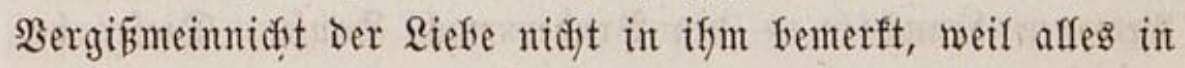
ifm woll Riebes = Blumen ftano, und weif $\mathfrak{B}$ ult felber jebst nidyt viet aus Den Weibern madyte. Sein Sdymollgeift, jagt' er oft, meibe Den weiblidjen; man münTe ans einem lacfirtent Stäfden, Das nur für bie weiblidfen Bhumen in Der Eroe

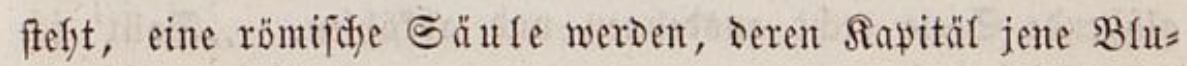
men blos befränzen.

Sefrr erftaunte $\mathfrak{B a l t}$ - Der int Dopwel = Roman mur Der Didyter, nämlid) Das ftille Neer gewejen, Das alle Bemegun= gen, Der Seegefedyte uno Des 5 immels, abjpiegelt, ofyne felber in einer zu fenn - als Sult aus Dem Budje von weitem fafließjen wollte, er liebe viefleidyt. (Er glaubte bem gereijetent Flöteniften aufs SBort; jagte aber felfer feines Davon und war

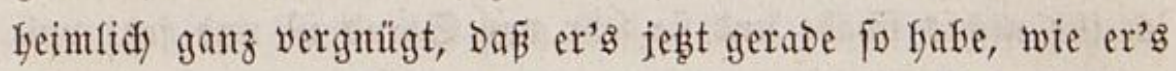
finfofreibe. Stundentang frappirte ifn eine neue Rofle, worin er etwas zu fpielen hatte, was fifon Miflionenmal auf allent Planeten gejpielet worden.

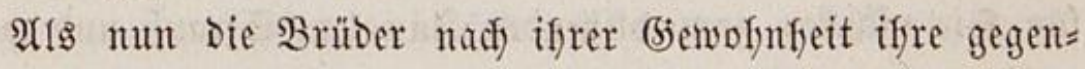
feitigen $\mathfrak{I} a g g$ gejeficften gegen einantoer austaujfhen wollten: io ging Dem Notar Die feinige fefy fodwer und flebent von Der 3utge; - er fielt fidf mefr an Den beneral und an Deflent mémoires érotiques, um jeine eignen zut Deffert.

Er lobte Die geiftige reine Blüte in jenten; $\mathfrak{B}$ ult läd)elte 


\section{0}

Darüber uno jagte: "Du bift eine verbammt gute Secle!" Die Riebe, weldye bas gauze 5erz affnet, jo wie veridfenft,

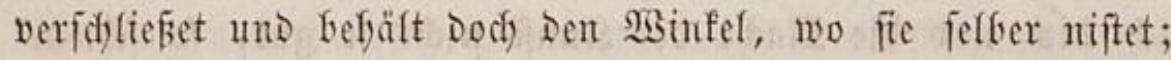
uno Diftirt Dem beften Süngling Die erite Rüge, wie Der beften Sungfrau Die längfte.

Walt begleitete - bei jeinen imnern Bewegungen, Deren Bhutfügeldyen wie föfere Siugeln einen freien Simmel zum Bewegen Graudften - Den Bruber nad) 5auje. Diejer bes gleitete erfreut wieder jenen; Walt wieber Diefen, un vor WBina's senftern auf Dem seimmege vorbeizufommen. So triefsen fie es oft, fis der Notarins fiegte.

Erinjam unter Dem freiten Stentenfinmel fonnt' er bie

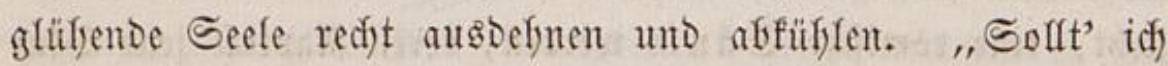
Denn Den romantifichen, fo oft gedidsteten fall jest wirflich in

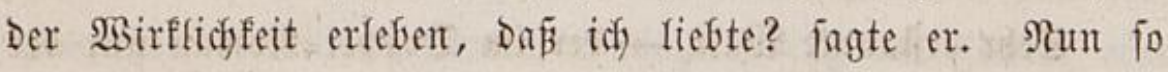

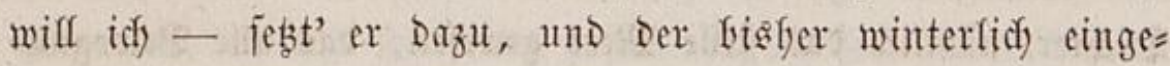

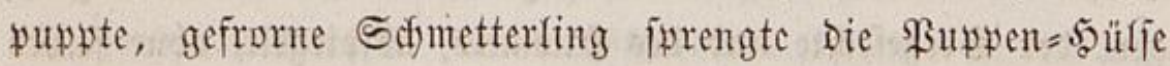
weit ab, und fuffr auf und wiegte feudfte Sdjwingen - lies Gen wie niemand und bis zum Tod und Sdfmerz - Denn idf fann's ja gut, Da Sie midf nidjt femnt uno nidft liebt, uno

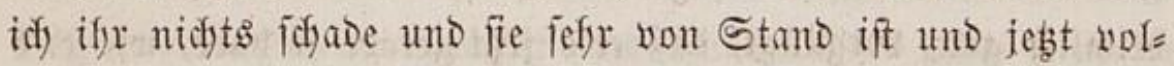
Iends auf 1 Mionat verreifet. Sa es jei $\mathfrak{F} f r$ ganz uno voll fingereidft, Das untefannte 5 erz, und wie unterirdifchen (5öt= tern, wiff idf ifr idfweigento opfern. D idf fönte bieje Sterne für Sie pflücten zum blikgenten Suwelen = Straús uno weidye Rifien aus Dem Montbe Darein bindent, uno es in Sfrem Sdylafe

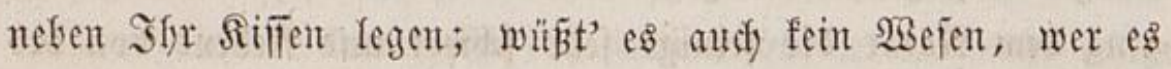
getfyan, idf) wäre zufrieden."

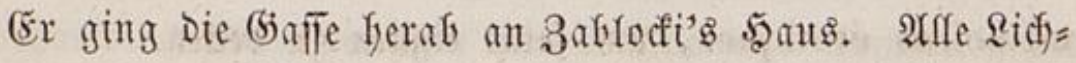
ter waren auggelöfdt. (Eine fermidfwarze 2 olfe fing fith 


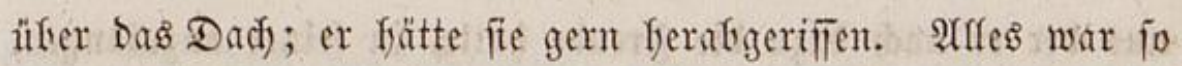
ftill, Daß̧ er die $\mathfrak{B a m b u b r e n ~ g e f j e n ~ f o ̈ r t e . ~ D e r ~ M o n d ~ j o u ̈ t = ~}$ tete feinen fremben Tag in Die Fenfter Des Dritten Stocfwerf'. „5 wär' id ein Stern - jo jang es in ifm und er förte nur zu - idf) wollte $\mathfrak{S} f r$ Yeudften; - wär' id eine Roje, id

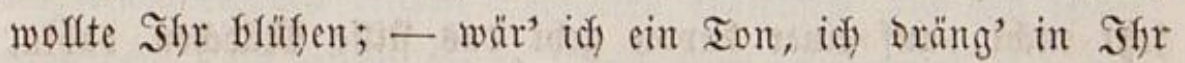
Serz; - wär’ idh Die Riebe, Die glüflidhfte, id) bliebe Darin; ia wär' idf nur Der Traum, idh wollt' in Sfren Gdflummer ziefren und Der Stern und Die Roje und Die Riebe und afles fern, und gern veridfwinden, wenn fie erwadyte."

(5r ging nad) 5ूauje zum ermiten Edylaf, und hoffite, Daß iffm vielleidyt träume, er jei Der Iraum.

No. 3\%. Sine autserlefene Rabintetsonitfe.

$\Re$ e u e g $\mathfrak{T} e$ it a ment.

Der September war fo fidoun, Der Die fiboupte Roje, Wina, verjeb̧t hatte, Daß̉ Dem Rotar Rodf, Stube und Stadt ful enge wurbe; er wollte ein wenig in bie weite $\mathfrak{W e l t}$ fin $=$ auts. (5̌r reijete unjäglidif gern, befonders in unbefannte (5jes genden, weil er untermegs glautste, es jei möglid), Dấ ifjm eines Der romantijuften lieblidgiten âbententer zuflattere, von Dem er nod de gelejen. Daher war Das erfte, was er in einer neuen Stadt madfte, fleine Stumbenreifen um fie bermm. Satt' er aber lange da gewohnt, fo lief er zut Beiten in eine neue (5ajpe ein, und madjte fidy mit bejonderem Bergnügen glaublidy, er jei eben auf Reijen in einer ganz fremben Staot, 
aus Der er nod Dazu Die Frente fatte, in feiner anzulangen, fobalo er nur um die (sfe umbog. Sa faf er nidyt träu=

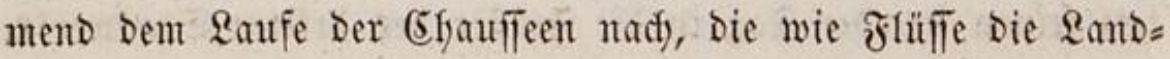
foraft fochmücfen, weif fie, wie bieje, ofne wolfin und woher unendidy zieben, und Das Reben piegefn? - Und Dadyt' er jeb̧t nidyt, auf einer bavon gebt das ftille Mäbdyen Dafin, und fiefst Den Glauen 5immel und Den $\mathfrak{B a t e r}$ an und Denft an vieles? -

Nur war er lange in 3weifel und Sfrupel, ob's nidjt Sünde jei, Das wentige von Den (5itern und Inftrumenten ge= wonnene (sielo blog vergnïgt zu verreijen, zumal Da Der Bru= Der $\mathfrak{B u l t}$ nad) jeiner (5ewolnhbeit wieber anfung, nidyt viel zut haben. Ěr las alle moralifden Regefn Des reinen Sab̧es

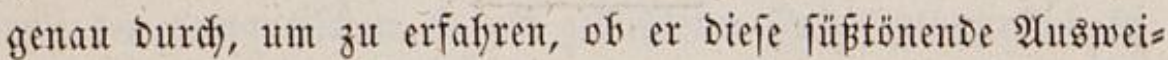
d) fein Rirdbenfüua aufnefmen Dürfe; und nody war er unent=

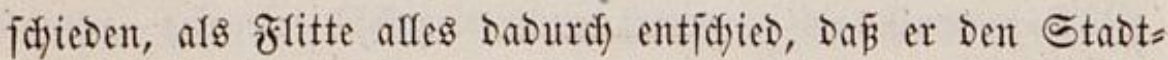
thürmer, bei weldyem er wohnte, zut ify fodifte und jagen

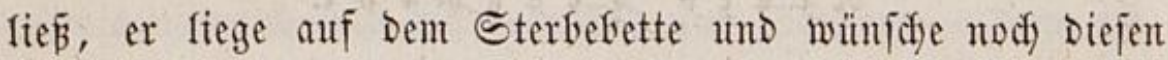
Abend jein Tefament Durdy einen Notar zu madjen.

Wenn Die Belt finter Dem Rotar Den Thurm Gefteigen

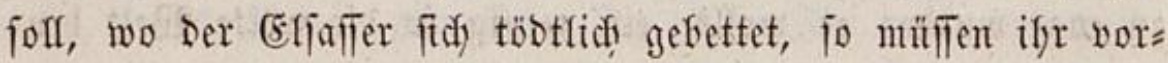
fer, ofne lange Darüber zu reben, Die notfwendigften Irep= yen fingeftellt werden, die zu jeinem Lager bringen; afles war jo:

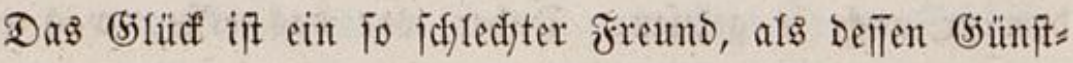
Yinge - Die Natur gibt Den Weijen auf Die Rebengreije zu wenig Diätengelder mit - Jlitte war ein foldyer Weijer, unt

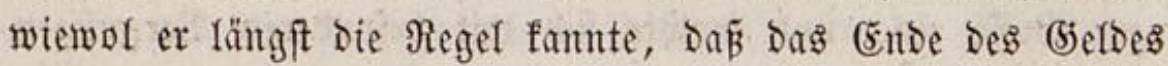

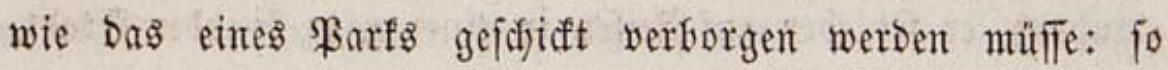


fefit' iffm body ber allgemeine nervus rerum gerendarum zu Diejer sift.

In Stäbten, wo flitte mur Durdfflog, vermodyt' er leid)=

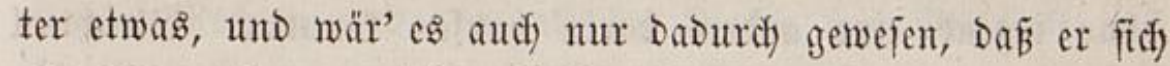
als feinen eigenen reidfen bebienten anfleibete uno fid felber ammeldete, als feiten şerrn, uno zum zweitenmal of me ben Serl wicder frm. In 5astau that es ifm einen Monat lang gute Dienfe, Daß́ or auf feine Soften einen Teich abzielyen und Darin nady einem foftbaren Iafelfteine ftodjern und wilf)=

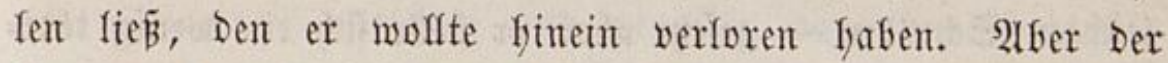
5unger, Der eben jowol als \$hilipw II., zumal unter Des leb̧= tern Regierung, Der Mittagsteufel heipen follte, uno nody mefyr Der Rleiderteufel, und jeber Ing fyatten ifm allmälig ein antändiges (befolge von Lefhnlafaien ober valets de fantaisie, Das immer finter ifm ging unter Dem befannten

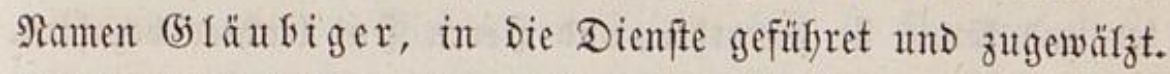

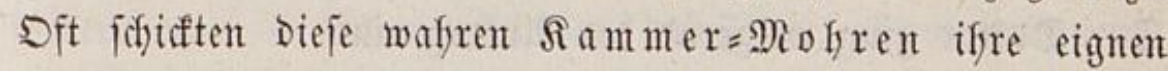
Laden = und andere Dienter als Mephiftopheleffe, die, ofne fitirt ful jern, ifn jelber zitirten.

Desivegen zog er auf Den Bjocfentfurm - peinen Edfuld = tfurm - um Durdf Die umzäfligen Treppen manche Befudje fut verleiden, ober aus Dem (sloctenftufle voraugzujefen. Hnt ten in Der Stadt fojwur er ftets, er frab' es getfan, um cine

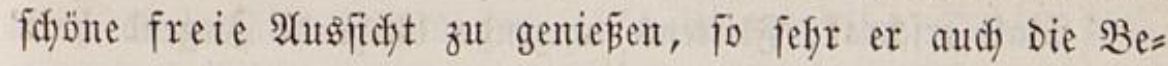
fofwerden fith yorfer babe Denfen fömen.

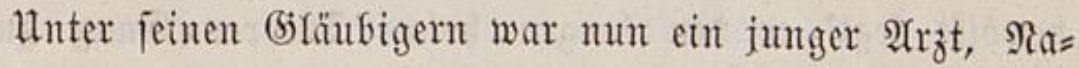

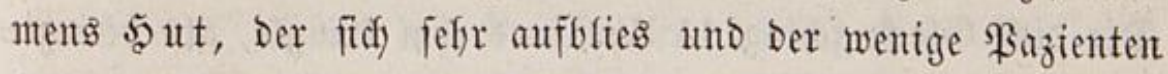
flatte, weil er iffnen Das Sterflidfe auszog und fie verflärte. Diejer Sut hatte Dent vier groß̉en Brownijđjen Sartentöni= gimnen feine vier ganzen (5efinfanmern eingeräumt - Der Sean yaul's auş getr. Worte. XIV. 


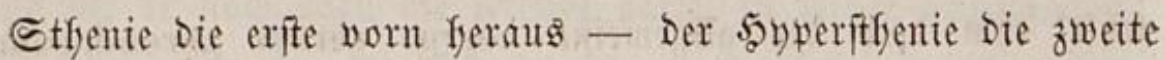
- Der affthenie Die Dritte - Der 5ayperafthenie die vierte ala widytigfte - fo Daß̄ Die vier groß̈en Soeen ganz bequem aflein ofne irgent eine andere Darin flaujen founten. Sileidfwol madyt' er mit Der fyeiligen Tetraftys won 4 medizinifichen fyllo= giffifdyen Figuren felber nody feine fonderlidje; Der alte Spais über Den Doftorfyut Des D. Souts wurbe fets erneuert.

Der galante frlitte that mun jeinem Bräubiger folgenden Antrag: ,Die Stadt flecfe volf Borurtheile - er felfer in leichtent Sdjulden - gejebst aber, er ffelle fich ein wenig töbt= Iid) franf, uno madje jein Ieftament: jo heife erfflid burdy einen Betrug fid Die Stabt von iffrem Eelfitbetrug, went 5. D. Sout ifnt offentfich wieder ferftefle; uno er feffer zmei= tent, wenn er fein Bermögen Dem 5oofagent Neutpeter ver=

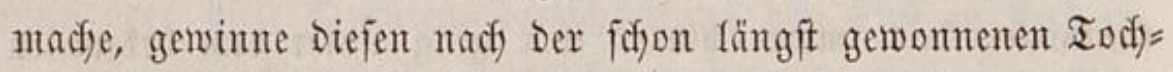

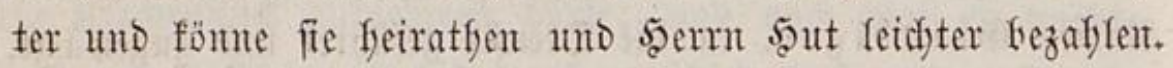
Der Doftor ging weigerno Den $\mathfrak{A}$ trtrag ein.

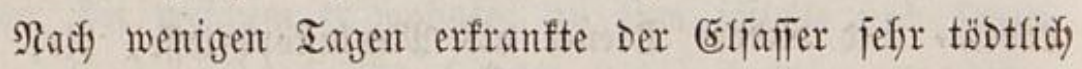

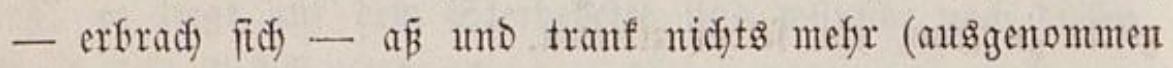

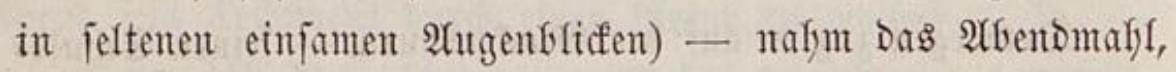
Das er und andere, wie er Dadfte, ja aud in gejunden Tagen

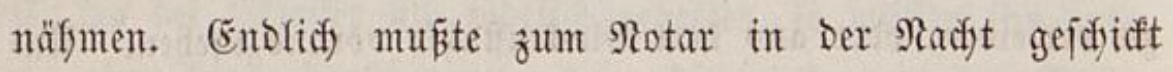
werben, Damit er Den Yebsten $\mathfrak{B}$ iffen auffebste.

SBalt erichraf; Flittens tanzente blüfente Sugend hatt' er geliebt und ifn Dauerte ifre Niederlage. Sdfwer, idjwül, bewölft legt' er Den langen fyofen Treppen = (5ang zurücf. Die biffe (5loffe follug $11 \mathfrak{u b r}$, und iffm flang's, als bewegte Der Todesengel Den Reichen = Rlöpwel Darit. Matt uno leife

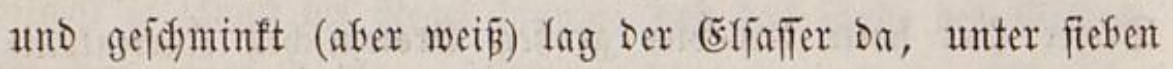
Ieftir $=$ Seugen, wovon Der Früfyrebiger Fladfs audf einer 
wax, Der es mit feitem blaffen Iangen befidft zu feinem Bešperprediger bringen founte.

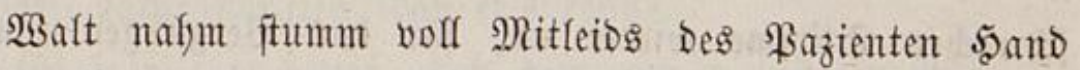
mit Der Nedjten und fog mit Der Rinfen jein \$etidjaft und Sapier aus Der Tafdhe; und überzäflte mit Den 2 ugen furz bie Beugen. (ङr forderte brei \&idfter, weil fie das promptuarium juris won iffm forberte $z$ Madjtteftamenten; war aber mit Einem elenden zufrieden, weil auf Dem gamzen Reudft= Thurm fein zweites zut fraben ftant, Desgleidjen fein Drittes, und er viel fut mitleidig und zut eifig war, jemand in bie

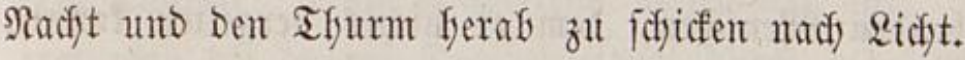

Der Siranfe fing an, Das erfte Bermädftní̄ zu biftiren, nad) weldyem Dem Raufmann Neupeter Ffittens ganze Divi= Dende am längit erwarteten weftindifoden Sdjiffe zuftarb, Des= gleichen ein verfiegeltes mit OUF bezeichnetes Sumelenfäft= d)en, Das won Den biebritbern 5eiligentbeil in Bremen abzu=

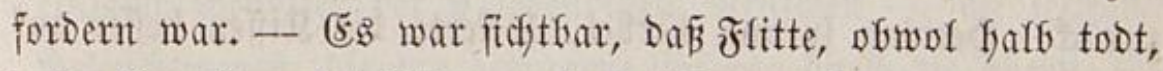
bod) überall auf Diftirte gut ftylifitte Sifreibart ausging.

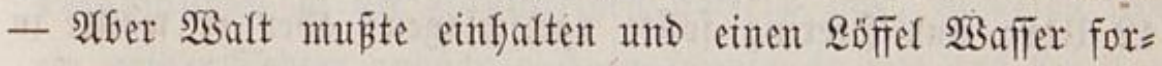
Dern, unt einige Dinte aus Dem Dintenpulver zu madjen, in bas er eintunfte. 2 (1/B bie Dinte fertig war, fant er wies Der fefre ungern, Dá bie nete gantz anbers ausfefye als bie alte, unD Dá er fo Das Snftrument - geradez̧u entgegen affen Rotariats $=$ Dromungen - mit Dopwelter Dinte fint=

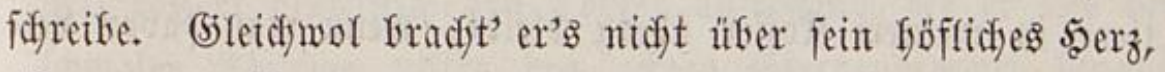
alles zut zerreipen und von neuem anzuffeben.

Darauf teftirte Der Siranfe Dem Durftigen Fladjg peine fitfernen Sporen und feinen mit Seefyuno fezognen leerent Rofier und bie Reitweitiche. Dem D. Sout vermadjte er alfes, was er an $\mathfrak{A} f t i v=$ Sdy ulden in Der Stabt zu fordern hatte. 


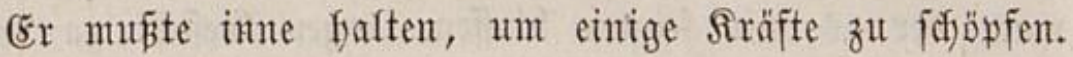

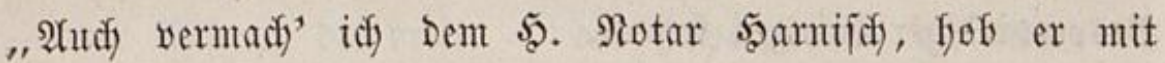
fodwadfer Stimme wieber an, für Das Bergnügen ifnt z"t fenten, afles, was fid theils an Baarjdfaft, theils an $\mathfrak{B e d}$ )= feln nad) meinem Tode bei mir vorfintoen mag, unt was fich gegenwärtig nidft über 20 friebridgso'or befaufen wirb, Da= Y)er idf iffn bitte, worlieb zut nefmen, und meinen goldonen Jingerring nodi beifüge."

Walt fonnte faum bie feber füfren; and wollt' es aud nidft mefr; Den er erröthete, vor fo vielen Bengen, und von einem fterbenden Menidyen, Dem er nidyts vergelten fonnte,

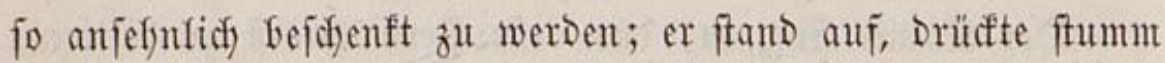
yor Nitleident und Riebe die gebende 5and und fagte: nein, unb bat ifn, nodh einen $\mathfrak{A r}_{\mathfrak{z}} \mathrm{t}$ zu wäflen.

"Dem 5yon. Stabttfürmer 5eering" - wollte fritte

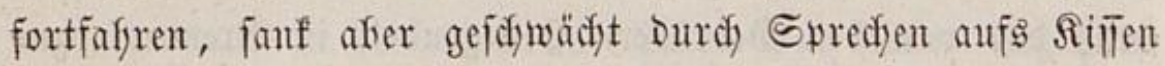
zunücf. Seering fprang ferbei, locferte Die Siffen beffer auf

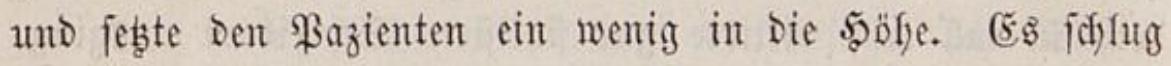
12 ufrr; und Secering follte nadjodflagen; aber er wollte in einem foldfen aftus nidyt främmern auf ber bifocfe, fondern erfielt Stifle, Damit man Den Teftirer forthöre: „iffn aljo Gedenf' idj mit meinem feinen weiß̄en Zeuge, Deggleidfen mit alfen meinen Rleidern - nur bie Reiffitefelu gefören Der Mago - uno alles was nodf yon einer reidhbejebten $\mathfrak{L} a b a=$ tiere in meinem Roffer Hibrig Gleift, wenn man Davon Rei= d)en = unt anbere Sioften beftritten frat."

Bald nad) einigen Legaten und madi) Den Formafitäten,

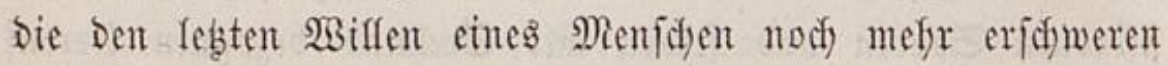
als ben fidfimmifen vorfer, war afles afgetfian. Roch Drang Der fichtbar mefyr ermattende Effājer Darauf, Daßj Der Notar 
jebst alle feine (Effeftent mit Dem Notariatsfefegel zupetichire. (Er that's, Da ifm afle Bromptuarien, fowol von sommel als

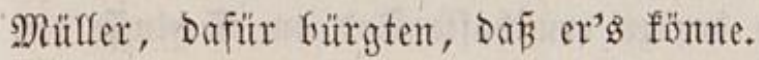

(5s war ifm bitter, von Dem armen fuffigen $\mathfrak{B}$ oget -

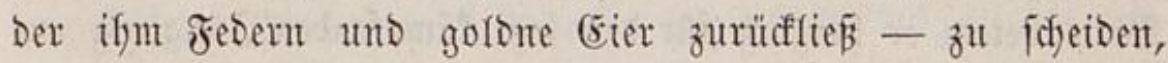
unb iffn fofon in Den Frallen Der rupfenden Todes = Eule um

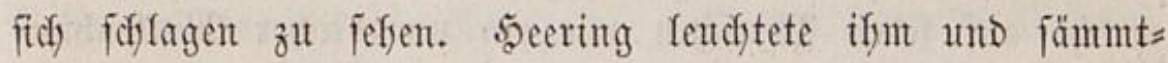
ficfen Beugen feraf. "Mir will's folwanen, fagte Der $\mathfrak{I}$ fyür= mer, Dấ er Die Nadjt nidgt üferftefl; idg habe meine furiofen

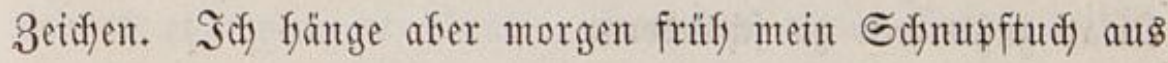
Dem Ifurme, went er wirflich abgefafren ift." Schauerlidy trat man bie langen Treppenleitern Durdi Die leerent Dumpfent Thurm = (jeflüfte, worin nidyts war, als cinte Treppe, herun=

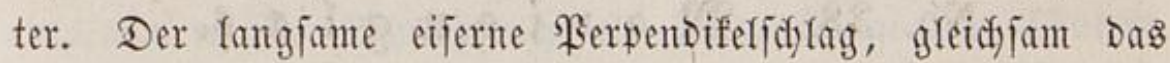
5̧in = und 5ermäfen Der an Die Whr geffangenen (Eijen = Senje

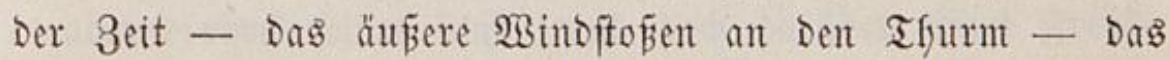
einfame Bewolter Der 9 lefendigen Menjiden - Die feltjamen Befeudytungen, Die Die getragene 2 aterne Durd) bie oberfe (5m= por finunter in Die Stuflreifen flattern Yiḗ, in Deren jeber ein gelber Toster andächtig fiben fomnte, fo wie auf Der Ran= zel einer ftefen - unb Die Errwartung, Daj bei jebem Tritte Flitte veridetion und als bleidjer Sdyein Durdh Die Rirdje fliegen föme - - Das afles jagte wie ein banger Iraum Den Notar in Düften Ranbe Der Siflatten und Sdyreffen um=

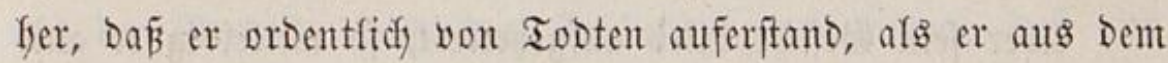
fdymalent Thurme unter ben offiten Stemenfimmel finaus: trat, wo broben $\mathfrak{A}$ uge an $\mathfrak{A}$ uge, Reben an Reben funfelte unt Die Belt weiter madite. -

Flachs, als (Beifflicher von Den vier lebzten Dingen mefre lebent als ergriffen, jagte zu $\mathfrak{B a l t :}$ "Sie faben brtüaf bei 
Teftamentent." A̛tber biejer bezog es auf jeinen Styl uno Stand, er Dadyte an nidjts, als an bas närrifade büpfende Rebens = Rarnaval, wo ber fu ernityafte Tod am Schluffe Den Tänzem nidft mur bie Rarven abzieft, audf Die befichter. Sm Bette betete er Gerzfic) für Den iełst fämpfenden Süngling um einige 2 fbendröthe oder früflingsffralen in Der wolfigen Stunde, weldye auf jeben Menfdyen wie ein unentidjer $\mathfrak{B a f f e n f i m =}$ mel plöbliç) obent herunter fäll und ifn zugefülflt auflöfet.

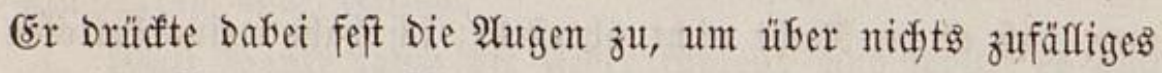
etwan zufantmen fu fodantern.

No. 38. M $\mathfrak{a} \mathfrak{r} \mathfrak{i}$ e $\mathfrak{n} \mathfrak{g} \mathfrak{l} \mathfrak{a} \mathfrak{s}$.

$\Re \mathfrak{a} \mathfrak{h} a \mathfrak{e} \mathfrak{a}$.

$\mathfrak{A}(\mathfrak{B}$ Gsottwalt erwadyte, lyatt' er anfangs affes vergenten, und Die Afbentberge vor jeinem Bettfenfter ftanden fo roth

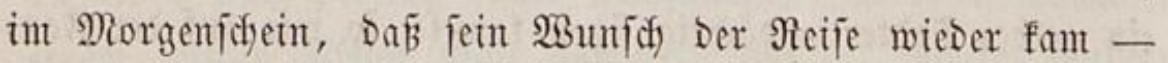

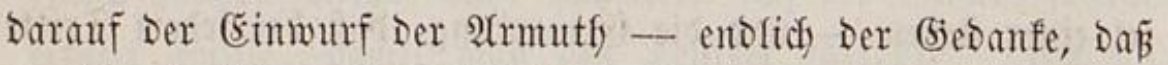
er aber ja 'über 20 \&ouisb'or gebiete. Da fafy er nach Dem Stabttfum, worauf als einem castrum doloris mun Der ver= ftorbne Flitte liegen fonnte, uno wollte traurig aufblicfen.

Ifber fein beficht blieb aufgelfeitert, jo mitleibig er aud

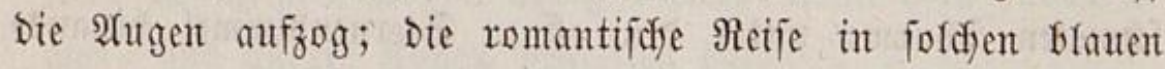
Tagen - in foldyen Berbältnifien - jo plöblitidy geidsenft - Das war ifm ein Durdigang Durdy Die hellefte (5Tüd's= fome, wo es Ridjt ftäubt uno man fich ganz mit frimmern überfegt. 


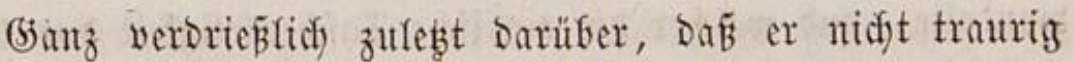
werden wollte, fuffr er of he befret aus Den Febern, unb hörte feit şerz ab. (Er modite aber fragen unto zanfen, fo lang' er wollte, und Dem 5̧erzen Den Glaflen jungen Reidfuam auf

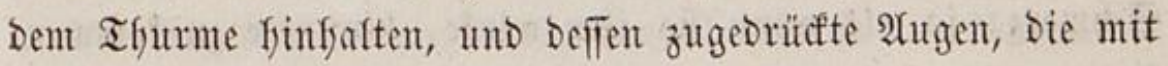
feiner Morgenjonte mefre aufgingent: es half gar nidjts, bie Reife und mitfin Die Reifegelder befielten iffren Boldoglanz, uno Das şerz faf jefor gern finein. (Endich) fragt' er auf= gebradjt, ob es Denu, wie er jefe, Des Teufels lebentig jet,

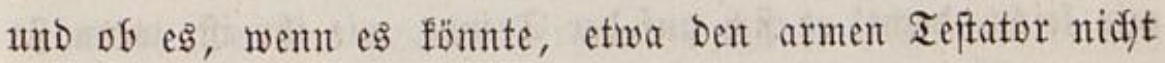
fogleid) und mit greuben rettete und aufbrädte? Man be= fänftigte ifn ein wenig Durdf Die 2Antwort: mit Freuben und

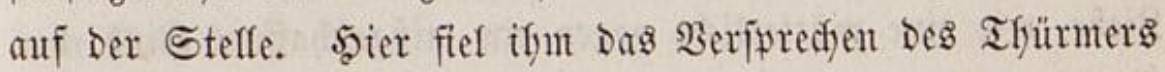
eit, cin weī̄es Sd)muftudy als Trauerflagge an Thurme

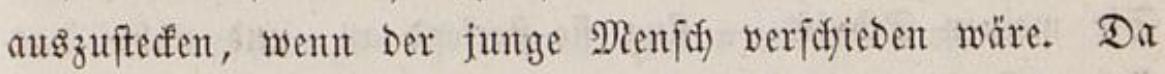
er aber Droben feines fand, und dod) Daritber einige Freutde

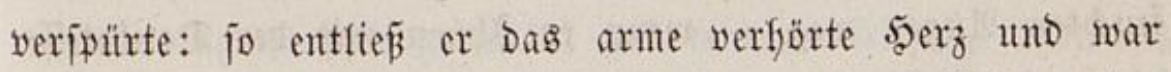

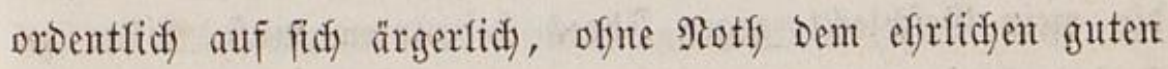
Schefm io zugeielzt zu habent.

(Ex Gätt' aber mur biefen Sdyelm fragent follen, wie ifyt Gei zefrumal gröperer (Erbjofaft z. B. Der Tod Des Brubers geftimunt faben würbe: fo würo' er, went er gefunden fätte,

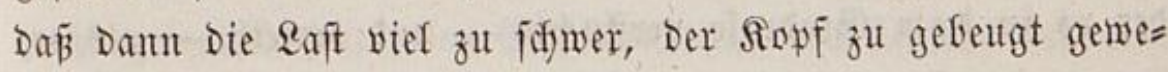
fen wäre, um nux etwas anderes zu felyen, als Das (brab

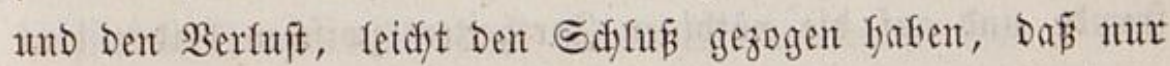
Die Riebe Dent Sdjuterz eridfaffe, uno Daß er vergeblidy einen zu gropen bei einer zu fleinent für Den Erfajer von fist) gefordert.

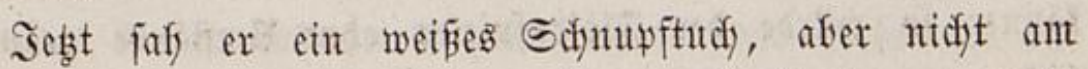
Thurm, fondern an Raphaelen, Die im $\mathfrak{B a r f e}$ _traurig luft= 


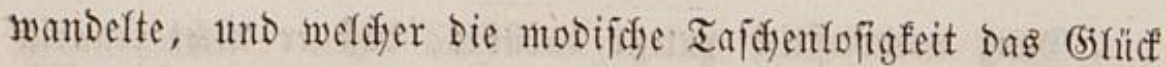

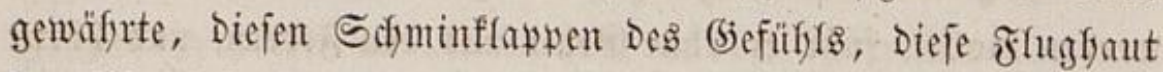
Der \$ryantafie in ber samb zu baben. Sic jafy oft nach Dem Tfurme, einigemal an jeint Fenfer, grüist' iffn mitten im Sommerz; ia als went fie ifm winfe, finunter zu fommen, foum es ifm vor, aber nidft glaublidy genug, weil er nus englifichen Romanen wuste, wie weit weiblidye 3artfeit gefhe. Sndeß faut flora utit bat ifn wirflich frinab.

(ro ging zur Bewegten als ein Bewegter. "Id Denfe mir leidyt, Dadft' er fich auf Der Treppe, wie iffr ift, wenn fie an Den Stabttfurm fieft, und Droben Den cinzigen Menfiden Gald aufgebafret glautben muí, Der nur burdy cine ferzlidjite Riebe, wie eine mütterfid)e gegen ein miß̈geidjaffnes ßino, Den

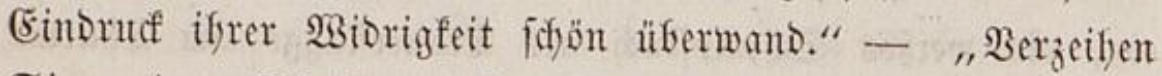
Sie meinen Sdfritt - fing fie ftocfeno an, uno nafm Das Ed)unftudy, Dieje Sdyürze cines trocfnen Serzens, yon Den feurdenten Augen weg - wenn er Shnen mit Der Delifatefle,

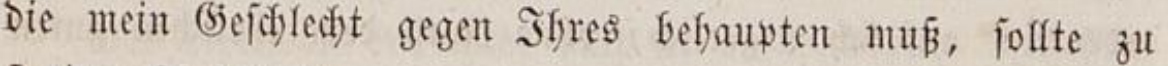
ftreiten fojeinen."

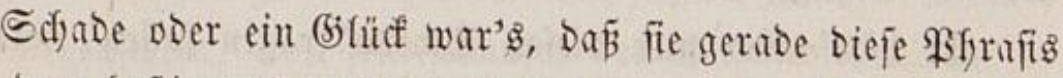
nidjt bem fraftigen Subdoeus Bult fagte; Dent Da es fojwer= Yid) in (Europa poer in Partis oder Berfin einen Maun gab, Der es in Dem (sinde fo verfluchte - uno errietl) - als er,

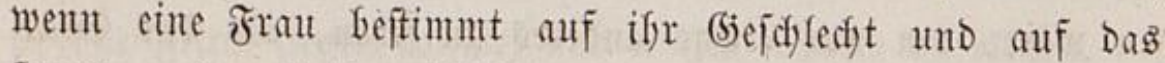
frembe und auf bie nötfigen 3artheiten zwijchen beiben fint= wies und es fräufig ammerfte, wie da mandjer samofú fie

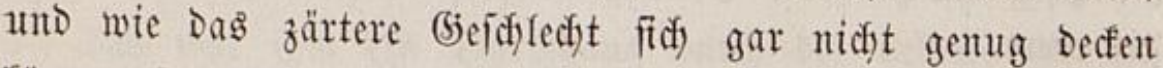
fömte: fo würbe ber frlötenfpieler ofne lumftände geäußert fabent: "eine freimütfige $\mathfrak{5}$ - jei eine fecfe 5 geifige gegen 
foldye Âgrümbe feiger und eitfer Simulichfeit zugleidy - er fentue Dergleidfen 5aerzen, weldye Das Sdylimme argmofnen, um nur es ungeftraft zu Denfen, Dic es wörtlici befriegen, um eg länger feftzuffalten - ja manche fefen fith wol gar in Der $\mathfrak{A}$ rzheifunde ein wenig $1 m$, Damit fie im Namen Der

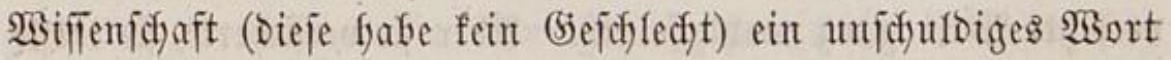
reben fümen - und lagern fich vor bem 2 (tar und überalf wie griedridf II. fo fdflagfertig, en ordre de bataille, wie auf Dem Sopha. - Wahrlid, febst' er Daz̧u, fie gefhen ins leibliche, oder ins geiftige 3ergliederungshaus, um bie Reidfen

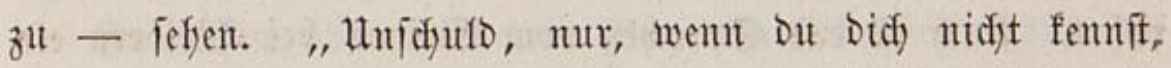

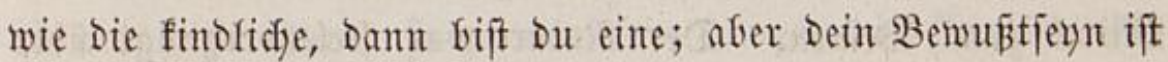
Dein IOD."."

So fajeint, gleidfnifipeife, zermalmtes (5ilas ganz weiz, aber ganzes ift beinafe gar unji d)tbar.

So Dadifte aler nidft Balt: fondern als Raphaela an ifn Die obige $\mathfrak{A}$ nrede gehalten, gab er Die aufrichtige 2 nntwort,

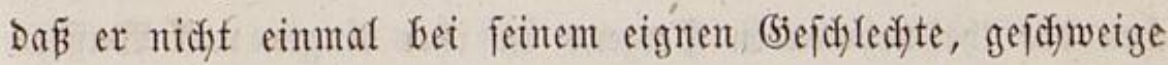
bet bem heifigften, Das er fenne, irgent einen Sifritt anders

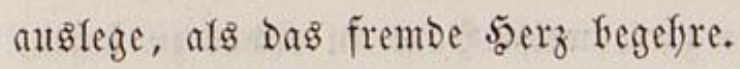

Intoé batte fie ifn weiter nidgts fut fragen, als: wie Der Sterbende - Demt fie als cinem freunde iffres $\mathfrak{3}$ aters wohl gewolfet, wie affen Menjchen, unb ben fie fefre bebautert

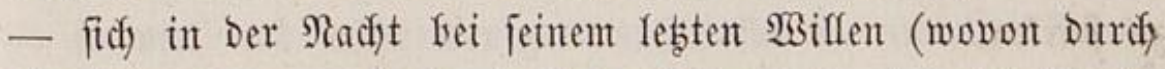
Die fieben 3eugen als Durdh fiefen Thore eben fo viele Brode finlänglicher Radfridften Der Staot fyerausgereidft waren) fidf benommen fabe, was fie gern fut wifien wünfdye, da ein Ster=

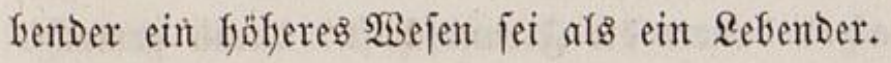

Der Notar antwortete gewifientyaft, Das beiß̈et als ein Notar, und fagte, er floffe, nady Dem Sdymuftudy fu idflie= 


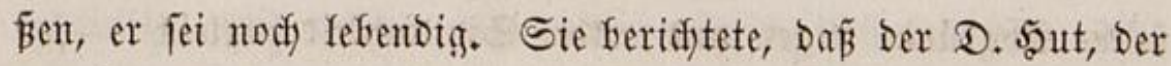
gerufen worben, ifn zwar angenommen, aber als einen ver= Yornen Menfdyen, und fie wünjote Dem Doftor, mit iffem

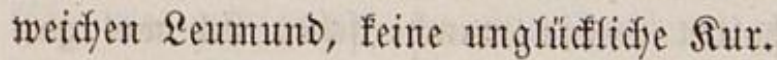

"Das ift Dody fdjon was, uno Die überlebte Nadjt Dazul

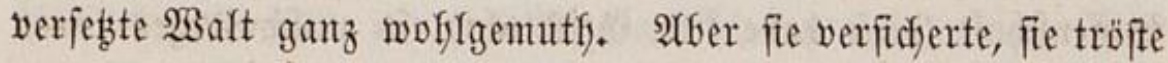

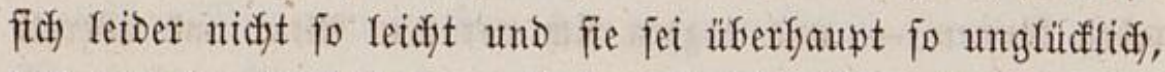
Dá̃ Das frembe Reiden, aud Das fleinfte iffer Berwantent, fie heftig angreife und fie Thränten fofte. Sie brad) in einige aus; fie wurbe von fich fo leicht, als von andern fodwer ges

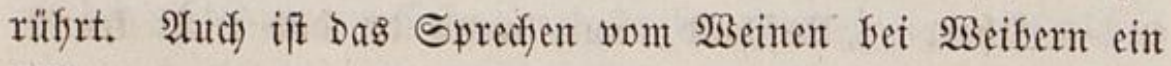
Mittel zum $\mathfrak{B e i n e n . ~ D e r ~ N o t a r ~ w a r ~ j e e l e n v e r g n u ̈ g t ~ u ̈ b e r ~}$ alle die Rüfrungen, Die er theils jaf), theils theilte. Riebes Frauten $=$ Weinen war iffm eine fo jeltene Roft, als langer grüner Ungar, Rierenfteiner 5ammelfoden, $\mathfrak{B}_{\text {ormjer liebe }}$ Frauen=\$Rildy ober andere Weine, Die bei S.. Raufmann (5or= thum in 3erbft zut habent fint. (Er friffte iffr mit affen $3 e i=$

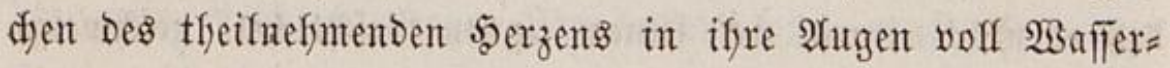
Feuer, und fätte wol gemünjdyt, Die Delifateffe englificher $\Re_{0}=$ mane verftatte ify, ifre zarte weiß̧e 5and in etwas zu fanjen, welche vor ifm ftarf im bejonten (5iüne gaufelte, unb in

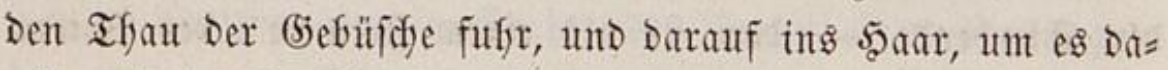
mit nad) Der Boridurift eines (Engläntoers wie andere (sewädyje zu ftärfen.

Beide ftelften fich jebst - Der Syramide uno Dem ftei= nernen (5roß̧vater auf Der Snjel gegentüber - an eine $\mathfrak{H}$ me aus Baumrinde. Raphaela hatte eine Rejetafel mit Der $\mathfrak{I n =}$ fdrrift: "bis Dafer Dautere bie Freundidaft" Daran gemadyt.

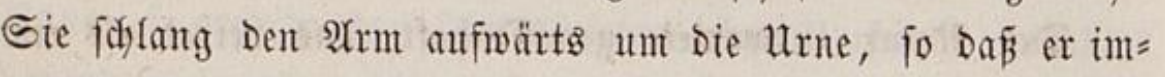

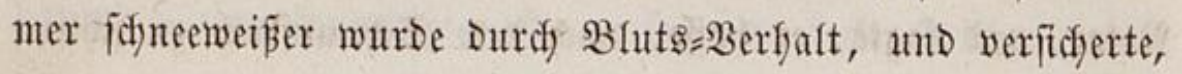




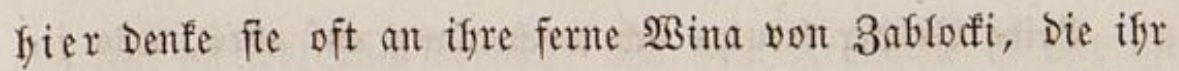
leider jäfrrlidy zweimal, Durdy Die Midfaelis = uno Die Diter= mefle, nad) Reipzig vom benterale entfüfyret werde, feinem $\mathfrak{B} e r=$ trage mit Der Mutter zufolge. Shne ifrr $\mathfrak{W}_{\mathrm{B} i f j e n}$ war $i f y r$ Ton Durdy Ianges Befdyreiben Der Sdfmerzen gुanz munter gemorben. Salt lobte fefre ifre Freundidjaft und ifre Freundin. Sie erfob bie Freundin nod) gewaltiger als er. Da fount' er nidyt länger mit Dem anfdyelfenden Şerzen Gleiben. Mit 3 urüafberufung Des alten Rlagetons und einem Trauerbficf gegen Den Thyum fodted fie von Dem Süngling.

In Diejem aber wurbe ein Flug von Dämmerungḡvögefn - um jeine Soeen fo zut nenten - wad) unt flog iffm 36

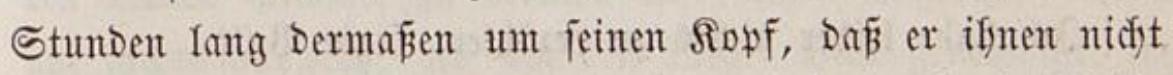

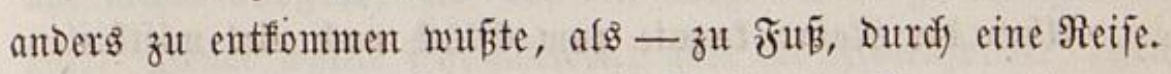
Bina's Yebendigeres Bild - Die September=Sonte, Die aus Glauem Aether Grante - möglidjes Reijegelo - und ein ganzes wünjchendes 5erz, Das alfes auf Der einen Geite und auf Der andern und fodfimmen D. Duts lautes Bebautern uno Rezeptiren - Flittes laute $\mathfrak{A}$ gonien - Seerings pein=

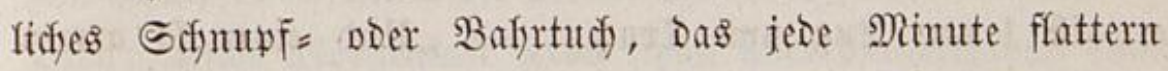
fonnte - $\mathfrak{B a}$ alts verfäumte poetijaje Sing = Stunden (Dent was war in foldfer Sirifis zu Didften?) - viele gefperrte Träume - unD endfid 36 imnere Fecht $=$ Stumben Daza - fo viel und nidyt wentger muspte fidh in einander hafent, Damit $\mathfrak{B a}$ alt, weil's nidyt mefrr auszuffalten war, feine weiteré Umifände ntadyte, fondern zwei nöthige (5änge, Den exften $z^{\mathfrak{H}}$

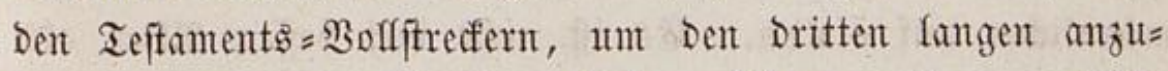
fagen als Notariats= Baufe; und Darauf Den zweiten zum flö= tempieler, um ifym funtert $\mathfrak{A n l a ̈ f e ~ z u r ~ \Re e i f e ~ u n d ~ d i e ~ \Re e i f e ~}$ fu melden. 
Beibe Britber freuten fidf wodyentartg auf alfes, was jes Der nun bem antern (sejdidftlidfes werbe zu erzäflen haben, went er wodjenlang weggewejen; jest war $\mathfrak{W a l t}$ ber beber. Bult fyatte fich über viel zu mutbern. Sefr idfwer fiel es

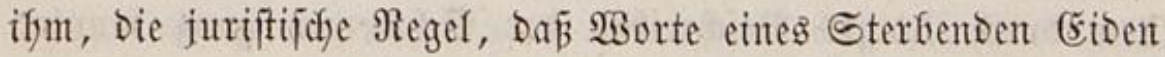

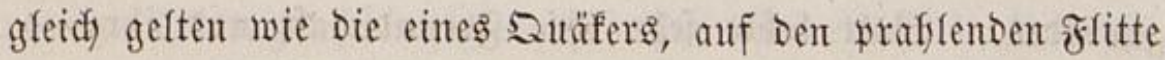

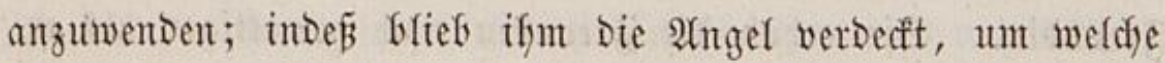
fidf) Die garze Täujoflung Dreffe. "Mir ift, jagt' er, als foüt= ten bie Narren bidf) zum - 2 seijen; idf weiß aber nidyt wo. um (5otteswiflen, juttger Menfd), fei eine Rutidye (folge einem ältern) und fabe finten Dein rundes genfferdfen, Damit fein

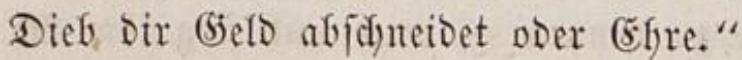

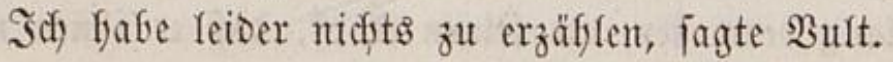

Afber Der Notar fonnte zum (siüaf nod) viel mittfeifen.

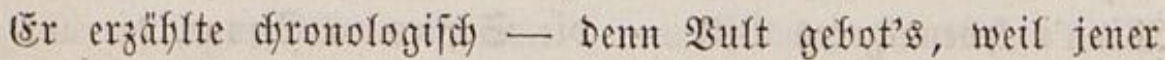
jonft alfes ausfié, - uno mit födjfter Befutjamfeit - Denn

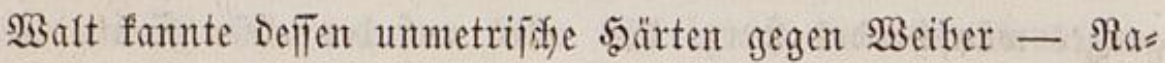

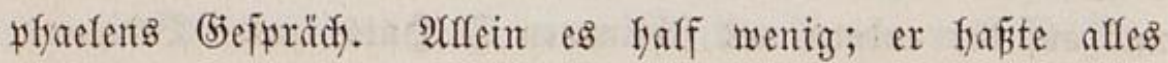

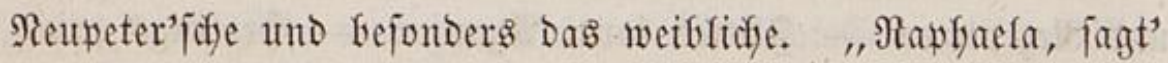
er, ift lauter Lug und Irug." - "Und einer fo armen

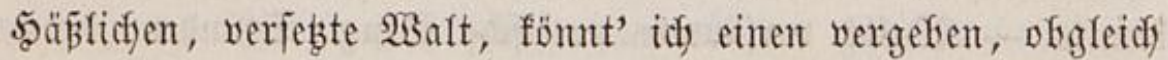
weber mir nodh einer nod) einem (5eliebten." — "Sie will nur, Das mein' idf - fuffr $\mathfrak{B}$ ult fort - fidf auf iffre innere Bruft brüften, und wäfrent Esin Riebfaber auglöfodt, einen

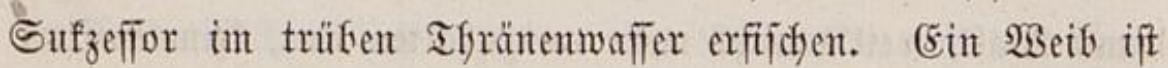
ein weiblidfer Reim, Der fidf alf zwei Iaute reimt; ein

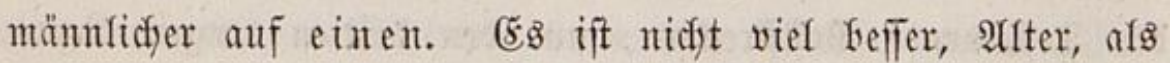
went fie als galfenter zut bir falfent fagte, unto fid als Inube bir vorwürfe: rupf, an, Mämdsen!“

"Die $\mathfrak{M}$ öglidjet foldjer Täujdyungen - jagte $2 \mathfrak{B a l t}$ 


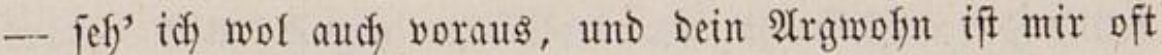

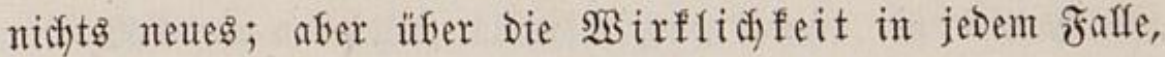
saribler ift Der Sfrupel. Hnd Siebe faum ia eben fo wol

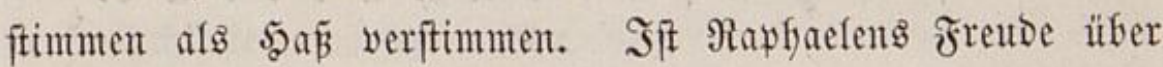

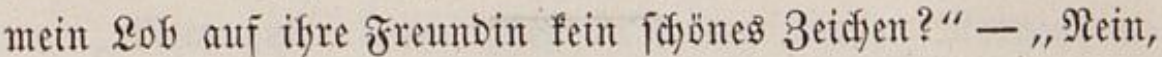

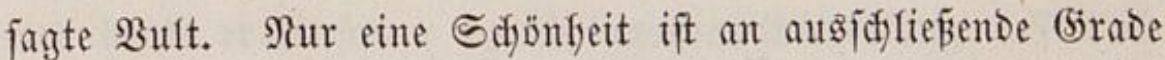
Des Lobes und Feuers verwöfnt und hafiet jeoe Unvolftän= Digfeit und Theilung Der fremben (Empfinoung; afer eine un= tergeoronete (seffalt ift genöthigt zur 3ufriedenfeit mit mitt= fern Stufent, uno vergibt mandhes, ausgenomment mand)es."

Walt fratte nidyts weiter zu Geridften, als feinen Plan, Den reinen şimmel zut atfmen auf eintgent Tagreifen, wo er auf nidfts atşgefe, als auf Den $\mathfrak{B e g}$. Sult genefmigte ifm ftarf. Sener wollte jefre idjeiden; afer ber flötenfpieler, Durd

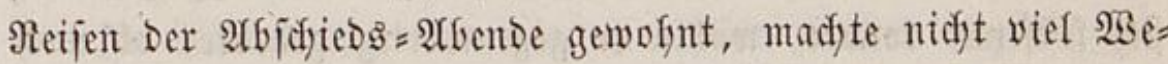

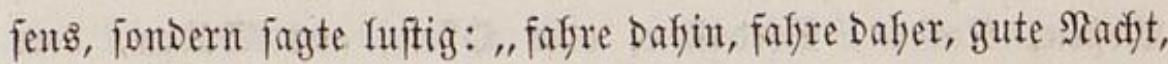
glüfflidje Reife."

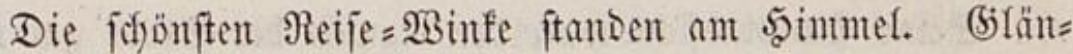

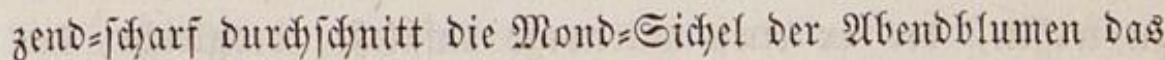

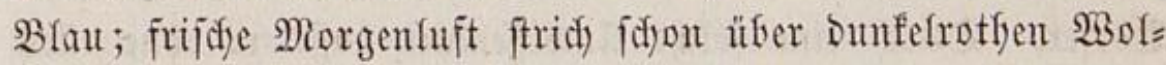
fen=Beeten am şimmel; und ein Stern nady Dem andern ver= fieß einen reinen Ing. 


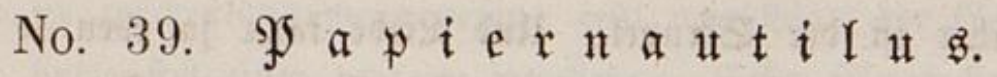

Sntritt ber Reife.

Am Morgen jaly er auf Der Sdywelle reifefertig nod eint mal feine Dunfle wefflidife. Stube an, Darauf jogar in bie Rammer fyitein, unto flog mit zwei liefreidfen Bliffen, bie cinen $\mathfrak{A}$ bidfied bedeuten jollten, uno mit cinem an Den Ifurm, Dem Der Tod nod) fein Sdymuftudi zugeworfen, freubig auf einen Yeeren $\mathfrak{B l a b}$ am Ifyore finaus, wo ex fich überall um=

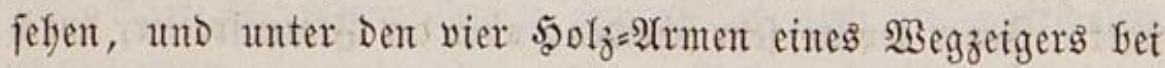
fich feitfegen fonute, wofin er gegentuärtig gedenfe, ob nady Seften, Norben, Norboften, doer Sfen; aus Siben, Dem Stadttyor, fam er aber fier.

Seine Sauptabfidyt war, Den Rament Der Stabt gar nidft zu wiffen, Der er etwa unterwegs -auffitiése, Deşgleicjen Der

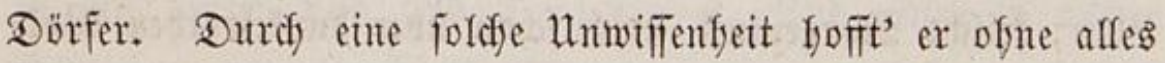
Biel unter Den gejodlängelten $\mathfrak{B}$ humenbeeten Der Reije umber zu fofweifen, und nidyts fut begefrent fo wie zut bejefen, als was er eben habe - in Einem fort bei jebem Tritte anzu= fommen - fich in jedes goldgrüne Ruft=\$Bälodyen zu betten, und fräno' es finter ifm - in jeber Drtichaft felber Den $\Re a=$ men Der Drtichaft zu erfragen, und Darüber fid ganz. Yeim=

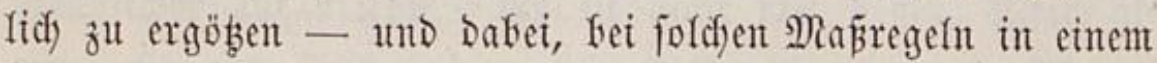

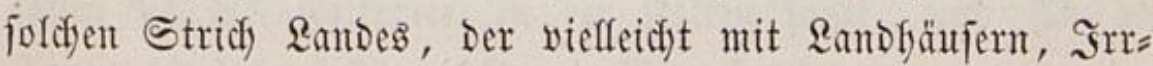

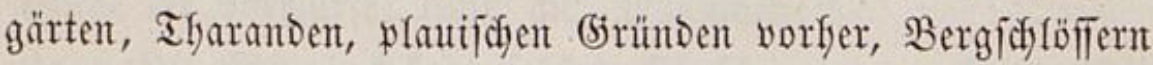
volf ferunterjeffenter fräuleins $=$ 2utgen, Sapelfen voll aufges 
Goluter Beter=22ugen und überfautht mit $\mathfrak{B i l g e r n , ~} 3$ ufäflen und Mäbdjen orbentfidy üfrerfäet jern fonnte, in romantifice Atbenteuer von foldjer 3 afjl und (büte finein zu geratfent, als er freilich nie erwarten wollen.

, Mein guter Untendfidfer in Deinem blauen Morgenfim= mel, betete er in jeiner Durchbringenden (Entzüufung, lafje bods Die Freube Dasmal nidjts yorbedeuten."

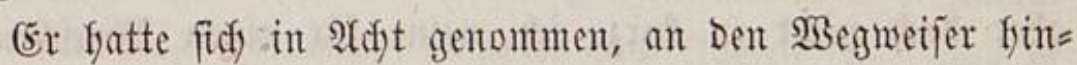
auf zu fefhen, Der wie eint 2 ffe vier $\mathfrak{A}$ rme hatte, un nidft etwa an Den abgewajdenen $\mathfrak{A}$ mmröfren einer Stelle aufichtios

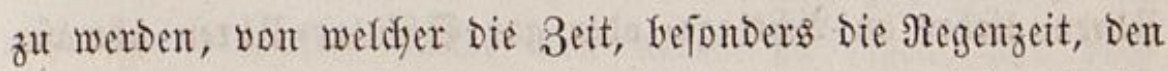
Namen Der $\mathfrak{F o f t}=$ Stabt nod) nidft rein weggerieben hatte.

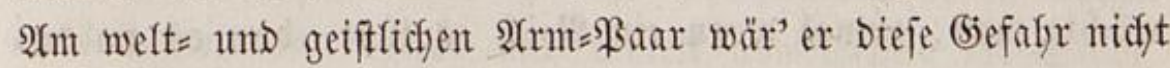
gefaufen, fondern biefes zeiget alfgemeiner ints Blaue.

In Norden Iag EIterlein; in Dften ftanden Die Peftizer

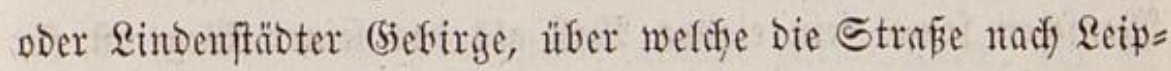

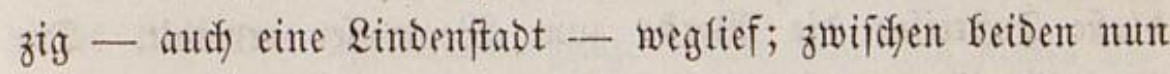

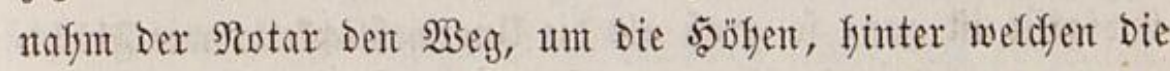

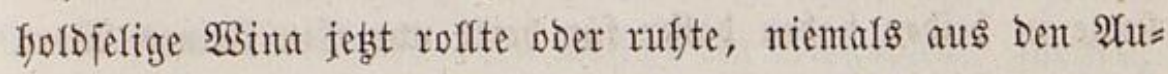
gent fut verlieren, weldje balo aus Blumenfeldyen, Galo aus

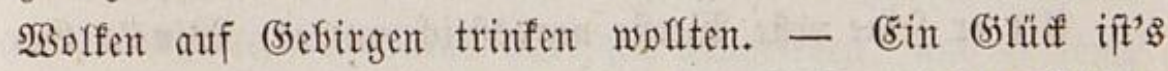

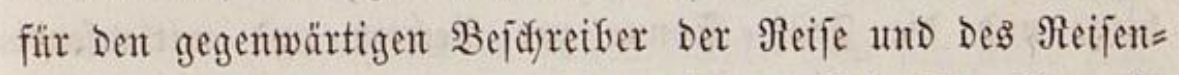

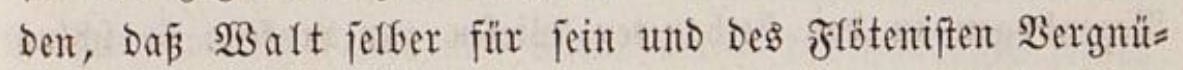
gen ein fo umftünolidjes Iage $=$ ober Sefunden $=$ Bud feinter

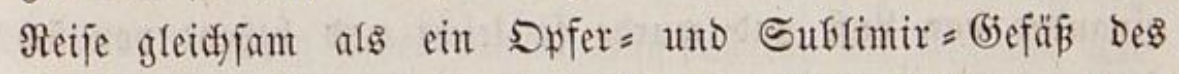
Rebens vollgefüllt, Dẩ ein anderer weiter nichts zu thut braudyt, als Den Deffel Diejen Buffer = und Nutterfaffe aus= zufd)lagen und afles in jein Dintenfá einzula fen fütr jeben, Der trinfen wifl. Der leibende Menjod, hat einen Erfreuteten

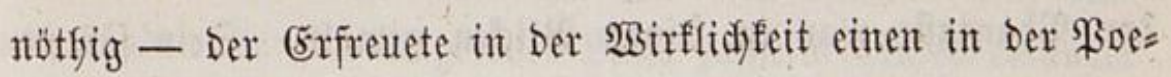


fie - und biejer, wie $23 a l t$, verooppelt fid wieder, went er fiti) beidyreibt.

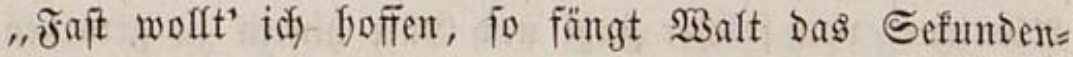
unto Terzienfuthy an Bult an, Daß̄ mein lebes Brüberlein midf nidyt augladyen werbe, went id meine unbedentende

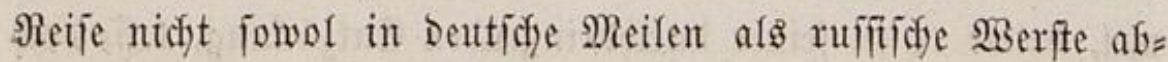
theile, weldye als bloke Biertelftunden freilidy feffr furz funt, aber Dodh midyt zu furz, id meine für einen Menjojen auf Der (Ertbe. So wie es nidjt augzufommen wäre mit bem flüd)= tigen Reben, went man $e^{B}$, ftatt an Minuten= uno Stunden=

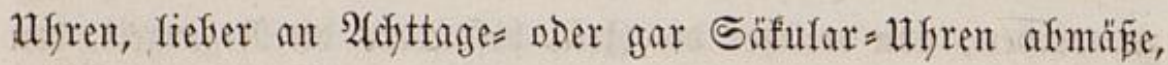

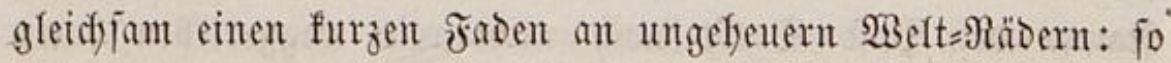
mödjte man, fumal wemn ein Reich es thut, Dem es am we= nigften an Raum fehlt, Das rufifiche, Diejelbe (Entichuldigung

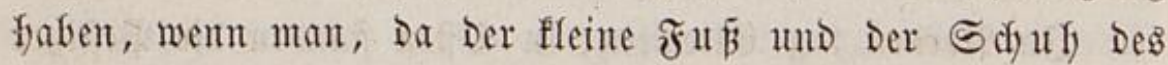

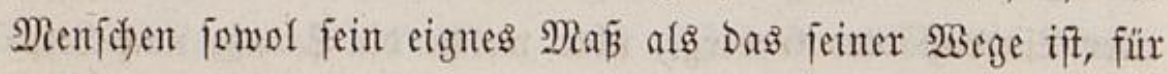

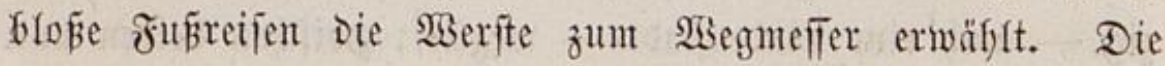

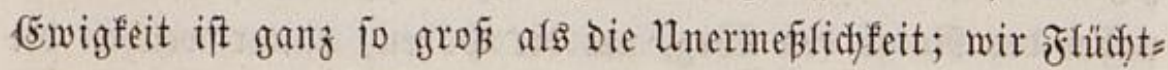
Yinge in beiden fhaben bafyer für beibe nur (Fin fleines $230 r t$, Bruder, 3eit = R a m."

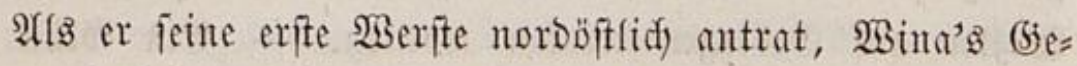
firge und bie grilly = Somme zur Redften und mitlaufente Regenbogen in Den betfruteten 2 Bejen zur Rinfen: fo jojlug

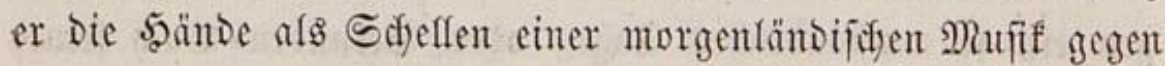
sinander vor Ruft und wurbe fo leidyt und Gefend von fids

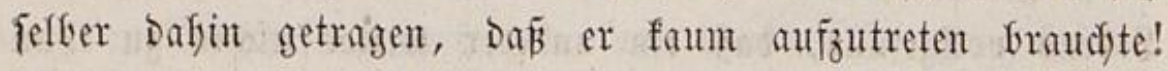

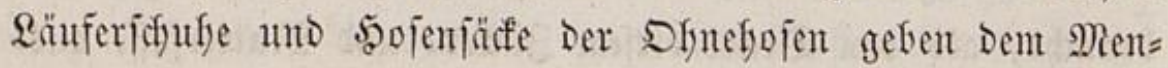
foren, wenn ex jonft lange Stiefel uno furze bojen trug, faft Frlügel. Sein (5jeficht war volf Morgentuft und ein Drient Der Shantafie war in jeinen Blifen gemtalt. Sein fămmt= 
ficfes Münzfabinet ober Studentengut batt' er eingeftecft als Eurphss= und Dperazionsfalle, um an Diejer beld=Sabe einen

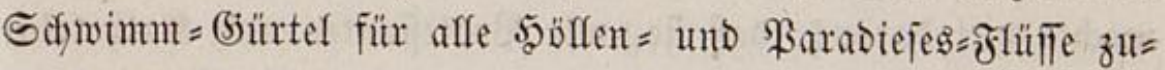

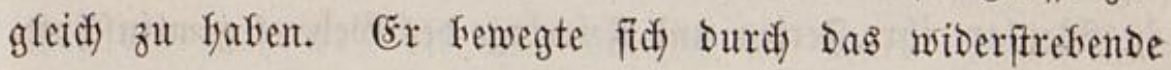
Seben io frei wie Der Sdjmetterling über iffm, Der nidftz braudft als cine Blume und einen zweiten Sdfmetterling. Der Runfttrẩe, woran er einen ganzen Ritumpen Reforma= toren und $\mathfrak{B e g}=$ frotteuts fampfen und flopfen faf, ging er aus Dem $\mathfrak{W}_{\text {ege, }}$ weil er fidf nidyt Damit plagen wollte, ent= weber (Einen Morgengrup lang Durdy fie finzuziefen, ober Dent nämlidfen läd)erfich inmer von neuem zu fagen, unb Dod'

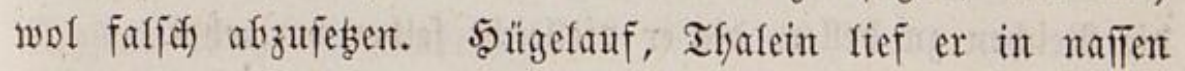
(5ras=Blüten und verlor uno erfielt abwedjfelno bie Stabt,

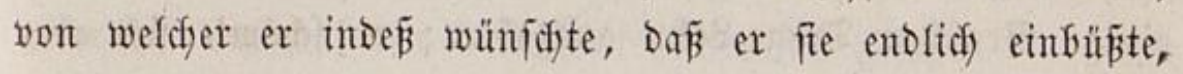
weil ifm fonft inmer nidft reefft war, als jei er fort.

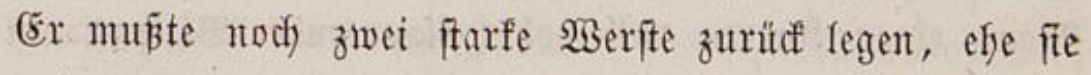
finter Den Shiffügefu unterging. Nody war ifm nidsts be= fonders unterwegs begegnet, als Der $\mathfrak{B} e g$ jelfer, als er feinen

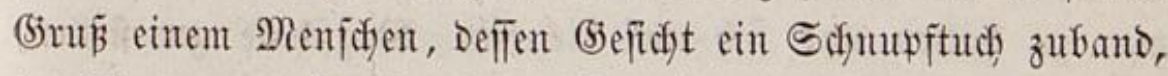
im shroge zuwerfen founte. Er ging fo lange fort, bis er glauben Durfte, Der Namn frabe fich umgefefen, und er fönn'

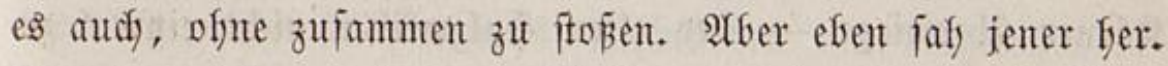
Er ging wieber weiter uno flicte um - Der Bambagift feiner

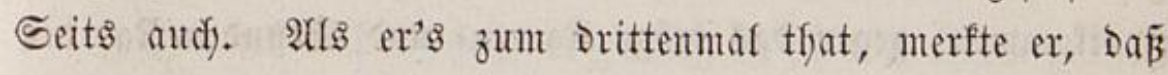

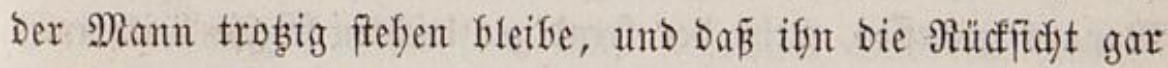

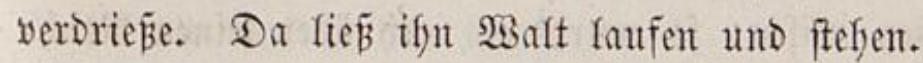

(5r ftien Gald - jo wudjen die âdenteuter - auf brei alte Frauten und eine blutjunge, weldye mit fyod)aufgethürmten

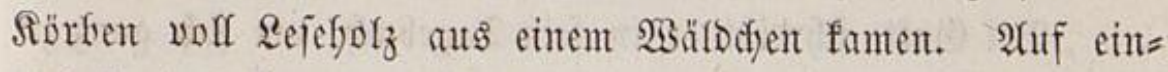
ntal ftantent fie alle in geraber sinie zugleidy finter eimander

Sean yaul's auşgew. 20erte. XIV. 
Fitll, Die fófweren Rörbe auf Den fofiefuntergeftellten Stecfen

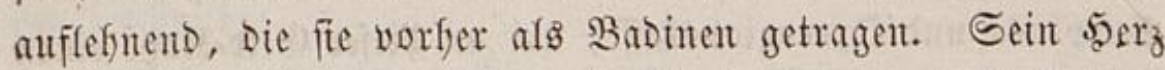
madyte viel Daraus, Dá fie, wie Broteftanten uno Satfyolifent

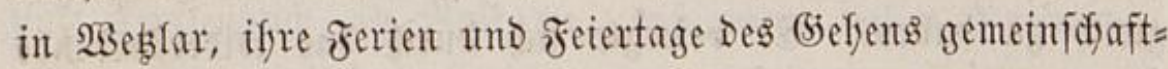
fich abthaten, um beifamment ful bleibent und fort flt redent.

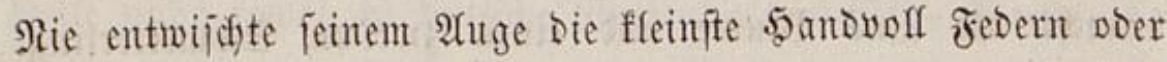

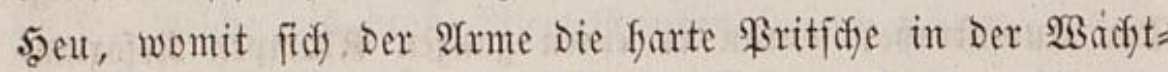
futbe jeines Rebens etwas weidfer bettet und fich bie Marter=

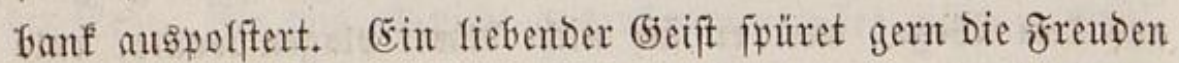

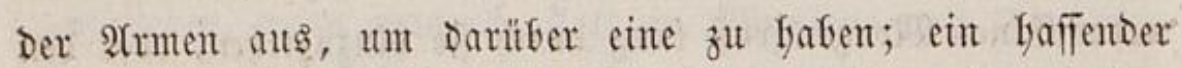
aber fieber Die \$alagen, feltener um fie zut fyeben, als um über bie Reidfen fut Gelfen, Die er vieffeidyt felfer vermefyrt.

Syerzflid) gern woult' er Den fradyt= unt Rireuzträgeriment

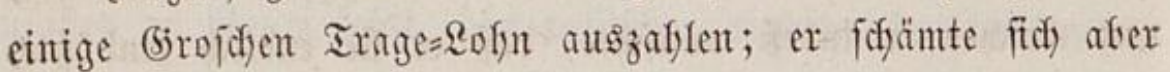
vor fo vielen Beugen einer warment Tfyat. Darauf fitob eir Nam einen farren voll holer flappernder Bledfwaaren ba= fyer; jein Tödfterdfen war als Borfpant vorgelegt; beide feudf)=

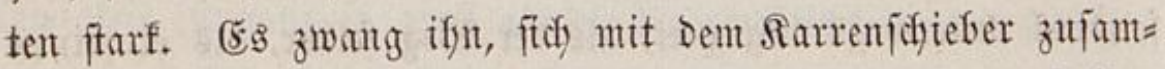

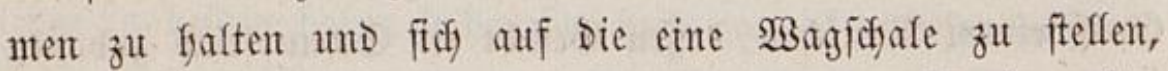
Den Rämer auf bie anbere. Da er nun fogleidf bemerfte, wie fefyr er mit jeinen Bslücfsloden uno 3ufferfyüten Dert

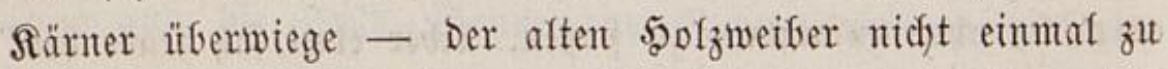
gedenfen -; Da er finton muß̄te, Dás jein freies fliegendes

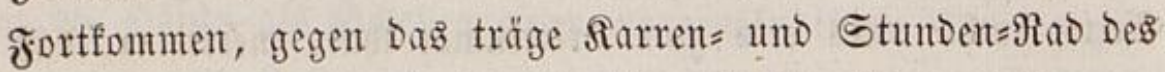

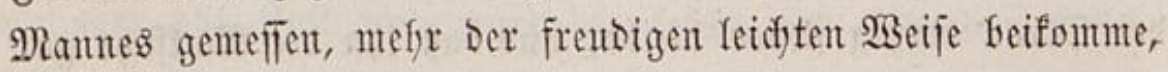
wie bie Bropen reijent: fo wuro' er roth über feinen Reiff = thum und Stano - er fafl bie 2 seifer nodf fraltent und lef)= nen - er lief zunüaf mit vier (5aben uno eilig Davont.

,Bei (5jott, fodreifter in jein Iagefudd, umt fids) gantz zut redftfertigen - Der armfelige flüd)tige Sinmen=Sibet einer bef= 
ferr Nafrutg, weldyen etwan ein paar gefdenfte (5rofdyen bereiten fömen, uno überfyaupt Der (5) en в̈, Der fant nie

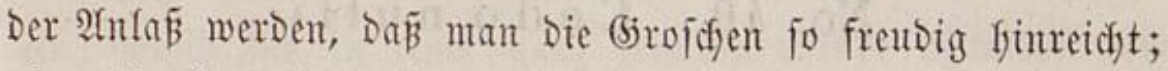
aber bie Freube, bie man badurd auf einen ganzen Iag lang in ein ausgefungertes

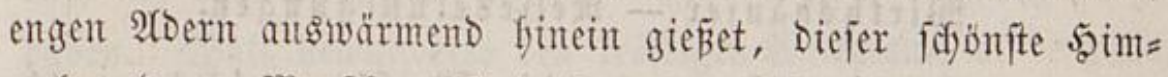
mel anderer Nenichen ift bod wol woflfeil genug Damit er=

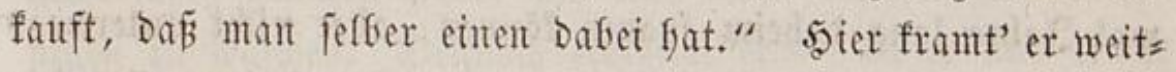
läuftig feinten alten Traum von Dem (5jtüfe eines retfenden Mulords aus, auf cinmal burdy einte offite yolle sant eit

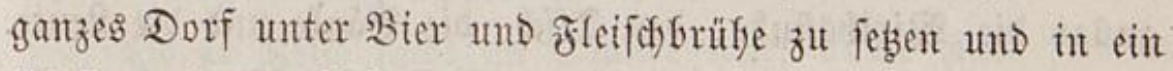
ELftüum langer Erinnertug.

Mit Drei Soimmelı im unfolfuldigen (5efidft - nod) einent mefyr fratt' er auf Den (befidftern finter fich gelaffen - glitt ex letift won Ifantropfen zu Ihautropfen. - Dag Saerz wirb wie ein Ruftichiff Durd) Den 2!uswurf Des fidwerften Ballaftes,

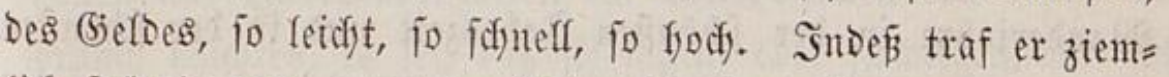

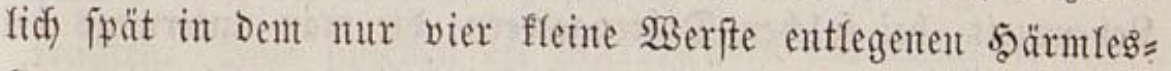

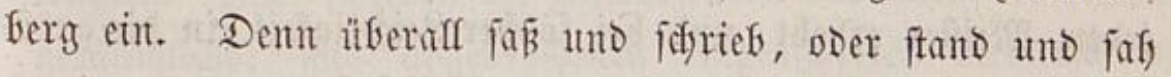
er oder las afles - jede Inidyrift einer Steinbanf - und wollte feine Rleinigfeit übergefen, fie müB̈te Denn Bevöferung, Stallfütterung, WBiefenturds, Refymboden und Dergleidjen be= troffen baben.

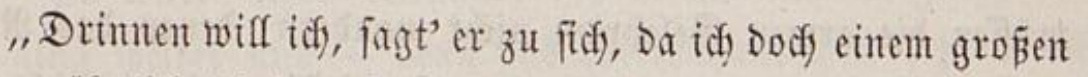
5̧erren äfntlich fợeinen folf, mein déjeûner dinatoire einnel)= men" uno trat in ben firug. 
No. 40. C e do nulli.

TBirthghäufer - Reifebeluftigungen.

Der Notarius, Der unter Die Menfichen geförte, welche wol Iafye lang Dafeim fwaren fömen, aber nidyt unterwegs - ringegen andere fefren es gerade um - forderte fecf fein

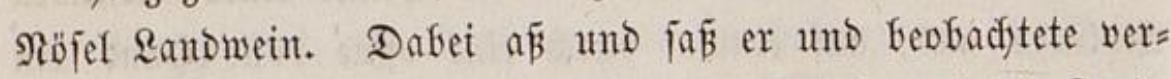

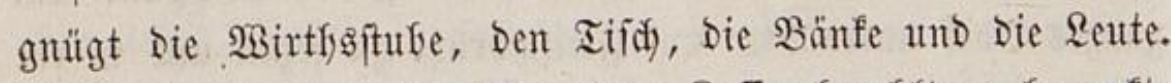

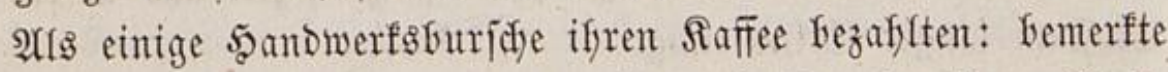

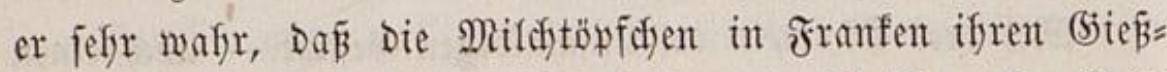
fdjnabel Dem şenfel gegenüber Kaben, in Sadjen aber finf's oder gar feinen. Mit gedadften Buridjen ging feine Seele

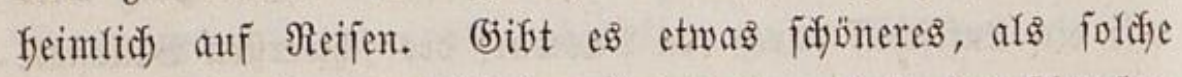

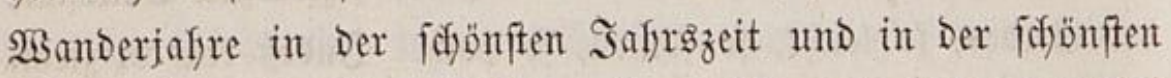
Lebenşzeit, bei foldyent Diätengeloern, bie man unterwegs bei jebem Meifer erffebt, und bei foldyer Qeidjtigfeit, in Die größ = ten Stäste Deutidjlanos ofyne afle Reijefoften zu gefyen, uno

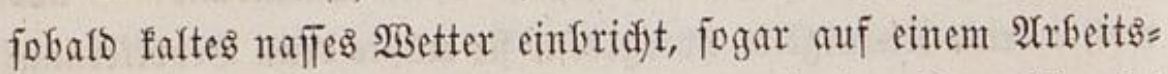
ftuffl häusfid zut niften uno zut brïten wie Der Sireuzidjnabel

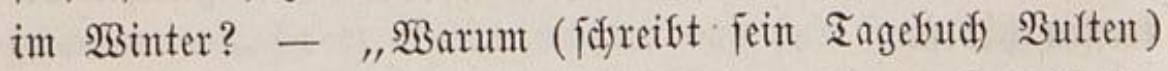
mitffen bie armen (jefefyten nidyt wandern, Denten Das Reifen

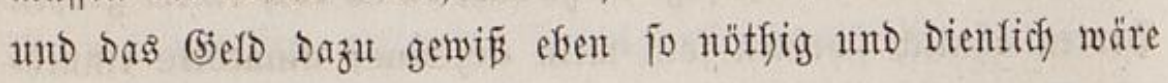
als allent Gejellen?" -

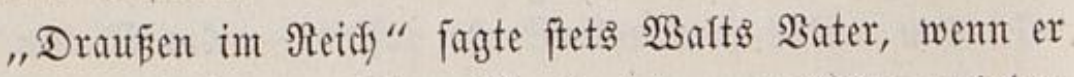

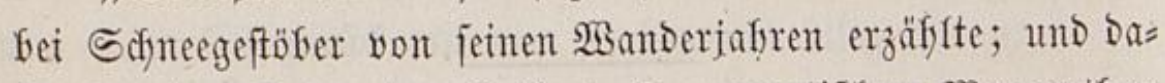

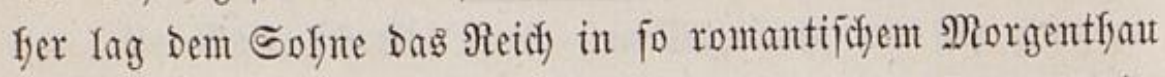
Griţend fin als irgent eine suabratmeile vom Morgenfand; 
in alfen $\mathfrak{S a n t b e r g e f e f l e n ~ v e r j u ̈ n g t e ~ f i d y ~ i f y ~ b i e ~ v a ̈ t e r f i c h e ~}$ Ber= gangentreit.

Seb̧t fufre ein Salzfämer mit (rinem $\mathfrak{B f e r d e}$ yor, trat cin, wujd fidf in einer ganz fremben Stube offentlidf und

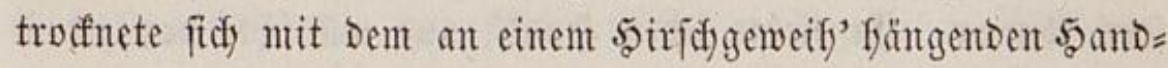
tudf ab, ofme nodf für cinen Rreuzer verzeffet oder begefort zut

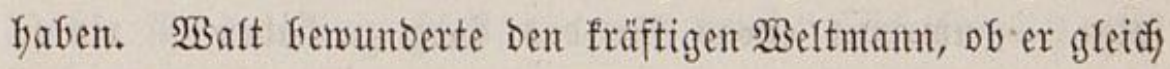
nidft fäfig gewejen wäre, fich mur unter vier âgen bie fei= nigen zut wajojen. Demtody exerzirte er - ba er nut etwas

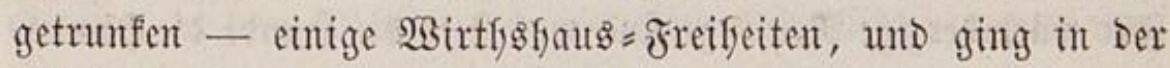
Stube woflgemuth umber, ju auf und af.

Ob er gleidf nidift im Stande war, unter einer fremten Stubendecfe Den $\mathfrak{g}$ ut aufaubefyalten - jogar unter jeiner fafs er ungen bedectt aus Dem genffer aus artigfeit -: fo fratt' er Dodif feine Freube Daran, Dás andere (bäfte iffren auf hat= ten, und fonft überall won ben Gerrlidjen afademijofjen orei= Geiten und Sndevendenzaften Der $\mathfrak{B}$ irthgftubent Den befen (5ie=

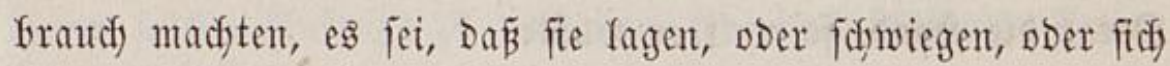

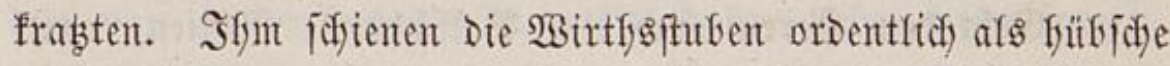

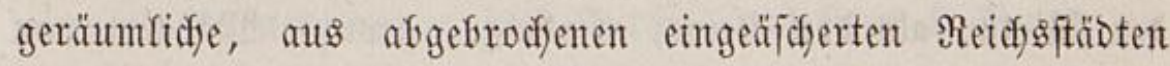
unverjefrt berauggefobene reidjanmittelbare Diogenes = Făfier

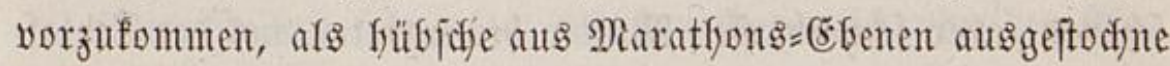
(5rünpläkge, vom Refler grünend gewäfiert.

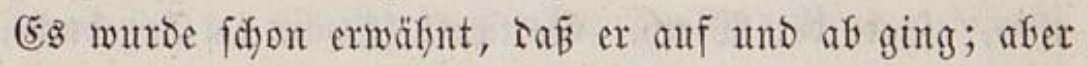

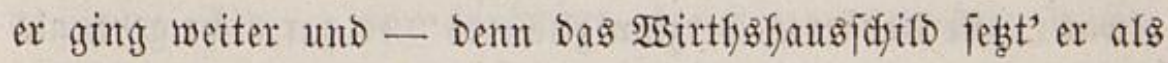

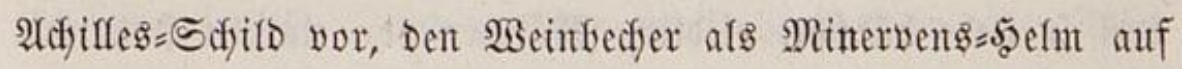
- fadrieb unter affer $\mathfrak{A}$ ugen ein und Das andere Iertesmort in jeine Sdfreibtafel, um, went or alfein wäre Afbends int Quartier, Darüber zul prebigen. Itudy trug er ein, Dẩ auf

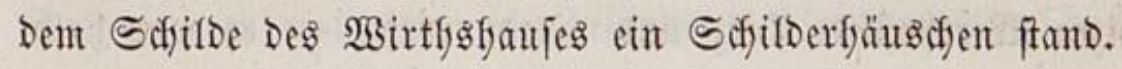


Der Muth Der Menjoden wädyjet leidjt, ift er nur fyer=

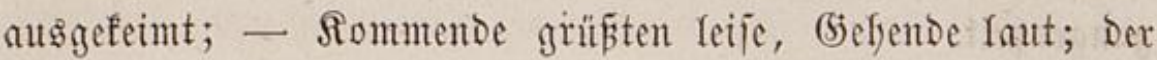
Notarius Danfte beiden lauter. (5r war io frendig bei einem

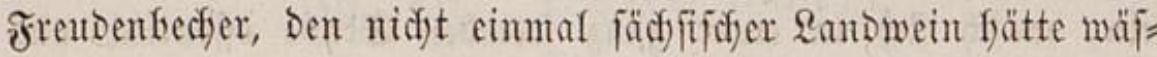

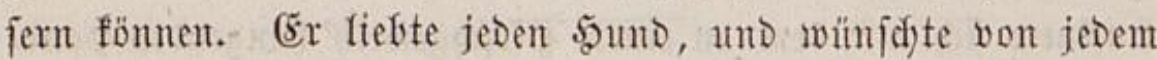
5yunde geliebt zu jern. Er fnüpfte seswegen mit Dem $23 i r t f g=$ fwibe - um nur etwas für Das beerz zut haben - ein jo enges Band von Babe = Befaumtidsaft und Freundidaft an,

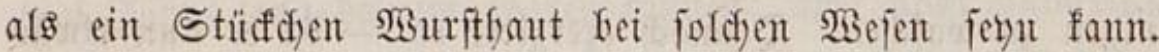

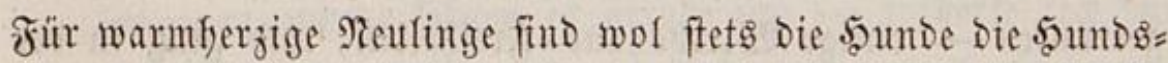

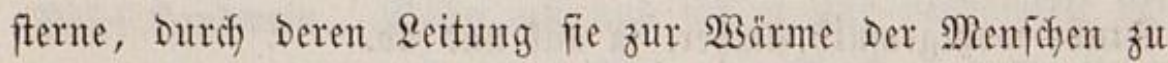
gelangen futyen, fie fint, jo zu jagen, Die Snufinder und Iriff= felfunte tief verftecfter 5̧erzen. "Svib, gib Die \$fote," rief Der 2 sirth in 5ärmlesferg. Spib, Doer Der Spib - Denn Der (5iattungsname ift, was bei Dem Menjonen jelten, in Deutich)=

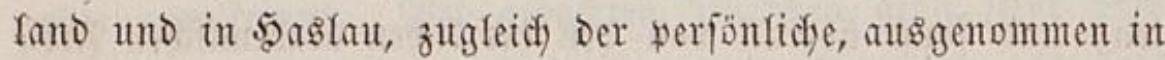

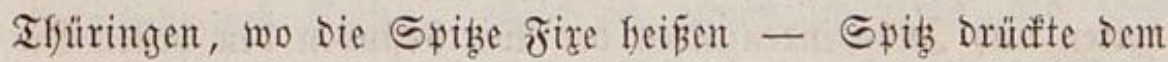
Notar Die 5ant, fo weit, er wuß̂te.

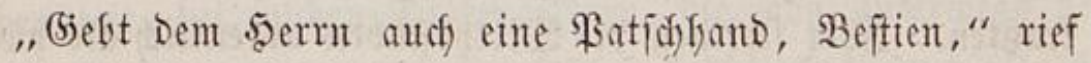

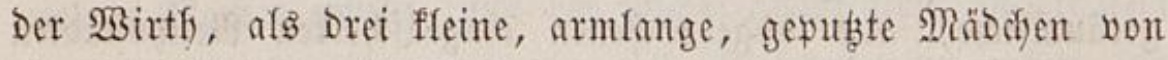
einertei Statur und Bryfiognomie an Der saand einer jungen fofjönen, aber fohneeblaffen Mutter fereintraten ats Der Sdylaf=

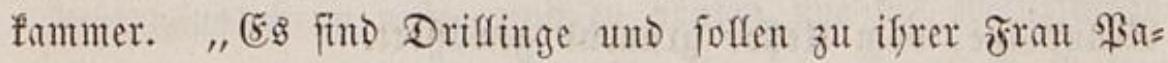
thin," fagte Der Wirth). (5ottwalt fofwört im Iagebutd)e, Daß etwas "allerliebferes, herzimniglideres" es gar nicht gebe, als

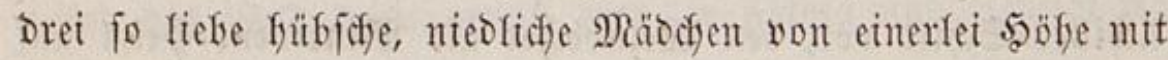

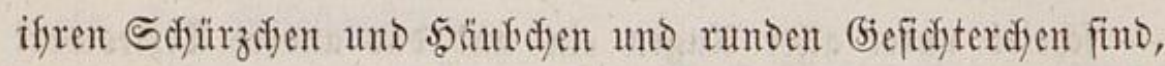
wobei mur zu bebautern jei, Daß̃ es Driflinge gewejen, und nicht

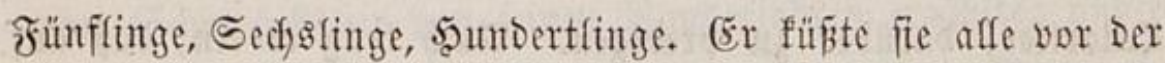
ganzen Wirtfisftule furz und wurbe rotf; - es war balb, 
als hab' er bie zarte Gleiche Mutter mit Der Sipwe angerüfyrt;

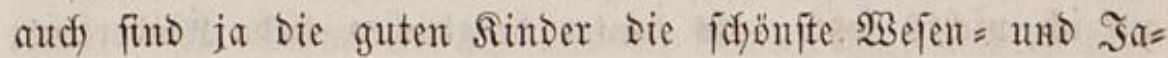

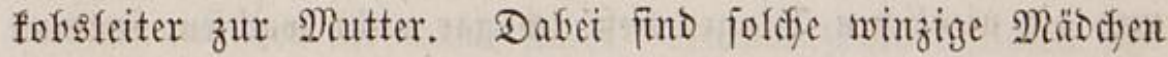
für Notarien, weldye ofne Nuth) und ofne Eleftrifir = und

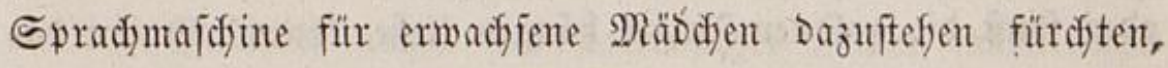

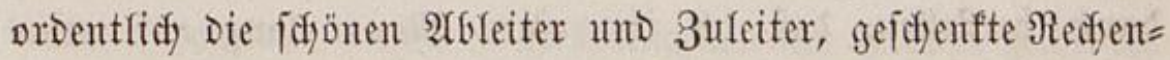
fnechte für Den $\mathfrak{A}$ gendbficf; - man mundert fich fröffich uno Yeimlich, Dẩ man ein Ding wie ein Mäbchen fo breift um= falpet. Walt wurbe Der Sileinen paäter jatt, als fie peiner. (Er war ja Dem Drilling - als eigner 3willing - viel ver= wantoter, als alle bäffe in Der Stube. (Ex bejodenfte fie gerb= Iich) zur fröcfiften Freute Der Mutter. Dafür befam er Drei

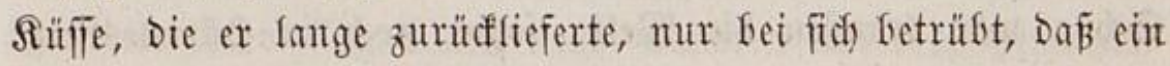

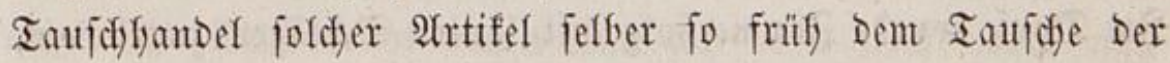

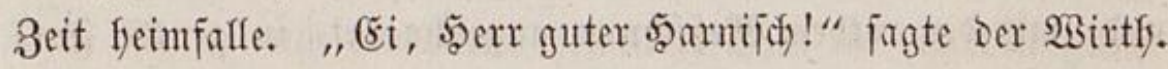
SBalt wunderte fich über Die Remntnif feines Ramens, afer

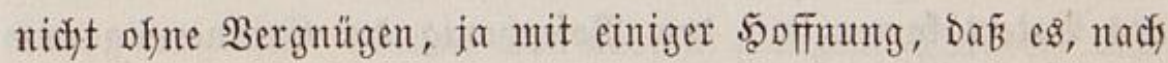
einem joldyen Anfange zu urtheilen, wol nod) feltamere $\mathfrak{A}$ wan= tïren fut erleben gebe. (5r wollte bafjer lieber nidyt fragen, wie uno wo uno want, aus Furdit, um jeine 5offrung fit foumen.

Mit $\mathfrak{B o l l u f t}$ faf er zut, wie Der Bater fich vou Den Rin=

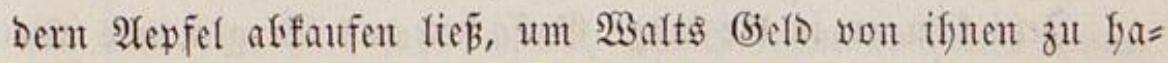
Fen - und wie Die Mutter Dem erften Drifling Broo julangte, Damit er wieber Davon furdfifam eine Biege unter Dem Fenfter abfnuppern ließse - uno wie Der zweite herzflaft in einen 2 tpfel

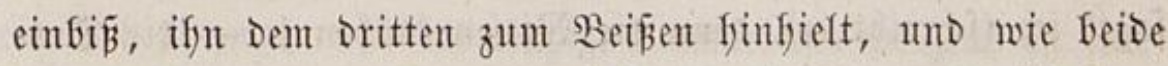
ifn wedffefno anbifien uno reidften und jedesmal lädyelten. "D wär' idf nur ein wenig affmädytig und unemolidf - Dadfte

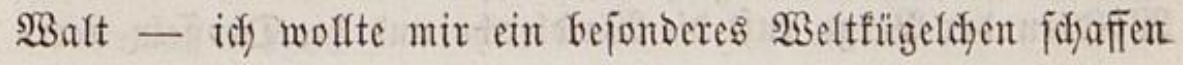




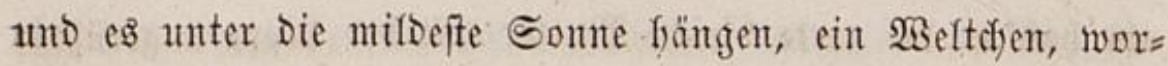
auf idf nichts febste, als lauter Dergleidhen liebe Rimberlein;

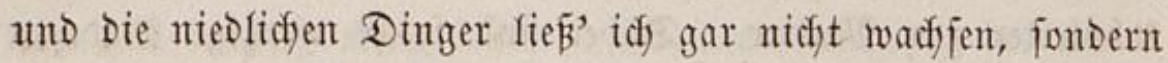
ewig fpielen. S5anz gewiß̄, wemt ein Seraph fimmelḡatt wäre

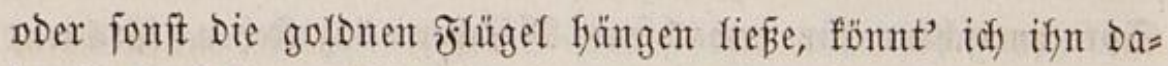
Durdif berfeflen, Dá̉ idf ifn einen Monat fong auf meine

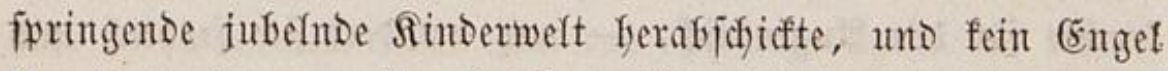
fönnt', fo lange er ifje Unidgulo jäfe, jeine eigene verfierent."

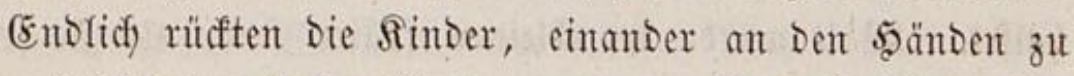

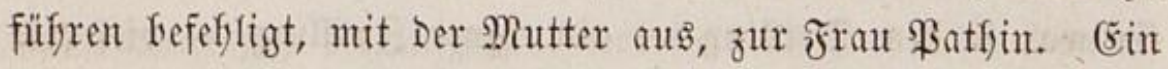
langer Tyroler mit grünem Sูut, yon weldyem funte Bänoer flatterten, trat fingent finein. - $\mathfrak{B a l t}$ tranf uno bradf auf.

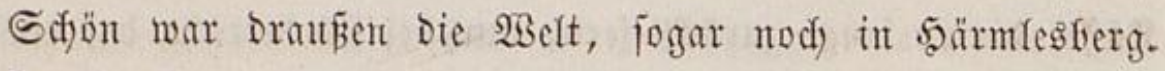
Sm Dorfe wurde 3immerfyolz mit fauten Edylägen zutgeffauen, unto, mit Der rothen Mejefidutr angeifhnellet, in gernde for= men afgetfeilt; - affe Sinderizenen unter Dem Banfyolz fei= nes Baters fomen mit Dem Rofenfonig Der Errinterung aus Den Rinofjeitšrofen Geladen zurücf. Bleidferimen mit groß̧en

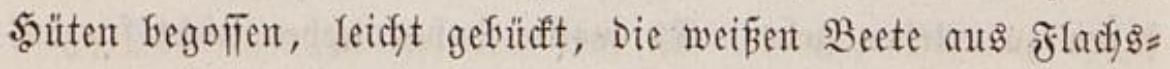
Ritien. $\mathfrak{A}$ แ⿰ Dem 5 ut, Den ein Mäodjen an Iangen Bändent an Der Şano ferunter fängen lié, flofy er zut Den blauen, gelben (jlasfugeln cines (bartens auf, und wiegte fid) üfrerall.

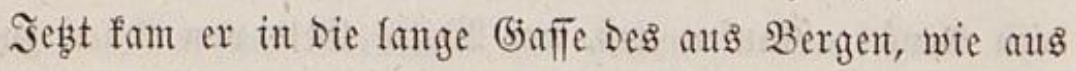

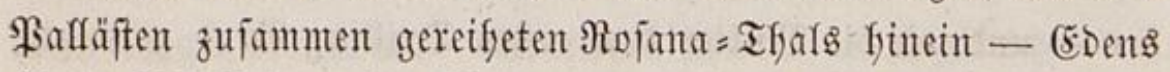

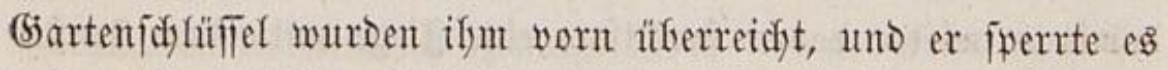
auf. "Der völlige frülyling ift Da, Der Drwfyeus Der Natur,

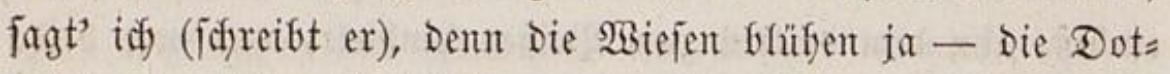
terbfumen feffen fo Didft - Den Saeu $=$ Bergen ziefyen fleine

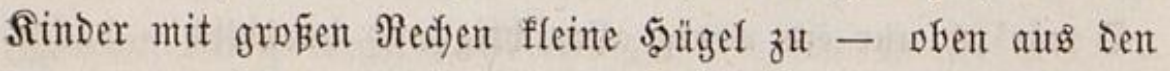
$\mathfrak{B a ̈ l b e r n ~ D e r ~ B e r g e ~ r u f t ~ b i e ~} \mathfrak{B a l b l e r d j e ~ u n d ~ D i e ~ D r o f l e f n ~ f e r r = ~}$ 
fich ferunter - föbüne Früflingswinde ziefent Durd Das fange Ifyal - Die Sdjmetterfinge und Die Mücfen fyalten ifyren Rin= Derball und Der Rofentadytfalter poer Das (5olbvögeldyen fibt ftill auf Der (Eroe - Die Blätter Der Ririç)bäume glüfent roth, wie iffre Früd)te, nad), uno ftatt blafjer Blüten fallen fojön bemalte Blätter - und im früfling wie im 5aerbfte zieft bie

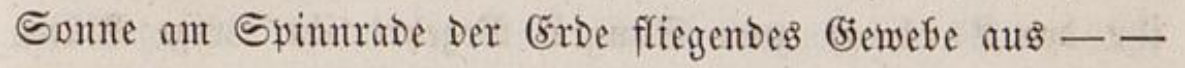
wafrrfaftig es ift ein fruffling, wie idf nod) jeltent einen gejefyen."

Sm foben Aletfer waren zarte Streifen, Silferbfumen gewebt uno Meilen=tief Darunter zog fangjant ein $\mathfrak{B o l f e n =}$ (5ebirge nach Dem andern fin; - zwififen bieje aufgebante Rluft im Blau flog $\mathfrak{B a l t}$, und wandelte auf Dem 5aimmels= werge aus Duft feidft Dafin und faly oben nody föfer auf. Dodh fah er audf berab ins heimlidye affal - fafy Den ftillen

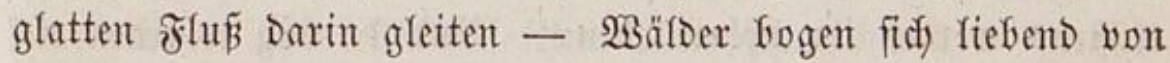
einem Bergrïffen finein, am andern glänzten Trauben uno

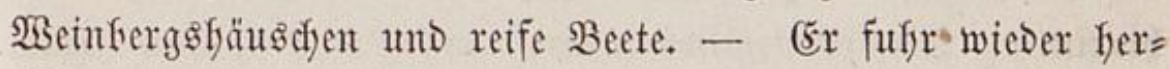
nieser in fein langes Thal, wie auf einen (Éttern $=$ Sdjooj.

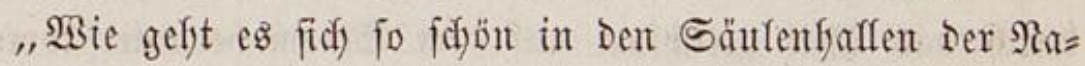
tur, auf Dem (5xün und zwiffcen Dem (5rün, in ewiger $\mathfrak{B}_{e}=$ gleitung Des unendfidjen Rebens! jaug er, ofne Gejondere Me= trif́, laut frin, uno faff fidf um, Damit niemand peine Sing=

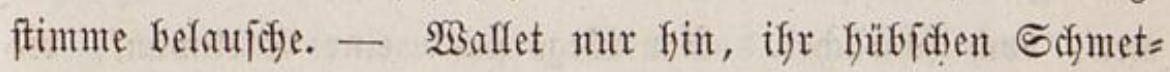
terfinge, und gentepet bie 5ontgwodye Des fleinen Seyns ofne \$unger, ofne Durf *) - ein fóbües Somenteben -

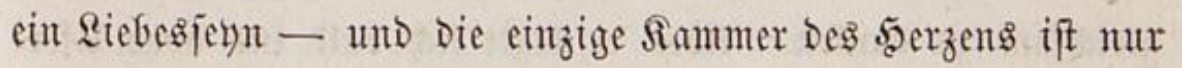

*) Scfmetterlinge haben nur eine Seerjfanmer und bic meiften feimen Magen. 
eine emige Brautfammer Der Riebe - Veugt Die Blumen -

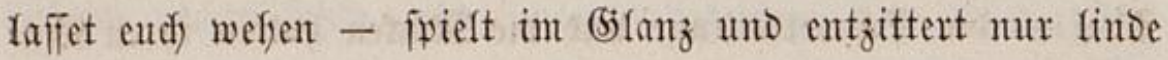
wie B̧lüten Dem Reben."

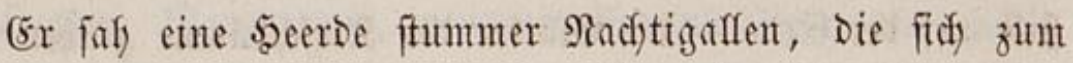

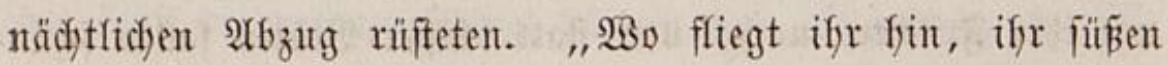

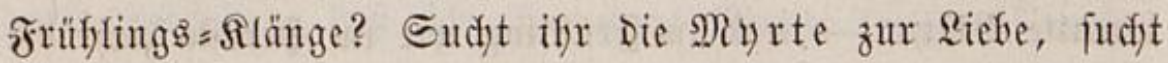
ifr Den 20 rbeer zum Sange? Begefret iffr envige Blüten und goldne Sterne? So fliegt mur ofne Stürme unter un=

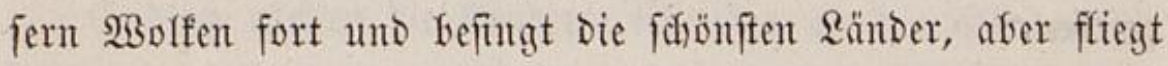
Dann licbesbrünftig in unjern früffling zurücf, und fingt Dem

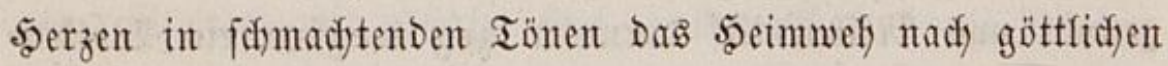
Eändern vor."

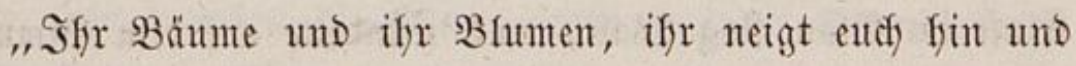
ber, und mödftet nodh lebentiger werden und reden und flies gen, id liebe eudd, als wär idy eine Blume unt hätte 8 weige; eimftents werdet ifre fioffer leben." Uno da bog er einen tief ans $23 a$ aler fich neigenten 3 weig gar ein wenig in Die 2 eflen fintein.

Plöblich fört' er in tiefer ferne finter fich cine Flöte Durd) Dus That gleidfam auf Dem Strom ferunter fommen, Dent $\mathfrak{B}_{\mathrm{e}} \mathrm{fen}$ entgegen. Die Ferne ift Die Folie Der Flöte; uno iffm, Der mefre ifrent Ton als iffren bang verftano, war feine stafe gute mur fyalb fo fieb. Die Töne fodienen nadjufom=

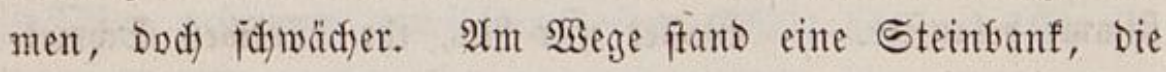
iffn in Diefer (Einfamfeit fodon an Die Menfohenforge für an= Dere Menjoden crimmerte. (Er fekte fich ein wenig Darauf, um

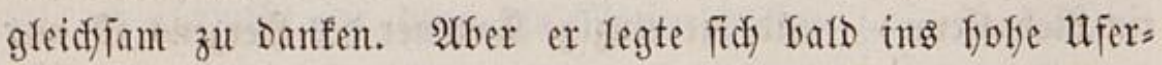
(5ras, um Der guten (Erde, Die zugleidf Der Stuff, Der Tifát

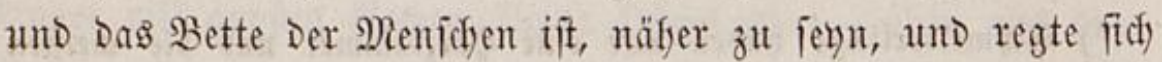
wenig, um die im warmen ftillen $\mathfrak{H}$ ferwinfel fpielenden Ein= 
tagg = Fi idd dyen nidyt wegzufdyreden. (5r liebte nidyt einent und Den andern Rebentigen, fontoen Das Reben, nidjt einmal bie

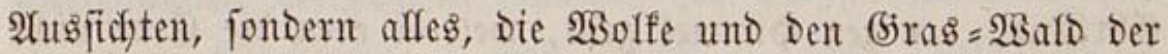

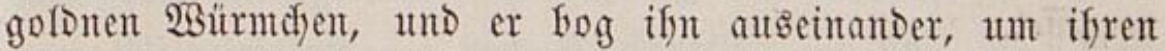

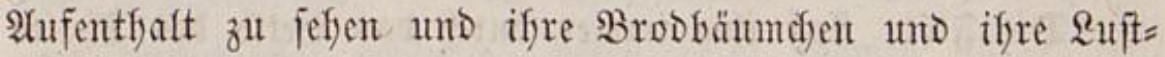
gärtchen. (Er fielt lieber mit Sdyreiben uno Didjten auf jei= ner Sifreibtafel innen, wem cin buntes weidfes 2 sejen über

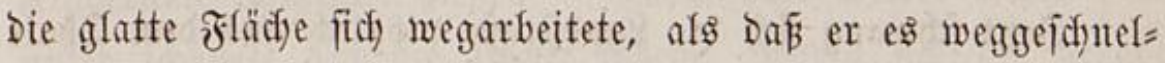
Yet ober gar eroriaft fjätte. "(5ott, wie fümte man ein $\mathcal{Q}_{e}$ ben töbten, Das mant redft angefefen, $\mathfrak{z}$. $\mathfrak{B}$. nur eine falbe Minute fang " fragt' er.

(Er hörte Die flüte, Die gleidjant aus Dem \$erzen Der

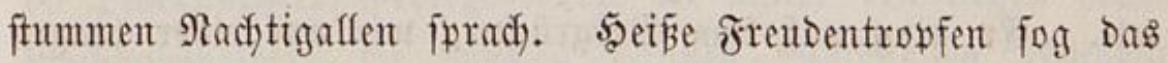
Dunfle (Setön aus feinem von taujend $\Re e i z e n$ überfüllten $\mathfrak{A}$ tge.

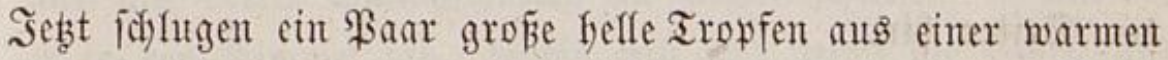

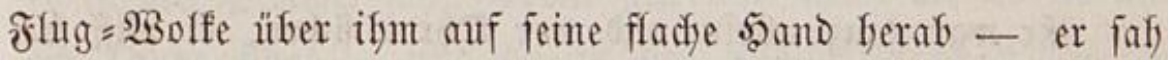
fie lange an, wie er es jonjt als Rint bei Regentropfen ge= madyt, weil fie vom fyolen, fermen, heiligen şimmel gefommen. Die Some ftad) auf die weike Saut, und wollte fie wegfinflen - er füpte fie auf und faf) mit unauşpred lidjer Riefe nady Dem warment 5jimmel auf, wie ein Sint an Die Mutter.

(Ex fang nidyt mefyr, feitbent er förte und weinte. (Eno = lidif ftand er auf, und febste feinen soimmelsweg fort, als er

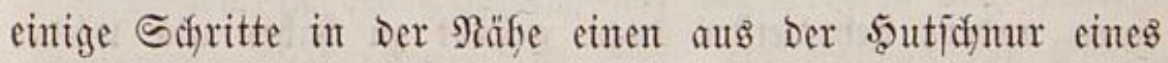
Fuffrmanns entfaflenen 3 ollzettel auf Dem $\mathfrak{B e g e}$ gewafyr murie.

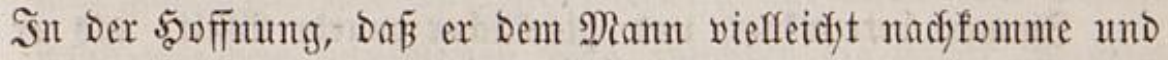
ifn finde, fyob er Das B̧ättudyen auf; weil ifm nidyts frem= Deg flein, wie nidjts (Ëignes widhtig vorfam, und weil fein yotijajer Sturm Ieidfter einen (3ipfel fog, als cine Blume. IBenn Die Reidenjdyaft glut= werworren auffliegt, wie ein fren= 


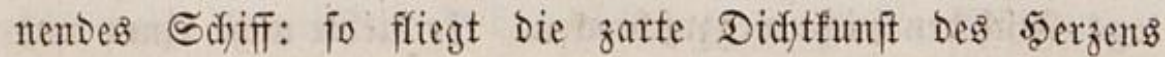
mur auf, wie eine goldne 2 (bentrotf $=$ Taube, ober wie ein Efrriftus, Der gen sammel geft, weil er eben bie (Erbe nidft vergintet.

Die Flöte floz ifm immer Durdh Das Bette Des Thaleg nad), ofne bodf weder näfer zut fomment, went er ftand, ober zurütef zu bleifen, wenn er lief.

Sebt fichwang fich Die Ranoftrape plöblich aus Dem Thale Den Berg hinauf. - Die Flöte Drunten wurde fitll, ba fidf oben bie $\mathfrak{B e l t f l a ̈ d}$ we weit und freit vor iffm auftlyat, und fids

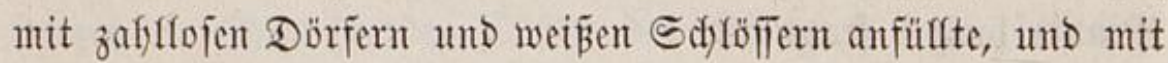

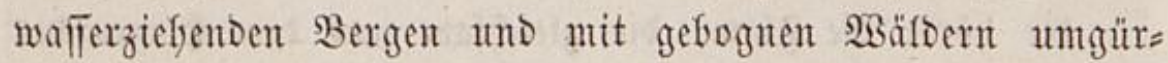
tete. (5r ging auf Dem Bergrüden, wie auf einer langen Bogen = Brücfe, über bie unten grünente Meeresfläd)e zut bei= Den Geiten fin.

(5r war ganz alfein und wor Dryen fidfer, er yfiff fret Dafer figurirte Shorale, Bhantafien, und zulebst alte $\mathfrak{B}$ olfs: melodien, uno förte nicht eimmal auf, wenn er einatfmete. (jegen Die গatur alfer andern Braginftrumente bleibt dieje Mundfarmonifa, wie Die andere, romantifíd und jü í in gro=

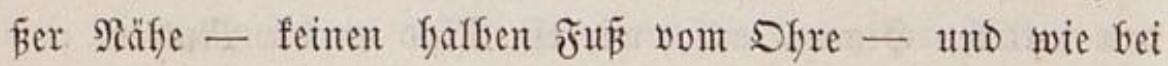
Der Mufif im Traum, ift fier ber Menf(h) zugleich Der In= ftrumentenmadyer, Fomponift und Spieler, ofne in geringften

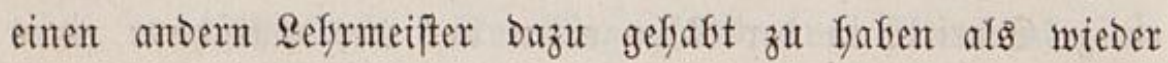
fidy, Den Sdyüler felfer.

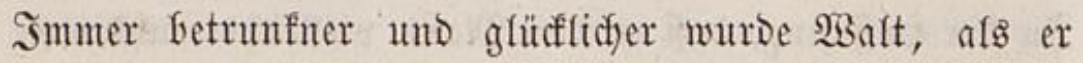
auf Diefer eriften Sdyäferwfeife, auf Diejem erften âtphorn fort Glies, Dem Morgenwinde entgegen, Der Die Töne in Die Bruft

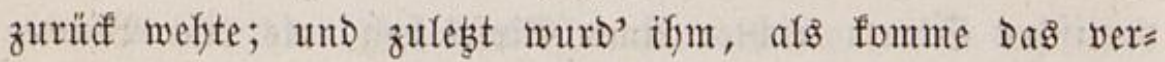
weffe (jetön aus weiter ferne fer. Da er lange fo ging 
Ino träumte - Da er von Dem Bergrücfen Gald finf́s in Die

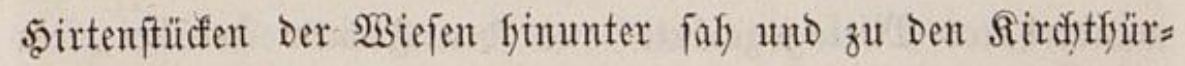
men von $\mathfrak{A}$ ltengrün - von Sobic - von Tfalfaujen -

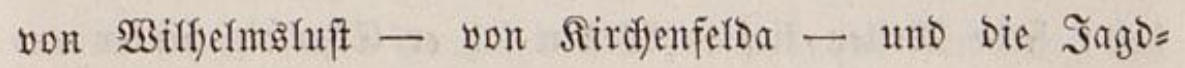
und \&uffidjöfier erblicte, Deren beide Namen affein, wie romantijaje 3auberworte, alte Begenden und Baradieje Der

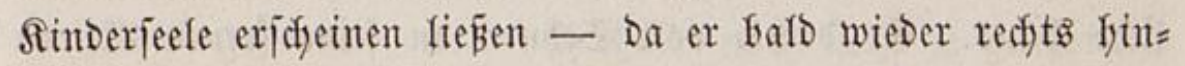
unter idjaute auf Die zweite (Ebene, worin fid Der gerabe Jfü feines Thales, die Rofana, frei gemorden auf einem blumigen Tamzlabs fodlängelte und Das Silber = Shill Der Sonne trug und immer zeigte - unb ba er bas $\mathfrak{A}$ uge auf Die Rindenftäbter Gebirge warf, wo unter Den hofen fieffent

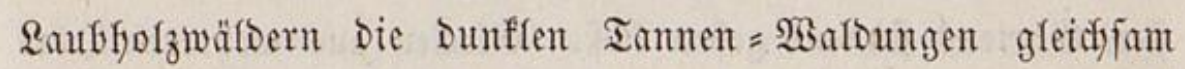
nur als breite Sdylagidoatten zu ftefyen idfienen - und Da er in Den şimmel fafh, worin fitfl und leidft bie $\mathfrak{B g}_{\text {olfe }}$ uno

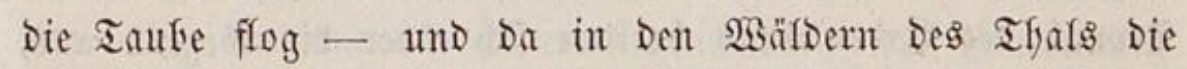
5aerbitvögel fodrien, und in Den Steinbrüchen einzelne Sdjüje lang fortfalfetent: io fofwieg er wie aus 2ndadyt vor (5ott, unt Dadfte Dem, was ex fingen wollte, nad), als of Der Un=

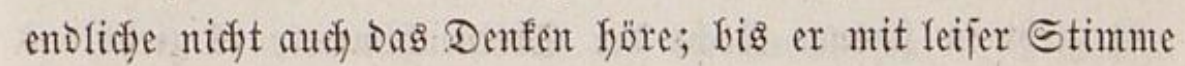
Dent Streffvers jang uno wiederfyolte, Dent er fifon längit gemadit:

5 wie ift Der sammel, wie bie Erod fo voll frentiger Stimmen! Biel fofouner als Dort, wo einftents Der (5forts laut jammerte, und nur Niobe fidwieg uno unter Dem Sdjleier

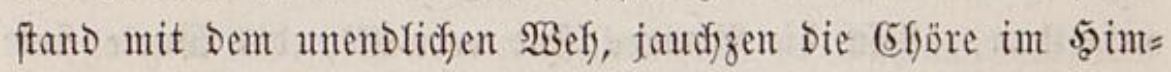
mel und auf Erben, und nur ber Allfelige ift ftifl, und Der Aetfer veridifeiert ifn.

Darauf jaf er gen 5immel, namute bjott zweimal Dut und fidwieg lange; und fielt es für erfaubt, jogleidy an 


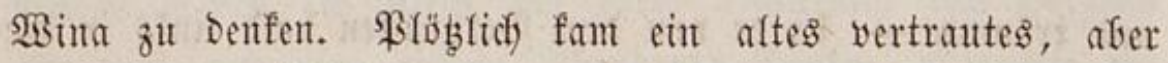
wunberfrares Mittagg̊geläute aus Den Fernen feriber, ein altes Tönen, wie aus Dent geftimten Norgen Dunfler Sinds= feit; fiefe Meilen=tief in 2 Beften faf) er Efterlein finter un= zäfligen Dörfern riegen uno glaubte Die alte Dorf = \$slocfe fut

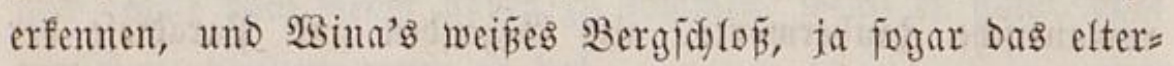

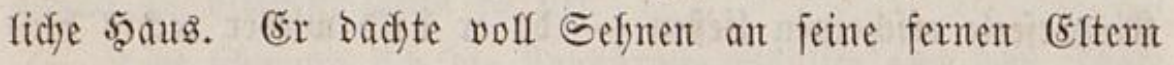
- an Das Stiffeben Der Rindfyeit - und an Die fanfte Wina, bie ifm, audy im Stiffleben ifrer Rindfeit, einft Die Aurifeln in Die 5 and gelegt - jein $\mathfrak{A}$ the bing an Den öft= lidfen biefirgen im fiffen Blau, fyinter weldye er wie finter

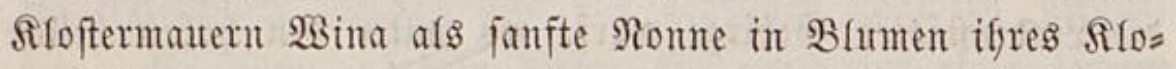
fter $=$ (5artens finnend gefen fię̧. (5itocfen aus mefreren Dör: fern tönten zufammen - Der Morgenmind raujofte ftärfer - Der binmel wurde Glauer und reiner - Der funte feidjte Teppich Des (Erbenlebents breitete fidf) über bie (5iegento aus, und flatterte an Den Enden, und $\mathfrak{B}$ alt wolnte, wie ein Traum, mur in Der Bergangenfyeit.

Er jang voll Seligfeit und namute iffren Namen nidyt:

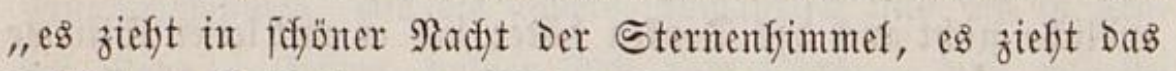

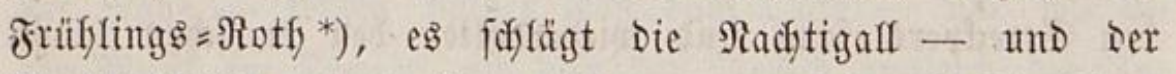

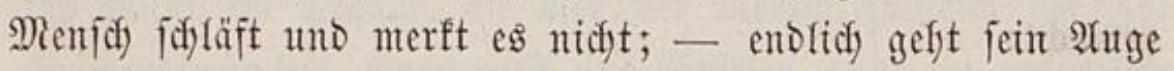

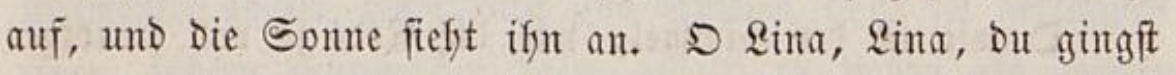

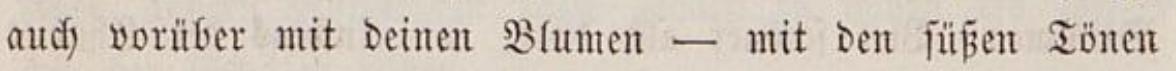
- unt mit Siebe - aber mein 2 unge war blint ; nun ift es aufgetfan, alfein bie Blumen find vermelft, Die Sorte find vergangen, uno Du glänzeft hod als Sonne." -

5ier fefrte er um vor Dem lauten 2 efent er fand bie

*) Die AGenbröthe in Rurben. 
Welt fonberbar ftifl unt fid ; mur bas belänte flang aflein uno reife wie Sdyafmeien Der Rintofeit, uno er wurbe fefr. bewegt. Er lief wieder unt jang immer freißer: ,naffes Altge, armes 5erz, fieffit du nidyt Den seimmel und Den $\mathcal{L e n z}_{\text {uno }}$ Das fajöne Reben? SBarum weineft Du? Saft Du was verlo= rent, ift bir wer geftorben? Idd) id) fyabe nidfte verloren, mir ift nidyts geftorben; Demin idf habe nody nicht je geliebt, o Iaाi]' midf) weiter weinen!"

Buleb̧t fang er nur einzelne รüne nod), ofne bejondern 3ujammentyang - cr fam eifiger Durdf Beete - Durd) grüne Ifäler - über flare Bädfe - Durdh mittageftifle Dörfer - vor rubendem $\mathfrak{A}$ rbeitgzeug vorbei - auf Dem 3auberfeis Der böben ftand 8auberraudf) - Der Sturmmino war ent= flofien, und an flaren şimmel blieb das grofe unendidfe Błaue zurücf - Bergangenfeit und 3ufunft frannten beff und nalie, entzündet von Der (5iegenwart - Der Brumenfelds

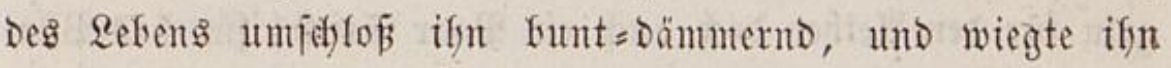
reife - und Sans Stunde ging aut. - -

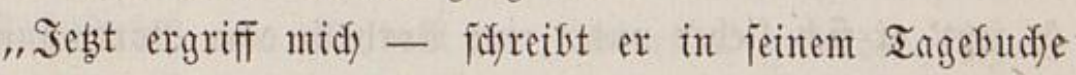
- Bans Stunde, wie allemal auf meinten Reijen. Sdf möchte

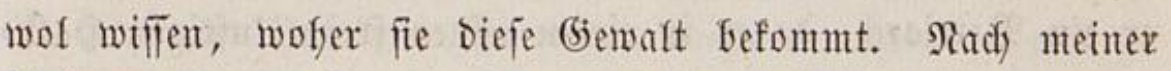
Meinung Dauert fie von 11 und 12 fis 1 uhr; Dafer glaut=

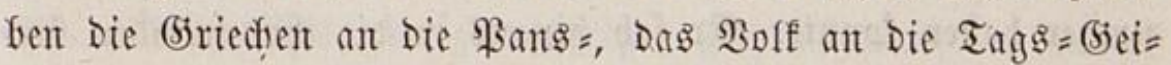

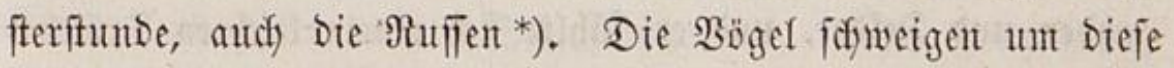
8eit. Die Menfoden idjlafen neten ifjem Artbeitszeng. In Der ganzen Ratur ift ctwas beeimliches, ia Untyeimliches, als

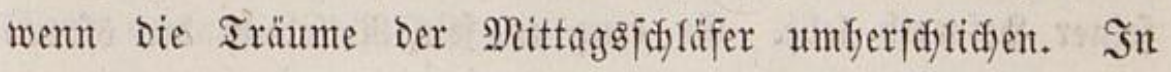

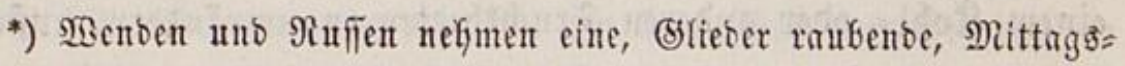
Teufelin an. Eaufitis. Monatofdjrift 1797. 12. Stücf. 


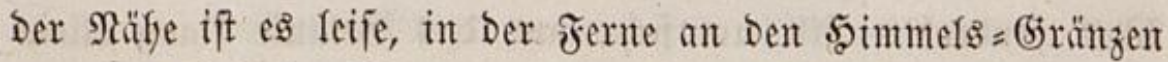
fidweifet (5etön. Man erimert fid nidjt fowol Der Bergan= gentreit, fondern fie erinuert fich an uns und Durdyziefyt uns mit nagender Selfnjudft; Der Stral Des Lebens bridft in jelts

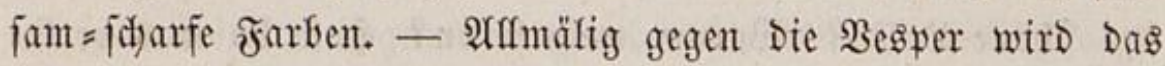
Rebent wieder frif̧er uno fräftiger." -

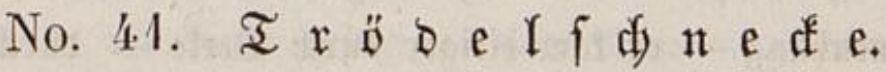

D e $\mathfrak{i} \mathfrak{B}$ ettel $\mathfrak{E} \mathfrak{S}$ t a b .

Sn ๒

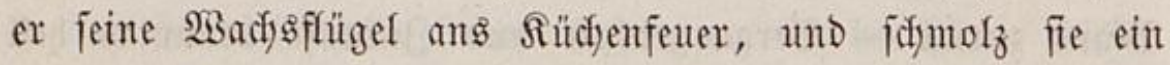
wenig. Sn Der That braudst Der Menich bei Den beften frü=

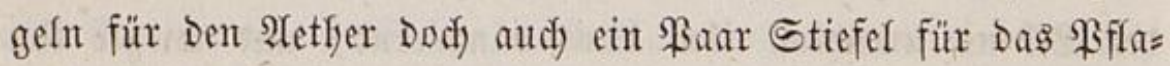
fter. Da der Epeifejal fifon volf sumbe und seerren war: fo fest' er fich Yieber unter einte Borfyalle ober Borbadyung zut Tija), bie fo freit war als der Tifa). (̌̌s war iffm, als jei

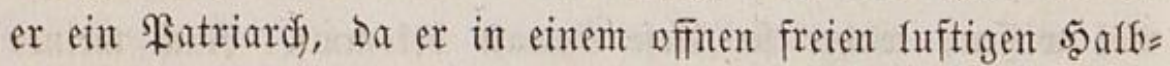

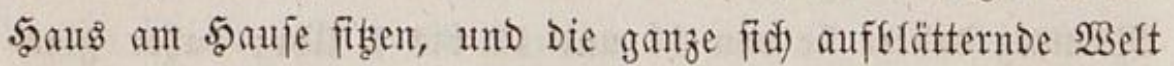

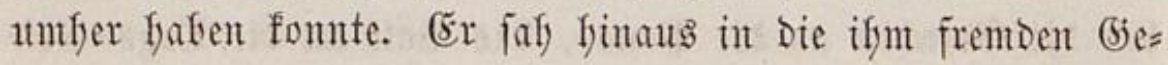
genden und Feloer, und er füflte fid einem Yeidften arouba = Dour alter Beiten gleidy, nacid) bent er zujammen geredynet fratte,

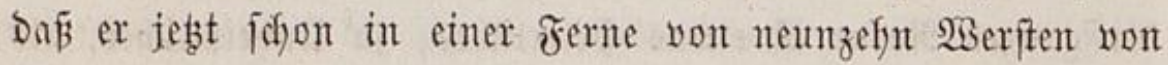
feiner 5eimatf) lefe. (Ér trug in jein Reifebud) Die öfono=

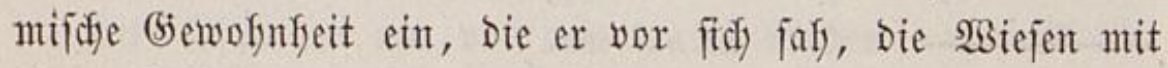
einem Rofl= ober anderen Fruddfbeeten zu umränbern, amftatt

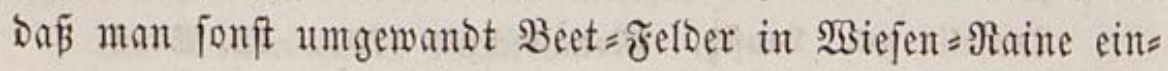




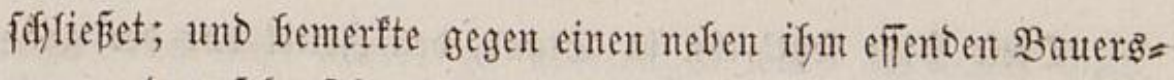
mann, bas jefje fefre niedfich aus.

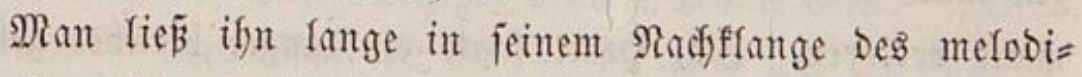
fiden Bormittags, in jener exiffen Stimmung fiben, worit

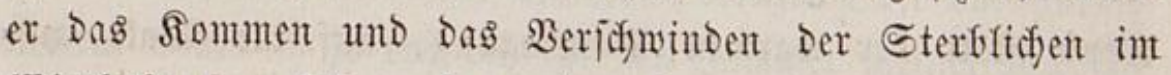
Wirtfighauje anfaf, und warten, bevor man ifm jein Tifd)=

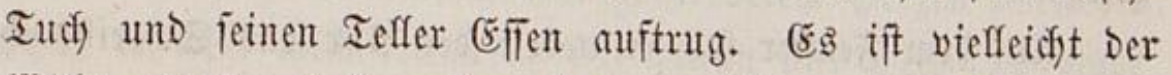

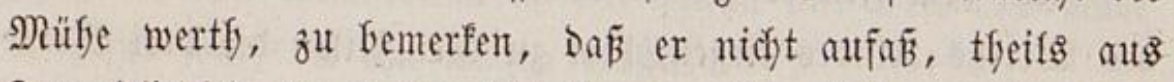

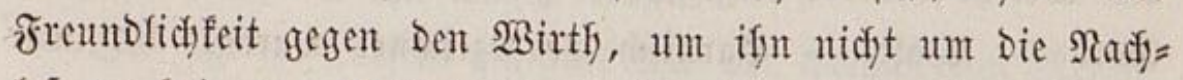
leje zut bringen, theils weil Der Menjidy, gleidf peinen Unter=

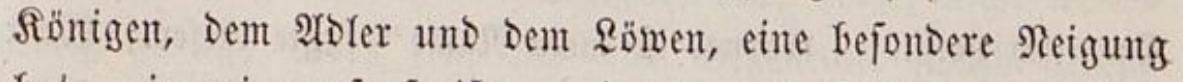
fat, nie rein aufäupeifen, wie man an Rinbern am erften wafynimmt. Der Notar begriff gar nidyt, wie Der Bauters= mann und andere (jäfle im Stande fern fonnten, Den Telfer

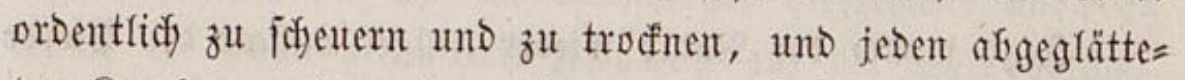
ten Rnodfen nod) zu trewaniren unb, wie Ranonen uno $\mathfrak{B e r}=$ Ien, zut Durdfoblyren.

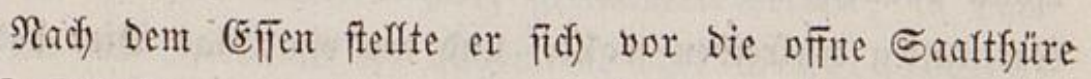
Der Iafelfube, um mit bem in 3aubertfal gefundenten 3olf= zettel in Der 5ant, und mit Deflen Mebergate zll warten, bis Dic fpeifenden $\widetilde{u f f r l e u t e, ~ D i e ~ e r ~ i n ~ c o r p o r e ~ a n z u r e d e n t ~ u n b ~ z u t ~}$ befragen fofluete, einzeln fyeraus fämen. Da ftand ein jun=

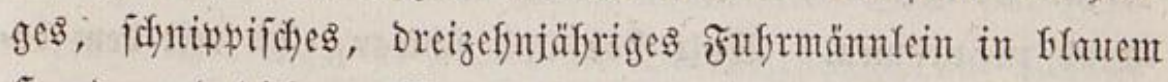

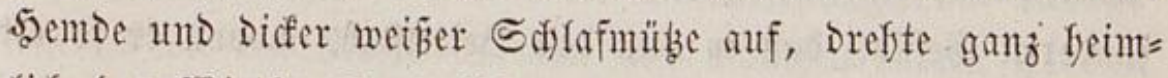

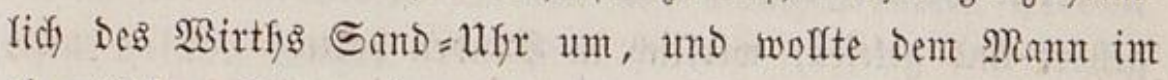
eigentlichen Sinne (bent es war erft ein Drittel Stumben= Gand verfaufen) Die Zeit vertreiben.

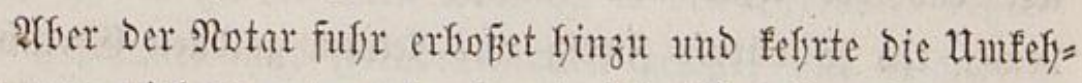
rung um, viel zu unvermbëgent, ein främifiches thuredft, Das er gegen fich eroulton fonnte, gegen cinten anbern zut ertragen.

Iean gुar's ausgets. פBcrte. XIV. 
Diefe Saibe febt' ifn in Etand, Den Bettel vor Der gane zen table d'hôte empor zul heben uno autşurufen, ob ifin je= mano verloren. Soth, 5yerr, fagte ein langer feriiber geftredf = ter 2 rem, und ergriff ifn, und nifte (simmal furz mit bem Siopfe fatt Der warment Danfiagurg, auf bie $\mathfrak{B a l t}$ auf= gejejent.

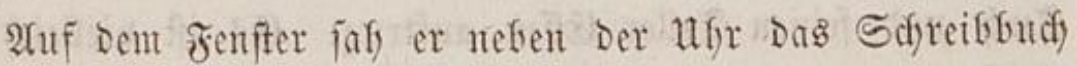
Des 2 Birffy = Sindes liegen, Dem zu Drei Beilen Die Drei 2 orte (5ott - Wart - 5arnific) vorgezeidfnet waren. (5r war fefre Darilber erftaunt, und fragte oen $\mathfrak{W}_{\text {sirth, }}$ of er etwan

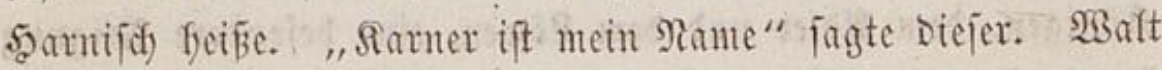
zeigte ifm Das Buch und fagte, er felber feíne, wie Da fefle. Der 23 irtf fragte grob, of er Denn aud wie Die vorige Seite Feise: 5ammel - Stromen - Sdfwanz - $2 c$.

Selit wollte Der Notar wieder Flïgel amftatt ber Pferbe nefment uno fort, unto vorfeer bezaflen, als iffn ein Bettel=

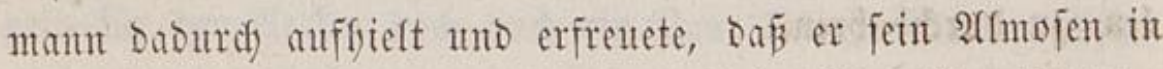
Naturalien cintreiben wollte, und um ein (5ilas Bier bettelte,

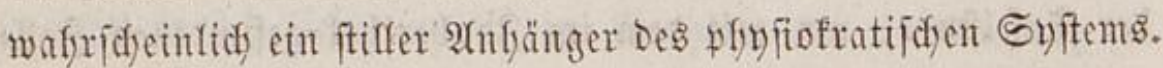
Da ber Mann unter Dem (Einfajitien Der fleinen Naturalbe= folbung feinen Bettelfatab in eine Ecfe ftellte: fo gab Das Dent Notar Belegenfyeit, Diejent Dornigen, Fofweren Stab in bie

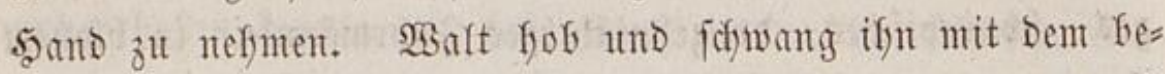

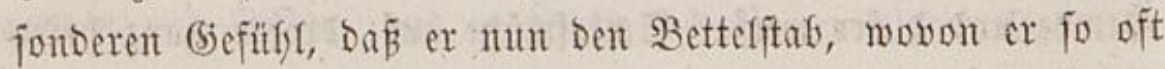
gefjört uno gelejen, wirflich in sänden halte.

3ufebst - Da er fict) es immer wärmer auseinander jebzte, wie Das ber lebste und Dümufte Maft cines entmafteten $\mathfrak{L}_{e}=$ Gens, ein to Ditrrer 8 weig ants fenem goldonen (Efriftbaum,

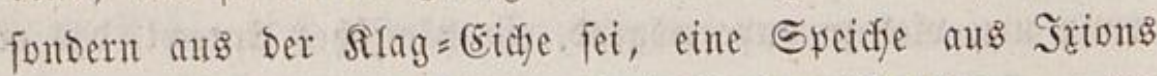
Rad - murd' er erfaffet; er fymbelte bem Bettefmam, ber 
boun (Ermft nidft anders zu überzengen war, als burd) (5elb, Den Stab ab, Die einzige Nippe, Die Der Mant fratte. "Die= fer Stab - jagte 2 alt zu fid - folf midh wie cin 3auber= ftab verwandeln, und befler als eine Rorenzo= Doje barmberzig

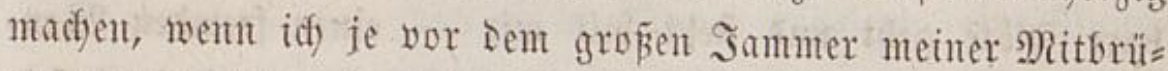
Der einft wollte mit faltem oder zerftreutem serzen vorüber= gefn; er wiro mid) erintern, wie braun uno weff und mübe Die Sand war, die ifn tragen muß̈te."

So fagt' ex frrafent zu fidf; und Der weidgherzige Nenfol warf fich, ungleich Den fyartferzigen, vor, er fei nicht weids=

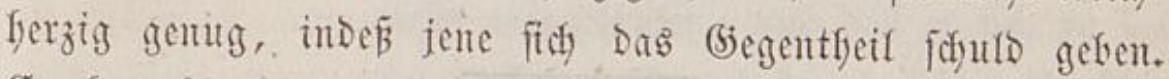

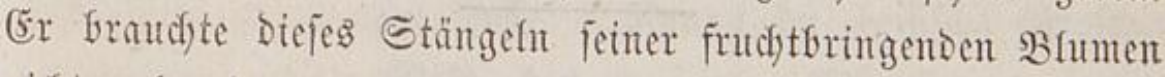
nicht; aber Da, wo Dieje $\mathfrak{B e t t e r f t a n g e ~ f e l b e r ~ s o u ̈ d j e t , ~ a u f ~ D e n ~}$ Sdjladjtfeldern, und um bie \&ufifibloffer vierzefnter \&udwige fyerum, bie fdon gledd) mit 3 äfnen auf ber 2 gelt anfom= men*), an Drten, wo die gefeimen Trewpen uno Ifronge=

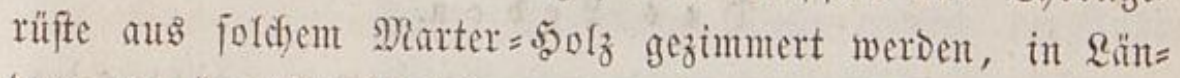
Dern, wo Der Bettelfab Der affgemeine oder (jeneral $=S_{t a b}$ ift, vieffeidft Durch) Den mifitärifochen felfer, Da müro' es ein erwünjojtes Regat jeyn, went jeder Bettler jeinen Stab it ein eignes Stants = 50 ölzer = Sabinet vermadjte; - wentgftens ift fu glaubell, wenn neben jedem fiommando = Stab und 8 ep ter eit foldyer läge, er Diente afs Balancirfange, uno fodlüge

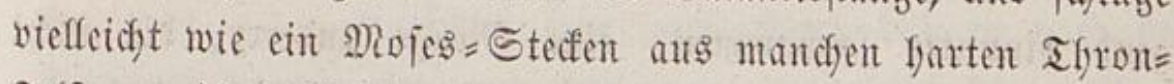
Felien weiches $23 a \pi j e r$.

Der Rotar verliḗ fein Suntier mit Dem Erulantenftab fo froh, als es fu erwarten war, Da er Den Berfüufer Deffel= ben in Erffaumen und Freutentfyäuen gejebst; und bejonders

*) Louis XIV. wurbe gezäfint geborent. 
Da er über bie golbue Ernte von Abententen finfäs, bie er blog in einem fyalben $T$ ang cingeerntet. "WBafrelich es ift

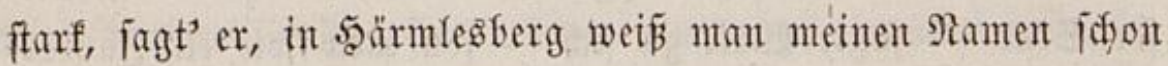
münolidy - in (5rünbrum gar forriftlich - eine wumber=

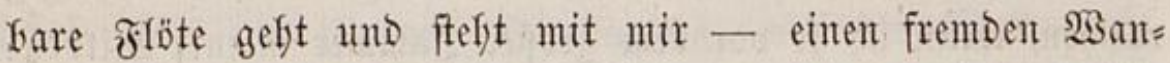
Der = Stab bab' idy Desfalfs - (jott, was fam mir nad) jol= (j)en Beidjen nidyt in einem ganzen langen Radjmittag paffi $=$

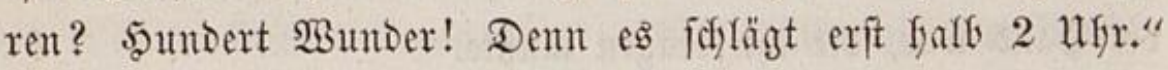

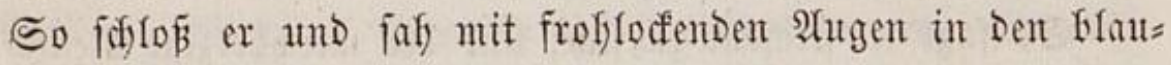
ausgewölbten saimmel finein.

" No. 42. $5 \mathfrak{d} i \mathfrak{i} \mathfrak{f} \in \mathfrak{x}\{\mathfrak{p} \mathfrak{a} \mathfrak{t} \mathfrak{b}$.

D $a$ \& $\&$ e $b$ c $\pi$.

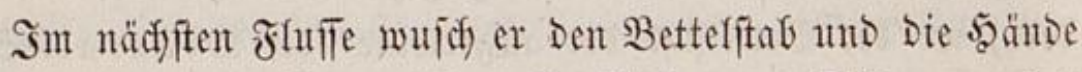
ab, in weldye er ifn vor bem Berfäufer ats Sdyonung frei genommen. Der erffe afft Der 20 oflthätigfeit, Den er nady Dem Raufe Des Stafes verridftete, war einer mit Dem Solze

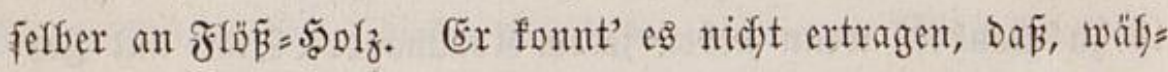

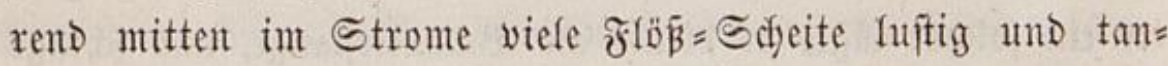
zent fintunter fofwammen, eine Nenge anderer, Die nidyt

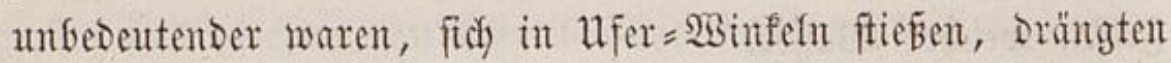

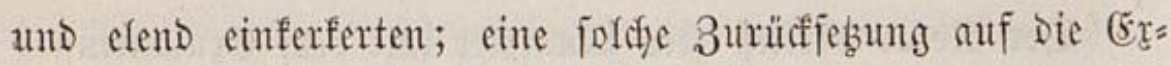

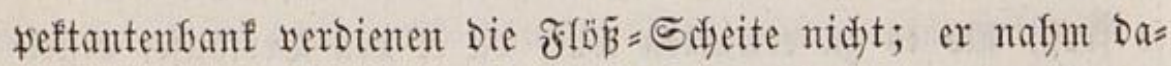
ber feinen Bettelfto of und half fo vielen fintangejebsten Echei= ten Durdy Sdyieben wieder in Den 3ug Der 2 ogen finein, als neben ifym Yitten; Denn afle Sifeite - jo wie alle Men= 
idfen - zu Gefördern, fefft auper Dem Bermögen eines Sterblidfent.

(5r) Yolte Darauf einen fleinen zerfumptent Sungen ein,

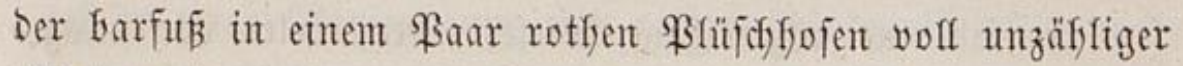
Bilabgen ging, Das, von cinem Manne afgelegt, eine Fump= unt Strumpfigofe zugleid an ifm geworden war. Der Snabe fyatte nidjts bei fidi) als ein (släsdyen, mit bejpen Galbe er fid utaufförfich Die rothfranfent $\mathfrak{A}$ ugent beftridy. WBalt fragte ifut fanft feine Reidenggeididy te ab. Sie beftand mur barin, Dá̉ er von feiner Etiefmutter weggefaufen, weil jein Bater, ein Militair, von biejer weggelaufen, und Daß̃ er fich zut Den Franzojen zu bettefn hoffe. "Samuft Du hefifiche (5rofden Graudfen?" fragte Walt, Der zu feinem Sdyrecfen zu gropies (jeld bei fich fanto. Der Sinabe fafy ifn Dumm an, lädyelte Dam, wie über einen $\varsigma_{\text {par }}$, une jagte nidjts. Want wies iffm eintent. "D, fagt' er, Das femn' er wohl, fein Bater hab' ifjn oft wedjfefn laflen." Der Notar erfufre endidy, Der Sinabe

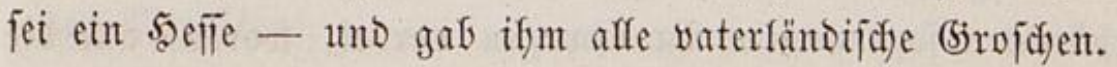

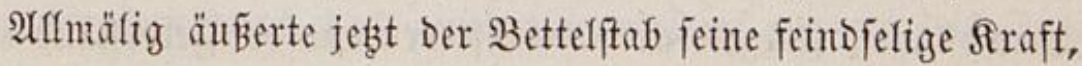
eine $\mathfrak{B}$ etterftange zu jetyn, weldje (jemitter zielyt. Salt fomnte Dett Frülyling Des Bormittngs Durdyaus nicht wieber zurüff fringen, fondern muste Den Saerbft wor fich fefen feffen, Der

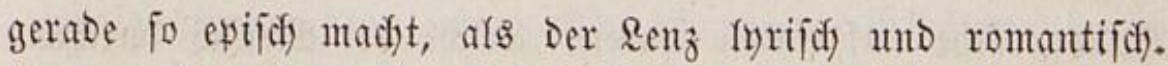

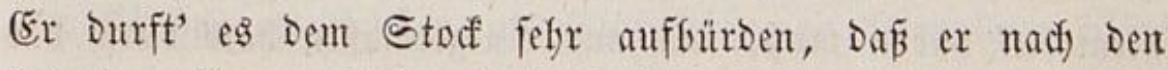
Leisziger Bergen falf und Dod) ganz vergeblid finter ifnen auf Der anden Seite in Die Reizziger EGenen Kerafzufafyen fuchte bis vor $\mathfrak{B}$ inta's (5artentfüre, weil ber Stodf fid) gleid)= fam unter Dem Berg= Sdylitten ftemmte und frülpte.

(5x jaf) nur Das Fliefjen uno Fliegen Des Rebens, Die

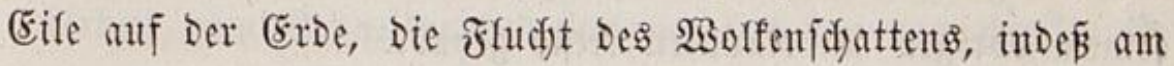




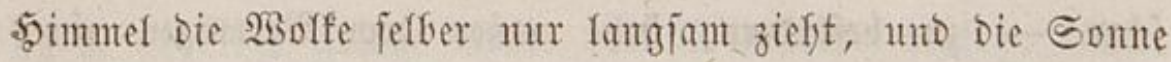

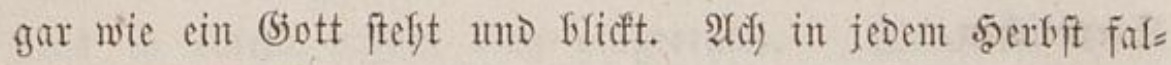
Yen audy Dem Menjojen Brätter ab, mur nidjt alfe.

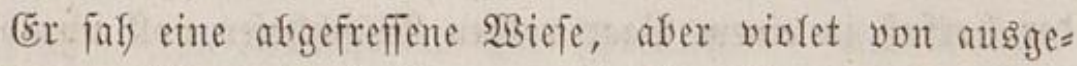
idfloffenen giftigen 5gerbftblumen. 2huf ifr lärmten Bugvögel, Die mit einander Den $\mathfrak{B l a n}$ ju iffer Padytreife zu beredent

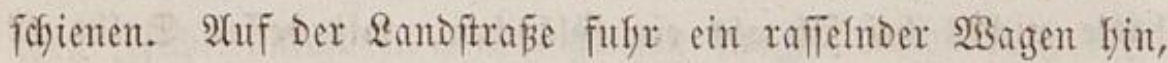
unter ben 5ointerräbern foll ein 5yut. Stm fernen Berg= Abrange fodritt eine weiblidye weike bieftalt faum merffor finter ifrem Dunfelfraumen Mante, um in irgend cinem un=

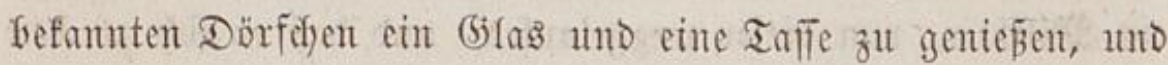

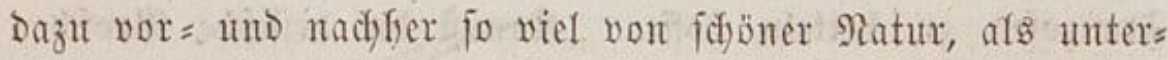
wegg gewöfntidif borfommt. In Der शäfe trippelten zwei

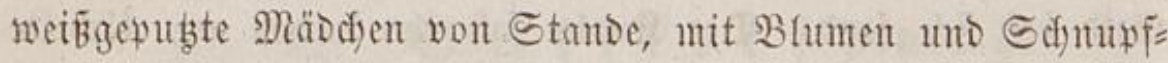
tïchern in Den Saünoen, Durdf Die grünen Saten= Furdjen, unb bie gelfen Shawls flatterten zurïct.

(5r) ging bor einem fis an Die şimmelswagen Yhitauf getfürmten fogenanten Brautwagen yorbei, worauf afle Die

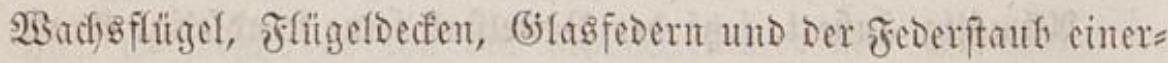
jeits, uno die Eteif = uno Sifwanzffolfen, Die Bruft = und

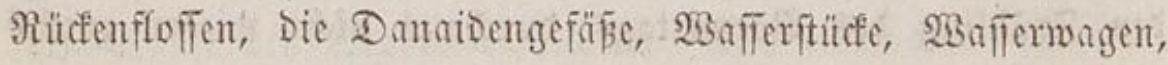
Regenmeffer und Irofenjeile anbererfeits unter Dem Ramen 5autggeräthe aufgetaden waren, weldye Der Menfód Durdyan

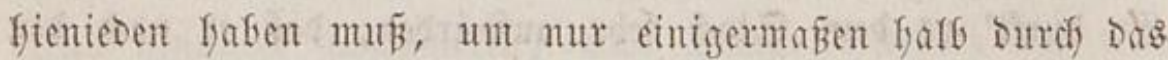

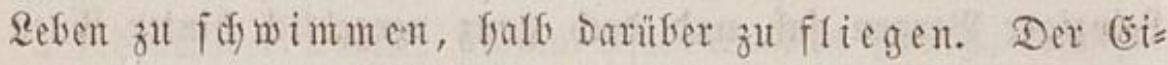

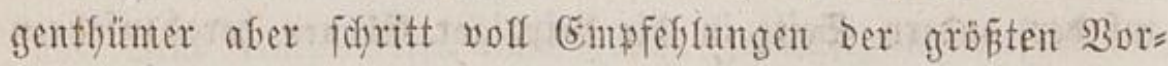
fidsteregefn für jeine aufgepacten glügel uno glofien nebent

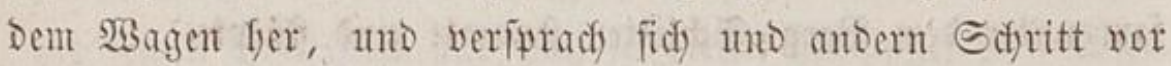
Sifritt gaulz atbere blauere Tage in Der Bufunft, als er it feinem vorigen unfefonnten Nefte gefiabt. 


\section{1}

Darauf fam 2 galt auf ein Giltal= Dörfolyen von fünf oder jects majdenden, fegenden säujern uns rauchenten Bact= öfen. Die Sünglinge foben mit Stangen uno falber Rebens: gefafre einen Narienbaum mit rothen Bänder = Fabnen in bie 5öfe, Der fïr ein Dorf wor nidft wentiger ift, als was eine Bogelftange für eine Mittelftadt. Die Mädden, weldhe bie

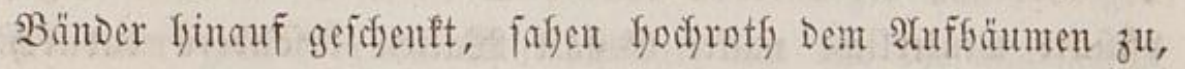
uno fratten nichts iut jefigen Sapf uno saerzen, als Dent mor=

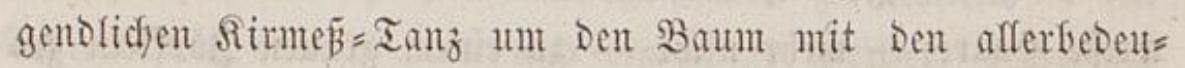
tenoften Buriden Des Drts.

Darauf begegnete Der Rotar einemt fojwer ausgefoljmüct= ten eiffiäfrigen Mädd)en mit ciner firüfe - was ifn un= fäglidf) erfbarmte - uno Die Frau \$atfin fief aus Dem Dert= d)en iffrem Sirmȩ́gafi fichon entgegent.

Darauf fant ein an fid) felber angefetteter Malefifant fwifden jeinen Serfer = Futhluern; alle pricjen, fo weit fie mit Worten nodf vermodften, Das Bier Des vorigen Dorfa; and Der Malefifant.

(Er fam Durdi) Das anjefnftefere Dorf, worin Das fifiaf nur eingepfarrt war. Da Die Mutterfirdjen= Thüre gerabe offen ftamb - aus Dem furzen Dicfen Ifyume wurbe etwas geblajen, worein wieder Der Bieffirt blies - jo ging er eir

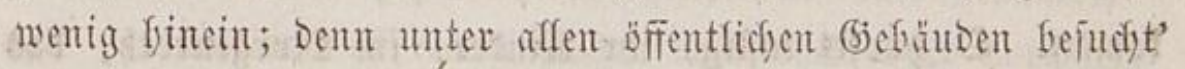
cr Sirthen am fiebiten, als (sispalläfte, an Deren leete SBänoe

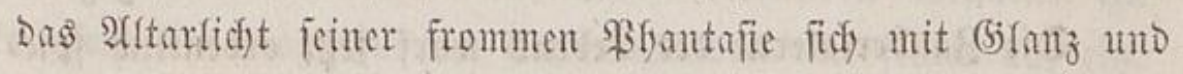

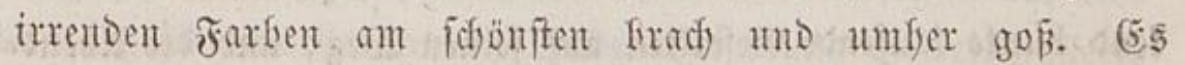
murde orinnen getauft. Der Täufer und Der Täufling fofrien feffr yor dem Saufengel. Bier ober fünf Nenfden waren nad) ifrer 2 rrt fountägfid) blafomirt, gravirt, mit getriebuer Arbeit vom Sdneider bedeff; mur aus Den vornefmften Rir= 
d)en=Rogen, Den abeligen, fodaueten Mägbe, Die Trme in Glaue

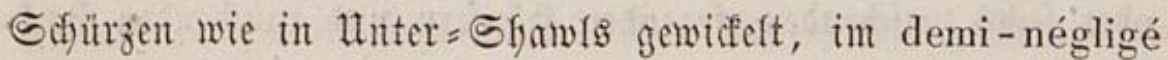
Des 2 sochentags fyeraus. WBirthichafts = Rleidung in feifiger Stätte war iffm Garter Miß̄ton. Der ßatfe Des getauften Urentels war Der $\mathfrak{H}_{\mathrm{r}}=$ (5rofivater Defielfen, Der Dag Sd)rei= 5älschen faum balten founte vor Safren, uno Deflen abge=

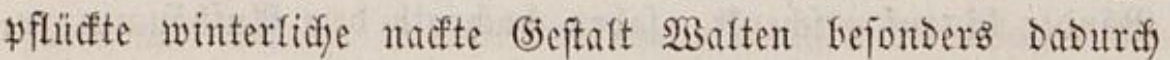

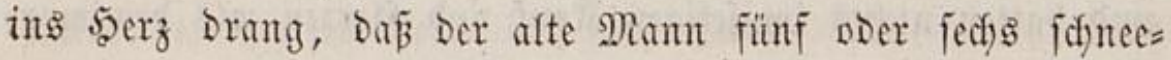

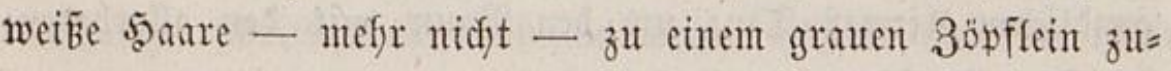
fammen gejanmelt und georefit fratte, um fid zu zeigen.

Daj Der afte Menfich Dem jungen fo nafe war, Das Rind Des (Srabes Dem Rinde Der SBiege, Die gelben Stopweln Dem Yeitern Maten=Blümchen, Das rüfyrte Den Notar nod) eine Stunde über Das Dorf finaus. "Spielet Dod) Rindtaufents" fagt' er zu einigen Rintoern, Die ein Freuz trugen und $\mathfrak{B}_{e}=$ grabens fpiefen wollten. (5ierabe aus Dem Saerzen flog ifm in Dén Siopf Der Etreffuers:

Spielet jaudjzend, bunte Sinder! WBenn ifyr einft wieder Sinder werdet, fü̈ft iffr eucf) lafju uno graut unter bem weinerliden Spiele bridjt Der Spielplakg ein und überbecft

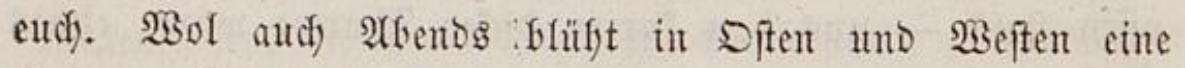
Aurora, aber bas (siemölfe verfinftert fid) und feine Somue fonmt. D füpfet lufitig, ifjr Sinder, im Morgenrotf), Dą eutif mit Blüten bemalt, und flattert eurer Soune entgegen.

Die 3auberlaterne Des Rebens warf jebst ordentlich fpie= Iend Gunte laufende Gieftalten suf feinen $\mathfrak{B e g}$; und bie $\mathfrak{A}$ bend fonte war Das Ridft finter Den (5)äjern. Sic murden gezogent 14n es muste yor ifm vorïber laufen unten im Strom ein

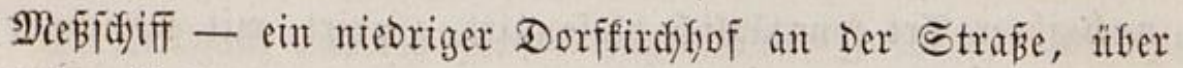
Defien Rajenmauer ein fetter Sdyooṕfumo fpringen fonnte - 
eine Ertrapoft mit vier \$ferdent und vier Bebienten vorntent

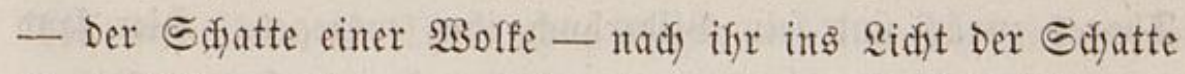

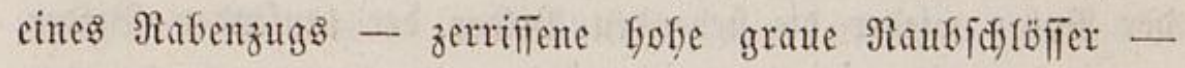
ganz nette - eine polternde Mïfle - ein zu Wferbe iprent= genter Befurts = 5elfer - Der Ditre Dorffalbier mit Sineer=

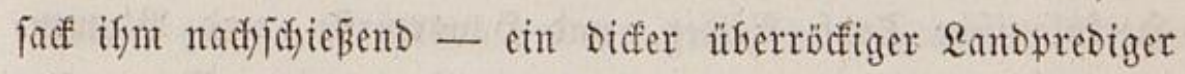
mit einer gefdrtebenten (Entepredigt, un für bie alfgemeine Ernte (5ott und für feine Den Butyörern zut Danfen - ein Sdjebfarren yofl $\mathfrak{B a a r e n}$ und ein Stab Bettler, beise um Die Sirmeffen zu beziefen - ein $\mathfrak{B o r}=$ Dörfofen won Drei

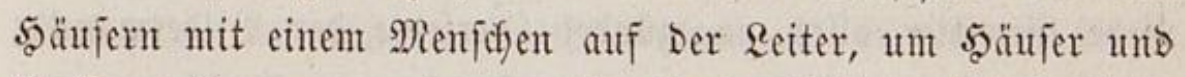
(5)affen roth zu muteriren - ein Sierl auf jeinem Siopfe einent weí̈en Siopf yon (5yps tragent, Der entweder einen alten

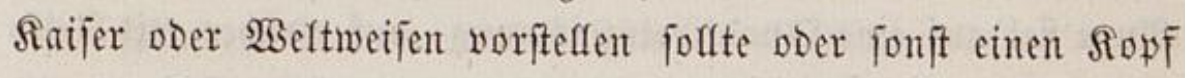

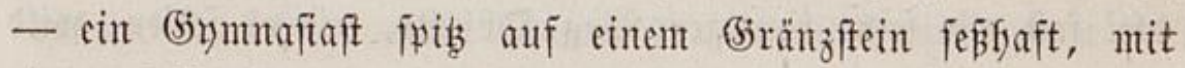
einem 2 eif $=$ Romane vor Den $\mathfrak{A}$ tgen, unt fid Die $\mathfrak{B e l t}$ und

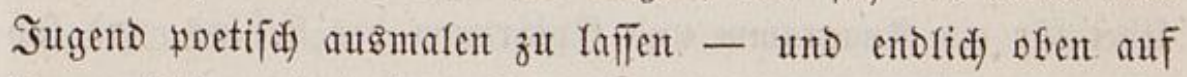
ferner 5äbe unto Dod, nod) jwifhen grünen Bergen ein vor= idjimmerndes Stäbthen, worin (5jottwalt ïbernadyten fonte, und bie helfe atbenofoune zog alle Spizen uno Giebel jefje Durd) (jold ins Blau emtyor.

"NBir find faufende Stridfregent, uno fralo ferunter," fagt' er, als er auf einem Soligel balo rudef = bald vorwäts falf, um die fiette der auscinantor eifenten (5eftalten zut fnübfen. Da ftieg ifym ein Bilber=\$änoler mit peiner auf eine Walze gefäbelten flatternten Bifber=Bibel uno Bilder=(5aflerie

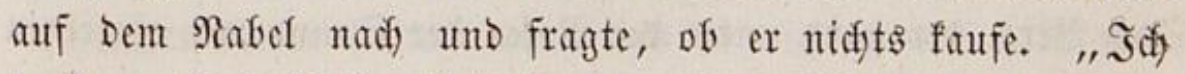

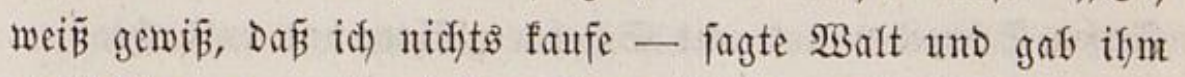
z'ölf Sirelizer - aber lafjen Sie mich ein wenig Dafür Darin Gerumblättern." 
"2Ber fiefer als id Iforar zurüte und jein Bifberbud) ifm entgegen. Şier fand Der Notar wieder bie feffenden Bilder Der Iaufenden Bilder, Das Refen futfre mit farben auf Dem Fapiere Durif einnder,

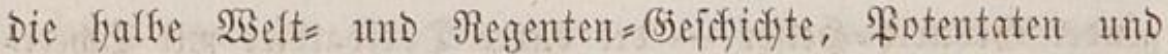

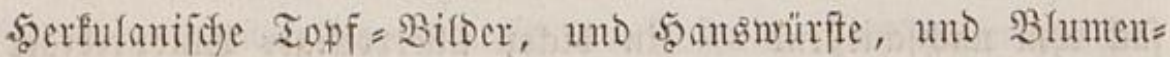
uno Militirir= Uniformen, uno afles ḧberfut Den Niagen Des

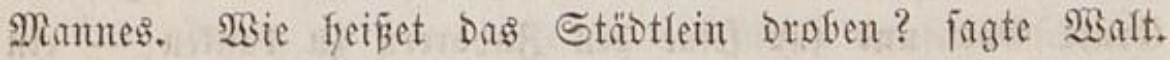
"Iftfladungen, mein lieber serr, mb Die Berge Dort fint cine prädytige $2 B$ etterfiched e, jonft fätte uns vorgefferm Dag fiebe (siewitter afles angezündet (beriebze Der Bildermant);

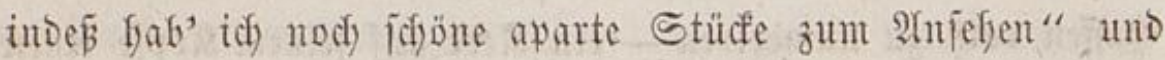

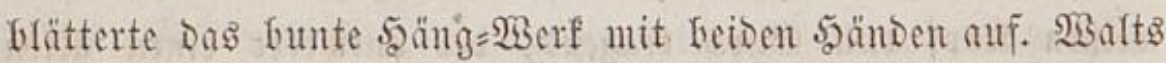

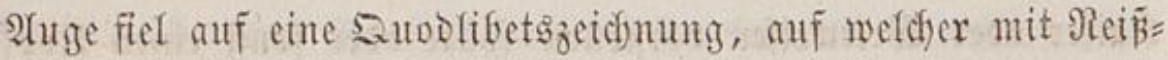
Glet faft alle feine feutigen $2 W_{e g}=$ Dbjefte, wie es fojien, wild fingemorfen waren. Bon jefer fielt er ein jogenamutes Suldo = fibet für cit 2Hagramm uno (Epigramm Des Rebens, und faf es mefre trïbe als feiter an - jebt afeer vollends; Dent es ftand ein Sonusfoyf Darauf, ber wenig yon jeinem und Bults (Befirifte verichieden war. Ein Engel flog über Dağ banze. Unten fano Deutids: was (jott will, ift wohl getfran; Dann Inteinifod): quod Deus vult, est bene factus. (ङr faufte für feinen Bruder Das tolle Blatt.

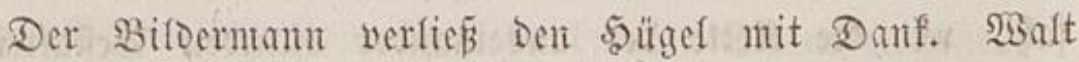
feftete Das yon Dem Borüberzuge unjeres malenden und ge= malten Sebens geriffrte Seelen = 2uge auf Den wetterfidetiont=

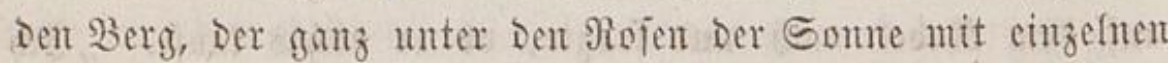
Feljen=Sdnetben uno mit Edafen glühte, uno er Dad)te:

"So feft feftet er nun ewig da - frül) als nodi feine Menfiden fier waren, fofnitt er aud bie fdweren 23 etter= 
wolfen entzwei, und zerfrady ifre Domnerfeile und madjte es fyelf und fichön, im Thafe ofne Augen - Hno wie trujendmal mag Das 2 bentoroth im ₹rüflinggglanz feertich ifn vergolbet fyaben, ba nody fein Reben unten ftand, Das in Die Serrlidyfeit mit Träumen verfanf. - - Bifft Du Dent niḑt, Du grop̧e

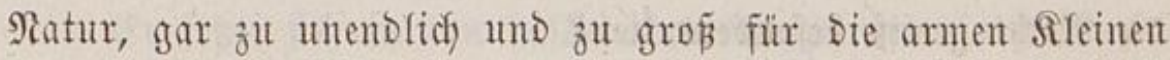
fier unten, Die nidyt Safure Iang, gefduweige Safrtaujente glänzen fönnen, ofn' es zul zeigen - Mno Didh, o (jott, hat noch fein (jott gejefen. Whir fint ganz gewiß flein."

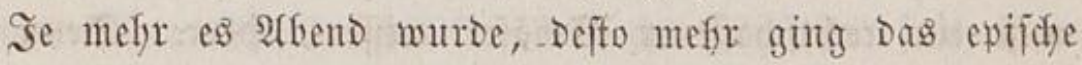

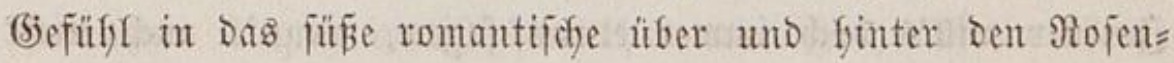
Bergen wandelte wieder $2 B$ ina in (5ärten. Denn Der 2 Gento färbet zugleidy Dic optifichen und geiftigen Edyatten bunter an. (5r) jefnte fidy nad) einem fremben Nenfdernworte; zuleşt Drängt' ex fid an einen Mam, Der einen Sdjebefarren yolf SBolle ungemein langjam fiflob, und immer ftand und nach Der Sonne fafy.

"Er jei, fagte Diejer fefre balo aufgeregt, jonft nur ein 5ytmann gewejen, uno babe auf einem gläjernen şorn fein Biel) fo in Der Etadt zujammen geblajen, Doß mandjer şut= mann ctwas Daran gewendet fätte, went -er's blajen balb

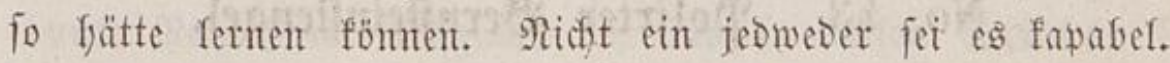

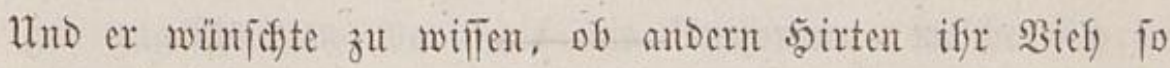
nad)gegangen, went fie Durdh Die (Elfe vorausgewatet; ifm fei es wie Soldaten nadggezogen; und (jott befjut' ifn, Dá er fici) Deffen ritfme, aber wafjr jei's."

Der Notar fratte über nichts fo viel freute, afs weut

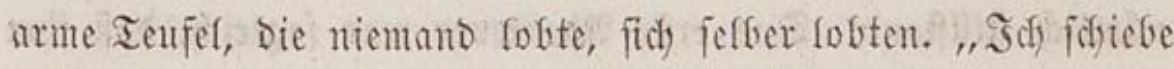
nodf ganzer fünf Stumben Durd) - jagte Der Namu, Den Der

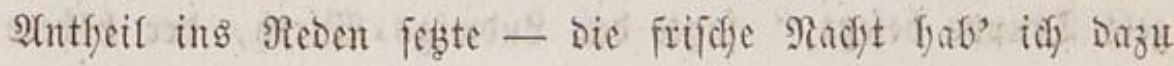


jefre gern." - Dab fann ich mir leidyt Denfen, mein alter,

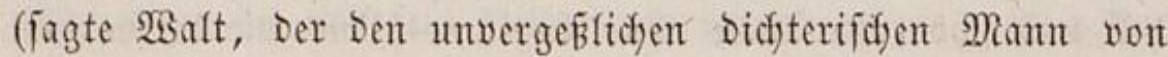
Iodfenburg vor fid) glaubte) im żweiräberigen Sdyäferfäus: (d)en, wo (Ex Dodf meit im Früfling fodläft, fatt' (Er ja Den ganzen Sternenfimmel vor fich), went (5r aufwad). Shm ift

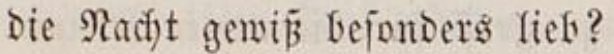

"SFanz natürlich, Denf' idd, verfebte Der Sdjäfer; Denn fobald's frifich wirb, uno es tapfer thauet, fo zieft bie 1 golle

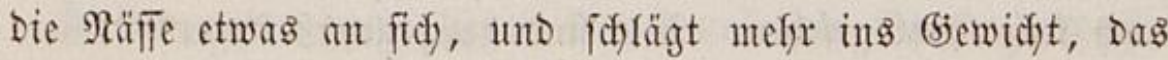

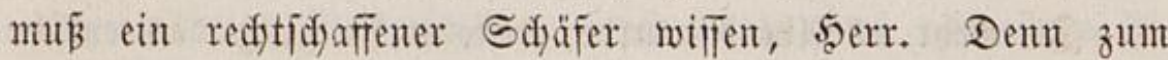
Bentuer will's Dod, immer etwas jagen, wenn's aud nidjt viel ift."

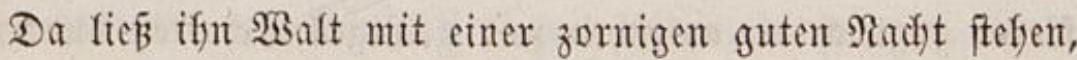
und eilte Dem raudfenten Bergifästdfen zut, wo er, nady den Geutigen Dörfern zu idyließen, im Nadjtquartier unter foldye afbenteuer zu geratfen verfoffte, Die viefleidyt ein anderer mit Wurzefn und Bhfiten gerabezu augheben uno in einen Roman verpflanzen fönnte.

No. 43. গुolirter $\mathfrak{b e r n f t e i n f t e n g e l . ~}$

๔đ)aupieler - ber Mazfentyerr - ber Eiertanj - bie (Sinfüuferin.

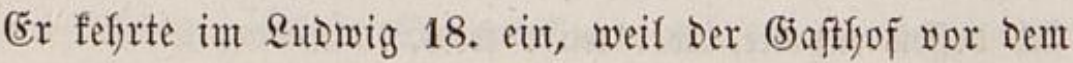
Ifore lag, yor Deffen Fragmajofinen or nie gern vorbeiging,

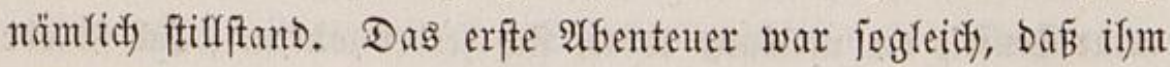
Der $2 B i r t h$ eir Bimmertyen abidflug; "es jei alles von frän=

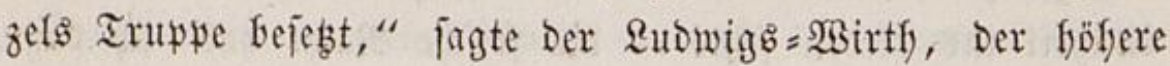


Soften und Stoffwerfe mur foldyen, Die auf Den Göhern Des

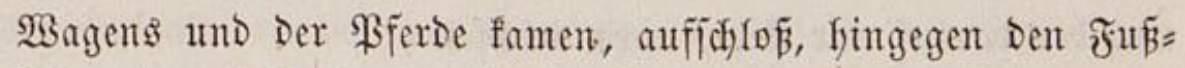
Goden Den Fuß̧boten anwies. WBalt faf) fich gezmungen, Den

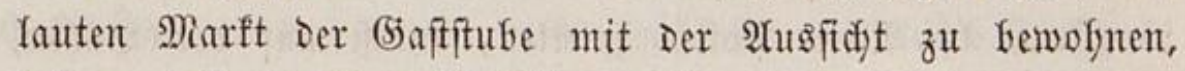

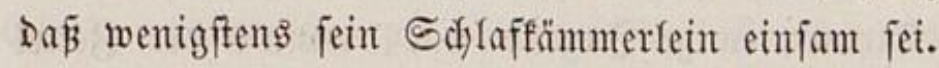

(5x) jetste fid in Den fralfrumben $\mathfrak{A}_{1}$ tijules fintein, uno zog einten sausfnedft, oa er nafe genug voriber fam, gelegentlidy an fid, uno trug ifym föflidy feine Bitte um Irinfen vor, Die er mit Drei guten (5ründen unter=

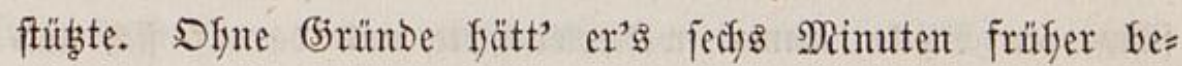
fommen. Am Silapptifididen that er nidyts, als in Einem fort bie Sifumpieler und Exielerimen im âlgemeinen fod aditen, Die auts = und eingingen, Dann nod) bejonters an ifnen funbert einzefne Sadjen - unter andern Den mit Dem Biätt= zaljn aufgeftridyenen Mamts=5aabit - Die entgegengejeb̧ten

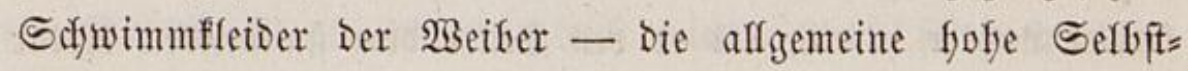

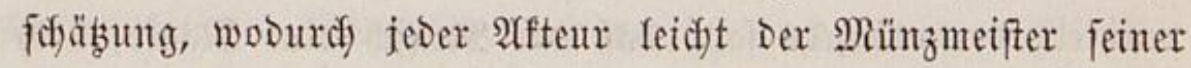
Preismedaiffen und fein eigner Chevalier d'honneur war, uno jede Aftrice leidft ifye Deforazionsmaferin — Den Büfly=

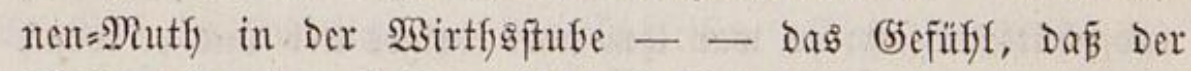

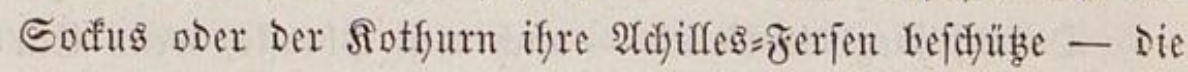
Gunte Nafyt iffrer Diffion, Die aus io vielen Stü ffen fo gut zugeidnitten war, als Die Mniformen, weldye fid Die Franfreidyer aus Bettbecfen, Borfängen uno alfem, was fie erplünoerten, madyten - uno Den reinern Dialeft, Den er fo fefrr beneibete. "Darunter ift wol feine einzige Perjon, Dudft" er, bie nidft längit uno oft auf Der Bülnte eine redfififaffene, ober befocidente, oder geleffrte, ober unjofulbige, oder gefrönte gefpielt," unto or impfte, wie Sünglinge pflegen, Dent 5olze 
Der Büfne, whe Des Ratheders und Der Ranzel, Den Menfifen cin, Der Darauf nur ftelst, nicht wächjet.

$2 B a s$ ifn betrübte, war, Daß afle (5efidster, fogar Die

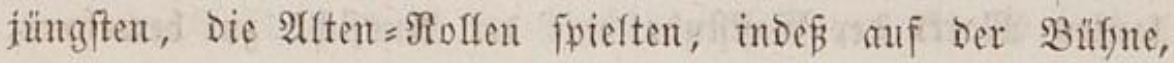
wie auf Dem Dlymp, ewige Jugend war, went's Der Bettel begefrite.

Sin arbendounfel fiel ifm ein Menich auf, Der feine Miente ritate, mit allen fprad), abev holyl, oft, wenn ifn ciner fragte, ftatt Der 2Untwort Didjt an Den Frager trat, mit Dent fdymarzen Blicfe eimmal wetterleutdete und Darauf fid uni

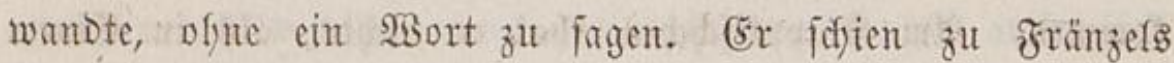

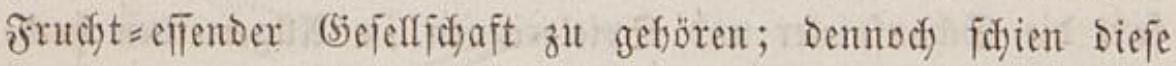
wieder jefre auf ifn zu merfen. Der Mann liế ficf) jebst eine Melone bringen, und eine Düte Gpaniol, zerlegte fie, beftrente fie Damit, und ẩ Die Iabad's= Sdynitte und bot fie an. Ebent famen Sidfter Gerein, als or Den Tefler Dem ftamenden rotar

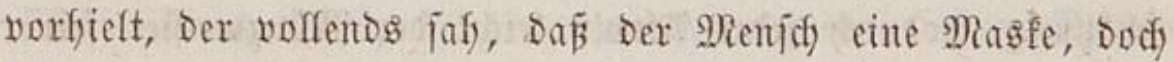
feine unförmfidye, vorfiatte und ber befannten eijernen glidis, Die fo alte Sdyauber in jeine $\mathfrak{B h a n t a f i e}$ gemorfen. 2 balt bog und foüttelte fid ; es war ify aber einiges lieb und er trant?

Darauf ftieg Die Magfe - auth Dieje Bfrajis, went Esit Wort eine ift, war ifm ein idwwarz=bebecter Wagen, ber Sodte und Tiger füfren fonnte - auf einen onenteritod, madyte Das Sberfenfter auf, und fragte einige affeurs, of fie ein (Ei Durch) Das Fenfter zu werfent fid getrauten. ", fagte Der einte, "warum nidyt?" Der andere. Die Ragfe madjte aber mit etwas Beriftecftem in Der 5ुand einige Rinient in bie Ruft und verjebste falt: "jebst viefleidyt feiner mefyr!" (5r wolle alle (sier zrweifady bezallen, fobald einer nut eines Durdfwerfe, fagt' er. (sin 2 fteur nad) Dem andern fofleuberte 
- affe (Sier futhren fojief - Die Mabfe verdowyelte Den Breis Der $\mathfrak{A}$ ufgabe - es war unmöglida - Walt, Der jonft auf Demt Lande fo oft in bie Sdylentertajde gegriffert, that die (5eldtaiche nuf und bombardirte gleidfafls mit einem (5rofiden (5ier - eben fo gut fätt' or eine Bombe gemorfent ofure Mörjer - Eine ganze Bruttafel uno Boutarderie von Dottern flok you den genftern hernieder.

"Es ift gut, fagte Die Mabfe; aber nodf bis morgen

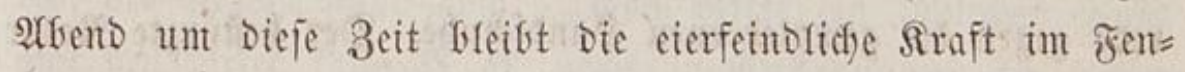
fter; Dann fant jeber Dutrdwerfen" - uno fo ging er fint= aus. Der $\mathfrak{B}$ sirth lädjelte, ofne fonderlich zu bemundern, gleidffam als fodien' er mefyr zu berechnen, Daj er morgen auf feiner Rechentafel aus biejen Criern bie befte Falfonerie yon Rnubbägefn ausbrüten fönte, Die ifm ie in Fängen cinen Fang zugetragen.

Da bie Masfe nidgt fogleich wieder fam: fo ging Der Rotar mit dem (Sebanfen: "Simmel, was erlebt nidyt ein Reifenter in Beit von 12 Stunden" audf fritaus - als jei er nad) neuen $2 B$ untern fungrig - nach jeiner 2 Beife bie Borftadt im 3wiefidyt zu Durdjidweifen. (Eine Borjtadt zog er ber Stadt vor, weil jene biefe erft veripridgt, weil fie lyalf auf Dem Rande an Den Feldern und Bäumen liegt, uno weil fie uiberall io frei uno offen ift.

Er ging nidft lange, to traf er unter Den funbert 2 Augent, int bie er fojon geblift, auf ein $\mathfrak{B a r}_{\mathrm{r}}$ blaue, weldye tief it

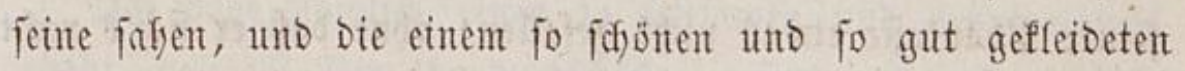
Mäbden angefiorten, Dấ er ben sout alizog, als fie vorbet war. Sie ging in ein offentes Raufgewölbe. - Da unter Den feften $B$ räben ein Raufladen Das ift, was unter Den be= weglichen ein Foftwagen, nämlich ein freier, wo Der Roman= 


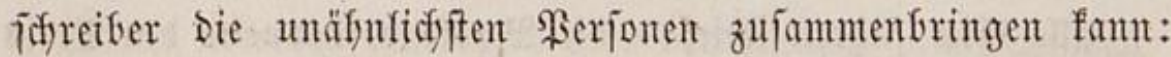
fo belyandelte er fid als jein Gelbit = Romanjoreiber und fidafite fich unter bie Sdhnittwaaren finein, aus weldyen er nidfts faufte als ein 3opfbant, um Dody einigermaken cin

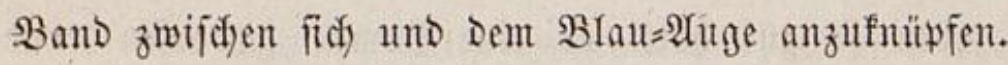

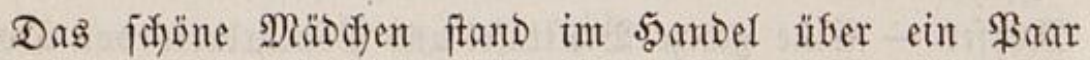
gemslederne Mamngfandiduff, ftieg im Bieten an einer Sireus zerleiter finauf uno fielt auf jeder Sprofle eine fange Sdymäf) rede gegen Die gemeledernen 5andiduthe. Der befürzte Notar blieb mit Dem 3 opffand zwijhen Den Fingern fo lange vor Dem Rabentifif), bis alfe Reben geendigt, bie Reiter erfitegent

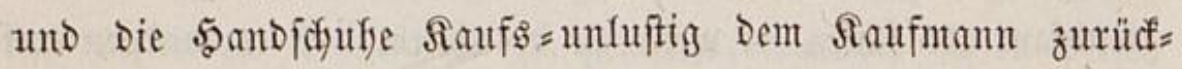
geworfent waren. Waalt, Der fid jogar ficheute, fefre und bes Dentent in cinen \&aden fol blicfen, blog um feine vergeblidjen

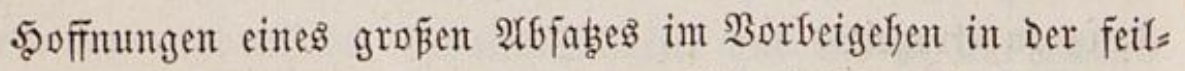

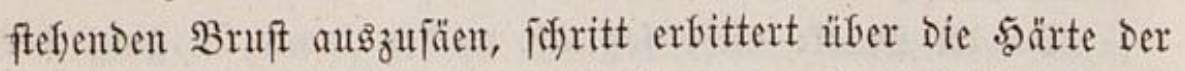
Sanftäugigen aus Dent (jemölbe heraus uno Yié̃ ifyre Reize,

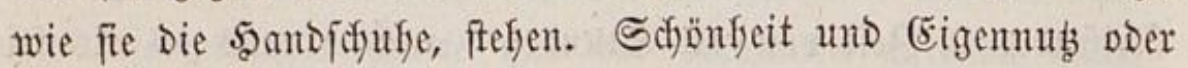
(beiz waren ifm entgegengejebste ßole. Im Erinfaufe - nidit

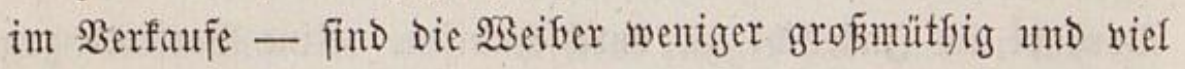
fleinlider als bie Männer, weil fie argmöfnif̧cher, bejonnener

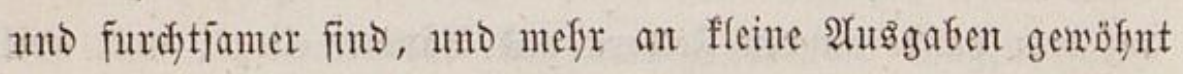
als an große. Das Blau=2luge ging yor ifym fyer, und faf fid) nach iffm um, aber er faf fid nad) Der Brief= Boft um,

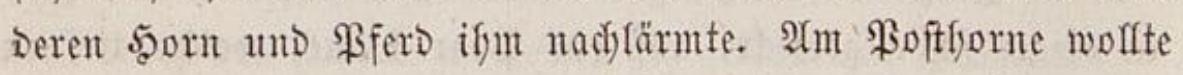
feiner \$ryantafie etwas nidyt gefalfen, ofne dañ er ficfs's redft

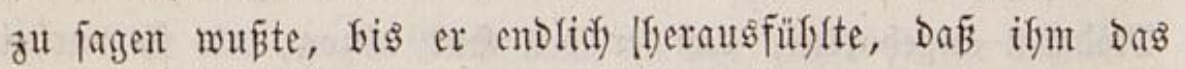
5ูorn - jonft Das รülfforn und Füflftorn feiter 3ufunft jebat ofne affe Sefmjudyt - ausgenommen bie nad) einer ba feffen laffe und anlilaje, weil ber filang nidjts male und 
berfprecte, als was ex eben lyabe, frembes 2 and. YUth mag Das oft Den Menfidyen falt gegen Briefpoftreiter unterwegg madien, Daß́ er weí, fie baben nichts an ifyn.

Int Inowig XVIII. Fand er Die Briefpoft abgefattert.

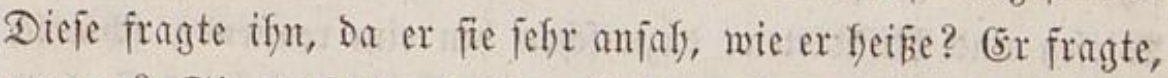
warum? Sie verjegste, farls er lyeipe, wie ex biej, jo habe fie einten Bricf an jeinen Ramen. (5r war won ßults \$and.

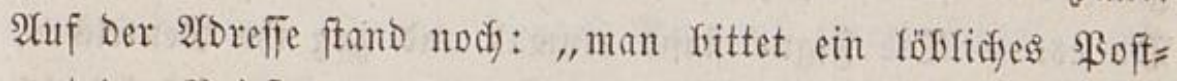
amt Den Brief, falls 5. 5. nidjt in Altfladungen fid befin=

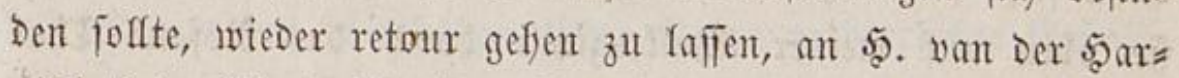
nifid) beim Theaterid)neider ßurzel."

No. 44. Rakzengulo aus Sadbfen.

A b c nte uc .

Der Brief won Bult war Diejer:

"Idf) fomme jebst exft aus Den Jebern - inder Deine Did) wol fidjon Berften weit getragen, oder Du fie - und fidreibe eifig ofne Strümfe, Domit Didn mein (siejoriebenes

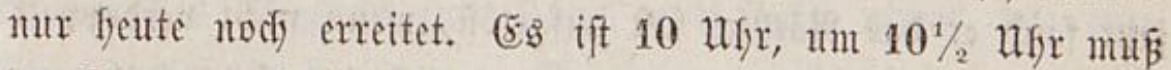
Der Traum auf Die \$opt.

S(t) babe nämlid einen fo jeltiamen uno prowlyetijoden

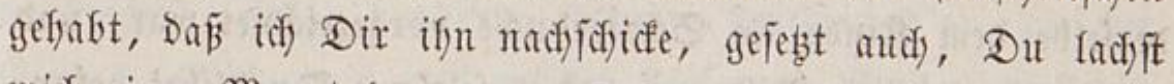
mid) einen Nonat lang aus. Deine ganze beutige und mor= gende Reijeroute fab' idf flar geträumet. Befügt mid́f Der Suintenmadjer yon Iraum und trifft or Didy in צ्Atfladungen nicht an - worauf idf f(f)ören wollte: - fo läuft er retour

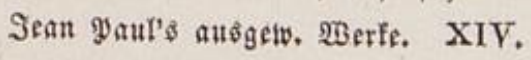


an midf, uno es ift bie Frage, of idf ifn eintem Epott = mo Spapvogel, wie Du, bamn je vorzeige.

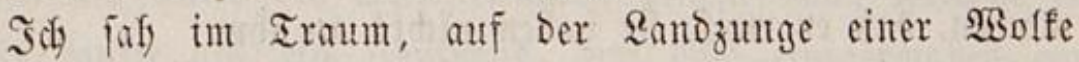

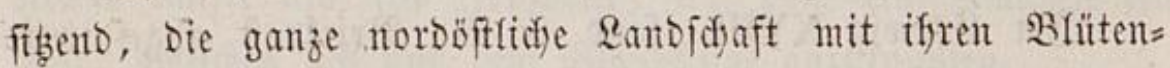

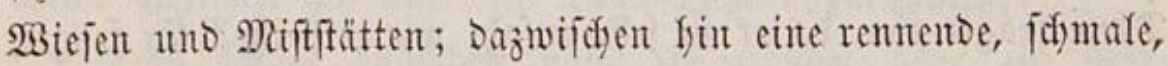
gelfröbafige, jufbelnde Figur, Die Den Siopf bald vor fich, Galo gen Simmel, bald auf Den Boden warf - und natürtidf warelt Du es. - Die figur ftand cimmal und zog ifre Benteldyen, Dam fufr fie in şämlesberg in Den Rrug. Darauf fall idy

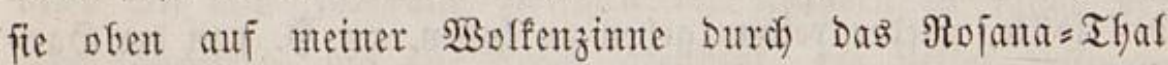
ziefen, Den Bergrü̈fen finauf, vor Dörfern vorbei. - Sin (5) rübrun verfdwand fie wieber im Sirug. Waffrfaftig Dichterifa war's vom Traumgott gedacht, Daßj er midf) aflzeit 6 Minuten vorfyer, eff' $D$ ut in einen Srug cintrateft, ein $D$ ir

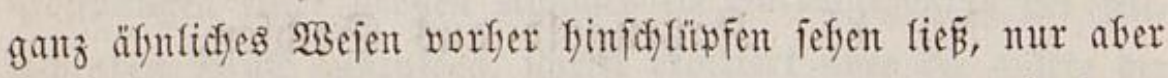
glänzenter, viel fëpner, mit Flügeldhen, wovon balb cin bun= fefflauter, bals ein felfrotfer Stral, fo wie es fie bewegte,

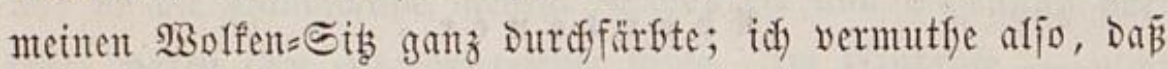
Der Iraum Damit nidft Did) - Denn Den langhofigen (belb= rocf zeigt' er mir zu Deutlid) - fontern Deinten (Sentub an= Deuten wollte."

- Nor Bewegung founte $\mathfrak{B a l t}$ faum weiter lejen; Dent jebst fano er Das Räthjel faft aufgelöft, wemn nicht verbopwelt - Durd ein gröferes - warum nämlich Der bärmteรberger 2Birtf jeinen Ramen fannte, warum bei bem (5rünbrumer Derjeffe Dem Sinde im Sifreiffuthe vorgezeidjnet war, und warum er bei Dem Bilbermann das feltime Subolibet gefun= Den. Srbentlid aus Sdheu, mun weiter und tiefer in bie auf= gedectte Geifterwelt des Briefs fincinz̧ueffen, erfyob er in fich

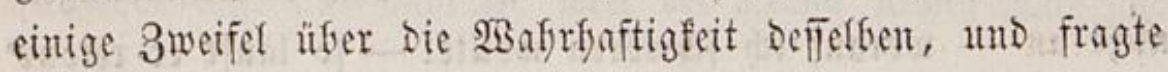


Den trinfenten Foftreiter, wann uno von went er Den Brief befomment. "Das weiź $i$ (d) nidjt, Serr, fagt' ex fpöttij(d); was mir mein $\mathfrak{B}$ oftmeiffer gibt, Das reit' id) auf Die Etajion uno Damit (5ott befofflen." Aflferbings, jagte $\mathfrak{B a l t}$ und las regierig weiter:

"Darauf fafy idf Didy wieder ziefyen, Durdy viele Derter, enofidf) in eine Sirthe geffen. Der (5entus fdflüpfte wieder voraus finein. Abends ftandeft Du auf eintem şügel, und nafymeft im StäDtden 2 ItffaDungen Nadftquartier. Saier faf idf yor Der Mirtfghaustfüre Deine verferrficfte (seftalt, nämlich) Deinen (Scnitus, mit eintem Dunflen befangnen $\mathfrak{B}$ ejen fämwfent, Deffen fiopf gar fein (beficht fatte, jonbern ilberall 5aare." - -

(3)ott! rief $\mathfrak{B a l t , ~ D a s ~ w a ̈ r e ~ j a ~ D e r ~ M a s f e n ~}=$ Menjad)!

"Das 2 bejen ofne (befidyt Gefauptete Die Thüre, aber Der (jentus fufr als cine fledermaus in Die Dämmerung fut mir

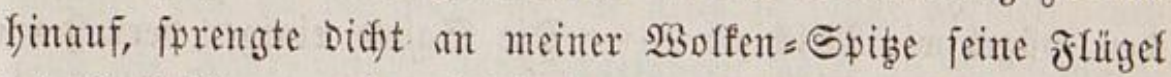
wie Srefsideeren ab uno finab und fiel als Maus oder Mraul= murf in Die Eroe (etwa cine Mieife von Altfladungent), uno fofien fortzumüflen (Dem idf) falf es am 2 eflentreete), bis wieber fu Dir und warf untweit einter Regelbafn einen şüge

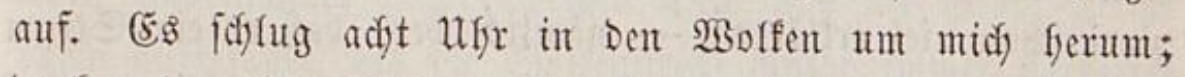
Da fam Das Ungefidft fum Sö̈gel uno ftefte etwas wie cine Maufwurfgfafle fintein. - Du aber warfi finterfer, zogft fie ferans und fandeft, indem Du Damit blos Den Errd=5jitfel

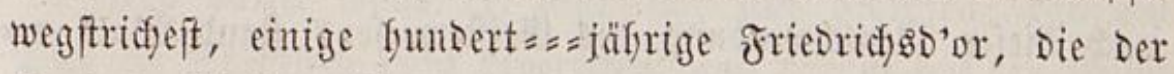
(5entus, (jott weī̄ aus weldyer Iiefe und Breite, viefleidyt auts Berfin, gerade an bie Stelle für Didf hergemüfft" . . .

Selgt fam wirflid die Nagfe wieder. Walt faf fie

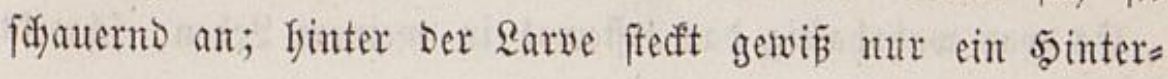


fopf, Dadft' er. (šs follug Drei Biertel auf adyt utre. Der Mann ging unrubig auf und ab, hatte ein rundes fidwarzes Bapier, Das, wie er einem 2ffteur fagte, an seerzensftatt auf Dem 5yerzen eines arfebufirten Soldaten zum Bielen gefyangen, und fidnitt ein (jefidft finein, wovon 2 alt im Tagefbudf fdreift: „es faly entweder mir oder meinem (5)entus gleidf. Die unabjeffidfe 2 sinternadst Der Beifter, wo Die Spfintye und Masfen liegen und gefen, und nidjt cinmal fid felber erblicfen, fodien mit Der Sarve ferausgetreten zu fern ins Sommerlicht Des Rebens."

Da es adjt 4 hr fodug, ging Die Larve finats - 2 alt

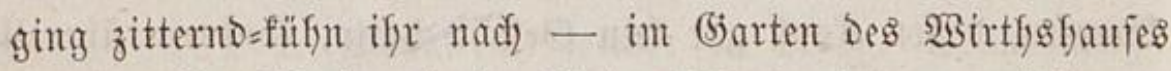

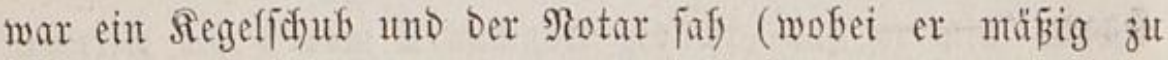
erftarren anfing) wirflid) Die Larve cinen Stab in einen Maul= wurrghtügel ftecfen. Sinum war fie zurüct und weg, fo trafm er Den Stab als ein Streichfoly und rafmente, fo zu fagen, Den Syutgel wie Mildy ab - Die Safme einiger verrofteten Friebridg.so'or fonnt' er wirflidy einidgöpfen mit Dem \&öffel.

Die wentgen baltbaren (5ründe, warum Der Notar nidft auf bie Steffe fiel, uno in Dfumadyt, bringt er felber bei im Tagebud, wo man fie weitläuftiger nadjlejen fann; obgleidf

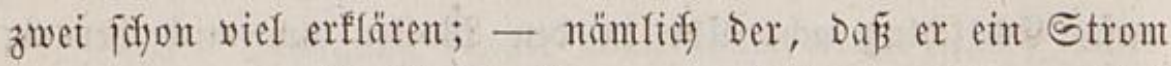
war, Der gegen Die ftärfite biegenwart heftig anfdhlug, inder

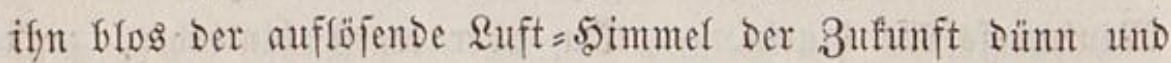
verfliegento in Die bäffe zog, wie er mur wollte. Selst aber nach Diejer Menjifwerdung Des (5eifterwejens ftand 23 alt ne= Gen feines (5ieidfen. Der zweite (5rund, warum er fefen Glieb, war, weil er int Briefe weiter lefen und jefen wollte, was er morgen erfaljen, uno weldyen $2 B$ eg er nefment werbe. "Es war wafrerfaftig Das erftemal in meinem \&efen, idjreift 


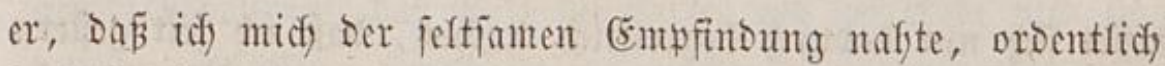
fo befl wie über eine Biegenwart finweg in eine Bufunft fin= ein zu fefyen, uno fünftige Stunten zweimal zu haben, jeb̧t und einft."

In Der (baffftube war die Masfe nidft mefyr. (Ěr las Jerzflopfent bie Narjdy= und Rebensroute Des Morgents:

"Darauf wurde Der Tram wieder etwas menfidflider. Эa) jaf), wie am Morgen Darauf Dein (jenius und Das Mn=

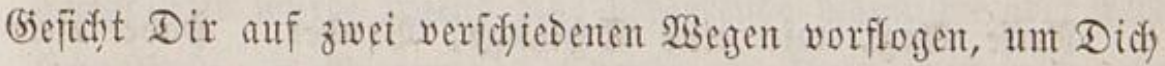
zu Iocfen; Du folgteft aber Dent Bsenius und gingeft fatt nady

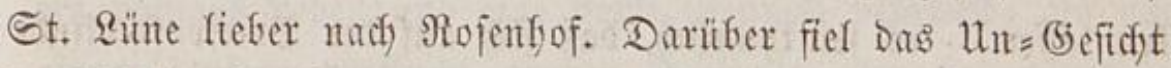
in Stïtefen ferab, einen Todtenfopf uno einige Sinodjen faf idf) Deutlich von Der 2 Solfe. Der Bentus murde in ber Ferne

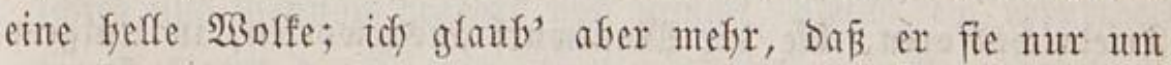
fici) gefdragen. Du trabteft fungend aus Deinem Mittagg $=$ quartier, Ramens Sodib, Durdf) eine Randidjaft volf Ruft= foblöfer bis an bie Rojana, die Didf fo lange aufbielt, bis

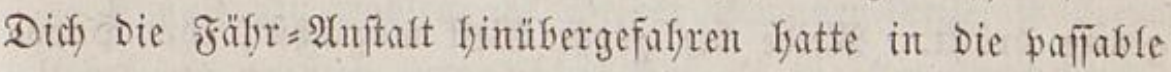
Etrot Roienfof. Mir fam's vor, fo weit id bie tief in Den sorizont fimunter liegende Stadt erfennen fomte, als

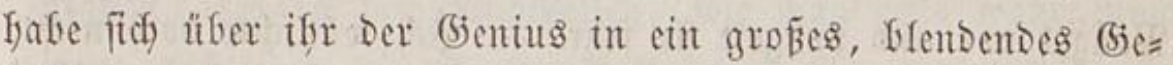
wölfe auseinanter gezogen, uno Didf uto Die Stabt zulebst

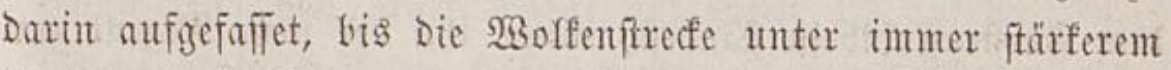
Reuditen und 21uswerfen you Sternen und Rojen und (sias zugleidf) mit meinem Traume auseinanoer ging.

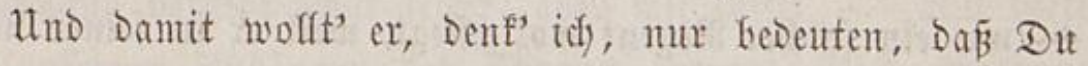
Didi im Stäbtfein redft Divertiren, uno Darauf auf Den \$̧eim= weg madyen mürbeft. -

WSie eine foldhe Träumerei in meinen Sopf gefomment, 


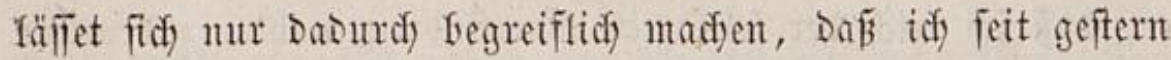
immer Deinent eignen mit jeiner Romantif Darin gefjaft.

Id) wollte, Dein Rame wäre fo berüfmt, Dá Der Brief

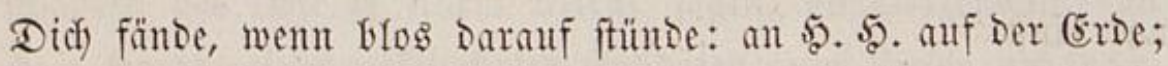
wie man $\mathfrak{z}$. B. an Den Mann im Monde redyt gut fo abref=

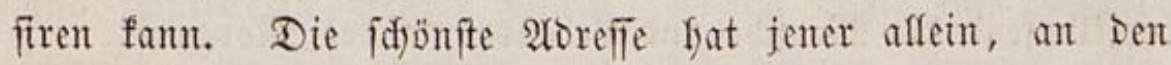

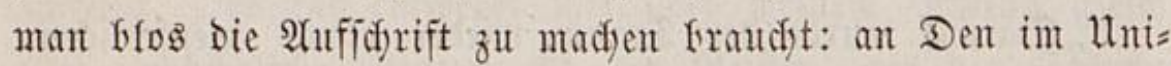
พеrjum.

Reije flug, wie eine Sdylange, Sruder. Sabe viele Beltfenntní uno glaube nicyt - wie Du Dir einmal mers

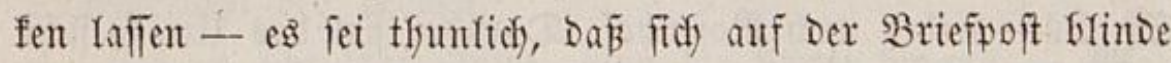

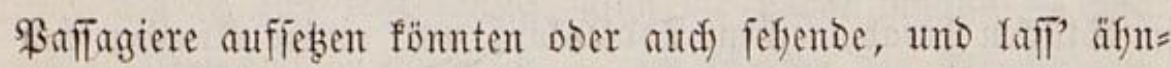

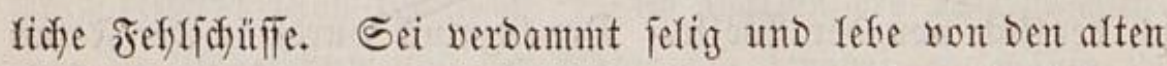
Friebridgso'oren, Die Der Mautwurf ausgeworfen, in einigemSaus unt Braus. (Erfief', o Freund, nur fein Trauerpfero zu einem Stecfenpferd; Da ofnefsin jedes Sireuz, vom Droens: freltze an bis zum Gjefofrentz herab, entweder genug trägt oder

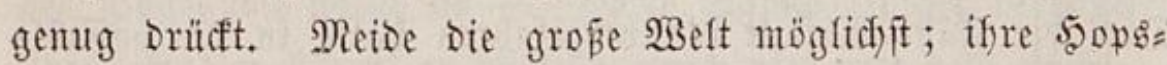
tänze find ans $\mathrm{F}$ mol gejebt. Das Sojiffial nimmt pft Das Diffe Süpholz, an weldem die Reute fäuen, als cinen gutent

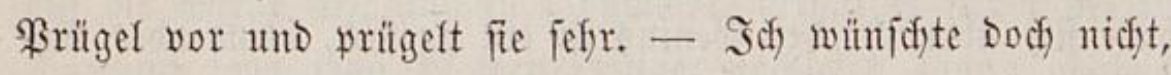
Dẫ Du gerade auf Der erften Stufe Des Ifrons gleich neben Dem Fürftenftuflbein ftändeft, wem ifn Der neue Regent zur

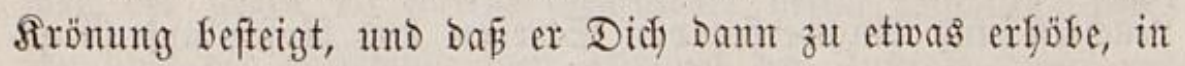
Dent Adelftant, zut cinem fiammer = oder Sagdjunfer ober jo; - wie ein foldher Regent wol pflegt, weil er in feiner neuen Regierung gerade nidfts früfer madyt als bas ebelfte, nämfidf

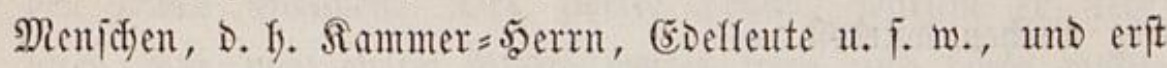
fpäter Den Staat uno Deflen (5) hü cf, fo wie Die alten Tfeolo= 


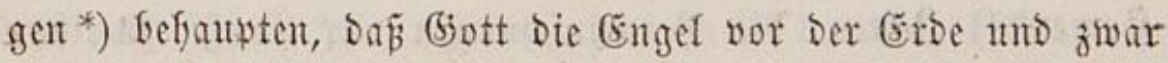
Darum erjoffen, Damit fie ifn uadjher bei Deren Sdypofung robten. -

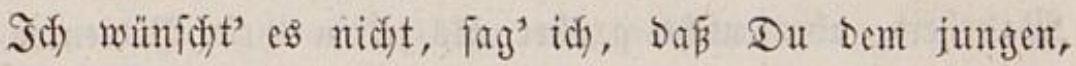
neugebactuen und neubafenden Jürften Die gebachte (sfire an= thäteft, uno eine antäfmeft; - wafyrfid, cin Ifron wird, wie Der Bepuv, gerabe föber Durefy 2tugwerfen won 5ुbुen und 5oben um ifn ber - uns mein (Srund ift Diejer: weif Du, gejegt Dir würde irgend eine bedentente münnfidje oder meifs=

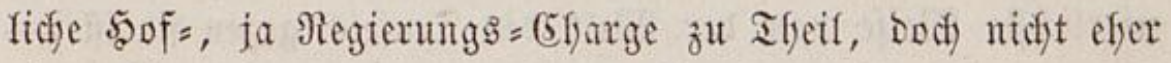
ein rulyiges $2 e b e n$ und eine ftarfe \$enfion befämefi, als nach einem tapfern verfludyt grop̧en Fefstritt ober bei gänzlid)er

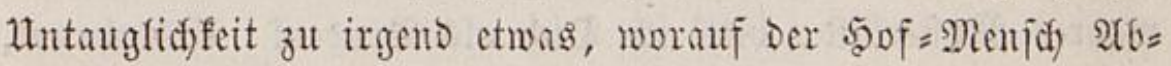
fidjed und Benfion begefyrt und nimmt, gleidy Dem berurtbeil= ten Sofrates, Der fidt) cinte äfntidye Strafe vor (beridyt Diftiute,

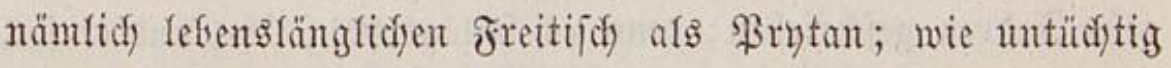
aber Du zu recijter untüd)tigfeit bift, Das weiśt Du am beften. - Ramnit Du wälyen auf Deiner Spamen= Reije, po bejucje fieber Den gröpten europäificen 5ूof als bie fleinften Deutjon,

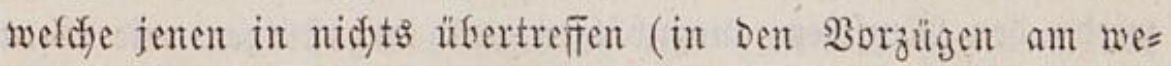
nigften) als in Den Radiffeifen, wie man Denn wafrgenom= men, Dấ audy Die Seefranflyeit (was fie gibt und nimmt, fennit Du) viel ärger wïrgt mf Seen als auf Meerent. Sudfe Dein 5eil an 5ुbfen mefr in groben Thaten als in groben Worten; Dieje werben fidwerer verziefen. - (sin \$ofman vergift zwar leidft, aber mit (sift. - Uuf Diejen fơlüpfrigen $\mathfrak{A b}$ ängen Des Ifrons betrage Didf überbant

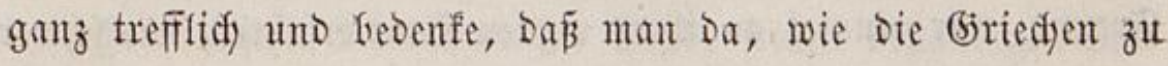

*) Bibliothèque universelle T. IX. p. 83. 
Somers*) Betten, Die Serwünjdungen nur feife fu thun habe, weil Die lauten auf Den Urbeber zuritdpringen. Gage Jürfen, Marfgrafen, Erzherzogen, Sönigen zmar Die 2Babrfeit, aber nidyt gröber als jebem iffer Bebienten, $1 \mathrm{~m}$

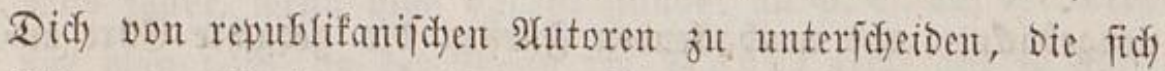
Yieber nor Berlegern als yor ßotentaten büden. - siegen Maltyejer Damen, fonjule f)ödyften Rang fei fein Barijer Bijam= Gdywein, D. f). feine parfümirte Beftie, fein verbindidfer (Grobian, ber auf Die ma= nierfidjite 2 seije von Der Belt Des Teufels gegen fie ift. Sei Der fdyönfte, lang gemadjjenfte, fdylanfefte Mann won 30 Safren, Der mir nodh vorgefommen - Surz, bleibe ein wabres Mufterbild, bitt' idy Didy als Bruber! Ueberfaut, jei pa|fabel!

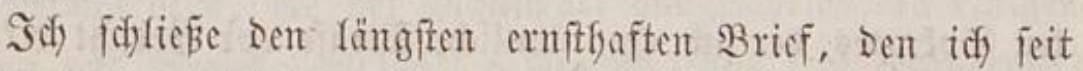

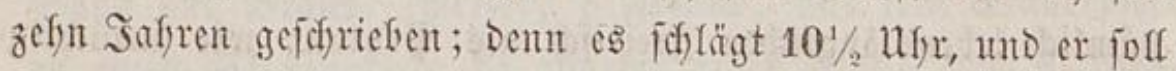
Durdjaus nod) fort. Simmel aber, wo magit Du jebt jern?

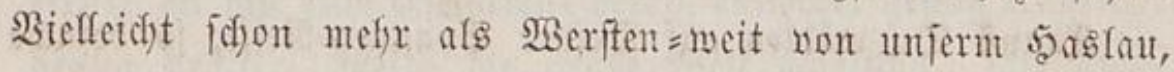
1mb erfäfreft num an Dir jelber, wie leidyt es groben Reijen wird, Den Pleniffen augjubälgen und umzuftülpen wie cinen

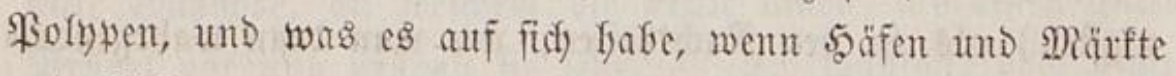
und Bölfer vor ung vorïbergeben, ober wir, was Daffelfe iff, vor iffuen - und wie es einem ziemlidy fifwer anfonmt, nicht zut berädytlidy auf Stubenfocfer berab zu fefon, bie viel= leidyt nody nie ilber 10 Meilen weit von ifrem Gparofen meg= gefrodjen uno für weldfe ein Urtfeil ẗber ein par Reijende, wie wix, eine Unmögfidfeit iff. Soldye Menidsen foflten,

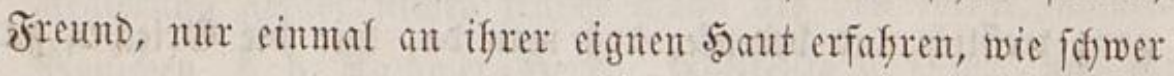

*) Şermanư Migtholog. I. 


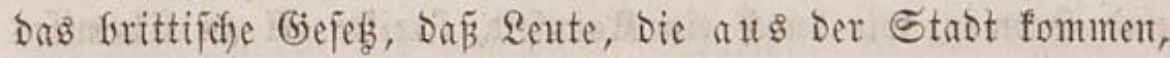
Denent antweidfen follen, bie in felbige reijen*), mandfem 2Beftmann moralifich of balten falle: fie fäben unts beibe an= Ders an. - Fafye wohl! Folge mir, noli nolle!

$$
\text { v. d. } H \text {. }
$$

Postser. Şebe Diejen Brief, im fall Du ifn befommft - jonft nidjt - auf, es find (5edanfen Darin für unjernt 5oppelpoppel."

No. 45. $\mathfrak{\Omega}$ a

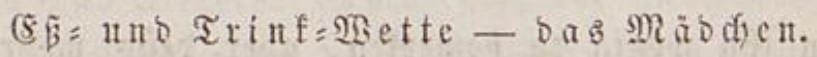

(5.) mag tun finter Dem Traum ein Geift ober ein

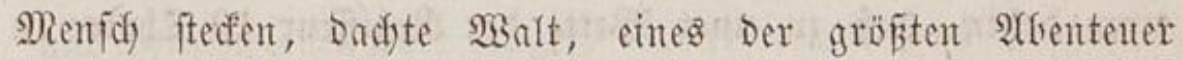
bleibt er immer. Das formang ifn über Die ganze Stube volf (s)äfte weg; or fufre auf Dem romantijoden Sdymanzftern itfer bie Erden finats, die wir fenten. Die Friebridfso'ore, yon benen er viel bertfut wollte, waren bie goldnen fitigel= Decfen feiner Flïgel, und ex fonnte olyte Eingriffe in Den vä= terficfen Beutef fidf ein Nïjel 2 eein ausbitten, gejebst audf, Der (sljaller Ieftator fomme wieder auf.

So frofy geftimmt und leidft gemadyt bafunte er fidf Durdh Das tfeatrafijoce (5owimmel Der Stube feinen beftündigen Sin=

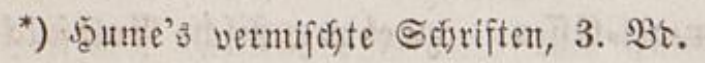


und Ferweg, wie burdy ein Rornfeld, ftreifte oft an (Shemifent vorbei, ftano vor mandfen (sruwpen ftill, uns lädyelte füfn genug in frembes (jejpräc) finein. Seb̨t trat Dic Blauäugige, welde feine Mannsfyandidulfe gefauft, ins 3immer. Der $D i=$ refteur Der Iruppe fofnaubte äffentfid) WBinen (jo verfürzt' cr Safo=bine) fart an, weil fie ifm zut thenere sambjolute mit= bebradyt. Mit Bergüigen entidyuldigte $\mathfrak{B a l t}$ imnerfidy ifren 5ambelsggeift mit Der alten Theater = (̌̈inridftung fold)er Trup=

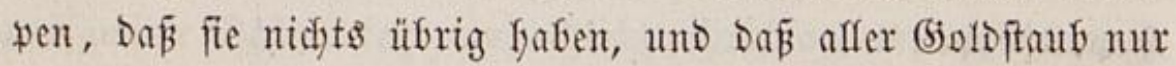
(5eigenfyarz̧utwer ift, Das man in iffr feuer wirft. Das Mäbdyen beftete, wäfreno Der rofye Direfteur um fie Donncrte, Die Keiterften Blide anf Den Notarius, und jagte endich, Der

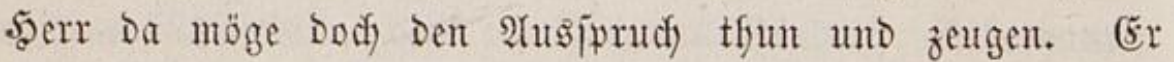
that's und zeugte ftart.

atber Der Domnerer wurbe wenig erichüttert. Da trat Die Masfe wieder ein. Walt idyente feinen bojen (5ienius. Sie jojien ifn wentg zu bemerfen, aber Defto mefre Den gei= zigen Frinzipal. Endlich) frachte fie es Durdh Yeijes Dispu= tiren Dafin, Daj zu einer $2 B$ ette Der Regiffeur 10 Thaler in Silber muf Dent Tifich legte und jene eben fo viel in Bold.

Fine Fla

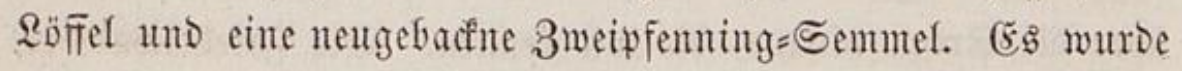
nun vor Dem ganzen Stuben = Fublifum Die 2 Bette publizirt,

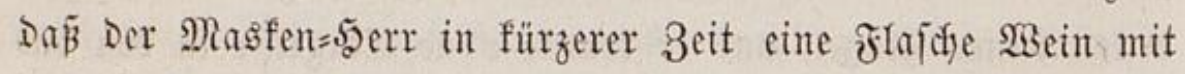
Dem Röfrel aufzuefien veripreche, als Der Direfteur feine Sem=

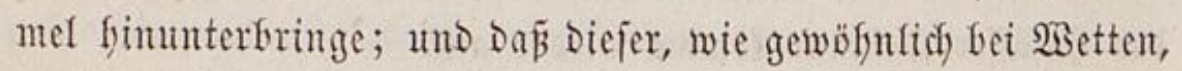

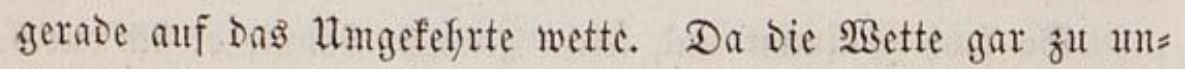
gleid) fidien: jo beneibeten bie meiften 5y-interfanten Des Theater= Refnsherm ifjrem Borgefebten Das ungeheure (siücf, fo reidft

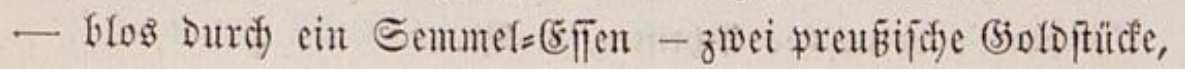


Die nidyt einmal aนs Dem Rande aแรgefüflyt werden burfen, in feines einzufüflrent.

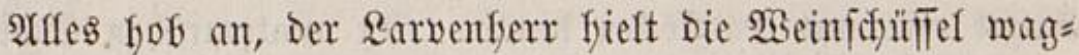
redyt an Sint, und fing Das finnellipe Sdyöfen an.

Der Brof = uno Brobferr Der Intwpe that einen Der

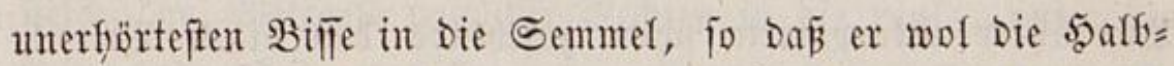

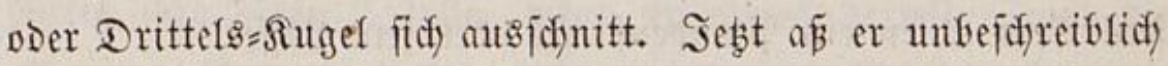
- er Yatte eine fyalbe $\mathfrak{B e l t f u g e l}$ auf Dem 3 ungenbein zu bewe= gen, zu zerftüffen, zu mazeriren, aljo auf trocfnem uto naाjem Weg zugleich zu fujeiden - was er von Dienit = Musfeln

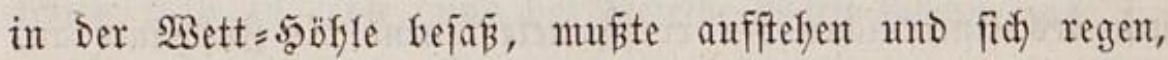

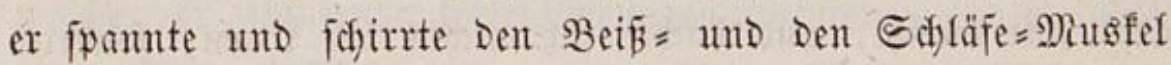
an, Die befanntlid immer zujammen ziefen - ferner Den in=

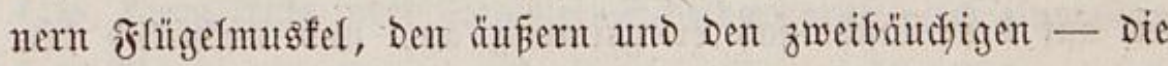
Musfefn Drücften nebenfyer Die nötfigften Speidjelorïjen, um

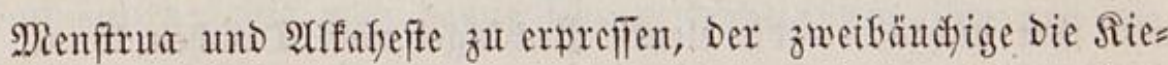
ferorüje, Der Beiß̄musfef Die Offrorüje, und fo jeder jebe. Aater wie in einem Baflfaufe wurde Der Magentraff im Mumbe frin= und hergefflagen; Die Sugel, womit er alfe zefyn Iffaler wie Regel in Den Magen fajieben wollte, wollte Durchaus Die Sd)lunbbafun nidft ganj yafifiren, fonbern balb und in flei=

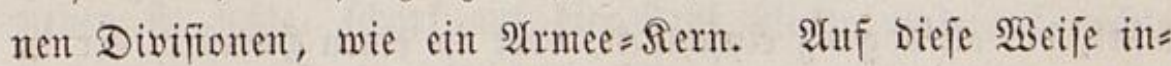
Deflen verlor Der theatralifiche Siommandeur, Der Den Earven=

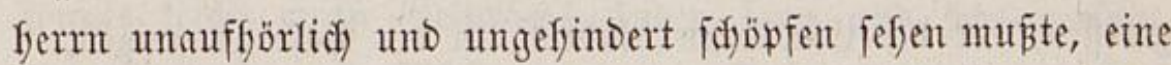

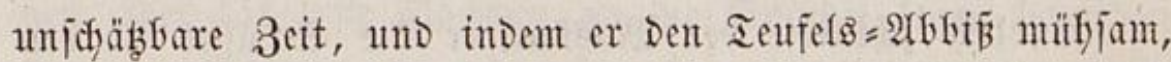
Cahiersweife, oder in Raz̧ionen ablieferte uno id lucfte, yatte

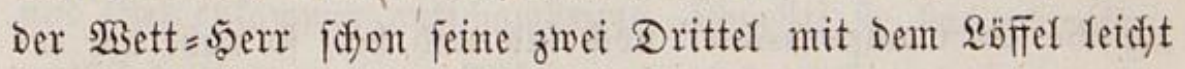
aufgetrunfert.

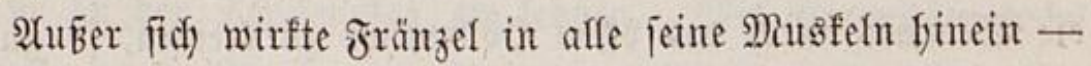
mit Den Eeratoglofitis und Den (jenioglofitis plattirt' er Die 
3unge, mit Den Styloglofitis exfavirt' ex fie -- Darauf hof

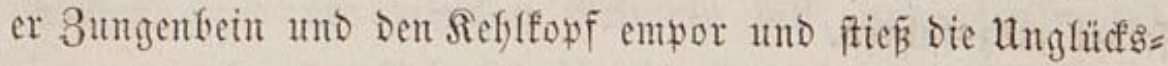

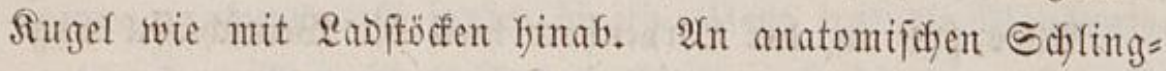
Regefn fefit' es ifym gar nidyt.

Nody lag eine ganze Drittels=Semmet yor ifm, uno Der Rarwenferr inforporite fidon zujefyentos bas vierte Biertel, fein $\mathfrak{A}$ rm fodjent ein \$umpenfitefel ober jein Roffer.

Der Ungfütlidge fdnawpte nad) Der z'weiten 5ूemijphäre

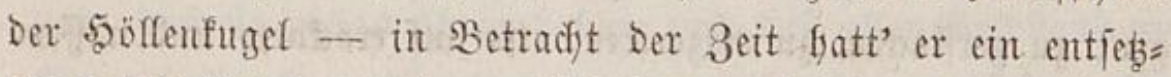
fidjes Divifiontserempel vor fidf ober in fidf, eine lautge atna=

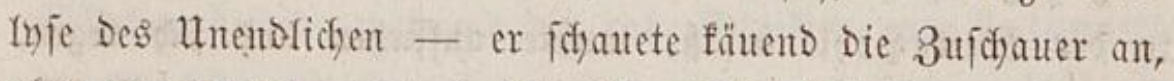
aber nur Dumm, unto dachte fidf nidhts bei ifnen, fondern

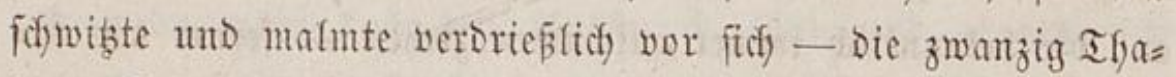
fer auf Dem Tifdye faf er grimmig an, uno wedfjefnt ben Söffel= Säıfer - zu reben war feine Beit und Das \$ublifum war ifym nidfts - Die elende Bedfugel vom Dradhen fount' or nidyt cimmal zu Brei zerjeben (ç flof iffm nidgt) - ans

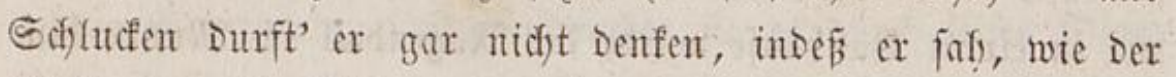

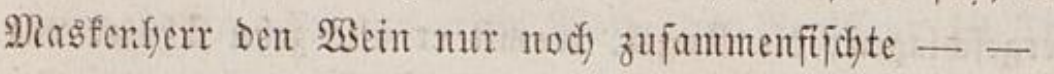

Das fitfylt' er wol, fein şeif uno seilanto wäre man gewejen, fuätte man ifn auf ber Stefle in eine Siflange ver= fefyrt, die alles ganz einjoluctet, oder in einen samtfer, Der in Die Bacfentajoch werffect, oder ifm Den Thyreopalatinus aus=

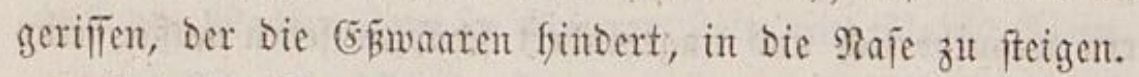

Enolidy foüttete Der Mnsfenterr Die Sdjuifel in Den Söffel aus - und fränzel ftié̃ uno worfelte Den Gemmel= "globe de Compression" noch frin uno her, fo nafe am er= weiterten Edflumbfopfe, aber ofme Das geringife Bermögen, Die Semmel Durdi das offine Sölfentfyor zu treiben, fo gut er

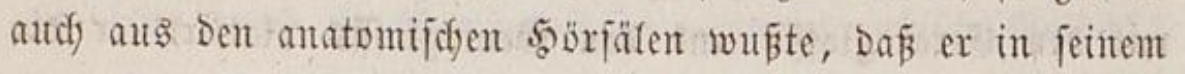


Miatle über cine Mugfel=5ebefraft von 200 SFund zut befef $=$ len babe.

Der Larventerr war fertig, zeigte endidf Dem $\mathfrak{B}$ blifum bie leere Schünel uno die volfen Bacfen Des Direfteurs uno ftricy Das 23 ettgeld mit Der Rechten it Die Rinfe, unter Der Bitte, 5r. Fränzel folle, went er etwas Darwider und die Semmel fodon finunter babe, blos das Maul aufmadjent. Fränzel that's audh, aber blos um Den teuflifiden Jangeball Durdy Das gröbere Thor Dawon zu fonaffen. Der Masfenterr fofien frof zu jern, and bot Diejelbe SBette wieder aus, bet weldfer er glänzende Erleidfterungen voridglug, z. \$2. ftatt einer Semmel blos einen ganzen fleinen fiul $=$ oder Biegen=

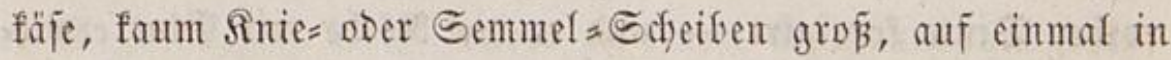
Den $\mathfrak{R u m b}$ zu nefymen und finabzuelfen, wäfrend er trinfe ut supra; afer man badjte fefre veroädytig von ifgm uno nie= mano wagte.

Den Notar Gätte Der Direfteur zu fefyr gedauert, went cr vorfin die fajöne Blonbine fanfter angefafren yätte. Dieje fá und näfte, uno hob, fo oft fie mit Der Nadel aufzog, die

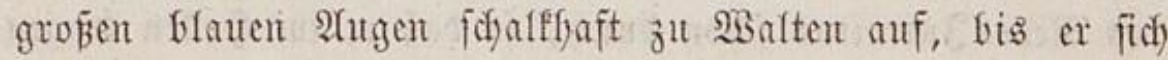
neben fie jebste, forarf auf Die Rafit blicte uno auf nidsts

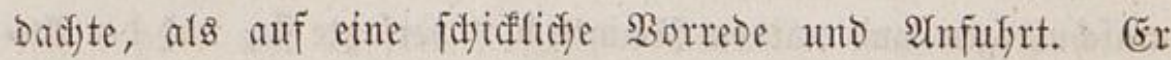
fonnte leid)t einen (bejprädys= Faben lang uno fein veripin nen, aber Das erfte folbcthen an Die Epindel regen fount' er fojwer. Sä̈frento er neben ifre fo yor feiner eignen Eeefe und Geffirnfammer antidfanbrirte, idnellte fie leidst die flei=

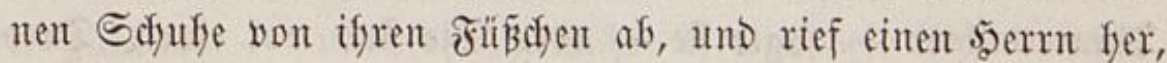
um fie an Den Trocfenofen zu lefnen. Mit Bergügen wär' er felfer aufgefwrungen; aber er wurbe zu rotf; ein weib= licher Sdjulf (Denu er gate faft beffen Juß Darum) war iffm 
fo Geilig, fo niedlidy, fo bezeidjnend, wie ber weiblidye şut, fo wie es an Manne (jein Sdfuf) ift nidfts) mur Der Heber= rodf ift, und an Den Sinoern jedes Sileidungefftüf.

"Sch Däd)te, Sie fagtent entilid) etwas," fagte Safobine gu Walten, an Dem fie fratt Der Bunge Den Reft mobil madite, invem fie thr Sinäul fallen fié, unb es am Faden lyalten

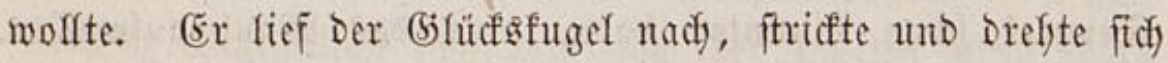
aber in Den Faben Dermaken ein, Dá safobine aufiftelen und Diejen von feinem Beine wie yon einer Spindel abwaifen muste. Da fie fich nun bücfte, uno er fid büffte, unto ifre

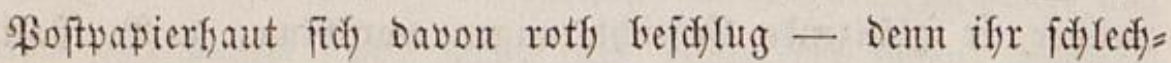

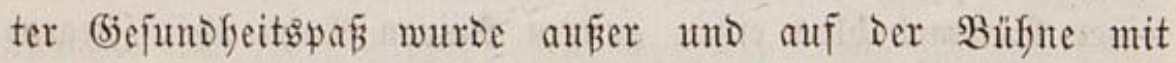
rother Dinte forrigirt - une er bie Röthe mit Sjlut erwies Derte; und ba beide fich einander fo nabe famen und in Den unorbentlidjfen 3wiejpalt ber Reoc: jo war Durdi bieje thä= tige (5ruppirung mefre abgetfan und getfan für sefannt= iduft, als went er brei Monate lang gefeffen und auf ein \$räludium und 2fntrittß̧rogramm gejomen bätte. - Er

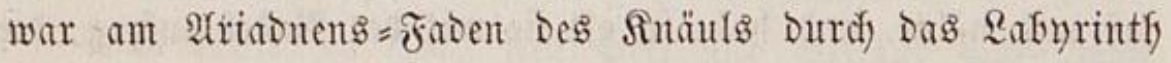

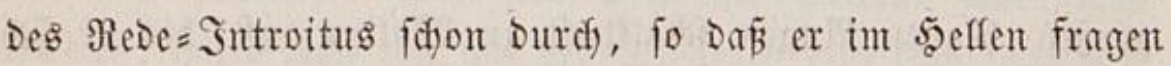

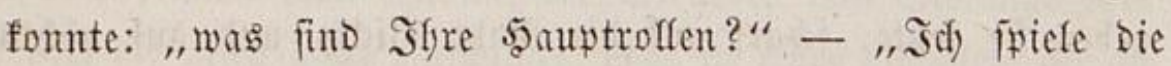

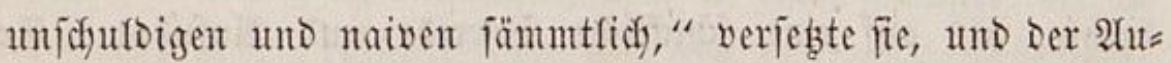

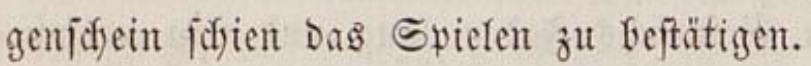

utm iffr redfte freute zut madjen, ging er, fo tief er

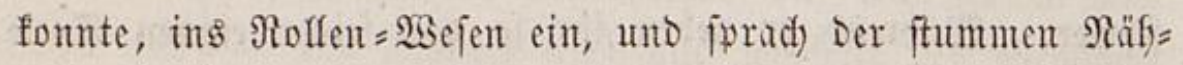
teriu feurig vor. "Sie reden ia fo fangweifig, wie der Ifeaterbichter - jagte fie - ober Sie fino wol cinter. Dero

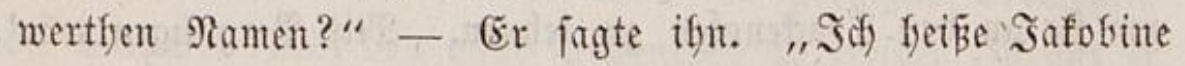

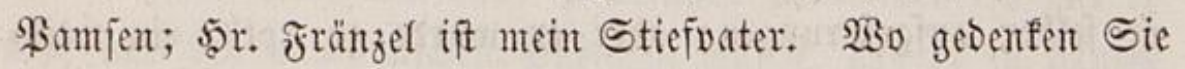

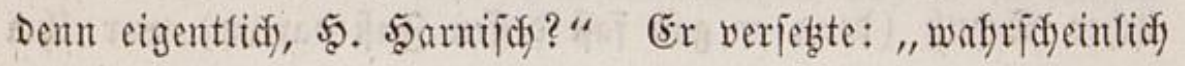


uad) Rojenfyof." - "5übja, fagte fie. Da fpielen wir mors gen Affend." Run malte fie Die güttliche (jegend Der Stadt, und fagte: "Die Bjegent ift ganl fuperf." "Nun?" fragte Walt uno veriprady fid eine fleine Mufter= und Produften= Sarte Der Ranofdaft, eir Dünnes Blätterffelet Dafigen Baum=

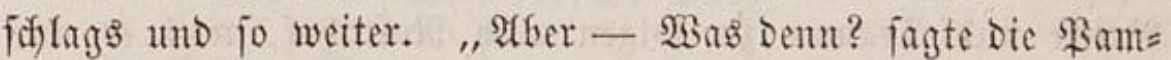

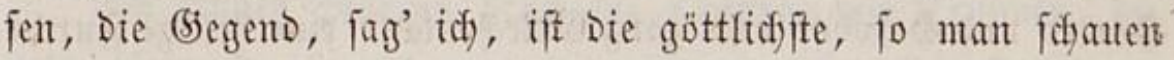
fant. Edfauen Sie jelfer nady."

Da trat Der Rarvenferr unbefangen fin und fagte ent=

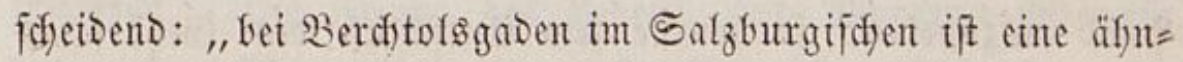

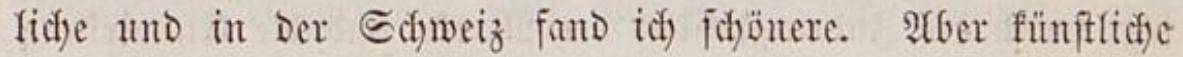
3afmitodher idnitzen bie Berdytolggabner" uno jog einen aus

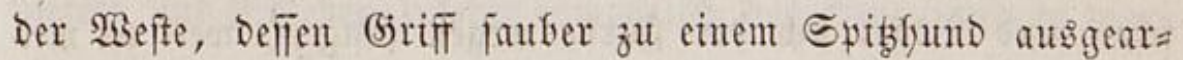
beitet war.

„'SBer Ruftreifen madyen faum, fuffr er fort, mein 5eerr, findet jeine Rechung vieffeicht befler im Babort St. Rüne, wo gegenwärtig Drei \$öfe verfitren, Der ganze faladjenfut= gif uno cin wafrer 3 uflū von Rurgăften. Sd) reije morgen fefber Dafint."

Der Notar madifte eine matte Berbeugung; Dent Das (5ejhicf hatt' ifn auf Diejen ganzen 2(bend verutheilt, zu er=

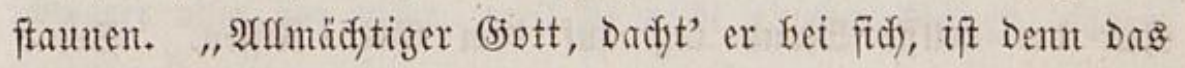
nicht wörtlich, fo wie in Des Brubers Briefe?" (Er ftand auf - (Jafobine war aus sa的 gegen Den um 10 fl. rei=

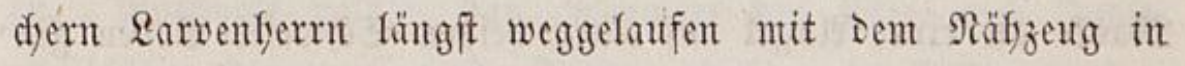
Den Sänden) - und jafy an Ridjte Dieje Brief= Stefle nady: „id) fafh, wie an Norgen Dein (Sentus und Das Ungefid)t Dir auf zwei verifdiedenen $\mathfrak{B}_{\text {egen }}$ vorflogen, um. Didi zu locfen; Du folgteft aber Dem Benius und gingeft fatt nady 


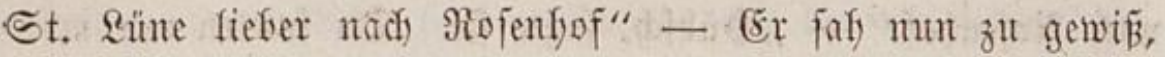
Die Magfe fei fein Göjer (bentus, Safobine \$ompen aber, nady mandifem zu urtheifer, fein befter, und er wünjofte fefr, fie wäre nidft aus ser Stute gegangen.

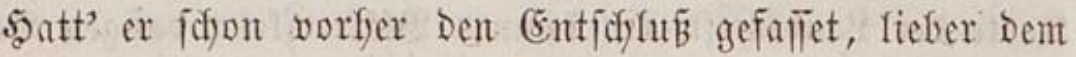
Briefe und Traume zu folgen nady Rojenlyof, weil er aus 5yomer und 5erodot und ganz (5ried)entand eine fyeilige fotrdyt gelernt, fü̈fern 2 Binfen, Dem 3eigefinger aus Der 230 lfe, mit

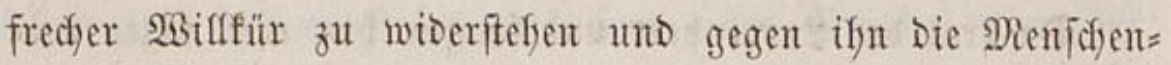

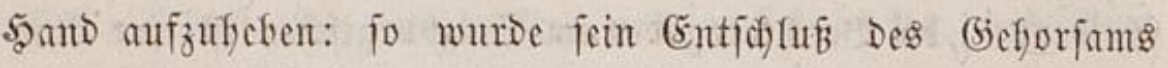
jebt Durdh Die 3utringlichfeit Der Masfe und Die Einvirfung Safobinens und Durdi Das Nebs nelt verftärft, worin Nen= fiden unt Bögel fich Der Farbe wegen fangen, weif es mit Der alfgemeinen Der (ErDe unb รูoffinung angeftridjen ift, nänt= (ich) Der grünen.

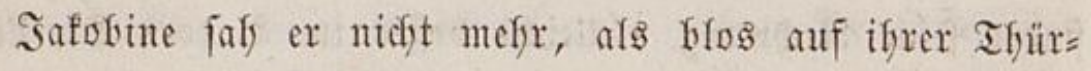
fd)weffe mit eintem Ridjte, Da er über bie feines Rämmerteins trat. (Er liberbadjt' es Darin lange, of er nidft gegen bie

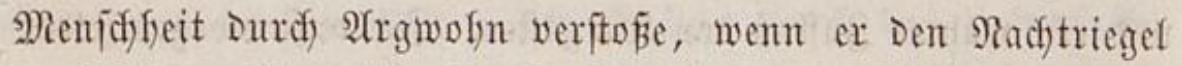

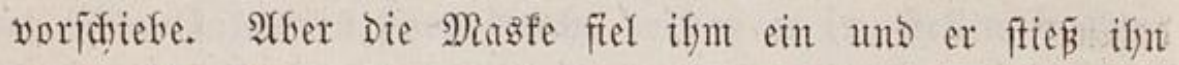
vor. Im Traume war es ifm, als werd' ex feife bei bemt

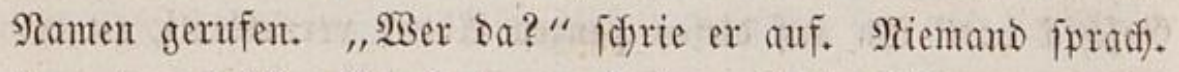
Nur Der helfite Nont lag auf Dem Bett= Ritien. Seine Träume wurben verworten, und Safobine febst' iffn immer wieder in Das rofenfarbne Meer ein, fo oft ifjn aud bie Maßfe an einer Angel auf einen heiß̄en Ecffwefel= Boben ge= fidleudert. 


\section{7}

No. 46. ङ $\mathfrak{D} \mathfrak{I} \mathfrak{e} \mathfrak{x} \quad$ (5) $\mathfrak{x} \mathfrak{a} \mathfrak{n} \mathfrak{a} \mathfrak{t}$.

Der frifde ag.

Ám früfen Morgen brad) Die Trupwe, wie Trupwen, bie Belte lärmend af und aus Dem Lager auf. Die Fufrrfente ftäubten das Radftftrofy von fidf. Die Rofle wieferten ober idjarrten. Die Frifide Des Lebens und Morgens fprengte Gremenden Morgentfau über affe Felder Der 3ufunft, und man fielt es fefyr Der Mäfye wertf, foldyen zuzureijen. Das (5etöfe und Strebent belebte romantifich Das bुerz, und es war, als reite unt fafre man gerade alts bent $\mathfrak{B r o f a}=\Omega$ ano ins Didfter=Rant, und fomme nodf an um $7 \mathfrak{u r y}$, went es bie

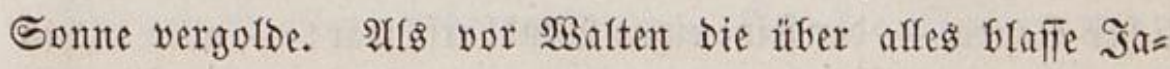
fobine wie ein Gleidfer beift einfáp, fafy er in Den Traum

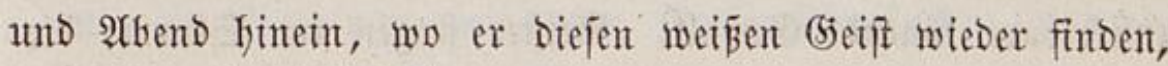

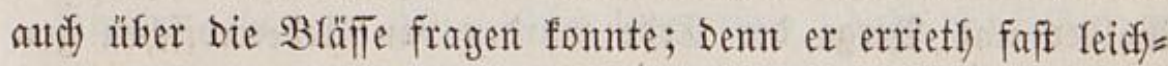
ter Seelen $=$ Sdyminfe, als $\mathfrak{S B a n g e n}=$ Sdyminfe, Dieje rothe Serbiffarbe falfender Blätter, ftatt Der Früflingeröthe jung=

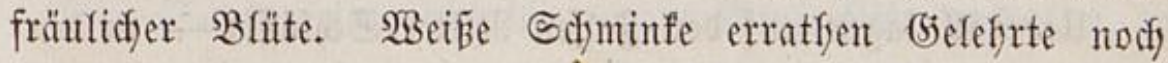
fidwerer ober gar nidft, weil fie nidgt abjeflen fömen, jagen fie, wo fie nut anfange.

Die Nasfe jẩ auf, und jprengte feitab nacif St. Rüne

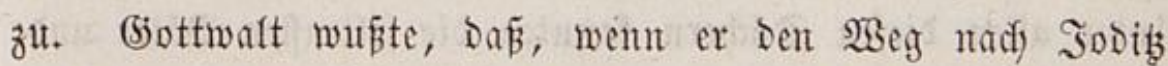

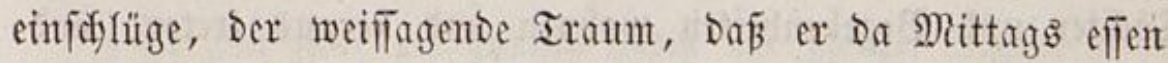
werde, folyon follb in Errfülfung gelse; - er nafm aljo Diefen

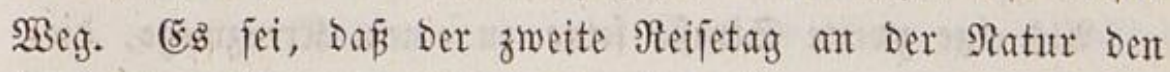

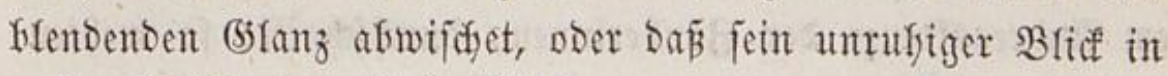

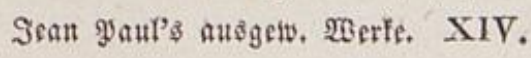




\section{8}

Das geweiflagte Rofentyof und Deflen (5aben Dns Yeife (5) rün Der Ratur, Das wie ein Bemälde nux in ein ftilles Auge

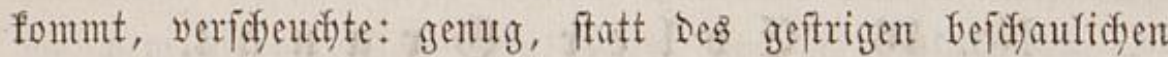

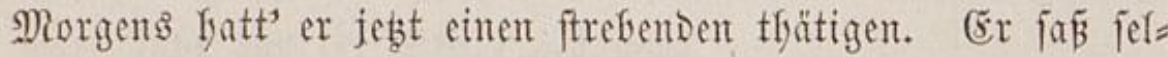
ten nieber, er flog, er fand und ging als Befeblsbaber an

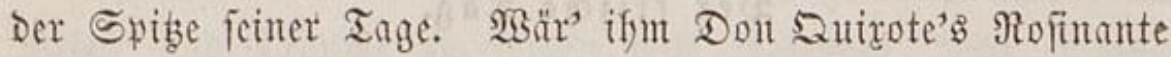
auf einer Sieje grajend begegnet, er bätte fich frei auf Die nadte gejdyungen (er wäre fein eigner Sattel gewejen), um in Die romantijue Welt finein zu reiten fits yor Die \$aus=

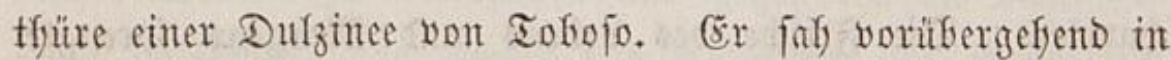
eine Gadente Defmithle, und trat finein; Die Riejenmajdyinen famen ifun lebendig vor, bie bauenden Rüfel, die unaufbalt= Garen Stampf = Räd) te und Slöbe wurben von feltiamen firäf= ten und bieiftern geregt und aufgebolien.

Durfh Den reintsfauten Simmel braujete cin unaufför Yidfer Sturm - Der feine eigne $\mathfrak{B}$ ind harfe war; - aber nidfos weht weiter in 3auber = uno 3ufunfts $=$ Ränder als eine fold)e unftd)tbare tönende (Siemalt. (Seifter flogen im Sturm; Die Wälder und Berge Der Erde wurben von Ueberirdifden ge=

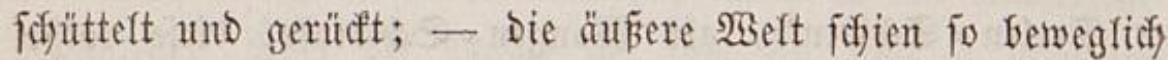
fu werben, wie es die intere ift.

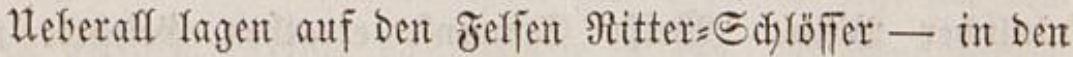

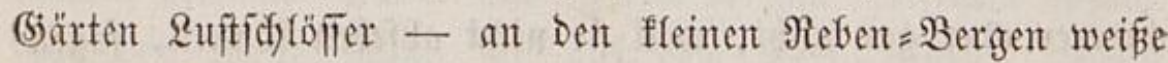
Ба̋ujerdyen - zuweilen Da eine rotbglänzente Biegelfütte, Dort Das. Sdjieferdady einer forn = ober \$aviermüfle. - Unter alfen Diejen Dädbern fonnten Die jeltenifen $\mathfrak{B a ̈ t e r ~ u n d ~}$ Söd)ter und Begebenbeiten wobnen und beraus treten, und auf Den Rotar zugehen; er veriafy fid De

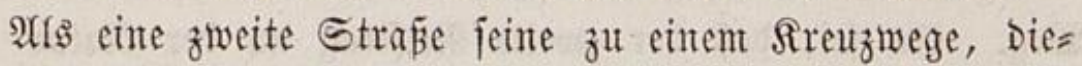
fem Anoreasfreuze Der Bauberimen, Durdjotynitt: fo webtent 
ifnt tiefe Sagent fofaner(id) aus Der Rinbfeit an; in Brenn=

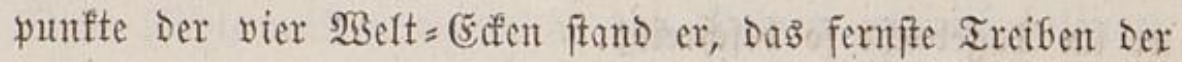
(Ertbe, Das Durdjeinanderlaufen Des \&eben's umipannt' er auf

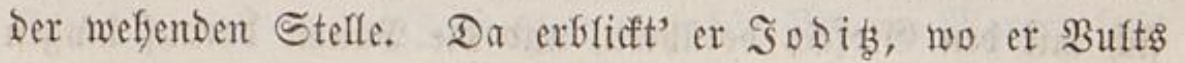
Traume nadh eflen follte. Es fam iffm aber vor, er fyab' es fđon längit gefefyen, Der Strom um Das Dorf, Der Bach

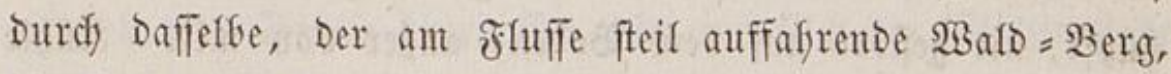
Die Birfen = Einfontung und alles war ifm eine seimath alter Bifber. Bieffeicht fratte eimmal Der Traumgott yor ifm ein

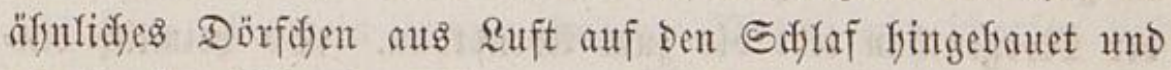

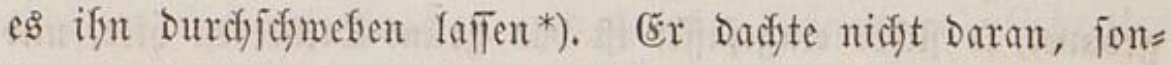

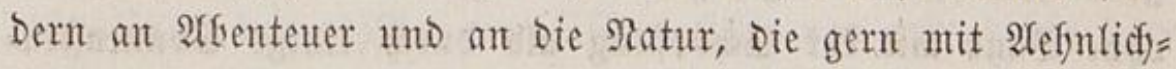
feiten auf Steinen und in $2 B o f f e n$ und mit 3 willingen jpielet.

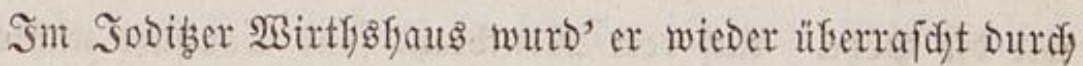
Mangel an affem Heberrajofendent. Nur bie Wirtfin war zu

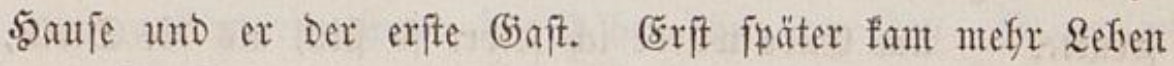

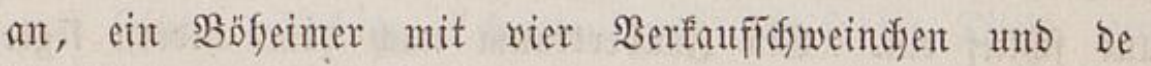
Sunte; aber da biejer fefjr lamentirte, Dá er lieber vier Seerben treiben und abjęen wollte als alfemal die lebten

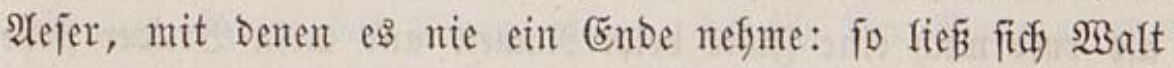
feine Somnenjeite nidyt länger zur 23 interjeite umbrefyen, fon= Dern zog mit einer Portativ=Mahlzeit Davont.

(rir gelangte in einen felfigen ftiffen $\mathfrak{B}$ ald und glitt vom $\mathfrak{W} e g \mathrm{ab}$, und fief fo fange einer immer enger ablaufendent

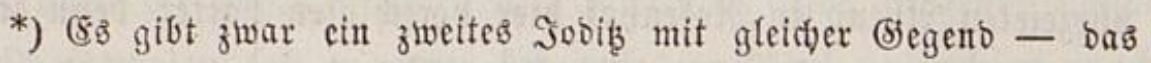

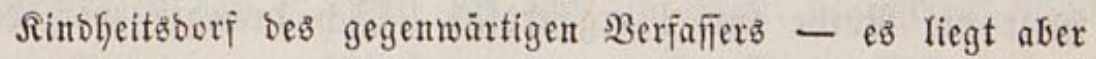
nicht in Şaร์lau, fonbern im Sogtlanb, wohin gebin nidjt ber Notar gefommen. 


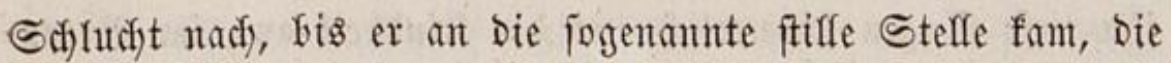
er im Iagebudje jo bejodreift:

"Die Felfent Drängen fid einander entgegen uth wollen fid) mit Den (5ipfeln berülyren, uno Die Bäume Darauf langen

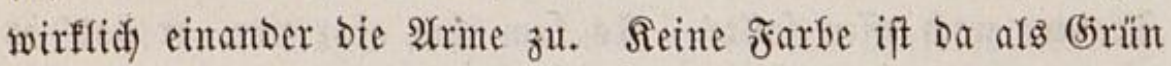
unt oben etwas Blau. Der bogel fingt und niftet und fü̈pft, nie geftürt auf Dem Boben, auper yon mir. Rüfle uno sueflen weben fier, fein Rüftchen faun fyerein. Esin

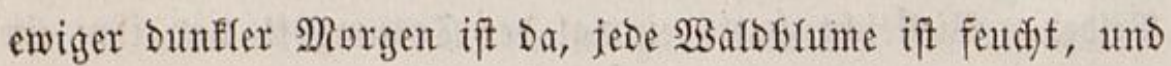
Der Morgentfau lebt bis zum Âbendthau. So feimlich ein= gebautet, fo ficher eingefajtet ift Das grüne Etiffreben fier, und ofne Band mit Der Sdjöpfung als Durdid einige Somenftra= Yen, Die Mittags Die fitfle Stelle an Den allgewaltigen 5̧im= mel fnüpfer. Sonderbar, dañ gerade bie Tiefe fo cinfam ift,

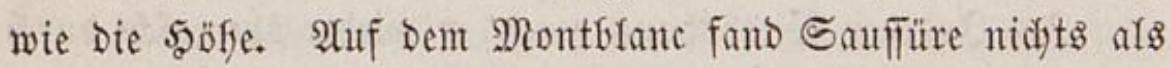
einen $\mathfrak{I} a g=$ unto einen $\mathfrak{R a d}$ tidjmetter(ing, was midf fefre $\mathrm{er}=$

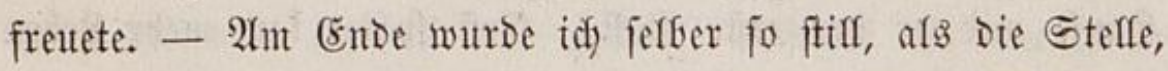
und foffief eit. (Fin 3nubertraum nad) Dem andern legte mix flügel an, bie bald wieber fut grofen Bfumenblättern wurben, auf Denen idf lag und fofwanfte. (Endlid) war mir, als rufe midf eine folote beim Ramen uno mein Bruber ftefye

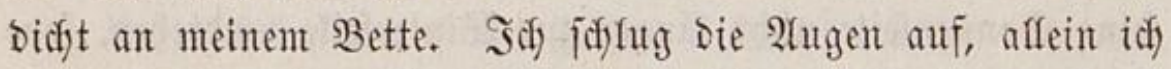

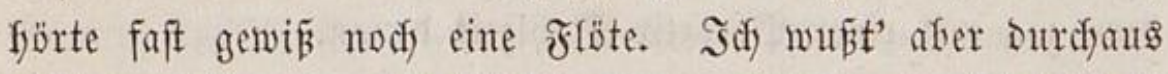

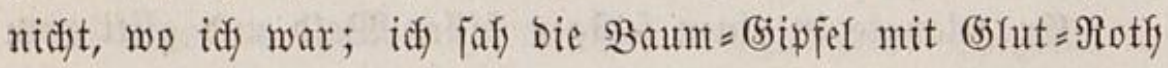

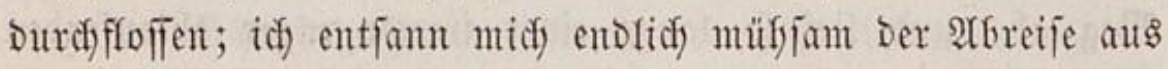
Sobib und eriffraf, Daß idf eine ganze Radyt und Den pros whezeieten arbento in Rojentyof fier veridylafen bätte; Denu idf

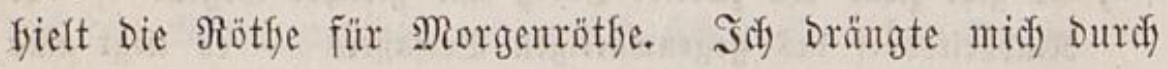

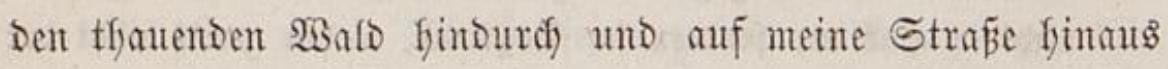
- ein prädtiges Morgen=sano faltete vor mir Die glühenden 
Flügel auf, und rí̄ mein şerz in Das alferfeiterfte Reidy. Weite Fidftentwäloer waren an Den Spiben gefbroth befäumt, freifid) mur burdy morbende Fidftemraupen. Die liebe Sonne

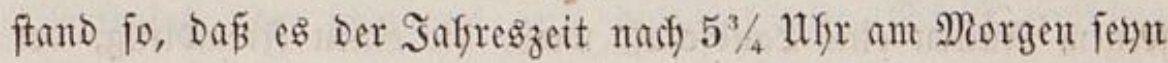

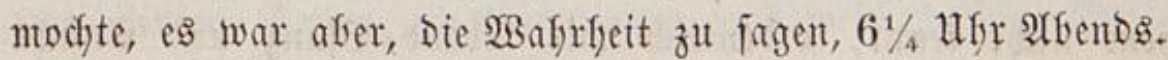

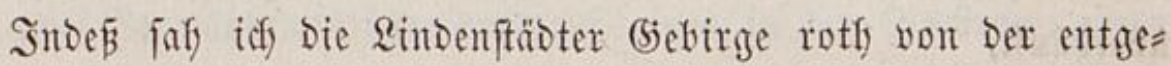
genftefyenden Eonne üfrergofien, Die eigentlich Der öftlidyen \&age nad) itber iffnen feten muste.

Id) Glieb im WBirrwarr, ofgleidy Die Sonne viefmefyr fiet als ftieg, bis ein junger fogerer Maler mit fidarfen und fd)önen (Sefid)ts = Snodjen uno langen Beinent und Sdjritten uno cinem Der gröften preusifden şüte yor mir Dafin vor= über wollte, mit einer Maler= Tajufe in Der 5ant. "(5uten Morgen, Freund, fagt' idy, iff Das Die Straß̄e nad, Rofenfof, und wie lange?" "Dort finter Den 5aügeln liegt's gleid', Sie fömen in einer Biertel= Stunde nodh vor Somnemunter= gantg anfommen, wenn die Fäfre eben da iff." (Er entlief mit feinen gedadjten Sdyritten uno idf jagte: Danf, gute Radft. (5s war mir aber gewartjam, als went fid bie Welt rürfwärts Drefte, und als wenn ein großerer Schatte über Das Somtent $=$ Fetuer Des Lebens füme, Da id) Den Morgen fum Abeno madyen mußste." So weit jeine $\mathfrak{B}_{0}$ orte.

Sebt ftand Der Notar fitll, Drelfte fich 1 m, eine lange (Evene finter ifm foldoflen unbefante Berge fu; vor ifm ftanden fie, wie Sturmbalfen Der (5ewitter, geffönt und ge= fwalten finter Den 5ügeln gen $\mathfrak{g i n m e l}$ und Die Berg= Riejent trugen Die fyohen Tannen mur fpielent. Der fliegende $2 a n d=$

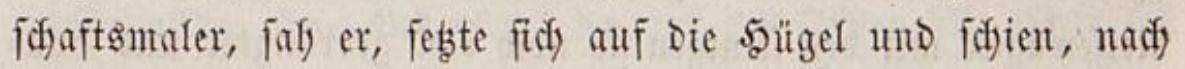

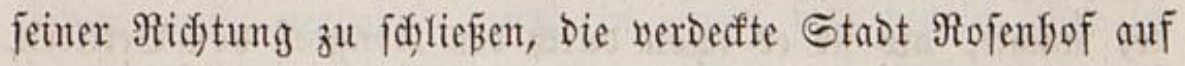
fein Beidyenpapier heraufatragen. (5ott, Dadjte $\mathfrak{B a l t , ~ m u n ~}$ 
begreif' idf's einigermañen, wie die Stabt liegen mag, wie

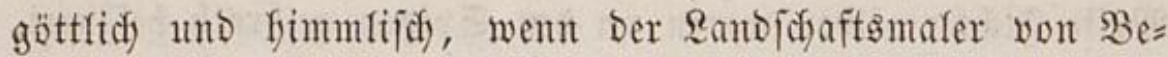
Deutung fich Davor febst, uno nur fie abreißet, inde er frinter feinem Rücen eine Ranbjofaft weiß̄, Die einen zrembling, Der

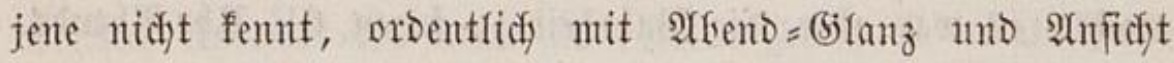
überfäuft.

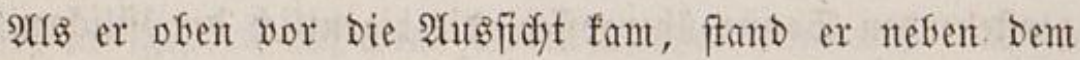
Stand = und Sibpunfte Des MaTers ftill, und rief nadi Demt

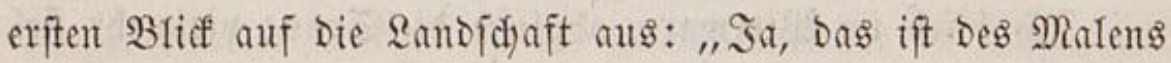

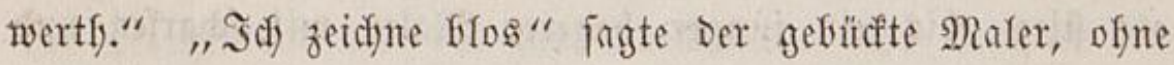

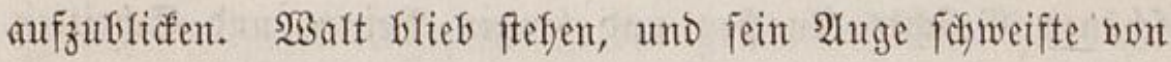

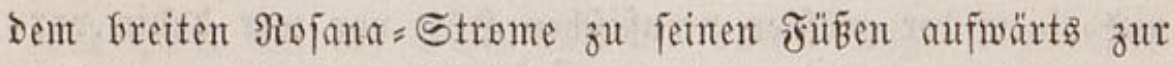
Stadt am ufer und bebirg, und ftieg auf Die walbigen zwei Feljen = (sipfel ïber Der Stadt, unto fiel auf Die Fäfre, Die, voll Menjoden uno $2 B a g e n$ zwifhen Geilen, zu feinem Ufer voll

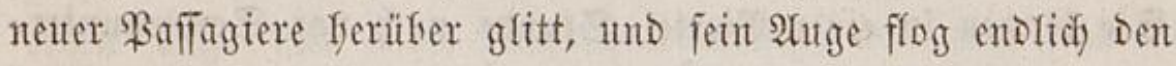

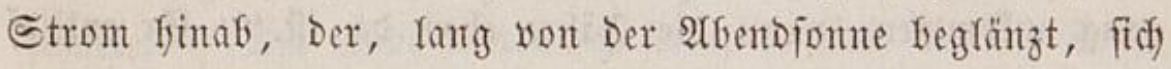
Durch fünf grüne felle Snfeln bremnend Drängte.

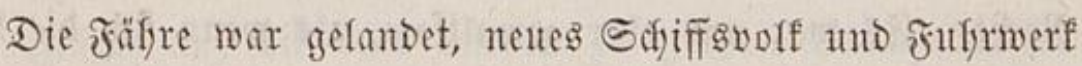
eingeftiegen, fie wartete aber nodh uno, wie es ifym vorfam,

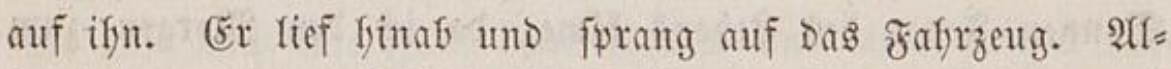
Yein es martete auf fodwerere Befradiftutg. (Fr fodjatete auf Dret fier einlaufende Strapen hinauf. Enofich bemerfte er,

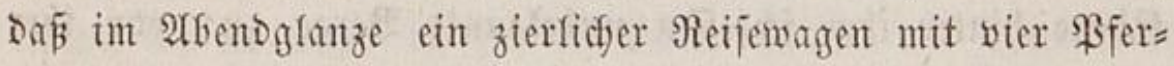
Den, lange Staubwolfen nadjidjleppent, Dafer roflte.

Darüber munte Der Notar froflofen, weil fidon cin Fuffrmants = Farrent mit SFerden auf Der Fäfre ftanto und Der Reifewagen mit Den feinigen fie nod viel gebrängter uno bun=

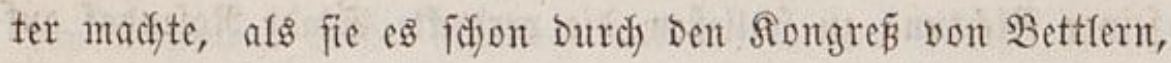
Boten, Spaziergängern, Şumben, Rintern, $\mathfrak{B a n t b e r g e j e l l e n t ~}$ 
uno Girummet $=2$ Beibern war, wozu nody Der Tyroler, Der Beburtghelfer und Der Bettefmann fam, Die ifm unterwegg begegnet waren. Die Fäfre war ifm ein zujammengeprester Rarftplabs, Der fidwamm, ein ftolzes Sinten = Sdyif zwifhen zwei Rinien = Seilen, ein Bucentauto, aus weldjem jeine Seele zwei Bermäflungeringe auswarf, einen in Den Seeftrom, einen

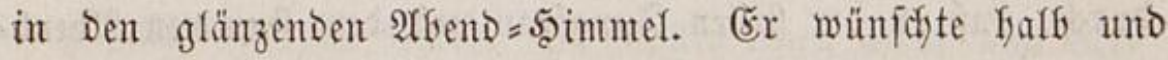
balf, Die Heberfahrt wollte fidy Durdy einige (5efabr, bie ant= Dern nidfts fichadete, noch trefflidyer belebent.

(Fin fơföner fattlidfer Namn ftieg vorfer aus Dem antge= fommenten $2 B a g e n$ aus, efy diejer auf Das enge Jafrzeltg ge= trieben uno Da gebörig eingejdidgtet wurbe; "er trane feinent ßfferden nidft" jagte Der Şerr. "Walt fubr ifym faft ofne auggezeidnete Şöflidyfeit entgegen vor Subel, Dent er fab Den (sienteral 8ablodi yor fich). Diejer Durdy Reijen bäufiger an foldse (5rfennungen gewöhnt, bezengte ein rubiges Dergnügen, feinen erotijdyen Sefretair. fier anjutreffen. Der lange \$oft= fug folperte enofidy in Die Fäfyre mit Dem Wagen ferein, und

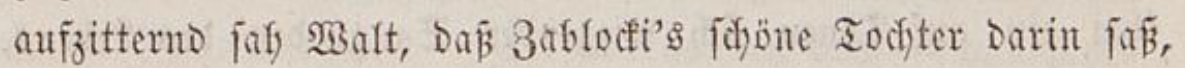
Die 2 ugen auf Die fünf Infeln beftend, welde Der Gonnen= glanz mit Rofenfener überfowmenmte. Sein \$ूerz brannte fanft in feinem şimmel, wie die Sonne in ifrem, uno ging felig auf und jelig unter. Sdhon ber lecre Befannte wär' ifm auf unbefauntem Boden wie ein Bruber erforienen; aber mun Die ftifl geliebte bieftalt — fie gab ifym cinen Geelen= Äugenblicf, Den fein Traum Der Pyantafie weiflagt.

(5r ftanto an Der Norgenjeite Des Sutidjenfolags und Durfte afloa ofne Bebenten, Da auf Der Fäfye alle ftefen mú, verfarren, uno in einem fort finein jefen (er batte fitc) gegen Den פ⿹agen ungefefyrt), er folflug aber Die 


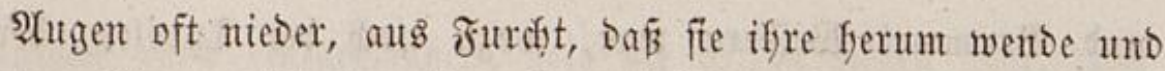

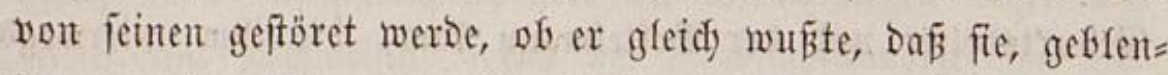
Det wou ber Soune, anfangs fo viel fäfle als nidfts. (Er

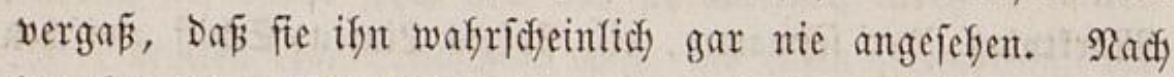
Der berrfidjen Fradjt= Somme uno nad) Den 5 Rojen= Injefn

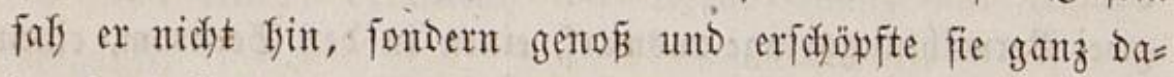
Durif), Dấ er Der ftiflen Sungfrau und Dem ftummen Abend = traume, womit fie auf Den golonen Snjeln ruffe, mit taujent

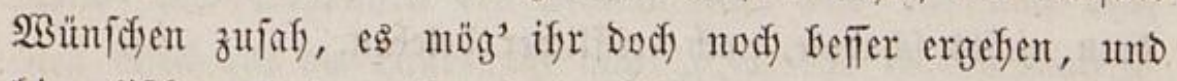
fimmlifich, und Darauf no dif fyertidfer.

Bon weitem war's iffm, als went die Rojana flölfe und Die Fäfre fojiffte, und bie $\mathfrak{B e f l e n}$ raufdjten, und als went bie

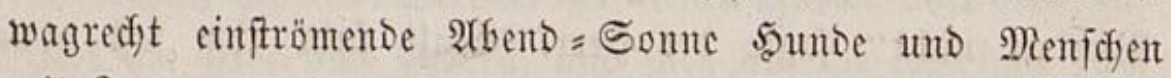
mit Sugent = Farben überzöge, und jeben $\mathfrak{B}$ ettler und $\mathfrak{B}$ ettel= ftab vergolbete, Desgleichen Das Silfer Der Jafre und 5aare. Afer er gab nidjt Gejonders âd, Darauf. Dent die Sonne fodmüufte $\mathfrak{B i n a}$ mit betenden Entzüffungen und Die Rojen Der

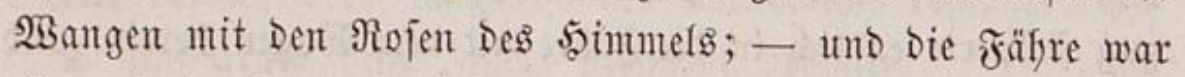
if)m ein auf Tönen fich wiegender Sangloben Des Lebens,

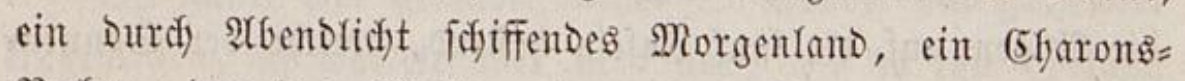
Radjen, Der Das Ěfyfiumt trug zum Tartarus Des Ulfers. Walt falf unfenntlich aus, fremb, überirdifach, Denn $\mathfrak{B}_{\text {ina's }}$ Berflärung warf Den 2 Btederfdein auf ifyt.

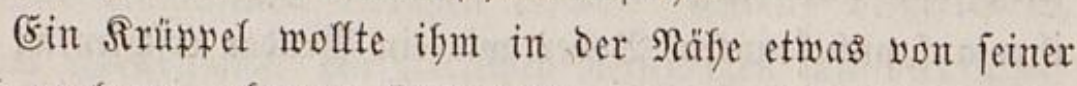
Rotfy vorlegen, aber er faíte nicht, fondern hajpete es, went ein Menidy an einem foldjen atbend nidjt felig war, wo fid bie bigfer betrilbte Sutgfrau erfeiterte, und fich Die Somne gleich jam wie eine liebe warme Sifwefter $=5$ and an Das 5erz Drücte, Das bisfier oft in mancher falten Dunfeln Stunde fither geidslagent. 


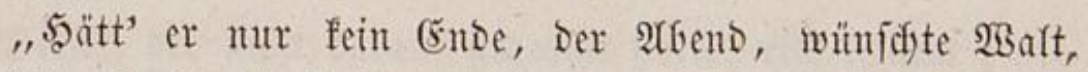
und feine Breite Die Rojana - oder man bejofiffte wenigftens ifre sänge, fort und fort, bis man mit frr ins Meer ver= fofwäumte, und Darin unterginge mit Der Sonne."

Eben war Die Some über Dem Strome untergegangen.

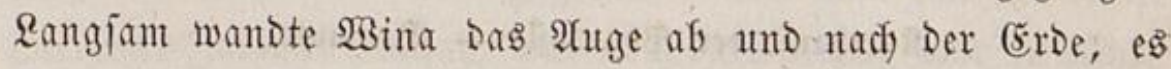

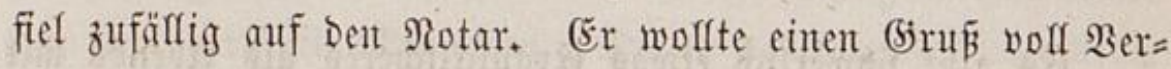

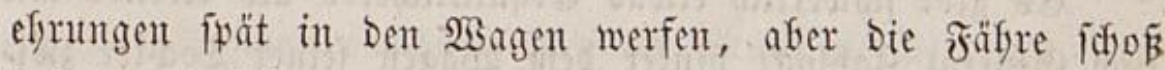
leftig vom ufer zurüce, uno zerftiés Das wenige, was er zu= fammen gebaut.

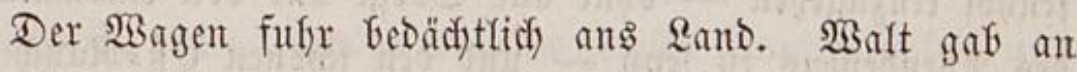
4 (5rofd)en Fäfrgeld: "für wen nod)?" fragten bie Fäfrlente.

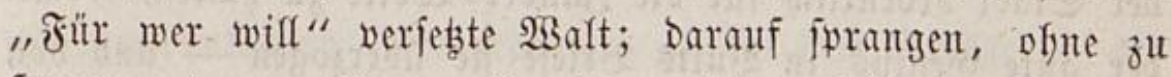
fragent und zu zafjlen, mefre als zu viele ants $2 a n d$. Der (jie $=$

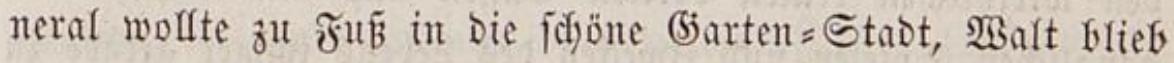
metien ifm. Sener fragte, of ifm geftern feine Romöbianten

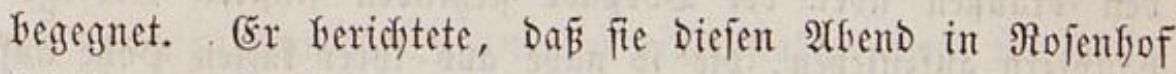

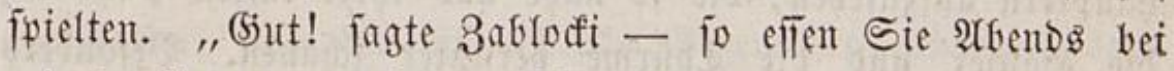
mir im (5ranatapfel - Sie übermadyten Dod) - und Mor= gens fiefot man in Eozietät Die ganz iplendide Jelfen = (sruppe, Die Sie Droben über Der Stadt Gemerfent."

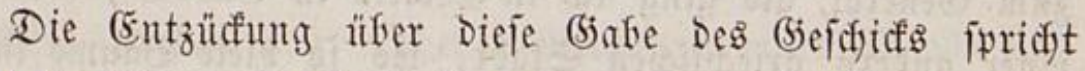
2 alt in feinem Tagefuch furz fo aus: ,wie idf vor iffm

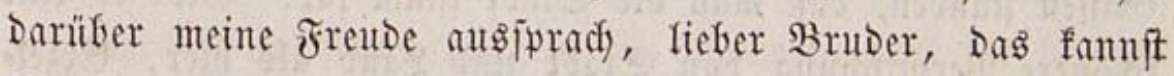
Du Dir viefleidyt befier Denfen als idj jeşt." 
No. 47. $\mathfrak{T} i \pm \mathfrak{a} \mathfrak{n} i \mathfrak{u}$.

Sartfaufe ber \$ुgntafie - Bummots.

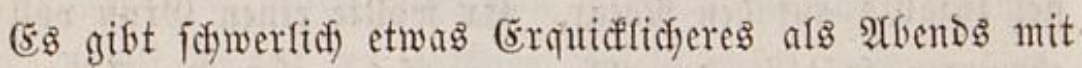
Dem (seneral Zablodi finter Dem $\mathfrak{W a g e n}$ jeiner Iodjter zwi=

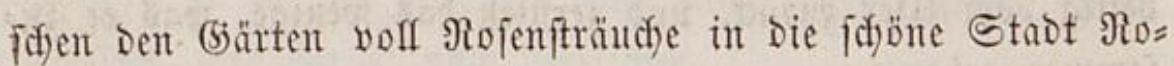
fentyof einzugeben - ofme alle Sorge uno voll Artsmalungen

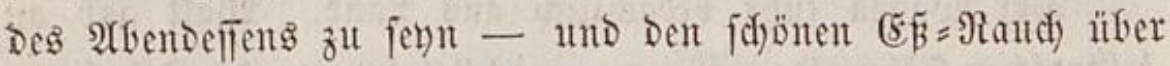
Der Stadt ordentlidy für Die 3auber $=23$ olfe zut halten, womit Der gute (jentus in $\mathfrak{B u l t s}$ Briefe fie überzogen - umb von Den wirtflidjen reinten breiten (5)affen und Den leidjten ver= gänglidyen Spiefent unto 3wecfent Des Lebens immer gerabe zut Den braupen über ber Borftast ftefenden fitfern biebirgs: fäuptern aufarehen, die fo nabe aus ifrer falten 50 bुe auf Die Säujer und bie Thürme ferunter fofauen. Bejonders nafm Den Notar Die grünende (5afje ein, wo Der (5ranatapfel logirte: ,mir ift ordentfich, fagte er begeiftert uno redjelig fum (jeneral, als ging' idh in (Shalcis in (Euböa*) ober autd) einer andern griedfifjen Stabt, wo fo viele Bäume in Den (bafien ftanden, Dan man Die Stabt faum far). (5ifit es cine

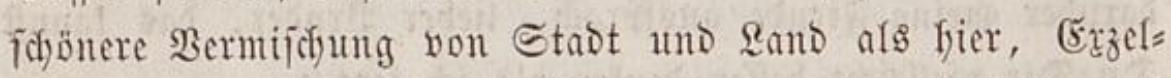

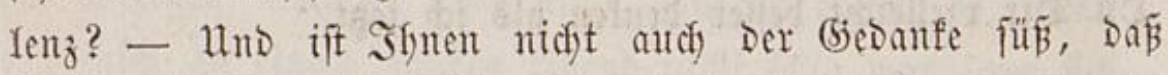
fier zu einer gewifien 3eit, fo wie in Montwellier, alles in Rojen unb yon Rojen febt, wenn man audíl) gleidy jebst nichts Davon fieft als Die Dornen, Feer Bjeneral?"

*) Pausan. in Att. 
Diejer, Der nidjt Darauf geffordyt fratte, rief jeinem Rut= fijer einen Derben fflud) $z^{u}$, weil er mit jeinem $\mathfrak{B a g e n}$ faft an Dem $\mathfrak{x}$ änzelfduen geentert fätte. WBalt jagte, Das feien Die Afteurs; und forderte vom $\mathfrak{B i r t h}$ ein vortreffliches $3 \mathrm{im}=$ mer, bas man iffm reidyt zugeftand, weil man ifn für einen

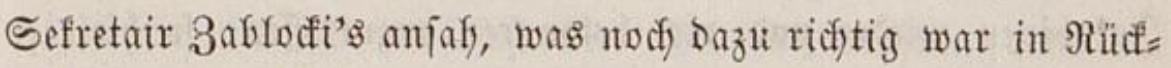
ficht Der erotififjen Memoiren. Da er Darein gefüffret wutroe,

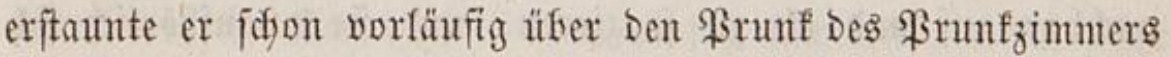

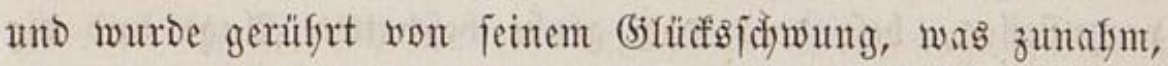
als er Den Bettelftab, Dem er jeinen 5̧ut auffebste, an Den

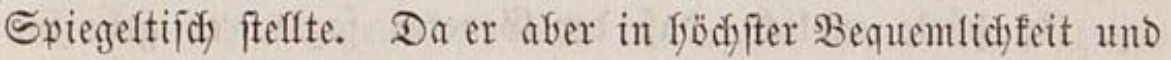
Seefen $=\Re u t h e$ auf = uno alging, Die \$apiertapeten ftatt Des ifm gewöfnfidyern Iapetenpapiers - Dic orei Epiegel - Die

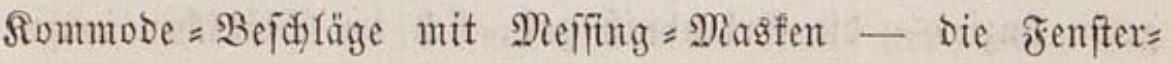
Rouleaux - und vollends bie Bedientenflingel ausfand: fo Yäutete er bieje zum erftenmal in jeinem Leben, um foglecid

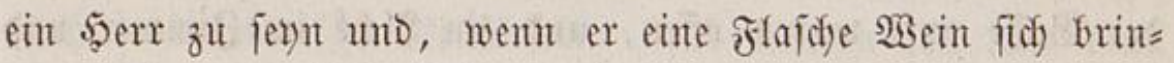

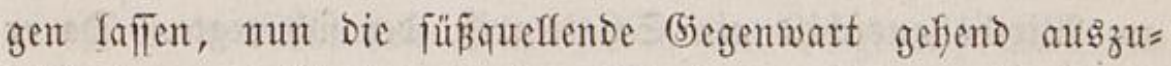
fóflürfen, und üferfyaupt einèn Alfent zu erfeben, wie irgend ein Troubaour ifn genofien. "Iroubabours, fagt' er fich, indem er tranf, übernadyteten oft in fefre vergoldeten 8 immern

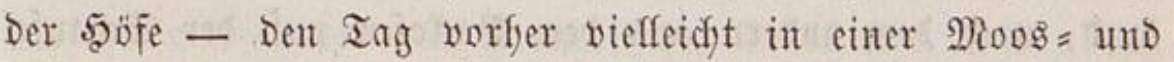
Strofhütte - wie Tone Durchbrangen fie fobe und bicfe Mauern - und Dann pflegten fie fich Darin nod) Die fonoufte Dame von Stand zu aufridytiger Riebe auszulejen und, gleid) Setrarfa, foldje in ewiger Didftung und Treute gar nie jelber

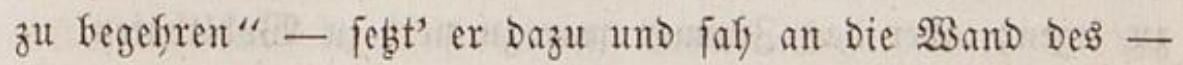
(5enerals.

3aflocti's 3immer war feinem Durdf eine zweimal ver= riegelte $\mathfrak{W a n b}=$ und Tranfito $=$ Thüre veriperrt uno verfnüpft. 
(Ev fonnte gefgent - Dent fefhend fuzufören, fielt er für

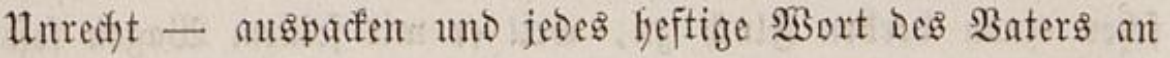
Bediente, uno Den füßen Ton, worein 2 Bina fie, wie eine Aeolsfarfe Den Sturmmino, auf Der Stefle überiebste, leidgt

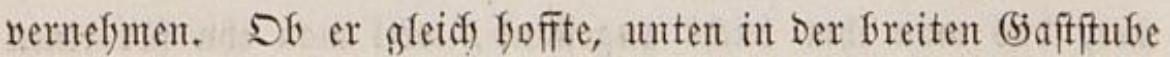
Safobinen wieber und viel befomenter anzutreffen: fo fielt er

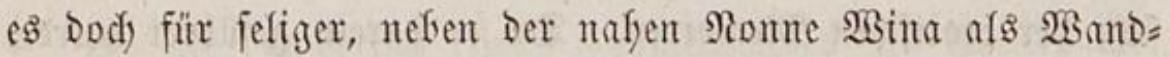
nadfbar auf und ab zu fpazteren, und fie utaufforlich fid vorzuffelfer, bejonders das grobe beiffattete 2 utge uno bie Freunolidffeit uno Stimme und Das âtendefien neben ifyr.

(5r förte endich, Daß̃ Der beneral jagte, er gefye ins

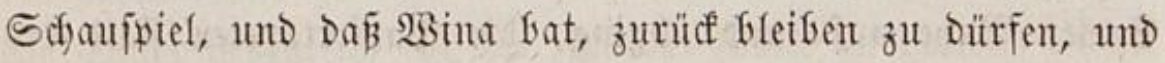
Daß̧ fie Darauf ifrer Rammerdienerin - Der gottlofen Sän=

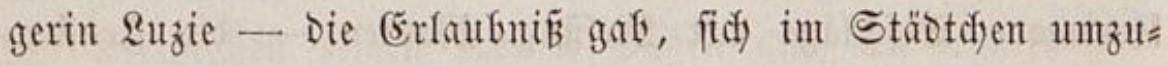
feffen. Arfesbant wurbe alles fitll. (Er faf) zum genfer finaus

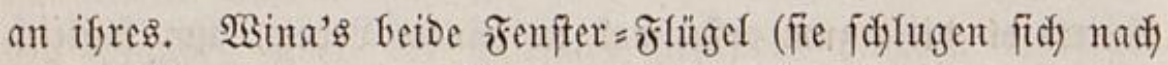
Der (bafle auf) warent offer, und ein Ridft im Bimmer und

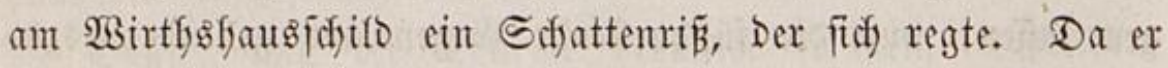
aber nichts weiter fah, fo fefrte er wieber mit dem fopf in feine Stube zurücf, worin er - jo gefend, trinfent, Didftent

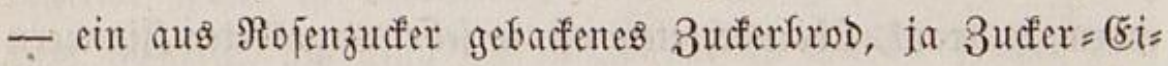
fand, nad) Dem andern aus Dem Bacfofen auf Der Gdyaufel

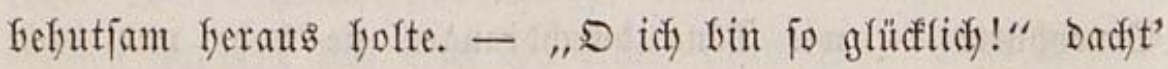

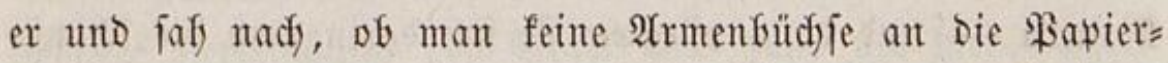

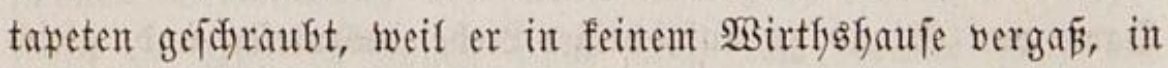
Dieje Stimm = Ribe unbefannter Rlagitimmen, jo viel er fonnte, fll legen; aber Das 3immer war zu nett $z^{4}$ Wofjlthaten.

(5: wurbe fefr bunfel. Der früfe 5erbitmond ftanto fodyon als ein fyalbes Silber = Diadem auf einem (jebirgghaupt. Der Siffner fam mit Ridft, Waalt jagte: idf brauthe feines, 


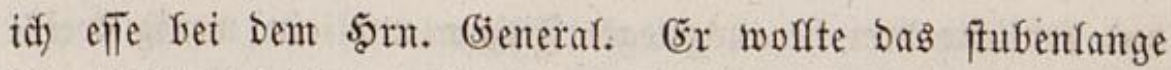

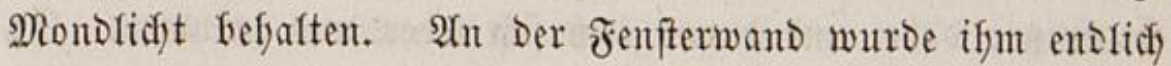
Daburdi cine und Die andere Reife=Sentenz von früfern $\mathfrak{P a f}=$ fagieren erfeudftet. (Er las bie ganze $\mathfrak{B}$ and Durd, nidft ofne 3ufriebenfeit mit Den jugendfichen Sentenzen, weldhe fämmt= fidf) Riebe und Freuntofdaft und (Eroen= Beradjtung mit Der Bleifeder anpriejen. - "Sad wein jo gut als jemanto -

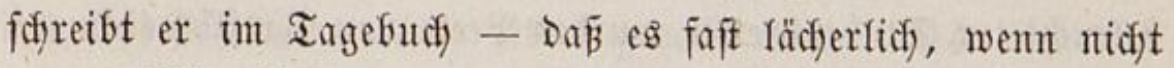
gar unbillig ift, fich an frembe Bimmer= 23 and anzufdreiben; Dentodf ergöbset Den Nadffaffrer ein Borgänger fefjr Dadurd, Dá̉ er audj Da gewejen, und bie leidyte Spur eines unbes fanten einem Unbefanuten nadjgelafien. Freifidy fodreiben einige mur Den Ramen und Iafreszafl an; aber einem wofl= wollenden Menfichen ift audf ein leerer Rame lieb, ofne wel= d)en eine entrücfte verreifete (5eftalt Dody mefr ein Begriff bliebe als ein Begriffents, wentiger cin Menfid) als einte luftige, audi wol ätherifose Renifdyeit. Und warum folf man Dent einent Yeeren Gedanfen lieber fraben und vergetien, als einen

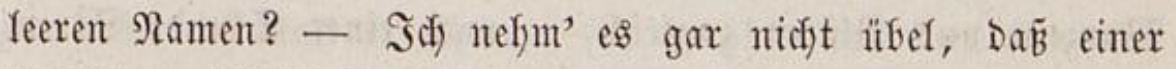
bloghin anffrrieb I. P. F. R. Wonsidel: Martii anno 1793 - oder ein anderer Vivat bie A. etc., Die B. etc., Die C. etc.,

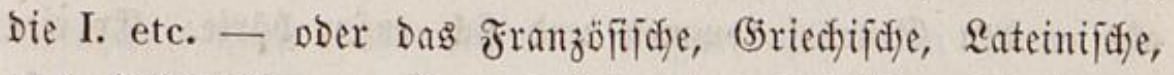
audi) sebräijaje. - Unto es ftefen ja oft foftbare Sentenzen Darin wie folgende: "im phyfichen saimmel glauten wir fets in Der Mitte ju fern; aber in Rüffidjt Des immerlidjen glau= ben wir immer am 5gorizont zu fefen; im öftididen, went wir froflocfen, im weftlidfen, went wir jammern." " Er wagte zuleb̧t felfer $\mathfrak{B}$ inta's und $\mathfrak{B a l t s}$ Ramen fammt Datum ms Stammbudi fo zu fidreiben: W - W. Sept. $179-$ (5x fojate wieder auf bie mondfelfe (ba)fe finaus nad) 23 inen, 
uno erflifte brei ferauggelegte finger und ein wentg weife

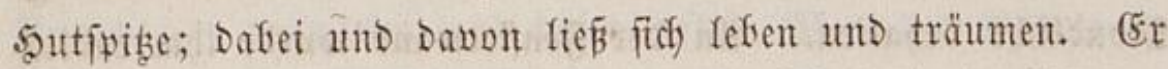
fd)webte und pielte, wie ein Sonnenfäubdjen, in Den langent Mondftralen Der Stube, ex ergänzte fich Das fitfle Mäbdyent aus Den Drei Jingern; or fifjufte aus ber nie verfiegenden 3utunft, Die beim Arbendeffen als biegenwart erichien. Freus Den flogen ifm als purpurne Edymetterlinge nad) uno Die befeudfteten Stubenfretter wurden Beete von Bapiflongbfumen - - Drei Biertefifumben lang münfót' er herz̧lich, fo einige Monate auf und nieber zu geben, um fich $\mathfrak{W}_{\sin a}$ zu Denfent

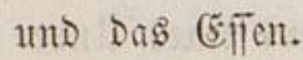

2(ber Der Menfod Dürfet am größ̈ten Freubenbedjer nady

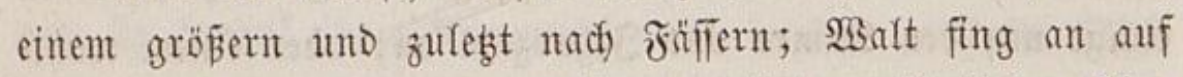
Den (jebanfent z̆l fommen, er föme nach) Der väterfidyen (sin=

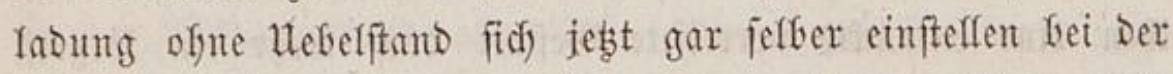

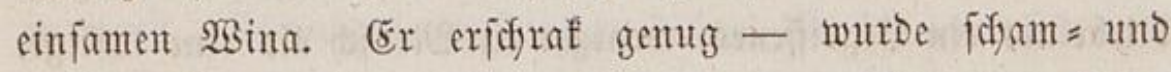
freubenroth - ging leifer auf und ab - börte jebst 23 ina audf auf = und niedergeffen - Der Borją̧ trieb immer mefyr Şurzefn uno Blüten zugleid) - nad) einer Stunde Streit

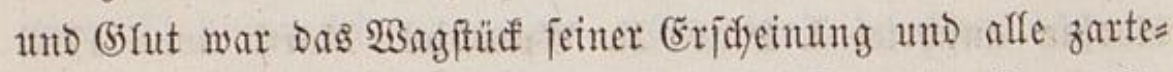
fent Entidyuldigungen Derjelben feft befdilofien und afgemadyt: als er Den (seneral fommen uno fidi) rufen förte. (5r ries

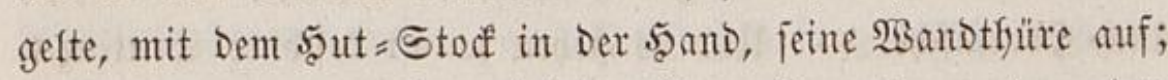
"Dieje ift jut, freund!" rief Der bieneral, uno er ging, Dent Mifigriff nadffüflend, erft aus feiner burdy die frembe ein.

Blüfyend yon Trüument trat er ins helfe 3immer; fyalb

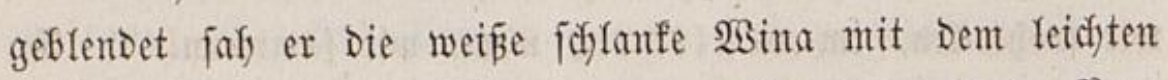

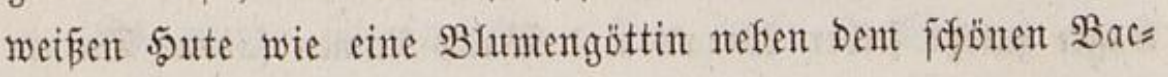
d)

Der Yebstere Gatte ein Keiteres Feuer in jeber Miene. 
Die Todfer fafy ifn unauflörfidy yor Frentbe über bie feintge

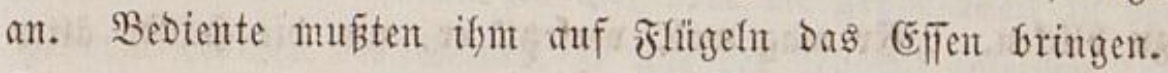
Der Notar wog anf ben feinigen, weridfwebt in Den Gstanz Diejes magifden Safbinets, nidft vicf üfer Das (semidjt von fünf Sdymetterlingen, fo Yeidft uno atfjerifid) flatterte ifm (bic= genwart und Reben vor.

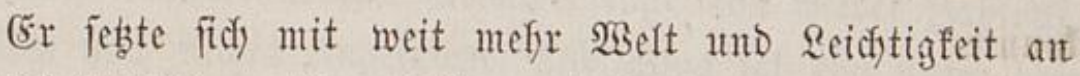
Das $\mathscr{E}_{\tilde{B}} \tilde{B}=\mathfrak{T a}$ feldyen, als er felber gedadft lyatte. Der Bjeneral, Der ein unaufförliches Eprechen und Unterfialten begeforte, foun $\mathfrak{B a}$ alten an, etwas zu erzäflen, ctwas $\mathfrak{A}$ figewecttes. Nit etwas Rüfrendem wär' er Yeichter bei ber santo gewejen; fo. aber fagt' er: er wolle nadjfinten. (ss fiel iffm nidfts bet. Sifwerer if mol nidfts af\& Das Smprovifiren Der Erimuerung. Biel Yeidfter improvifirt Der Sifarf= und Tieffinn, Die Bhant= tafte, als bie Erimterung, zumal wemt auf allent (jef)im = geln bie freubigften Jeuer fremen. Dreitaujent fatale Bon= mots fyatte Der Notar alfemal jojon gelejen gefrabt, jobals er fie bon einem andern erzäflen förte; aber er jelber fam nie zuerft Darauf und er forämte fich nadjfer vor Dem Sivrrefe= renten. Sefr fätt’ er Das Sdyämen nidyt nötfig, ba foldye

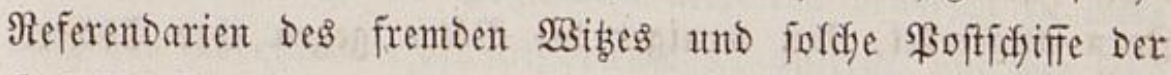
(5efellichaft meift platte befinte tragen, auf Deren Tente nie bie Blumen wadfjent, bie fie ba aufipeidyern und auftrodten.

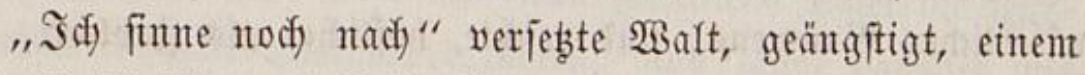
Blicfe 3abrocti's, uno flefte bott um einigen Spañ an; Dent nodh faf) er, Daß́ er eigentlich) nur über das Sinnent füne,

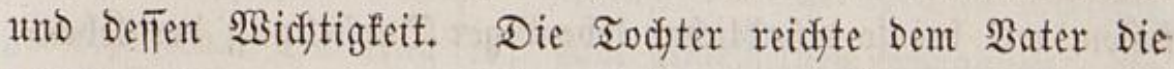
Jlafde, bie mur er - feine Briefe aber fie - auffitegelte. "Irinfen Sie Dię́ (5ewäc) für 48 ger "oder 83 ger?" fagte Der General, als man 2 Balten bas (5ias bot. Er tranf mit. 
Der Seele auf Der 3unge und judfte foriffento an Die Deffe zu bliffent. „Er mag wol, verfebst’ er, um Die 5älfte älter

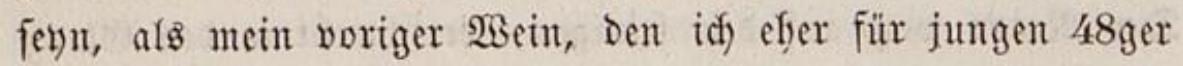

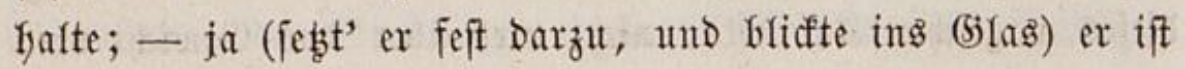
gewié herrliche 83 Iafre alt." 3abloçi lädyelte, weil er eine 2nefoote, ftatt zut hören, erlebte, bie er fdjön weiter geben founte.

Der seneral wollt' ifn aus Dem ftiflen interfidyen Sdynap= pen nady Bonmots Geraugfragen Durdy Die Rede: wie er nady Rofentof fomme? $\mathfrak{B a l t}$ muste feine redjte oftenfible $\mathfrak{H}=$

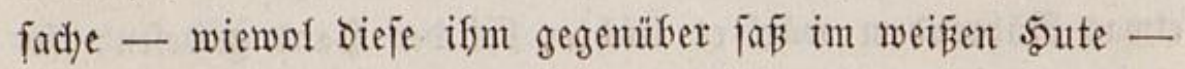
anzugeben, ausggenommen Ratux und Reifeluft. Da aber Diefe feine (sejdaffte waren: fo begriff ifn 3aflofti nidyt, fondern glaulbte, er balte finter irgend einem berge, und wollte Durdfaus finter ifn fommen. Walt fojüttelte von feinen poes tifchen Sdywingen Die föjtfidfen Berge und Thäler und Bäume auf Då Tifodtudy, bie er auf Dem feligen $\mathfrak{B}$ ege melyr aufges

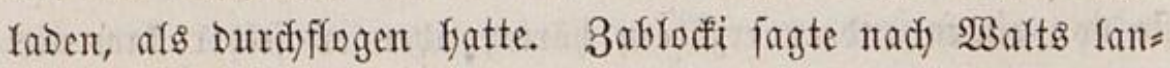
ger Ausfpente von Bifbern: "beim Teufer! nimm' ober idf frefl' nidyt!" Wina - Denn Dieje fjatt' er in jenem Riches= 3orn angeredet, Den wentger bie Bäter gegen iffre Tüdfter

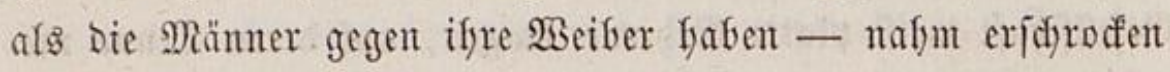

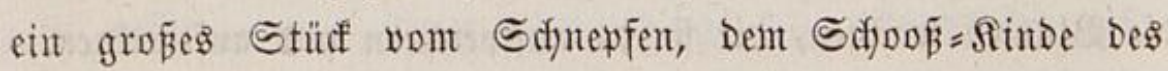
väterfidfen (saumens, uno reidfte, föfficher als $3 a$ frocti, Den Ieffer Dem betretenen Rotar finüber, um cin paar funbert Berlegenfyeitent z̧u erjparen. Walt fonnte auf feine Weife faffen, wie bei jo mündidfer lebentiger Darfieflung Der leben= Sigen beinafye münofidyen Natur, afs jeine war, ein Sdynepfe mit alfem jeinem Album graecum nody einige Senfazion zut

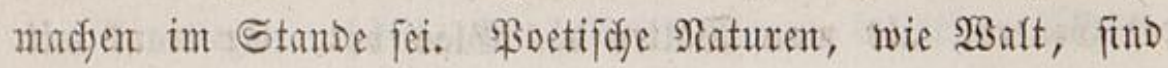




\section{3}

in Rorbländern - Dent cin 50 of ober Die grope $2 B e l t$ ift ber geforme Rorden Des Beiftes, fo wie Der geforne Bifeidfer Des Rörpers - nichts weiter als Elephantenzäfne in Siferien, bie unbegreifficl) an einem Drte abgeworfen wordent, wo ber (Elephant erfriert.

Mit einfdymeidyefrnoer Stimme fragt' ifn wieber 3ablocti, ob ifm nod) nidfts eingefalfen; und $\mathfrak{B}_{\text {ina }}$ faf ifn unter bent Afbendrotfe bes rotfiaftenen sutfutters fo lieblidy augen= nicfend und bittent an, Dar er feryr gelitten frätte, went ifm nicht bie brei Bommots, auf bie er fid gewöfnlidy befant, entich) zugefommen wären, und Dẩ er wieber nafe Darant war, ein gelicferter $\mathfrak{R a n n}$ zu werben, und afles zut vergeffen,

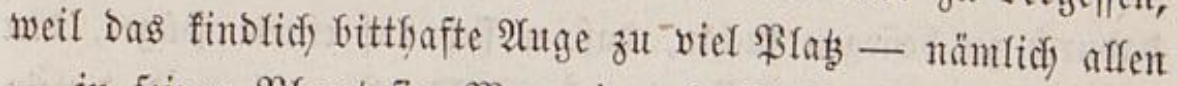
- in feiner \$frantafie, Memorie und Seele wegnafm.

"Ein fartföriger Rinifter - fing er an - förte an

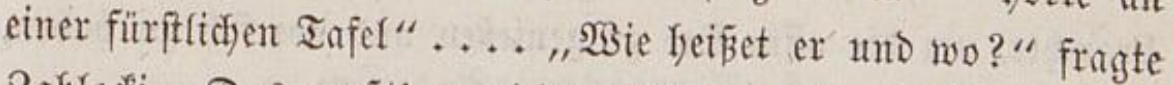
3ablocfi. Das wuít” er nidyt. Affein ba Der Notar Den we= nigen Sifforien, Die ifm zufielen, feinen Boben, (3efurtstag und (5eburtsfdecin zuzumentert nuṕte - vorfabeln wollt' er nie: - fo brauddyt es Sozietäten nidyt exf́ bewiejen zu wer= Den, wie farbenlos er als soiftorienmaler auftrat und wie fefr eigentlich) als ein fuftiger fiftorifocer Smprovifator. "Ein Y)artföriger Miniffer yörte an einer fürfflidjen Iafel bie ₹ür=

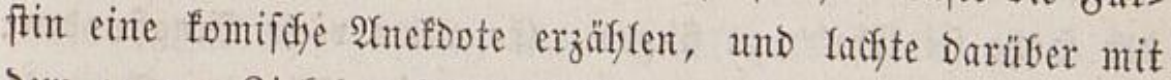
Dem gamzen Birfel unbefdreiblich mit, of er gleidf fein 13 ort Davon vernommen. Sebt verfprach er eine eben fo fomiche żt erzäflent. Da trug er, zum allgemeinen Erftaunen, bie ebent erzäflte wieber als eine nelte vor."

Der bieneral glaubte, fo fonnapy es nidjt ab; Da er aber

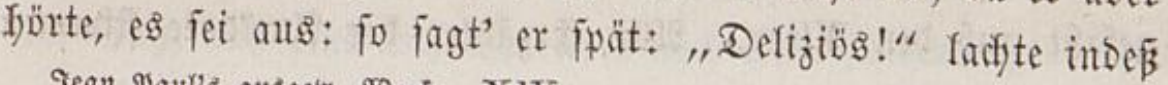

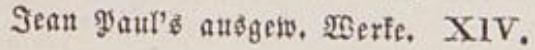


erft zwei Minutent päter fell auf, weil er gerade fo viefe

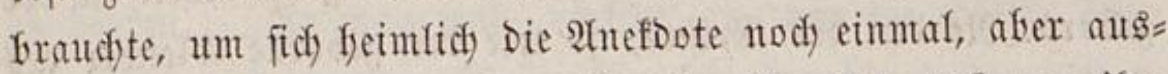
füfrrliçer, vorzutragen. Der Menjich wifl nicht, Dak man ifm Die jpize, Glanfe Fointe zu fribig auf Der Sifmelle auf bas 3werdffelf jeb̧e. (sine gemeine 2 (nnefoote ergreift ifn mit iffrem

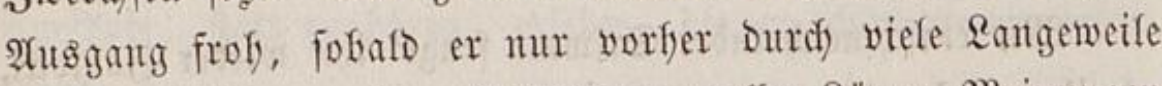
Dafin getrieben wurbe. (Se çdidften wolfen Ränge, Meinungen Rürze. Waalt trieb bie zweite anonyme (5ejofidyte von eitem

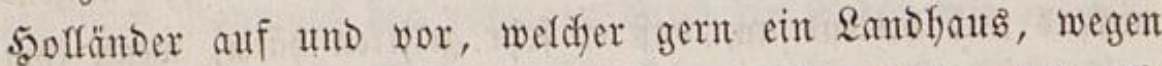

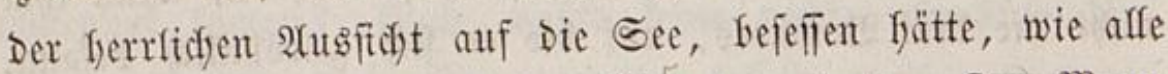
Welt um ifn, afleein nicht Dab (jelo Dazul fratte. Der Maum

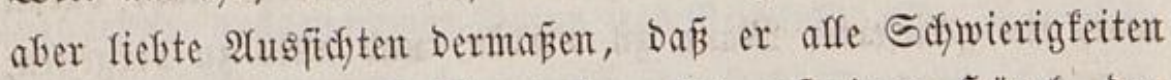

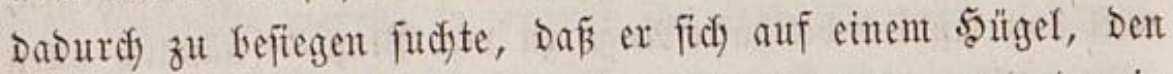
er gegen Die See fratte, eine furze $\mathfrak{B a n d m a u e r , ~ u n d ~ D a r e i t ~}$ ein Fenfter frecten lies, in weldes er fich nur zul legent

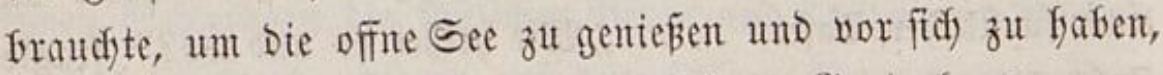
fo gut als irgend ein Nachbar, in feinem (5artenthaus.

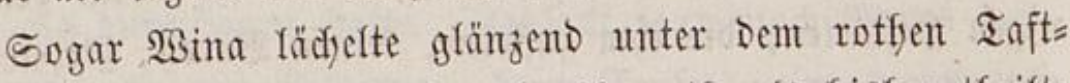
Sof atten hervor. Mit nod) mefor 2aumuth als bisher theilte Waalt bie Dritte $\mathfrak{A n e f D o t e}$ mit.

(̌in Früfyrebiger, Deffen Reflfopf mefyr zur Ranzel= Brofa als zur $\mathfrak{A}$ ftar = Poefite geftimmt war, rücfte zu einer

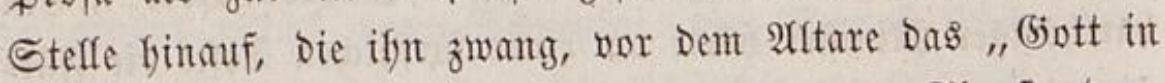

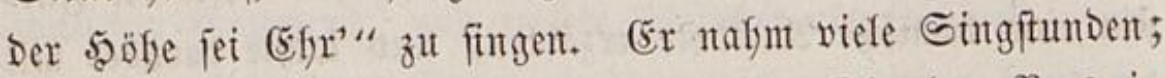

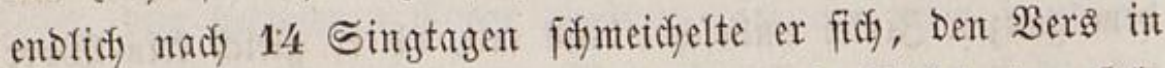
Der (S) walt und Sieble zut Gabett. Die Yalbe Etadt ging frit: fer in Die Rirche, unt Der Antftrengung zuzulförent. Bantz mutfig trat er aus Der Safriftei (Deun er hatte fich Darin vom Singmeifter nody cimmal reife überförent laffent) unto ftieg

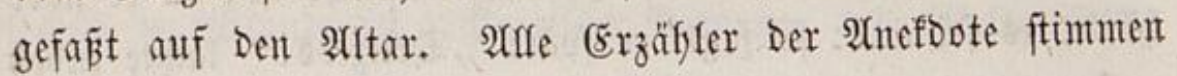


überein, Daß er trefflich angefoben, uno fich anftänbig genug in Den Sfyoral fyineingejungen fratte: als zu feinem Ruin ein Glafender \$oftillon Drauken nor Der Rirche vorbei ritt, und

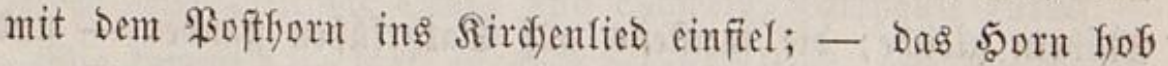
Den \$rebiger atts Dem alten Sing=(5eleife in ein neues fin= eirt, und er faff ficif gezmungen, das crmfe Ried mitten vor Dem $\mathfrak{A}$ (tare nad) Dem vorbeireitemben Irompeterfitüfdyen auf Die Luftigfte Beife fintauszufingen.

Der (Seneral lobte fefre Den Notar, unto ging fyeiter als Dem 3inmer; aber er fam nidyt wieber.

No. 48. $\subseteq \mathfrak{S} \mathfrak{a} \mathfrak{f} \mathfrak{f} \mathfrak{i} \mathfrak{s}$.

Die Rofenföfer $\Re$ a (d)t.

TSeder Safobine nod Der (5ieneral madjten je ein (5iefleim=

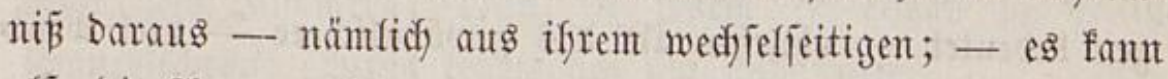
aljo Die Inverwanten von beiden auf feine 2 seife zut etwas Suriftifont gegen Den Berfaffer Der Flegeljafre beredytigen, went ex im Stralfies blog falt erzählet, Daßj 3ablocfi ein wenig in Den nädfften (5arten fwazieren gegantgen, uno bie Aftrize Iafobine zufällig nidjt fowol, als in Der guten $\mathfrak{A} b=$

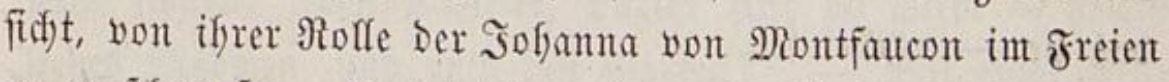

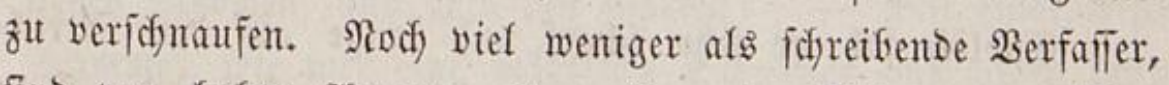
fint won fobjen antwerwantent alfgemeine Säbe anzugreifen, wie z. B. Diefer: Daß̧ fefre leidjt Der weibliche theatralijoje Lorbeer fich rilfwärts in eine Daphne verwande - und

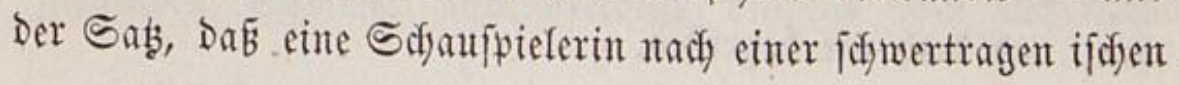


Tugent $=\Re$ olle am beiten ifyr eignes Theater aux Italiens und ifre eigne Parodie werde - am wenigften diejer, Daß̃ das

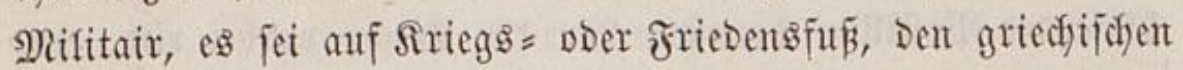
Mübeln gleiche, bie meiftens auf Satrrfü̈̈en ftanden - und

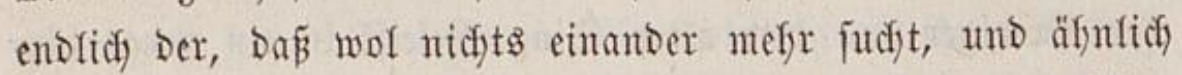
findet (Dafer fofon Die 20 orte Srieggtheater und Theaterfrieg, Affion und Staatsafzion, Iruppen) als efen Theatertruppent Die Firiegstruppen, und vice versa.

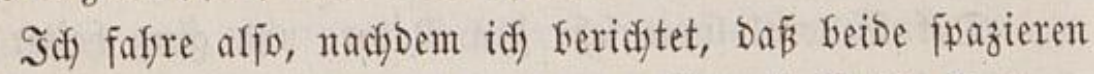
gegangen, gleidf ifnen rufig und ungeftört, hoff' idj, fort.

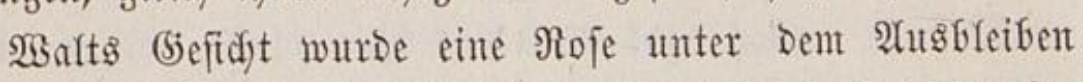
Des Baters. WBina heftete Die 2 Hgen, Die fid) wie füpe Früchte unter Das breite Laub Der 2 ugenfieber verffectten, unter bent 5ute auf ifr Stricfzeug nieber, Das einen langen Rinberfand = for)uff vollendete. Hefier Den Notar fam mun wieder bie Furdyt,

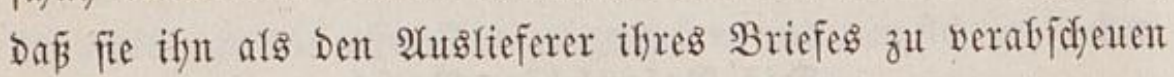
anfange. (Er fafy fie nidyt oft an, aus Edyeu vor bem zut=

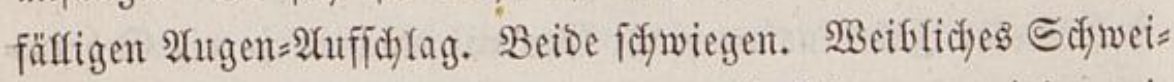
gen bebentet - ofnefin als bas gemöfnfichere - viel went=

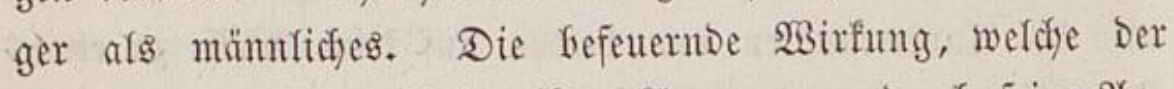

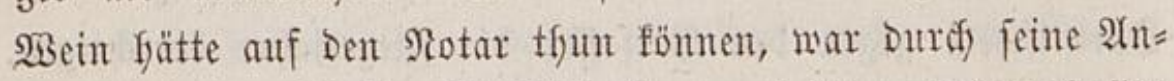
frrengung, Den feinfen (5ejellichafter zu fpielen, niedergefyaltent

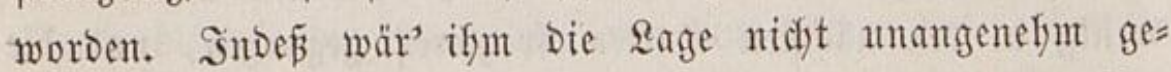

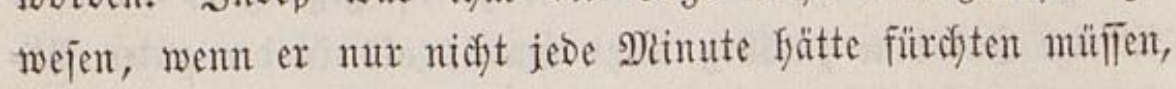
Daß̃ fie - vorbei jei.

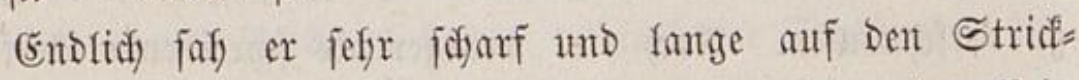
sandidyuly und wurde fo glüfflidy, fich einen Faden Der Rede Daraus zu ziefyen; er fojüpfte nämlidy Die Bemerfung aus Dem 5andidjuf, Dak er of́t Stumbenlang das Stricfen bejes fyen, und Dody nie begriffen. 


\section{7}

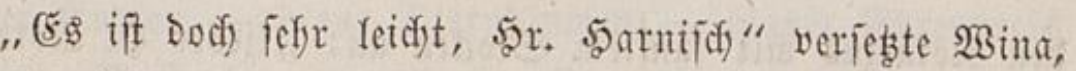
nicht pöttifich, fonbern unbefangen, ofue aufablicfen.

Die 2Urrede: "\$orr 5arnifd)" jagte Den (Empfänger Der= feffen wieder in bie Denf = und Sdfweig= Rartfrauje zurüd. -

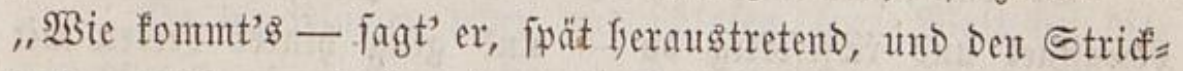

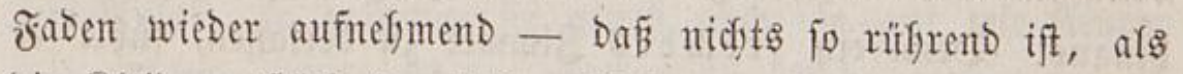
Die Rleibunggftülfe Der lieben Sinder, z. B. Diefes fier - fo ifyre Soütdyen - Edyüfdyen? - - Das freipet freilich ant Ende, warum lieben wir fie jefber jo jefre?" -

"Es wirb vieffeidyt audid) Darum fern - verjebste 2 sina, und frob bie rufigen volfen Augen zun Notar empor, Der yor iffr ftand - weil fie umfduldige Engel auf Der Erode fint, uno Dodf fidon viele Saljmerzen Yeiden."

"WBafrffaftig, fo ift e

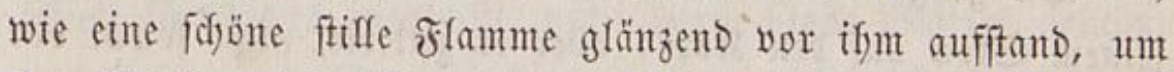
ifrr Mäbdyen ferzuflingeln) - Uno wie dürfen (Ermadjfene flagen? - Sat) will wafrlid) Das Sterben cines Rindes (icht' er finzu, unb folgte ifr einige Sdyritte nady) ertragen, aber nidjt fein Sammern; Denu in jenem ift etwas fo heifig= fid auterfiches." Wina fefyrte fich um uno nicfte.

Quzie fam; $\mathfrak{B i n a}$ fragte, of Der (5ieneral ifyr nichts auf=

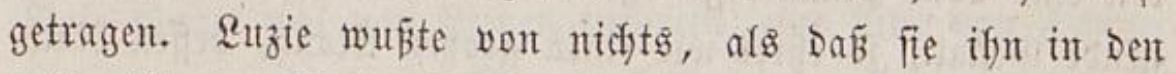
nafen barten finein fpazieren fefen. Rajey trat 2 sina ans monofelle Fenfter, atfmete (sinmal redyt feufzento cin, unto

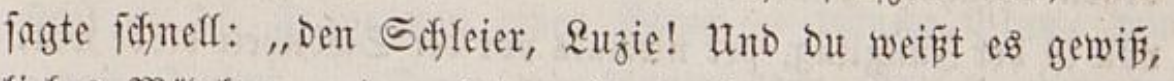
liebes Mäbdjen, und auch) Den (5arten?" - Mit einer leifen Stimme, wie nur eine mäfrifode Sdbwefter anftimmen fann, verfebte \&uzie: „ja, Sinäbigfte!" 2 Bina warf Den Shleier über Den Shut und rebete, finter biejent geweften Rebel und fliegendent Sommer unbefdreiblid) blüfent und rebreizeno, 
Dent Notarius mit fanftem Stofen an: "Yieber 5 . Notar Sie lieben ja audj, wie id börte, bie Ratur - und mein guter Bater - - "

(Ex war fidon uadi Dem şut= Stodf geflogen, und ftanto bewafinet uno reifefertig $D a-4 m$ ging finter beiben mit finats. Dent cin frembes 3inmer zu verlaflen, füfylt' er

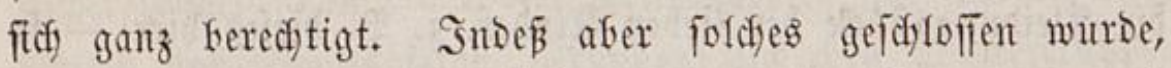
fam er wieder voraus zu ftefyen, nafye an Der Treppe; - und in ifym fing ein furzes Ireffen und Siffarmübel an diber bie frage, of er mit entweder bürfe oder folle - oder weder

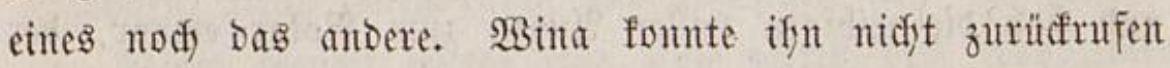
- uno jo fam er innen fedstento auf bie areppe, und trug

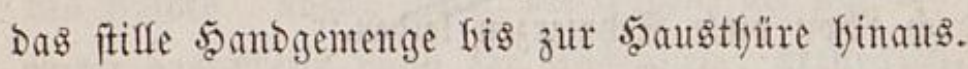

Da ging er ofne weiteres mit uno febte Den 5ut won feinem Stod auf Den Sopf; aber er zitterte, nidyt fowol vor furdst ober vor Freube, fonbern bor einer Errwartung, Die beibe vereinigt. D es ift eine lädserfidye und reine 3eit im früfyen Sünglinggalter, wo im Süngling bie alte franzüfijche Ritteridaft mit ifrer beiligen Edyen enteuert, und mo ber Rüfnfte gerade Der Blöbeffe ift, weil er feine Iungfrau, für

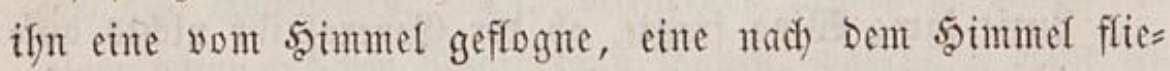

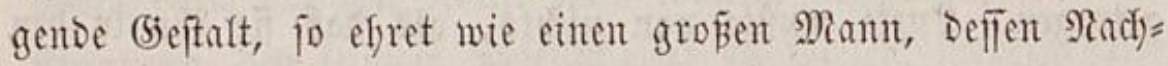

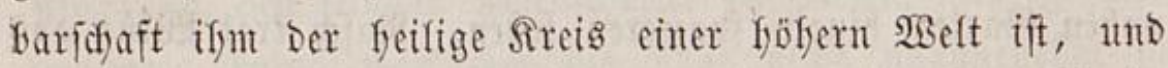
Deflen berüfrte sand ifym eine (batie wirb. Unjefig, fofulds= voll ift ber Süngling, Der niemals vor Der Sejönfleit blöbe war.

Die Drei Menjoden gingen Durif) eine waldige (Sajpe Demt (5arten zu. Der Mond zeidynete Die wanfende Bitpfel= Rette

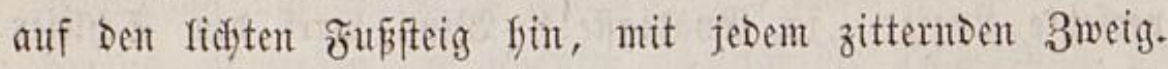
Quzie erzäfite, wie fojont Der (5arten, und bejonders eine ganz

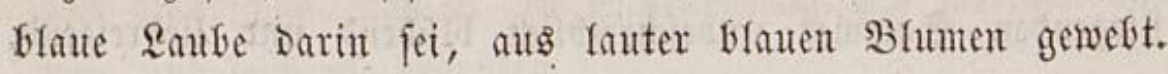


Bfater Enzian - blaue Etemblumen - blauer Efrenpreis - Glaue 2 Baldoreben vergitterten fid zu cinem fleinen bim=

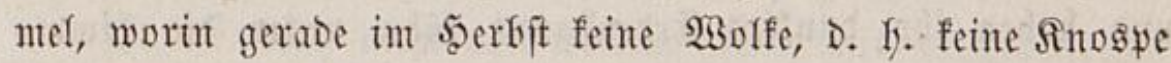
war, fondern offine Aetyerfertife.

"Da Die Blumen leben und fidlafen, jagte walt bei bie=

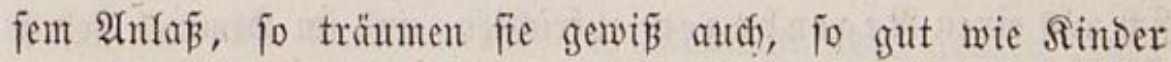

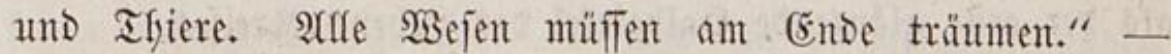

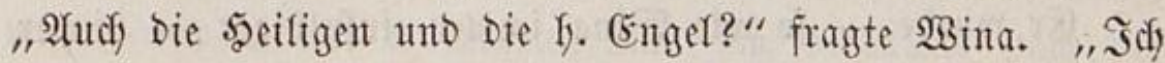
wollte wol jagen $\mathfrak{\Im} \mathfrak{a}$ - fagte $\mathfrak{B a l t}$ - injofern affe $\mathfrak{B}$ ejent fteigen, und fid aljo etwas \$obheres träumen fönnen." -

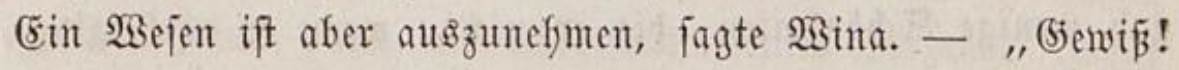
(5ott träumet nidjt. 2 (ber went idy mun Die Blumen wieber Getrachte, fo mag wol in iffren zarten bauffen Der Dunfle Traum yon einem leidjtem Traume brüfen. Sfre Duftente

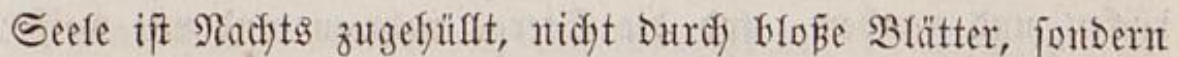
wafrryaft organifid, wie Denu unfere aud nidyt Durd blofe Augentieder fugejdyloten wirb. Sobald nut eimmal bie far=

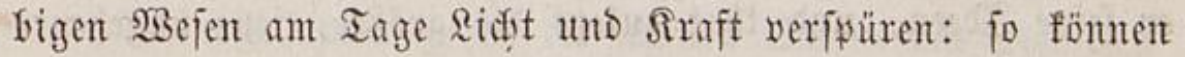

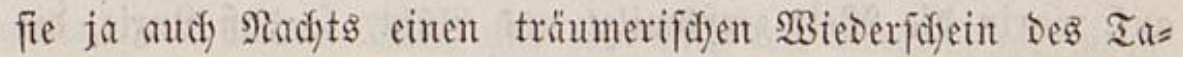

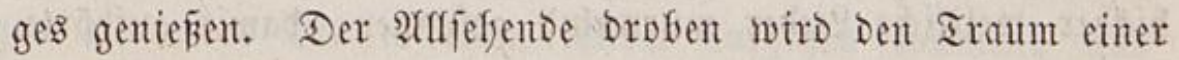
Roje und Den Traum einer Rifie fennen und ficheiden. Sine Roje fönnte wol von Bienen träumen, eine Rilie von Sdymet= terfingen - in biejer Minute fommt es mir ordentlid fajt gewifjer vor - Dag Bergismeinnidyt won cinem Eonnen= ftral - Die Tulpe von einter Biene - mandje Blume von einem 3ewfyr - Denn wo fünte Denn Gotteg oder Der

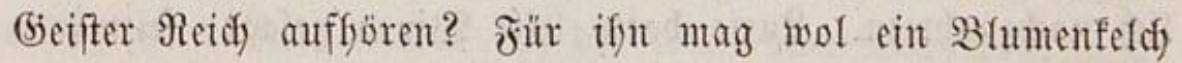

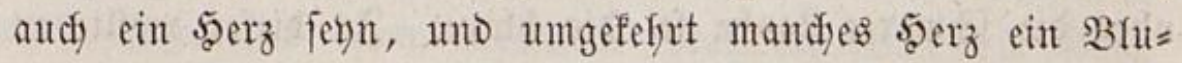
men $=$ Reld.$"$ -

Sebst tratent fie in Den 3auber= (jarten cin, Deflen weipe 
(5)änge und funfere $B$ lättergrupwent eintander wed) felno färb= ten. Die Berge waren, wie Radjtgötter, fjodh aufgeftanton, und hoben ifre Dunfles Erdenfraust füfn unter bie fimm= Yijuent Steme fintein. Der Notar falb Den bisfer ausein= ander liegenden farbenthau ber Didtung an Winn's band fidi) als cinen $\Re$ egenbogen aufridyten, und im simutel fetyen als Der erfte glänzende Salfzirfel Des Rebents = Streifes.

Er murbe - fo wie $\mathfrak{B i n a}$ inmer einfylfiger - immer vielfyllsiger und betranf fich im Taufwa jer feiner 2 Borte, Das er über jeden Berg und Stent gove, Der iffuen vorfam. (5̧ gatb menige Sifönfeiten, Die er nidft, wenn er vorfeiging,

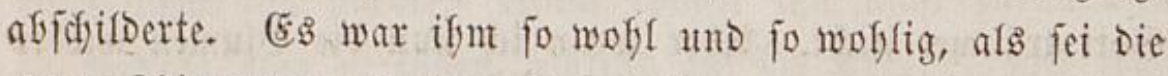
ganze fojimmente 5alffugel um iffn mur unter feiner şirn= fonale von einem Traume aufgebantet, uno er föme alles

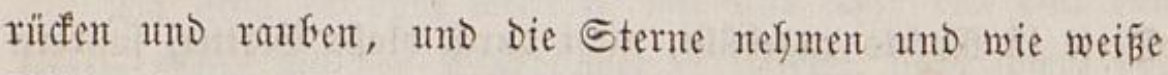

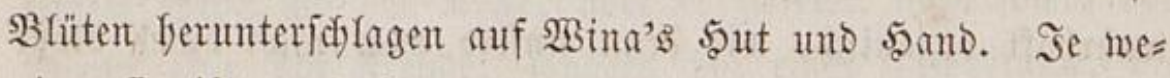
niger fie ifn unterbrady unt abfilfite: um fo gröfer madyte er feine SDeen, unb that zulebgt bie größ̈te, jene ungeheure

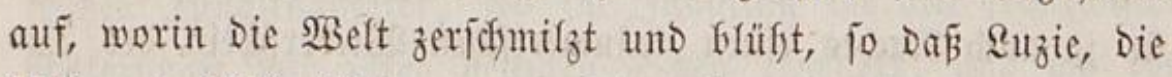
bisher meltfiche Rieder murmelnd gefungen, Damit aufbörte, แts Scjelt vor (5ottes 2 sort.

(5ben wurde Das Completorium geläutet, a!s $\mathfrak{B}$ ina yor einer üferlautbten fleinen Siapeffe vorbei ging. Sie ging wie verlegen Iangiam, ftand, und fagte Ruzien etwas ins Dfr.

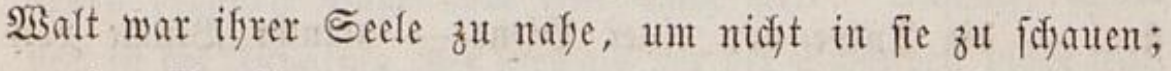
er ging fiflefll voraus, um fie beten zu laflen, und fie freim=

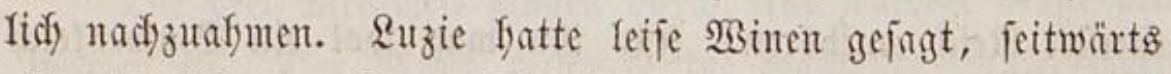
oben bie fojwarze Iaube jei bie blaue. In biejer wollte er Die Beterin erwarten. $\mathfrak{A}(\mathfrak{B}$ er näfer trat, flog aus Der \&aube Jafobine luftig lyeraus, und warf ifym idjerzent einen Sfawl 
Itber Den Ropf unt entfüfrte iffn am 2(rme, unt an jeiner

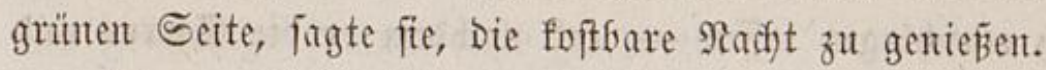

Of er gleidy nicit von weitem afnte, mit weldjer frechen Barodie Der Morpheuts Des 3ufalfs Den Menfdyen oft mit feinem (sejdjicfe parre uno entzweie: fo miderfano Dody Der

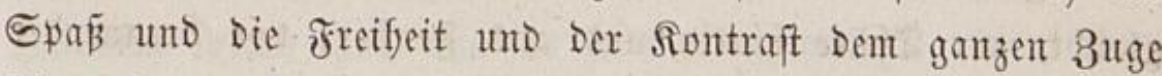
feiner föblern Bewegungent. (Er febzt' iffr eifigft auseinander, woffer und womit er fomme, und faf bedentento nach ber Siapelle, als werb' ex vou dort auts farf erwartet. Infobine

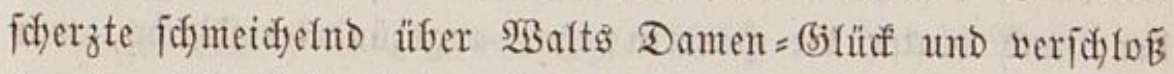
ifm den Mund Durdh Das Ueberfüffen feines 5erzens. SndeÉ er mun äuberlich fodferzent fodft - und inten es auf allent Seiten überidhg, wie er ofne wafre Grobheit Safobineng Arm von feinem fofuttefn fönne: - fo faf er, wie yout

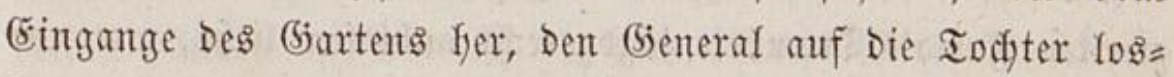
fonmen, fefr frentig ifre $\mathfrak{g a n t}$ in jeinen $\mathfrak{A}$ rm cintuafen, und mit Dem (Engel Der Stente Dawon uno nad) 5auje Laufen.

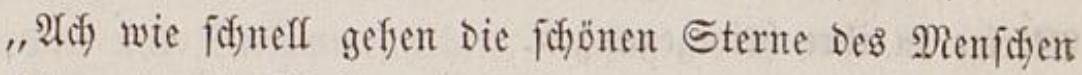
unter!" — Dadjte Walt, uno fafl nady Den Bergen, wo mor= gen eit paar Bilder davon wieder aufgefen founten; und war nicht in Stante, Safobinen zu fragen, of fie Die Reize Der fóbün Radyt empfinte?

Dieje flog falt vor Dem Rotar ins 5aats und verichwanto auf Der Ireppe. (Er fraudste Diejen Afbent nichts weiter als

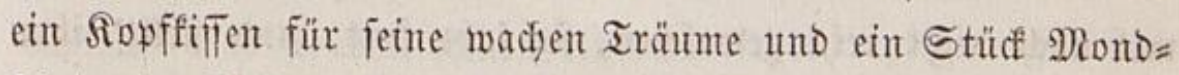
foljein im Bette. Alber in Der Radjmitternadift - jo lange

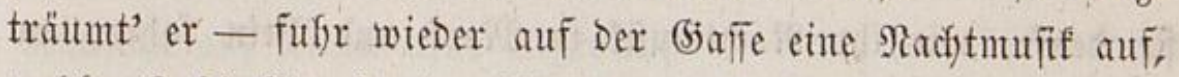
weldye 3ablocfi's Reute abfliejent. Radjoem 23 alt Die (5iafle

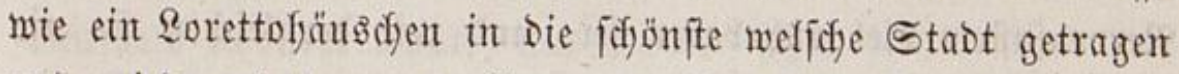
unt niebergefebt - nadfoem or Die fyerrlidfen Blibe Deß 
Ranges, Die ant Den Eaiten wie an Metafloraft herabfulyen, auf fich einfdylagen la fien - und nadjoem er Die Steme und Den Mond nach Der irdifden Spfärenmufiff in Tanz gefeb̧t - uno nadjoem bie \&uft falb aus war: fo flatterte Iafobine, Deren früftern er vorffer faft im Rebenzimmer zu fören ges glaubt, zur Ifyüre fintein und ans Fenfter, vor frentender Ungeduld, Die Töne zu Gören, nidjt aber Den Notar.

2Balt wupte nidft jogleid, wo er war ober bleiben follte. (Er joflid) fid heimlid) uno leife aus Den Rifien in Die Rlei= Der, uno finter Die 5̧orerin; wie angezündeter Fladjs, war

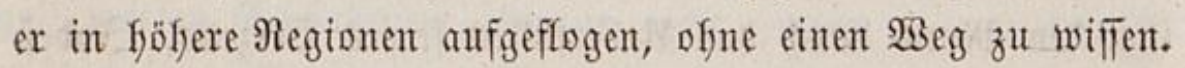
Nidjt Daß er von iffr oder yon fich etwas bejorgte; aber nur

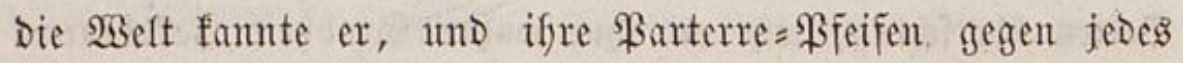
füfue Mäbdhen, ein Unglüd, wogegen er lieber fith yon Der zweiten Fama's= Trompete jagoggeredyt anblajen liếe, um nur Das 2 seib zut retten; - - und er wuíte faum, ob er nidft aus Der Stube fo Iange unvermerft entflüdyten follte, bis bie Aftrize in iffe heimgegangen.

Sie foörte drei Seufzer - fuffr um - er ftand da Fie entichuldigte fich) jefrr (zu feiner \&uft, Da er gefürdftet, er

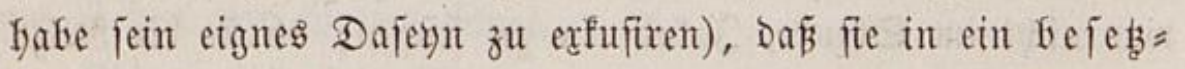
tes Bimmer gefommen, Das ibr, da es ofjne Nadytriegel ges wejen, frei gejdienen. - Er fofwur, niemand flabe wentiger Dawider als er; - aber Safobinens Reinfeit glaubte fich $D \mathfrak{a}=$ mit nody nidft rein gewaidyen, fie fuffr fort, und ftell't ifm unter Dem mufifalifichen (5etöje, fo laut fie fonnte, vor, wie fie Denfe, wie ifr $\Re a d y$ tmuffif in Marf und Bein fafre, an Fait = und freitägen ganz bejonders, weil ba viefleidjt ifyr Rerveniyftem biel ruifrebarer jei, und wie Dergleidfen fie nie unter Dem Bette falle, fondern wie fie Die erfte bejte $2 B a j d)=$ 


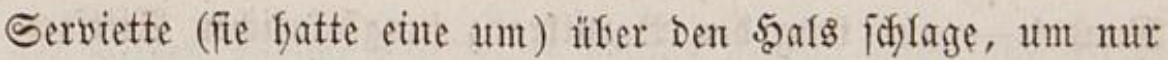
ans Fenfter fut fomment und zut hören.

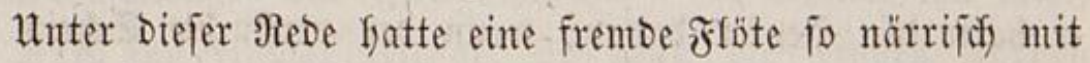

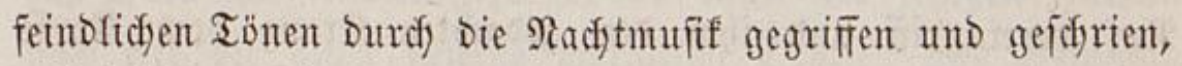
Dá̉ Dieje es für angenefmer fielt, überbaupt aufaubören. Safobine fprach Iaut, of n' es ô merfen, weiter: „man über= fommt Dann (sefüfle, bie niemano gibt, weber greundit nod Freutน! !“

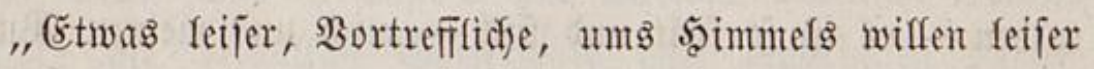
— jagte Balt, als fie Den Yeb̧ten Sals nadj Der Mufif ge= fagt - Der (jenteral fidläft gerabe neben an und wadjt. 230 , wol ift meiftens für ein weifliches 5eerz eine Freundin zut unmännfich und cin รreund zu unmeiblidy." - Sie fprady fo

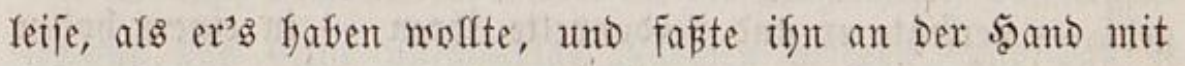
beiden 5änden an, wodurdi bie dife plumpe Serviette, die fie Gisher mit ben fingern wie mit Rabeln zutgef)alten, ausein= ander fiel. (Er erfulfr, was boulfenangít ift: Denn Das leijere Spredfen und Beifammenfeffen, wupt' er, fonnt' ifut ja jede Minute, wenn Die Thüre aufging, bei Der $\mathfrak{B}$ elt in Den Ruf

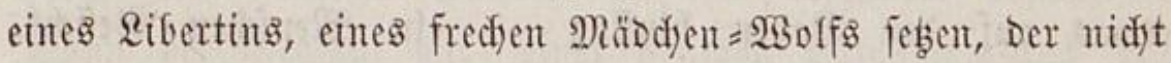

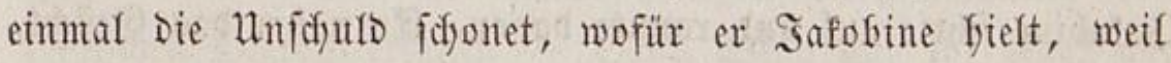
fie fanfte blaue $\mathfrak{A}$ ugen fratte.

"Âtber Sie wagen beim soimmel zu füfn!" jagt' er. "Schwerlidy, fo bald nur Sie nidyt wagen" verfeble fie. Err Deutete, was fie von feinen Anfaffen fagte, irrig auf feinen

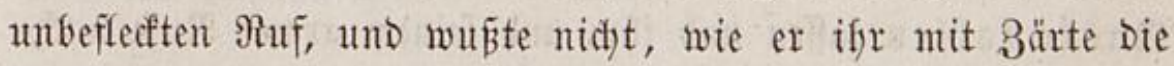

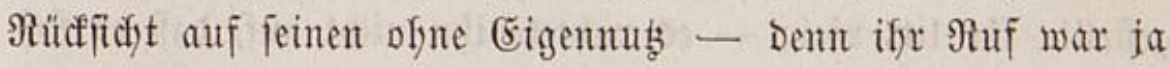
nod) widstiger - in Der größ̈ten (Eife uno Rürze (wegent Des (benerals und ber Tfüre) auseinander feben follte. Hno bod war er bon jo guten effrlidfen (EItern, won fo unfeidoltentem 
Bandel - und trug Den Brautfranz jungfräuficfer Sittjam= feit fo Iange vor Dem Bruber uno jedem mit Efren - er hatte Den senfer Davon, wenn Der verfludite Sdyein und Ruf hereingrifi und ifm Dett gedadten Riranz bom Sopfe

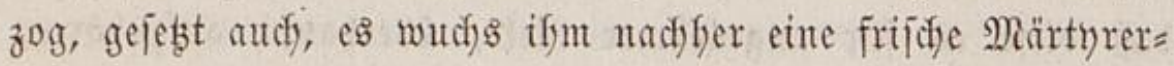
frone nadi).

Sfut wutrde gaulz warm, Das (jeficht roth, Der Blicf irre, Der Intutant wild: "gute Safobine, fagt' er bittent, Sie er= ratfen - es ift fo fpat uno fitf - mid) uno meinen $\mathfrak{B u n}$ id gemi⿷匚." -

"Nein, jagte fie, falten Sie midy für feine Eulalia, 5. v. Meinat. Sdhaten Sic liefer bie reine feufhe suna an!" - jagte fie, und verdowpelte feinen Irrtfum. - „Sie gefft - verjebte er uno verboppelte iffen - in cinem foffen Blau, Das fein (Erben=2Burf Durdfreidft. So will idf wenig= ftens meine Thür zutriegeln, Damit wir ficher finto."

"Nein, nein," fagte fie leife, liefi ifnn aber mit einem 5amodruct los, unt ifre Gerviette zuredjte zu faltert. (ro

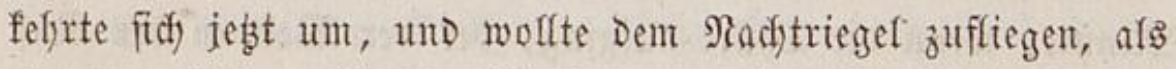
etwas auf Den Boden binflog - efn Menfditen = (jeficht. Safobine fafrie auf und ranute Davon. (Er nafm Das (sieficht, es war Die Marfe Des Larventerm, Den er für Den böfent (5entus geffalten.

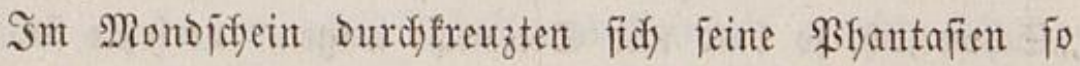
feffr, Dá̧ es ifm am Ende vorfam, Safobine fabe felber bie Masfe falfen faffen und ifm und feinem armen $\Re u f e$ nadid= gefeflft. (Er litt viel; - es ridftete iffn nicht auf, Dafi er fich Der beften Befauptungen feines Brubers erimnerte, Daß $\mathfrak{z}$. $\mathfrak{B}$. foldye Beflecfungen Des Rufs heut zu Tage, gleid) Den Flecfent won wofjlriedjenten $\mathfrak{B a f j e r n}$ aus Den Sdyupftüdfern und 


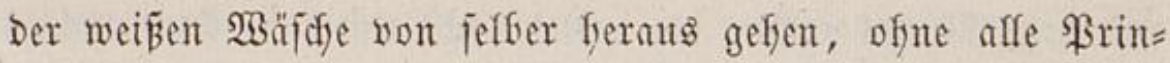
zeñen=2Baid wa

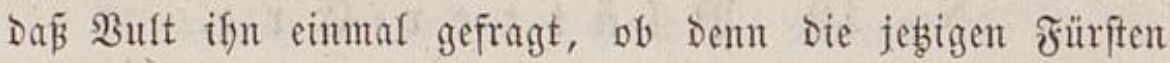
nodi wie die alten gewijie moralifiche Devifen uno Symbola fätten, Dergleichen gewejen "praesis ut prosis" und andere fpielenbe, und Daß Der glötenift felfer geantwortet, Dergleidfen frabe jebst nidift einmal ein tiefer Stant, und es fönne über=

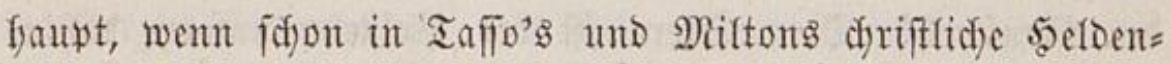

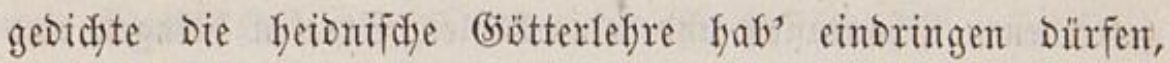
auch in unjerem (5friftentfum fo vicl (bötterlefre (wenigftens

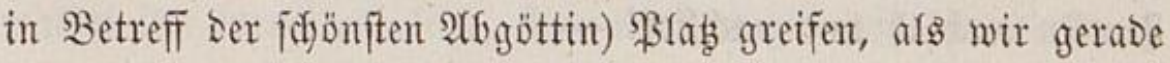
bedürfen und begefren.

Darauf Dadjte $\mathfrak{W a l t}$ wieder an Die $\mathfrak{N o ̈ g}$ glichfeit, Daj itgend

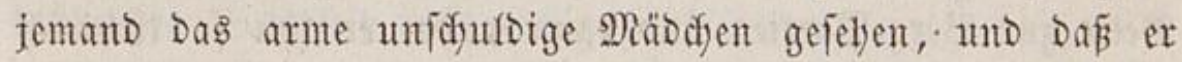

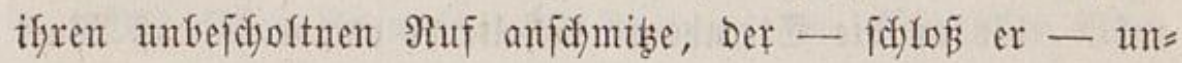
befadreibfich rein uno feft fern muste, da fie fo viel gegent die SBeiblichfeit fid Gerautshefmen burfte - Dann fiel ifm bie

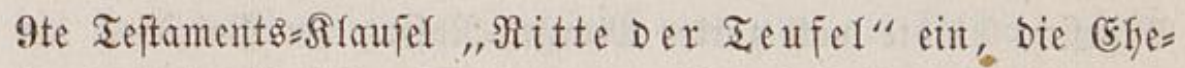
brudi und älnulidje Sünden an ifm bejonders beftraft Dann Der Beneral mit jeiner keifigen Brieffammlung von

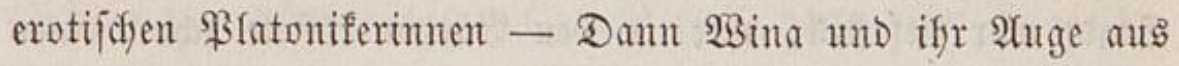
Dem Şimmel - - Der Notar Frad)t' eine Der Dümmftent und elendeften Rädste zu, Die je ein Nenfid Durdhgelegen, Der unter Dem Rücfgrat feine (Eiderdunen gelfabt, weldje freilidy nod) ftärfer einfeizen. 
No. 49. $\mathfrak{B} \mathfrak{i}$ ä $t \mathfrak{t} \mathfrak{e}=\mathfrak{F} \mathfrak{x}$

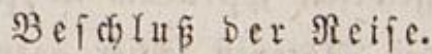

Seiliger Morgen! Dein Thau beilet Die Bhlumen und Den Menfonen! Dein Stern ift Der Bolften unjerer Dafin= getriebenten \$Gantaften unb peine füblen Stralen bringen und füfyrent Das verwirrte erfibste $\mathfrak{A}$ uge zurecht, Das feinen eignen Junfen nadjafy uno nadjfief! -

U(B nod) viele Sterne in bie Dämmerung idfienen, rief Der (Senteral Den Notarius mit Der frofeften Stimme auts Dent Bette zur Berg=\$artie; und Dam nafm er iffn fo liebreidf auf - bis an bie Stimbaare läd)elte er empor - Daß̄ $2 \mathfrak{B a l t}$ feffr berufigt war uto befeligt; Der (seneral, Dadft' er, mürde ganz anders mit mir reden, wenn er etwas wüB́te. WSinta's

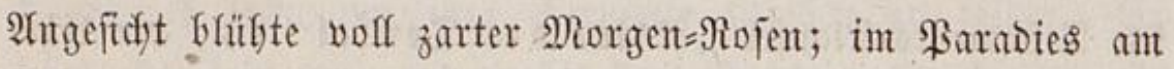
Siföpfung $g=$ Morgen blüften feine volfern.

Sie gingen zu శ̋̄e Dem zeripaltenen Bsebirge zut. Die Stadt war tief ftill, mur in ben (5ärten rüftete fodjon einer und Der andere Beete uno Rojentyecfent fïr Den Früffing zu, und Die Raudfö̈ulen bes Morgentrods frogen fidy über bie Dächer. Drauken flatterte fifon Lefen auf, Die Singoroffel wurbe in Dent nafent Tamten wad̆, unten an Der Făfre flang

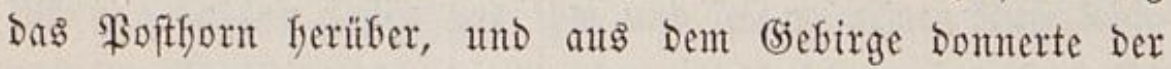
ewige $\mathfrak{W a f f e r f a f f}$ heraus. Die brei Menfjuen ipradjen, wie man am Norgen pflegt, gleid) Der grauten Natur um fie her, nur einzelne Raute. Sie fafyent gen Difen, woran Das (5es= wölfe ful einem rothen Borgebirge bes $\mathfrak{I} a g e s$ anfing auffu= 
blüfen, uno es wefte fofjon leije, als atfme ber Morgen vor Der Eomue fer.

Bina ging an Der einen 5 and Des Baters, Der in Der ambern einen fogenamten fodmarzen Spieger hatte, um Daraus Die Natur zum zweitenmale als ein \&uftidjlofi, als cinen $\mathfrak{A}(\mathrm{b}=$

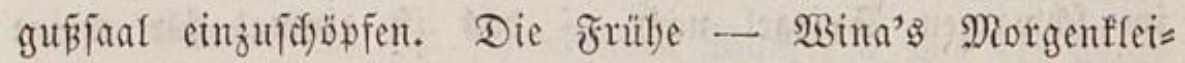
Dung - Das Iräumerifiche, Das Der Morgenftern nuftöfend im serzent fo unterfält, afs feffe er am 2tbenthorizonte und Walts Sewegungen von Der Nadjt her, fo wie feine Syinfidyten auf Die nahe Scheide = Sefunde: Das zufammen madyte ifn fpradjlos, reife, fintueno, bewegt, wolf wunderfarer Riebe gegen Das näfere Sungfrautenferz, weldye fo weidy uno vielfnospig war, baß er fidch auf unterwegg freute, um in ber Glïfenden Sefigfeit redyt rufjig zu ban̈ttern.

Mit jüßer Stimme afer that an ify 2 Bina die Bitte un Berzeifung Des geftrigen 2 Useinanderfommens. $\mathfrak{D a}$ er bie Bitte nidjt zunitfgeben fonnte: jo fofwieg er. Darauf

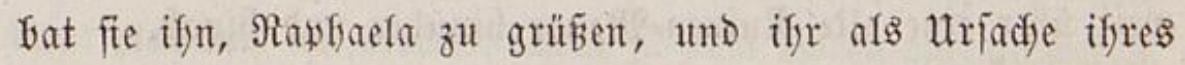

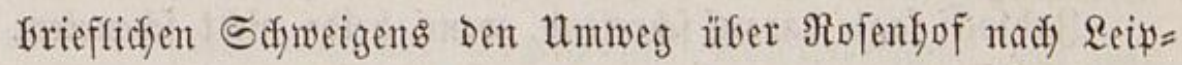

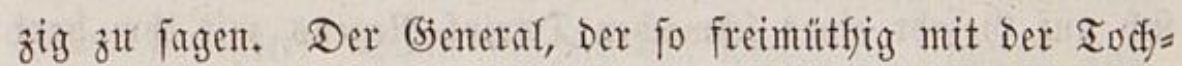
ter yor Dem Notarius fwrad, als laufe Diejer als eir tauber Edfattenman oder als ein fummer verfofwiegner 2 ffe mit, madfte Winen gerabez̧u Borwürfe über ifre vieljeitigen Sor= gen und Safreibereien und liber bie ewigen Dyfer ifres Shas. Sie verifeste blos: "wollte Gott, fie verbiente Den Iabel!"

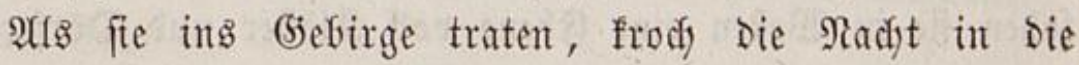
Sdyludften zurüf, und unter bie Thal= Nebel unter, unto Der Tag ftanto mit Der G5lanz= Stime fofon in Den bäfen Des

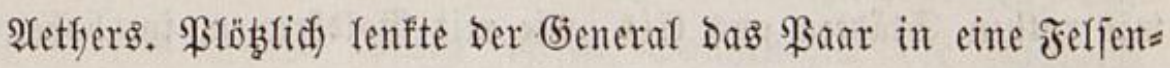
Sparte finein, worin fie hod oben bas eine hödfite Berghorn 
fdyon vom Morgen=\$Hrpur ummidfelt fahen, Das andere tiefere vom Radytidjleier ummunden, zwifoch beiDen forimmerte Der Morgemfern - Die Sungfrau uno Der Süngling riefen mit einander: o (5ott!

"Nidyt wafre? fagte Der (5ieneral und fafy Den soimmel int fdwarzen Exiegel nadi - Das ift eimmal für meine Sdywärmerin?" - 2 angjam und ein werig nifte fie mit Dem Rovfe, und mefrumals mit Dem 2 ugenliebe, weil fie vom geftirnten şimmel nicht wegiefen wollte; füfrte aber bie vä= terliche $\mathfrak{S}_{\mathrm{and}}$ an Den betenden Muno, um ifm ftiffer zu Dan= fent. Darauf zanft' er ein wenig, Dak fie fo ftarf empfinde, anto die Befüfle fo gern aufnefme, Die er ifr zuleite.

Sdfnell füfrte er Beide Durdid cinen fünftlidfen $2 B e g$ yor

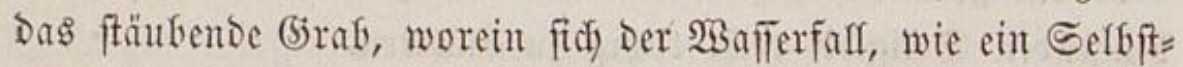
mörder, ftürzte, uno woraus er als ein langer verflärter Strom auferftand und in bie Länder griff. Der Strom ftürzte - obne då̃ man fefen fonnte, aus weldjer şöhe weit über cine alte Ruinen=Mauer finüber und finab.

Bablocti fagte Darauf forreient, wenn beise nidyt fideuten, fidf) auf (jefabr eines fdrwadyen Dampf= Regens mit ifm fyart an Der Maucr fin, und Durdi Deren niedrige von Iauter grünen 8weigen zugewebte Pforte Durdid zul Drängen: fo fönnten fie auds etwas von ber ebenen Lanofichaft fefen.

(5x) ging voraus, mit langem $\mathfrak{A}$ rme fid $\mathfrak{B}$ inten nadid $=$

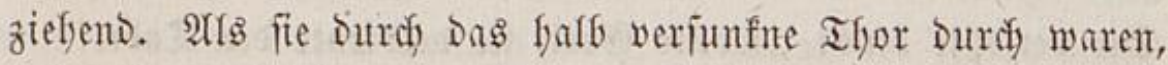

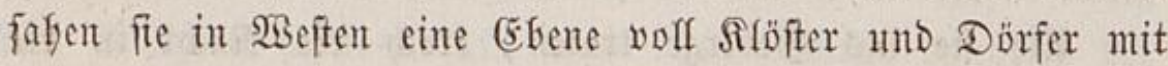
einem Dunfefn Strom in feinem Thal, und in Difen Die (5) $=$ birge, bie wieber auf befirgen wofnten und, wie bie 3yfele, mit rothen Etäoten aus (ङis, wie mit Goldronen, im fohen Simmel ftanden. Die Meniffen ermarteten Das Durdfbrennen 


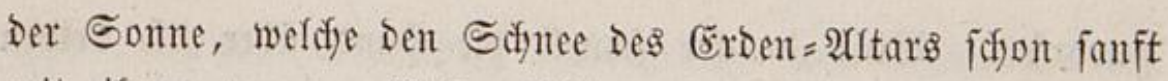
mit iffen warmen Rojen füllte. Der Domer Des $\mathfrak{B a}$ aters

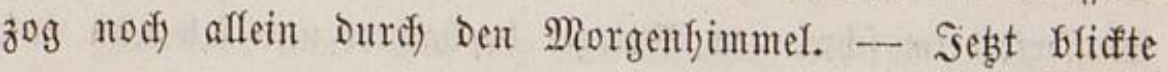
(5ottwalt von Diten weg und in bie babfe, Dem ein felt= famer (5oldichein überflog das nafTe (5rün - Da fah er über feinem 5aupte Dent feft iffwebentent $23 a$ fierfall yor Der Mor= genfonme brennen als eine fliegende flanmentrücfe, über weldye Der Eomentagen mit feinen $\Re$ offen entzüntent rollte. - Er warf fidf auf bie Sinie, und Den şut ab, und bie

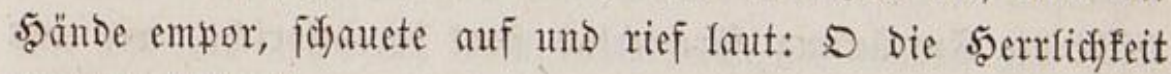
(jopttes, SBina!

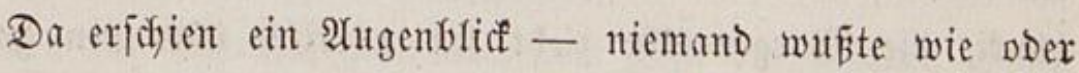
wenn - wo Der Singling auf bie Sungfrau blicfte unb faf, Dá fie ifn wumberbar, neu und fefre bewegt anfdoute. Seine

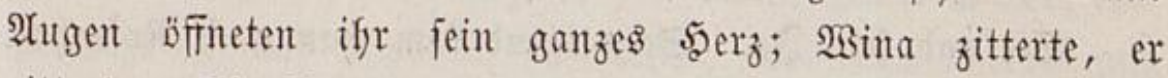
zitterte. Sie fidsuete auf zum Rojen = imb Feuerregen, Der

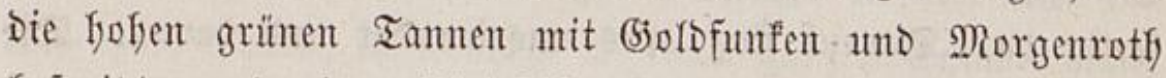

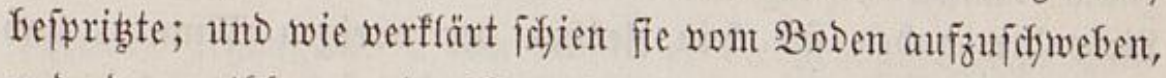
uno Der rotffrennende Regenfogen Ieudiftete fojön auf ifyre (beftalt fyerunter. Dam fafy fie ifyn wieber an, fodnell ging iffr $\mathfrak{A}$ uge unter, uno idnell auf, wie eine Somme am $\mathfrak{B}_{0}$ Das herzerhebende Domern und Das $\mathfrak{B}$ etterlendjten Des Stroms

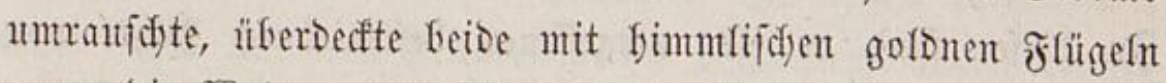

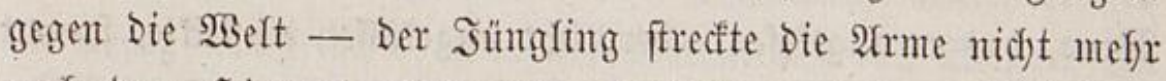
nady Dem ssimmel affein aus, fonbern nadj Dem Gdjünten, was bie (Erbe bat - -

(Ex bergan beinafe alles, und war nathe baran, in (5ies genwart Des Baters bie 5and Des $\mathfrak{B}$ ejens zu ergreifen, Das

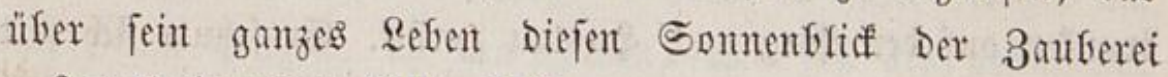

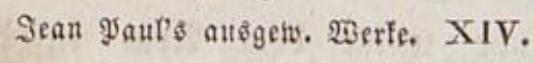


geworfen. WBina brücte fonelf - bie 5and über bie beiben Augen, um fie fu verbecfen. Der Bater hatte bisher Den פBajlerfall im fidwarzen Epiegel beobaditet uno fah mun auf.

atfes wurbe geentigt. Sie feffrten zutrïf. Der Beneral

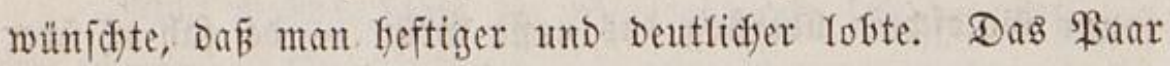
foumt' es nidft. "Selgt, fagt' er, nad) foldfer Freude fefrnet

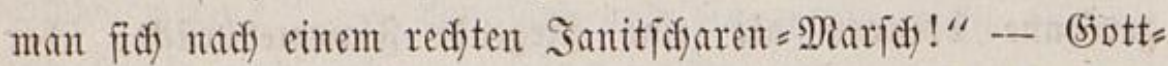
walt ermiederte: ,D wofl, nämlidif nadh foldhen Steflen bars aus, Die viano uno ats Molf zugleid) gehen, woburd viel= leidyt bie Entzulufung fürdyterlid) ftarf hereinfpridgt, wie aus einem (5eifterreid)." - „Ë regnet foute nod), veriebte $3 a=$ Glocfi, bie Morgenröthe zieft fich närrifol über Den ganzen Sorizont, fo ganz bejontoers; aber Der fiföne Norgen war Dod) wentigfens Des Sefyens werth, MBina?"

Sie galb fein Ia. Sdjweigend fram mant nady Rojentyof. 3abloct's Wagen, Fferde unt Bebienten ftamben foron reife= fertig Da. Darauf flog alles auseinander uno Davout. Die Riebenden gaben fich fein 3eidyen Der vorigen Minute, und Der $\mathfrak{B a g e n}$ roflte Davon, wie cine Ingend und eine hei= lige Stunde.

Walt ging im (5ranatapfel nod) einige nadyblitgende Mi= muten in jeiner Stube auf und ab, Dam in bie bes Gjencrals. Sn biejer fanto er ein vergeffenes bejactiebnes Blatt yon WBina, Das er ungelejen, aber nidjt ungefuiliet, einftecfte, fammt

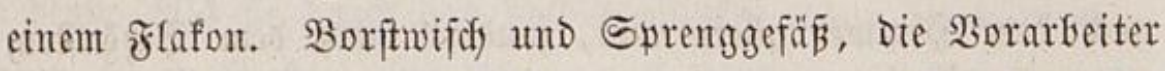

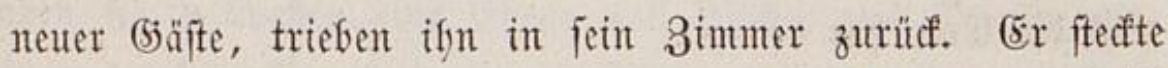
Die fonderbare Rabfe zu fich. Darauf madyte er - gleidf unvermögent, länger zu bleiben unt länger zu reijen - fid

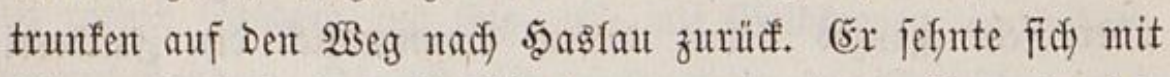
feinem folioband volf âbentener unter Dem $\mathfrak{A}$ rm in bie 
Stube Bults. Sein Saerz hatte genug, uno braudfte feinen 5immel weiter als ben blauen.

Safobine warf ifm you Der Ireppe, bie fie finauf ging

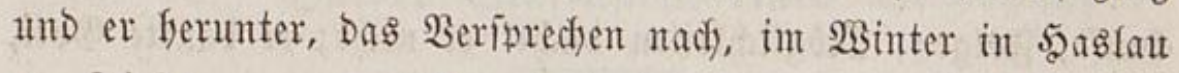

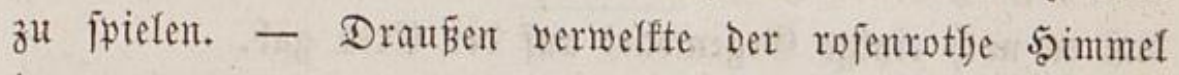
immer grauer und bis zu Regenmolfent. Án Der fäfje muşt’ er lange warten. (ङ̌s fing endlich) an zut regnent. Adber ba Der Borfantg vor Dem Singipiele der Riebe aufgegangen war:

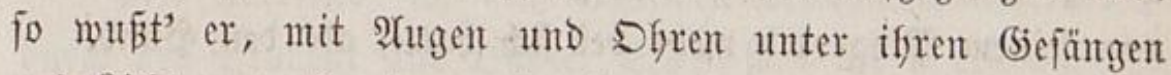
und Sidjtern wofnent, wenig oder nidyt, ob es auf Das Dady Des Spernfaules regne ober fifnete.

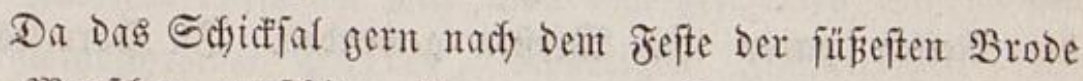
Dem Menjofen veridjimmeltes, wurmvolfes aus Dem Brob=

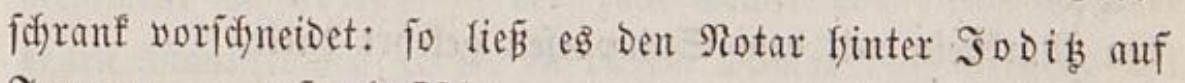

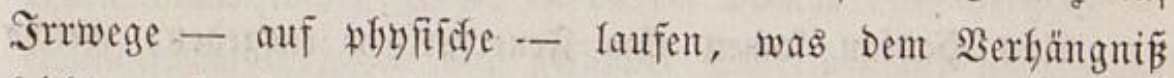
leidyt murde, Da er offnefin nidfts Dertlides befielt, nidyt Dent $\Re i \overline{\text { cines }}$ ßarf́s, in weldyem er einen ganzen Sommer lang

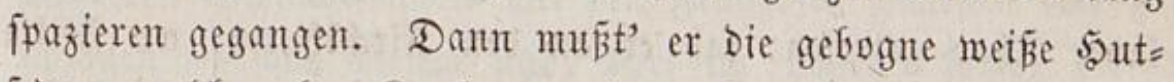
feber, weldye ofne Sopf yon einem Rawalleriften aus einem

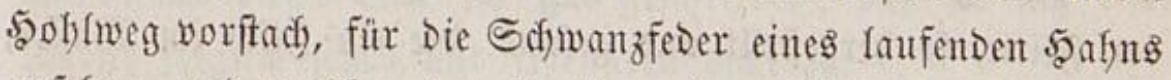
anjefen, und nadffer ben Irthum Dem Militair gutmeinend

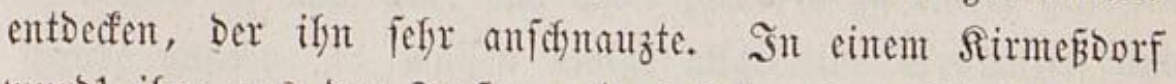
wurb' ifm aus Den Fenfern cines betrunfuen 23 irthsfaujes

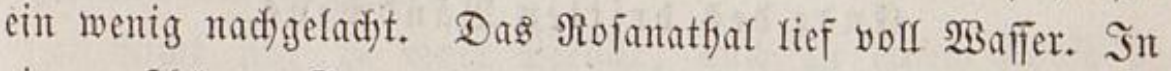
einem fóbunt (sartenfaus fpielte Der Regenwinto auf Der Windfarfe einen miß̈tönigen Räufer und Rabenzen volf Sdyrei= töne, da er vorüberlief.

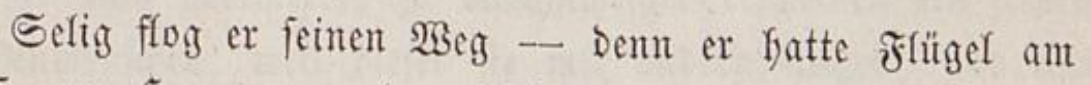

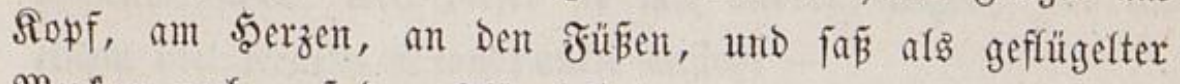
Rerfur nody auf Dem glügelpferd - uno ofne es faum zu 
merfen, fam er Durify Die vorigen Dörfer. (5) Ieid Dem Blige fief fein (5eift mur an Den Bergoldungen Des $23 e l t=$ (3ebäubes

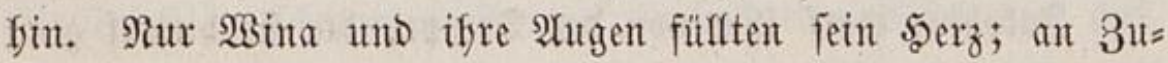
funft, Folgen, Meöglidffeiten Dadjt' er nidft; er Danfte (5ott,

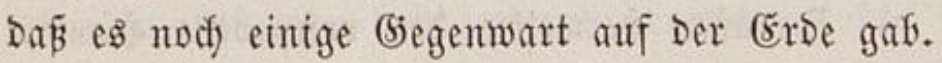

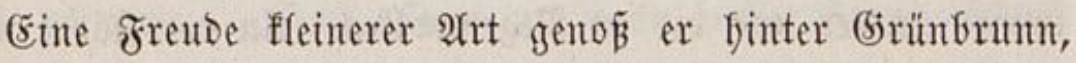
wo ifm Der Böheimifiche Sdyweintreiber, Defien Rlagen er in

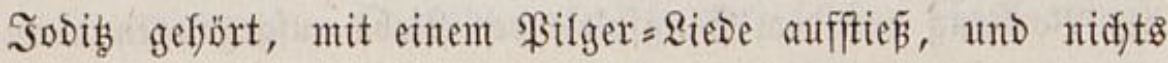

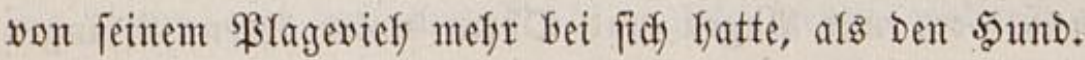

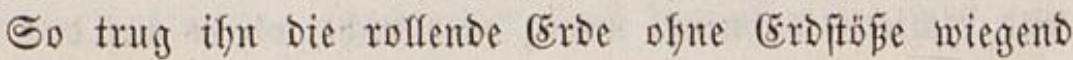

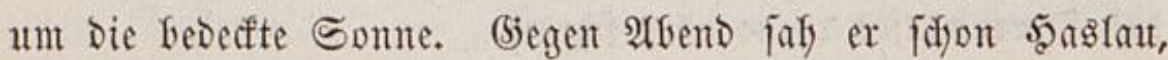
Die Meilen waren ifm $\mathfrak{B}$ erften geworden. Sn \$ärmlesberg regegnete er noch einer alten Diebin, bie man Daraus bis an Den Marfftein mit Dem Staupbejen gefefyrt batte.

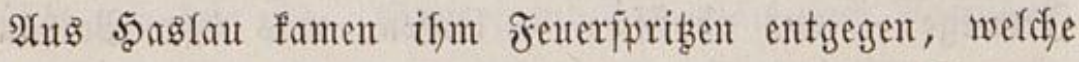

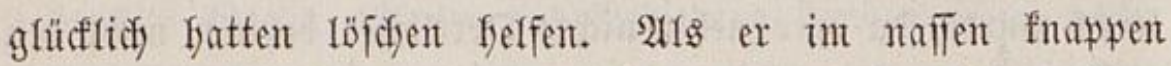

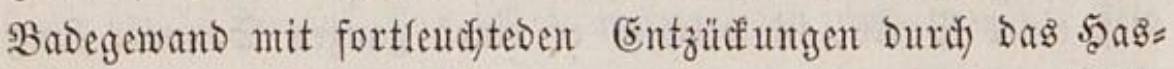
Iauter Ifyor getreten: fafy er an Den Sirdfthurm, wo fritte

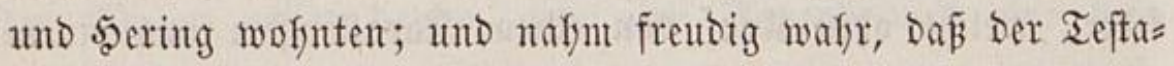

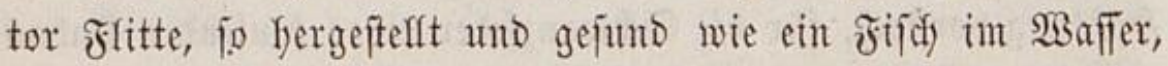
aus Dem Sifjaflodi) guctete.

(5nDe Des oritten $B a ̈ n D$ d)ens. 
No. 50. 5̧alber Blafenftein eines Dadbshunds.

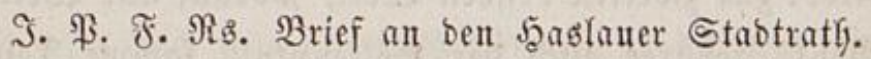

P. P.

Sier überjend' idj) Ien trefflidyen Teftaments = Erefutoren Durdf Den Stubent und Didfter Sefufter Die 3 erften Bände unjerer Flegeljafye fammt Diejem Briefe, Der eine $\mathfrak{A r t} \mathfrak{B}$ or: und Radyrede vorftellen folf. Ron Dem gefdidten Sdjöt = und (Sichwindofyreiber \$̧alter, bisferigen Snfanteriften beim Regiment (5furprinz - Der zum (Stü̈fe Des elend gejd)rie= benen Manuffipts gerade in Diejem Monat aus Bregenz mit freundidjem âfidied und gejunder Sdyreibs5and nady Saaje

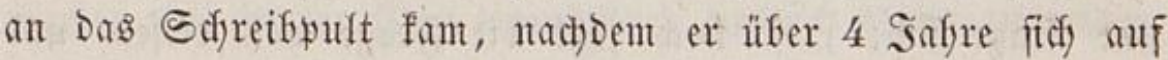
mefreren Sdyladffeldern mit Den Jranzojen geme fd)lagen - von Diefem find, Darf id, foffen, fomol die 3 Bände als Diejer Brief jo gut gejdyrieben, Dañ fie fids lejent Iaffen; folglidy jeşen und rezenfiren ofnefin.

Will ich midy über Das $2 B e r f$ fier bis zu einem geniffen (5irade äupern: fo müffen einige aflgemeinte Sentenzen und (5nomen vorauggefoen:

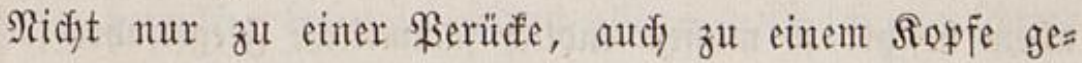
fören mefrere Röpfe -

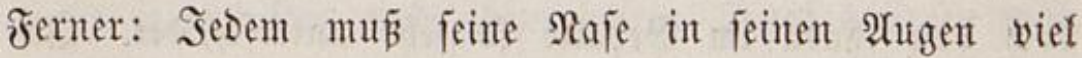
gröper und verflärter, ja Durdyfidjtiger erjojeinen als feinem Refenmenjichen, weil Dicjer fie mit andern $\mathfrak{A}$ ugen, und aus einem viel fernern Stanopunfte anfiteht - 
WBeiter: Die meiften jebigen Biograpfen (worunter aud Die Romanciers gefören) Gafen Den Spinnen wol Das Spin= nen, aber nidyt Das $\mathfrak{B}_{\mathrm{C}} \mathrm{ben}$ abgejefen -

Fenter: Die Serbaung fpüren, Geiß̈et eben feine fpüren, fondern viefmefyr Unverdaulidyfeiten -

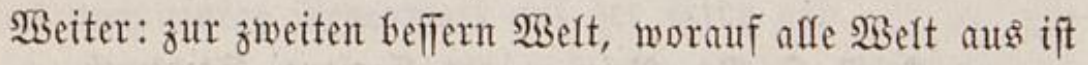
und auffieft, gefföret aud Der şöllentpfuffl fanmt Teufeln -

ferner: Der Sdyatte und Die Radjt fehen weit mefyr als

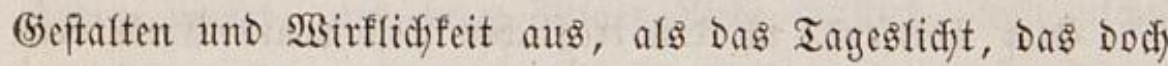
nutr allein eriffiret, und jene fodjeinen räfịet -

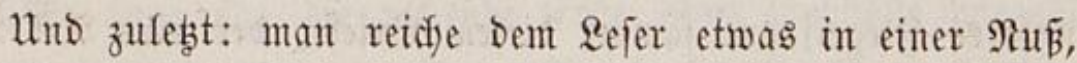
fo verlangt er's nod) enger als Nuḱ=Der; man bred)e für iffn aus ber fteinigen Schale eine föftlidye Nantel, fo wifl er um Diefe wieder eine 5aülfe von 3udfer faben -

Blos Diefe wenigen idfwadjen Säbze wende ein verefjr:

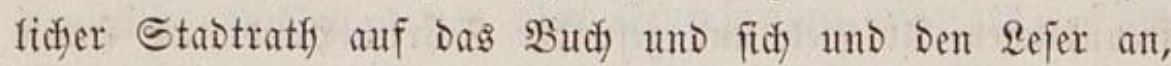
und frage fict) "ift nod jebt Die Frage von Diefem unt jenem?"

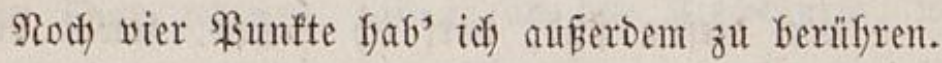

Der erfte Punft ift nicht Der erfreulidjte. Siod hab' idy nidjt meffr als 50 Rummern vom Rafelidjen Raturafien= fabinet (Denn Diejer Brief ift für Den fralfen Dadfshunds: Blafenftein) erfacrieben, mo fafre fhon mit Drei Bänden vor, Die afzuladent find; Da mut Das Rabinet 7203 Rummern in

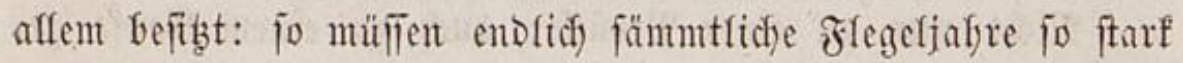
atsfallen, als bie allgemeine Deutfdye Bibliothef, weldhe fid

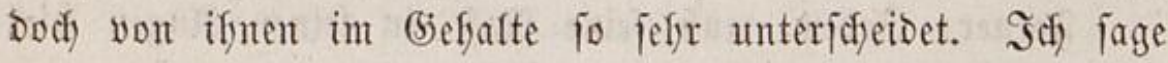
Yekgteres nidyt aus Bejodeidentheit, fondern weil idj's felber

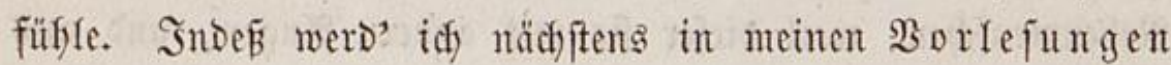
über bie funft, gefralten in Der Leipziger Dfter= 
meffe 1804*), erweifen, erftlidf) Da zweitens warum Der (špifer (in weflen (bebiet biejes 2 Berf Dod) zut rubriziren ift) unendich fang werbe uno nur mit Demt

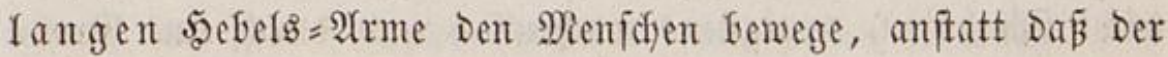
\&yrifus mit Dem furzen gewaltig arbeitet. (Fin epifoder Iag hat, wie Der Reidfstag, faum einen Afbend, geidjweige einen (5araus; und wie lang Giöthe's Dorotfea, Die nur einen Tag

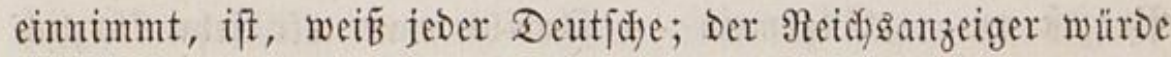

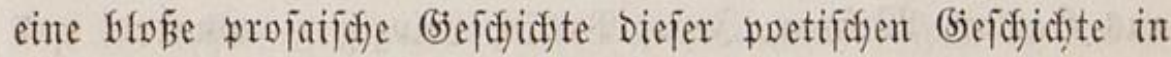

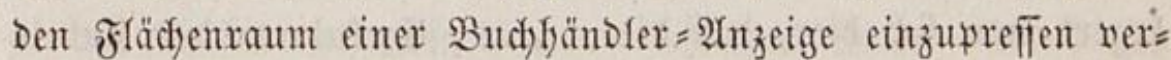
mögert.

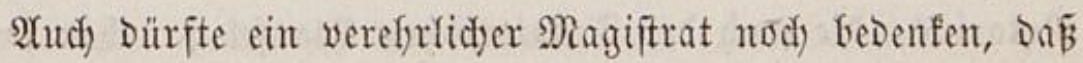
Die Ylutoren gleidf gepanuten Saiten - welche oben uno unten, Yhrangs und Endes fefre hod flingen, und nur in Der Mitte oroentlidf - efen fo in Eingange und nadffer int

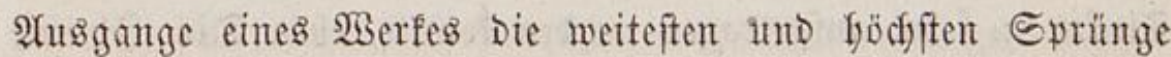
madjen (bie immer \$labs eimnefymen), um fidh theils zu zeigen, theils zu empfeblen, in Der Mitte aber furz uno gut zut Berfe gefen. Sogar Diefen Dreibano lyab' idy mit Briefen an Teftaments = (5xelutoren begonnen und beic) loten, um nur zu fdinmern. Sd boffe von Den mittlem Bänoen Der Flegel=

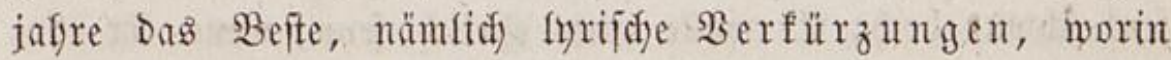

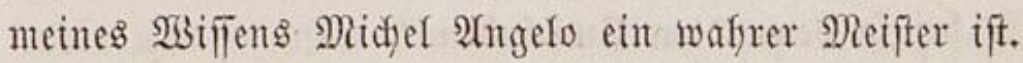

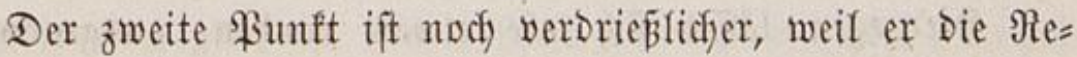

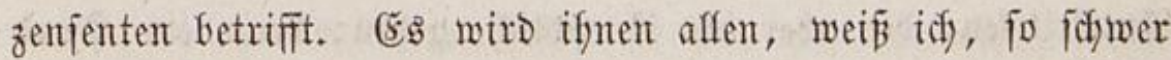
werben, fich alfes feinen und groben, fidon aus bem Titel Flegeljafre geidgöpten uno afgeralmuten, Spapes gegen midy zu erwefren, als es mir wirflich felber, fogar it einem offit=

*) Sn Der Midyaclis = Meîe 1804. 
żelfen Sifreiben an verefrridge (Exefutoren, fauter anfommt, foldyen Berjonen mit feinen verffecten Retorifonen uno 2 (ntis zipazionent Des Titels entgegen zul gefyen. Dod) Das ließé viel=

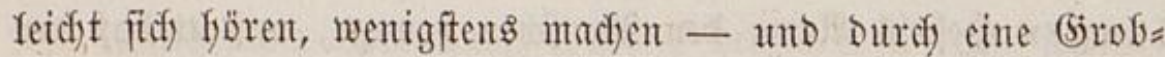

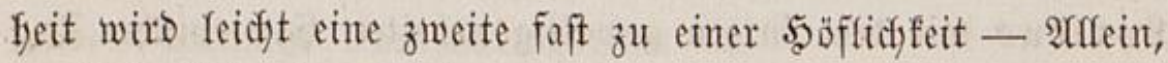
yerefrte Bäter Der Stadt, wie Der Borftidite, man pact Sic an, mant fängt mit Der Errefuzion bei Den Erefutoren Den

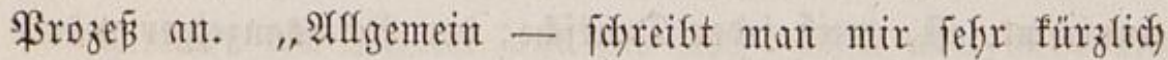

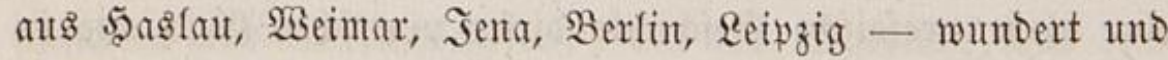
ărgert man fich) fier, Daß Die ...... (Exefutoren Dez Siabel= foren Teftaments gerabe Dir (Ifnen) Die Biograpfie Des Notarits, Die nady Der Ieftatorifden Rlaujel ja eben jo gut Ricfardion, Beflerten, Wielanden, Scarron, Sermejen, Nar= montelı, (jötfyen, Lafontainen, Spieß̄en, Boltairen, Rlingern, Mifolain, Mds. "Stral uno Mereau, Edjiflern, Dyfent,

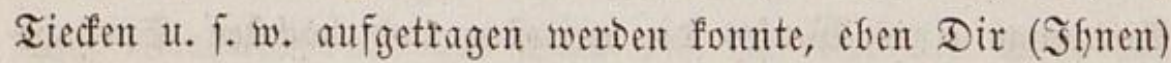
zugewand und Das Yjerrliche Naturalienfabintet Dazul, Das viele

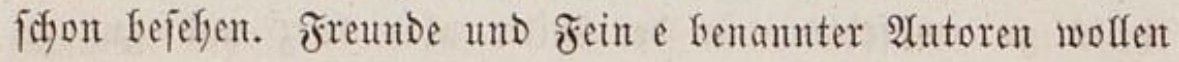
- Didf (Sie) Dhnefjin - Den 5nglauer Magiftrat in Sour= nalen verdammt herunter jebgen uno heimfdicfen. Dod bitte idf) Did) (Sie), midi nid)t zut nennen. (sin fünftiger Rezen= jent fidmutr lyody: (Er wolle nidft effrlid) feyn, went (Er effr= Iich) Gleibe bei fo bewanten umitänon."

soiergegen läfl̄et fïd) nie etwas machen, ausgenomment Antifritifen, bie aber ins unendidfe gefen; Denu ein bauto billt Das (Ed)o an; es tritt Der alte $3 y$ ffus von Süfen uno Sraben, uno won Sraben und Sücfen ein. Dả find aber böfe 5iftorien; uno Der 2 futor leibet Dabei unjäglid); er frat

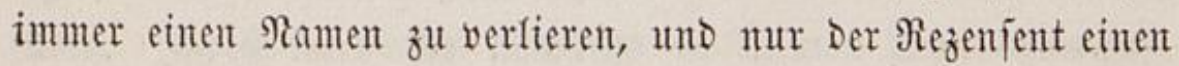




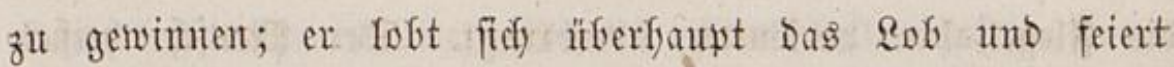
fo ungern nad) feinem Ramenstag nod einen (Éfelnamens= Tag. (Es ift iffut terribel und fo unangentefm als irgend

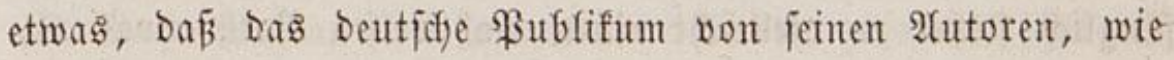

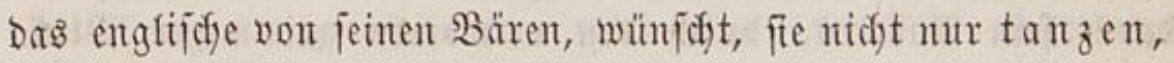

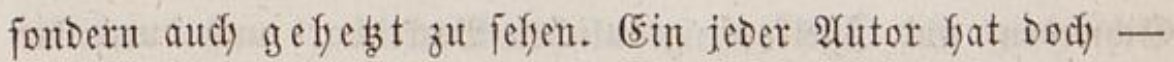
ober foll's faben - fo viel Stolz als irgeno ein $\mathfrak{B e f} a$, oder Iezet, oder $\mathfrak{F} \mathfrak{B}$, oder cin anderer Rapital $=$ Retter von flop $=$

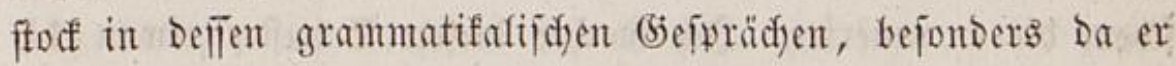
ja ber Ghef biejer aufgeblajenen XXIger Hnion ober biefer grand Bande des 24 Violons ou les vingt-quatre ifit, Die er in Ssfieder fteflt auf Dem ßapier, wie er nur wiff.

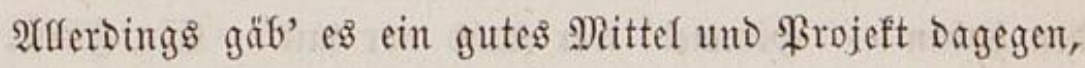
fodjedfer Stadtratfy, went es angenommen würbe. Soundert= mal fabs idf gedadft: fömute nidft eine Rompagnie waderer Autoren yon einerlei Grrundjäben uno Qorbeerfränzen zujam= men treten und fo viel aufbringen, Daj fie fid iffren eignen Rezenfenten bielten, ifn futoiren liepent uno falarirten, aber unter Der Bedingung, Daß $\bar{\beta}$ Der Fierl nur allein feine Brod= ferren offentlich in- Den gangharen Beitungen ftreng, aber un= parteiija) uno nach ben wenigen äfthetijacen (srundjäben bes urtheilte, bie ein foldyer framulant und Valet de Fantaisie

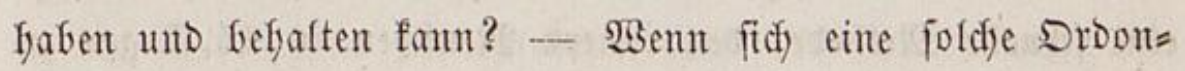
nanz, fo zll fagen, in feiner (5hefs Manier einjojölfe, nidyts weiter triebe und minste: follte fie fidf nidyt niederjebent und finfodreiben fömuen: "Da und da, fo und fo ift die Sadhe; und wer's läugnet, ift jo gewín ein Bief), als ein $\mathfrak{A}$ ffe."

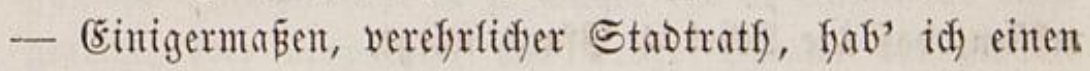
Anjalag; uno er Getrifft eben Den jungen Mann, Der Shnen 


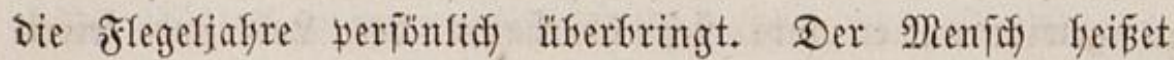
eigentfidy $S_{\text {d) }} u$ fter, hat aber Den Dumpfen $\Re a m e n$ Durdi) (sin Stridfeldyen mefy in Den fyellem Şefufter umgeprägt. Aln= fänglidi) ftößet er viefleidyt einen wohlweijen Rath etwas ab,

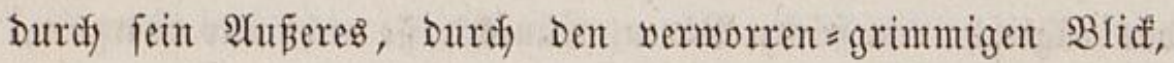
Sdywedent und Igelfopf, gräulidyen Bacfenbart uno Durdi bie Aefrnfidffeiten, Dic er mit fo genannten (5robianen gemein frat. Sgeimfid) aber ift er böflich, uno er frat überfaupt feine Men= fdyen, Die er venterirt. Id modjte biefen Gefufter etwan 14 Inge, nachbem er fein (5ymnafum als ein idjeuer, fiffler, Ieifer Menjá werfafien, Der eben feinen bejondern $3 y$ flopen und (Enaf veriprad), 14 Tage Darauf in Sena wieber gefun= Den babent - \$simmel! wer ftand yor mir? (sin รürit, cin (jigant, ein Flegel, aber ein edler, ein Attą, Der Den şimmel

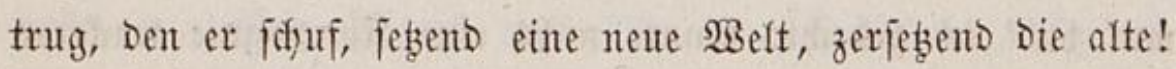
Utnd Dod) batt' er faum ful fören angefangen, und muiste eigentfidy nidyts (Erffeblidfes; er war nod) ein ausgeftrecft=lie= gender 5afn, über Defien Sopf und Sdynabel Sdyelling jeine (5)eidjer=8inie mit Sreide gezogen, und Der untvertüft, ia ver= rüctet, Darauf finftarrt und nidyt auf fann; aber eben er war

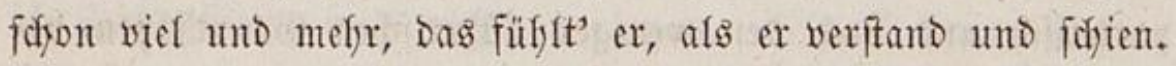

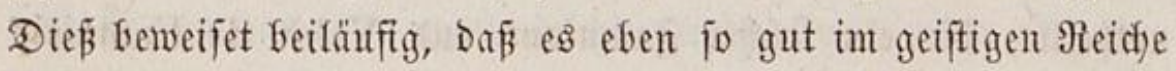
eine fonnefle Methooe, Den intern Menjoden in 14 Iagen zu

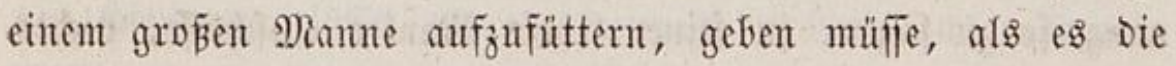
äfntidye im föwerfichen gift, eine (5ans. fdy webend geffan= gen, die $\mathfrak{A}$ gen verbunden, die Dhren verfopfit, Durdh Räfren in nicht längerer 3 eit fo weit zu fringen und zu mäftent, Dá̉ Die Reber 4 ßfund wiegt.

In Der That Geftimmte mich Diefes, Da Der gute (5igant 


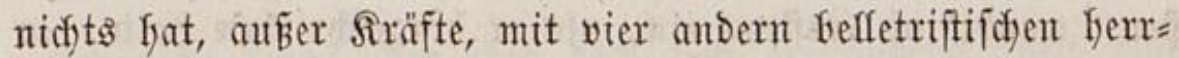
fidfen Berfaffern - (id) werbe ifnen nie bie Sdyufriement auflöjen - gefest, fie verfangten's) aus ber Sadje zu fpredfen und fie zu fragen, of wir ung nidht fömnten zufammenfólagen, umb ify auf Den nötfigiten $\mathfrak{A} f a d e m i e n$ für unjer (beld $a b=$ folviren lafien: "wir fobeln Gefuftern, jagt' idf, ganz nad' unjern $\mathfrak{B}$ erfen zu, oder vielmefyr er hat jeine Deduzirenden Theo= rien nady Dem Meiffer = und andern Stülfen feiner Softtherren einzuridaten, um einftens im Stande zu feyn, als unjer Firftern = Trabant, Brautfüfrer und Chevalier d'honneur umperer 5 Mujen, furz als unjer Nezenfir: Marför in Den ver=

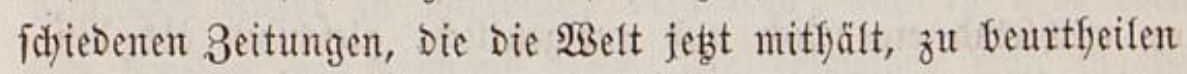
unD zu fod äben."

Das nafym man an. Hno wir Fünfer fyatten wafrefraftig feine Urfacje, umjere $\mathfrak{A}$ usgaben zu bereuen, als wir fpäter, im erffent Semefter fyörten, Daß̉ er Die ßolaritäten und Die Sn= Differenz leiden fönne, Daß̃ er cin trangzendenter Áequifibrift

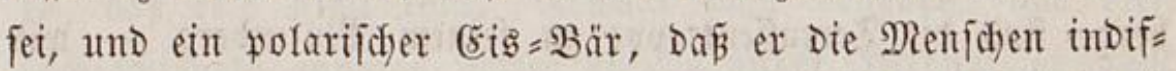
ferenzire, fich aber potenzire, Daj er zwar fein Didjter, fein

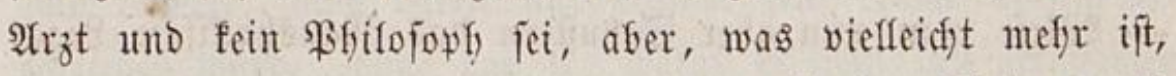
alles biejes zujammen genommen. Und in Der That naunt' er uns Gald Darauf in feinen Rezenfionen Die fünf Direftoren, ja Die funf Sinne ber gelefyten $\mathfrak{W e l t}$, id foll Darmuter Der (bejodymacf jernn, le Goût, el Gusto*), fwridyt aber Dodf ver= Dammt frei von jebem andern. "(Bejeb̧t, mein feuriger Sefu=

*) Für ben Epractjorfdier ift le Goust von el Gusto bas Ana= gramm, ober umgefelyt, uno welche Spradje verifigte bie andere? 
fter," wantt' idy einftens ein, als er fingejdrieben batte, er feffe vorats, in 4 ober 5 Saljen fei (sötfe fo tief herunter

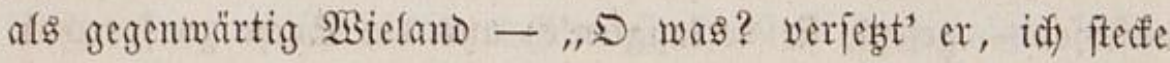

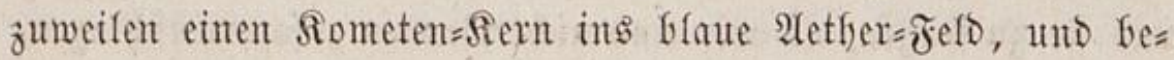
fümmere midh nidyt, of er aufgelyt uno fliegt als feuer=Bhume.

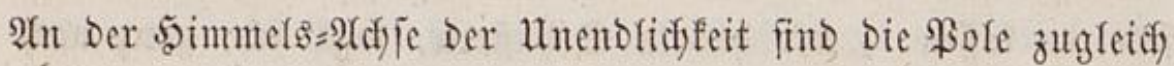
(5itectder, alles ift cines, 5.. Regaz.!"

Rut halten vier Treffer Der Riteratur (fünf würb' idf) fagen, wär' id) nidyt Darunter) frei einem fodyed (en Rathe um Das Mauglfacfifige Legat, Das eben für arme Studen= ten aufgeht, für Den guten Dfnefojen an; Denn rebsteres ift er, wechjeltnd eigentlidif) uno uneigentlidh, gleidfjam als diffe= renzitre uno indifferenzire er audh fier, und wäfle Realismus

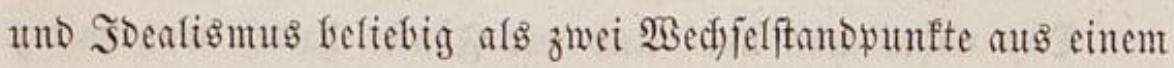
britten. Sth meinte aber jo: er hat nidfts. Sein Marquisat de Quinet*) wirft fli wenig ab - er frauddt zul viele er= regende $\mathfrak{B}_{0}$ tenzen, werm er jelfer eine fern foll, und $\mathfrak{B}$ ein= berge finto Die Terraflentreppe zu jeinem Mujenterg - wir fünf Marfis veripüren Das (Enäfyren eines jedjfent aud) ftarf - Biefe man mun aber Sefujtern Das Mausfacfijde Legat fu: fo fönt' ex's pro forma in Sent oder Bamberg ver= zeffren; und Dabei gemädflid) beurtheilen, einige befränzen und ganz weg laben, unzäfrlige faum yon Der Seite anjeben, Die (siemeinfeit berzfid) veradyten, viele Sadjen Deduziren, wie

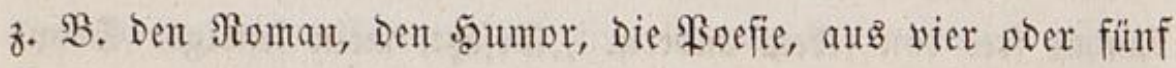
Termen unt Edfreifern, und völlig unter bie fogenanntent ganzen Reute gefören. Der jelige Maushadf felber — Den id

*) So naunte Gcarton feinen (Éfrenjolb yom Bucthänofer Suinet. 
zwar nidst fenne, Der afer bodh won Der andern WEelt mú endidf profitiret fraben - würoc Droben, went er von biejen Frühten feines शadjlaffes Görte, feelenvergnügt fagent: „Kerz= (id) gönı’ idf Der wildent Fliege Drunten Das 2 egat, flos

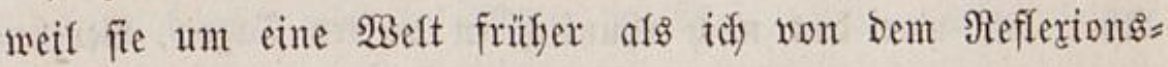
\$unfte weggeflogen."

D S5ott, Stadtratf! waร wäre nody zul jagen, würo’

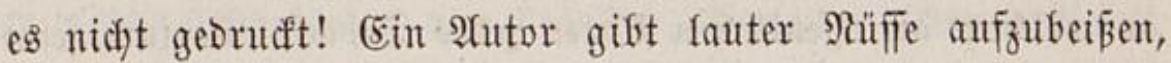

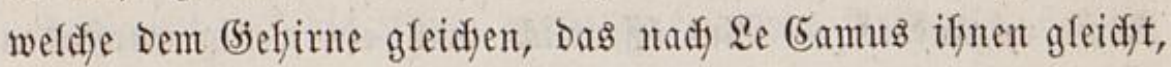
uno bie alfo 3 5äute haben; wer aber fdälet fie ab? - Esin befamter Autor ift afferbings bef heiben; Das ift afer eben

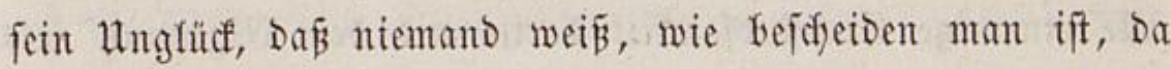
man won fid nidyt fprecten und es fagen fanm. Corr fönte jeinem Stiefelfnedyt funtert Rivréefarben anftreidjen, er fönnte

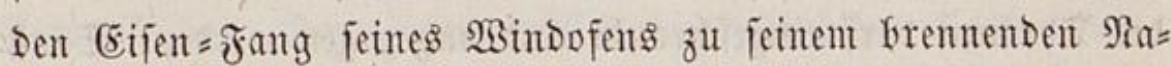
mens= 3 ug veriffweifen und ringeln lafien, aber niemano weí

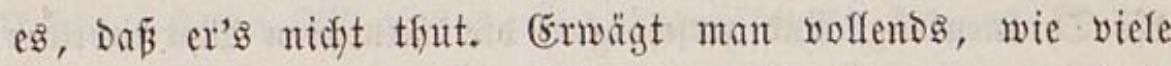

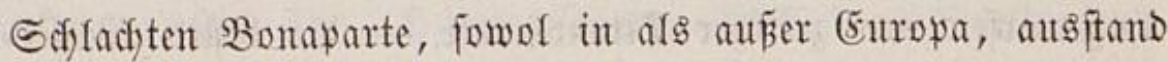
mito lieferte, filos bamit mur einmal fein Name ridftig ges fdjrieben würde, ofne bas $\mathfrak{U}$, wofür er ję̧t den franzofen jenes $\mathfrak{X}$ madyt, jenes algebraifobe Beidyen ber unbefannten

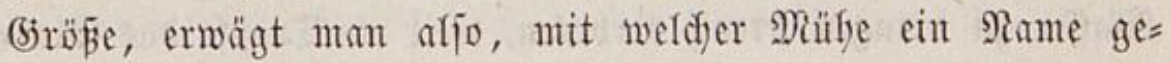
madyt, uno mit wie leidfer er wieder auggewifidt wirb: fo

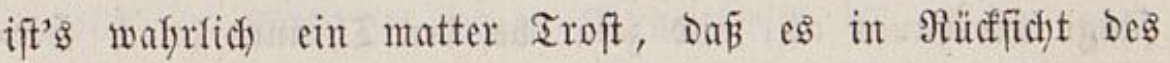
Berfennens aud andern gröpten Männern nidyt befier er= gangen, 3. B. Dem groben (5ottiched, Der felfer fogar int (beflertijcyen Reinzig fo mandyes erlitt, was man fier nidjt wiedertyofen wifl.

Der vierte \$unft, wovon idy einem fodjeden Nagiftrate 


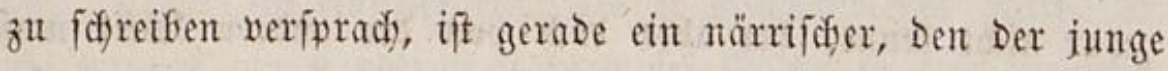
Seflufter am beften ausfechtent würde, in öffentfidjen Blättern.

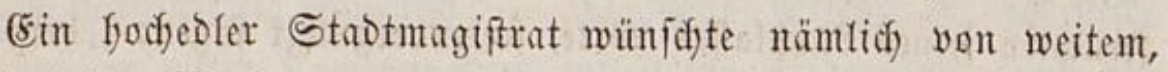

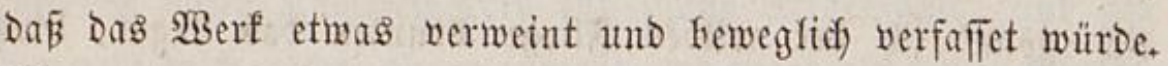
After wie war bas nodh tfjunlich in unfern Iagen, Berefs=

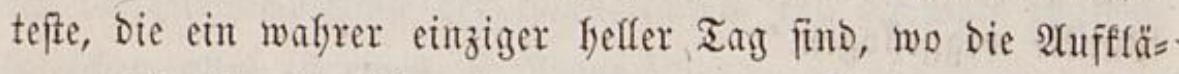
rung als cin eingeflemmter: angezundeter Strid fort glimmt, an weldyem an biffentlidjen Drten jedes Tabad'sfollegium feine Röpfe anzüntoet? - $\mathfrak{B e r}$ öffentlich nodh ein wenig empfinden Darf - uno Der ift zu beneiden - Das find entweder bie Buchfänoler in iffen Bücher = (5eburtsanzeigen, indem man alfe etwanige Empfundamfeit Darin mit Dem (Eigennuls ent= idfuldigen farm; oder es fint's bie Iadjenden (rrthen in iffren Todeš2Anzeigen, wo aus Demfelben (5rumbe Der Rorfziefer Der Thränen Darf eingefofraubt und angezogent werdent. Sonft

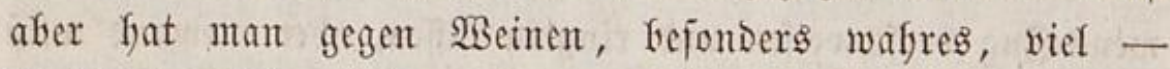
Die Thyänenftüge fint zerid)lagen, Die weinenden Marienbilder umgemorfen von zeitiger Titanomanie - Die beften 2 Baffer= werfe find nod) friffer angelegt als bie Bergwerfe, weldje Davon auszutrocften find - wie in Sdymelz=5nitten, ift it Die Seelenfomel $z=50$ thtten, in Die Romane, einen Tropfen 2Baffer fu bringen ftreng verboten, weil ein Tropfe Das (5) fut=

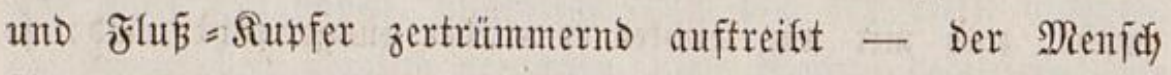
fängt überlfaupt an, unt zwar bei Den Ifränen (nac) Şit=

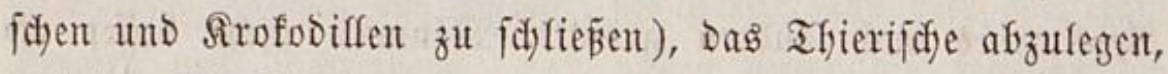
unt Das Menjofliche anzuncfment, wo mant bei Dem Radhen an= fängt, fo Dá̃ jelst eine poetijoje Bauberin, wie fonft eine pro=

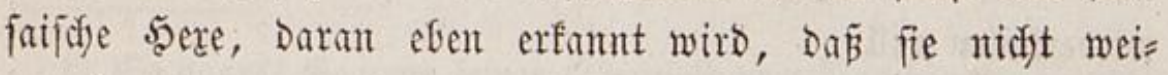
nen fonn. 
Rurz, Rüfrung wird gegenmärtig nidyt verf́tattet -

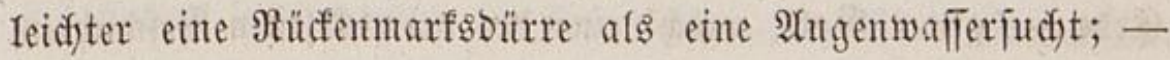
und wir $\mathfrak{A}$ utoren geftefyen es uns mandymal unter einamber feimlidf in Sriefen, wie erbärmlidy wir ung oft wenden und

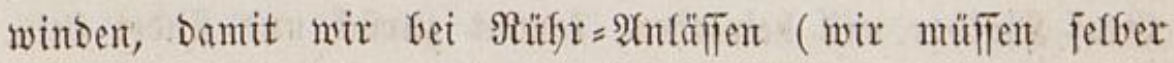
Daruber ladbent) feinen Tropfen fafren lafpen.

Id) f(d)lé̄e dieje Beifen ungern; aber ber Sfnelyojen Sefuifer ftefyt finter Dem Ropiften, Salter, fodon gefticfelt und wartet auf Die Ropie Derjelfen mit Der Sagotajdye; Dem es wäre faum zu jagen, was idf) Den trefflidfen Ieftaments:

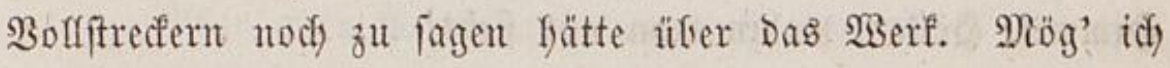

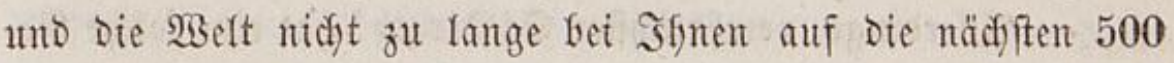

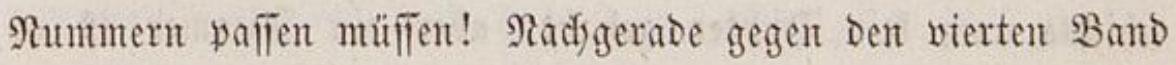
fpinnt fidf in Der Biographie ordentlid) merffur cine $\mathfrak{A}$ rt von Snterelfe an. Denn nun münen Die foftrarften Gadjen font= men und im গ্Unzug fertt; und idy frente nady Nummern. Ueberall ftefon Tellerfallen, und Dampffugeln fliegen, Wild= ruforeber idsleidhen, Summeridjeeren flaffen - Walt's und

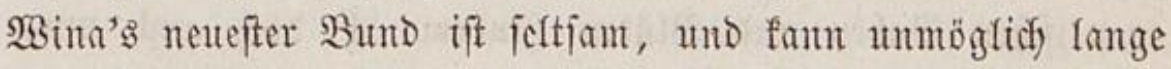
bleiben ofne die gröbten Stürme, die Bände=lang rajen von

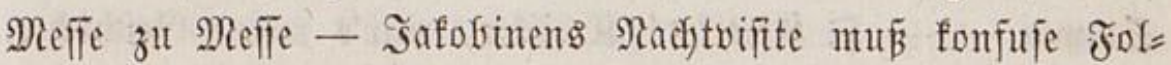
gen baben, oder fann's Dod - Der Sarvenferr mú entlarvt werden (wiemol idf) ifyn wabrfich erratge; Denn er if mir zu fenntfidj) - Rult bat jeinen Sdfmollgeift, iff erlogen won

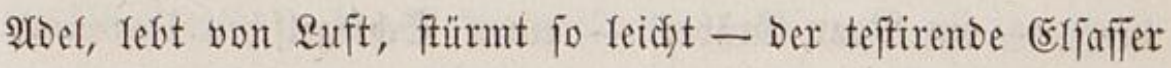
ift ganz hergeftellt und fieft zum Sdyallod heraus - Die

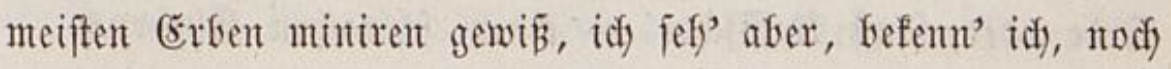

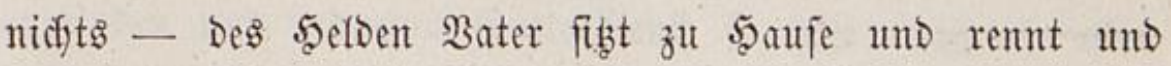

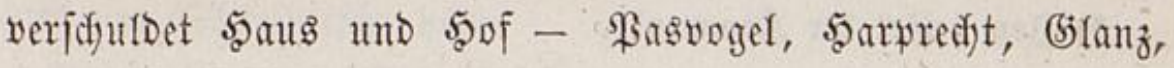




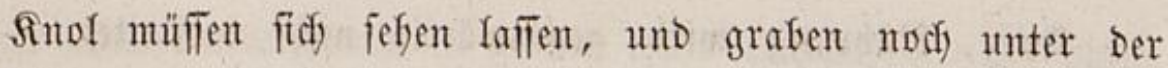

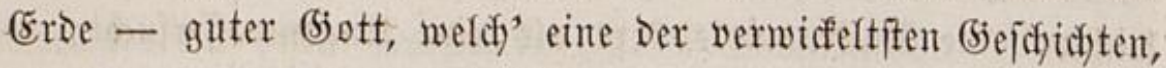
Die idf fenne! Walt foll Farrer werden, und idf begreife nidjt wie, und humbert andere Dinge nidyt beffer - Der (braf Slothar wifl heirathen, fonment zurüd und findet beim

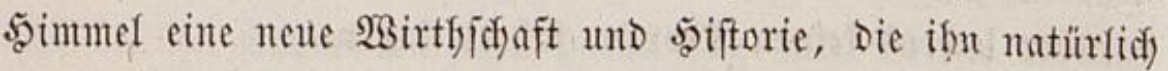
etwas frappiret $-\mathfrak{W}_{\text {alt }}$ will unendlid) gut uno willig blei= ben uno cin zartes, ein (5ottes $=2$ amm, und foll saraus ein

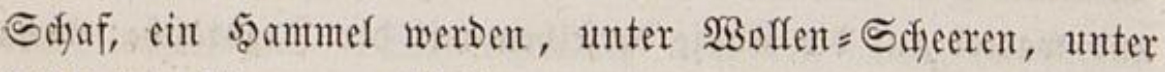
Sdyladtmeflern - Sdylingen, Flammen, Feinde, Freunde,

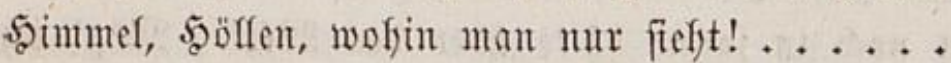

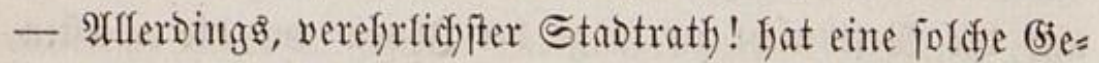
fchichte nodf fein Didster geflabt; aber ein Jammer ift es

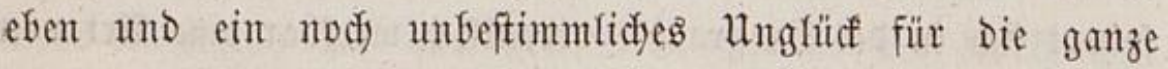
fóböne Riteratur, Dañ fie wafyr ift - Dá mir jo etwas nidjt

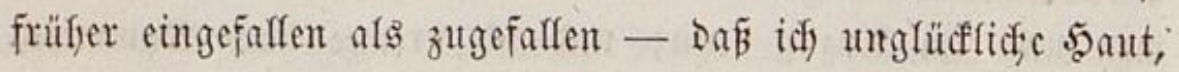
an Teftaments = Rlaujeln und Raturalien $=$ Rummern gefeffelt gehent, wie an flein=idyrittigem $2 B e i b e r=\mathfrak{A} r m$, nidjts won ro=

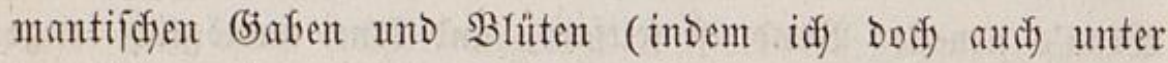
Den Romanciers mitlaufe) fünftlidy pelzen Darf auf foldyent Stamm - - D Rritifer! Rritifer, wär's meine (jej fojidyte, wie wollt' idf fie für eudif erfinten und fidrauben und ber= wirren, und quirlen und fräufefn! $\mathfrak{B}$ ürte idf $\delta$. $\mathfrak{B}$. etwan nut ein idjunles Sdifladtfeld in eine foldhe göttlidje Berwict= fung - ein Faar (jräber - einen Edflegelfiden Revenant

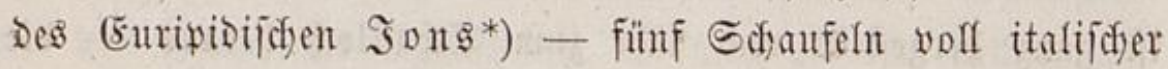

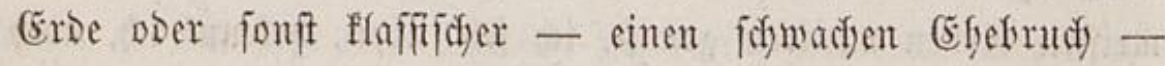

*) Son hcip̃et ber Rommente. 
einten Siloftergarten fammt Nomten - won einent Iolffauje

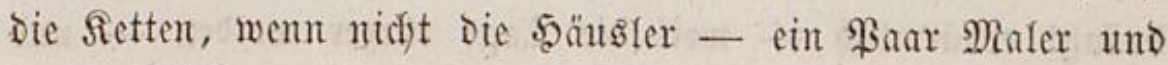
Deren Stücfe - und Den 5 enfer und alfes: $-\ldots$ - idf glaube, Solffitrecfer, es fiele anders aus als jest, wo id filos nur nadjodreibend zufefyen mus, wie die Sadhen geben und

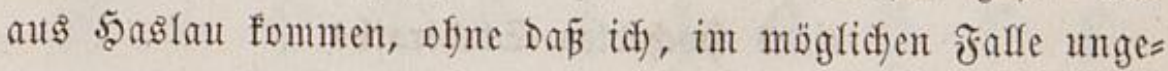
wöfnlicher sangweile, ctwas anteres für die $\mathfrak{B e l t}$ und für 5. Cotta in Der (Semalt fyätte, als wafres Mitleiden mit beiden, faft zu felyr vom bewifien und fonft eingeflemmt und angevfähytt.

- Aber mein Rezenfent, Der junge Sefutfer, Der eben

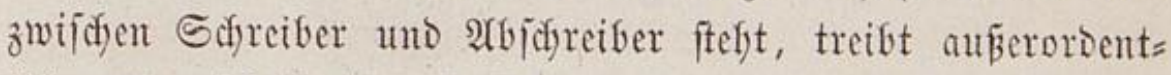

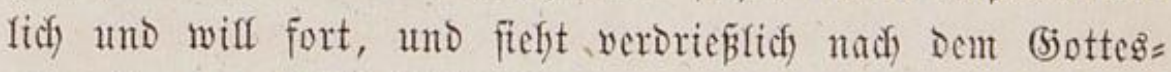

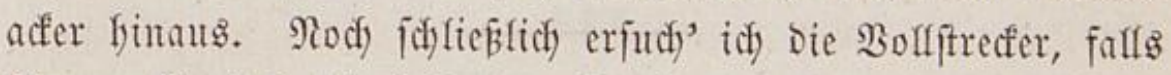
finere Rapitel, Die hefondere Siraft und Stimmung fordern, im 2 drzuge feyn follten, mir fie bald uno jebst zu fificfen, wo gerabe mein $20 f a l e$ (mozu aud) mein $2 e i b$ zu rechnen), mein Edjreibfenter, Das den ganzen Ilzgrumb befjerridyt (Dent id)

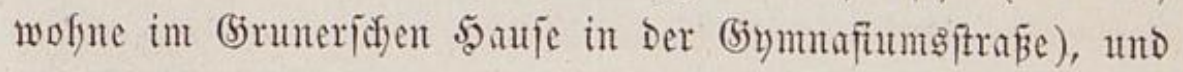
Dag Slüfen Der Meinigen (morunter mein empirijofes $\mathfrak{J}$ h) mit gefjört) midh ficftbar unterftüben; ja ich würbe - went nidut jolde Gelgft= \$erjonatien efjer vor ein \$ublifum, als vor einen Stadtrath geförten - Dazu jelber Den gedacften (5ottegacfer fodlagen, wo man eben jeşt (es ift Somntags $12 \mathfrak{u f r}$ ) half in Der Salvatorsfirche, halb auf Deren Sirrofyofe

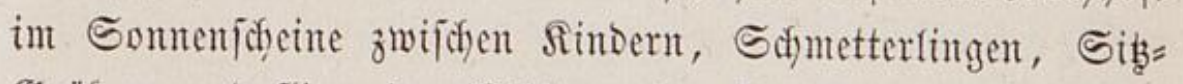
(5räbern und fliegenden Blättern Des \$erbftes Den fingenden,

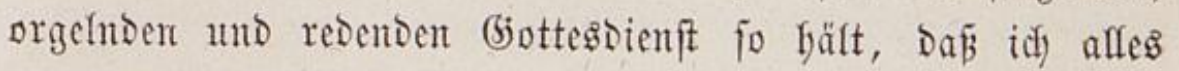

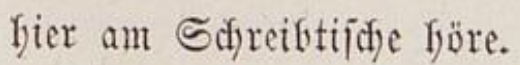

Sean yaul's ausgew. werte. XIV. 
Sad) fönute Dabei mandjes empfinden; aber Rezenjent Drängt erfärmfidf - weil bie Iage fürzer werben - unt

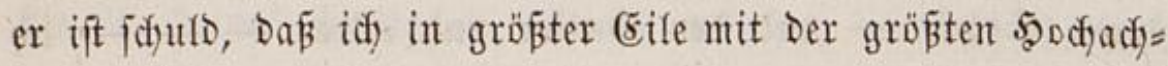
tung erffarre

\author{
eines 5yodjeden Stadtratho
}

(5oburg, Den 23. Dft. 1803.

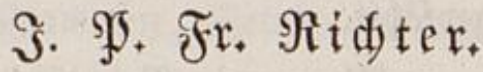


$\mathscr{F} \mathfrak{l} \mathfrak{e} \mathfrak{g} \mathfrak{e} \mathfrak{l} \mathfrak{j} \mathfrak{a} \mathfrak{b} \mathfrak{r} \mathfrak{e}$

Eine $\mathfrak{b}$ i o grapbie

bon

$\mathfrak{S} \in \mathfrak{a} \mathfrak{n} \quad \mathfrak{P} \mathfrak{a} \mathfrak{u} \mathfrak{l}$.

Biertes $\mathfrak{B}$ änd den. 


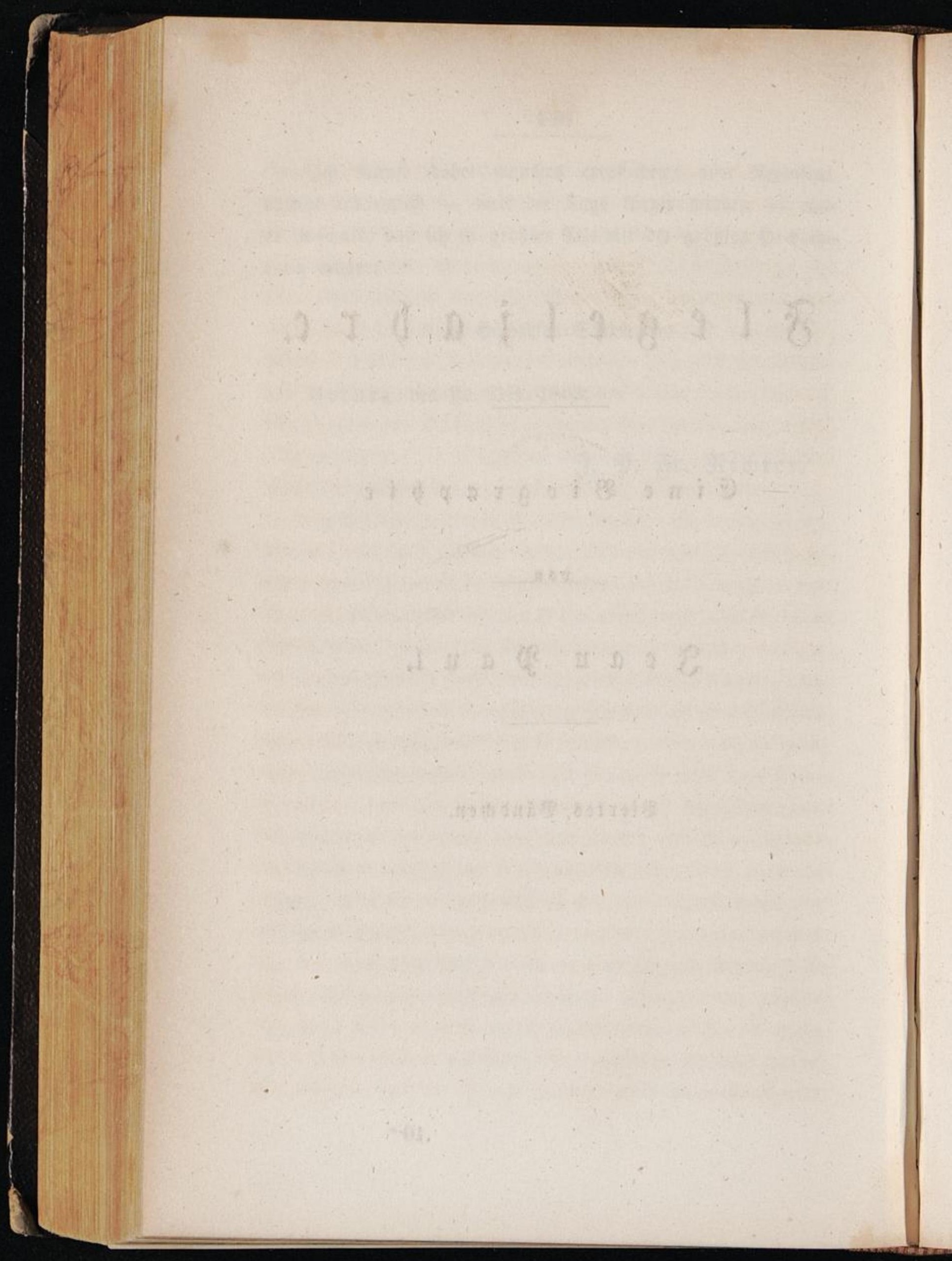




\section{No. 51. 2Atşgeftopfter Blaumüfler.}

(Entwidfugen ber Reife - und bes Motariatb.

Der Notar glaubte wie ein erwadjter Siebenldyläfer cine gantz umgegontene Gtaot zu Durdjtreten, theils weil ex einige Iage Daraus weggemejen, theils weil eine Feutgbrunft, ob= wol ofne Shaden, Da gefraupet hatte. Nod) in Den (5ajen

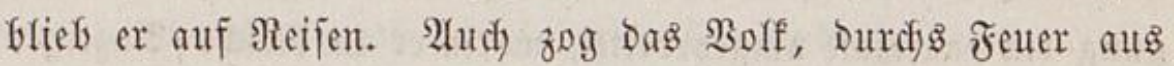

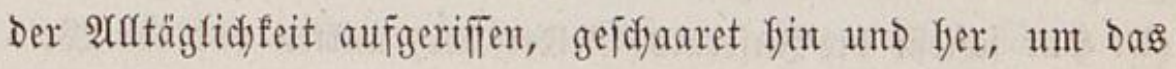
unglücf zu bejeben, Das fötte gejobeben fönnen. Walt lief zuerfi zum Bruber mit Dem größ̈ten Drange, Deflen Neugierde unglaublidy zu fpamen und zu ftillen. Sult empfing ifnn ruthig, jagte aber von fidf, er jefge erfibst aus und gebe das glüfento (Sefidyt Der Jeuergnotf) Gduld. Der Notar wollte ifyn fofort mit Den erlebten Reijemundern in Die 5öbe jodrau= ben und Droben erquiden; er fodidte Daber bie locfendften $\mathfrak{A n}_{n}$ fitndigungen voraus, indem er fagte: Bruber, id habe dir Gadjen zu melden, in Der That Sadjen - , צud idf, unter= brad) Bult, bin mit einigen fieben $\mathfrak{B u n d e r n}$ Der $\mathfrak{B}$ elt ver= jefyen und fann erfaumen Inffen. Nur erfi Das erfte! Flitte genas! Nod) ftaunt und farret Die Stadt." - "Unter Dem 


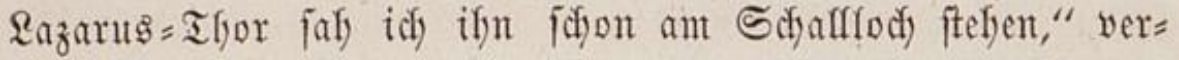

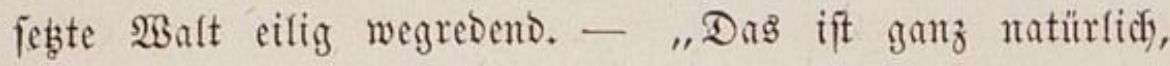
fufr jener fort. Denn Der D. 5ut, ein wafyeer Chaupeau wie wenige, hat ifn wieber auf Die 5inter= Beine geforadyt,

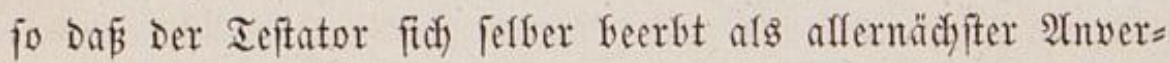
wante und Du fo wenig befommit als ber Reft. SBie frei= Iid) Darüber bie alten Aerzte, Gejonders bie älteften, weldye

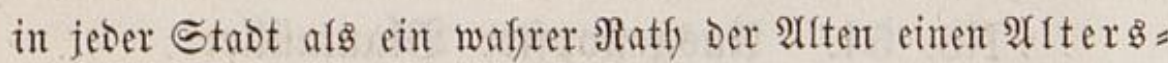

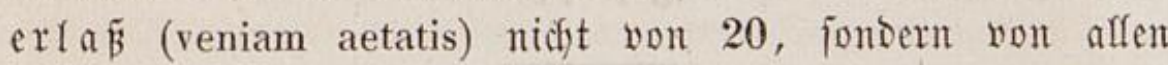
iroifdyen Safrent Dem Süngfen ertheifent und fo Die Sterb=

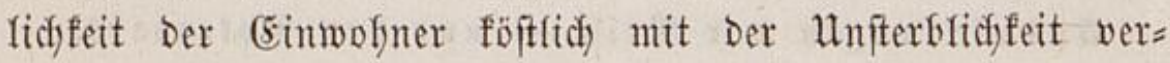

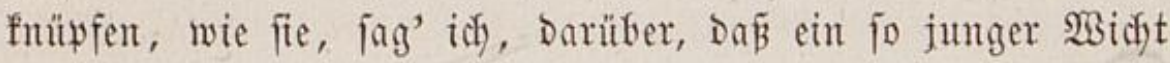

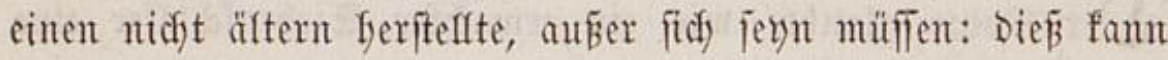
man ganz natürfidif nodf wenig oder nidft beftimmen, bevor gar eine befannte 2 rrbeit von Flitte georucft und befannt ge=

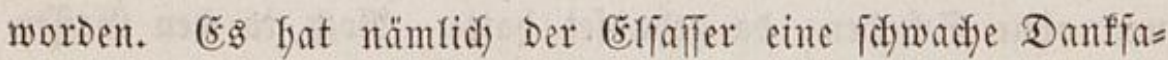

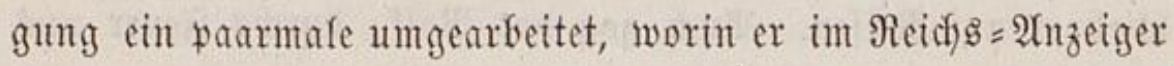

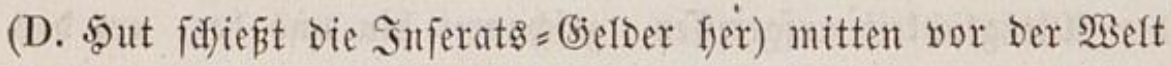
5ुuten gerüfrt genug Danft uno betheutert, nie fönn' $\mathrm{er}^{3} \mathrm{~s}$ ifgm fohnen; was ein fo wafres (sefühl ift, Da or nidyts fyat."

Walt fonnte fich nicht länger eindämmen: "Yiebftę Srü= Derlein, begann er, wafyrlid) mefyr beinen (sinfällen als bei=

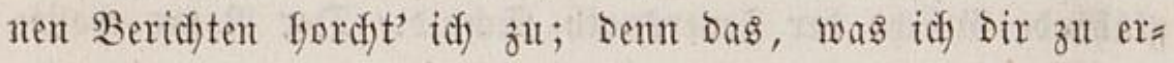

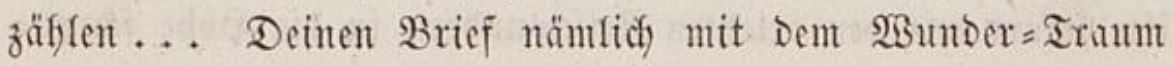
Gab' id wirflidy uno in Der I Ihat empfoutgen; aber was wäre blos Dieß́? Eingetroffen ift er von \$unft zu \$unft, von Somma zu Sommta; före mur!"

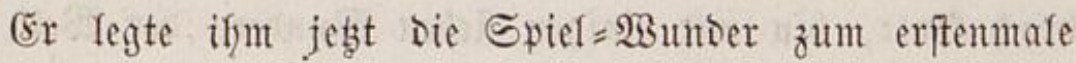

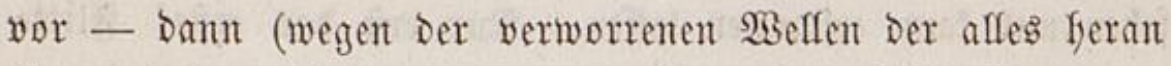

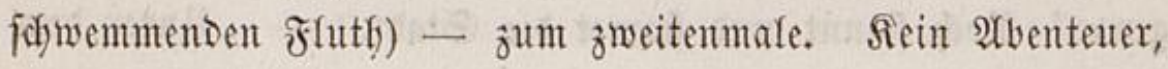




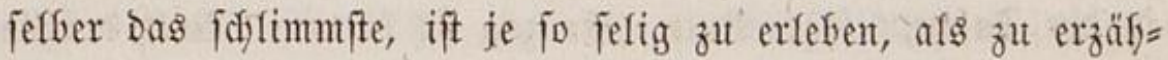

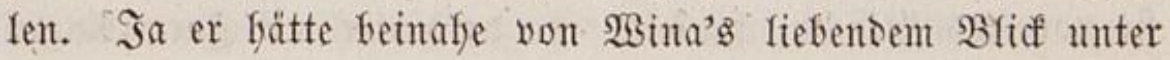
Dem $\mathfrak{B a f l e r f a f l e ~ i n ~ f e i n e m ~ S t u r m ~ D e n ~ S d y l e i e r ~ g e f o b e n , ~ f y a ̈ t t e ~}$

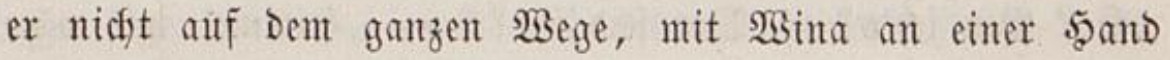
und mit $\mathfrak{B}$ ulten an Der andern, Das $\mathfrak{B}$ iddigite vorläufig bes

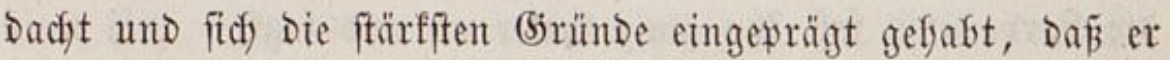
Durdjaus 2 Bina in Den beneral einfleiden müfle und (Empfin= Dungen, obwol nidyt Thatifachen, unterfidflagen; fo gern er audf) in Das einzige, ifm vom Reben aufgeidlofine seerz bie beiden 2 rrme jeines in Riebe und in Freundofdaft getheiften Stroms ergotien bätte.

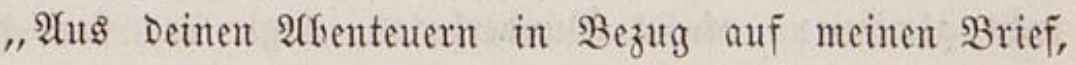
fagte Bult, madh' idf elen nidft Das Meifte - idj lege bir nachfer eine fefr gute syyothefe sarüber vor - fingegen in

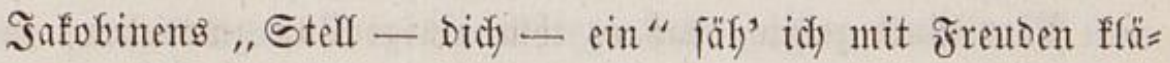

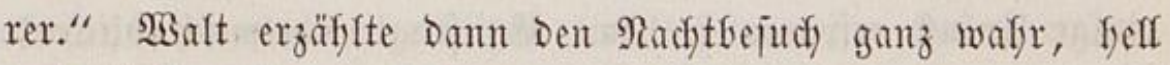
und reidft und verga feine einzige (Empfindung Dabei.

"Nichts will $i$ d. leidyter erflären, fing entlich $\mathfrak{B}$ ult ant. Ramn Denn nicht ein Serl, Der affe Berfältnifie weiß̄, Dir

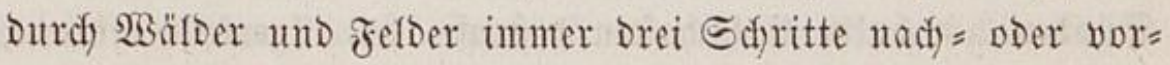
gejdyfidyen fern - mit Der flöte geblajen fraben - Deinen Namen in Den Firügen unb Sotels voraus gejagt - Die fleinfte Sadje beftellt unto angeftellt, z. B. mit bem Bilder= fänoler und Dem Suodfibet uno Deflen quod deus vult est bene factus, ftatt factum -... uns fo fort? $\mathfrak{B}_{\mathrm{a}}$ Den Brief anlangt, fo war er ja in meinem Namen und Styl fo reidjt zu fafreiben, unterwegs aufzugeben, Darin alfes zu weiा̄agen, was man eben jelfer vollfüfrren worlte, Das beld aber cine Mimute vorfer einzugrafen!" — "Mmmöglidy! fagte $\mathfrak{B a f t}$. Und vollends Der Rarvenferr?" - "Saft du Dic Rarve etwa 
in. Der Iajofe," jagte Bult. (5r zog fie ferwor. Bult oritute fie vor Das (sieficht, funfelte ifn Darfinter mit 8 orn= an, und rief wild mit befamter Stimme Des Sarventerrm:

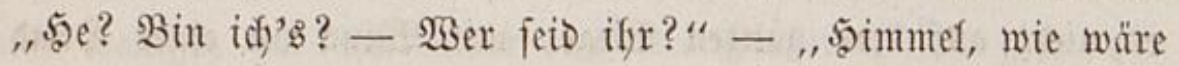
Dem das?" rief Der erfidroffene Balt. - Ganft hob Bult Die Sarve $a b$, fabj iffn ganz feeter an und fagte: , id weir nidht, was Deine (5iedanfen über Die Gadje fino; id jentire,

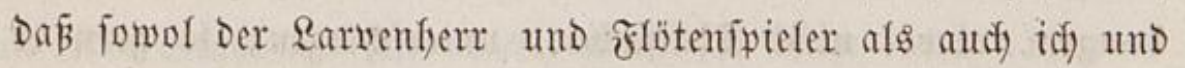
Der Briefidureiber Diejelben \$Serjonen find." - Mein Ber= ftand fteft ftill, fagte $\mathfrak{B a f t . ~ " R u r z , ~ i d f ~ w a r ' s , " ~ b e j o f l o f i s ~}$ Bult. Âber Der Notar wollte jeiner eigenen Beftürzung nidjt red)t glauben: „etwas $\mathfrak{B u n b e r b a r e s , ~ j a g t e ~ e r , ~ f t e c f t ~ g e m i ́ n ~}$ nod) finter Der 3auberei; und warum bätteft on midy über= faupt fo jonberbar fintergangen?"

Aber Bult zeigte, Dẩ er ifm cinige $2 u \mathfrak{t}$ zuwenden, ja einige Unfuif exparen wollen. (5r fragte juelmifid)=blicfend, ob er ridht zur redjten 3 eit jeine Masfe ins Bimmer gemor=

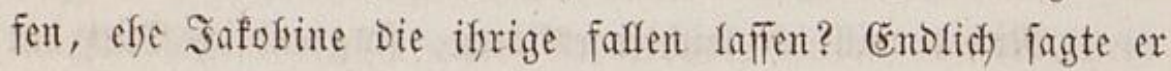
gerade feraus, die Rlaujel Des Ieftaments, weldye für Fleijdyes= Günoen um balbe Erbidjaften beftrafe, fei allgemein befannt,

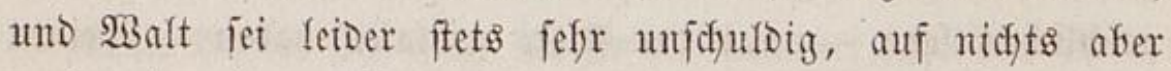
werbe in einer affion öfter und fefler gefdonten als auf Gdjimmel megen Der garbe Der Uniduld - Die fieben Erben Decfen, wie fluge Feloferm, ifr Rager mit Moraft - furz,

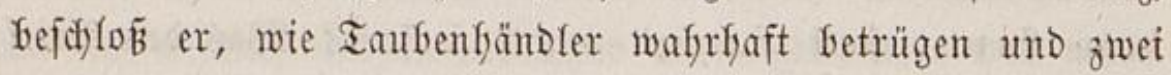
Täubinmen oft für ein orbentfidjeg ßaar (Éfetauben auggeben: fätte man es mit Dir und Der Yftrize nidyt eben fo madjen

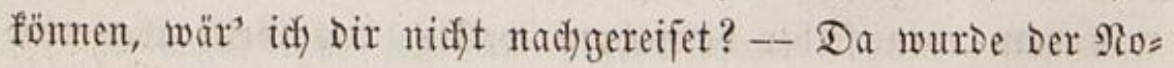
tar blutrotf vor Sajam und 3orn, jagte: "D garitig liber Die Mallen," jebte unter Dem Umberfabren nad) Dem Sute 
finzul: "in Diejem Ridiste fetht ein armes Mäbdyen bei bir? Und Dein eiguter Bruter Dazu?" lief fort - fagte mild wei= nend: "gute Radjt; aber bei (bott, id) weis nicht, was idy

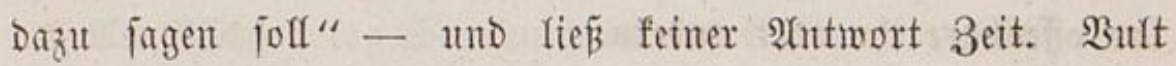
ärgerte fith faft itber Den unvermutfyeten 3 orn.

„Id), idy? - wiederfyolte $\mathfrak{W a l t}$ auf Der (5anje imnigit= berlebst - id) bätte midh werjündigen foffen an cinem Iage, wo mir (jott Den rïfrentofen Reijeatend bejdecte, und Die fromme $\mathfrak{B i n a}$ mir fo nafe lebte? - Das wolle Giott nidut!" -

Ats er aber in fein Stübdyen trat: überflog ifnn eine ganz bejontere Seligfeit und zeffrte Den Sifmerz auf: - eine neue Ëmpfintung wirb an einem alten Srte lehendiger; -

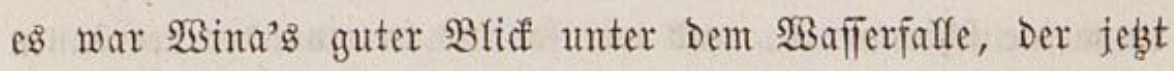
ein ganzes Reben wie ein Morgenlicht golden überftralte uno

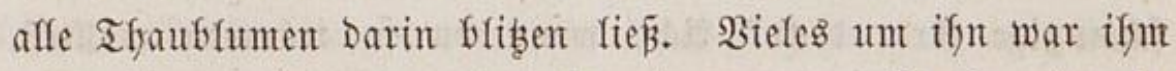
nummefyr zu eigen geworben, fo wie neu: Der \$arf unten, in Deffen (jängen er fie einmal gejefen, und Raphaela im 5auje, Die iffe Freunbin war, gefjörten unter bie 5 abjeligfeiten feiner Bruft. Selfer jeinen eignen Roman 5 owpelpowpel fannte er

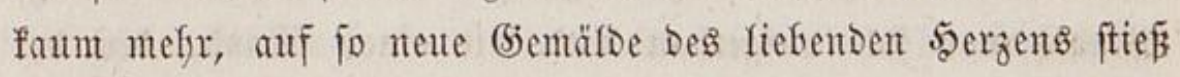

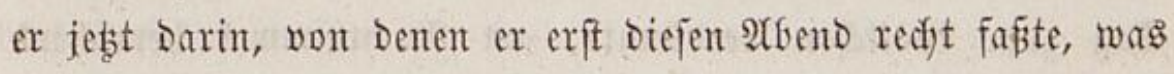
er neulidf etwa damit faben wollen; nie fano ein $\mathfrak{A}$ utor einen gleidftöniger geftimmten $\mathcal{L}_{e}$ er als er fycute. (Er baute fidf) joglecic) ein zartes Bifberfabinet für Die Gjemälde von Den

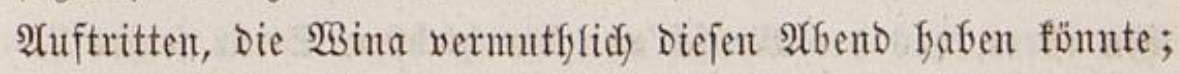
z. B. im Safaupielfauje, pder in Den Reipziger (5ärten, oder in ciner gewählten (jejellichaft mit Mufif. Darauf jebzte er fich fin und befdorieb es fidf mit geuerfarben, wie ifr etwa Geute fei in Giludfs $\mathfrak{s p h i g e n i e ~ a u f ~}$ Iauris; Dann madfte er 
fefige (bebidfte auf fie; bann fielt er bie şapiere voll Ebent ins Ialglicht, uno verfoflte alles, weil er, jagt' er, nidjt eits= felye, mit weldyem Redyte ex ofjne iffr $\mathfrak{B}$ Biffen fo vieles von ifre offenbare ifre ober ambern.

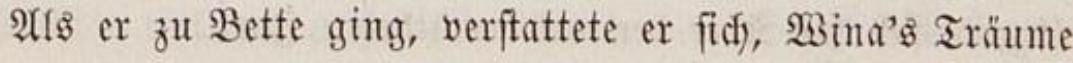
ficif) zu erträumen. "פ⿹er fant mir verbieten, fagt' er, ifre Träume zut bejudfen, ja iffr fefre viele zu leifen? Sit Der

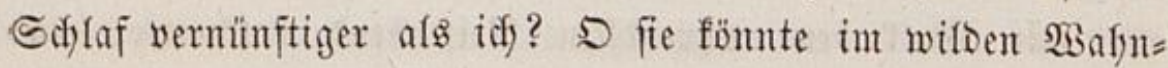
finu beffelfen ia recht gut träumen, Dá̧ wir beibe unter Dem Wafferfalle ftänden, verbunden aufflögen in ify, umarmento finfd)wämmen auf feinem flüfifigen Fetergolde uno zum Ster= ben herabftürzten mit ifm und vergöttert ftifl mun weiter

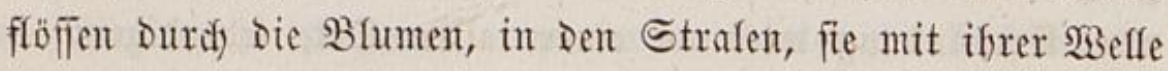
in meine iffinmento, und wir fo uns in cinander verrönten in Das weite, fyolee, blaue, reine Meer, Das fid über bie

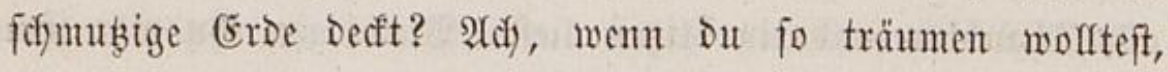
Wina!" - Damn fafy er auf Dem Siopffifien redyt fyell und fojarf - weil Radyts in Der wilden Beit Des Bortraums vor Der Seefe alfe blaffe Bilder junge Rebensfarten annefmen uno Die beftalten blikente $\mathfrak{A}$ ugen öffiten - Das Yiebe, miloe $\mathfrak{A}$ uge Wina's vor fich) aufgethan uno wie einen Mont, Den ber

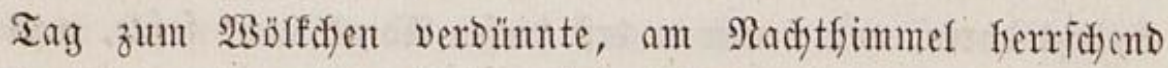
ftralen; und er fanf in bas liebe 2 Uuge, wie ein frommer in Das $\mathfrak{A}$ uge, unter weldyem man (jott abbilbet. WBie leidyt uno Dünn ift ein Blicf uno ein erinnerter! Raum Das Afpentös=

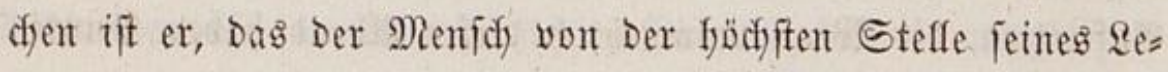
bens ferunter fringt. A(fer Dod) fält Der Menja unter Der

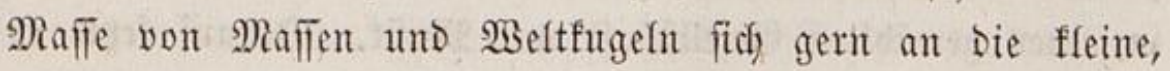
bie ein $\mathfrak{A}$ ugentied bedecft, an einen verfsautchten, faum entffan= Denen Blicf - und auf Dem fimmlipejen Nidjts ruff jein 
Farabies mit affen Bäumen feft! So find (Scifter; Dent Da

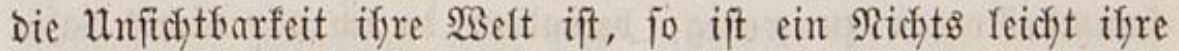
Sidntbarfeit!

Am Morgen lag Sonnenjochein mo Seligfeit um ifn her. Anfe Blüten zu 3anfäpfeln waren abgefaflen. Die Morgen= ftunde lyat (5old, aber Das reinfte, im Numb; Die Eome fochei= Det Das in Sdyfactent vererzte (jemütf); Das finfere Hebermañ, bejonders Des 5afies, fört auf. Waalt faf fid um im Mor=

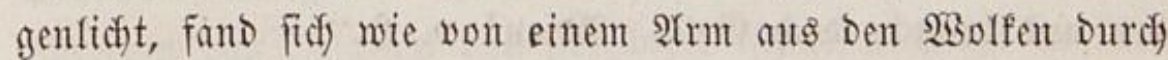
alle üfereinanoer ftefenden $\mathfrak{B S}_{\text {offen }}$ Des Rebens Durdggelyoben ins Blaut. - $\mathfrak{B e r}$ lieft, vergibt, wenigftens Den Reft Dem Reft; er fragte fidf, wie er Dem geftern, gerade am becimfefrs= Fefte, jo gegen Dent armen Brttoer auffraufen föntent.

"Ia wol Den armen Bruber, fufre er fort; Senn er flat gewiß̄ feine Beltebte, Deren Riebesblicf ifm wie cin Rebeng= brempunft im 5erzen bleibt." Nun ging er ganz ins (Ein= zelne und fteflte fidc - nad) feinem Infinfte, Der ifyn fets in bie frembe Secle trief und in ifre über fie finzufdyauent zwang - an Bults Stelle, wie Diefer nidyts fyabe, nidyts wiffe (yom 2 anterfalle nämlidy), wie er afles ober vieles fo

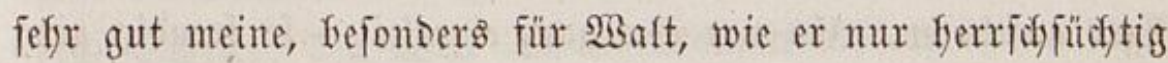
Gart verfafire u. .. w.

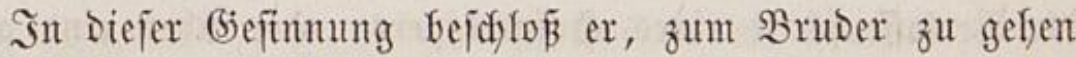

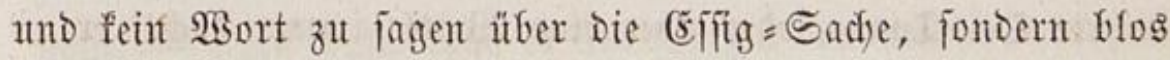
mit feiner 5ant cine fidon im Nutterfeib verfnüpft gewejene anzufaften und einiges gelafien zu bejpredjen, bejonders was Die bevorftefende $\mathfrak{B a f h}$ eines neuen Erbamts betreffe.

Bult war werreifet. (Ein Briefdent an $\mathfrak{G a l t}$ war an Die Thür gefiegelt: ,Beffer! Sad reifete beute flutdytig ab, um in Rofenfof mein verfprodjenes Ronzert zu blajen. Siüftig 


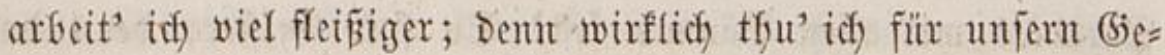
fammt = Romant zut wentg, befonders ba idy gar nidyts Dafür

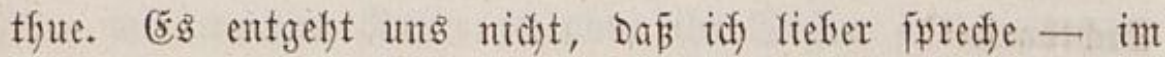
reißentiften Strome midy fidwenmeno - als jodreibe. (sit aber iff's nidyt, weder für bie Riteratur noch Das sonorar.

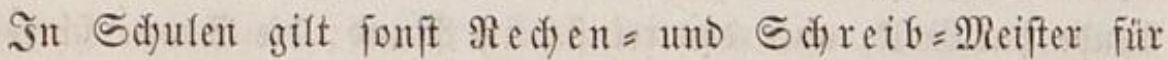
(Einen; ein trefflicher $\mathfrak{B u d}$ ) = Sdyreibmeiffer fingegen ift felten ein Redfenmeifter; leiber bin ich nidit einmal einer von bei= Den und frauche Doch (BefD. IDDieu! v. 5."

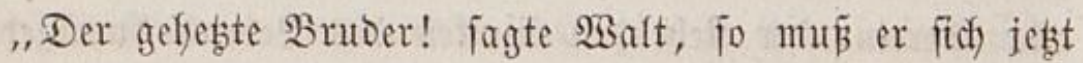

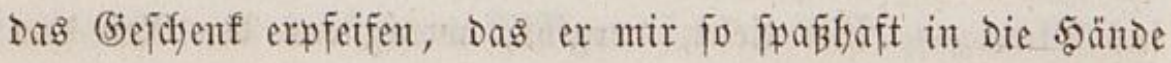
gejpielt; warum fall' id immer fo beftig aus und brücfe ben (5uten?" (Er faß̄te Den exufflid)en Borfabs, fünftig feinem Sturm= und Poltergeifte ganz anders Den Bügel anzuziefyen. -

Aber Rojentyof warf bald heiteres sidyt auf alfes und Heiligte faft Den Flötenfpieler, Den er in Den nachjochimmernden

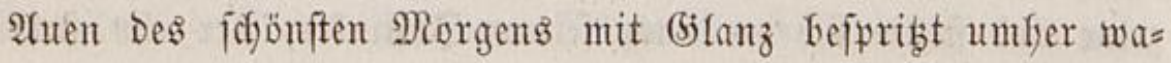
tell faff.

Wacferer als je retrat er mun feine Notariats = Sänge wieder, Die fich) gegen Das (rnde feines (rrbamts immer fäu= figer aufthaten. (58 war ify ganz einerlei - fo freubig ging

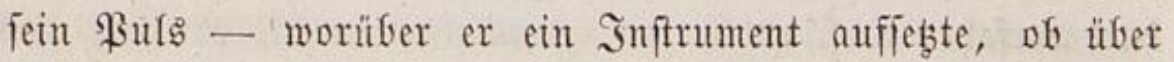
Die Berlaffenfichaft eines $50 f$ predigers, Doer über eine anges Gofyrte Del = Tome, ober über eine Wette: immer Dadyt' er an

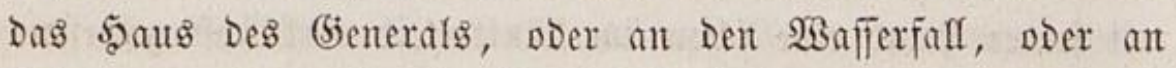
Reipzig, und es founte ifym gleidggulftig jern (Denn er gab nidft Darauf $2(d) t$ ), was er niederifdrief als offner fuijer= Yicher Notar.

So glänzent = umpponnen vom Radjfommer Des 5̧erzens fam er ats Dem September und Dem Sotariat enolidy in Den 
Detober fintuber, wo er vor Den Rabelfochen Teftaments = Ěres futoren Die Redjnung über Das Gisferige Ertbamt abzulegen fatte, yor weldyer ifym nidjt im geringften bange war; Dent WBina's Blicf batte in ify cinen jo feurigen 5erzichlag ent=

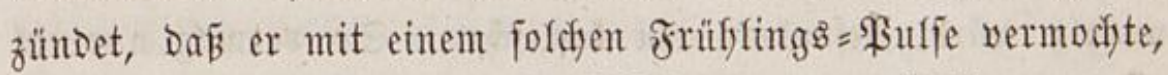

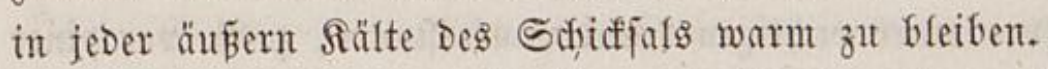

Sein $\mathfrak{B a t e r}$ Sufas fyatte ifn neuerfidy in melfreren Sopien yon Brief= Driginalen (Die Der Sd)ulze befielt, weil im Brief= fodreiben Das Sriginal Das fojledytere ift) feine Angft vor Dem Notariats = 5aintergrund und Die Betbeurung feiner "Soerbei= funft" wiffen laffen. Walten wurbe Die MBieberfolung Def= felben Dürren (Siedanfens, Die fo mandyen frifochen erbrütefte, feffr zur $\mathfrak{L} a$ ft und er wimfojte nicjts weiter als bie alte frei= beit, an funbert Dinge zut Denfent: ,warum if Dent ein Jrt= weg fo verbriesplid), fagt' er, als flos weil man fo lange, bis man ben rechten wieder erwijot, immer bie abgejolyabte wlatte

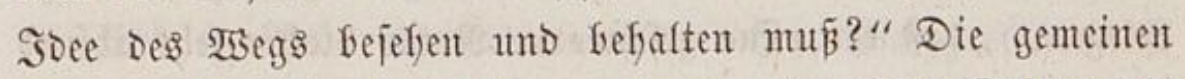
Qualen bes Rebens belaften weniger unter ifrer (5eburt als wäfrent iffer Gdywangerichaft uno Der eigentfiche Reidenstag gefft 24 Stumben oder 3eiten früfer an als Der äußere. Der erfte Sifritt, Den 2 alt am anberaumten Norgen ins Ratf)= faus that, madjte iffn ju cinem andern Nenichen, nämfićn fum alten - bie Eadje war für ifnn vorbei, Denn fie war fo

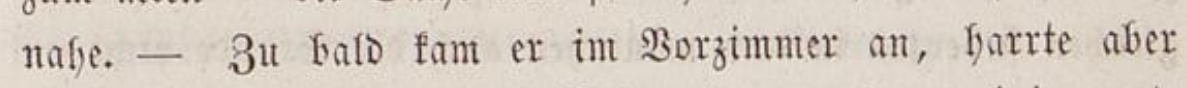
vergun̈gt uno madjte einen Folymeter, worin ex einige gute (5ruppen befang, bie in falberfobner $\mathfrak{A r b e i t}$ am Rath:ofent mit afler Der $\mathfrak{B a}$ äme Dargeftellt waren, weldye Die Safreşzeit an einem falten Dfen erlaubt. Tanz $=5$ goren, Füffyöner volf 5̧eu, Jrudthtidnüre oder Striffe, Büjdyel von biffent feftent

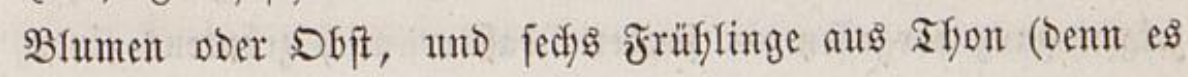


war cin 3irfultrofen) waren afferdings im Stande, einen Didhter wie or zu feizen. - $\mathfrak{A}(\mathfrak{B}$ nod) immer bie Ratfegftube zublieb, fo gerieth) er auf Reben = Soeen, of nämlich nidyt ein ganzer Roman aus Dfen= \$aften Darzuftelfen und zut ent= wiffefnt wäre, bejonders ein fomijher. So vermag utur ein Maum vor einer widhtigen Bendepunftgftutbe, $^{3} \cdot \mathfrak{B}$. vor ciner frönung, Sdyladjt, Selfitermoroung, nidyt aber jeine frau vor einer äfnlidjen, $z$. B. vor einem Bafle - zu Didyten, zu joldafen, z̆ lejen.

Da endfich Der Sdyirmfyerr Der Siabelichen enterbten (5r: ben, Der \$falzgraf Finol, eintrat, fo fing alles an uno wurbe gefyörig vor Den Bürgermeifer Rufnnold geftelft.

In feinem Refen war ifm nie fo feberleidyt in einer Ratbgftutbe gewejen; auf Dem Staubfaden einer Silie bätt' er fich) f(d)aufeln fömter. (Er fiel aber bald yon feiner Rilie ins Beet ferunter, als Der Sifirmberr anfing vorzutragen uno zut

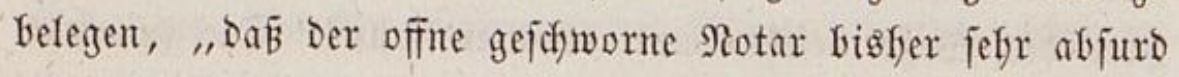
gewirtfichaftet" - Dá er nicht nur erfiflich und zweitens zlweimal in Snftrumenten abfreviret - Drittens ein näbst= liches (bas $\mathfrak{T}$ furm = Teftament) mit zmeierlei Dinte und vier= tens bei einerlei \&idjt geidfrieben - fünftens cinmal rabirt - Fechftens cinmal gar nicht angegeben, Daje er nusbrücf́lidf fur Âfrichtung Des Snftruments vorgefordert worben - Des= gleidfen fiebentes in Dem nämlicfen audy bie Stumbe nicht adftens Den nägelein = Grauten Binbfaden, womit Die Rilagidurift N. N. contra N. N. ummidfelt gewejen, als eitten geffent zut Protofolf gefracht - neuntens 5 antszentgen, als fie ciofid)

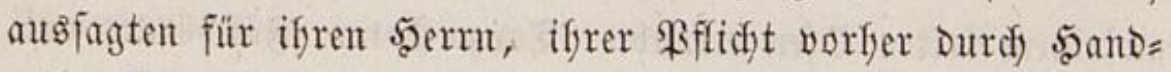
geben jowol żt entla zeigen ganz verge 


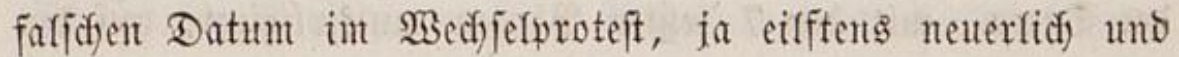
gantz zuletget ein Inftrument gar an einem 31. September, Der nidft eriftire, auszufertigent wenig 2lnftano genommen. Nun wurb' er gerid,tlid, fefragt, was er Dawider einzumenden

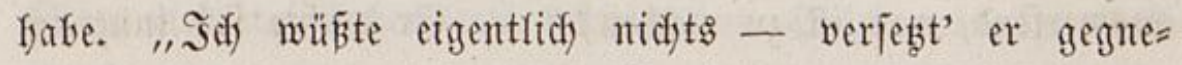
riffhen Seits; - audf trau' idf frembem (siedädytnís fier weit mefre als cignem. Dodh was bie santszeugen anlangt, to fielt idf es für eigenmäd)tig uno unmöglich, fie Durds

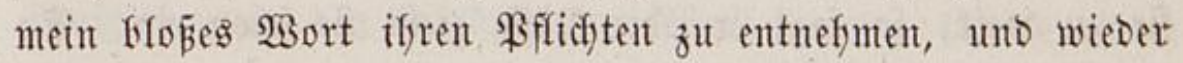
zurücf zu geben." Darauf fagte 5 . Rulfnold, Diejer (5rund jei mefre edel gedadyt als juriftifich, und berief fid auf born. Fisfal Rnol. Nidyts fei lädherlidfer, verjeb̧te biejer uno fdyob

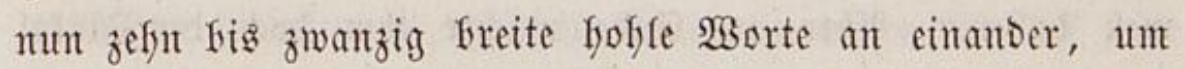
bei Den Teftaments = (Exefutoren um Das nad)zufuchen, was fith won felfer verftand - Die Erröfinung Des fier eintretenden gefeimen $\mathfrak{A}$ rtifels.

(5)' es Siufnold 'that, erwies er Dem 'Sfalzgrafen, Daf́

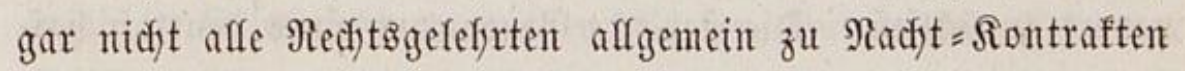
Drei Sidyter begeffrten, fondern nur mancher; und langte als Snol auf feinem Sabze belyarrte - blos Das promtuarium juris von 5̧ommel oder Müfler als Den nächften Beweis aus Dem Gifranfe vor. Die Rathabibliothef war nicht höfer als Die vier Bände Des promtuarium ftarf; Dennod) fefilte ifre, wie Den meiften offentlidyen Birliotífefen, ein Ratalog.

Sinol befielt fid Das Seinige vor; Sutfnold gab aber nidyt nady, jontoern verlas Den Straftarif: "Dap näm(id) für "jeden juriftifden Notariats = Sdyniker Des jungen Sarnificy ,jebem Der 7 (Erben ein Tannenfaum in Rabels $\mathfrak{B a ̈ l d o d j e n t}$ "3u fälfen verftattet jernn follte." Da er mun in 10 Sünden geratfen war - ofne Die freitigen Ridyter - fo belief fidy 
Der Decem, mit Den 7 lebgten \$lagen multipliziret, auf Den anjeffntidyen Sdjlag von 70 Stämmen, fo Dan $\mathfrak{B}$ alt nie balf

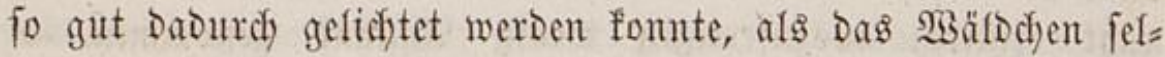
ber. - "Nu, fagte Der Notar, fdnell beide bände feitwärts auswerfent, was ift zu madjen?" - (Er mupte fid imnerlid über bie 3ufälle Des Rebens fo erfeiternd zuzureden, wie cin Sdfufter Den Rumben über neue Stiefel, Die er fringt; find fie zu enge, fo fagt Der Meifter, fie treten fict) fidson aus; find

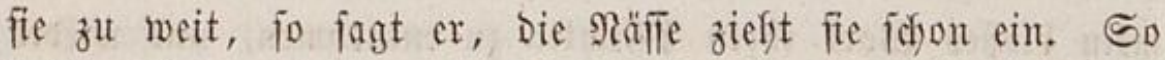

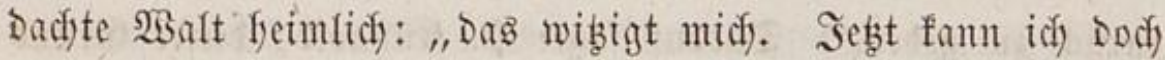
als Notar rufig alfe meine Inftrumente madjen, ofme Daß mir gefeime Artifel Das bieringite zu befeflen oder zu nef)= men fraben." 2Aber am (Ende madjte ifm Dod) Der Fisfal

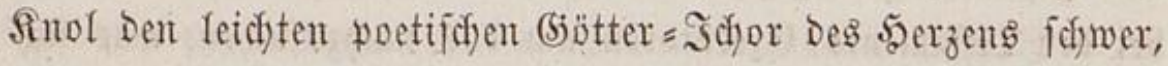

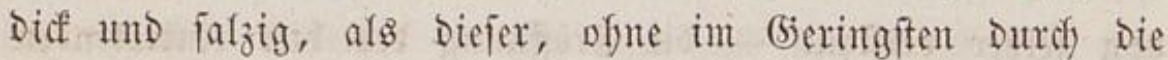
Frentide üfer Den Bseminn won Edylagholz irre ober trunfen zu werden, feine Froteftazion im Sunfte Der 3 Riditer cr=

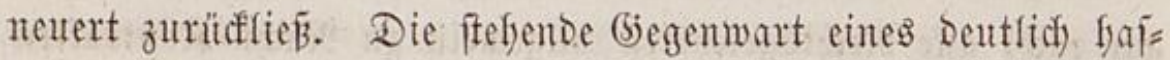

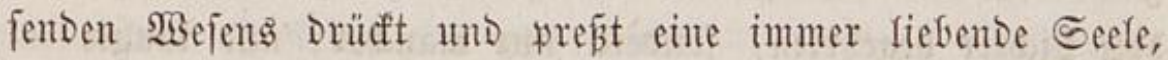

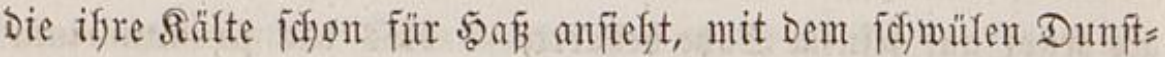

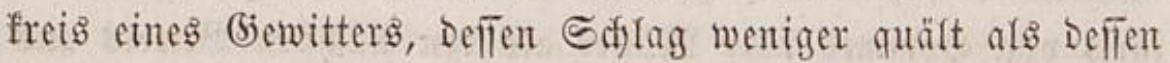

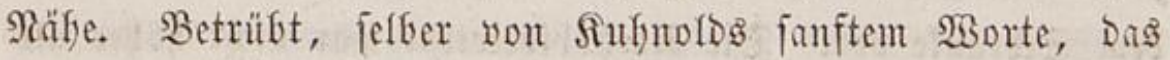
ifm jo vermeiolidfe feffer eben als bie unverzeiffidjern vor=

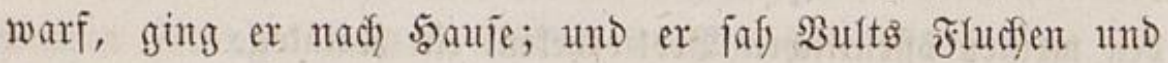
Gijerzen Darüber fojon entgegen.

Das erfte, was er zu Saule machte, war ein Sprung aus Demfelben auf bie fdjönen ftiflen säben Der Sftober=

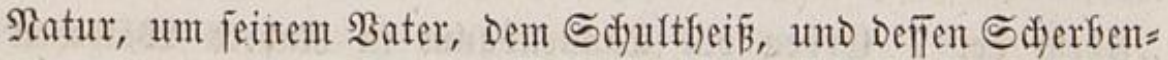

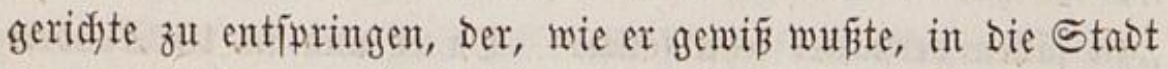
Iaufen würde, um jede Sdjerbe Des zerbrodjenen (Slüfostopfes 


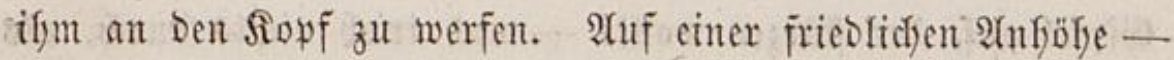
Dem $\mathfrak{B a ̈ b}^{2}$ dhen gegenüber - fonnt' er, wäfrend er Das me=

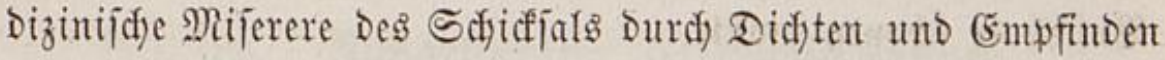

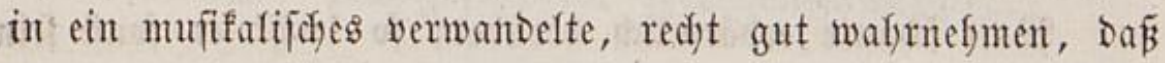

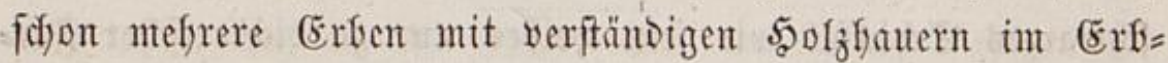

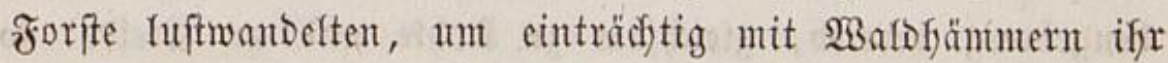

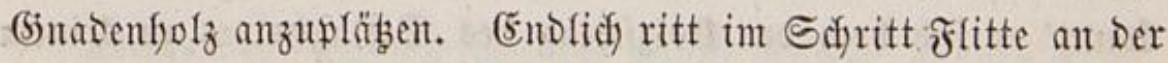

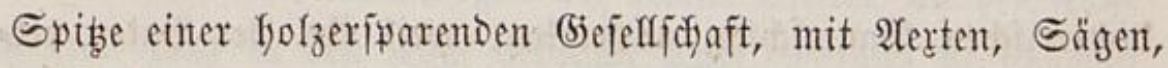
Maßjtäben in Den 5änden, Den $\mathfrak{B a l}_{0}$ finant. (5)leidy einem

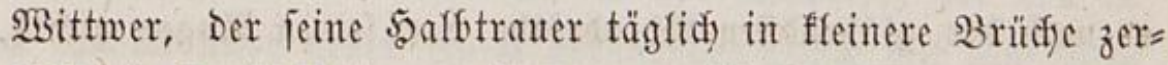
fällt, in Drittelstrauer, in $1 / 4,1 / 8,1 / 64$ Ifyeil - wiewol bie Irauer poer ber 3 äfler nie nulf werben fann, nad mathe= matijhen biejeben - verfefrete $2 B a l t$ bei biejem 2 Anblicf peine

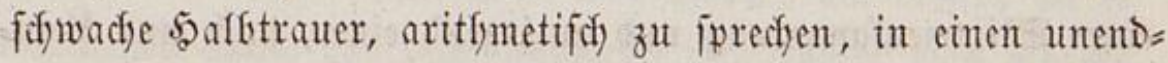
(id) grofen Renner und in einen unendidf fleinen 8 äfler, D. f). er wurde das, was man gemeinfin frof nemut. "(5s ift fdyon redyt, Dadft' er, Daß id Dem guten Flitte für feine gut= mütfige Errbeinfebung meiner Berfon Dod) einen fdjwadyen Danf Durdh meine Fefler zufdanze; er habe recht viele Freute Dafei, nur feine Edfadenfrettoe." Afber Die Ruftigfeit üfer bie $50 l_{z}=$ Einfuke wurde $\mathfrak{B a l t e n}_{\text {etwa }}$ verfümmert, als er Den alten Sdulzen aus Der Stabt forreiten und ins şolz Dringen faf), Märtyrerfrone und Bepter tragent. Wuf Die angewläßz= ten Stämme lief Rufas zut - fragte, jagte Diȩ́ oder das uno feifte - Durdjofjutt Den (jefjau nach) alfen (Ëfen - ftritt

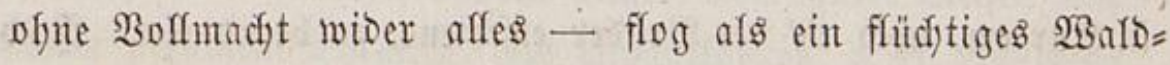
geridgt und Forffolfegium fin und ber, an jeben Bupd, neben

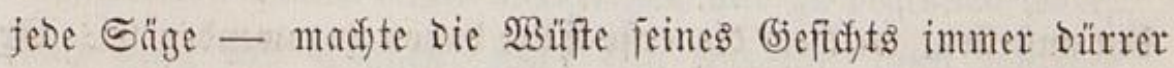

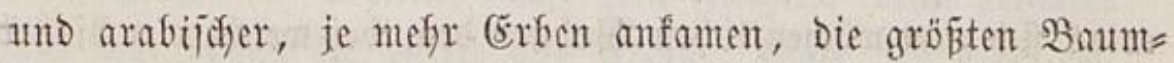
fodutber, bie er fich Denfen fonnte - jafy jeufzeno zu jebent 
(3ipfel auf, ber ftürzen wollte - und trieb nidfts burdis, als forftgeredyt Den $\mathfrak{W}_{\mathfrak{B}}$, auf weldyem Der falfente Baum Das Buidjyolz forjonen mußte.

Balt fouate erbärmlich berïber; fo leidst er fonft jein

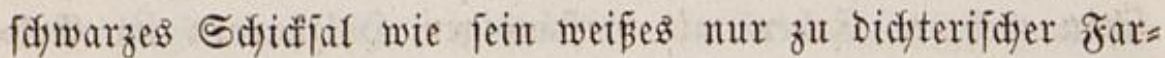
bengebung verrieb, gleidjpam ful fiofle unt zu firetDe: fo

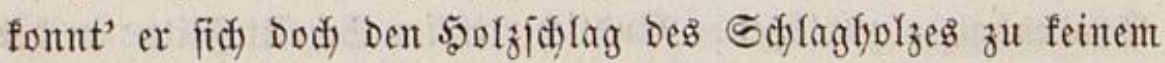
Didfterifden Baum[d]lag ausmalen, weil ifn Der Bater pei= nigte. (Fr wartete aber feft Deflen $\mathfrak{B}$ eggang ab; Dam fragte

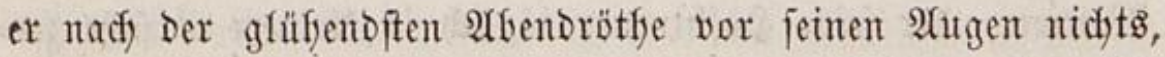

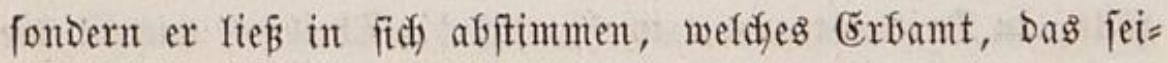
nen Bater freubig lafje, er jeb̧t zu wäflen lyabe.

Nun feflte es ifm aus Mangel des folotenjpielers an einer Stimmenfammlung uno an irgento einer, auds nur flein= ftert, Minorität, weil bie Majorität fefber (er) nur 1 Mann ftarf war, weldeses, went nidyt Die flemife - Denn oft ift gar fein Nann bein Stimmen - Dod) feine beträdytlidfe iff.

(Enolid) wäblte er Das fürzefte Afmt, nämlidid) Das fiefen= tägige Rebent bei einem (Erben. Die Stefle Darüber heí̈et im Corpus juris bes Teftaments claus. 6. Litt. g. fo: „er

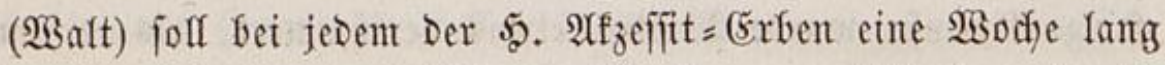
wofnen (ber (Erbe müft' es fidf Denn verbitten) uno alle

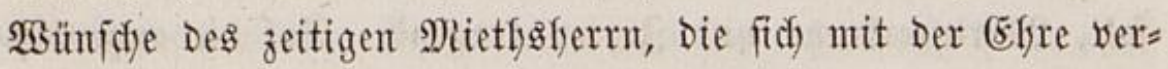

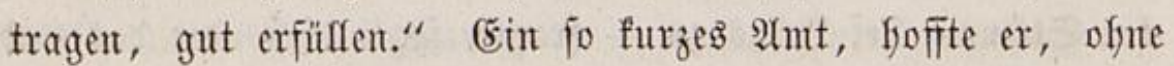
grose Fefftritte uno gefliprünge und mit einiger šfre und

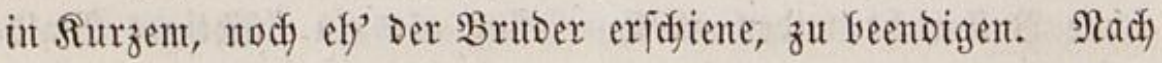
Der $\mathfrak{B a f f l}$ Des 2 mts muñt' er wieder Die neue Desientgen (Er:

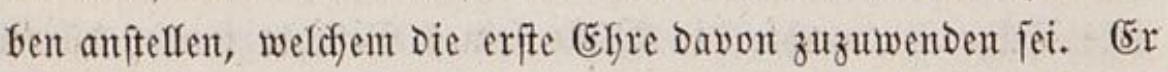
exlas fich zunt wödyentlidyen $2 B o f n e n$ Den, bei weldyem er bigher

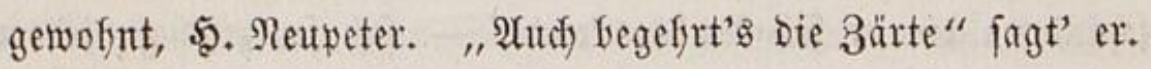


No. 52. $\mathfrak{A}$ tisgeftopfter Fliegenfdunäpper.

B o r ne h mes \&eben.

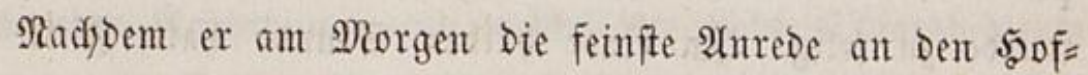
agenten ganz in Den Siopf gebracht hatte, woraus fie ofynelyin nod) nidft gefommen war: trat er vor Neupeter, Der ifn in Der Edrreibftube neben einem brementen \&idfte mit Dem ßet=

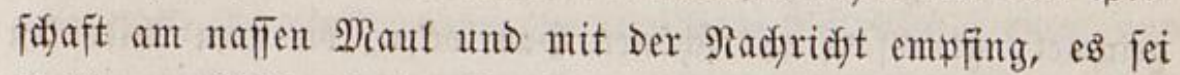
Bofttag. WBäfrent Der Raufmunn fortfiegelte, fielt er finter

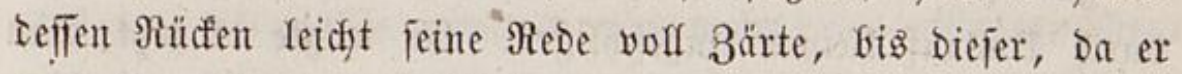
ausgefiegelt hatte, Das Ridjt auspubte und fragte: was gift's?

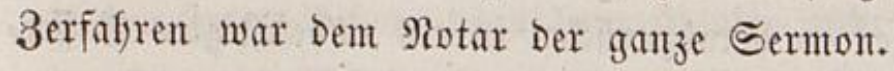

Siein Menjid fann Diejelfe Rede zweimal nacheinander falten; in Der (Ëile muß̃te er nur Darauf Denfen, aนs Dem (5e)agten einen Dünten Bleiertraft zu Yiefern. Der 5̧ofagent

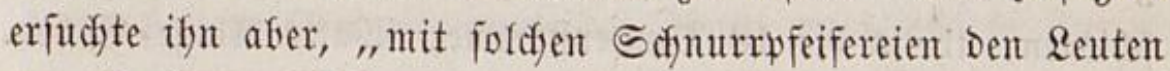
wom 5alfe zu bleibent."

Alle möglidje Sünden in neuen ante bätt’ er lieber getragen, als Diejes farte Thürzufiflagen vor Demjelfent. Semanten mut ferner Drbensfetten Durd) gefdenftes Borfaufs=

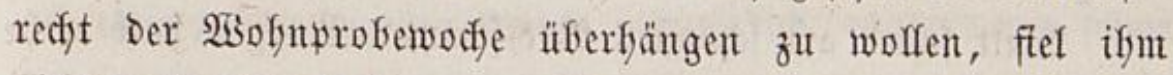
nidjt mefor ein: jonbern wo ein armer, aber guter Teufel, mit

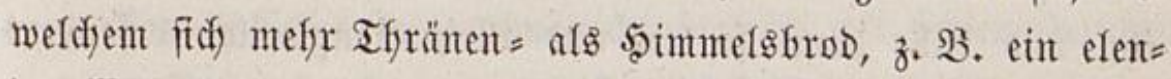
Deß $2 \mathfrak{B o f n u l o d y , ~ t h e i l e n ~ l i e ß e , ~ a n z u t r e f f e n ~ u n o ~ z u ~ b e g l u ̈ f e n ~ w a ̈ r e , ~}$ Darnady ging jein Sefnen, nidjt jein Fragen; Denn bejagter

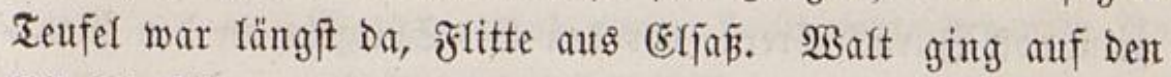
Nifolai= Thurm uno trug, aber furditam, flitten Den Borzug 
an, Dá er bei ifm die erfte Probewodhe balten wolfe. Der Elfaffer umbarfe ifnerfreut, und verficherte, er ziefye biefen

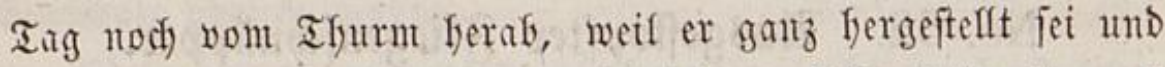
Der frif(d)en Thurmluft wentger bedürfe. "Id) miethe für uns ein \$aar foftbare garnirte 3immer freim Caffetier Fraisse; pardieu, wir wollen leben comme il faut," fagt’ er. Wantt wurbe zu fefig. Sn einer fyalben Stumbe hatte frlitte ein= und Darauf ausgepact'; Denn mit feinem (jeräthe Gatt' er, wie cine Raupe mo Spinne mit ifrem Fabengejpinnfe, gewäln=

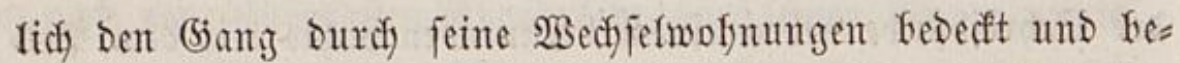

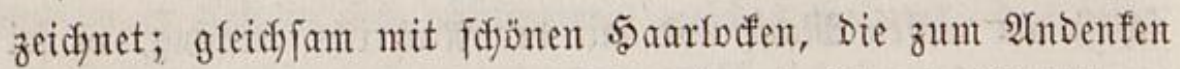
auggerauft werben; unb fyatte fidy, wie gedadyt, wie $\mathfrak{S B}_{\text {eltförper }}$

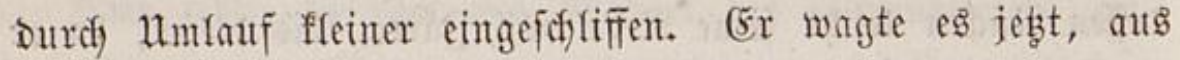
feinem Thurm - peiner fisflerigen Baftei und brănzfeftung

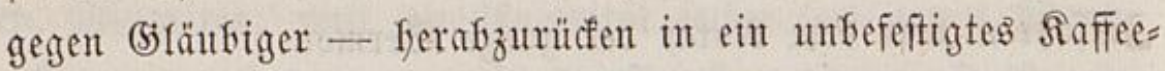
Y)aus, weil er theils fein eignes Ieftament beerbet batte, näm= Yidf Den Firebit Davon, theifs Das Rabeliche, in Deflen (bitter=

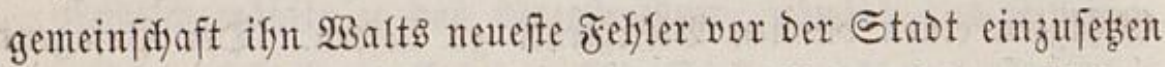
fojienen, theils Die 10 Iannenftämme, $2 B$ alts Silage= (Eid)ent. "Der ausgeftopfte Blaumüfler" Nro. 51. erwäfnte folon weit= Yäuftiger, mit weldem (5epränge er bie Durd) Walt gejüete Fefler = (Ernte von Steinofit uno Sienfuäujern aufgefnact uno ausgefernet fratte, un fid Der Stabt zu jeigen.

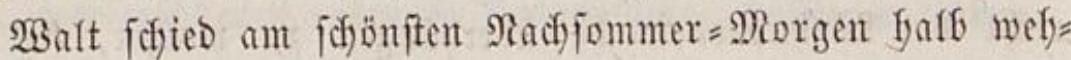
muttfig aus feiner Yeijen Rlaufe; ifm war, als fraudhe fie ifn und babe bann fo feer uno aflein 2 angweile, bejonders feit Eeflet. A̛ber wie fufyr er, ba er beim Caffetier Fraisse eintrat, vor Der (5arnitur Der 3 immer, vor Den fangen Epies

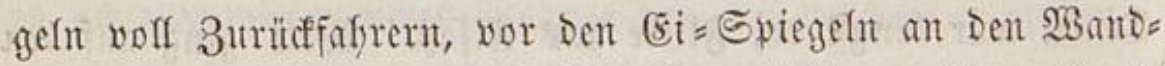

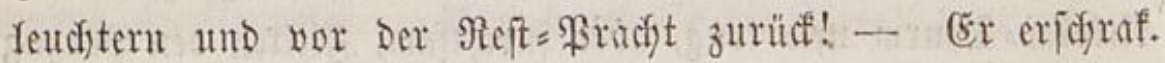


Fitte lädjelte - Fremben wollte $\mathfrak{W}_{\text {alt }}$ ein Criparer feyn; Daß̄ Der gute Elfajer foldje \$alläfte von Stuben miethe, bes Dadft' er und ftöfnte fefre. Denn er fieft's für âfunand feinetwegen, weil er nidyt vorausfebte, Daßj zlitte unter bie wenigen fogenamten Berfagmender geföre, Die wie Der Deut= idje Sinifer fdjwören, nidjts auf Die Radjfommen zu bringen, Reidf oder Reichtfum, uno weldye wie holge Staatsbediente Athens zum Beidyen ifrer Baterlandsficbe nichts finterla fert, als Radyrufm und Sdyuloent.

SBalt zog ofne weiteres das ats Der fiafelfifen Dpera= zionsfalle für Die Srofienwodje Gewifligte Goloftüf fervor, uno

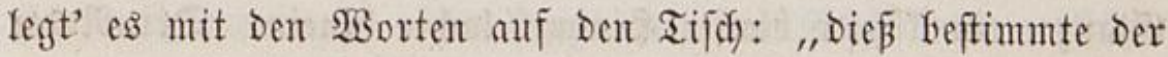
Ieftator; ich) wollte gem, es wäre mefr." - $B$ enige Mens fiden wurben nod) fo ftarf angefafiren, als er vou Flitten, Der ifn fragte, of er Denn beim b̧enfer nicht fein (5n fit jei?

Áber mun batt' er nod) cinen feinern Punft, nämlidy Dent

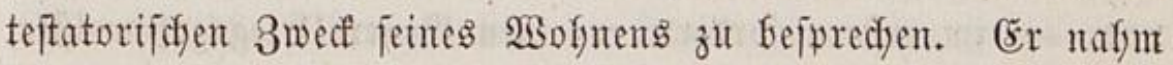
folgente $\mathfrak{B e n d u n g : ~ " e s ~ w i r b ~ o r d e n t f i c h ~ f o d w e r , ~ i n ~ b i e j e n ~ f o f t = ~}$ Garen beitern 8immern und bei Shnen an etwas fo Surifti= fiches wie Das Teftament und Deffen 5aupt= RTaujel zu Den= fent; Da idi afer meine zrente nidjt meiner Obliegenfyeit ges gen meine EIten opfern barf: fo - Darf id eben fdowerlid,

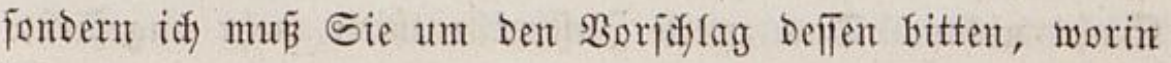
(id) etwa gefler begefjen fömte. Waffrlich, eg wiro mir fojwe= rer, zull fragen als zu flantoeln." -

Der (Elfajper fañte ifnn nidyt pogleidy mit feinen geinfyei=

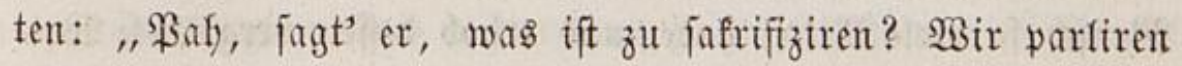
und tanzen zufammen; Das gefft ben alten Rafel nidjts an." - - "Farliren und tanzen? (verjebzte Der vom $\Re_{0}=$

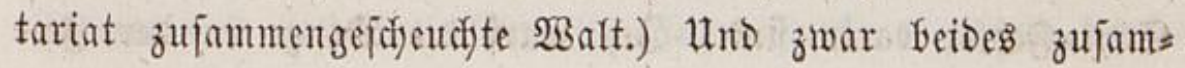




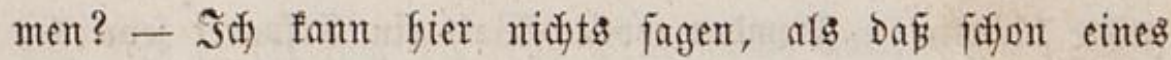
von betien einen unabjefybaren Spiefraum folt geflern auf=

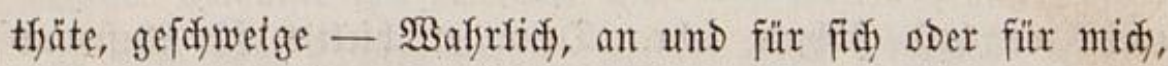
Yieber 5eerr Flitte - aber..." - "Sacre —! wo= von reden wir bent eigentlicf ? - WBird dent ein Menfid auf Der Errde prätendiren, Daß̄ man zum Yangnafigen Bür= germeifter läuft uno ifym es voringt, wie man luftig gewejen

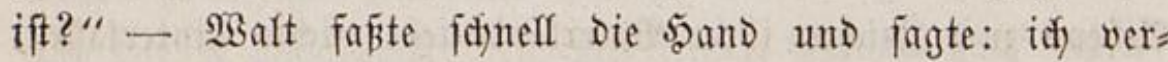
traue; und fritte umarmte ifn.

Sie frühftücften unter freubigen Gefprädyen. Die lan= gen renfter und Spiegel füllten Das geglättete Bimmer mit (5)Ianz; ein filffyer Glauter şimmel Iadjte fintein. Der Notar

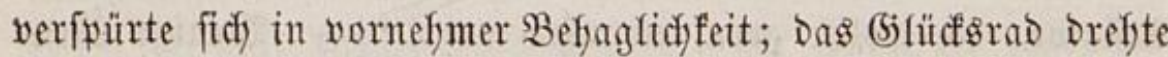
ifn, nidyt er bas Rab, und er braudute es nidyt wie cin Wagenrad erfit roth zu malen. Flitte las ifm zmei für Den Reid) $8=\mathfrak{2}$ nzzeiger in wenigen. Tagen auggearbeitete Injerate vor; - im erftern forderte er einen (5enteralfrieggazalmeifter, 5. v. N. N. in B., auf, ifm Die Gumme von 960 भtbus= thalern für $\mathfrak{B}$ ein innerfalb 6 Monaten zu bezafhlen, wern er

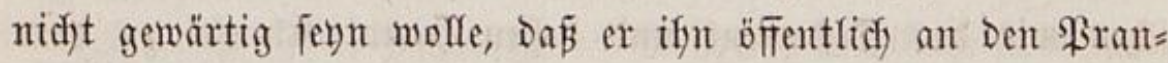
ger in Dem $\Re$. Anzeiger fteflte. Dem Rotar entoecfte er gern Den Ramen Des Mannes und Der Stadt; indeffen war an Der Sadje nidjts. Das zweite Injerat entfielt mefyr ungefärbte

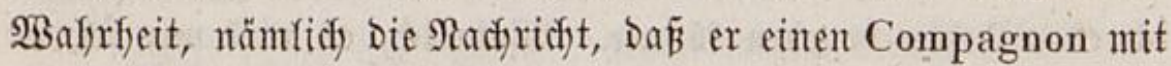

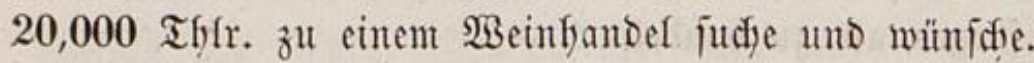

Walts Geficht glänzte von Freude, Dañ Der gutmütrige Menich fo viele Mittel habe, und erfob deffen vergoldete $\mathfrak{B e t}_{\mathrm{e}}$ terftangen Des Rebens red)t farf.

Fritte aber verfebte: "Sagen Sie mir aufridytig, ob feine Etyl= Fefler Darin fint? Id warf Die Dinge in Der Zeit 
einer fleinen Stumbe fin." Wart erflärte, je fleiner eine $\mathfrak{A}_{\mathrm{H}}$ = zeige jei, Defto fidfwerer werbe fie; er wolle leidjter einen $\mathfrak{B}_{0}=$ gen für Den Druct ausarbeiten, als De Det wol überlyaupt lufulviren viel? 2 nn Der Mafrobiotif fa=

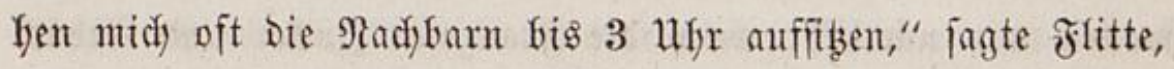

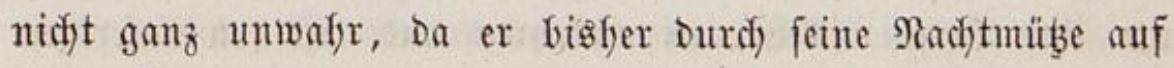
einem 5aubenfto of und Durdid ein Ridjt Daneben einen mafro= fiotifichen 2 ejer auf Die leidftefte uno gefündefte 2 seife vorges feellt Katte. Darauf fonuurte er vor Dem Notar, Deflen herz=

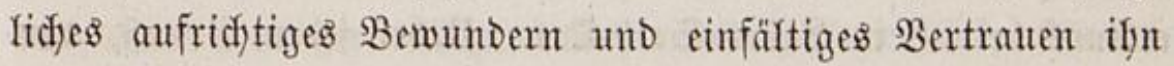
mit füß̈er $\mathfrak{B}$ ärme Durdfyog, ein Bünoel feiner Riebegbriefe an fid) auf, worit er, fein 5aerz und fein Styl jefre gejdüzet

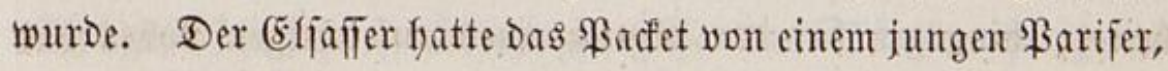

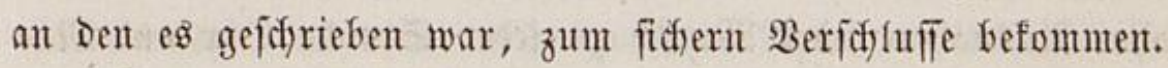

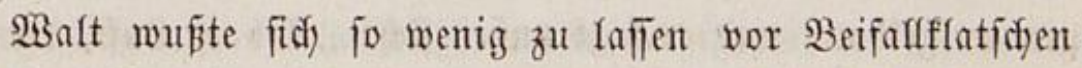

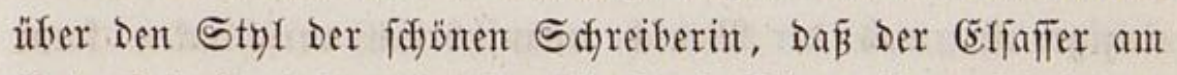
(Ende beinabe felber glaubte, bie Sadje jei an ifh gejorrieben; aber jener that's jefr Deshalb, um nidft über Die Siebe jelber viel zu reden. Da er als ein unerfafyner veridjämter Süng= fing nod) glaubte, Die Empfindungen Der Riebe müften fin= ter Dem Rloftergitter, fö̈dyftens in einem Rloftergarten Yeben fo fagt' er mun im Aflfgemeinen: ,Die Riebe Dringt wie Dpfer= rauth, fo zart auch beide fino, Dod) im Dicfen Regenmetter Durdh bie fifwere \&uft empor" - wurbe aber ungentein roth. "Surement, fagte Der Erlaffer, Die Riebe frebt jeben $\mathfrak{I} a g$ imt= mer weiter."

Flitte ging nod) weiter und zeigte fich feinem (5ajte gar gebruteft, or wies ifm näm(id) bie feinften Riebes = Minorigale, Die er, wie er fagte, orucfen Iaffen in (5entefimo= Bigefimto= Format und nie über einen $1 / 20$ Bogen ftarf; es waren $\mathfrak{B}$ erje= 


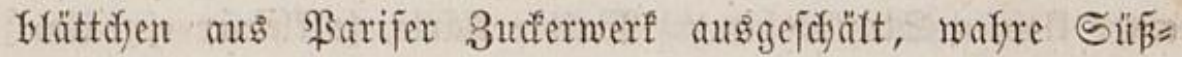

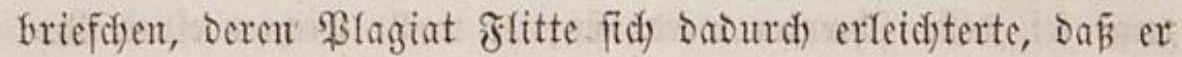

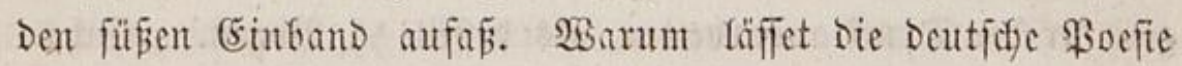

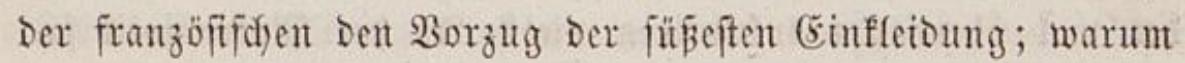
wollen wir nämlich, wenn Die granzojen Buffer und Bebäaf um ifye Berje wiffeln, es umfefren uno mit Den unjerigen 3uterer und biswürz cinfletoen und einpacfen - fömute man fier fragen, wenn es Der Drt wäre, fier zu antwortent. -

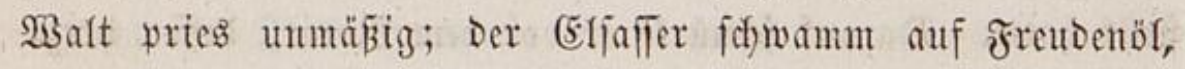
ertranf beinaly in Robes= Salb= Del. Heber jeden Bjemur, Den man Den Menfden wofylwollend zubereitet, waltet Der 8 ufill Der $\mathscr{2}$ funafyme, Des (5) mumens, Des Magens, Der ifhn verar= beitet; Gingegen für Den (jenuß eines aufridytigen \&obes fat

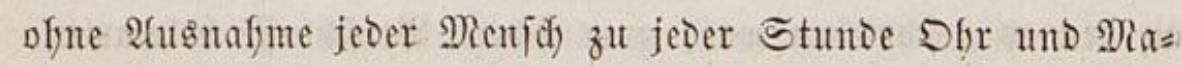
gen aufgetfan; und er jagt auker fict): „2ob ift \&uft, Die Dab einzige ift, was ber Menidi unaufbörfich verid)luten fant

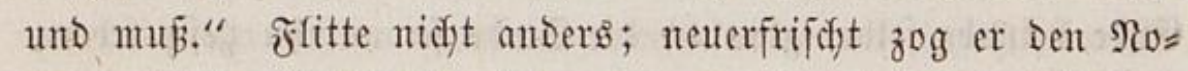
tar auf Die Stabtgafien finaus, um ifm einige freuben zu madyen uno fict) Plaţ. Rämlid) Die alten (5) äulviger jagtent ifym fo eifrig nadi als er neuter; Da er mut Die Marime Der Römer fannte, weldhe nad) Nontegquieu fo weit als möglids vom 5amije firieg füfrten: fo war er jelten zu 5auje. Beibe Durdfifrichen Die Morgenftadt; und Balten murbe fefr wohl. Da Flitte Der StaDt fid zeigen wollte - nämlid Den Sinfels:

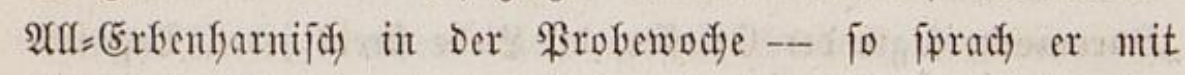
vielen ein 20 ort; uno Der Notar ftano glüflich Dabei. Bor jebem Barterre = Fenfter - par-terre, fagte Flitte, fprectyent Die Deutjden ganz fulfod aus - flopft' er wie an einer (5) asthüre an uno jagte bem aufmadyenden Mä̈dyenfopfe,

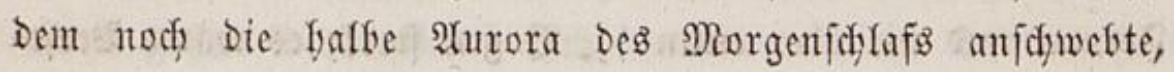


Guntert gute Dinge, und Die Todyter in Der Norgenfleidung mußste am zenfterrafmen fortnäfert. Dft gab er ofne weite

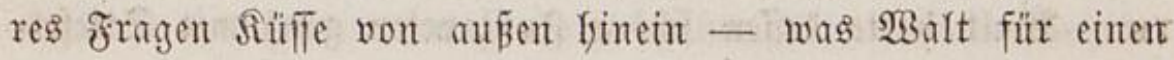
(5rad yon Rebensart fielt, Den mur einige bünftlinge Frant= reidys erreidyen. Raudjte ein anjefnlidyer $\mathfrak{M a n n}$ in Der Siflafa feibe mit Der Ffeife aus bem zweiten Stod heraf: fo fprady ober ging flitte finauf und $\mathfrak{B a l t}$ that's mit. Sener fannte jeben lange; Denn bei Dem 5adf bürgerftande lefyrte er Die Sinder tanzen und feim Arbel bie şunde; reb̧terem ging er

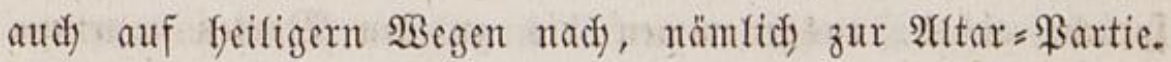
Dent Da Der 5ablauer adoet, wie befannt und fonft gewöfn= lidi) ift, in corpore offentlidf) auf eimmal als cine fycilige

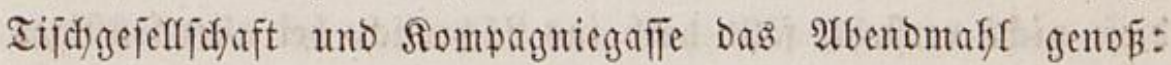
fo war er finterorein uno Der lebste Mann, wie finter Den Bürgerlidfen Der Edyarfridyter; Das einzigemal ausgenommen, wo er wie cin Sdfieferdecter es blog nafm, weil er cinent Ifyum beftiegen. Waalt betrat nie mefyr Bimmer als an bie= fem Morgen. Sprengte ein 5aerr vorbei, Flitte wuß̄te ein Bort über Den (baul nady zufficfen, etwa diejes: er finfe.

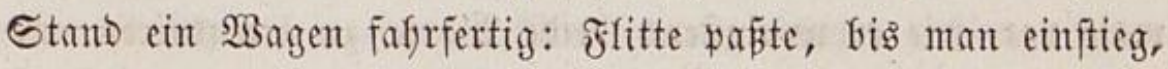
uno verfie

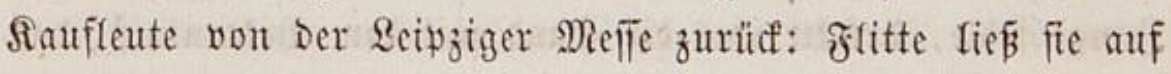
Die Nieß = Reutgfeiten von 5aglau nie fo lange warten, bis fie unter Dad) uno Fach waren, fondern er pactte aus, wäf)= rent fie auspacten.

Balt wurbe alfer $\mathfrak{B}$ cit vorgeftellt und redete mefrmals.

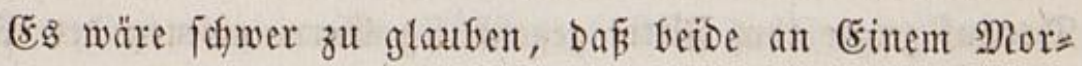
gen fo viele bejuche abgeftattet haben, wäre nidyt bie (benvi Jeif Da. Sie gingen zut Dem Spiben = pber Rtöpwefferm

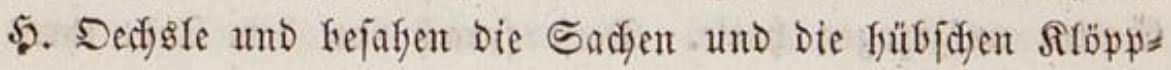


Feriment aus Sachjen und viele Snöpfe aus (Eger, in weldje Bögel falb mit Farben, falf mit eigenen zedern gefajpet wa= ren. Waalt fratte Defien fojöne Funtapeten ganz mit Stiefel= fpuren veridjont burdy einen einzigen tapfern $\mathfrak{B}$ eitjadritt, Den er über fie fogleidh in Die gebolynte Stutbe that.

Sie gingen ins (Sartenlyaus Des Rirchenratl) (5) fanz, wo Frltte jeine Ratinität an Dem Supferfitid) eines Sanzelreoners fodwad) zu zeigen judjte, indem er Die Darunter gejebten Iatei= nifden Berfe uno Notizen fertig uno mit gallifher $\mathfrak{A} u s=$ fpradie ablas, ausgenommen bis zut Den 2 sorten mortuus est anno MDCCLX. Dent wer foldhe frembe Baffenzeichent mefre in eigner als in frember Spradhe ablefen mus, weil er Dieje nidyt werftefyt, fällt halb ins \&ädjerlidye bei aller jonftigen (5elef)rjamfeit. -

(Fr ging mit $\mathfrak{B a}$ alt zum $\mathfrak{B}$ oftmeifter, blos $14 m$, wie er gewöhnlid that, nad Marjeifler Briefen vergeblid zu fragent.

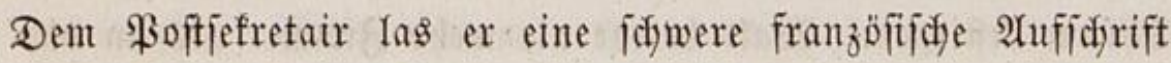
vor. Walt wries Defien Accent und Prononciation aufridif $=$

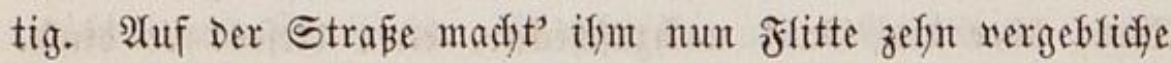
male vor, wie er wentgftents beibe 28 orte fut accentuiren und zu prononciren babe. WBalt geftand, Daß ifyn mefr Dhr als

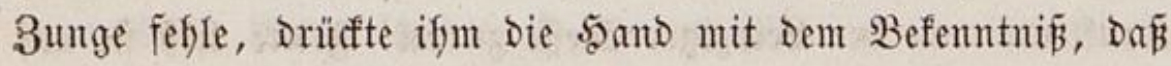
er Die meiften franzojen gelejen, aber nod) feinen gefjört, und Daß̉ er Deswegen fo eifrig auf jeden Raut von flitte hordye;

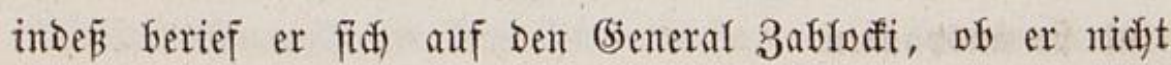
viefleidyt eine erträgriche Saand von Sdyomafer Davon gefradjt. Darauf zeigte ifm Flitte gegenfeitig (5ermanigmen Der \$hra= fen, die ifym nodi anflebten.

Sie gingen zur Stücfjunferin, bei weldher $\mathfrak{W a l t}$ neulich Saiten aufgezogen hatte. Diefe jprady won Dem Tode ifres 
Names und Der (sinäfderung eines \$alfajtes, Den fie im belagerten Toulon gelfabt, aus weldyem fie nidjts gerettet, als wab fie zur (Erinnerung ewig aufbewahrte, einen Rachttopf

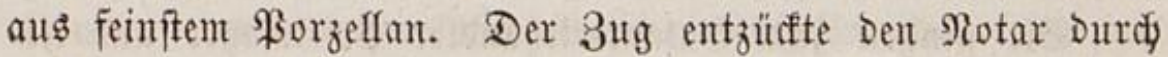
Dent vornefmen 3ynismus, womit er im 5appelpoppel Reute

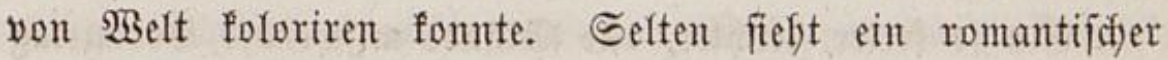

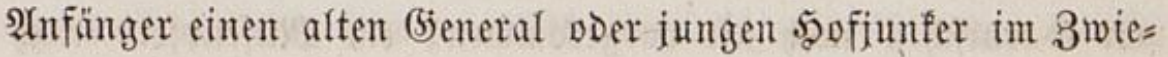
Yidjt z. B. piffen, ofne fidh an Den Edyreibtijid nieder zu

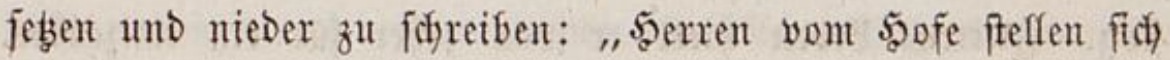
gemeinfin im 3 wielid)t in (Éfen." Man fprach viel fran= zöfific); und $\mathfrak{B a l t}$ that was er founte und fagte fäufig: comment? - Flitte zeigt' ifym nadyfer Den Bjermanismus it Der Frage.

Sie gingen in bie weiblidfe ifm Durdy Bult befannte ßenfionsanftalt, worin nod) mefre (sallizismen uno nod mebr Sijönfyeiten regierten. Flitten war nidyt nachzufliegen im freien 2 rrtig(e)n; Dod) war's ifm genug, mur nad)zubliffen und zwifichen Den Beeten voll Seefentifien eng bie eine Fup =

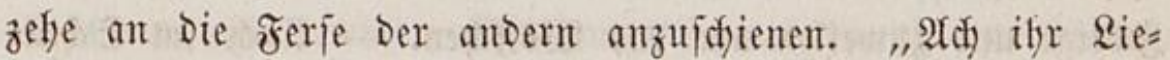

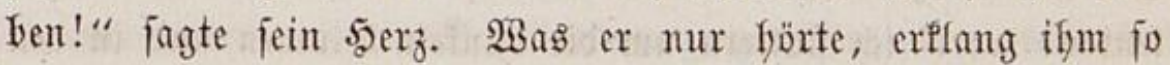
zart; ",aber, Dadyt' er, find Dem frauenzimmer anders? Mits

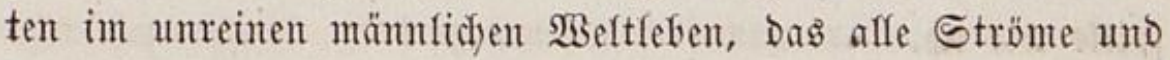
Reiden aufnimmt, finto fie ja abgefondert voll eigner Rein= heit; im jalzigen $\mathfrak{B e l t m e e r} \mathfrak{f l e i n e}$ Injeln woll frifodjen flaren WanTer: ; D Dieje Guten!" -

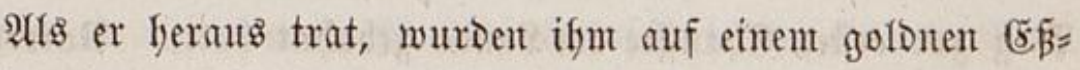
geiduirr des regierenden Füriften leidyte Farichen, Rouletten

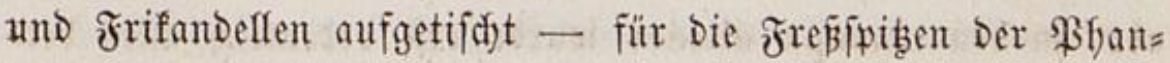
tafie. Das (jejhirr - Das (jejojenf eines alten Rönigs wurde nämlidy jäfrlid zweimal öfrentlid auf Dem Marfte 
afigeicheuert unb gewntgit unter ben 2 tugen eines fleinen fiom=

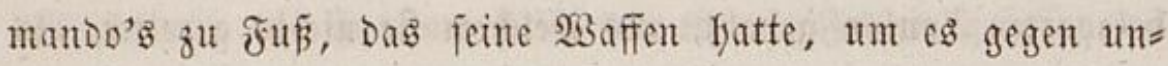
geratfene Landesfinder fol Defien.

Sie gingen zum Garanterieffänder Frielmayer uno lie= fen fitif von Der Bradyt Der weiblidyen $2 B e l t$ ungefen.

(Ein jo freier, leidyter, afle Stände mifdyender Bormittag war 5arniffen nod nie vorgefommen; ein Mujenpferd nady Dem antern wurbe feinem Siegeswägeldhen angefohirt und es flog. Flittens Reben fielt er won jefer für ein tanzenteg Jruifffiticf uno für einen the dansant; fein eignes fielt or

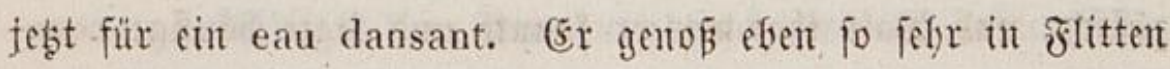
- Den er fids wie fid begeiftert Dadyte - alb in fich feller Ginein; dic elfafifidgen Somnenfäubdyen vergoldete und bejeelte

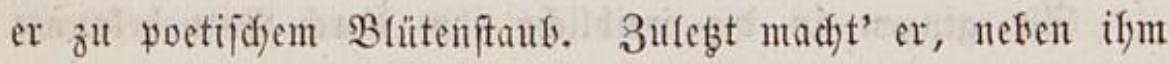
getheno, beimlidy folgende (brabjdrift auf ifn:

(5) rabidifift bes 3 ephyrs.

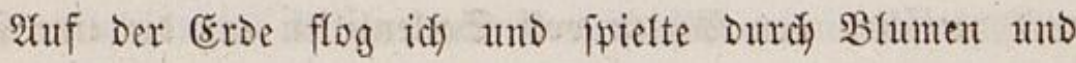

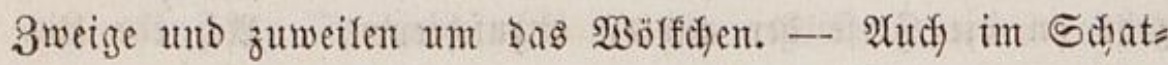
tenland werb' idf flattern un bie Dunfeln Blumen und in ben Saanen (Etyfums. Stefe nidft, 2 anderer, fondern cile und fpiele wie idf.

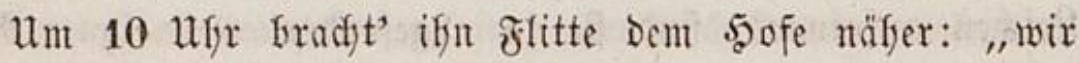
getent in bie champs élisées uto nefynten cin dejeûner dinatoire." (Es war ein bejafyter Fürftengarten, weldyer Den

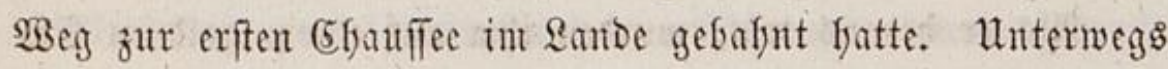
fingen zwar $\mathfrak{B}$ armungstafeln gegen Simber und sumbe an; aber in Den champs élisées wurbe erft ordentlidy alles ver= Goten, befonders bie elyfiffyent Felder felber - in feinem $\mathfrak{B}_{a}=$ radies gab es fo viele verbotene Bäume und frudt = und 
Blumenfperren - auf affen bängen Glüften oben ober feim= ten unten Ferfer $=$ Diplome und $\mathfrak{A}$ tus $=$ und Einwanderungs $=$ verbote - unter (Exweftanzofreten Der 3üdytigung Durd)=

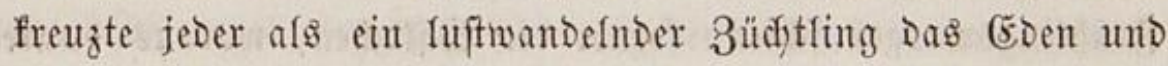
feierte $\mathfrak{B e t r i}$ Rettenfeier im (jefen und frapazirte fid finter feinem Rüden - mefr wie eine $\mathfrak{B a f l f a f y r t}$ Durdg Dante's 5ölfenfreife (Der 5̧immet frteb nirgends, als üfer Dem Ropfe),

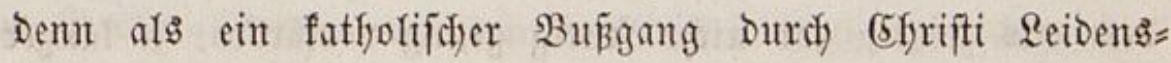
Stazionen fam jebem unter Dem fodriftlicten $\mathfrak{A}_{n j}$ jonauzen affer fluchenden Bäume und Tempel fein Ruftwandeln yor - in Der Menfd verfimmte fid zulekgt in Den champs uno fam fatigirt beraus.

WBar 23 alt je frof und frei: fo war's in biejen Felbern; fein innerer $\mathfrak{R e n j}$ क trug ein Thyrus=Stäbchen und rante

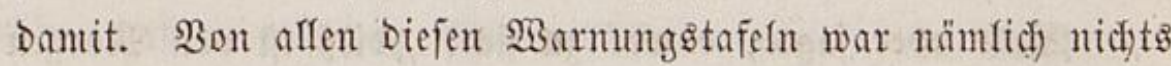

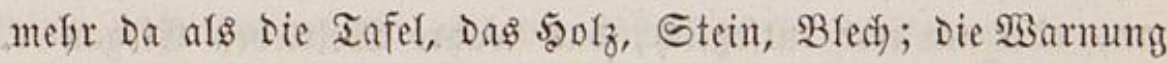
aber war gut vermoofet, verrajet, werjandet. Sïftliche frei=

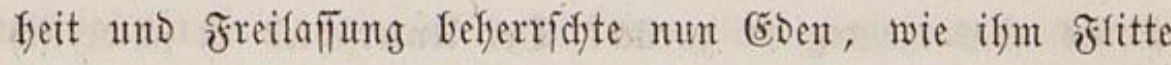
beffiwur und bewies. Die ganze Sperroromung war blos in jenen Beiten an Der Tagesoromung gewejen, wo grofé uno fleine färften - ganz anters als jebgt bie grofen, (höflich) zut fprechen) etwas grob gegen Untertfanen waren, uno wo fie als Efrentilber Der Bottheit - weldye barin efen nidyt non Demt Maler geiffmeifyelt wurbe - Dem melfr jübijofyen als evangelijchen (sotte Der Damaligen Ranzeln äfnlich, bifter Don= nerten als fegneten. "Waas die Бerrichaft jelst etwa im \$arfe fefre lieb uno gern bat, fagte Flitte, bien ift fodon befonders red)t eingezäunt, fo Da of ofnefin niemand finein fann."

Seite nafment iffr déjeûner dinatoire, Norgenfroo unto Morgenwein, in einem offenen und fuftigen Ritosf, unweit Deß 


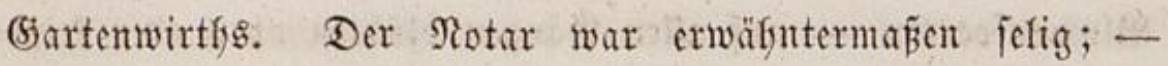
Den auf $=$ und abfiteigenton Iag $=$ und Nacjtgarten fammt Dem leidyten wie herabgeflogenen suitid lofle, bas ein verfteinerter Früflingsmorgen foften, ferner bie $\mathfrak{B a ̈ l}(\mathrm{d} d) \mathrm{en}$, woraus bunte Suffyüusden wie Tulpen heraus wanften, Deggleidyen bie ges malten Srücfen uno weipen Statuen uno Die Regeljonnüre vieler şeffen und ssänge - Das fonnt' er Dem Elfaj̄er, Dem er's zeigte, gar nidft feurig genug vorfärben, je länger er tranf. Dicjem geficl's natürlidf); Dem gewöfnulidy füfyrte

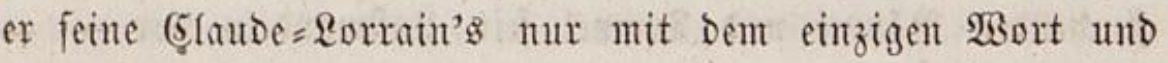
Etridje waffer aus: füperb! - Seder aber frat jeine andere Sauptfarbe Der Bemunterung; Der eine fagt: englifac)! - Der andere: fimmlifid)! - Der Dritte: göttlids! - oer vierte: ei Der Ieufel! - Der füufte: ei! -

Walt aber jagte, obwol ful fids): "Dief ift von Morgen an, ober id irre entiebzlid), Das wafre Weltefent Eleganter. Bin idy nidyt wie in Berfaiffes und in Fontainebleau; und Souis quatorze regiert zurüf? Der Muteridfied ift fofwerlid erfeblich. Dieje âteen - Diefe Beete - Büjue - Diefe vielen Reute am Morgen - biejer fichte $\mathfrak{I}$ ag!“ - Waltent

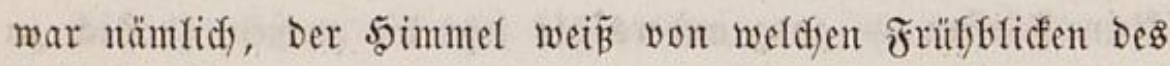

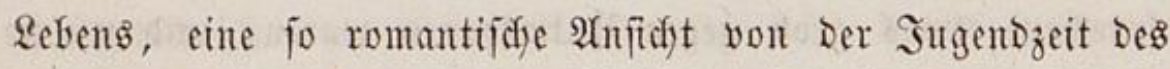

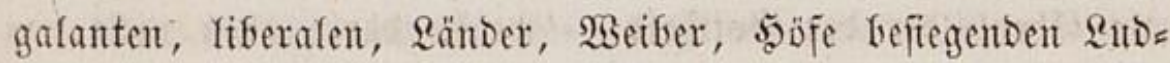

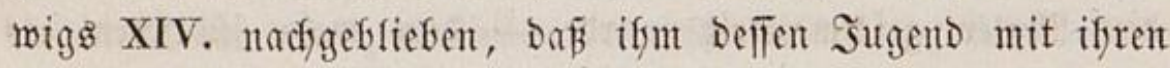

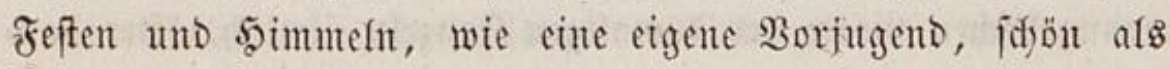
fanftes Fenerwerf in ben Rüften voridiwebte, und wie Der

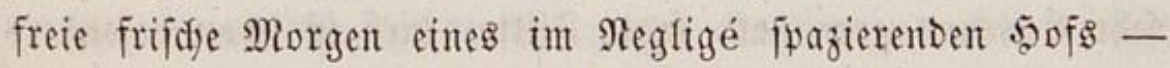
fo don iffu jeder Springfrumuen nadi Marly warf, jede ges farniegelte Allee nady Berjailfes, und fohe fontanger Sutpfer=

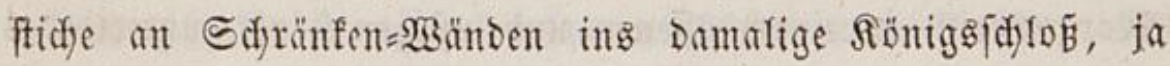


fogar bie autgefdynttenen aufgepapsten- Bilbdyen auf feinent Edjreibtifide flogen mit ifm in jene luftige $50 F=$, wemt aud

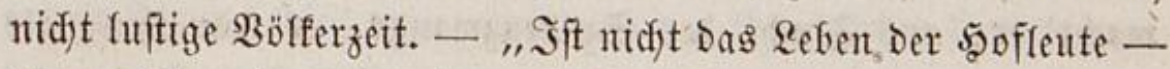
hat er fich) mefrmals gejagt - fortgethende Boefie (wem anders

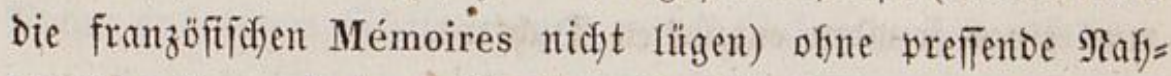
rungg̊qualen uno in geflügelten Berbältniffen, uno bie 5̧of=

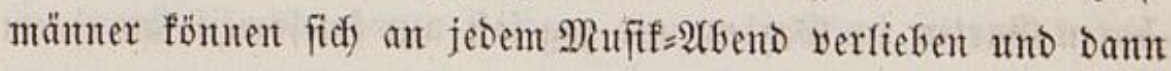
am (5arten $=$ Morgen mit Den berrlidffen (5jeliebten fpazierent gefen? D wie ifnen bie (söttinnen blüffen mü|Ten im fri= fdjen fdjminfenten Morgentoty!"

Daburd) gentó er im (5arten einent gantz andern fodjont beerdigten; als Feuerwerf fing Das phantaftifiche Nachbild über

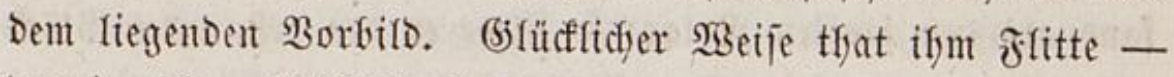
Der in jeder (sejellidyaft ftets eine neue fudyte - Den (5ie=

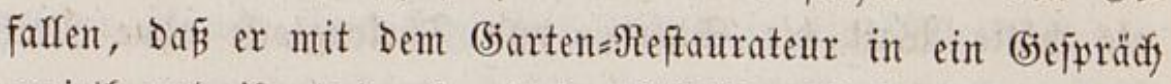
gerietf) und ifn Daburch mit Der föftlichen (Einfanfeit zu eini= gen träumerijd)en Streifzügen bejchenfte. Wie freutig that er bicje! (rr jafh alles und Dabei an - Die grünen Scfatten, von Sommenfunfen Durdyregnet - bie fermen Seen, einige wie Dunfle Âgenfieber Des $\mathfrak{B a r f s}$, einige wie lidjte $\mathscr{A}$ ugen - Die Barfen auf $\mathfrak{B a f f e r n ~ - ~ D i e ~ B r u ̈ f e n ~ u ̈ b e r ~ b e i b e ~ - ~}$

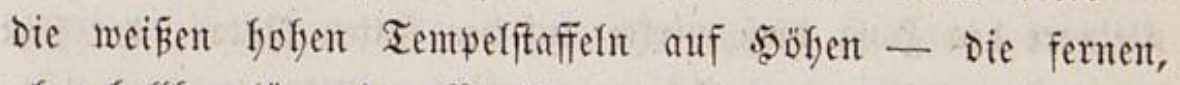

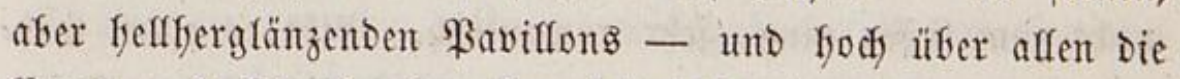

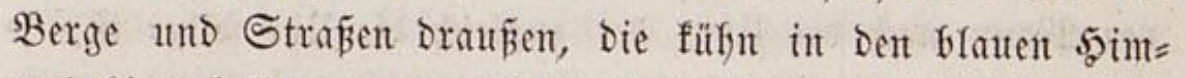
mel finauf flogen. - Sein Bormittag fratte fidy ftünolidy

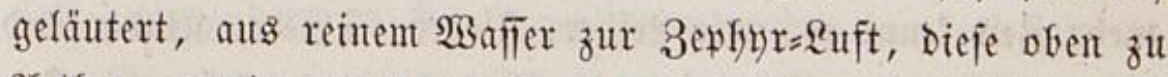
Aetfer, worin nidyts mefir war und flog als 2 Belten uno Sidft. Den Bruder fuätt' er gern hergewwünjod - $\mathfrak{B}$ ina's

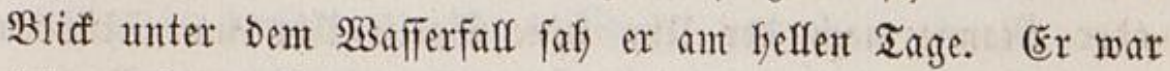
felig, ofne redyt zu wiffen, wie ober warum. Seine gacfel 
Srannte mit geraber Spize auf in ber fonft wefenden 2 Beft uno fein Rufftdyen bog fie unt. Ridyt eimmal einen Streffvers macht' er, aus fludit Des Sylfentwongs, es war ifm, als

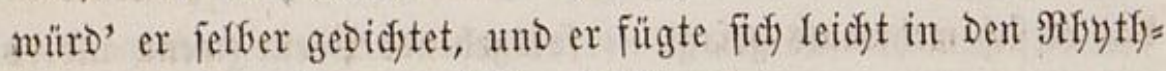
mus eines fremben entzüuften Dichters.

In Diejem innern 230 flffang ftand er vor einem fonder= baren (5arten im (5arten und zog faft nur pielsweipe an einem (5)löfdcen ein wenig. (5r hatte faum einigemale geläutet: fo

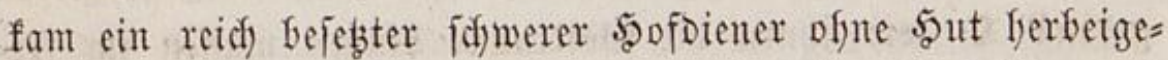
rutbert, um einigen von ber fürftlichen gamilie Die Thüre auf= zureißen, weil Das (5löfdfen Den 3 werf einer Bedientenglocfe f)atte. $\mathfrak{A}(\mathfrak{B}$ aber Der vornefyme Menjidy nichts an Der Thüre fand als Den fanften Notar: io filzte er Den exftaunten bilöct= ner in einer Der längften Reben, Die er je gefjalten, aus, als bätte 2 alt bie Sturm $=$ und Tüfenglocfe ofne Noth gezogen.

Diejent war inder jein Inueres fo leidyt und feit ge=

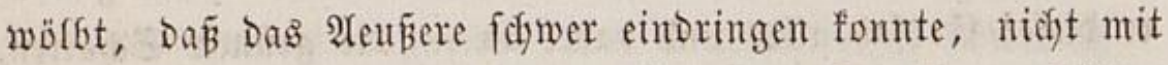
einem Tropfen in fein leidstes fliegendes Edjiff; ful Flitten

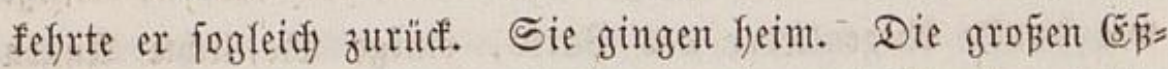
glocent riefen bie Staot zujammen, wie zwei Stunden fpäter fleinere Den 5ุof; Dieß̄ wirfte auf Den jatten Notar, Der jebst

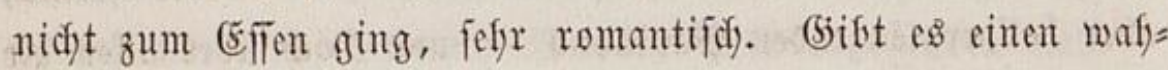
ren Mann nady Der Mhr, Der zugleidy Die Mhr felfer ift, fo

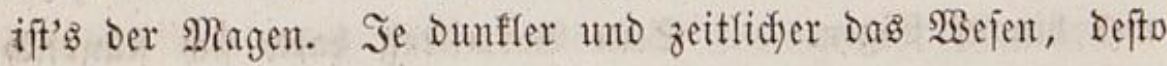
mefr 3 eit fennt es, wie Reiber, Fieber, Thtere, Simber unt SBabninnige beweijen; nur ein (beift fann die Beit verge len, weil mur er fie fduffit. Birb num Dem gedadjten Magen

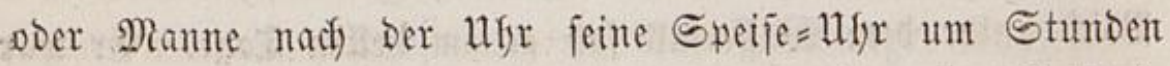
yoraus ober zurüf geftellt: fo madyt er wieder den beift io 
irre, Dafa dabiefer gantz romantifí wirb. Dent er mit aflent

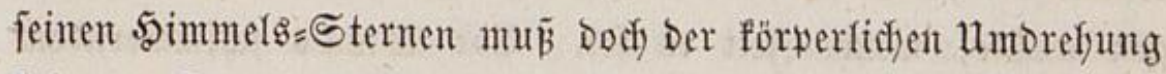
folgen. Das Frülfftücf́, Das ein Spätitüaf gewejen, warf Den Notar aus einem (sleife, worin er feit Safrzefenden gefafyen

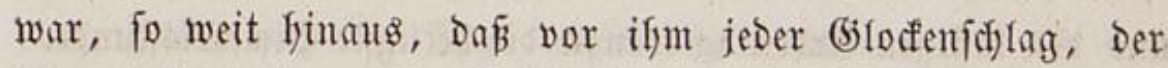

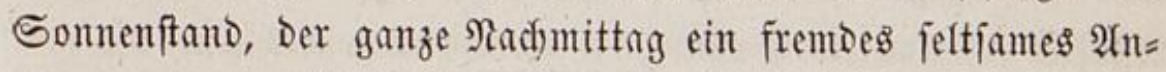
fehen gewant. Bielleidft madyt Dafer Der Ririeg Den Disziplinir= ten Eoldaten Durdy Die Berfefyrung aller Zeiten in unordentlichen

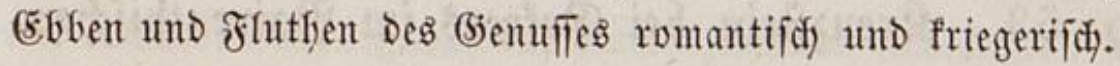

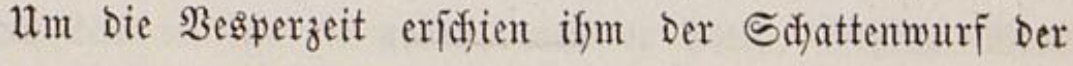
5ăufer nod) munderfidjer uno in Fraifiens 3immer wurb' if)m Die Zeit zugleich) eng und lang', weil er wegen feiner un= tergrabenen Sternwarte nichts yorausfefen fonnte. (Er wollte wieber Monde, unb begleitete Ffitten in ein Biflarozimmer,

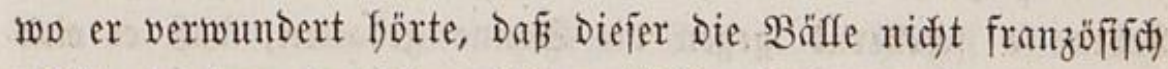
zäflte, fondern Dentiof. Soter entfief er bald aus dem magern

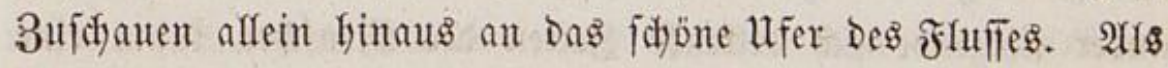
er Da bie armen Leute erblicfte, weldite an biejem Tage nads

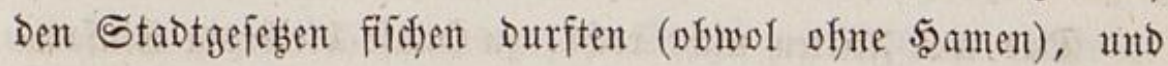
5oolz lefen (ofwol ofne Beil): fo erfielt er plobslid an ifreen

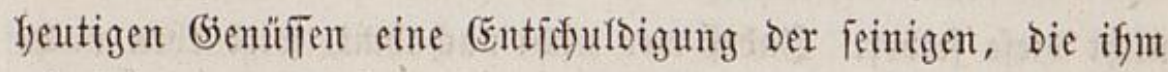

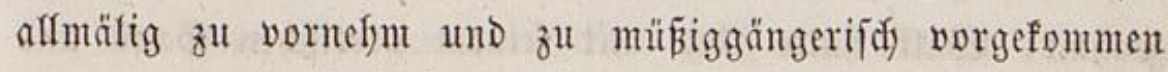
waren: "aud id babe, Dadit' er, heute vornefym gemug ge= fdjwelgt und fein 2 bort am Roman gejdrieben; Dod) morgen foll gantz anders zu 5auje geftiefent werben."

Die langen $\mathfrak{A}$ fend $=$ Sithatten am $\mathfrak{H}$ fer und bie langen

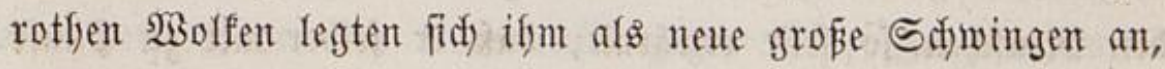
weldye ifyn bewegten, nidst er fie.

(5r Durdhftreifte aflein bic Dämmernden (5a) afen, Gereit zu jebem Afenteuer, fis ber Nond aufging, und feine Monds=

Sean Yaut's sutgerw. Wetie. XIV. 
Unjr wutroe. Da war Der Wirrwar gelidytet, und Der Mas gen wußste, weldye Beit es jei. Bor $\mathfrak{B}$ inta's forimmernom 5aule trug er Das vielfach erregte 5erz auf und ab; Da fanf ify in bafferfe eine fiffle Gefnjufft wie vom 5immel nieber,

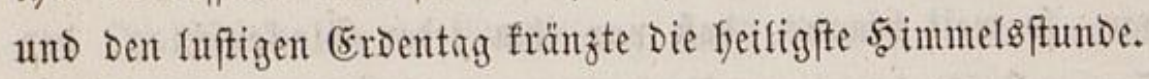

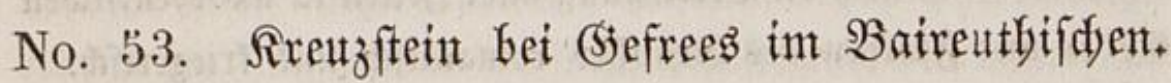

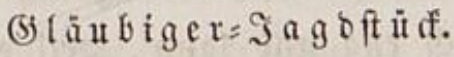

$\mathfrak{A m}$ Morgen frente fids $\mathfrak{W a l t}$ findifid in Den verganges nen Iag zurüt, weil biefer Durd) eine fleine $\mathfrak{B}$ endung fein Leben to fojiflerno gegen bie Some gehalten, Dá er eine Menge Iage an Einem verlebte, indé fonft viele fintercin= ander fliegento fich Deffento 3eiten Des Menjoden faum eine żeigent. Saeute aber blieb er jut 5amje und farieb fefrr.

Das war Flitten nidyt recht; 孔̆ 5auje bleibende (sinjam= feit war ify wol wïrze und 3 ufoft der (bejellidfaft, aber

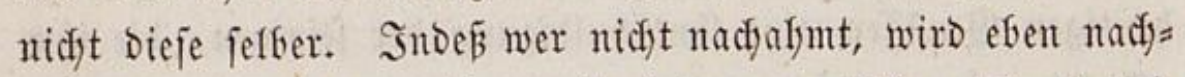
geafyut; Balt hatte ifm mit feinem poetifoen Saus und Brauts fo jefyr gefallent - ob er fid) gleid) als feine profaifoche

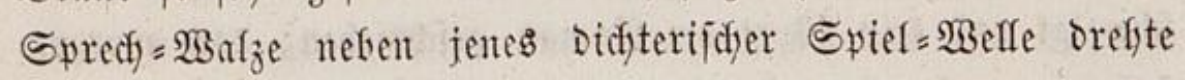
und ifn jelten verffefyen oder feantworten fonnte - uno Deffen

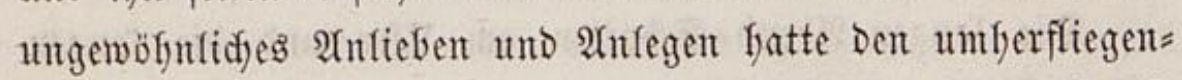

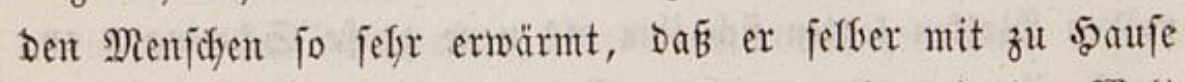
frleb, blos bet iffm, of er gleidy beffer als einer in ber $\mathfrak{B}_{\mathrm{e}} \mathrm{lt}$

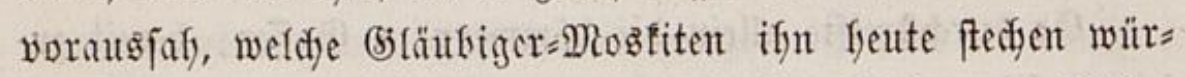
Den, da Mücfen befanntlida uns mefr im Stefen als (5seben 


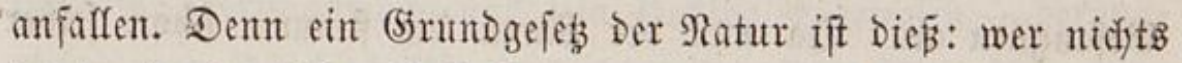

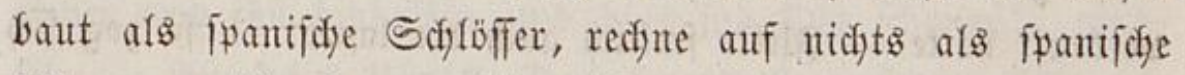
Fliegen, weldye fo gemaltig ziefyen. (sin zmeites (sejebs ift: man faun nidft früf) genutg bei einem fojledgten Sdyuldner voriprectyen, Der efen Tags vorfer belo befommen.

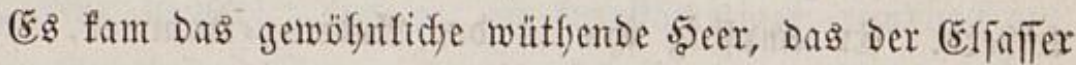
immer als ein gefjeiltes zuriud idficfen mupte, zu redjter frï= ber Iageszeit an; und flitte fonnte es fier wie überall in Der befonters Dazu gewäflten Âtubienzfammer emtyangen, um foltyem Das einzige zul geben, was er fyatte, (jefjör. Blos

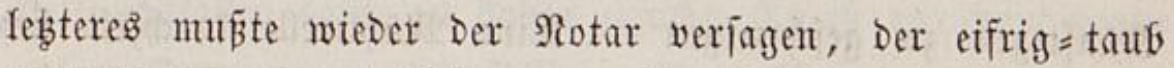
fortoidftete, wäfrent Flitte-von weitem jeine Sdyladjten joflug.

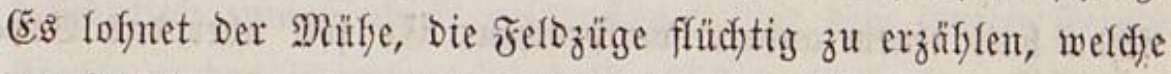
Der Elfaffer an einem Tage that, bevor er Afents Das warme Winterquartier Des Betts bezog. Der linfe frtügel Des täg= lid) angreifenten seeres war aus SttDen geworben; uno Dest redjten formirten 3 immer $=$ und Pferde $=$ und Büdjer $=$ Ber $=$

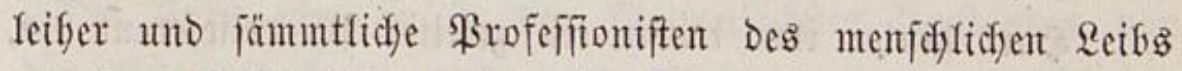
und Deren Fifdyeifer; und an Der Spibe zog als bienteraliffitmus ein Mann mit einer Tratte; - Die pffizieflen Beridyte Davon find aber folgente:

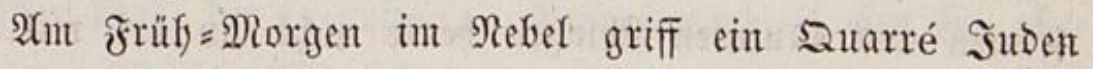

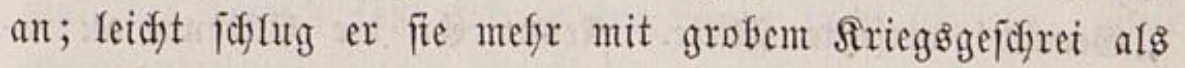
feiner Ririegglift zurüaf uno jagte mur: "fie wärent nur Juden, und er habe nod) nidjts, und was fie weiter wollten?"

Beim Früffftücf mit $\mathfrak{B a l t}$ berennte ifn ein Mfrmadjer, you weldyem er cine Repetirufyr gegent feine Beigenfr und (5eld = 2Nifignate eingefauft fratte. Flitte fojwur, fie repetire fojledft, feine fei ifjm eben fo rieb - aud repetirt eine Beiges ubr wenigftens bas 3eigen - uno bot $\mathfrak{A}$ uв̈wechalung ber 
Befangnen an. Da nun Der Maun bie fumme fodjon felfer verfauft fratte - Flitte freifich aud bie faute: - jo zog fid

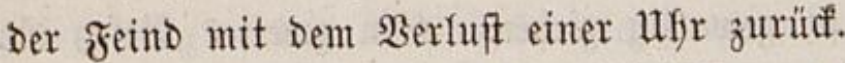

Später faf er zul feinem Gilüfe aus bem fenfter und Die Bewegungen Des berittenen Feindes, eines $\mathfrak{F}$ ferde $=$ Ber $=$ Teifers. (Er empfing ifn in Der Âdienz= Siammer, befannt mit Deffer einfautender Stimme und Rriegsgurger; erfitifte aber Deffen Feldgefdrei Durdh Die Dampfugel, Die er fo warf: "Yieber Mann! fennt Err bie Ecttanne in Rabels $\mathfrak{W a l d}$, Die eben mein Errfftülf geworben, fammt vielem anderem bes

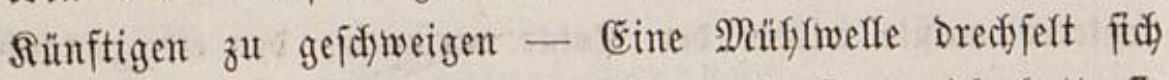

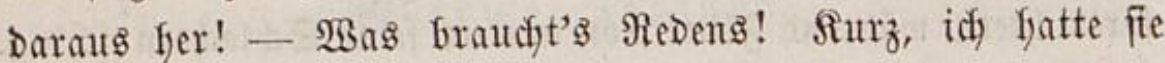
fdjon fralf einem ambern verfwrodjen; (5x foll aber Das $\mathfrak{B o r}=$

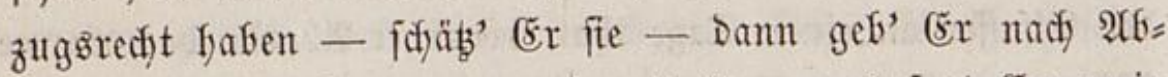
zug Der Safuld heraus, was fonett ift - was jagt (Er, meit Freunto?" - Sein Feino verję̧te, Das fei einmal ein 130 ort,

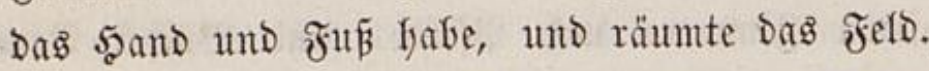

fart finter ifm trabte ein zweiter $\mathfrak{B j e r d e l i e f e r a n t}$ ein, in Yangem, Glauen, über Dem Schurzfell aufflaffendem $\mathfrak{H}_{e} f e r=$

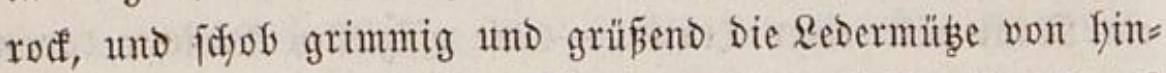
ten über bie fralfe Stime finein: "wie wird's, fragt' er? Finten und suinten idslagent freute nidyt an bei mir." -

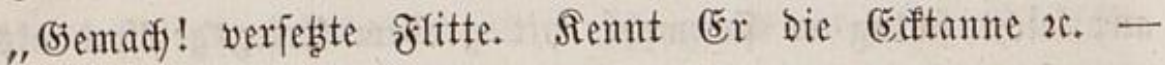

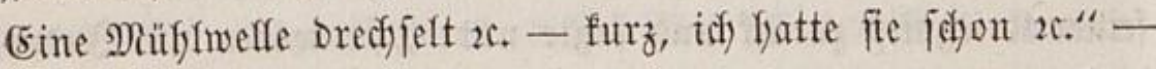
Der Feino verfebste: ift's aber Berirerei: (5ott foll - (5ott befolylen!

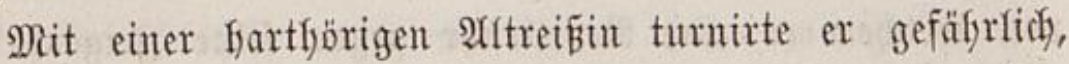
weil iffr (Sefdrei nur mit einem foldyen empfangen werben

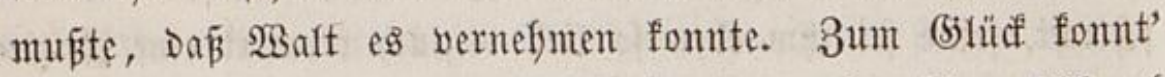
er cinen alten vergoldeten Sdyaupfennig - Der fidon $100 \mathrm{mal}$ 
feine Befagerungamübe and fein Secttfaler gewejen - yeraus=

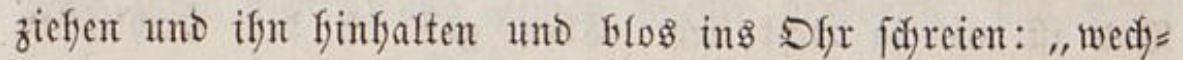
feln - Afbends 6 ungr!“ Dody fetterte fie auf Dem SdyIadyt= feld nod) lange fort, weil fie fidy nie verido of. Die weiblidye Bellona ift furdhtbarer als Der mäunlidye Mars.

"Nur biefer!" rief er; ein furzffänmiger, runobacfiger,

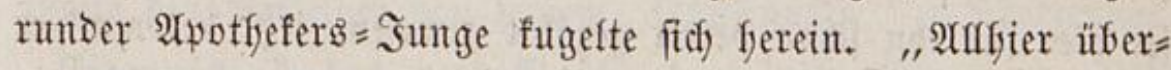
bring' id als Diszipel unferer bedytifdsen Dffizin laut Red)= mung Die Redfnung für Die arme Bitterlicfin in Der şopfen=

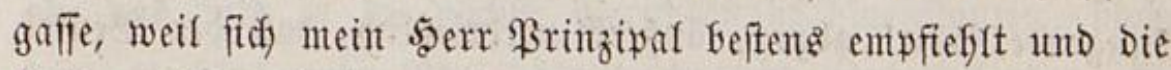
5eifunggfoften Dafür zu fraben erfucht. (Es ift nur von wegen unfrer Dronung in Der Dffizin; Denn übermorgen werde id befauntlich fum Eubjeft gefprodjen." Bor Dem fanften Feinde ftrefte er Das (5ewelfr, eine halbe Biftole (auf alten $B$ iftolen=

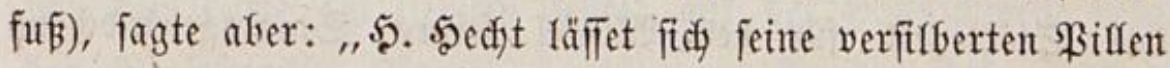
ftarf vergolden. Den (SefurtBfelfer - ridyt' (Er's aus fab' idf idfon farbiret." (Juter, guter Mann! fagte Walt. "Die frau war ia in Den fümmerfidgften $\mathfrak{u m}_{\mathrm{m}}$ fänden ron

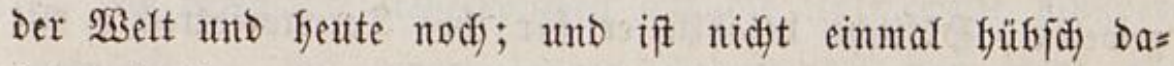
bei," jagt' er.

Ungejefen war eben ein Secerbaun eingeriaft, Einent Banner ftarf, Der fo anfing: „Sjehorfamer! - Ein für afle=

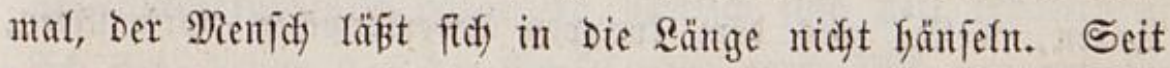
Bauli Befefrunt bin idh Sein Narr und laufe nad) Dent Bischen Miethgzins. 5err, was Denft (Ex Denn you Mnjer=

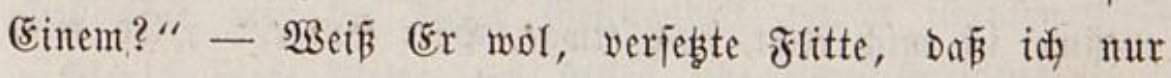

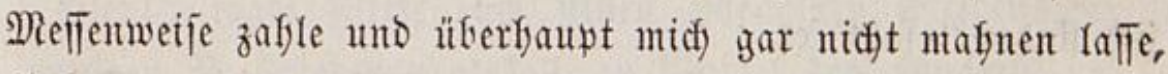
Er? - "So? erwiederte der Bauter. Saly und nod) bret 5augferren und fer Etiefelwizer baben ung fdjon zufammen=

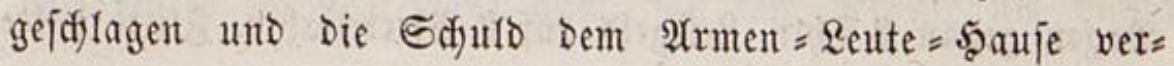




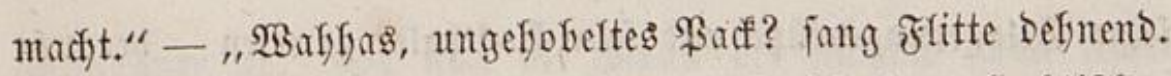

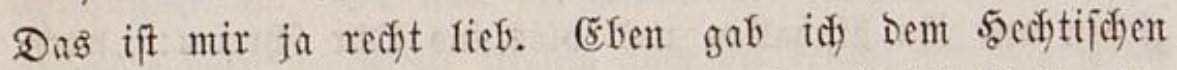
Subjeft (ber serr da zeugt's) ein falfes (5olsfutucf für bie Glutfrembe flutarme Bitterfid); was gefft fie midy weiter an?" - 5jier fielt er ifm ben einen, mit einem Ringe zu= geffiraubten voflen Beutẹlpol mit Der Erffärung vor, Der 3ins fei fier für ify fodjon bereit gezählt gewejen, jeb̧t befonm? er feinen Deut; - worauf Der Feind nach vergeblichen (Finfens

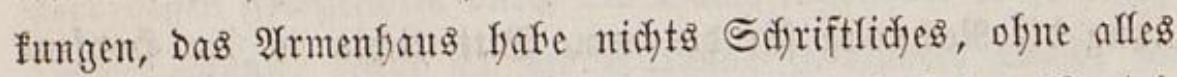

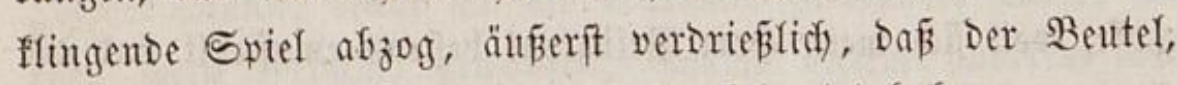
wie bei den Türfen, Das Beld felfer bedentet frabe.

Diejem folgte Der 23te Serr, Der Ierritorialferridjaft üfer ifyn ausgentbt - Dem 23ten fufzedirte Der 11te - Diefem Der fünfte - jeber, un Den (5rundzins, Die Suatemberftener,

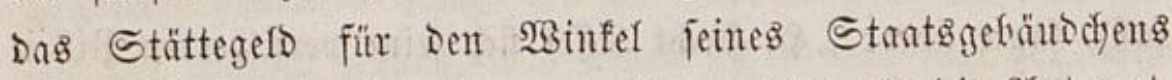
einzutreiben. (5roben şerren gab er nidyts als bie Antwort,

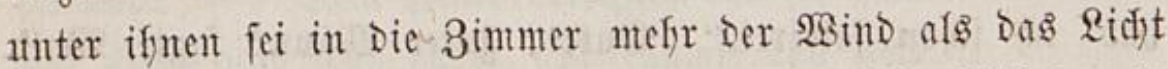
eingeorungelt, Dic Alufwartung idhledyt und Die Möbeln alt gemejen. Sabfliche bezahylte er für ifyre Ierritoriafredste mit Territorialmandaten auf bic 10 (Erb= Stämme, mit Den Bon= fons Der Bons. Darmf fam Der Serr, Der vor Dem Thür= mer regiert fratte, ein frommer 5 uter, mit zwei großen grauten Sodfen, welife ats Dem fnappen Rederfäpwdyen vorwalleten, 1mo bat ify um ein Darlefin, gerabe die bälffte Der Edjuld. Fritte gab ifm bas (jeld und fagte: "ofneffin reftire $i d$,

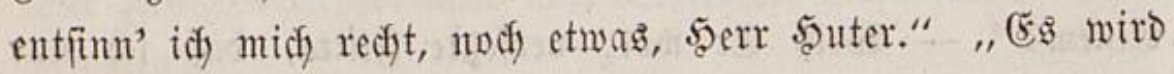
fich finden," jagt' er.

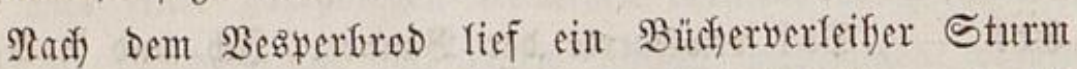

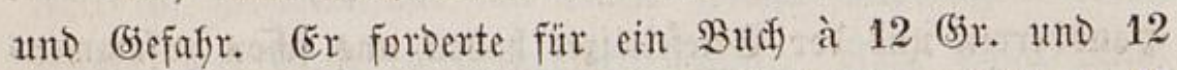
Bogen gentau 2 Iffr. Sejegelo nuf 2 Bierteliafyre. Flitte fatte 
nämlidg nad) feiner Weife, feine Sadje abzuborgen, Die er

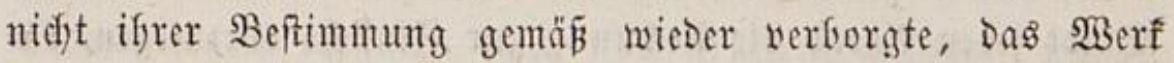
fo lange umfaufen lajien - Dent jeber afme ifm nadh Daß̧ es verloren war. Umiouft erfot cr fidf zum Drittel, zum Sinfe; Der Berleifer beftand auf Refegelo unto fragte, ob viel mefir als ein $\mathfrak{P}_{\mathrm{f}} \mathrm{ennig}$ auf Die Seite fomme? Selfer $\mathfrak{B a l t}$ futhte Den Berleifer von feinem "Eigennuben" zu üferzengen. "Eigennübig? Das verfyofl' ich cben; vom (Eigenumben left Der Menidy," fagte Der Berleifer. Flitte lick ifn gauz furz $a b=$ und wild in bie nädyite (jeridy tsftube fineinfaufen, nad)= Dem er blos zefin Reujafrşmünjhe und fünf Ratender, Die

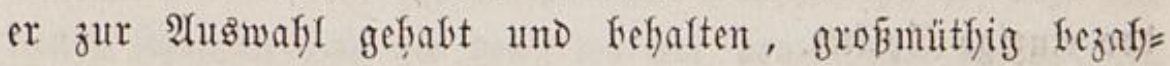
let lyatte.

Surz vor 6 urfr wollte das $\mathfrak{B a n}$ ein wenig in Die Ruft, won ber Flitte am Yiebfen Yebte; auf Der 5ausfchwelle febte Der \$infelmadjer \$urzel - jüngerer Bruber Des Thenter= fifneiders - ifnen entgegen mit einem auggelyäflten (jefidht wie cin 5ूoffglas (Stim = mo Rimn = Ründer waren fonver)

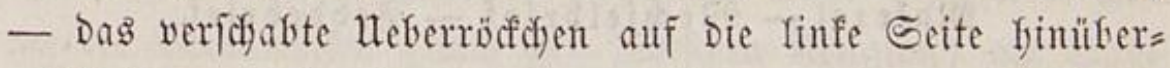
gefnöpft - mit cinem langen Fabenwurm yon 30 pf aus 3opfant - und wadefno mit Dem rechten Sinie: „Sfro gnäbigen (s)taden, fing Das Sammerbildodien an, werden mei= nen Miniaturpinjer vorgeftern ferrfid) uno nett erfalten -

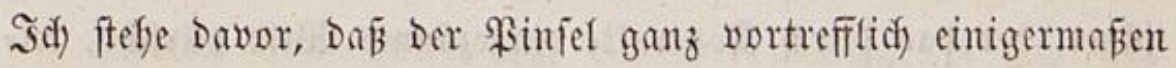
- uno bitte Dent um Das 2 Sentige, was er foftet, uno aud),

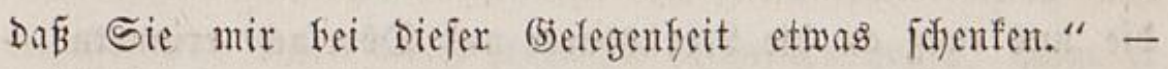
"Soier!" fagte Flitte zum ftiflen rebendigen Friedensfeft, ja rufigen $\Re$. Friebensprotofoll, zu \$urzel Dem jüngern.

Abends madite Den $\mathfrak{a}$ affentanz Der Caffetier Fraisse mit einem (sroß̧vatertanz aแs, (Er fam herauf, um fyöflid) 


\section{4}

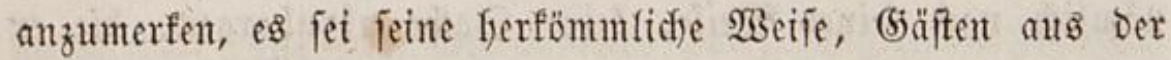

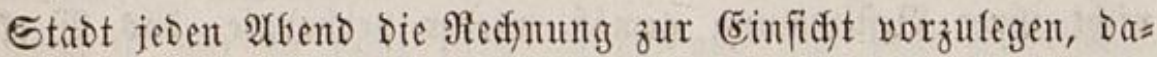
mit fie foldye fäfent uno faloirten. Waalt faf fier zum erften= male einen franzöfififjen ober elfafififyen 3orn ofje Dhren; es war ein ftürzent = fortroflender Streit = und Sichelwagen,

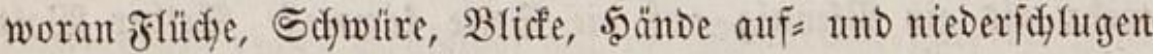
und zerfäbelten. Fraiffen wurde das nöthige (jeld vor die Fübe, $j a$ at Den Sopf geworfen, Dann eingepant und fludend fortgezogen it Des verreifeten D. 5ats leeres 5anus. Walt wefle Durd) feine nieberflajenten friedenspredigten Die Flam= men nur höher auf. (Eine verlebte Stunde war für Flitte Der einzige Eppiftet.

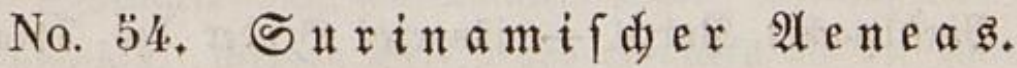

$$
\text { Malerei - 2Bedjelbrief - Fefoebrief. }
$$

Ridjt uno leidyt flogen bie 5goren in D. Şuts vielgebäu= figem 5auje ein uno aus uno fyolten 5onig. 5aier, in Diefem

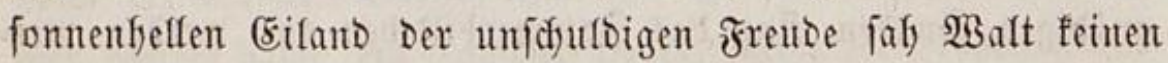
Göflicf)=groben Frailie - Görte feinen (jelowerber und (5eld= jăger, Der Das Durd, Siontrafte eingezäunte $\mathfrak{2 B i l o ~ p u ̈ r j d y t , ~ f e i = ~}$

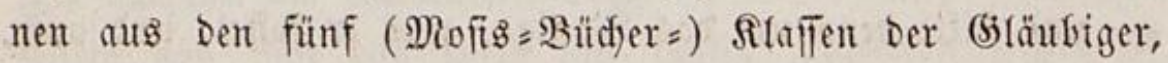
Die unt entig an Die Rebensbarre unt Dörriud erimern fier fört' er nur Rieberdfen und Sprünge; fjer waren ganze Gadfgäвctyen aus Dem neuen Serufalem. Dent was aus Dem alten theils von Suben, theils bon (Shriften cinwanderte, fonnt' or nidyt fören, weil glitte fids von feinen 2 rejentf= 


\section{5}

fönigen Der Metalle, ben Bjäubigern, blos in einem fernent Edhmollwinfel vergiften lię. Im erften Storfwerfe wofnte Die ftreitende Rirche, Flitte uno Die Rönige; im Dritten bie triumplirente, Flitte und $\mathfrak{B a f t}$.

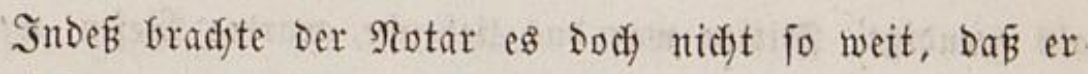
gar nidyts gemerft bätte. "Ist) wollt', ich wäre furzfichtiger (Fagt' er ficd); bedenft man, wie frof und freigebig ber gute Menfof fifon ift in Drangfalen uno wie er's roflendos wäre

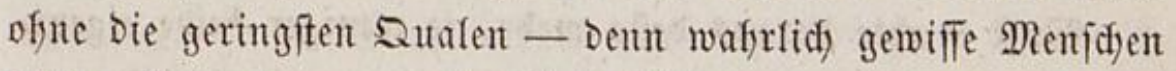
Gätten Iugend, wenn fie (5eld bätten - uno mit weldjer

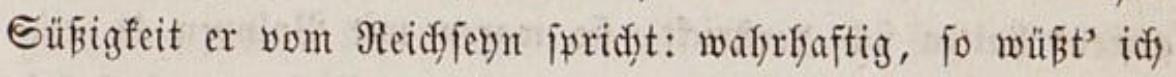

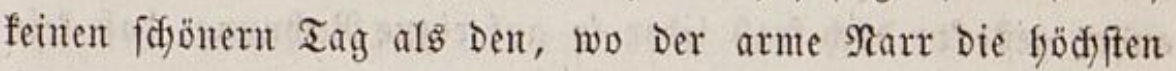
Geldfäften und (Sieldfäcfe plöblich in feiner Stube ftefyen fälye.

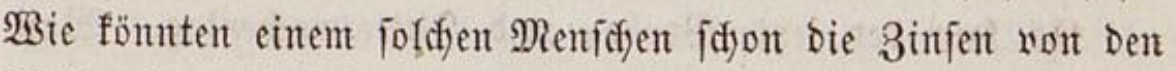
3infen Der 3 infen der englifiden Razionalidfuld auffelfen!" Er fragte, warum, da alle Reiden Ferien finden, Denn bie cine\& Deutidjen Sdjulfuners nie abjeben, inder in (Englano Dod) Der Eomitag ein Rubetag Des veridjuldeten Dhrs ift, wie fo gar um Die Berbammten (nad) ber jübijchen Religion) am $S_{a b}=$ bath, am Fefte Des Reumonos und unter Dem wödyentlicyen (5ebete Der Suden Die şolle erfitrbt und ein fanfter fülyler

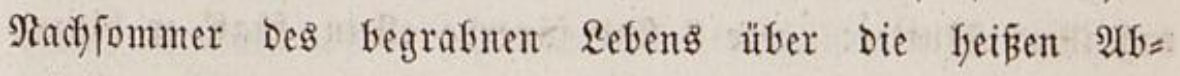
gründe wefht.

Sieblidf) überwallete iffm Das berz, wenn er fich Das Eeelenfeft ausfärbte, womit er Den Flötenipieler Durdis Dent Eljaffer uno diefen Durd) jenen zu bejdenfen hoffte, went ex Bulten bie unjoulbige, liberale, poetijdye Rebensfreifeit Flit=

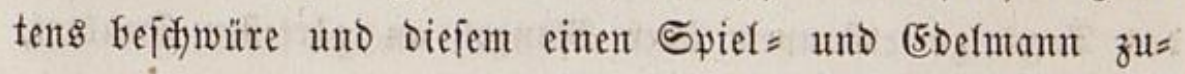
gleich) zufüfyrte: „o idf wifl babei Dem wactern Bruber Das 


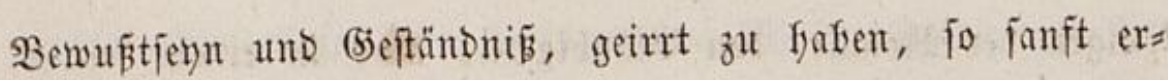
fwaren!" iagt’ er entzüctt.

Smmer wärmer lebtent beide ficl) in bie 20 odje und in einander finein, fie frätten bie Frobemoche lieber wieberfyolt als geendigt. Flitten war Das liebende, warme $\mathfrak{B}$ ejen, womit Walt wie mit einer eleftrifocen $\mathfrak{A}$ tmofphäre umgeben war, etwas neues und anziefjendes; er fonnte zulebt fidwer mefyr ofne ifn aus Dem 5aauje.

Walt madyte Daraus Defto mefre, je weniger beide eigent= fich), wie er füfylte, einander unterffalten fonnten; ifre Rerven=

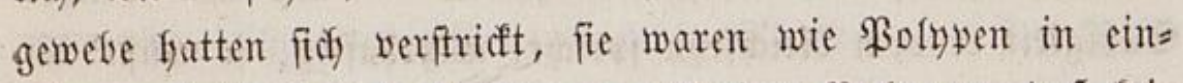

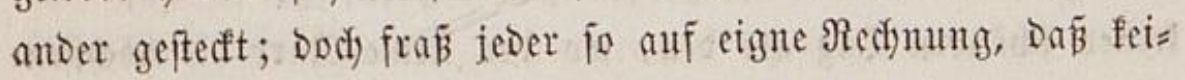
ner weber Der Magen, nodh Die Naffrung Des andern war.

(5: fam Der leste $\mathfrak{B}$ robe = und Flitterwod)entag. Walt

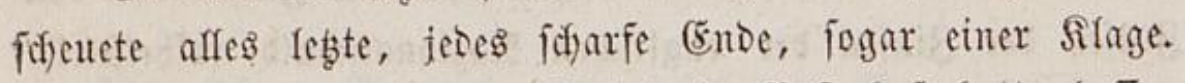
Ein Ripienift von $\mathfrak{B u l t s}$ Spiele in Rojenfof fratte Deflen

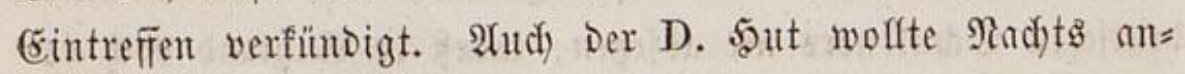
fangen. Einige fifone Mitternadytaröthe ftand ifjm Gevor. Flitte bat ifn, Diefen leb̧ten Radfmittag, wo fie beifamment

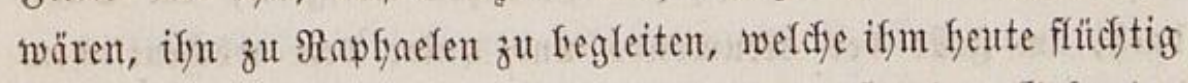
fib̧e zu cinem folled)ten Miniatur= \$ortrait für Den (5eburtg= tag iffrer Mutter: , wir 3 fins füperbe aflecit, fügt' er finzul. \$2enn idf mun male, parlir' idy menig; uno bod animirt Reden ein (Seficht unglaublich." Do Whalt gleid) wenig Delifinte

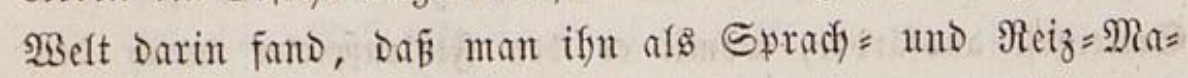
fajine vor ein Sibgefidyt aufalfeflent tradiftete: fo folgte er

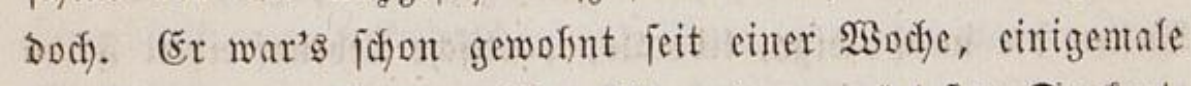
Des Tags zu erftaunen über $\mathfrak{M a n g e l}$ an zärtefter Denfart, fowol auf Dem Sarfte alş in Den beften 5äujern, weldje

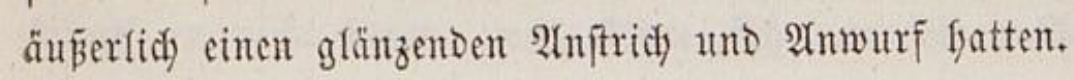




\section{7}

Rit $\mathfrak{B e r g m i g e n}$ fam er in Dem eigenen $\mathfrak{5}$ aufe wie in einent fremben an. Raplyaela rädyelte beiden yon Der oberifen

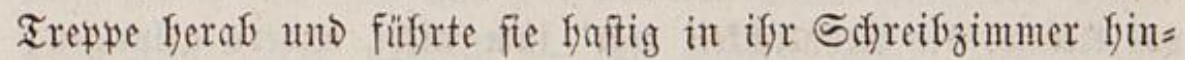

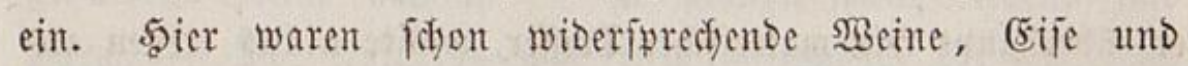
Su(t)en gelyäuft. Da eine grau leidyter das Sgerz als ben

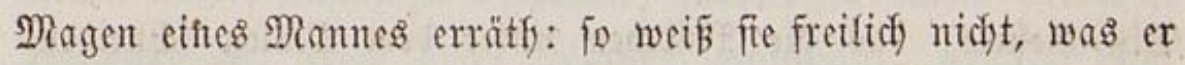

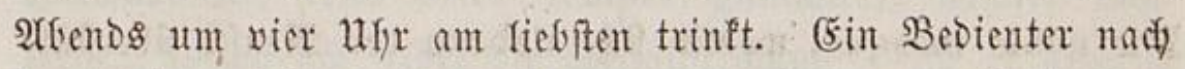
Dem andern faly Durdy bic Thüre, um einen von Rapfaelens Wünjd)en zut fyolen und erfüflt zurüd zu fringen. Die ganze Dienerfd)aft forien ifre Regierung für eine golone von Saturn zu balten; man faf einige von ber weiblidyen fogar im Sarf fpazieren gefjen. Die immer voffer ins 3 immer fineinftrö= mente Afrendjone und Der Frentonglanz, Der jebem (befidte ftelft, Ecwarfen Dns Mäbdyen und Die Gituazion mit anjefn=

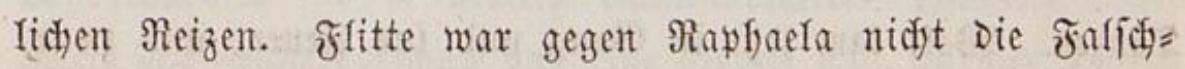

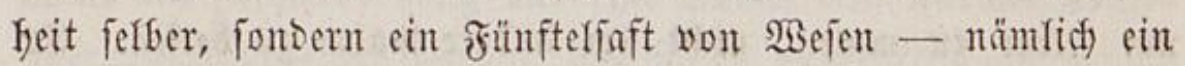
Jünftel gafant, ein Fünftel gut, eines finnlid), eines getojüd)=

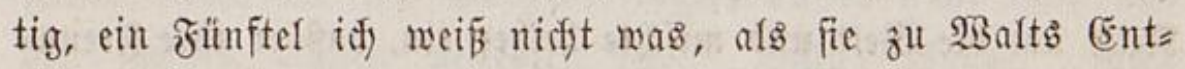
züfen gelagt fratte: "Siffmeidheln follen Sie meinem (Sefid)te nidyt, es rilift nidjts; madyen Sie es mur, Dañ ma chère mère es wicber erfemut." -- Im Notar frodh heimlidy bie ftifle Freube herum, Daß̃ er jelgt gerade unter feinem eignen Bimmer

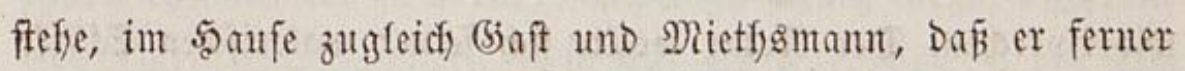
nid)t bie fleinfte Berlegentyeit fpüre - Demn Flitte war ifsm nitht fremb und nuber (Eine Frau war fid)on zu regieren -

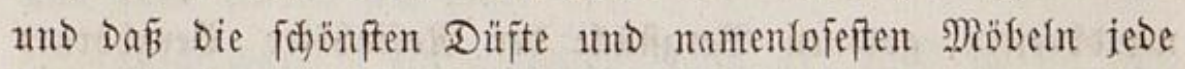

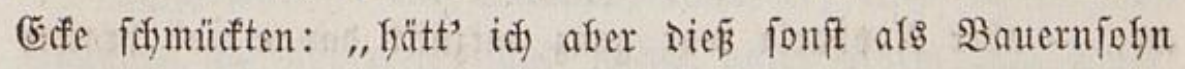
aus EIterlein Denfen follen?" Dadif' er.

Flitte zog nun Das (Elfenbein und Das Jarbenfifift)en bervor uno erflärte bem Moiefle, ie freier uno belebter es 


\section{8}

fize, Defto beffer glüef' es Dem Maler. Sndeß bätte fie chent fo gut auf Dem Roropol fikgen fönten, er afer auf Dem Sitd= pol fleben: Die Aefrnlidffeit wär' ify nidyt anders gelungen; er, überfantw fein maferifider Ireffer, wollte nidyts treffen als Das, was fie anfratte. Sie jebste fid hin und verfertigte bas

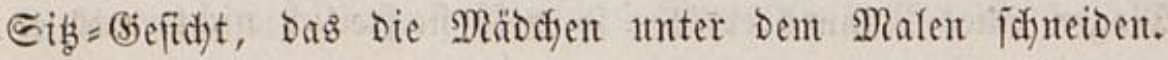
Die noble masque, womit fich alsoan Der Renj(d) überfitul=

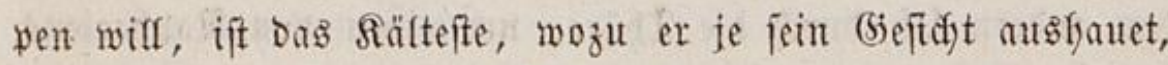
fo Daß́ jeltner Menjofen als ifre Buffen portraitirt werden.

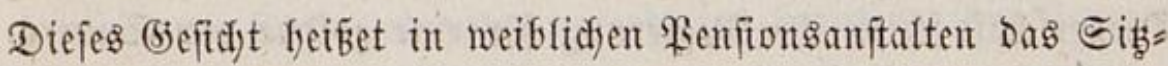

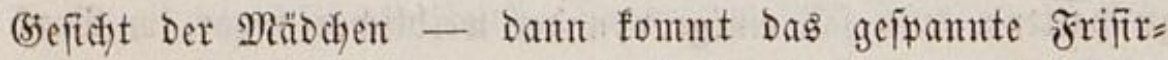
geficyt - Daun Das efiende Butterfrodgefidyt, eines Der brei= tefen - endidi zwei Ballgefichter, Das eine, Die 2 Betterjeite,

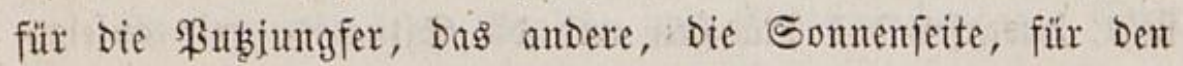
Tänzer. SBalt fam jeb̧t in (5antg uno ins Feuer, uno zwar, um felber zut malen, nidyt um andere malen zolt helfen. (5r

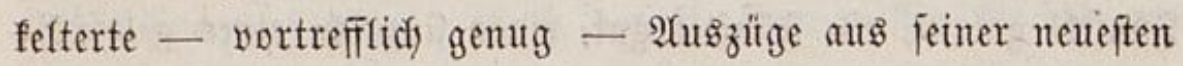

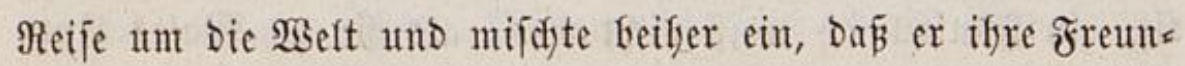
Din, $\mathfrak{B}$ ina, unter Der Ratarafte gefefgen. Unter alfen (Erzäf)= Jern uto Unterfaltern fino Reijebefdsreiber bie glüaflidffent und reidjften; in eine Reije um $1 / 1000000$ Der $\mathfrak{B e f t}$ fömuen fie Die ganze $\mathfrak{B e l t}$ bringen und niemand faut ifnen (zweitens) wideripredyen. Der Notar wollte fï jeiter malerijuen Stärfe in Sommer $=$ und Saerbiftandid)aften - Flitte Yieferte Die $\mathfrak{W}$ int terfantofdaft - nod) färfer bebienen und jebste zul einem wandobreiten goldnen Bergftüfe Der Rofenföfer Berghörner an; - aber Rapfiala war ganz entzüfft Davon und bradjte bie Rede buld auf ifre Freuntin $\mathfrak{B}$ sina, um joldje allein fort= zufpinnen. Sie erfob Deren Reize uno saanofungen mit zener - fie zeigte ein Mafagonty= Räfthen, worin Deren Briefe 


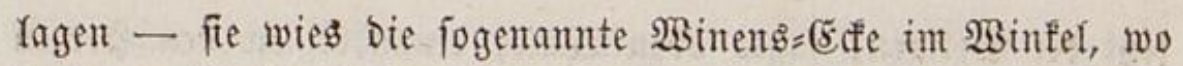

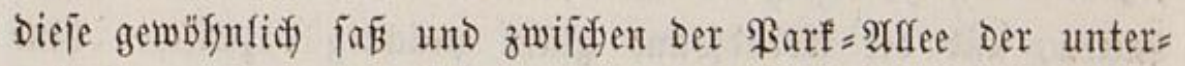
gefhenden Somte nadjafi - fie glänzte gauz liebend und warm. - Der Notarius war ziemfidy fdyad bei fidj; nadis feinen fitflen $\mathfrak{A}$ ugen zu urtheilent, jubelte er laut, feierte er Bacclyanalient, trieb artes semper gaudendi, lieferte $2 u f t=$ treffen, fwrady fid felber Die Sefigipredyung - ja er ging fo

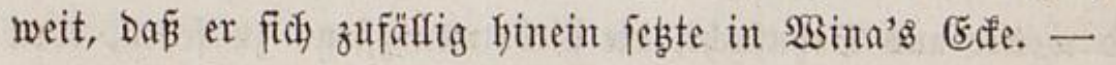

Der Subel wudfs ganz. Man tranf fort - in jeder Galben Biertelftunde madfte ein Diener Die Thüre auf, um einem zweiten fpätern Befefle wegzufangen. Flitte wuß̄te gar nidut, wie er auf einmal zu Der Bifücfeligfeit gelangte, Daß man fo viel fprach ofme alles Sangweilen zum 5̧enfer, und

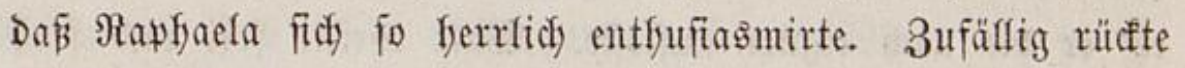
Walt Den Fenftervorfyang und eine Some volf warmer Iinten

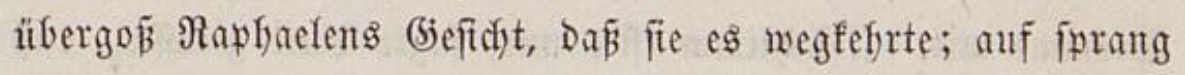
Flitte, wies iffr ifyr Slopzzo, fragte, ob es nidjt lyalb aus

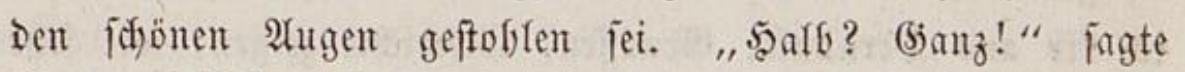
Walt aufrichtig, aber einfältig; Denn fie Gätte Demjelben $\mathfrak{B}$ ild = d)en eben fo gut mit Dem sointerfopfe und Stafylfamm gefef:

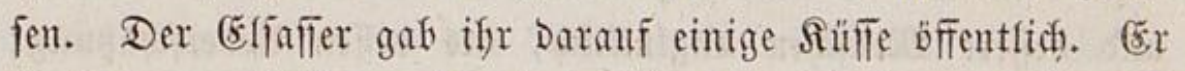
that's vermuthlich zul abrupt, badfte zu wenig baralt, Daß auth erblicfte Empfinoungen - io gut als gelefene - vor Dein 3uichauer wollen motivirt fern; Walt jaf eifigit in Den $\mathfrak{B a r f}$ uno ftand endicly gar auf.

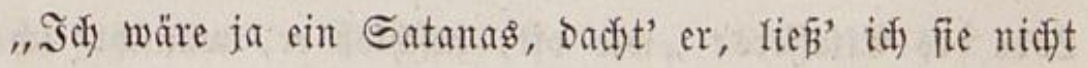
cinanoer fid abferzen" uno fidlid unter einem landidafts= malerifiden Borwand ein wenig auf jein Bimmer. Flitte madjte

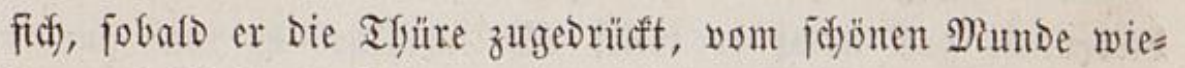
Der ans Maten Deffelfen uno punftirte fleísig. „SBie müffen 
jebgt Die Geligen, jagte oben $2 B a l t$, eintander an Den Saerzent balten, uno bie afbendionte glüft prädytig Dazwifdyen fins ein!" - In jeine eigne Stube quoll Das fülfforn Der Abentorofen nod) reidfer uno weiter aus; Dentody fandert

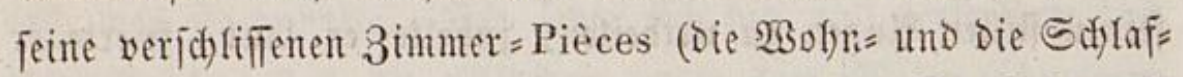

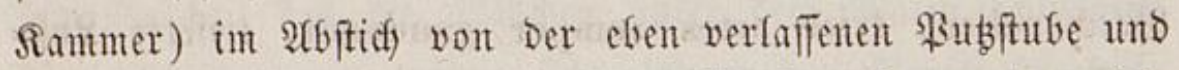

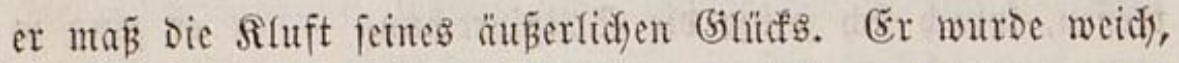
und wollte auts Gefnjudyt, Die Riebe wentigftens zu jefent, ebent

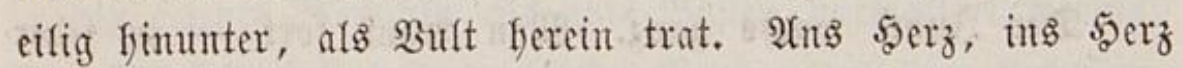

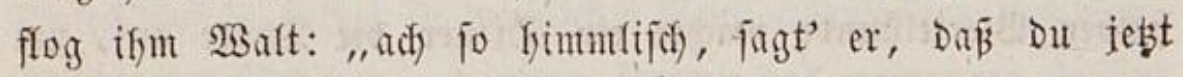
eben fommit."

Bult mit janfter Stimmung zurüffeffrent, that zuerft

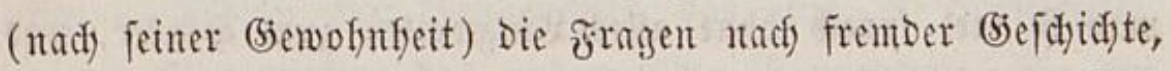
el) er bie nad) eigner nufloifte. Salt theilte frei und frob Den AGlauf Des Rotariats= 2Amtes und Den Berfuft Der 70 Stämme mit. "Soflimm ift's nur, jagte $\mathfrak{B u l t}$ gelaffen, Da id) gerabe felfer verifjwende uno (jeld veradjte; fonft wirto'

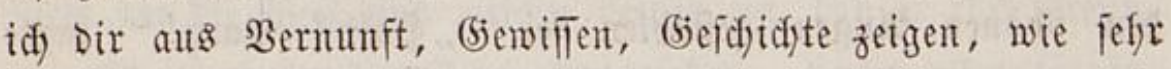
und wie redyt idy meine (Ébenfilonerei an andern, $z$. B. an bir, verfludje. Beradjtung Des (5efoes madyt weit mefrere

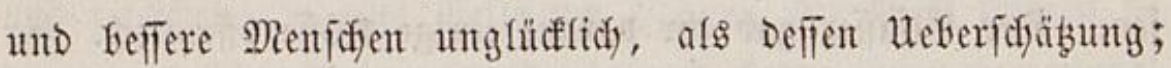
Dafer Der Mentid) oft pro prodigo, nie pro avaro crflärt

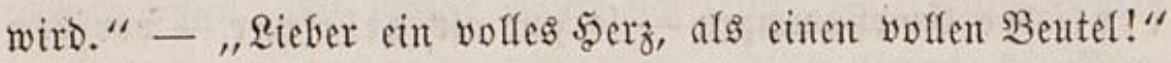

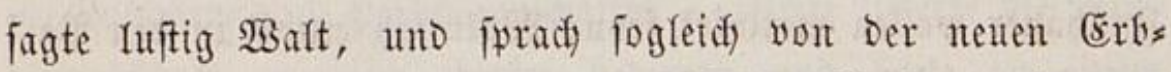
amtswafl, uno von Der fojonten Flitte's $=290$ dye, und vout

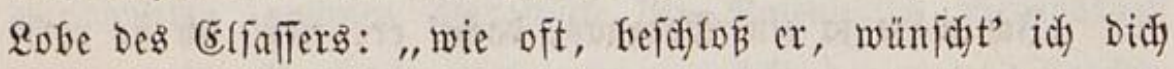
her in unfere heimtidyen geflügeftent Jefte finein; audy). Damit

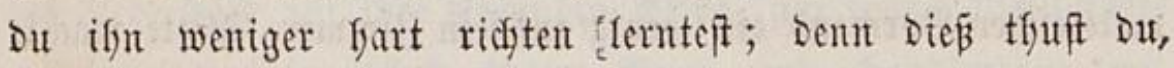
\&icber!"

"Flitte fajeint Dir erfaben? ein Seclentlajififer ober fo? 
Uno feine Ruftigfeit poetifoces Segel= uno Flugwerf?" fragte

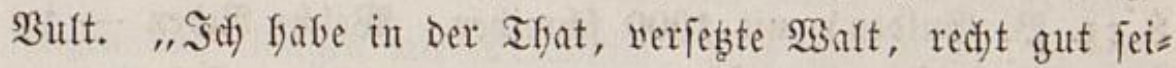
nen föbnen Temperaments = Reidftiun, Der nur Begenwart afweibet, von bem bidyterifden reidfen Sdyweben über jeber unteridjieben; er freute fid) nic lange nad)." -

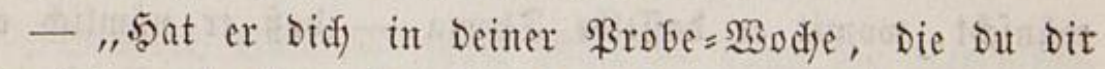
felber fefre gut ofjue affen fremben Rath gewählt, feine bes Denfficjen Sprünge madyen laīen, Die etwa Bäume foften?"

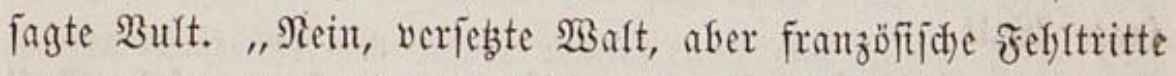
Gat er mir afgewöfnt." \$̧ier fuffr Der Rotarius fort und bebiente fich Der fragenden Figur, of Flitte ifm nidft Dag Feinfte entoecfet habe, z. S. Dấ man nie oder felten comment fragen mülie, fondern fyöflidjer Monsieur oder aud

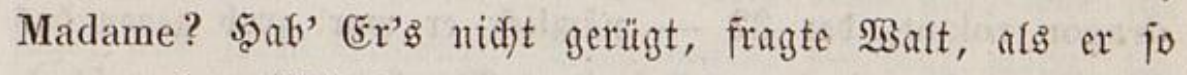
ganz unfranzöfifoly bon appetit wünfdyte, oder cine fiammer= frau, femme de chambre, fur Rammerjungfer madfte, oder

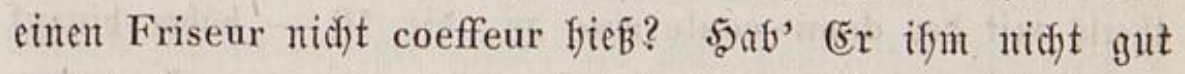
erflärt, warum porte-chaise Dumm fei, weil man bie $\mathfrak{B a f h}$ fabe zwifchen einer chaise à porteur und porteurs de chaise?

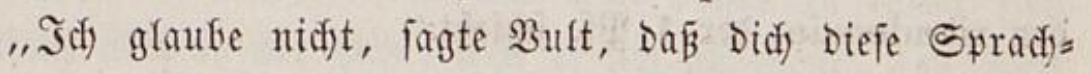
ftunden mefr foften als Den Reft Des Rabel=23ards." - „Ein

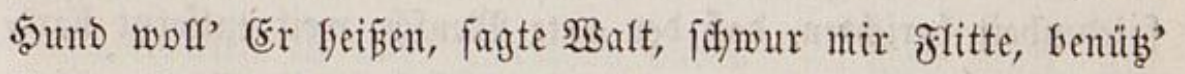
(Er's. In Der Redftidfreifung aber Dient' idf Sfm, 子. B. jabot fidrieb er chapeau. $\mathfrak{A}(\mathfrak{d})$, befäme Der $\mathfrak{A}$ rme nur wentiger (5)läubiger uno ntefre (5eld!" "Das wird eben Deine Rlippe auf ifm, fagte Bult. Ser arm wird - nidjt wer's ift verbirbt und verberbt, unt wär's nur, weil er jeden Tag einen andern (siläubiger oder Denjelben anders zu belügen hat, um nur zu beftefjen. So fetert or jesen ang ein Jeft

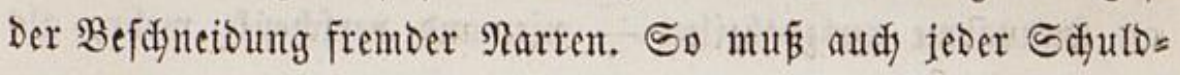


ner ungemefien praflen; er mus mit Reibnikens Dyabif bie 8 (z. 23. (5ulden) mit 1000 idfreiben. Wreldye ReDen - je= Den Iag eine andere - hab idy oft Denjelfen Edyufomam an peinen Fauft = und $\mathfrak{B}$ fand = (5läubiger falten fören uno feine herrlidje Uneridföpflichfeit Didftern und Mufitanten ge=

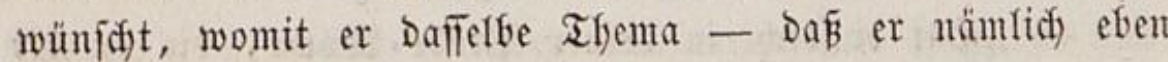

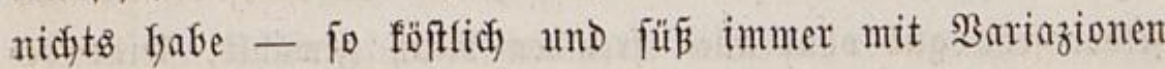

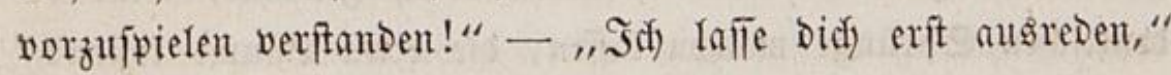
figte $\mathfrak{B a}$ alt.

"So befodop z. B., um es furz zu madjen - fulfr Bult fort - Der polnifac)e fürft *** in $\mathfrak{B}$. jebent (släubiger an=

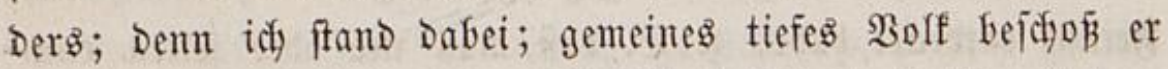
theils mit Dem dragon, Der 40 PFumb fojieńt, theils mit Dem dragon volant, Der 32 - nämlidf er war grob gegen bas Srobe - 5anorazioren, befonders Aldvofaten, Denen er fod ul=

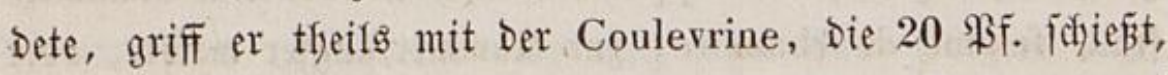
theils mit ber demi-coulevrine an, bie 10 - höfer finauf gebraudft' er Den Pelican, Der 6 - Den sacre von 5 - Den sacert von 4 - unb gegen feines (5leidfen, einen fürffen, Den ribadequin, Der 1 PF. fóferét."

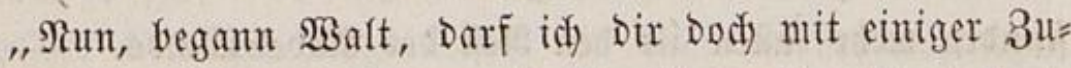

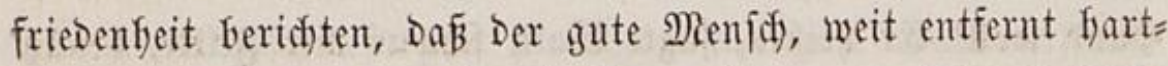
ferzig zu fern, eben Durdh Arme felber cin âmer wirb. 24us Iauter guter Freude über ifn frezaly/t' idf) finter feinem Rücfen zwei Damenjidneiderinnen; Denn ex felfer Graudft Dodf nur einen szerrenfdjnetber, und zwar Einen; fo aber überafl; 8. B. Die Bitterlid)."

Da entbramite Der Brutor - jagte, diés jei volfends der Sntan, im Dezember 5̧äufer aแžzünden, um einige Brände an sautarme auszutfeilen - niemand veridhenfe mebr, als 


\section{3}

Berfonen, bie man päter henfe - nidjts fei weidjer als Sd)lamm, Der verfenfe - Tyrannen, foldje Ifyränentäuber, fängent uno flängen wie Serapbim, aber mit $\Re_{e}$ d)t, oa $S_{e}=$ rapfim feurige Schlangen bedeuteten - unb fall er etwas, fo jei es biefe Mifdnung von Steflen und Schenfen, von Maujen uno Maufern - -

„S Bott, Bult! - fagte $\mathfrak{B a l t ~ - ~ f a m ~ D e r ~ S t e r b l i d u e ~}$ fo fyart ridjten? - Soll Demu ber Menfid) fid gar nidjt ein wenig lichfraben uno etwas für fich thun, da er bods ben ganzent Iag bei fich felber wofint und fich immer fört und Denft, was ifn ia fdon mit ben niebrigften Menfden uno Ifies ren zuleb̧t verföfnt, näm(id) Dns Beifammenfern? $\mathfrak{B e r}$ nimmt

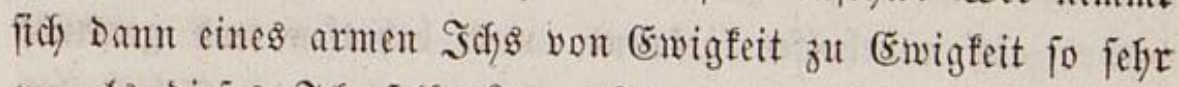

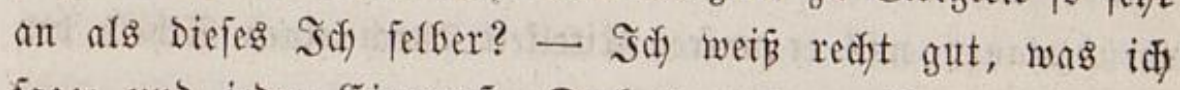

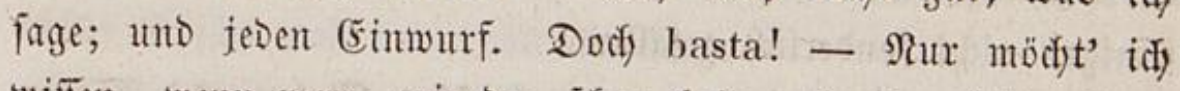
wiflen, went man, wie Du, ifjon falt uno of ne Reibenidraft Die armen Renfiden fo raufy ridjtet unt nimmt: was Dann werben folf in reftiger sibe, wo man von felber übertreibt? Bieffeidyt wie mit beiner ufrr, wovon su mir jagteft, oa Der Stift, blos weil er eben und recfyt walle, in falter Zeit gut thue, aber in ber bibe, weil er fid ausbefne, Das $2 \mathfrak{B e r f}$ auffalte."

"Sollteit Dit nidjt getrumfen fraben? - - Fagte $\mathfrak{B}$ ult. Dut foridjft leute fo viel; aber in Der Ifhat fefre gut."

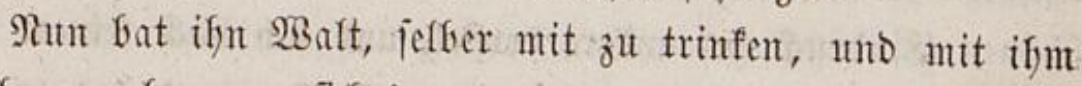
finab zu gefen, um fidh) Drunten 'mit eignen Dfren won jei= nem fodyen $\mathbb{L}_{\text {eben mit }}$ flitte zu überreben. "Der Tolffeit

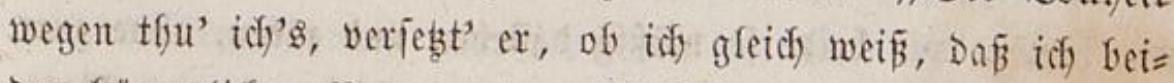

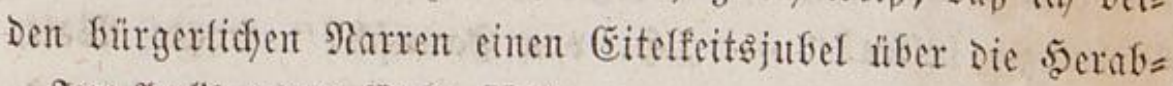

Sean gaul's aus̆getw. 2Berfe. XIV. 


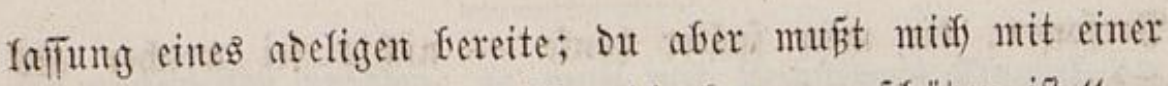

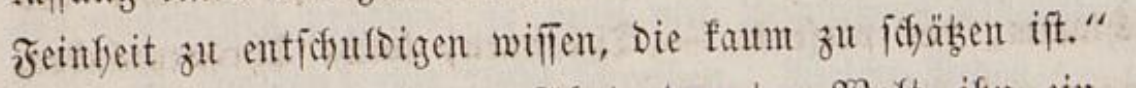

"5. v. 5aanija - füfrte Drunten $\mathfrak{B a l t}$ ifn ein fand midy in meinem Bimmer; wie follt' $i d$, Demoijelle, mun mein Bergntügen joüner theilen, als $D \cap \tilde{B}$ idf's mit Sfrmt und mit Slnnen zugleid' theilte." (5r warf Dieß jo leidht hin und bemegte fid fo leidft auf uto ab - auf Den theils yon fritte bigfer polirten Räbern, theils auf Den vom Wein eingeblten

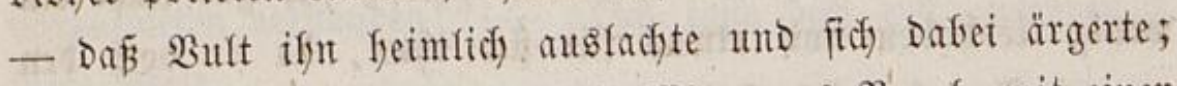
er vergfid) ftill Den Bruber mit Minervens Bogel, mit einer

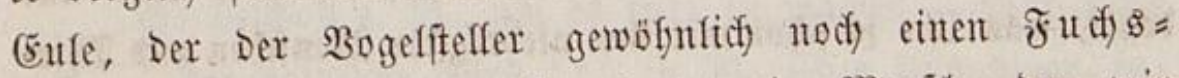
fómanz antheftet. Das erftemal, Da ein Mentich, Den wir vorfer als unbeforfen gefamnt, uns befolfen und gemanot vorübertanzt, wifl er unjer (Eitelfeit Durdy einen Gdyein Der jeinigen nicht jonderlidi) gefallen.

Bult war jefr artig - jwraid) über Malen uno Siken

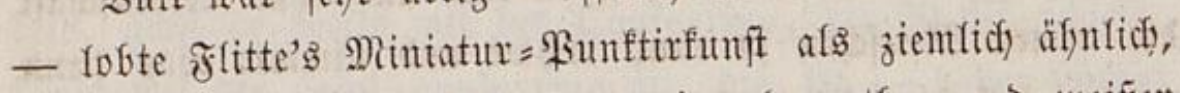
ob bie Farbenpunfte gleid, fo wenig als rother und weiper Friejel ein (Siefidit Darftellten - und lofte Daburify Den Bru=

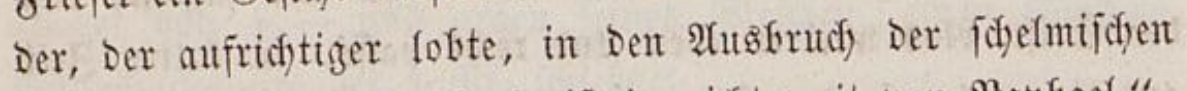

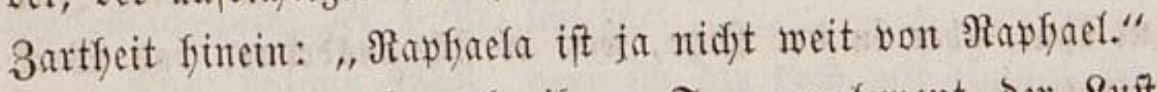

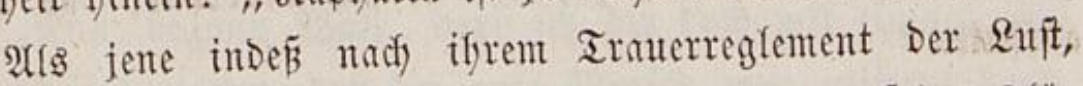

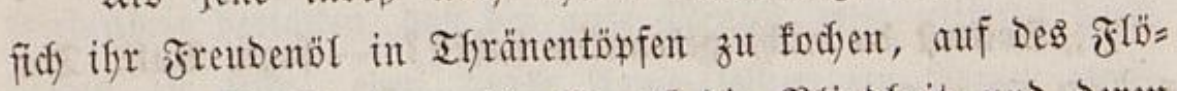
tenpiplers Muffe, Dant foneff auf Die Blinblyeit und Deren

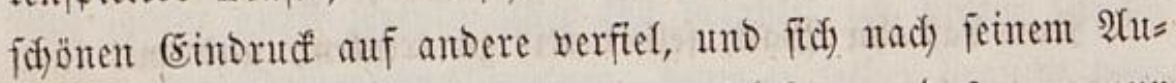
genitand erfundigte: unterbrad) Bult fie furz: ,Das war nur ein Gdjerz für midy und ifí vorüber . . . . . . \$̧r. Notar, wie fömen wir freide fo milbig Daftefyen und reden, ofyte zum

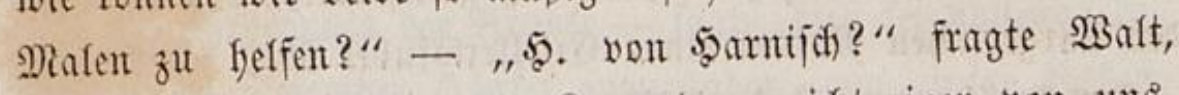
ofute comment fu jagen. "Rann Dent nidyt einer von ung, 


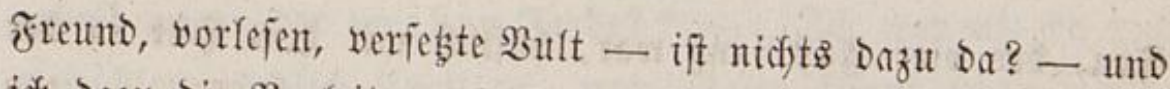
idi) Dazu bie Begleitung blajen? - WBie oft jafy idi) auf mei=

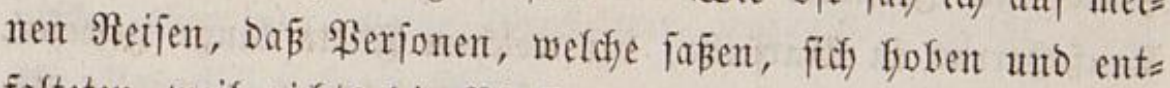
falteten, weil nichts Die Bfyfiognomie, weldye Der Maler auf= fangen will, in cin fo fdyönes $\mathfrak{L}_{\mathrm{b}} \mathrm{en}$ jeģt, als eine mit Mufif begleitete Borlejung von etwas, Das gerade amañt!" -

Rapfacla fagte, fie neffme freilici) cin Dopwelgeidjenf von Mufift uno Deflamazion Danfeno ant. Bult faß̧te einent nafjent

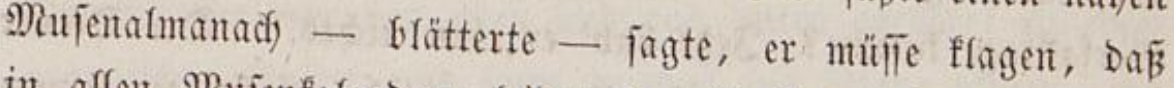
in alfen Muienfalentern Yeider Der Ermit zu hart mit Dent

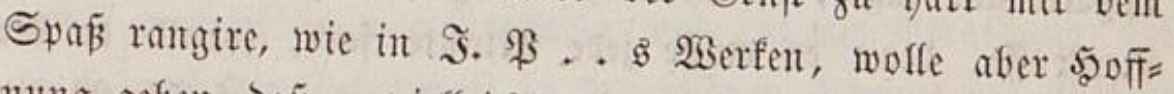

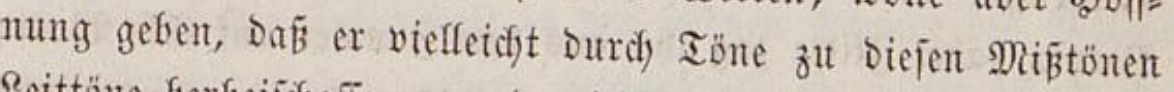

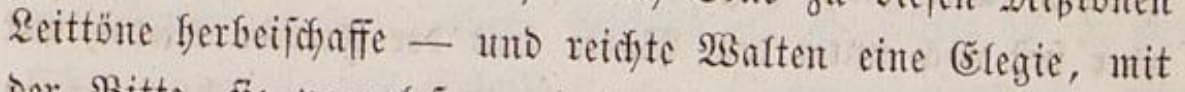
Der Bitte, fie vorzulefen uno Darauf unbefümmert die jati= rifiche Eyiftel und Dann Das Irinflied.

Da biejer erfreutet war, Dá̧ er jeinem Feuter cinte Spradje,

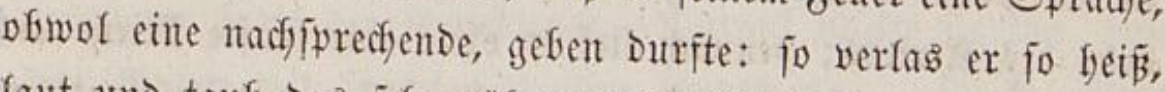

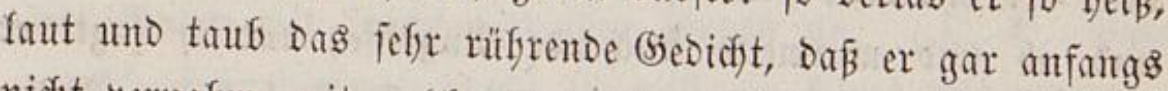
nidjt vernafm, mit weldfen närrifdyen $6 / 8$ Taften, $B$ allet $=\mathfrak{B a}=$ faben, fogar mit einem 2 aadjtefruf ifn ber Bruber flötend fefumbirte. Errft als er bie jatirijche Eviftel vorlas, fyörte er in Der Rälte einigen $2 B$ toerton, Daß nämlid) Bult Dem $2 B$ ibe mit Lagrimosi's \$afjagen uno, einigen Sylfent aus Haydn's fieben $\mathfrak{B g}_{0}$ ten zur Seite ging; er nafut fie aber für Uleber= refte yoriger Rübrung. Dem Trinffiebe nadjfer lebste Bult meffrere Languido's-5ुalte, gleidy fau fodwarz uno weipe Trauter= idnepwent ant. Der Miderftreit prešte Den 3ufjörern einen

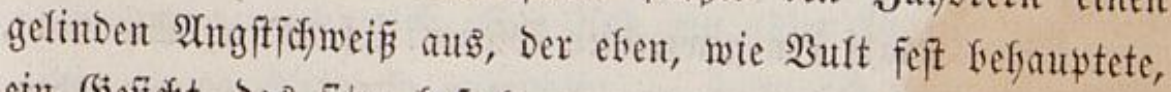
ein beficht, bas fibe, bejeele.

Afber wlöblidy trat ein ganz anberer $\mathfrak{M i} \tilde{B}=$ und Dur= 13 * 


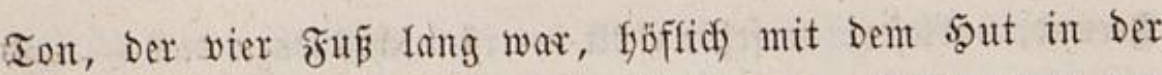

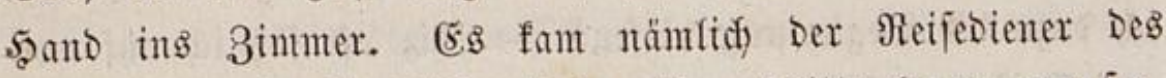
Rauf=5erms in Marjeifle, bei weldyent flitte lange gewejen,

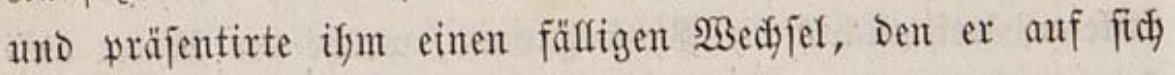
ausgefterllt.

Flitte verlor Die Farben, Die er Raphaten getiefyen, und verffummte ein wenig, und wurbe wieber reich an rother. Enolicy fragte er Den Reifediener: "warum or fo fpät am Berfalltage fomme? Sebst hab' er eben nidjts." Der Diener lächelte und jagte, er habe ifhn vergeblich) gejudft zut jeinem Serorulfe, Demu er müle jede Nimute fort, fobald er bie Saluta fabe. Flitte zog ifn aus Dem 3 immer auf (5in $2 B o r t ;$

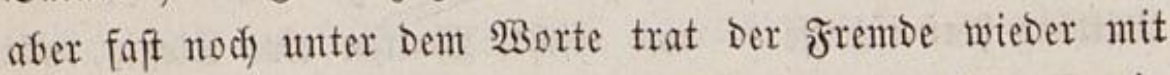
gezuften $\mathfrak{A} d$ jeln ein und fagte: ,entweder - ober - ; in

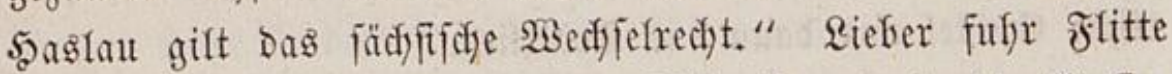
in bie 5äfle, weldye wentgitents gejellig ift, als in bie crinfies Delei Des Ferfers; Dennod) fief er ofne eine fanfte Miene auf und ab und mumelte fludjende Angriffe; endicly fagt' er franzöfija Raplyaelen etwas ins Sfr. Dieje frat Den Reife=

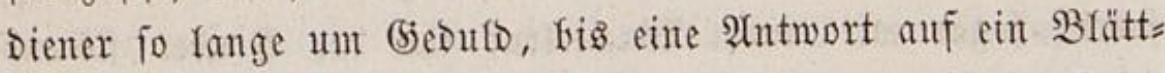
(f)en von ifr zurücf jei; es war eine Bitte an iffren Bater um (5eld voer Bürgicturt.

Flitte febste fid wieber zum Malen mit jener Folie Des Stolzes nieder, wovon Der Diener eigentlidid Den Sumel be=

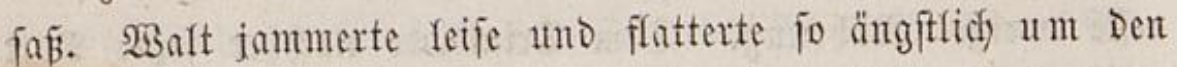
Baucr, als Flitte in Demiclfen, und folgte jebent Umfyerichies

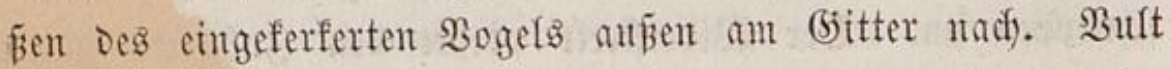
beobadtete fidarf Den gewmoten Diener: "follt' idi Gie nicht, fagt' er, in Der (jegend von Spolletto idjon gefeffent fraben, woyon bie alten Rönter, wie befmut, bie Dpfer= Thiere her= 
gefolt wegen ber weizen farbe?" - "Id war nie ba uno reife blos nörolid) (jagt' er), mein Name flingt zwar italiä= nijđ), aber nur meine (5ropeltern waren's." " (5r heipet Mr. Paradisi," jagte Flitte.

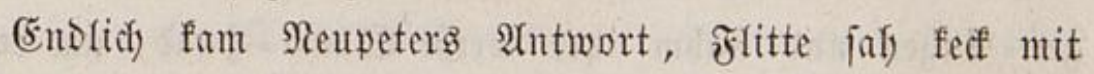
Ravbrefa ins aufgehende Blatt: "idi) glaube, Du bift ketrun=

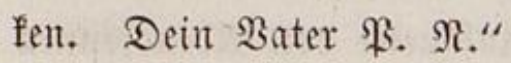

Mit großem Sdymerzen blicfte fie finnend auf Die (rrde. Der Elfaffer war von ofen und von unten geräbert zu einem organifhen finäul, uno fann, wiewol ins Blaue finein. $\mathfrak{B a}=$

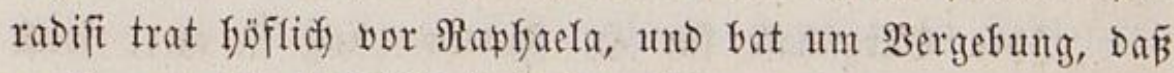

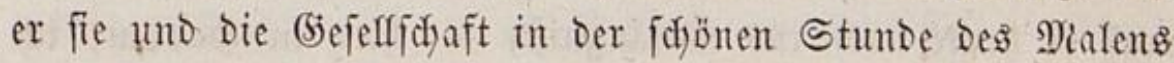
unterbrodyen habe; "aber, bejdyló er, 5 . Flitte ift in Der That eir wenig mit Eduld." — ,D sacre! jagte er, wa\&

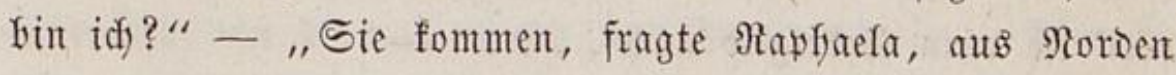

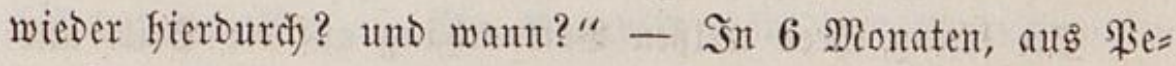
tersburg, fagte Der Reijediener. Darauf brifte fie ifn, Dann Den Notar mit feudyt=bittenden $\mathfrak{A}$ ugen an. „D, 5g. Barn= "Dift! (fufyr biefer heraug) idf wifl ein $\mathfrak{2}$ ort mit wagen „eint Sirieggzaflmteifter, Den $\mathfrak{2}$. Flitte im $\Re$. Anzeiger auffor=

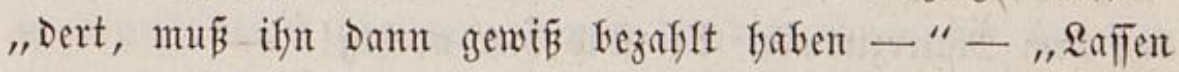

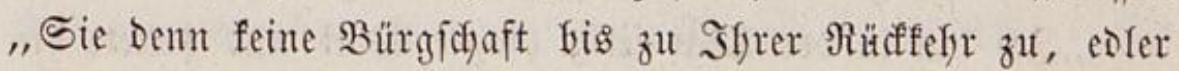

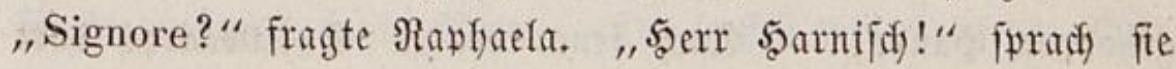

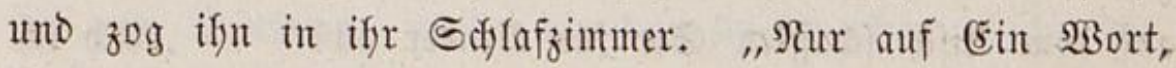
5. Notar!" fagte Bult. "(5ileich!" verfebste $\mathfrak{B a l t}$ uno folgte Rapfaclen.

"'્A(d) guter Sarnifob, fing fic leife an, id bitte Sie mit

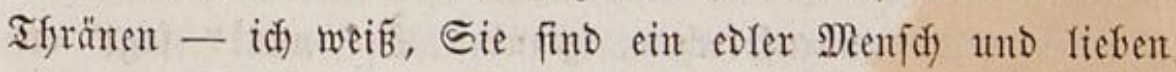
Den armen glitte fo aufridgtig - Denn idy wein es von iffm felber - uno er verdient's, er gefyt Freunden Durdjs feuer 


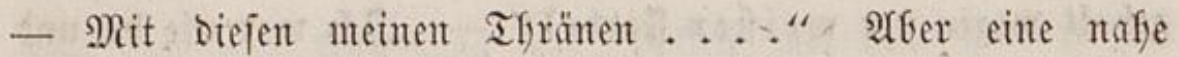
Iaute Trommelfodule von Sriegs=2Anfängern, ein taub = ftumm = mad)endes Snffitut, zwang fie unwillig tune zu falten. (5r Glifte ifr unter Der Rärmtrommel in Die gropen, rumben Res

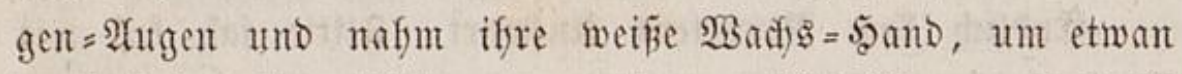

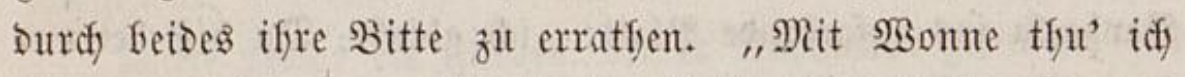
alles - rief er im moflduftenden Rabinette voll Arbendjonten

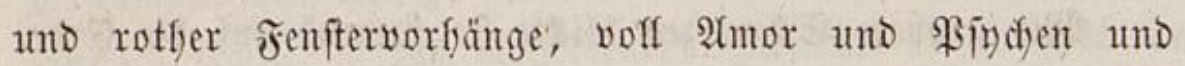

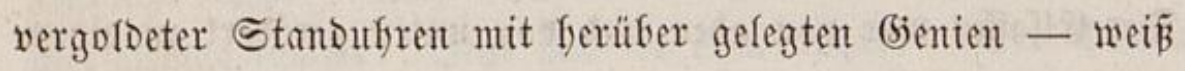
(id) mur was."

"Shre $\mathfrak{B u ̈ r g i d f a f t ~ f u ̈ r ~} \mathfrak{b}$. Flitten (fing fie an), jonft

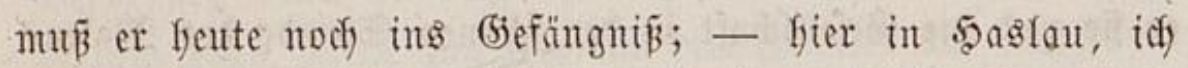
betheure Ifnen, forgt und bürgt für ifn fein Menfich, felfer mein liefer $\$$ ater nidjt. — $D$ wäre meine $\mathfrak{B}$ ina Da; - oder f)ätt' id) mein Rabelgeld nod. . . . " -

Sie idyg iffen weiken Bettvorffang auf Die Seite und wies ifn oben auf Die furze Furdje Des Glendenten Deffbettes

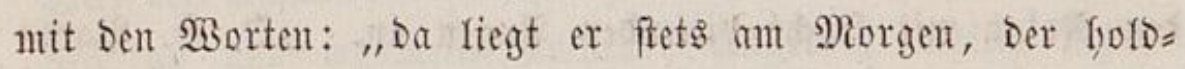
felige 23 urm, Den idf ernäfre, ein Soldatenfino — aber idy

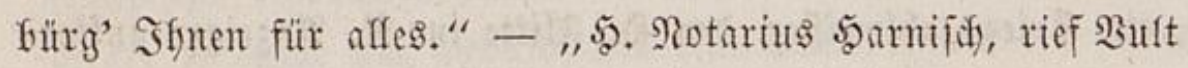
aus Dem Malerzimmer, Sie fund fier nöthig!" -

"Id) bin in Der Ifyat felig (fagte $\mathfrak{B a}$ alt und faltete bie gefofmen รänoe) - 2uch jene theuren Spictwaren Dort

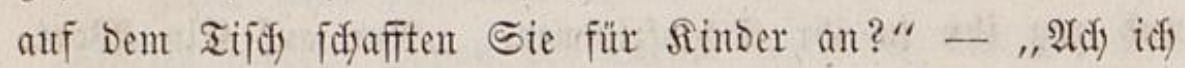
wollte lieber, id fyätte Das Bjeld nody," fagte Raphacla. ,. Mit weldyer (5efunung idy S. ßaradifi'n Bürgid)aft leifte - Dem idf leifte fie - brauddy idf wafrlidf Ifnen in foldyem Bimmer nicht auszuprechen; glautben Siê mir!" jagt' er. Sie fürzte ats einer von iffr balf angelebsten umarmung zurülf, Drüfte Die sand und füfrte ifn Daran feiter in 
Die ङejellichaft zuritid, Der fie alles meldete. Der Reijediener Danfte Dem Mäbdyen lange und verbindfid, fam aber mit

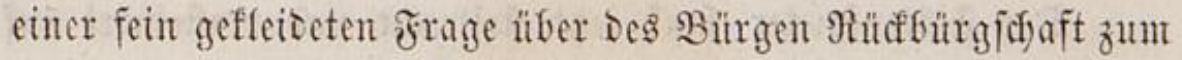
Boriffein. Sie forrieb baftig eine Bitte an ifren Bater, Dent Der Dienter längft für folti gefannt, Damit er Diejen über

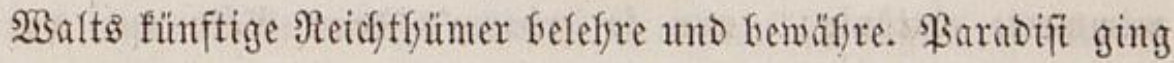

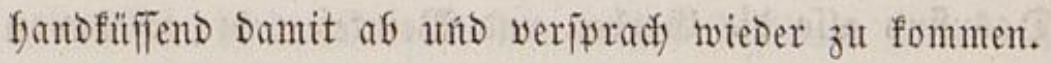

Sult Gat freutolidf Den Rotar tm einen $\mathscr{A}$ genblicf auf feinem 3immer. Âf Der Treppe Dafin fagte er: "Soimmel, 5ölle! Rafeft Du? - Deffne nur furtig! - (sile, flef)' id)! - D $\mathfrak{B a}$ alt, waB haif Du heute gemadit im Sajlafzim= mer! - Dref' nifyt - es ift Brod im Edylintel - Slowf' ifun aus - Sit Dem Der Nenich ewig cin sumt, Der zu waffen hat? - $23 a s$ foft Du barin gemadyt! - $23 i e b e r$ cin Ebenbilo yon bir; - went mut Fener wäre! - Afber fo

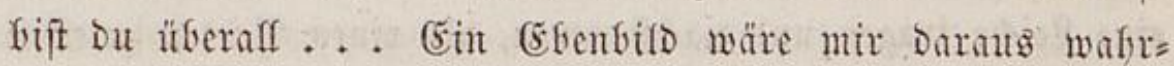
fich) Yieber entgegengefütsft als ou felber - (5ottlob!" Die Stube war offen. SBalt begamn: idj erifaune ganz. - "Du

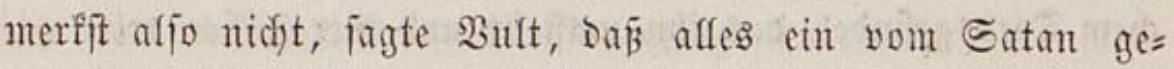
Dreffer Fallftrief ift, womit fie Dich 5. Bürgen würgen uno in Den Jublocf fofntren, Damit Du Didf ifnen Der Dumment Teftamentsflaujel ${ }^{*}$ ) fo lange verzinjeft, als bu fibseît?" "Io dh

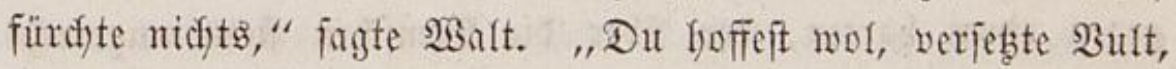
Der alte Raufmant werde bir Den firebit fidon abjonneiden, Dấ man Deine Bürgidjaft gar nidjt anuinmt?" - "Das

*) Sn ber neunten ftelyt ausbrücflid): "Tagreifen unb Gisen im Rerfer fömen nidyt zur Erwerbzeit ber (Exbid)aft gejdlagen werben." 
verfüte Der Simmel!" Fagte 2 Balt. - "Du verfürgit Didif?" — "Bei (5ott!“ ffiwur $\mathfrak{B a l t .}$

Der Flotenipiefer janf jeşt fteifredyt uno verfenert auf Den Stuffl, ftarrte wagredit yor fid fin, jebe sand auf cines von Den aufgejperten, redytwinflidyten. Snien gelegt, uno wimmerte eintönig: „nun fo erbarm's Denn (5iott uno wer will! Das find alfo bie Barben und SBeintefen, bie id Davon

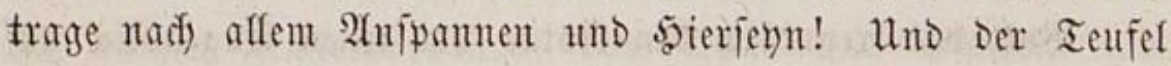

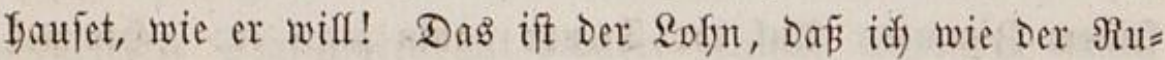
mormeifter bald finten, bald vornen im saeere ritt bei jebem

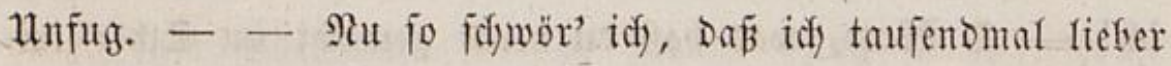
einem Sdjiffsolf mitten im Sturm auf einem Sdhaufel= Sijiffe Den $\mathfrak{B a r t}$ abnelymen will, als einen Didfter fauber focerent, Den afles bewegt uno erjojüttert. Rieber Den Brocfen

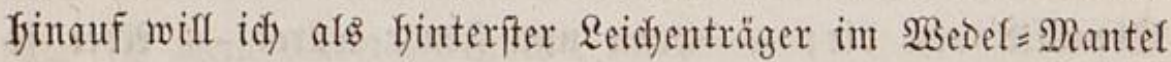
eine Reidge tragen und nadyftemmen, als cinen \$oeten geleiten

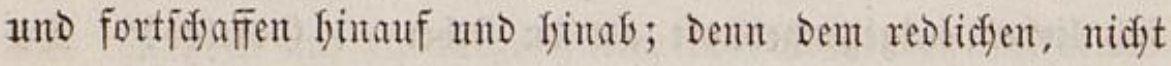
ganz viefloummen Bruber glautbt Der $\mathfrak{F o e t}$ wentger als wei= (f)em Diebsgefindel, Das ifn umftellt und mit fünen tritt wie ein Töpfer Den Thon, um ifn z̆ fneten."

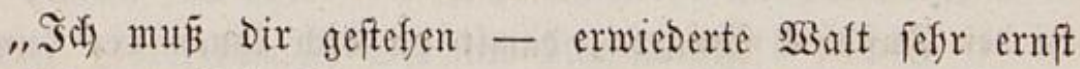

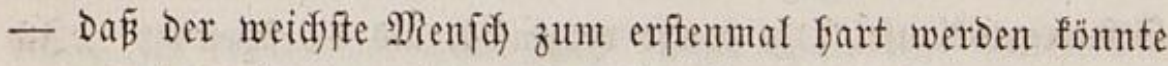
gegen einen fyarten, Der liber Die Menjoden fets ungeredft richtet."

"Wie gejagt, fufyr $\mathfrak{B}$ ult fort - Das thut er nidft, Der

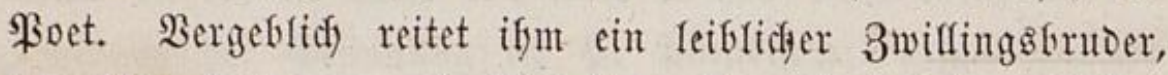
wie Dem Sumarow ein Sojact, naci) und hat sen leidften

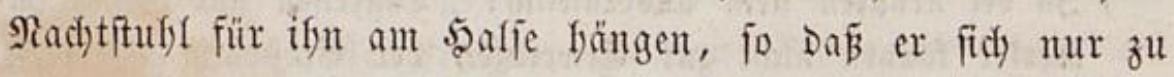
feben braudyte aufs (jeftell - er thut's nidjt, fondern er zeigt

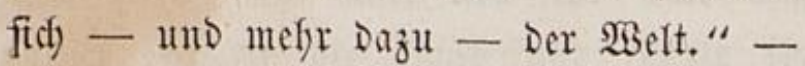




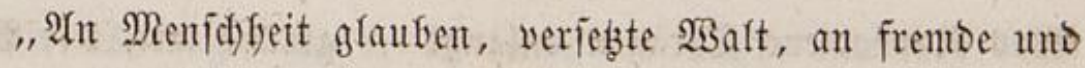
eigne - Durd) jein Smeres ein frembes efren und fenten Das ift's, worauf Das Reben und bie Efree anfommt; afles Hebrige hole Der Senfer. Whie, gröbere Rente faben in grö= Bern (jefaf)ren auf $\mathfrak{L}$ ben und Iod vertraut, ein $\mathfrak{A}$ ferantoet

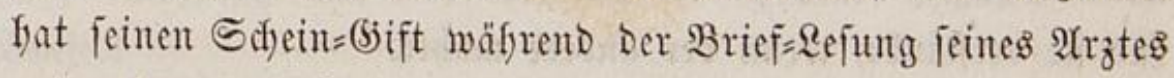

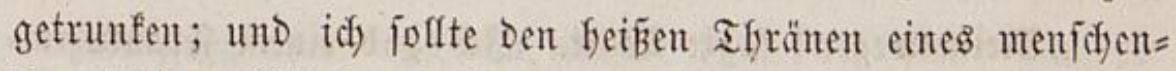
freundidyen Mäbdyens nidyt glauben? Rein, lieber nefym' idy Diejen Etab, Der ein Bettelitab ift, und gelye Damit, fo weit mid) meine fün̈e tragen ..."

"Weiter fant audf fein Bettler nidyt - fagte $\mathfrak{B}$ ult - aber Du unterfridgft. So Daß alfo, will idf mur nod) zujebsen, Die Alten nicht ofne 2njpielung Dem (3otte Der Didjter ein=

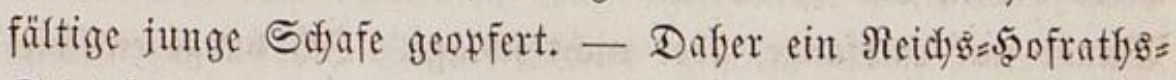

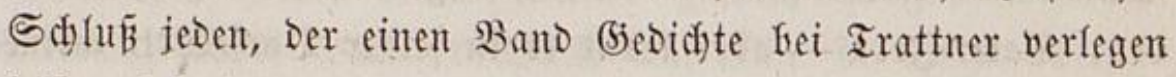
lafien, fofort pro prodigo erflären follte, Da er in Betradjt feiner ewigen göttlidfen $\mathfrak{U}_{\text {pollo's }}=$ Sugeno von 15 Iafjen zu Gürgerfichen 5 gandungen, $\mathfrak{z}$. $\mathfrak{B}$. Gdjenfen unter Den Reben=

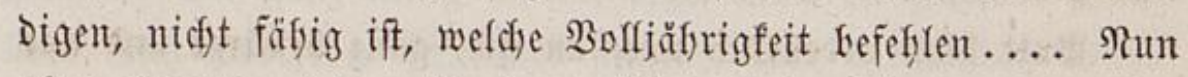

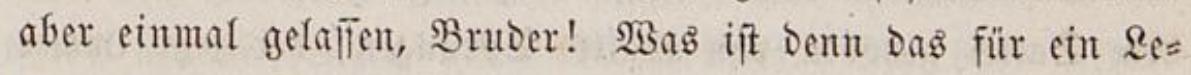
ben Dafier, zum Sacrament? - atber ganz rufig! Bater, Mutter, 3willings̆bruder willit bu Reuten opfern, yon Denen id) - nichts weiter jage? Bebenf' alles - fiebzig eben ges fälle Notariat $=$ Bäume - eine fo unerwartete Derfettung fo vieler Sietten - mandfe Deiner Srrjale auf Dem $\mathfrak{B}_{\mathrm{eg}}$ nady Rofentyof - uno in Der Tfat bift Du aud beute ganz..... belebt Durdy Den $\mathfrak{B e i n t}$ - 2 dm (Ende fliegit Du wol gar mit Sperber = und mit $\mathfrak{W}_{\text {Beifes }}=$ Fittigen un Das Brautferz Der

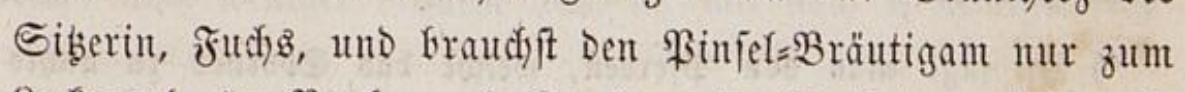
Locfvogel, Du Raub= und Spaṕoggel! Dodh Du wirft roth. 
Waล Raphaclens If)ränen anlangt - glaube mir, Die $\mathfrak{W e} i=$ fer baben grópere Sd)merzen als die, worüber fie weinen."

"Gott, wie Defto trauriger!" rief $\mathfrak{B a l t . ~ " W B e i b e r ~ u n d ~}$

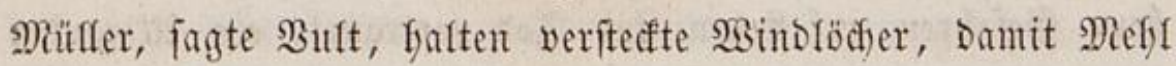
fur fie verftäube, went Der andere mafit." -

"Neinetwegen! jagte $\mathfrak{B a l t . ~} \mathfrak{S}$ (i) gab einem Frauenzim=

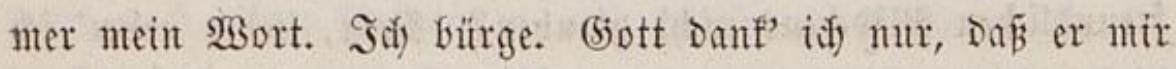
cine bielegentheit feidjeerte, Das Bertrauten zu zeigen, Das man zu Den Menfden flaben folf, will man nidyt das eigne ver=

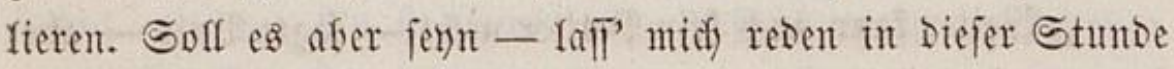

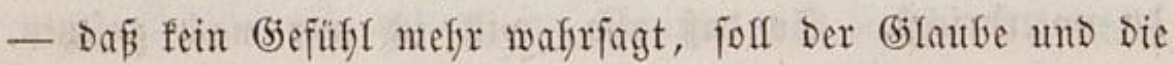
Siebe bluten uno verbfuten: o fo freu' $i d$ midf, Daj idf bie

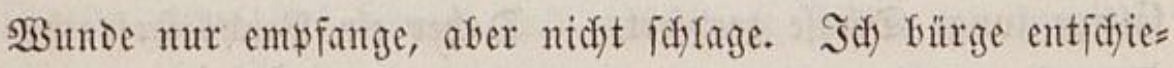
Den. Bater=3orn - aber fennt er in feiner Dorf=\$Belt meine föhern $\mathfrak{B}$ erbältuifīe? - uno Nutter=3orn - uno Rerfer und Noth: es frect) ein; idf bürge. Bürne bu. Sth bürge und gefye rinab."

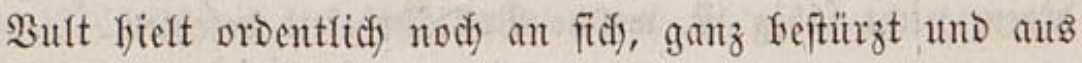
Dem Sattel gelfoben vou $\mathfrak{B a l t s}$ Sprüngen, Der jeljt immer wentger fu regieren war, je mefre er iffn fad utho trieb; vielleidst, weil Der fanftefte Mienid, fobard man feiner freifeit ftatt zu fodmetifeln Droft, foornfetig*) wiro. - ,Du

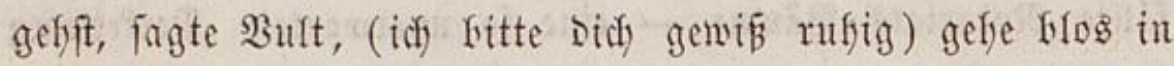
Didf. Faffre nidft, wie ein geblendeter Bogel, gerade in Die

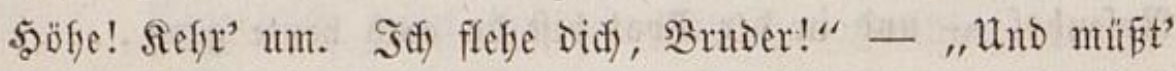

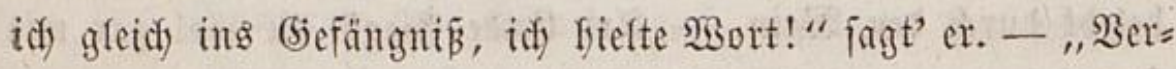

*) So fagt man von \$ferben, weldje Sas Spornen zu nidjts bringet als jum Steben. 
fofimmle Da, fagte $\mathfrak{B u l t}$; id wefr' es nidft; nur aber bie flärfe Bermmft und Bifligfeit belyalt' ifre Redjt - nur Das (5efindel triumpfire nidyt -2 Am Endoe wirb nody bazu er=

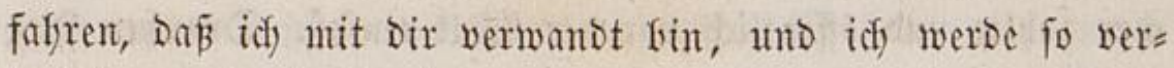
flud)t ausgetadft als einer von uns - Freund, Bruber, före, Ieufer!"

(Er gintg aber. „D Du wafuer Sinfer*) (jagte glüflento Der Flötenift)! Dod zufehen will id) Dir unten, wie Du vor

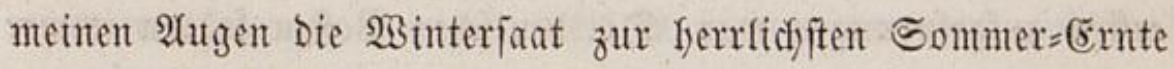
won Diftelföpfen für รinfen auşäeft!"

Alls fie cintraten, fanden fie Das Riebes=\$aar affein; Der

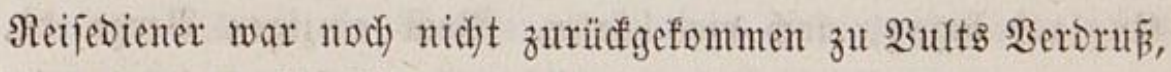
Der oben mandfe Reben fo lange geponnen flatte, um ver=

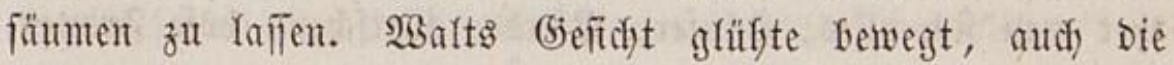
Stimme; Dabei warf er Bhiçe auf $\mathfrak{B u l t}$ in $\mathfrak{A}$ gift, Diefer werde grob. After gegen alfes Errwarten war Der Flotenjpieler eine flöte; er fidanete fo unbefangen an uno fprad) fo janft. "Malen Sie ganz luftig weiter, fagte $\mathfrak{B}$ ult fut flitten. Dar=

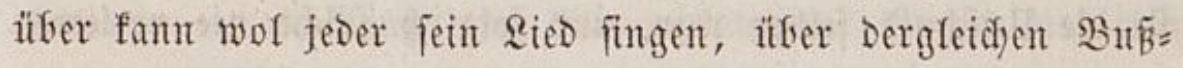
terte; mandhe befizen ganze-Lieberbüdher. Sal bafe jelber einmal in Diefem (bejange Der Drei Ränner im Jetter auf eine Weife eine Stimme gefabt, Daß̄ ich's beinaly' fyer zum Beften

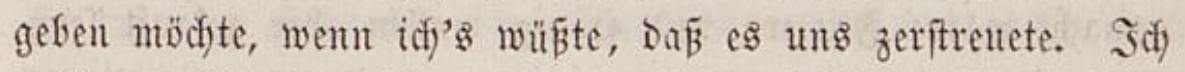

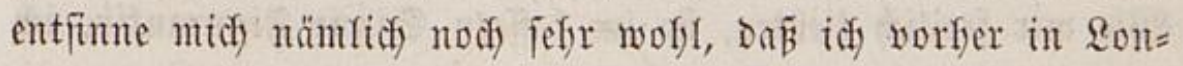
Don eine Beitlang in einer Gafriftei wofnte uno Radits Den Siniewolfter Des Altars als Ropffiffen unterfjatte, weil mir bie

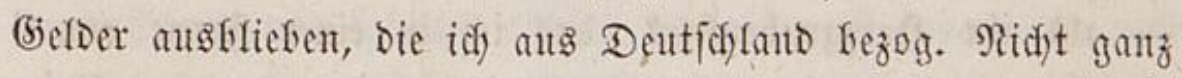
reidy, nod) wentger bequem fam idf) mit nod) 6 (Emigranten

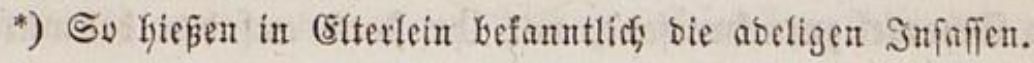


muf Der Boft nady Berlin, aber nidyt frino, fondern fammt

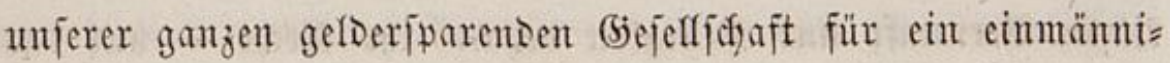

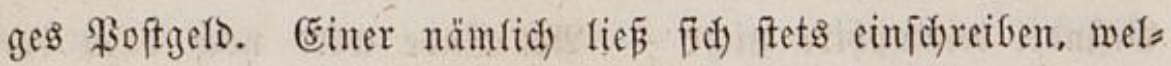

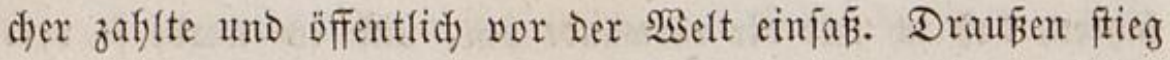
einer um Den anbern von uns auf, nact) Der ancienneté Der

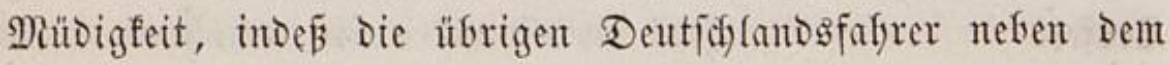
Waagen auf beiden Seiten mitgingen; jo Daß́ vor Dem zweiten Boftyaus immer ein anderer $\mathfrak{B a}$ alfagier abjurang, als vor bem erften aufgefprungen war. Die Deutichen $\mathfrak{B}$ often fafren immer

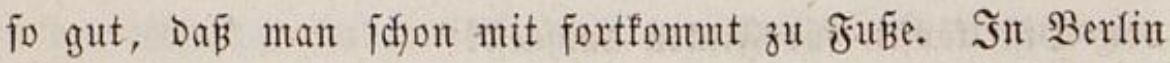
felfer fuffr idf), weil mir bie (befber augbfieben, bie idf aus Fuglano bezog, nody viel färter. Bom cinzigen Berge Da, monte di pietà, hatt' id̆ 2 usfid dyt; in groß̉en Stäbten mies

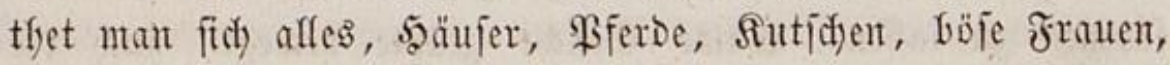
bejonbers aber zuerft (belo. In leb̧terem ging idi) weit. Sdyul= Den füfyren wie antere Silber=\$Biflen erft Den Morgen Darauf, went man ausgeid)lafen, bas ab, was man nod) fyat. (Eine Figurantin bei bem Balfet, weldye idy beiratfen mollte, weil fie bie Unfdufo felber war, und folglidf joldhe nie verlierent fonnte, fteigerte Das Leid ofne Beileib, Die Sdjulden, nod)

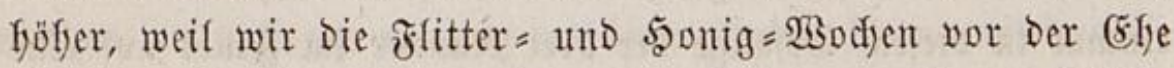
abtjaten, Damit bieje nachfyer ungeftört aus (rinem Stücfe gemadyt wäre; Flittern uno şonig wollen aber gefauft iebn. SBie wir freilidy liebten, fie im befiern Sime Figurantin, id Figurift, mit weldyen Sonfigurazionen - Davon ift fein andes rer Beuge mefr da - Denu fie wollte fein frofes Bruftitüf

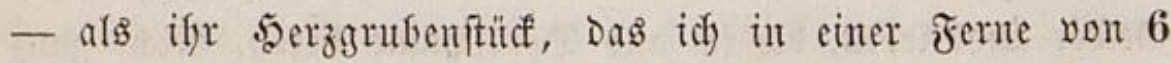
Sdyufen malte, indem id) nämlidy, jelber ein Yebendiges Snie= ftülf, Die niebrigen Beine aus (Efrfurdyt finter midh ober meine Sdyenfel zurüfwerfent, vor ifr ftano auf Den befauntent 


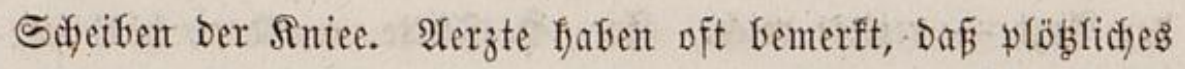
Eridfrecfent Den sörper und Deffen Finger fo froftig = fuapp einziefe und einflemme, Daß Ringe, Die lebztern fonft nidyt ab= zufidratben waren, von felfer abglitten. (5s follte mir fo gut

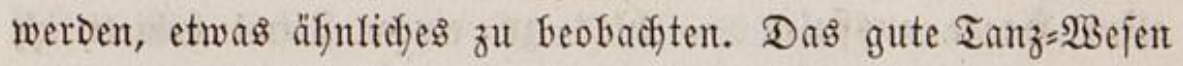
erid)raf io fürdyterlich, als idf nadyber befdyreiben werde, Dent 7. Februar im Rarneval. Sch ftiē̄ bei iffr vorfer meine ge= wöfnlidye $\left.\mathfrak{A n}_{z} a f\right)$ Seufzer in einer Minute nus - nämlidy vier uno zwanzig, wovon, weil man in einer mur zwölfmal atfmet, die 5älfte aus =, Die \$älfte eingezogen wird - that Die alten $\mathfrak{B u ̈ n}_{\text {ăde, }}$ idy mödhte meinen Geufzern \&uft madhen fönnen, als ob ein Seufjer aus etwas anderm beftände, und rief endlich im fouter aus: "wie viel, Du Roptlare, bin id

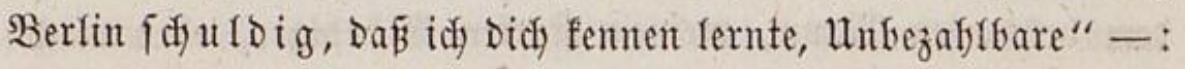
als plöblich bei biejen Worten, wie bei Stidyworten, meine ganze Dieneridaft von Rafaien unt meinte ganze \$oerridaft von 5antherren an Der Spibe eine Sofers herein Drangen auf mein Theater - Yeider feines, worauf meine Rebsbraut fwrang - und Dinge von mir verfangten, bie idh natïrlid) nidjt bewifligen fonnte. Meiner biefiebten - Die wentiger Darauf vorbereitet war als id - entglitidyte vom erjofrocfnen

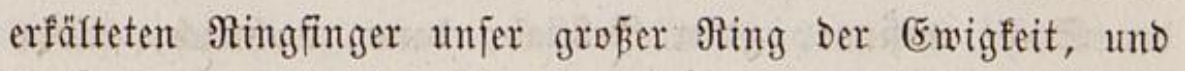
fie fagte im Sdfreden of von Rumpenfyuto!

Ber in Berlit war, wumbert fidy gar nidft, fondern weí̄, wie man ba zuweilen angeredet wirb, wenn man zwar won Stand und folglidy nidyt zut bezahlen ift, aber aud nidyt

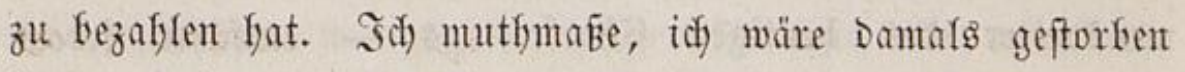

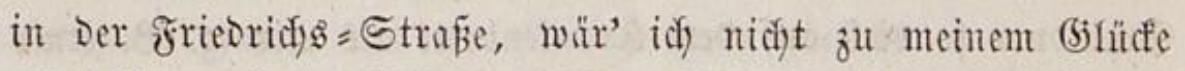
erfranft an einem fibigen gieber. Die Siranffeit - wentger 


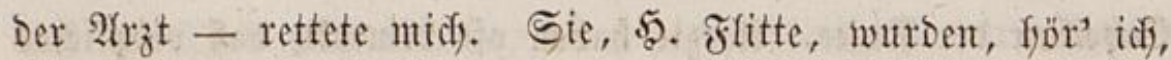
yon Der Sfrigen suf Dem Tfyurm Durd) Die Rumft gerettet; wafricheinlidi aljo eine ganz andere als bie meinige. Nein Fieber organifirte midf fo fontorbar, Daßj mir nicht nur bie

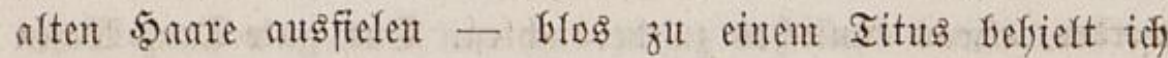
fidwadyen furzen $\mathfrak{B e l} z$ - jonbern aud Die alten Soeen, vor= z̆̈̈glich) verorię̧liçe.

Blatner bemerft redft gut - jo wie Den tefeologificen

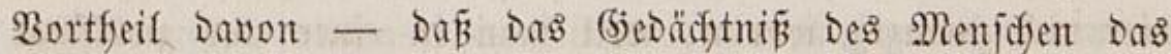

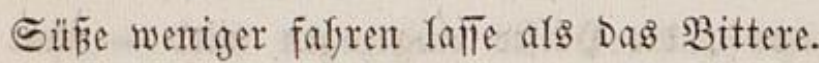

Mit mir - ofwol nidgt vom franfentager - fanden meine (5läubiger auf. „Irefflidger 5. Mufiffyändler Rellftab! - mein Bedienter verfichert, Sie fiejen jo - (jagt' idj) zalt Dem Gefannten Mann, meinem ftarfent (şäubiger) eben mad́s'

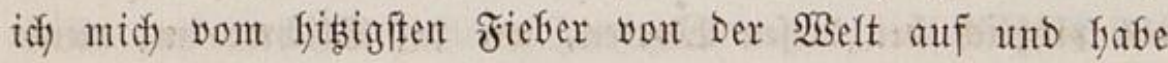
alles, 100000 Dinge, ia Dent Namen vergeffen, Dent idj ges

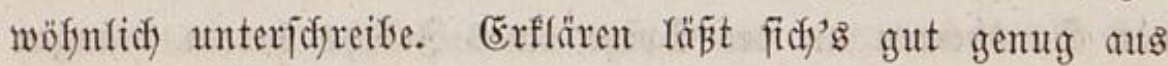
Bfyfitologie, aแt Sdfweipen, Fieberbildern unt Ermattungen;

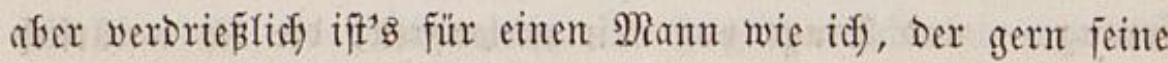
Rota von Mufifarten abfüffrt, und Dem Dod) affes entfallen.

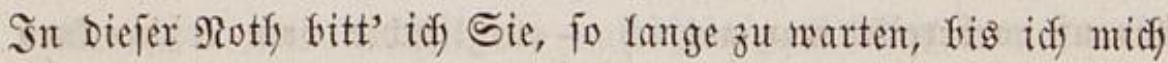
Der Sadfe entfinne, guter Rellftab; Dam, wafrlidy, Yabent Sie Sfr (jeld auf der Stefle iut 5ante, was fid) im anberent Sinne ofnefin verfeft."

Darauf erfofien Der erfte Tlyeater = Sifneidermeifter und (5arberobier und erfudfte midy um bas Seinige. Salf antwor=

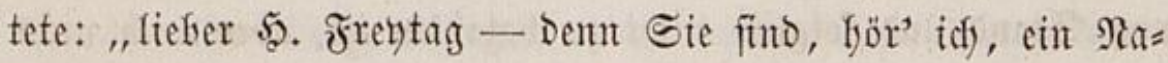
mengvetter des feutigen (sfarfreitags - entfäfrt jedem Sdjulbner fo viel auf Dem Riranfenbette als mir (z. B. etwa

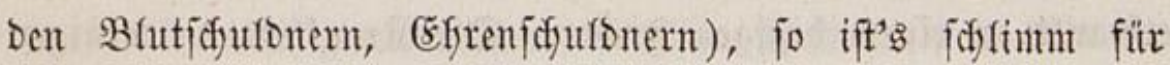


(5)täubiger. Dent mir für meine Berion ift rein alles ent= faffen, was idf fifuldig fin; - Sie werben mir faum glau= Gen, went ids Sie an meine Sirmfenmatrabe füffre, wo idf fo

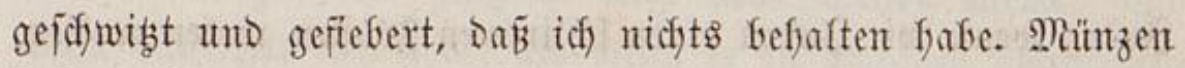

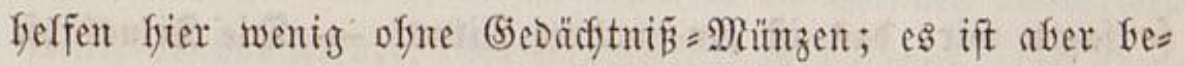
trübt, Rellftab."

(Er fyeipe Freytag, fagt' er. "Das hole Der Ieufel, fagt"

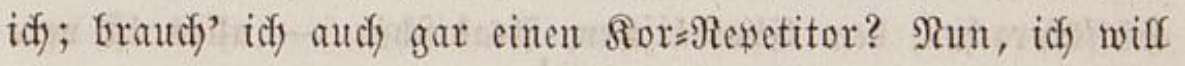
nidyt vergetien, midy zu erimment." -

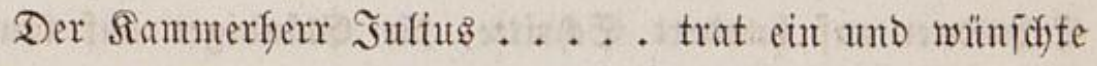

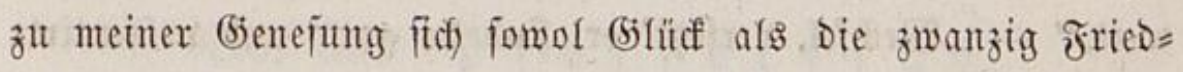
richgo'or Spielgeto won mir. "Id) foll Sie fennen," frot"

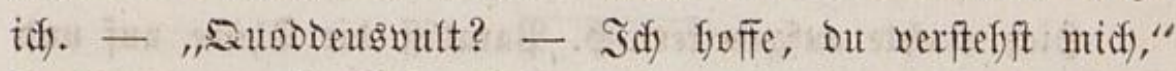

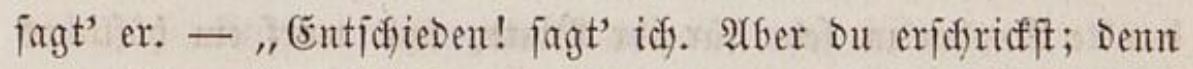
wenn idf weí, of idf mefr Dir oder Dem Mann im Nond

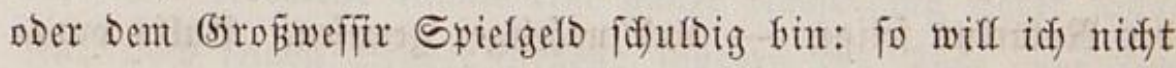
franf gemejen fern. Redft flajt Du gewi $\bar{\beta}$; aber follte man fidf) Denu nicht jedeşmal, eff' man in ein fibsiges fiefer ver= fällt, taujeno finoten ins Sofnupftud) mact)en, um gentejen mandfe beffer zu löfen als Durdf Das 3uwerfen Des Sdyupf= tudfs? Spridh, Rammerfyerr! - \$all aljo, fis mir bie Me= morie wieder auffilft! - aber verfludft fatal, Daß́ $\$$ frr Reute yom 5abfe ganz gegen $\mathfrak{B l a t n e r s}$ Bemerfung gerabe nur bas Fatale (weniger faft Frtalien) befaltet. Afber wie geft's

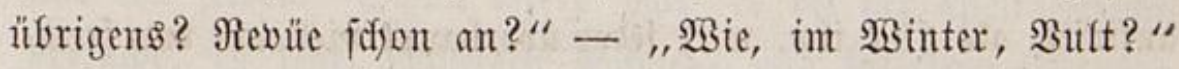

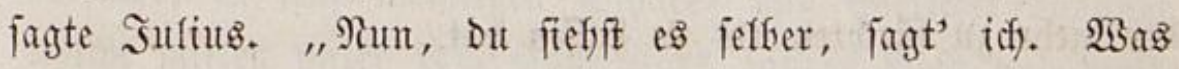

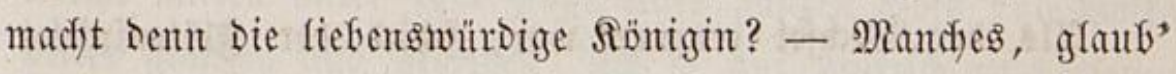
idj, vergińt man weniger." - - Darauf bat idy ifn, nädfftents mid) zu erinnern, uno wir fofieden ganz gütlidf.

Anders ging's, als idf von Der fangen Brüce in bie 
Sönigğftrape wollte uno midh ein gefilbeter Sube aufbielt: "Yieber Mofes! fagt' idh, Föfe Radfridften! Das Fieber hat

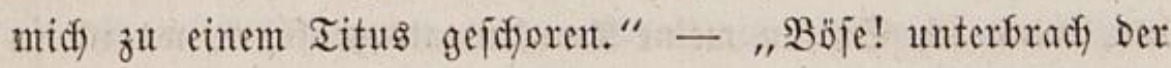
Sube; wenn wir Suben einen folfimmen güriten malen wollen, fo jagen wir: Das ift ein wafrer Titus! - Die Titusfüpfe bauen uns fein. Serufalem." "Sonft - fufjr idy fort - war

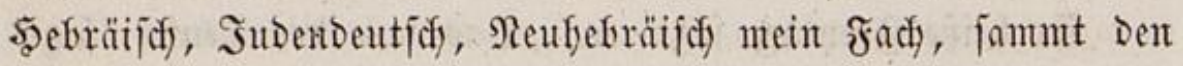

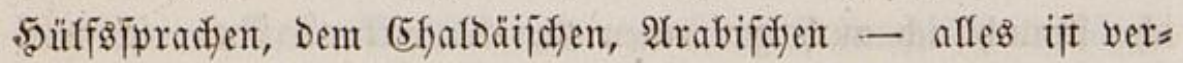
gețen Durdjs ftarfe fieber, Mojes — Sonft fannt' id meine

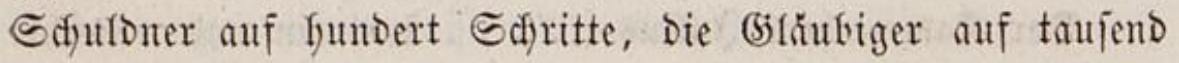

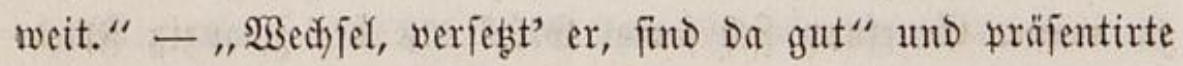
mir einen fälligen nod̆ über Der Spree" . . . . .

5̧ier madyte aufgefeitert 5 . Baradifi Die Thüre auf und Donfte Raplyaten jelyr für ifyr Blatt, uno warf ein höfliches Auge auf $\mathfrak{B a l t .}$ (Er nafm Defien Bürgid aft an. Selten war Der Notarius jeliger - und unfeliger gewejen. Sults paros

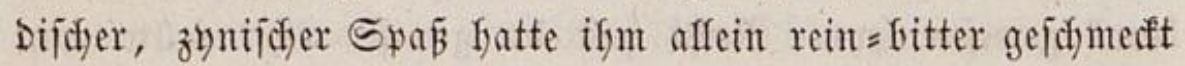

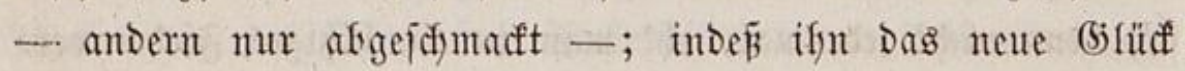
erquicfte, Flittes Entjag uno Sdjukgeift zu werDen. Sor

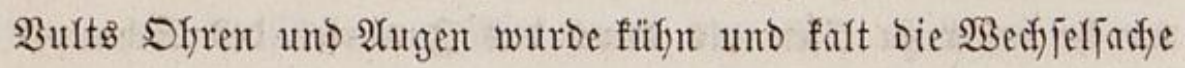
volffüffrt und gerünbet und Der Flötenjpieler wurde üfer bie fo frei auseinander frülyende (5egenwart beftürzt uno erzürnt, obwol beimlid); fo wenig verträgt jogar Der Rraftmenid frembe Stärfe und Sonjequenz, jobald fie mefr wider ifnn auftritt, als für ify, weil jeder üferlyaupt vieffeidyt von frems Der mefjr zu fürdyten als zul hoffen hat.

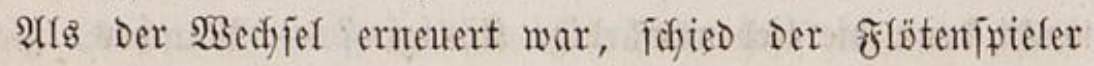
fanft von Der Giejellifinaft, Gejonders von 23 alt. Diejer bes gleitete ifjn nidyt. (Fr fragte Flitten, of er Die wenigen Stun=

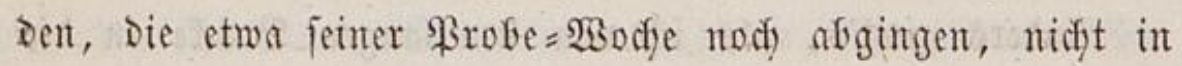




\section{9}

Feinem eignen 3 immer verbringen Ditrfe. Flitte fagte frentoig Sa. Rapfacla Drücte Danfend $\mathfrak{B a}_{\text {alten }}$ nod) ifre zarte \$auto in Die feinige. (5r ging in peine ftifle Stube zurüd, uno beim (sintritte war ifm, als wen er in Ifyränen augbredfen follte, of vor Freube, oder Einjamfeit, ober Trunf, ober üfer= f)aut, Das wupt' er nidft; am Ende vergof er fie vor 3 orn.

\section{No. 5̋. भु $f \in f f \in \mathfrak{f} \mathfrak{f} \mathfrak{a} \hat{\beta}$.}

\section{Eeiben bes jungen $2 B a l t 5$ - Ëinquartierung.}

Der Notaring formte eine ganze Nad)t lang weber fofla= fen, nody jeinen Bruber lieben; fonden ber 3 orn war jeit

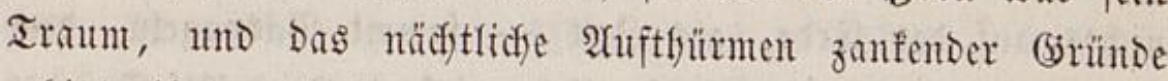

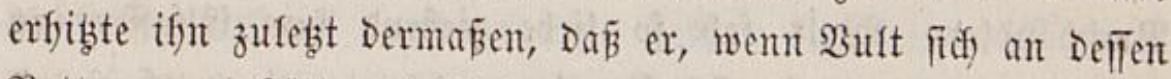
Bett gewagt Gätte, viefleidyt fälfig gewejen wäre, iffm zut $j \mathrm{a}=$

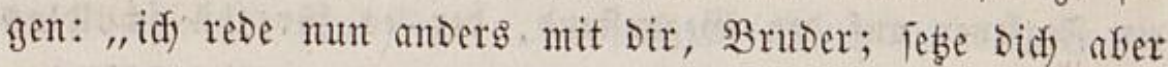

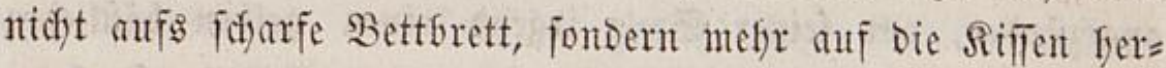
ein!" - Unbegreiflid) unt unverzeiglidi fano er De Renfden ins (sefidyt finein fu martern, Den armen fritte

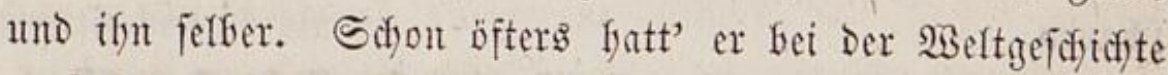
verfudit, in jene mäditigen Sdynee $=$ unto (sleticher $=$ Männer,

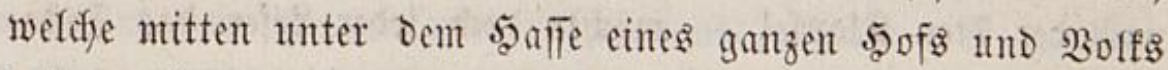
fyeiter glänzen und gebeifyen, fich fo gut poetifol zu verfebent als in andere (Sharaftere; aber es batte nie bejondern Erfolg - er wäre eben fo gut einer Statue Durdo Den Pund ints

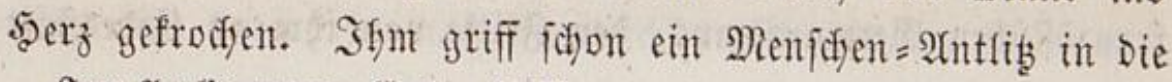
Scan 9aul's aนฐgew. Bserfe. XIV. 
Seele, und wär' es punftirt an Der Fuppe eines Radyt= (d) metterfings erfótenen, ober wädyern in Der ßuppe eines Sindes; er fyätte beide nidyt falt cinbrücen fönnen mit Dem Daumell.

(Ex) ftieg aus Dem Bette in einen wlatt=gemäften serbfit= tag; Denn or wollte, wie er pflegte, liefen uno Der fübeften (Empfindoung faum mäd)tig fern; fand aber nichts Brauthbares Daz̧u, jontoen mur die Bucferjäure Der vorigen 3ucterinjel.

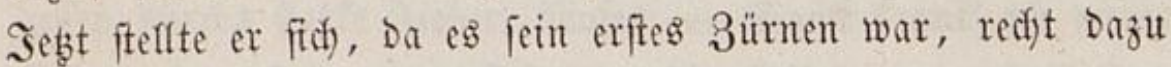
an. Ein seerz voll Siebe fann afles vergeben, jogar bärte gegen fid b), aber nidyt bärte gegen andere; Demn jene zu ver= zeifen, ift Berbienít, bicje aber Mitichuld.

Darauf madyte ex fich auf Den matten $\mathfrak{B e g}$ aufs Ratfy= frats, um $D a$, wie bisher, fich für feine Erbamts = Sumben wacter abjtrafen zu lafjen. Der Swapuogel flitte, jebzt fein geftrenger Unglüfévogel, war fichon Da - Dent er hatte faft nidyts auf Der Eroc, als Beit - jammt Fasvogeln, Demt

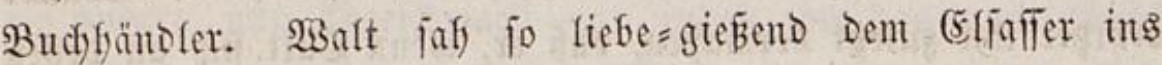
Atuge, als frätte biejer fich für iffn verbuirgt; nie warf irgent ein zegfeuter auf Den Biegenftand, Der es fiur ifn fodulolos angezüntoet, vor feiner Seele irgeno einen gelben lä̈̈́liçen Wieberidjein; viefmeffr freute er fidh recht, affein im Fegfener zu feffen, und Den frembling rein aแร Den Flammen ăzu= idjatert.

Der Ieftament $=$ D ber $=$ Bollftrecfer $\mathfrak{5}$. Sulfnold eröfinete nad) Der 7ten Silaufel - mödste Dodh jeber Rejer Das Iefta= ment aus Dem Budye berausgejdyitten, brochirt, immer neben fich bafen - Den gefeimen Artifel Des Regulirtarifs, Der redytmäßig zu offnen war. In Der That war Darin auf jeben

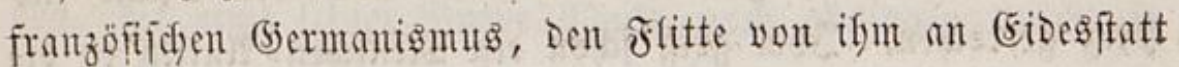




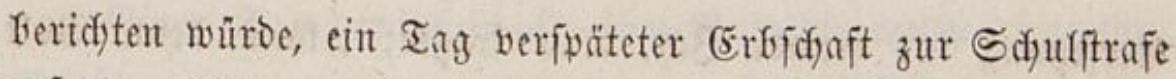
gefest. Flitte ermiederte Darauf: ,er wiffe Niemano, Der fo viel Drgan für franzöfifide Epradje befize, fo wie Ralligrapfie Dafür, als Şerrn $\mathfrak{B a l t ,}$ und er entfinne fid feines erfeblichen Fefflers." Waalt griff nad) Deffen 5anto, und jagte: "D wie f(d)ön, Dafi id mir Sie fo immer Dacijte! âter meine Frente ift nicht fo uneigennubig, als fie fodeint, fonbern nod) uneigen=

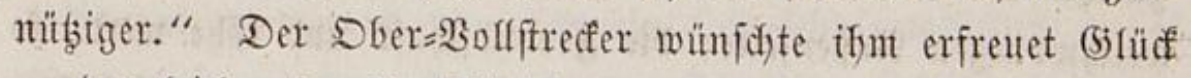
- Desgleidfen Der Budffändler - uno jener bat if̆n um die Wafil Des neuten Erbamtes.

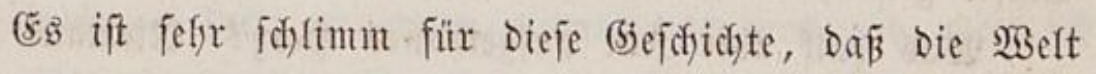
nidyt bie fedjite Rlaujel "Sparbly aft und leidft mag's" ausmendig faun, auf weldyer doch gerade die Bfeiler Des (be= Gäudes ftefen. Der Notar wufte fie ganz gut, uno ber Budfy= Gänder am beften. $2(t s$ Balt in Dem Geelen= Raufhe über bie fdyönfte Redftfraberet, Die es gibt, fidf) nümlidy nicht in-

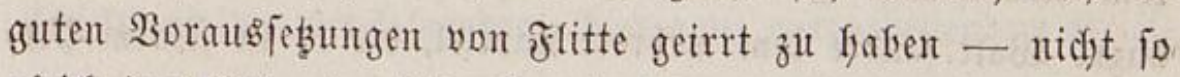
gleid) Das (5rbamt erlefen founte, Das er begleiten wolle: trat Pasyogel fut ifm, uno erinterte ifn an Den Budfifaben C Der Rlaujel, weldyer fagt, ,er foll als fiorreftor 12 Bogen

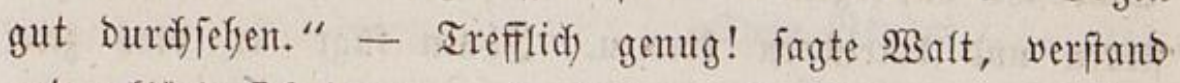
unb erflärte fich) Dazu; - in Dab vom Nadyt=3orne zerfreflene 5erz floflen die fleinften (Ergü̈le menjoylidfer Milde bal= famifich=heilento ein.

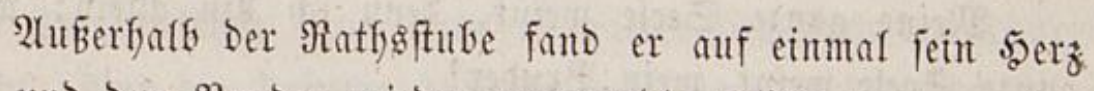
um= und bem Bruber wieber zugemant; Flitte war gerecht= fertigt, er felber entiduldigt, und er verzief) in Mafjen, bloz weil er fo viel - Redyt geffabt. Radjem er eilig feinemt

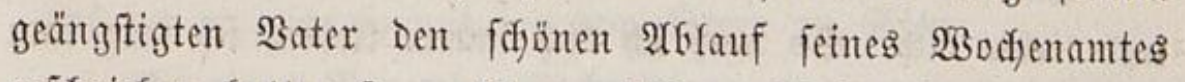
geforieben fiatte: fo madjte er fid ermiflyafter an feine alte 


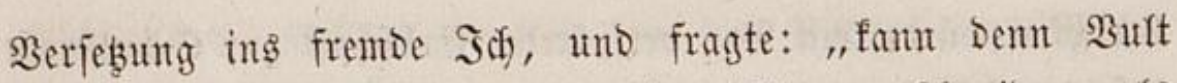

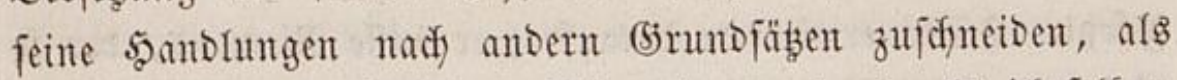
nach feinen eigenen? Hnd wollt' er Denn anbers, als idf felfer,

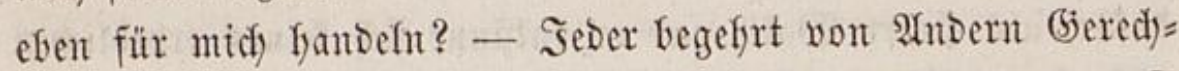

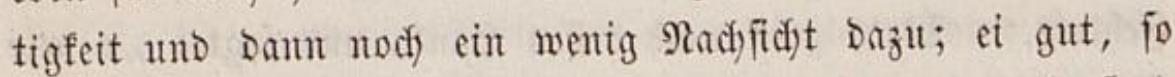
geb' er Andern aud beibes, und das will idf thun." (Er fand zuleb̧t in Bults Stopfrnft einte Ergänzung feiner eigenten

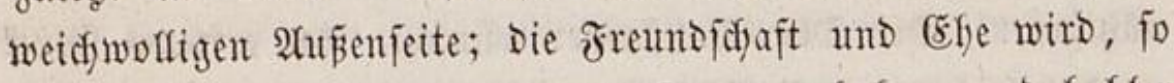

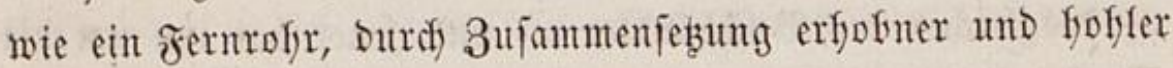
(5läfer gemad)t.

Waas half aber jein aufgetfjanes 5erz? Riemand ging finein. Riebes=fdyamfyaft farrte er, Dap Bult mur eine Biertels=

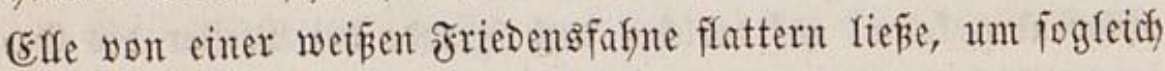
mit Riebesangen in bie frembe Geele einzuziefen; afer nidjt einen Fingerbreit Davon ftrecfte biejer aus, fondern er fodifte

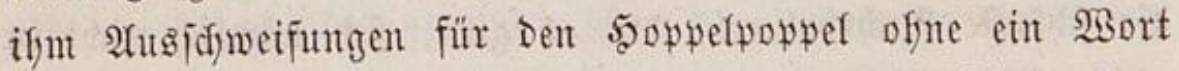
Dazul. Waalt fandte ifym mefrere Rapitel, Die er in jeinem 5yer= zensflofter um fo reidyter aufgejebt, Da ifn \$asuogel nod immer auf Den erffen Rorrefturbogen warten Yié, fo wie bie Stadt ifn auf irgento ein Notariats= Snftrument, Das ifn bätte ftören und bereidfern fömten. Shnen fügt' er blos zwei Streffuerje bei:

I.

Meine ganze Seele weint, Dent idy fin alfein; meine ganze Seele weint, mein Bruder!

II.

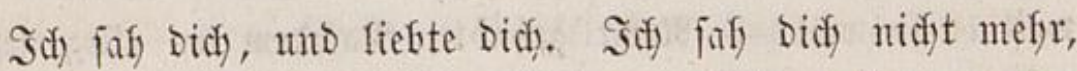

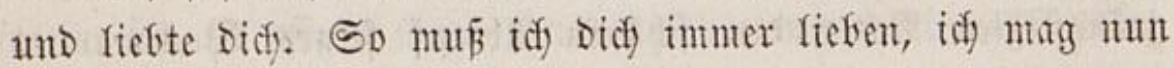
froflocfen ober weinen tief im soerzent. 


\section{3}

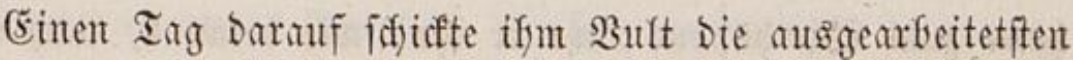

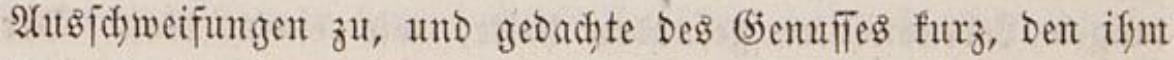

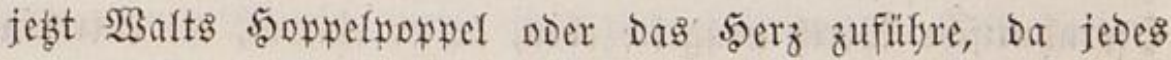
Rapitel mit wafrer Runftwärme erjōffen jei und überfeilt - und jorreb nods, er jelber jareibe aber eifriger alo je, Dürfe aber nidft entidjeiden, wie glüdlid) - und jidrteb weiter

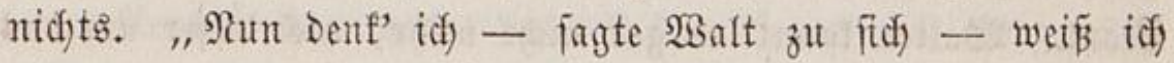

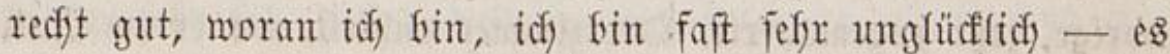
ift vorbei mit Dem şimmel, Der fid) fier aufthat für mein Armen=? Auge - Nuf ewig ift mix Der Bruber begraben unD

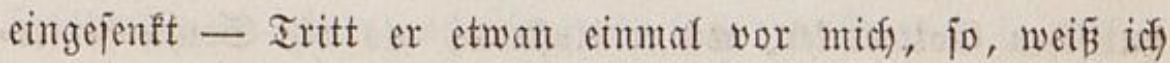
wol, ift's ein Antlig grimmig verzogen, und midi wird fod au= Dern Durdy mein bुerz. D mein Brutber, wie fidjün war es , cinft, als idh Didf nody umarmte, und zwar weinen mub́te, aber gantz anbers!"

Darauf fidrieb er wieder ein gutes Rapitel an Romane, fojicft' es ifm mit folgendem, fier ganz mitzutfeilenden Briefe:

Brutier!

5iter! - - - - -

\section{Dein Brutoer}

(5).

Bult verjebste nidhts Darauf. (Sottwalt erzürnte fich) nadi) Der Terzien=ltfr; Daun Gatt' er wieber lieb nadj Der Tfurm= ufr. Nur Die Iräume brangen mit ifren gräulidgen aufge= rif̈enen sarven in feinen Gdylaf, jede mubte wie ein Bruber aแริ|jefen, Der ifn marterte auf einer unabjeblidjen Folterleiter, auf Der ex auggejpannt lag von Gtern zu Stern.

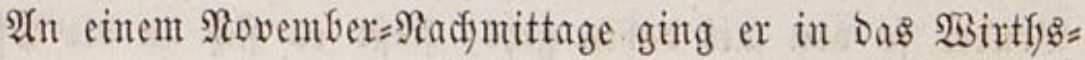




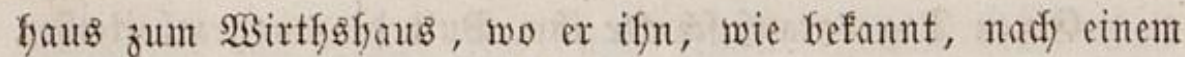
Iangen Rebenswinter gefunben fratte, wie einen Mat. Der

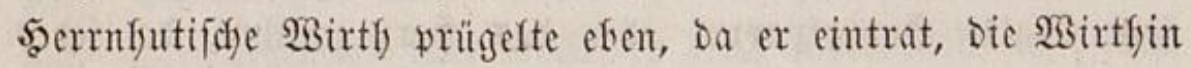
auts Dem (Safthofe finats, warf ifr feinen Sungen nad), und fodrie: wär' er fecin (sfrift, fo würd er fie anders befandefn;

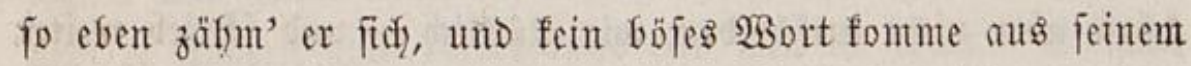

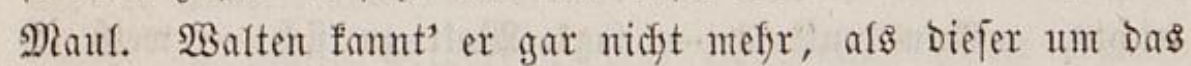
worige, jeģt zugemauterte, Dberzimmer anfielt, wo er im Juli geidhlafen batte. Theils Wourfte, theils Flachs auf Stroh waren Darin auseinander gebreitet. (ङre entflof) auf ben \$sern= Futififen (5ottesader, wo er einfents, als Die Eomte unter= und ber Bruber aufging, jo froly und fo nelt geworden. Aber bie Bäume waren, amfatt begrafne bicrippe laubig zu bedecfen, felfer fteilredyte geworden - Dabei idnneiete es regs nerilá) - mefrr das (5emölfe als die Sonne ging unter und 2tbeno und Radjt waren fidwer zu fontern. Der Nota= rius faf aus wie Der eben regierende November, Der, nody weit mefre Dem Ieufel als. Dem 2 pril äfnlich, nie ofne bie verorieß̧lichften folgen abtritt.

Bon Da trug er fidf verarmet - fern von jenem reidfen Norgen, wo er nefent Dem reitenten Bater zu Fuke fergelau= fen - zurüf in bie Stadt. $\mathfrak{A}[s$ er über bie falt wehende Brücfe ging und nidfts um ify war als bie öbe Dunfle Radit: fo flogen zwei Diffe Bolfen auseinamber - Der Yelfe Nons lag wie cine Silferfugel einem weipen $2 B$ olfengebirge im Sdjoof und Der lange Strom wano fid erfeudytet finab.

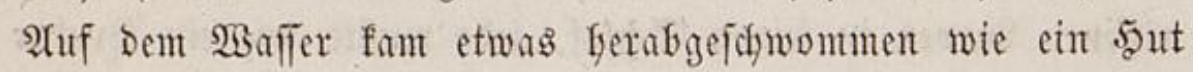

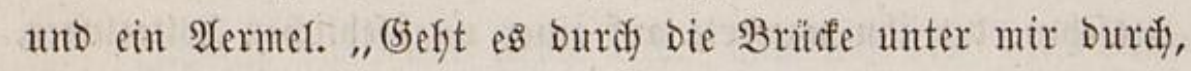

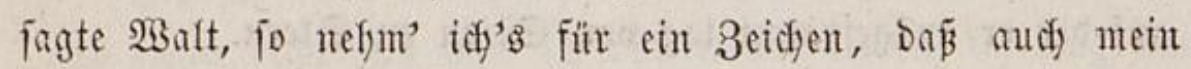
Bruder fo vor mir Dafjin gebt; föṕt es fidy an Die Pfeiler, 


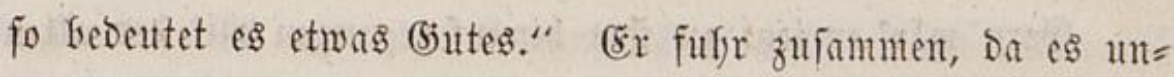
ten wieber herwor fam; endich fiel ifm ein, dá wol gar ein ertrunfener $\mathfrak{M e n i}$ í unter ifm ziefjen fönne, ja $\mathfrak{B}$ ult felfer.

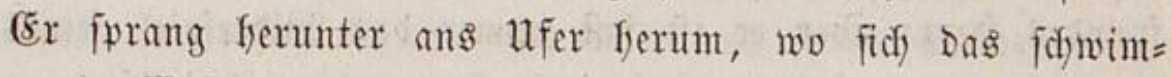

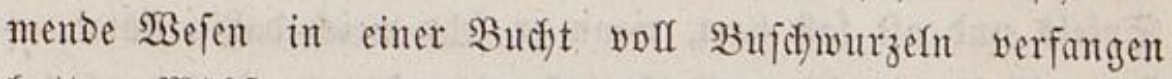
fatte. Mübfam und zitterno hob er mit feinem Stabe einen Yeeren Aermel, Dann nod) einent und Darauf gar noch einige auf,

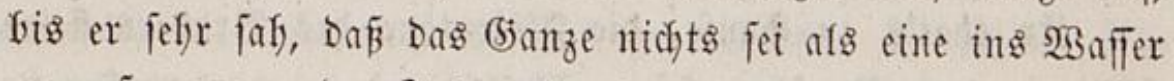
geworfene, won Der Safrezzeit abgedanfte - Bogelidyeudje.

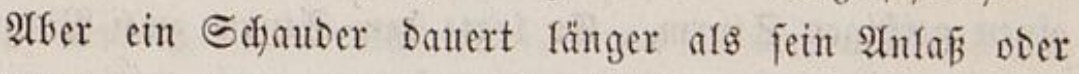
Srrtfumt; or ging nod) forgent für Den $\mathfrak{B r u b e r}$ in Deflen Wolyngafle, als feine flöte fochon von ferne berauf tönte und

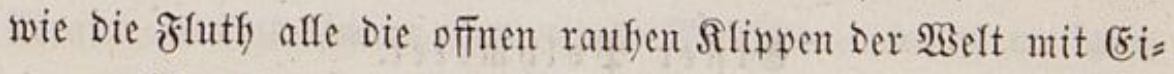
nem weidfen Meer zudeffte. Der elende Rovember, Der Serm=

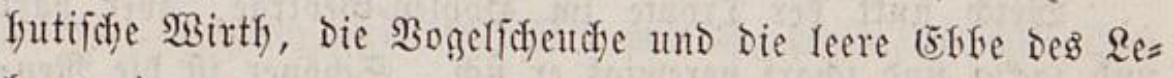
bens gingent mun unter in fojonen $2 \mathbb{S}$ ogen. Waalt trat, weil's finfter war - Denn an Tnge fdymete er mur bie lange (5anje finab - bidft vor Bults 5 aus, obwol in sie Monds=Sd)at= tenjeite. Er Drücfte Den Tfürorücfer wie eine \$anto, weil er

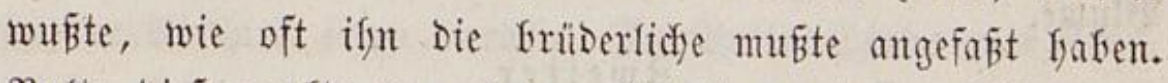
Bult, Dié̃ merfte er aus Dem Echatten und Dem Sidntidjim= mer gegenüber, muß́te mit Dem Notenpufte naf) am Fenffer

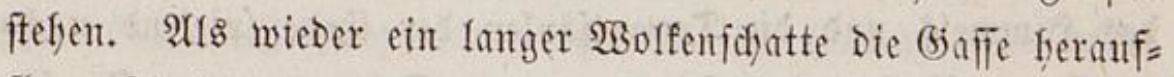
flog: fortitt er quer über uno gucte finauf, uno faf finter Demt erleudsteten Notenvulte Das fo lange begefrte (5efidst; und weinte bitter. (Er ging an ein grofeses rothes Ifyor feit=

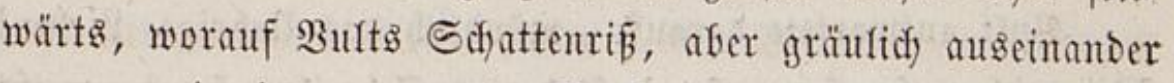
gezogen wie ein angenagelter $\Re a n f v o g e l$ Ying, uno füpte etmas vom Sdhatten, aber mit einiger Müfe, weil fein eigner viel verbecfte. 
(jern wär' er jebgt flt iffm frinauf gegangen mit Der alten Brutoerbruft an jein berz; aber or fagte: "blief idf felfer Droben, o fo weis id alles woff - nein es gäfe für mid fein

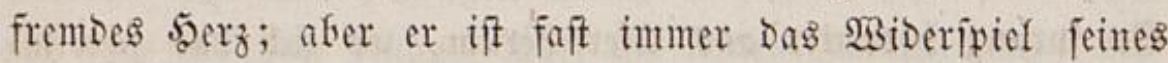
Spiels uno oft faft hart, wemn er fefjr weidh Dafjin flötet. Ich wilf ifn in jeiner (sieifterfuft nidjt ftören, fondern lieber mandfes zu Bapter bringen und morgen fojicfent."

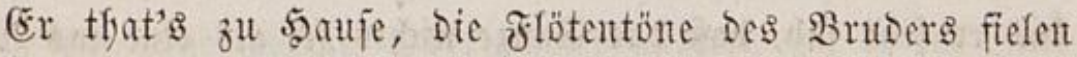
fojön in Das Raufden feiner (befühle ein - er verfiegelte einen geiftigen Stum. (Fr legte Dem Stum zwei \$ofymeter über Den Tropfitein bei, Deflen Säulen uno Bifbungen be= fantlidy aus weidyen Irowfen erffarren.

\section{Ěrfer $\mathfrak{B}$ olymeter.}

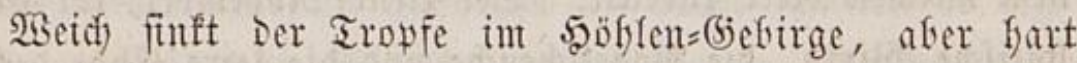
und zacfig und idfarf verewigt er fich. Sofjoner ift Die Men= finen $=$ Iffrüne. Sie Durdjidneidet Das Âge, Das fie mund gebiert; aber Der geweinte Diamant wiro endid weid, Das Auge fiefft fith unt nad) ifm und er ift ber Ifrau in einer Błlume.

\section{3 weiter.}

Blicf' in bie 5abfle, wo fletne ftumme 3äfrent Den (5) fantz Des bimmels und die Tempelfäulen Der (rrde ppietend nad)=

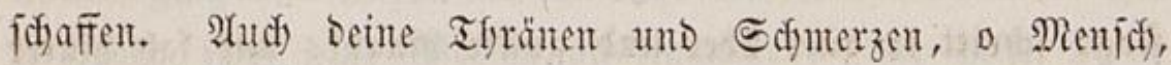
werben einft fodmmern, wie Stene, uno werden bich tragen als $\mathfrak{B f e i l e r .}$

Bult antwortete Darauf: "Mühofid) Das Uebrige, Sieber!

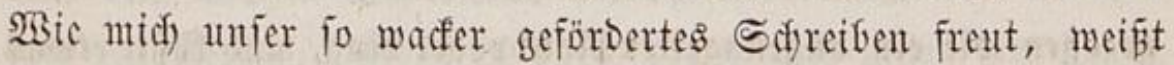

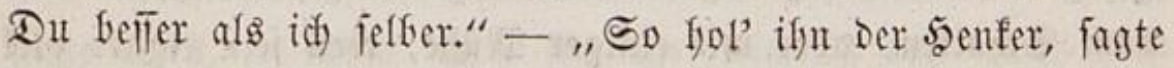
23alt, idf) frabe mefre eingebüfít als er, bent idf lieb' ifn ganz 
anbers." (5r) war nun fo unglüffich, als es bie Riebe auf Der (Erde fern fann. (Er webte - ganz entblöb̆t von Men=

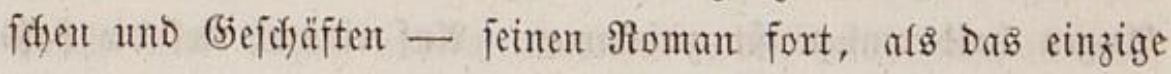
Dünue Yeidjte Band, Das fid nod) a!s jeiner Stube in bie Griiberliche jwanten lę̄.

An cinem $\mathfrak{A}$ fento, als Der auggewadjene reife Mono gar zu befl unto löfend fodjen, bedadyt' er, of es benn nidgt

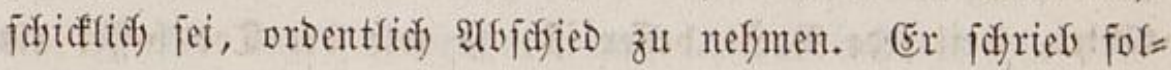
gentes Briefifen:

"Empfange midy nidft l̈̈bl, werut id) Diefen Arbent un 7 ufyr fomme. Waafrlich, idf nefme mur abichied; afles wird auf Der Errde ofne âtriffied auseinanter geftürmt; aber Der Menid) nimmt jeinen von cinem Mienjifen, went er fann, went fein Meer = Sturm, went fein Erobeben Die Seelen=

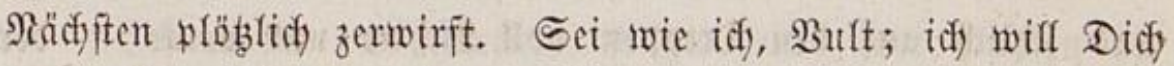
nur wieder fefen und Dann nidjt Yünger. Antworte nur aber nidft; weil idf mid. fürdfte."

(Er: befam audf feine 2 fntwort, uno murbe nod furdft= famer und trautriger. (Ex ging atbents, aber iffm war, als fei Der Afbidied fifon vorbei. In Bults Stube war Ridyt. SBeldye Bürde trug er bie Treppe finauf, nidyt um fie oben abzuladen, fondern fu verdoppefn! Arfer niemand fagte: fomm? ferein! Das Zimmer war auggeleert, Die Rammertfüre offen - auf einem Stafleudfter wollte ein fterbentoes Ridyt veridfei= Den - Die Bettfeffe fefferbergte, gleidy einer Sdyeune, nur fatales Strofy - verzettelte $\mathfrak{B a p i e r}=$ Späne, Brief=Ulmidjläge,

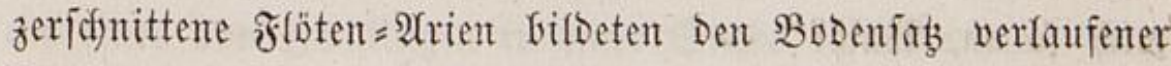
Tage - es war Das Gefeinfaus oder Gebeinzimmer eines Menidhent.

Walt Dadyte im erften Hninn Des Sdyrefens, Bult 
föme, wenn nicht Damals, Dodi fpäter, im $\mathfrak{B}$ alfer gelegen fern, uno griff alle $\mathfrak{s a p i e r}=$ Reliquien mit gro $\tilde{\beta}=$ tropfenden

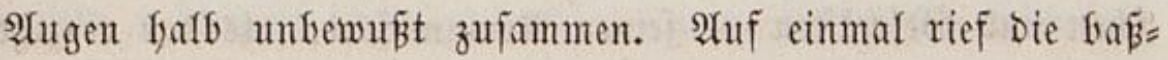
ftimmige Frau Des Theateridnneibers ferauf, wer Droben um= trabe. Sarnifid, verfebst' er. Da fufre fie Die Treppe herauf

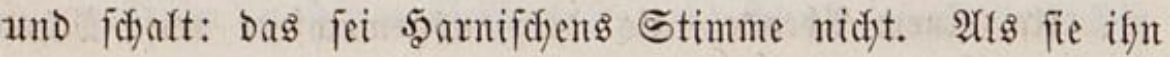
gar im finftern faf - Denn er fyatte Das fterbende Ridyt ge= töbtet, weil jede Radyt Gefier ift, fo wie Der Tod fefler als Sterben - jo muß̃t' er fich mit Der Theaterfonetoerin in ein

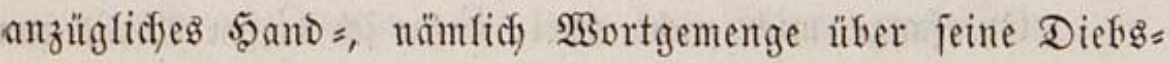
Tendenzen einla fen und zulebzt über fein Rügent. Dem er

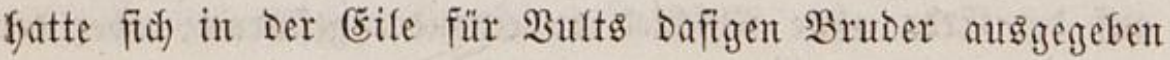
uno Dod) gefragt, wofin Bult gefommen jei.

Berworren und geicholten wanderte er feiner Stube zu

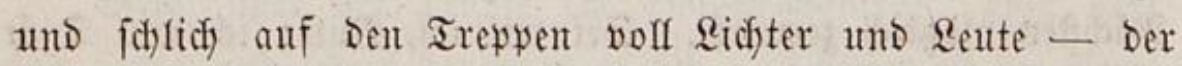
5ofagent gab einen tanzenden shee - gebücft hinauf.

Da fand er fein 3immer aufgetfan und einen Mann Darin mit 5̧ämmern arbeitend, um fid gut einzuridyten in feiner neuen $\mathfrak{B}$ ofynung. (5: war $\mathfrak{B}$ ult.

"Srwünjder - fagte Bult und nagelte an einer Theater=

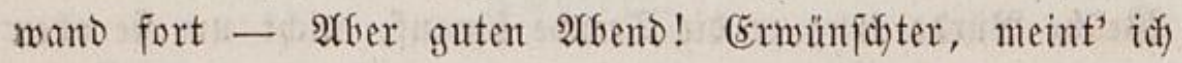
nämlidy, faun mir nidyts fommen, als Du endich fommif. Sdyon feit Sdylag fieben verir' idy midh ab, um alles aufs Befte aufzufteflen und etwa fo einzuridyten, Dañ feiner vont uns nadjyer frumme ober grunze; unterftübe midy afer Dabei, bei ocr gemeinfdaftlidfen Finridytung, und filf! - Du fieffit midif fo an, Walt?" -

"Bult? - $\mathfrak{B} i c$ ? - Sprid) nur! (jagte $\mathfrak{B a l t )}$ (5:

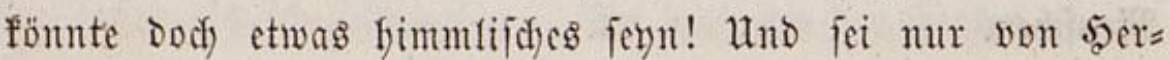
zen wiflfommen!" şier lief er mit $\Re u \tilde{\beta}$ uno Umfralien an 
ifn; Bult fonnte aber, ba er in Der einen saanto Den Ragel fielt, in Der andern ben sammer, nichts dazu abraffen als (5efidst und 5als, und antwortete: "Die bauptiadje ift wol,

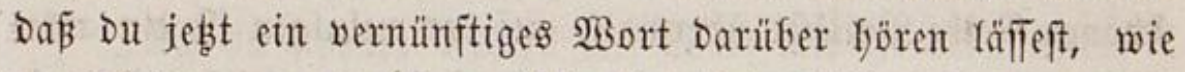
Die Sadjen zu traftiren find für heiderjeitige $2 u f t$. Dent ift einmal alles feft genagelt: fo ändert's Der Nenfod ungern. Midi) Dändyt afer, fo befibeft und beferridjeft du gerabe bas eine Fenffer uno faft orüber, uno idf Das andere; ein brit= teg felylt."

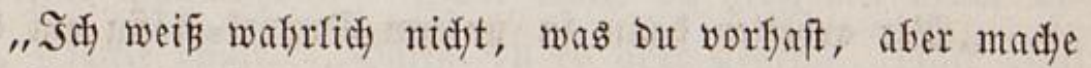

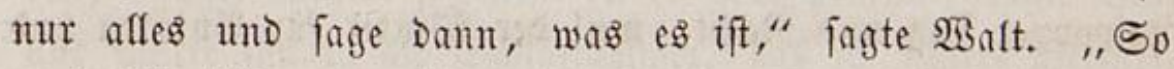

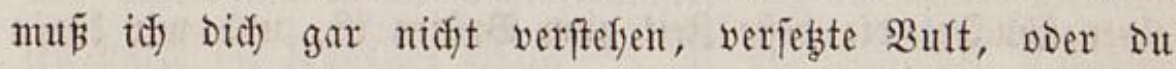
mid) nicht. Sollteft du fein Briefden von mir erbalten ba= ben?" fagte Bult. - Nein, jagte er.

"Id) meine bas heutige, fragte jener fort, worin idf fojrieb, idf würbe Dein Sifweigen für ein $\mathfrak{S} a$ anf meine $\mathfrak{B}_{\text {itte }}$

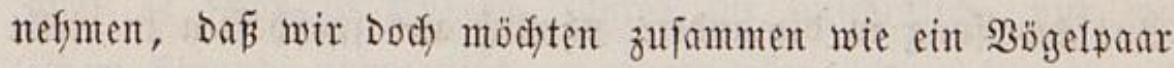
(Ein Reft oder Quartier bewolnnen, Diefes nämlich? $\mathfrak{B i e ? " ~ - ~}$

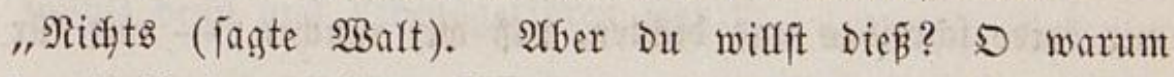

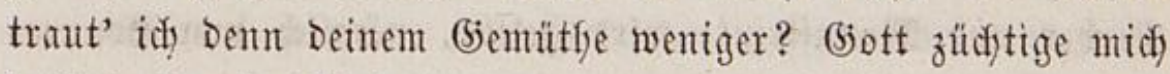
Dafür! $D$ wie bift Du!"“ -

"In Diejem Falle muß̃ idy Das $\mathfrak{B}$ latt nody in Der Tafdye tragen (verfebzte $\mathfrak{B}$ ult und zog es fiervor); zuvörderft mülīen wir aber unjern Stuben= (Etat für Den 2 Binter ing Reine uno aufs Troffne fringen; Denn, Freunt, leidjter verträgt fid) ein Simultaneum bon Refigionsparteien in einer Rirche, als eines von 3 wiflingen in einer Stube, wie fie Denn ford als fleine Sirafen nicht einmal im Mutterleibe es ein $\mathfrak{S} a$ ro lang ausbautern, fondern fied fondern. Mein $\mathfrak{B u n}$ id ift

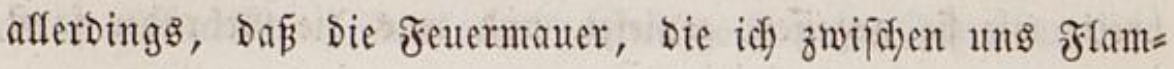


men gezogen - und bie Büfntenwand langt zum (5lüaf fo nett - uns förperlidf genug abtrenne, um uns nidjt geifitig zu tremten. Die Siffeidemano if auf Deiner Seite mit einer

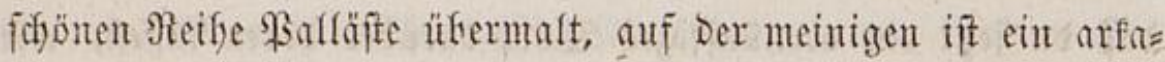

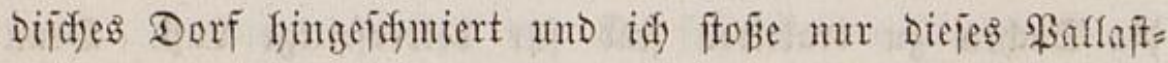

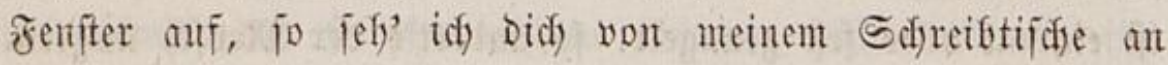
Deinem. Reden fömen wir ofhefin burd Die Nauer und Etaot findourct."

"Das ift ja föftlicf)," fagte $\mathfrak{B a l t .}$

"NBir arbeiten Dann in unferm Doppel= Räfig am 5op=

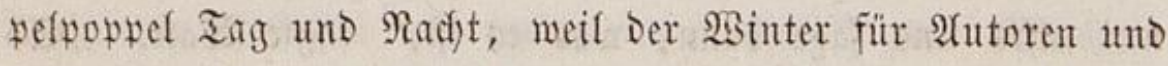
Sirenzidnübel bie befte Beit zum Britten ift, und wir Darin uno bie fofwarze Riesnurz (was find wir anders als Nies= wurz Der $\mathfrak{B}$ elt?) im frofte Glüfent."

"D fecrutidy," jagte $2 B$ alt.

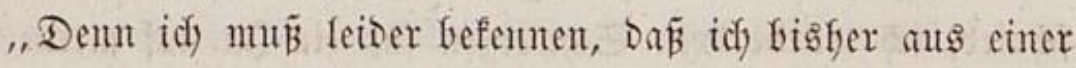

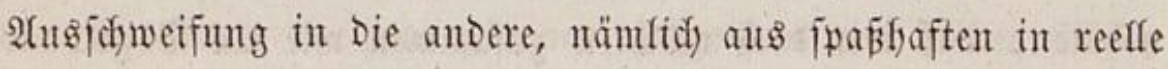
geratfen uno in Der Ifyat wenig gegeben. So aber werben

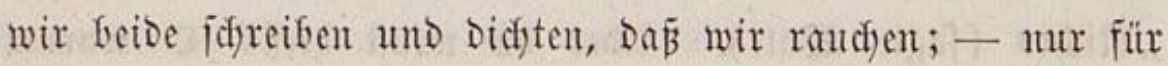
Büdfer uno Mamuffipte wiro gelebt, nämlidf) von 5onora= rien. - In 14 Iagen, mein guter Freund, fann fdon

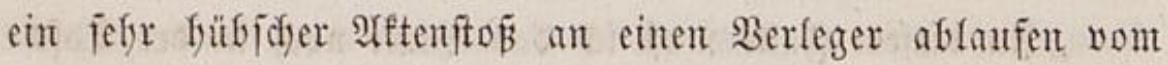
Etapel."

"D göttficf)," jagte $\mathfrak{B a}$ alt.

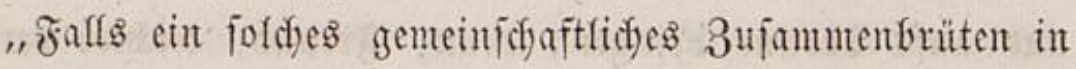
(Einem Refe - idf) als Iauber, Du als Tüubin - niḍt am

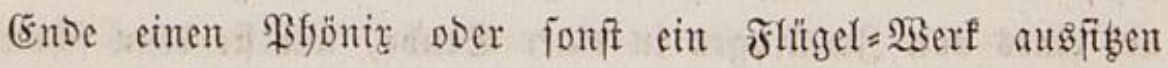

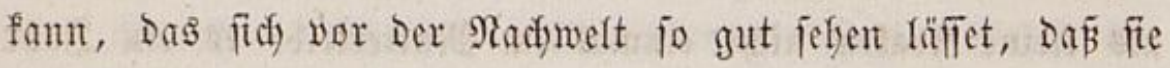
iffre Borwelt fragt, wer feibe Brüber waren, wie lang, wie breit, wie fie gegefjen, geniejet, uno was Die Gsefrüber ponft 
für Sitten und Nöbeln und Narrfeiten gefabt; wemt Das,

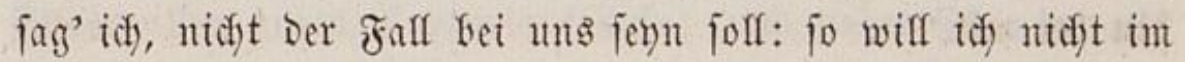
Empte geiprodien fraben."

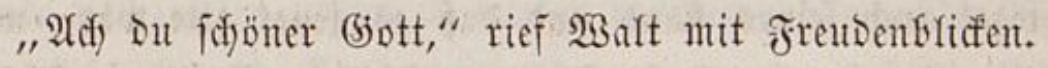

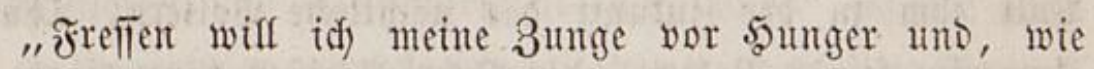
man von Bomben fagt, frepiren, crêper, went wir uns fier nidyt lange vorher lieben, ef) wir uns zanfen, furz über= frupt went nidyt Sadjen vorfaffen, wowon in Bufunft ein Mefreres mündfidj." - "Bei (5ott, Dut gibft mir neues $\mathfrak{L}_{e}=$

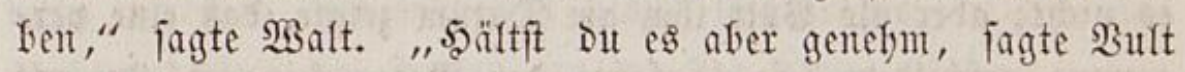

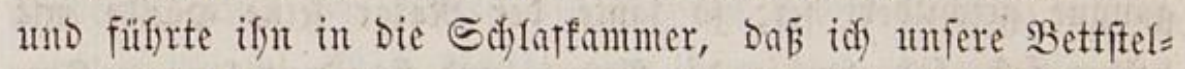

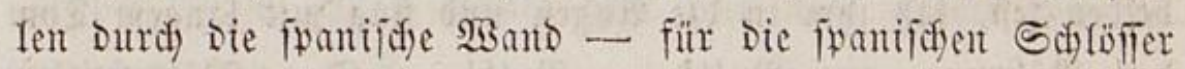

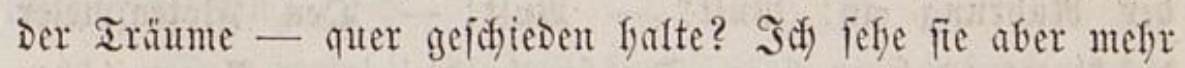
für einen alten Bettichirm an."

"Du fenmit Darüber meine (5rundjäbe, fagte $\mathfrak{B a l t}$; $i$ d)

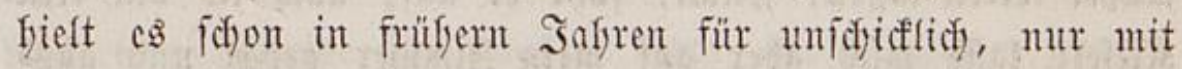
einem freunde gymnaftifi ful ringen ober iffn fu tragen, eg müßte Denn ats Refenggefafren fern."

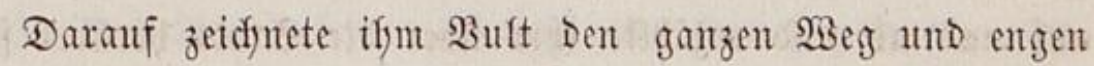
ß̊n vor, worauf er hereinfonmen, ferner jeine Bufunftsfor:

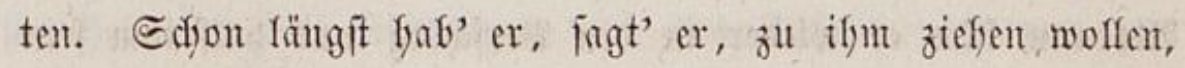
theils ans Riebe für ifn und Den sowpelpowwel, theils ses fralbirten Mietfyinjes halber, theils fonft. Reulid) auf einem Epaziergange fab' er fid in Die (jumft Der guten Rapfaela zurücf gefd)wungen, mit weldyer or als mit einem bebels: Rangarm Dann Den Bater habe bewegt. Bor einer Stunte fei er mit Der Tfenterwano yon $\mathfrak{B u r z e l}_{\text {und }}$ mit Dem foffer eingetroffen uno frabe Den Stubenjolüfjel im befaunten Maus= Iod) gefundert. "शun erbridy aber Dody mein Edyreifen," he= 


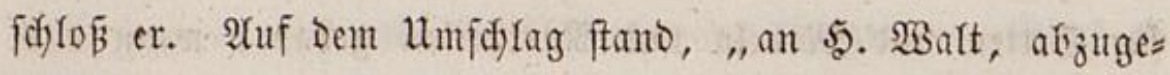
ben bei mir."

Walt bemerfte nidyt, Daß̧ nuf Dem Briefe neben Bults Siegel auch feines ftano und daḱ es jener alte war, worin Bult ifjm in Der 3ufunft das nädytliche $\mathfrak{B}$ oltern, Thüren= 3uwerfen feimes Bolter = oder Edfmollgcifes vorausfagt, um nadber entichuldigt zut feyn, und ben wir frülyer gelefen als Balt, ooer viefmelyr fpäter*). WBalt glaubte eilig, or meine cine von lyeute an zufünftige Bufunft uno jagte, Dafin fomm? es nidyt; aber als Bult ifym am Datum zeigte, Dañ eine ver= gangne gefoilloert fei: fo fapite Der Notar jeine saände mit beiden feft, faf ifm in Die $\mathfrak{A}$ tgen tmo fing mit langem Ion Der Rüfrung an: $\mathfrak{B} u l t !$ - $\mathfrak{W}$ tt! - Den flötenfpieler Drücfte es, Dấ er einige Tropfen in bie eignen 2 ugen, liber Die cr mit Den gefangnen 5änden nidjt fint fafyren fonute, muste treten la Siefel; Iatie midy aber auf mein Bimmer geben unb aus= pacfen," und fuffr finter bie Büfnentrant.

(5r pacfte aus und ftellte auf. WBalt ging im feinigen nuf und ab und erzäflte ifm über bie Stadt ferüber feine bisferigen Berjuthe, ifren Seelen= Iaufbund zu erneuern.

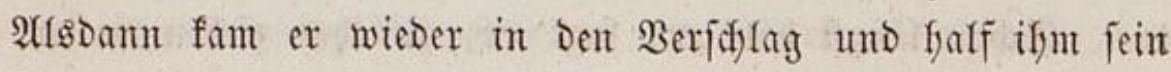
5aus = oder Stubengeräthe orduen. (Er war fo fülf= fertig, to freundicd)=thätig, er wollte bem Bruber fo viel \$lab auf= Dringen fammt Fenferlicfl uno Möbeln, Daß́ $\mathfrak{B}$ ult Yyeimlidy

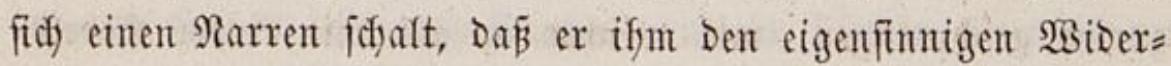

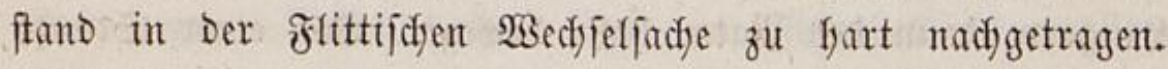

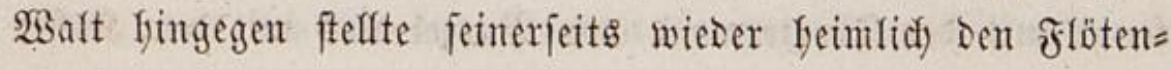

*) B. II. ؟. 167. 


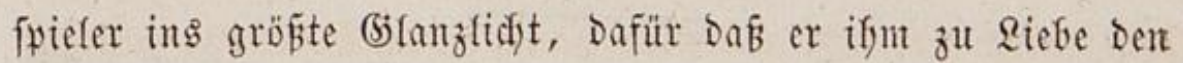
Wiberwiflen gegen Raphaeta erfitife; uno nafm fid vor, afle fofonen 3üge Deffelben unbemerft aufaud reiben, um fie als Rezepte nad)zulejen, wenu er wieder fnurren wolle. Die (soü= tergemeinidgaft und Stubenverbritberung wurbe auf Die hell= ften (5ränzuerträge zurïffgebradjt, Damit man am Morgen gleid) anfangen fönnte, beijammen zu jelnn. Sdjön bemerfte

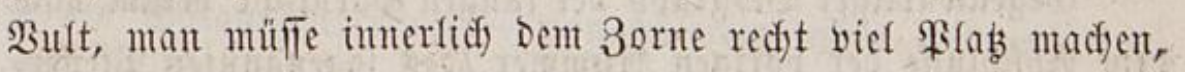
Damit ex fich abtobe uno toot renne an Den (siefirnmänoen; Dann werbe ia Dem Menfonen nidfts leidfter als mit Dem ge=

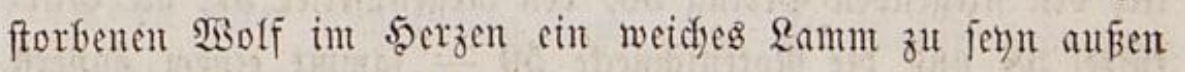
mit Der Bruft. Man fömte aber fier nod) andere Bemer= fungen madjen, $\mathfrak{z}$. $\mathfrak{B}$.

- Die farfe Riebe will für Fefler nur beftrafen und Dam Dod) vergefen - - Bent mandjer von fleinen Belei= Digungen Der Freundjoflaft zu tief getroffen wirb: fo ift Daran blos eine baffende Denfungsart über afle Menjchen fould, Die ifn Dann in jedem einzelnen Fafle ergreift und Diejen zun Exiegel des (5imzen madyt - - Die födjfe Riebe fennt mur Ia uno Rein, feinen Mittelftand; fein Jegefeuer, nur

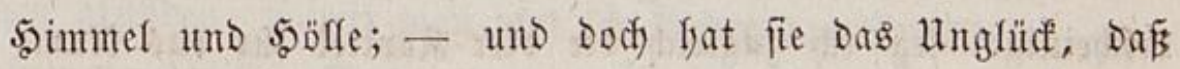
fie Beburten der Stimmung und des 3 ufafls, die nur zut Borfimmel uno Borfölle füfyren follten, zu Pförtnerinuen von 5immels = und 5ällentforen madyt. - Beide fleideten vor einanoer die eigentfrümlidjften (jefüfle in allgemeine Säbse ein. $\mathfrak{A}$ ber als Bult finter Dem Sifirme ins Bett einftieg: fagt' er: "verfebe mir nidyts Darauf - Denu id ftopfe mir eben Die Sfren mit Dem Ropffifien zu - aber idh glaube

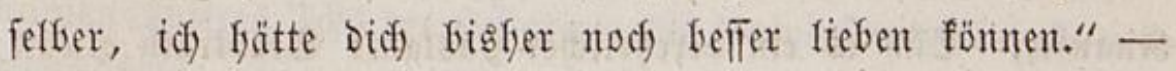
Nein, idf Did, , fdrie $\mathfrak{B a f t .}$ 


\section{No. 56. Fliegente $\mathfrak{f}$ f e $\mathfrak{i} \mathfrak{i n g}$.}

Brief bes Biographen - Tagebud).

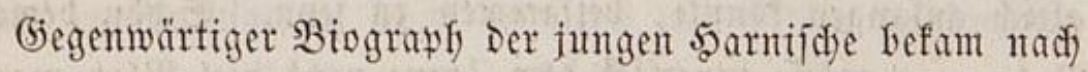
Dem 2Ubjulute Der vorigen Nummer (Des jogenanten Pfeffer=

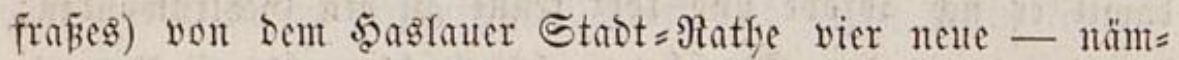
(id) Dent fliegenten מ̧ering 56, Den Regenwfeifer 57, Die Bift= futtel 58 und Die Notenfdnecfe 59 - jammt einem äuperft widstigen Iagebuch Bults über 2 salt. Darauf antwortete er Den trefflicyen Ieftaments = (Exefutoren Folgendes, was Durdi)= sus als ein Beitftülf Der flegefjafje bereingefjört.

P. P.

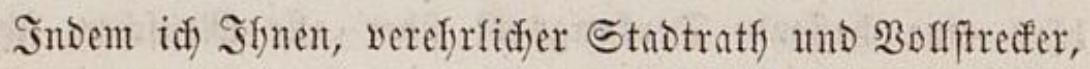

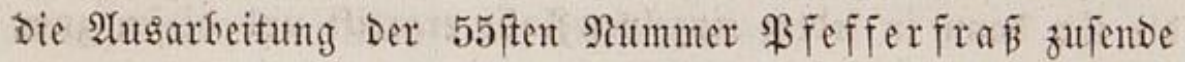
uno Den Empfang Der vier netueften Raturalien, Der Num=

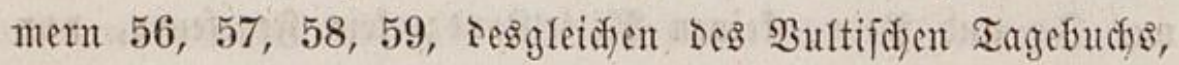

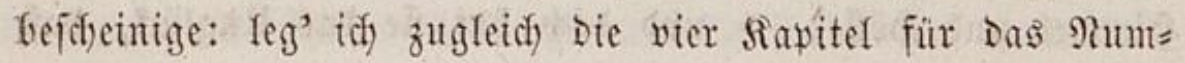

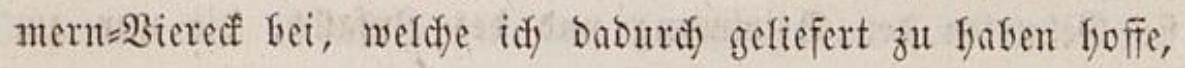

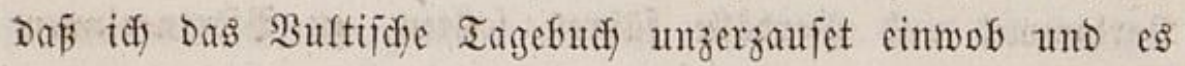

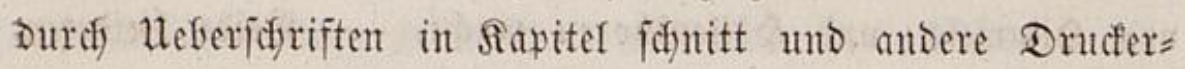

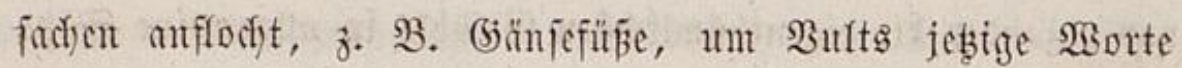
won meinen fïnftigen zu fdeioen. Man griffe ofne weiteres meinen (E)arafter an, wenn Gie midy Deshalb etwan einen

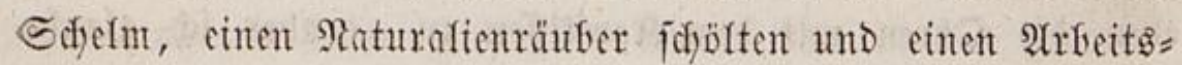

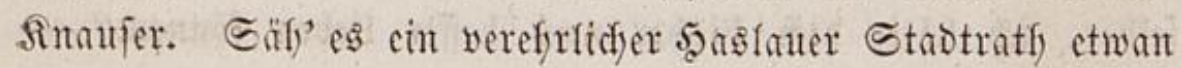
fieber - was fo ummöglid) zu glauben - went id Den berrs 


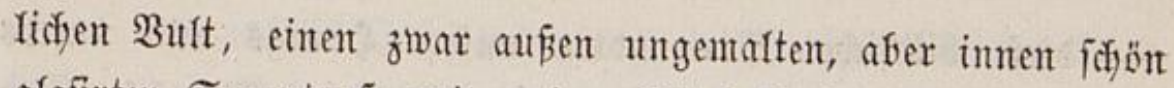
glafirten Sauertowf, mit meinen నöpferfarben umz̈̈ge? Ooer faun irgent cin Teftament anfunten, Dẩ $i$ d) einem fremben (Efjarafter etwas aus meinem eignen voriftreffe? Ridi) Dünft,

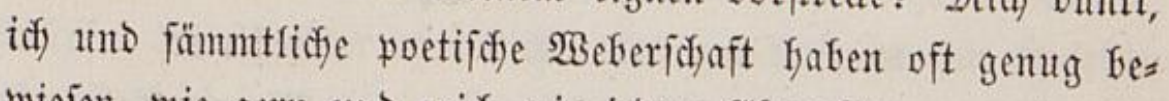
wiejen, wie gern und reid) wir jebem (SGarafter - und wär' er ein Satan oder soott - von unjerem reifyen uno zuffecfent. Wir gleichen am wenigften - Dię́ Dürfen wir fagen - jes nem englifichen (5eizhalie, Daniel Dancer, weldyer auf einent fremben Acter nidyts yon Dem, was bie Ratur bei ifyt üfrig fatte, wollte falfen laflen, fonbern wie toll vorfer auf jeinen eignen rame mit ber Sadje. Sondern redjt freul= big leifyet ber Romancier alles, was er hat uno was er $i f$, feinen gejoriebenen Renten ofye Das geringfte Anjeffen Der Berion uno des (5fjarafters! Folglicy bätte wol niemano Bults Tagebuch fo gern umgeacfert uno befäet als ich, wär' eE nütrjig gewejen.

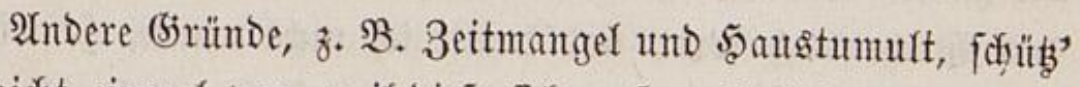
id nidyt eimmal vor, weil bieje fich auf perjönlidje Bertrauun=

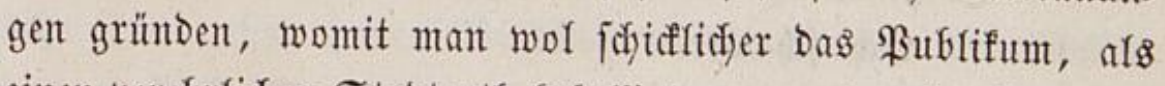
einen verefrridyen Stadtrath befyelligt; worunter aber in jebem

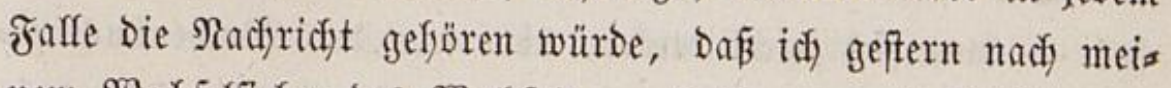

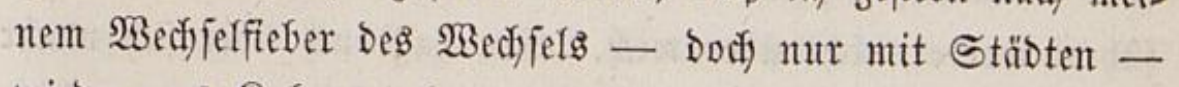
wieber aus Sloburg abgezogen bin nad) Baireutf. Niemand

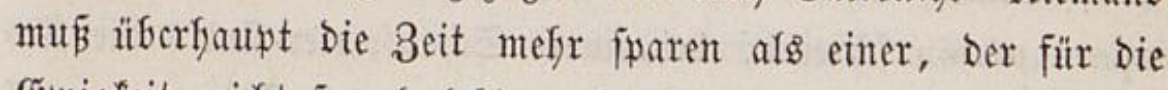
(Ewigfeit nidft fowol lebt - bas thut jeber (ofrift - als fajreibt. WBie viel Blattjeiten Yäffet Denn bie Biographia bri-

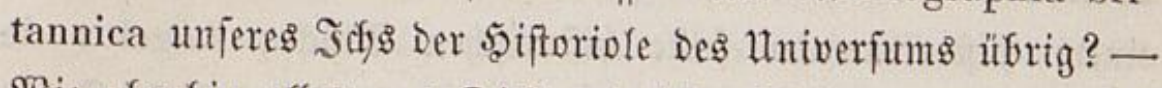

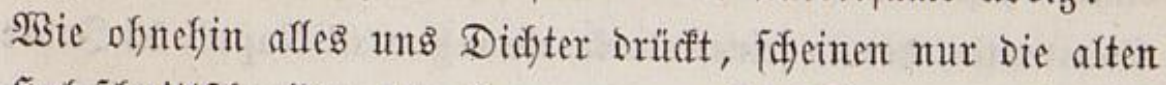

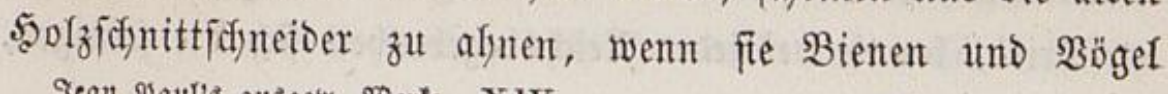

Sean Yaut's aus̉ Betw. Werte. XIV. 
- Dieje bitblidjen Berwanten unjers 5onigs und unjers Flugs - blos als fliegende Sireuze zeidfuent. WBer fyängt an Diejen Sreuzen als wir Sireuzträger, $\hat{\delta}$. $\mathfrak{B}$.

Ifx

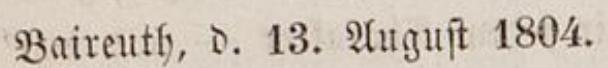

teftirter

Biograph,

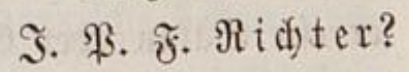

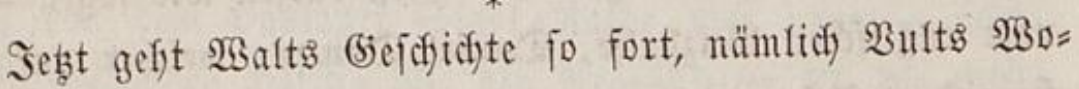
d)enbud) fängt fo an:

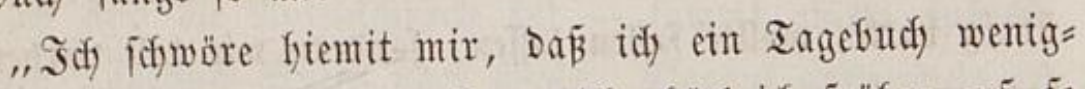

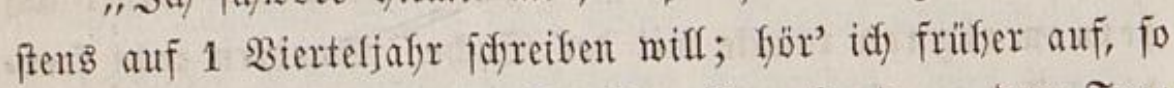
ftrafe midy (5iott oder ber Ieufel. Bon feute - Dem Tage nad) Dem geftrigen (Einzuge - gel) es an. Sa wenn midf

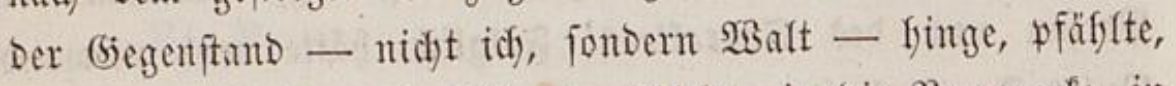
fnebelte, zerfebste, nad) Siferien idjiffe, in Die Bergwerfe, in Die zweite $\mathfrak{B e l t}$, in Die Dritte, ia in Die lebste: jo füfret' idy Das $230 d y e n t u d$ fort; und Damit id nidjt wanfe, fo wifl idf mit Den fingern, Die man fonft Dazu auffebt, es heridjreiben:

Эa) fdumöre.

Die Selt - weldje aber nie diejes Blatt befommen foll - fann fid reidyt Denfen, über wen Das 230 denturdy ge=

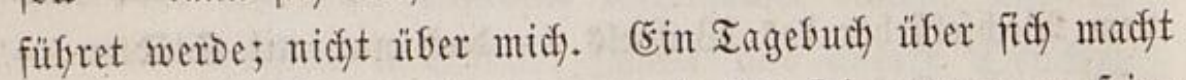
jeber Dinten $=$ Nanu fdon an und für fids), wenn er feine opera omnia fdrreifst; bei einem Edfaupieler finto's bie fios

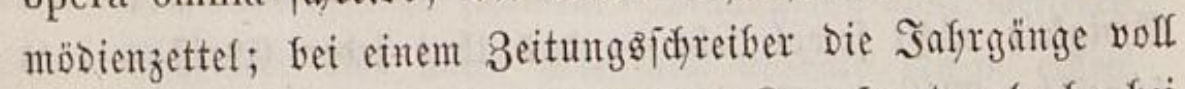
2Beltfändel; bei einem Saufmann Das Rorrefpondenzbud); bet einem Siftorienmaler peine fiftorifiden Stücfe; Angelus de Constantio, Der an feiner storia de regno di Napoli 53 Jafjre

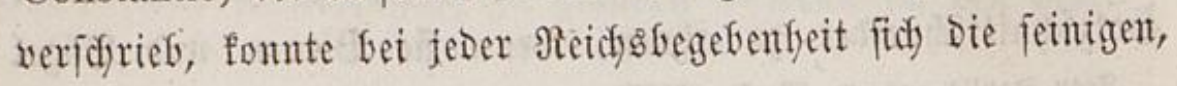


blwol mur auf 53 Safre, Denfen; und io fofreift jeder Ber=

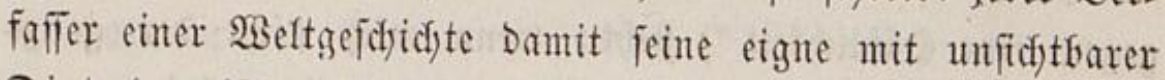
Dinte Dazwifjen, weil er an bie Eroberungen, imern $\mathfrak{u}_{\mathfrak{n}}=$ rufen und $\mathfrak{B}$ anderungen Der $\mathfrak{B}$ öfer peine eignen berrfich frübfen fant. WBer aber nidyts bat und thut, woran er jeine Empfindungen bindet, als wieder Empfintungen: Der nefme Lang = uno \&uerfolio = \$apier uno bringe fie Dazu, nämlidy fu Fapier. Nur wiro er Danaiden = und Ieufelsarbeit haben; wäfrento er fofreibt, fällt wieder etwas in ifm vor, es jei

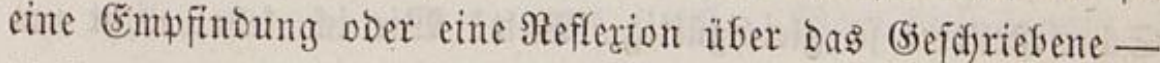

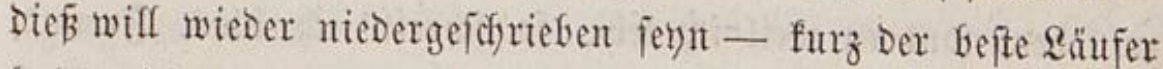
folet nidjt feinen Sifjatten ein.

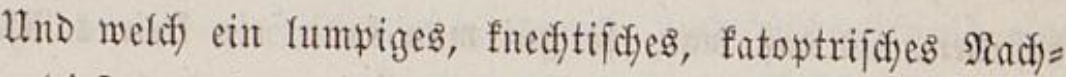
Reben, Diejes grabes=luftige Burütfatfmen aus lauer Bergan= genfyeit ftatt eines frifoden 3 ugs aus frifder $2 u f t !$ Das flitch = tige betümmel wird ein $\mathfrak{W}_{\text {ach }} s$ figurenfabinet, Der blüfende, flatternde Rebensgarten ein feftes pomologifches Rabinet. STit's nidyt taujenomal flüger, Der Menjol if von (jegenwart zu (5ie= gentwart wie bott von (Ewigfeit zu (Ewigfeit, und Der fröf)=

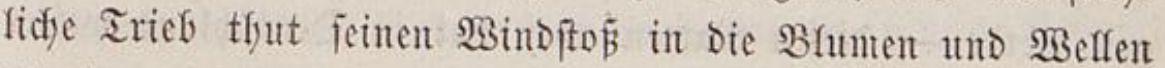
binein, wirft Bhumenftüubdyen uno Sodjife an ifren ort uno gäfnt unt ftoffnt nicht wieder erfärmfich furüaf?

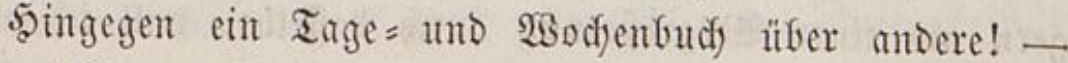

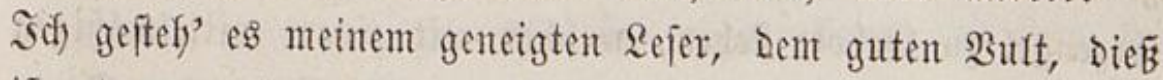
ift etwas anderes; aber idf mus freilid) feben uno - an= fangent.

Dod) io viel lifilfet fich auch), ofye anzufangen, antely=

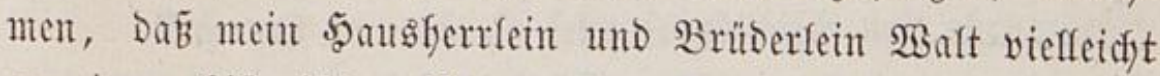
fu cinem fiftorifichen Roman (Den Iitel "Tölpeljafre eines

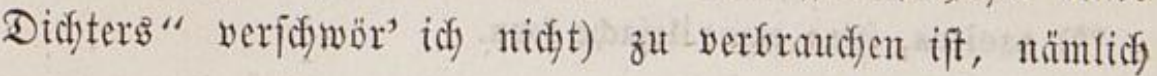




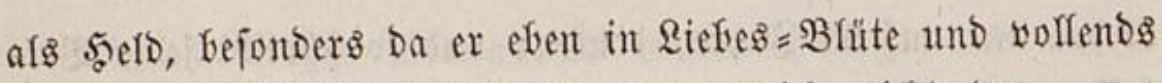
gegen eine 5ä̈ßlidjfeit *) fteft; wenn midj nidht Der ganze

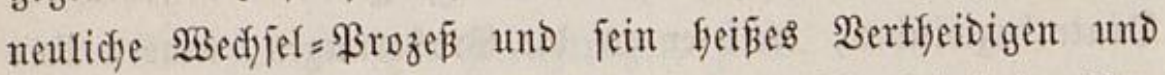

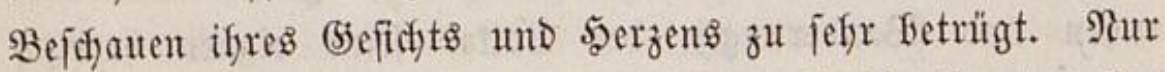

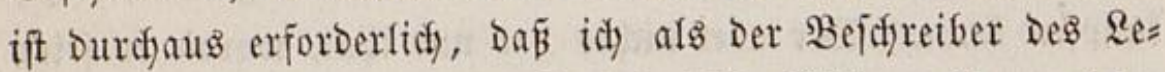
bens ifjn geidjictt, wie eine berfulanijofe Büd)errolle, ausein= ander winde und Dann fopire. Sol felf' aud nidjt ein, warum id nidft überlyaupt fo gut einen göttlidyen Roman fdyreiben follte, wie Biflionent andere Leute. Mir felfer ift Sdyriftifeflerei fo gleichgültig, Bult! WBie idf lebe, nidyt um

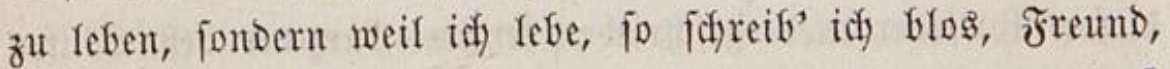

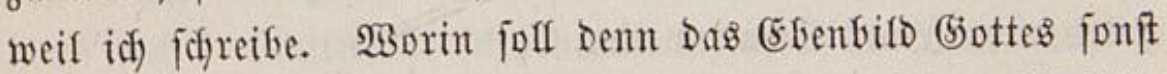

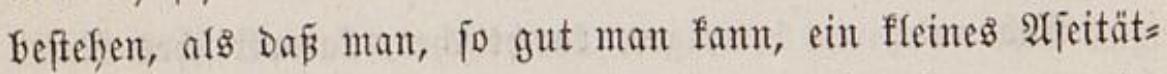
d)en **) ift und - Da fidon $\mathfrak{B}$ elten mefor als genug $D a$ find - wenigftens fid Sdjöpfer täglid eridafift und ges

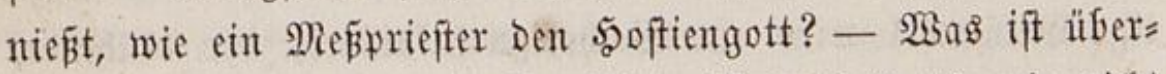
foupt Rufm frienieden in Deutichlanto? Sobald id mir nidjt

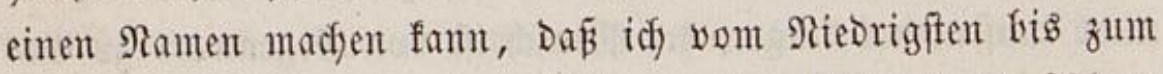
5äbffen triglich genannt, gelobt unto vor Begierde verfidun=

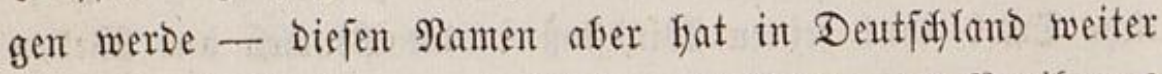

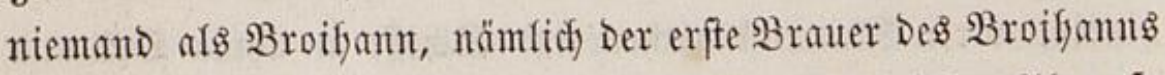

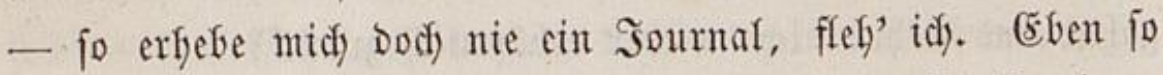

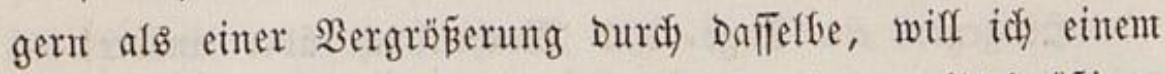
Erzengel zu Bjefote ftelyen, weldyer mit einem mittefmäß̈igen Somten = uno 2 Geltemmifroffop auf Dem Marftplap Der Staot (5ottes etwas verbienen wifl und Dafer, um andern nengies

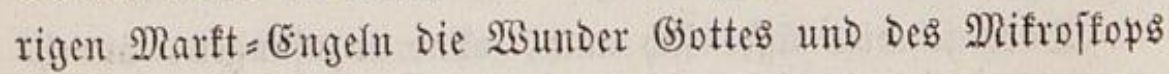

*) Begen Paphacla, glaubt er.

**) aseitas, feine cigne $\mathrm{H} r$ fadje f(t)n. 
zut zeigen, mich als bie nädffe Rauts einfängt und auf Dent

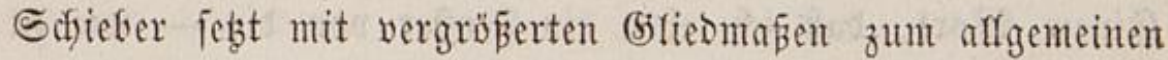
Bemundern und Efeln.

Dien bei Seite, fo merf' id nod) für bidy bejonders an,

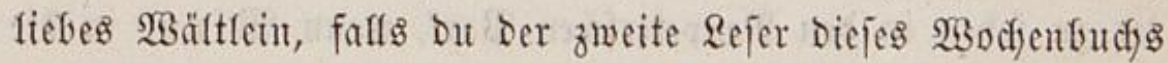
würdeft, wie Dein Bult Der erfte ift - in welchem Fafle Du aber eit ausgemad)ter, ausgebälgter Spibbube märeft, Der fein geftriges 2 bort bräche, nie in meine $\mathfrak{B a p i e r e}$ zu bliffen

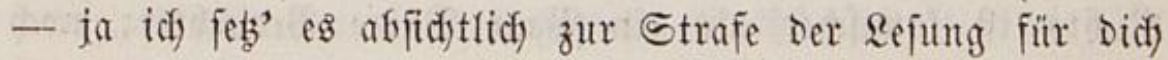

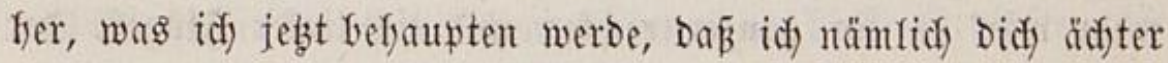

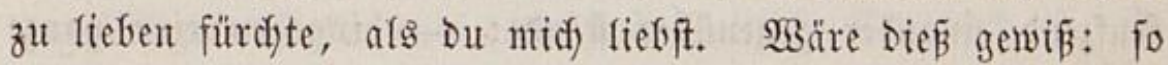

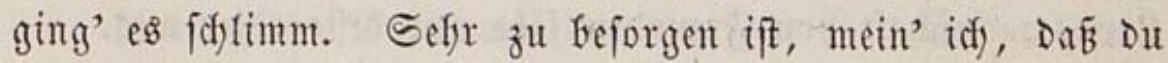
- ob bu gleidf fonft wafjrlid) fo unf(d)ulbig bift wie ein Bief) - mur poetifa) lieben fannft, und nidyt irgeno einen Sants voer $\Re u n z$, fondern fei Der größ̄ten Rälte gegen bie

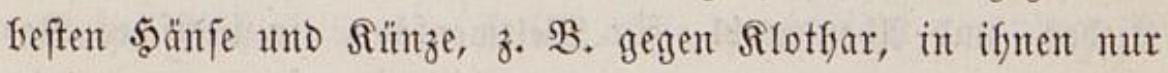

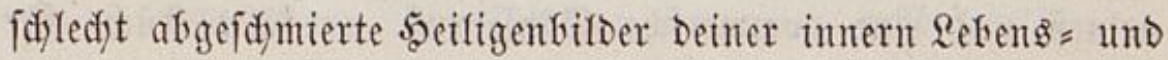
Seetentilder fnieeno verefrift. Saly wifl aber erfít fefent.

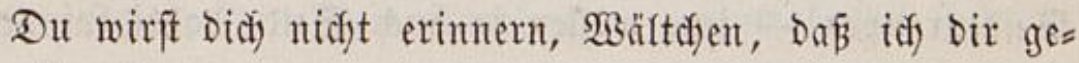
ftern oder fleute ober morgen weísgemadyt, Daßj ich nidyt aus andern (5ründen, fondern beinetwegen allein in Deine Sdjweíz=,

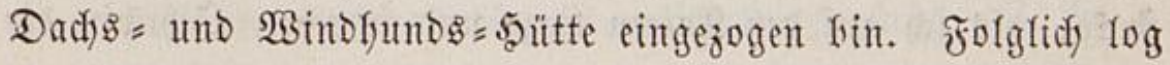
idf) nidfts vor. Nur feine Rüge fage Der Menjón, Diejer Spib= bube von saaus aus! Jaff afles ift gegent einen beift eler erlaubt, weil er gegen afles fid webren fant, nur feine Rüge,

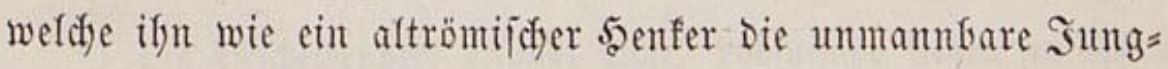
frau in Der form Der innigften Bereinigung fodänden und finridften will.

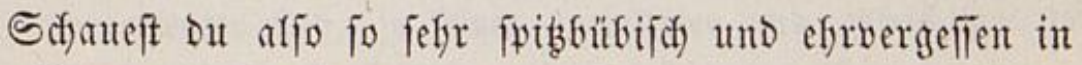
Diejes Journal: fo erfäfreft du fier nady Dem vorigen Dop= 


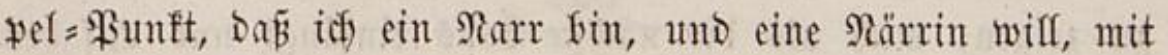

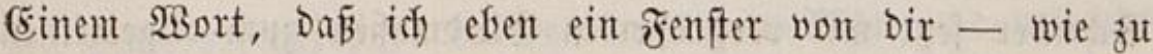
einer 5̧inridjtung Damiens um vieles Bjeld - gemiethet, blos um aus Dem zenifter mid felfer finzuricften, nämlid finun= ter zu jefyen in Den Reupeterfiden Parf, wenn $\mathfrak{B}_{3}$ in a, in bie ich midh vergafft fabe, zufällig mit Deiner Raphaelit luftwan= Deft. Id) freue midh Darauf, wie wir beide an unjern ren= ftern ftefgen und finabjofmadyten und lädherlidy fern werden.

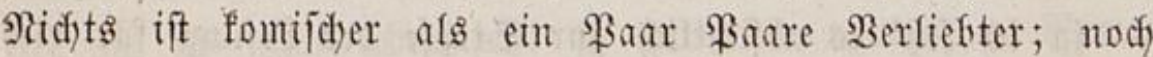
mefyr wär’ ę ein ganzer recfter uno ein linfer flügel, Der feufzend einander gegenüber ftände; - fingegen eine ganze Randsmamuldifaft yon Freunden fäfe mur Defto edler aus.

Für jeden ift eine grau freilidy etwas anderes: für Den

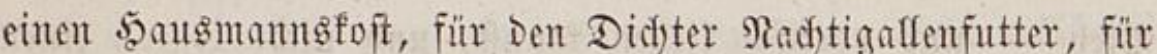

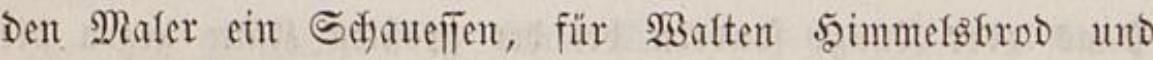

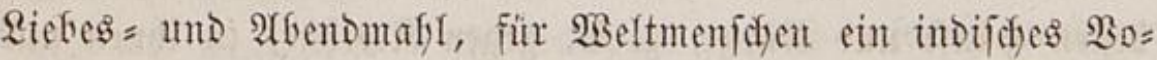
gelneft und eine pommerfde binfebruft - falte Ritche fïr midc. Die Rungenfudst, weldhe Riebente und Die 2 Bärter Der Geidenraupen - jene wollen ia aud Geide dakei fimmen Dawon tragen, wirb midi als Seladon efer vertaffen als er= greifen, weil idf fo lange Die lungen =gefährliche glöte ein= ftecfe, als idy auf Den Rinicen liege und preche. Id bin bir aber wirflidh jefrr gut, WBina, zumal da Deine Singitimme fo fanonifid) ift und fo rein! - Afber idi wifl Demn mein fentiges Iagebudid über Den Bruber anfeben... 


\section{1}

\section{Nadjtrag zu No. 56. Der fliegente 5̧ering.}

Das voriftelende war zur Teftaments = Ergefuzion abges fidictet, als idf es von Derjelfen - Dem trefflidjen Sulfnold - mit Diejem Briefe wieder befam:

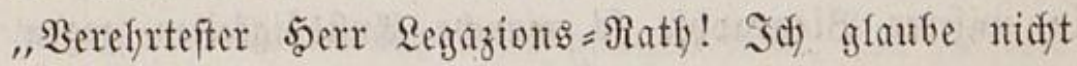

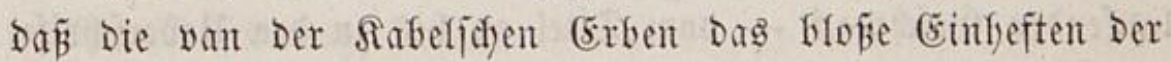

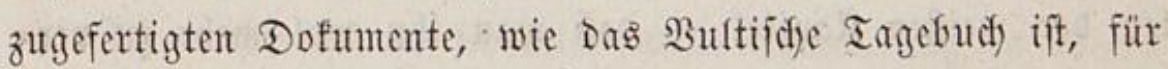

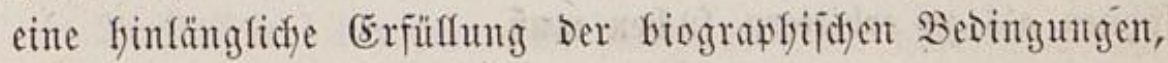
unter weldyen Sfynen das Raturalienfabinet teftiret worben, nefymen werden. Uno id jeffer bin, geftefy idy, mit Den Bor=

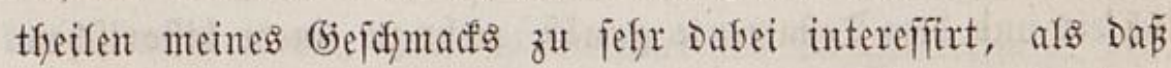
es mir gleidggültig jern follte, Sic Durdh Bult verbringt zut

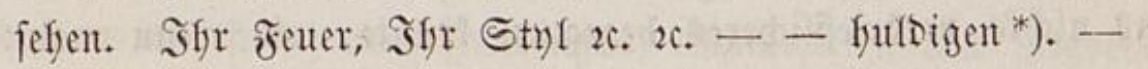

Daz̧u fteft nodi) vieles andere Dagegen. (5s fomment im Berfolge Des \$ultiffen Iagebudfs - zumal im Jebruar, wo or in wollen flammen tobt - Steflen vor, Deren $3 y n t b=$ mus fofwerlidy Durd Den Saumor, weder vor Dem poetif(d)en, nod) fittlidjen Ridyterftufle, zu entidfuldigen ftelyt. 3. B. Die am 4. Fefruar, wo er jagt, "Das junge Reben als eine Sonne veridjlingent verdauen und es als cinen Mond facen." SDer Da, wo er Dem Dezenten Bruder, um ifhn zu ärgern,

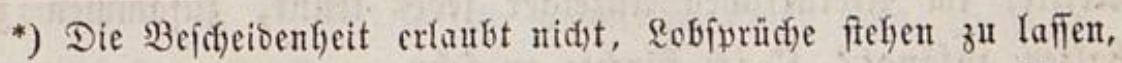

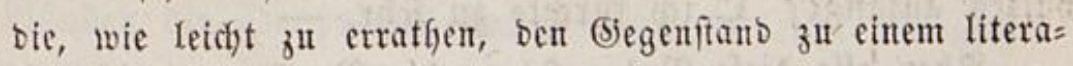

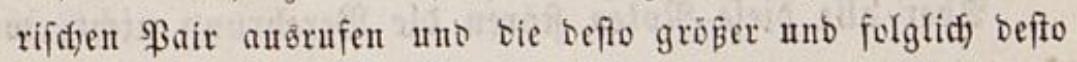
unverbienter find, je feiner, gebilbeter und aufridjtiger ber

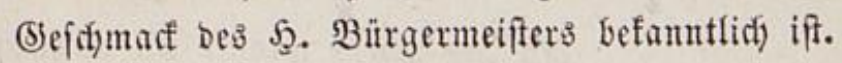




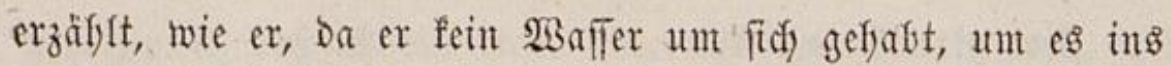

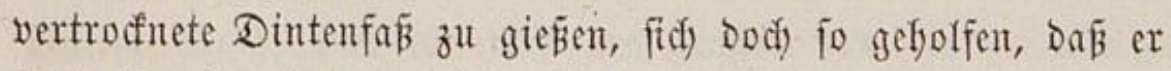
eintunfent fomte, um fein ßacfet Briefe, jeinen ,Briefbeu= tel," zu fátreiben. Das zweite mag efer bingeben, Dá̉ er, wenn er mit vielen Dblaten Wadfete geftegelt und Dody feine

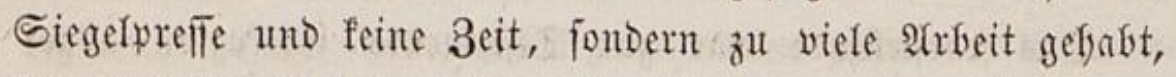
fidf) blos eine 3eit lang Darauf gejebst, um andere Gadjen zu madjen unter Dem Siegeln. (5: füD überfyaupt, Berefrtefter, in unferer Biographie fo mandhe âfifößigfeiten gegen Dent Iaufenden-(sejdymad - vom Titel an bis zu Den Meberidhrif= ten Der meiften Sapitel - Dá̃ man ifnn wol melyr zu ver= föfnen als zu erbittern fudosen muE.

Rod) einen (Sinuto erlauben Gie mir, Da er ber lebste iff. Unjere Biograpfie foll Dod), Der Sadje, Der fiunft, Der Sdjict=

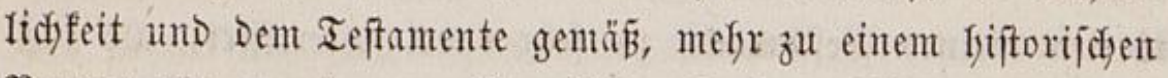

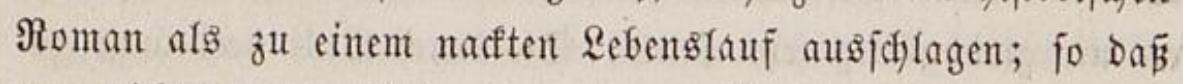
uns nidyts verbriefifidjeres begegnen fönnte, als wenn man wirflid) merfte, alles jei wafyr. Werben wir aber biejeg ver=

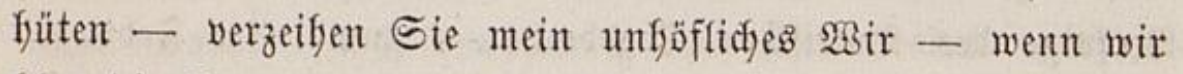
blos Die Namen verändern, nidyt aber Den Gtyl Der Afteurs? Dent wiro man uns nidyt auf Die Spur fommen fojon Durdy Bults unverändert gefieferteg Iagebud allein, fobald man Deflen Styl mit Den Gtyl Des 5oppelpoppels (aud) Diejer

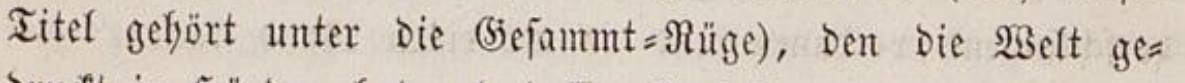

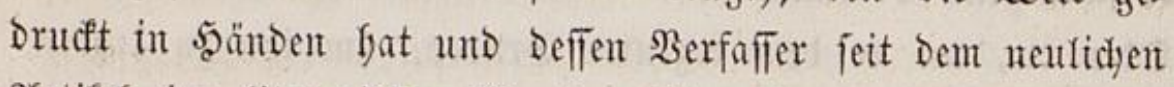

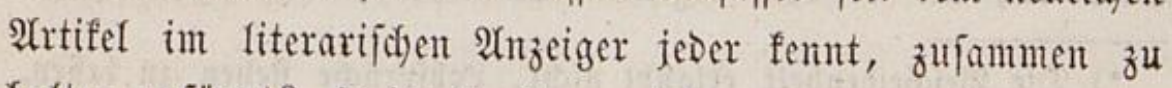
balten anfängt? $D$ idj) fürdyte zu fefr. -

Xfber alle Dieje Noten ftören Die Berefrung nidft, womit idi) ewig $x$.

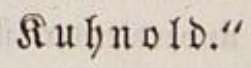


Id) antwortete folgentes:

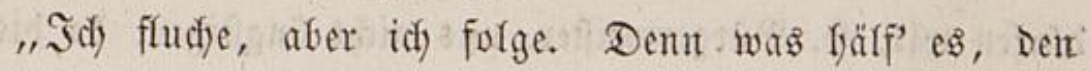
Deutichen zuzumuthen uno das Beipiel zu gefen, mur we= nigftens auf Dem Drucfpapier - nidft eimmal auf Dem Reidys= boden - fo fecf zu jern, als ifre Borfafren im 16ten, 17ten Säful auf beiden waren? (5ebad)te fagen, fie hofften feit= Dem von Den Franzofen weiter gebradjt zu jern. Unjer Dia= mant ber freifheit ift aus unjerem Ringe in einen Dradjen= fowf gefommen, wo er nidyt efyer glänzen fann, als bis wir im Dradjenfidwanze fethen.

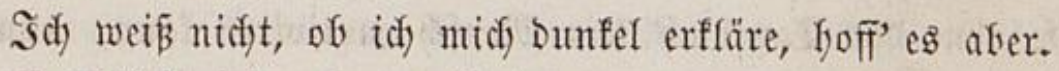

Trefflidyfer! Der Soumorift bat zwar cinen närrifden, wi= Derlichen Berghabit zum Einfafyren in feine Stollen; - er

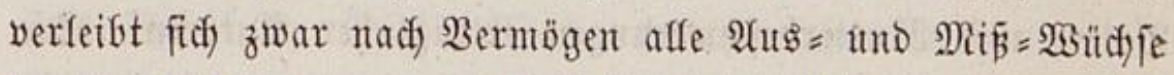

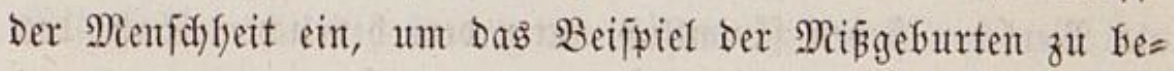
folgen und zu geben, Die in vorigen $\mathfrak{a} a f r f u n t b e r t e n$ blog Darum mit fleifdernen Fontangen, Manidyetten uno Pluber= fofen geforen wurben, um Damit ber $\mathfrak{B e l t}$, wie Die Straf= prebiger errietgen, iffe angezogenten vorzumerfen; - und fies= mit wäre Bult entidfuldigt -; aber wie gebacht, idf folge und idylage nidyts ein als ben alten arifotelifdyen Mittelfteig,

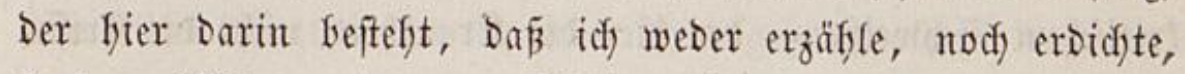
fondern bidyte; und went Sfaliger in einem $\mathfrak{B}$ erffyen von 8 Bogen liber feine Famifie im Stande war, vierfundert und neun und neunzig Derfälichungen anzubringen, wie Scioppius

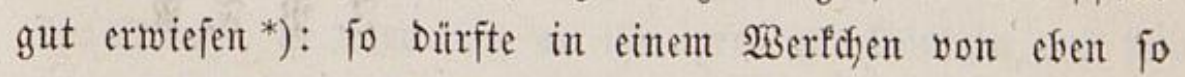
vielen Bänden Die Doppelzafl Davon eben fo Teidjt als mïb= lich) ausfallen.

*) Menken de Charl. erud. ed. IV. 
Bor Dem Errathen Der wafren Ramen unjerer (jeforjidyte Dürfent wir, 5. Bürgermeifter, uns nicht ängftigen, Da fişfer für feine von aflen Stäbten, Die idy in meinen vielen Roma=

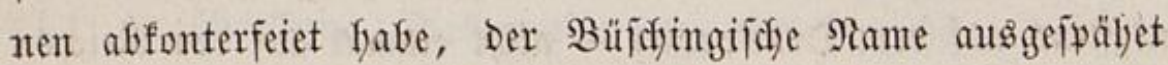
murbe, ungeadfet idf in einigen Davon felfer wofnte, fogar z. $\mathfrak{B}$. in Haelwebeemcebe und Efgeerenengeha.

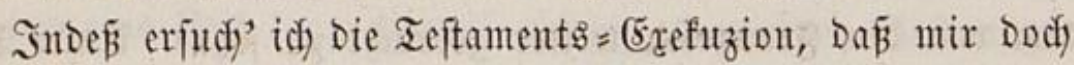
Bults Crinteitung zu feinem Iagebuch fammt unjerem Brief= wedffel Darüber in Den fliegenden 5acring (Nr. 56.) einzuntely= men zugelaffen werde, weil Sadjen Daburd vorbereitet werden, Die ofne Das Tagebudf fein Menid) motiviren fann, nämfid Bults idnelles (Einzieffen und Berlieben. WBafrlid) Sie, ver=

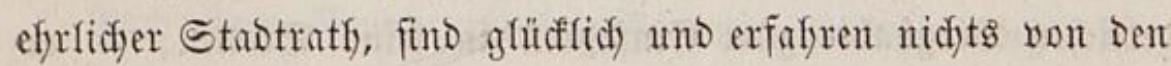

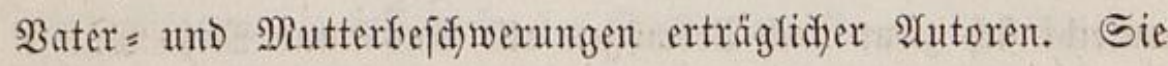
als Menfiden feflen fämmtlidy unter Dem fyerrfichen Sabze Des (5runtes, und Der freifyeit Daz̧u, und afles, was Sie mur madjen oder fehen, befommen Sie jogleidy motivirt - -

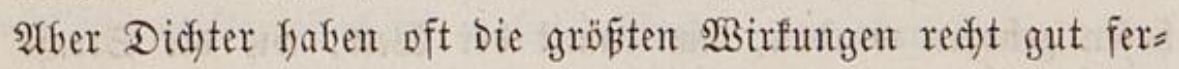
tig yor fid liegen, fömnen aber mit allem serumlaufen feine Urjachen Dazł auftreiben, feine Bäter zu Den Sungfernfindern. Wie iffnen Dann Sritifer mitfpielen, Die wentiger mit als yon fritiffem Edjweipe - Der Gier Die Arranffeit, nidyt Die Rrifits ift - iffr Brod berdienen, wiffen Der şimmel und idf am beften.

Der id werfarre 2c. 2 .

ร. $\mathfrak{H}$ ร. $\Re$.

Meiner Bitte wurbe, wie man fieft, willfafren. 
No. 57. $\Re$ e $g$ e $\mathfrak{p} f$ e $i f$ e .

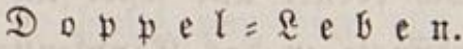

"Der Sommel befteft wafricheintich ans erften angen -

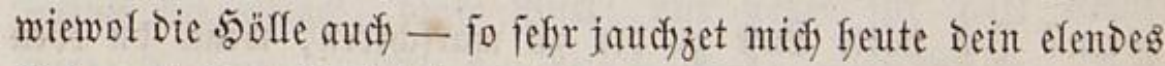
Reft an," jagte Bult beim Frillytülf. Beide gingen in iffre $\mathfrak{B}_{\mathrm{oh}}=$

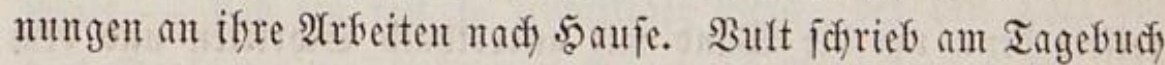

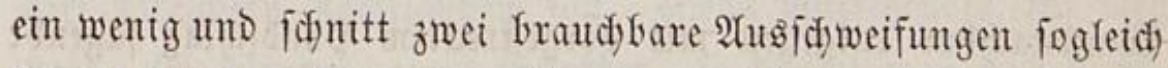
heraus für Den Soppelpoppel. Dam fall er aus Dem genfer unb fprach zur fremblicten Rawfinela ferab, weldye auf $\mathfrak{B}=$ ters Befefyl im Barten $\mathfrak{B a c h e}$ ftefen muß̈te, weil man die Bilbfäuten wie bie Drangerie $=$ Räften in Die $\mathfrak{W}_{\text {Binterquartiere }}$ trug. Da er voraus fah, Daß $\mathfrak{B}$ alt ifn förent müpte, io

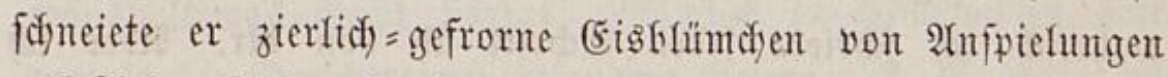
auf Riebe, Rälte, 5albgötterdien uno gauze bjöttimen finab,

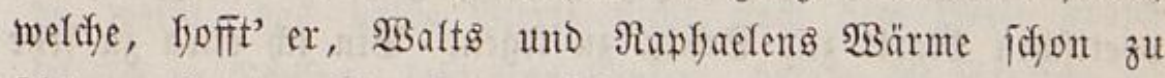

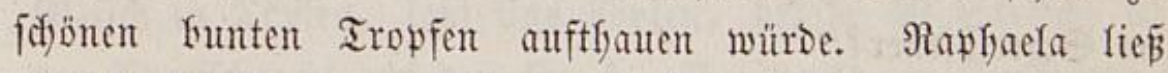

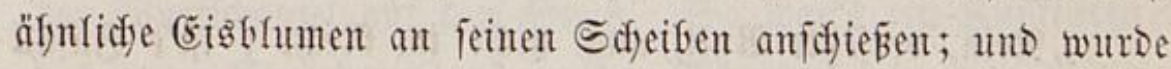

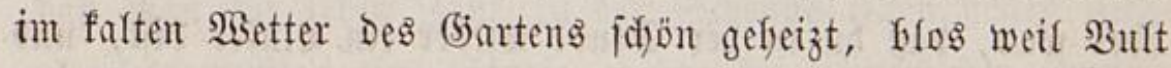
ein Mann unt ein Esdefmann war. F̈̈r mandfes Mäbdhen fibe ein Afynen = Mann auf feinem Stammbaum io entgfiebert und zeridonfen wie ein Sdyübenvogel am Dritten Tage auf Der Stange, fie wirb Dod) an ifym gern zur Rönigin uno will ifn erzielen. Mit einer శrente ofne Eiferjudyt gab fie ifm auf Die Frage, wann Der General mit jeiner Iodyter fomme, Die ફ口offnung ifrer Räfe.

Raum fatten Die Gebrüber mit größ̄erer Müfe wieber 
fut fliegen und fut fiderzen angefangen im Roman: fo frant Bult auf und murmelte fo zut fid - Walt muñt' ren - : "id) whifite nidft, warum idf nidft zu meinem ein= famen Bruber einmal einen Spaziergang madjte, Da Die $\mathfrak{B e g e}$ won bier zut iffm nod) ebener und fefter find als felfer in (5f)ur= fachjen." Darauf effrnete er Das Rappfenfterdyen am gemalten Ballafte Der Büfnenwand und rief findurd): fammft du midy Gören? Id) bätte Rujt zu Dir zut marjdiren, wem bu eben allein märeft. "Du Schelm, Du guter," fagte $\mathfrak{B a l t . ~ S e n e r ~}$ reifete Dent um Die $\mathfrak{B}_{\text {and }}$ mit andertfalb Sdyritten und Dem Wandnadfar entgegen mit vorgeftrecttem sandidjlag fagend:

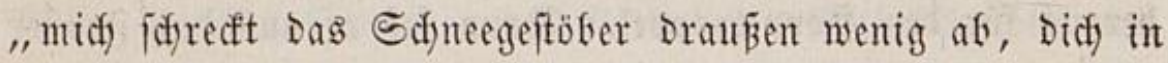
Deiner Finfiedelei aufajudyen und fie viefleidyt zu vermandeln in eine ladfende 3weifiedelei." - "Bruber, fagte $2 B a l t$, vom

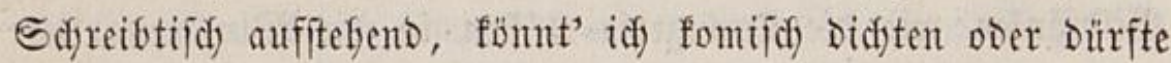
man einen Freuno abidfatten in Riा̄en uno Sdyattenrifīen:

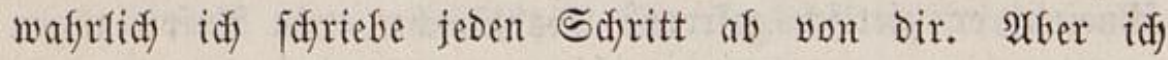
glaube nicht, Dá̉ es fich geziemt, ein geliebtes Sgerz alf Den poetijocjen Marft zur Sdjau zu legen. Bin idj etwa zu jefr. im Sd)reibfeut?"

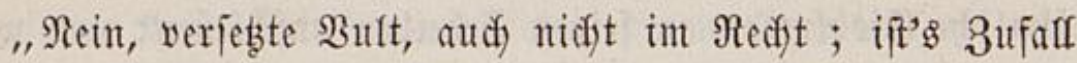
oder was, Dá̧ Du in Der Stube wieder ein Rinfer bift, und

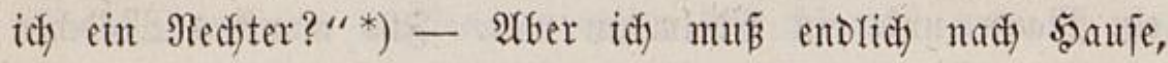

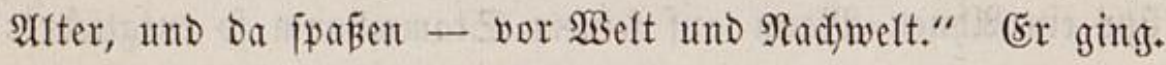
Walt lielt es für \$fflidft, ifgn aud bald zul befuchen, um ifym Die (Einperrung in eine halbirte Stube ein wenig zu verget=

-) Befanntlid) Geinen im Dorfe Estterlein bie fürftlidjen unter= thanen am red)ten Badjujer bie Redyten, bie abeligen, am linfen bie sinfen. 
ten. (Er fagte Bulten, wie heute fo viele andere 3 ufälle fich

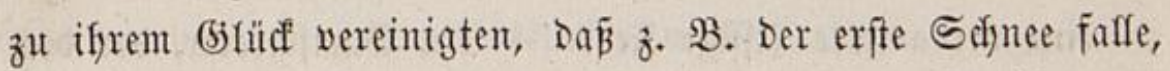
Der von jefer etwas fräuslidjes uno heimifdes für ifn aus

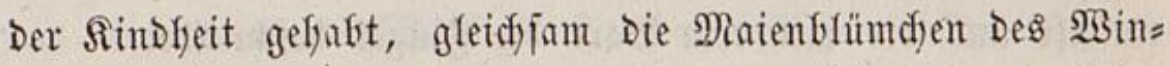
ters - und Dá̉ er heute yon fier aus die erften Drefder

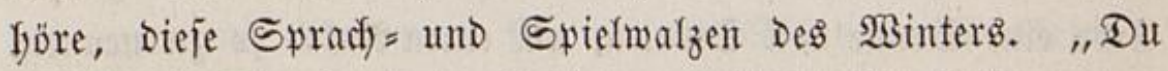
meinft Die frlegel, fagte $\mathfrak{B u l t ;}$; nur ftöret iffr a aft meiner Flöte ifren." - „\$Bie fommt's beiläufig, mein 2 Ifter — jagte 2Balt - Daß ein faft fo einfältiger Bers, Der Den Taft von Drei Drefdern nadfflappen foll, etwas 2 nzziefendes für midy fat: „im 2 Binter, mein (sünther, fo Drifift man Das Sorn; wern's falt ift, nidyt alt bift, tapfer gefror'n." " -

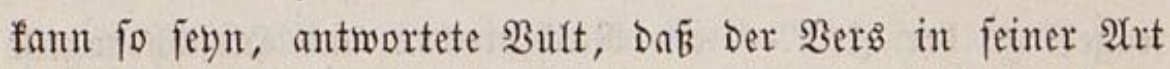
vortrefflich ift, uno nadjafyment, wer will's wiffen? - Doer audi, weil ifn uns unjer Bater fo oft aus 5 . v. Rofjrs

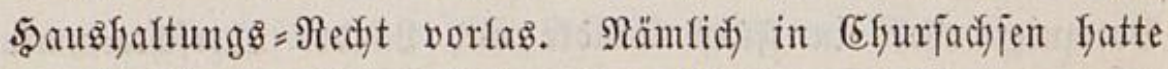
Damals Die Drejderzunft bejondere Bejebse. 3. 3. wer, wie Du weišt, Das balbe Bierte nidyt nady Dem Berje Drajad:

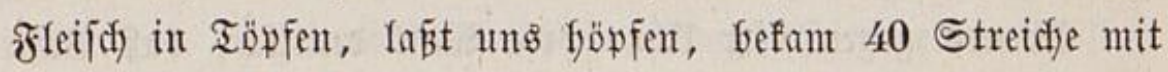
Der $\mathfrak{B}$ urfídyaufel auf Den Steiß̄. So war's ein 3 unftartifer, Dá man für jeden 3 nuf in Der Sdjeune einen neuen Flegel abgeben muste; eine Strafe, weldhe bei literarifdjent 3wiftig= feiten fidon im Felyler felfer abgefülyrt wirt.

Beide hoben wieder Das Sdyreiben an. "Id Dadjte jeb̧t Daran - rief ifym $\mathfrak{B}$ ult aus Dem $\mathfrak{B a f l a f f e n f t e r l e i n ~ - ~ a l s ~ i d f ~}$ Didh laut Das Fapier umwenden förte und innen fieft, wie von foldyen Rleinigfeiten ganze europäijofe StäDte, für Die wir etwa arbeiten, mit ifjen feinfen (Empfindungen gerabezu abfängen. Esine von Staub verdicfte Dinte - oder eine

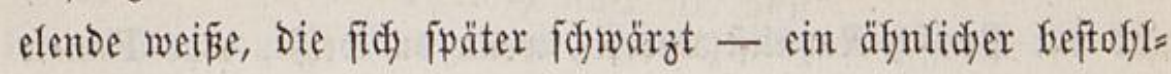




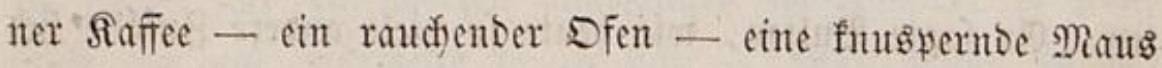
- eine verdammte rififige feber - ein Bartideerer, Der bid

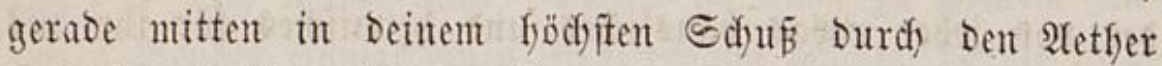
eimjeift uno bir mit Dem Bart Die Flügel befonneidet - -

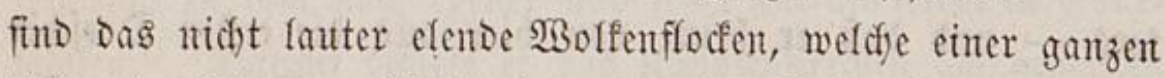
(Erbe eine Soune voll Stralen, um cinen $\mathfrak{Y}$ utor fo zu nemten, verbecfen fömen? Es ift ja orbentfiche fopwerei ber $\mathfrak{B}$ elt. $\mathfrak{A}$ uf Der ambern Seite ift es allerbings - fdyreibe aber Dann fort - ebent fo ermunterno uno erfaben, Daß̃ Der Tropfe Dinte, Den Du oder idf nadjher aus Der Feber aufs Bapier

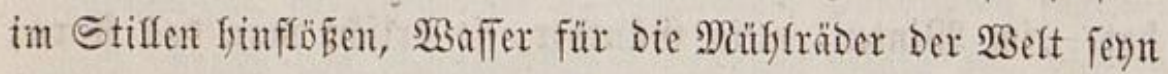

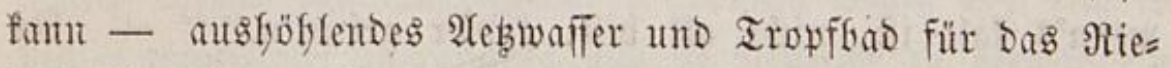
fengebirge ber Beit - ein Riechpipitus und sirichforngeift für manches $\mathfrak{B}$ olf - Der $\mathfrak{A}$ ufentfyalt Des Meergottes als 3eit= geiftes - oder fonft etwas äfnlidjes Dem Iropfen, womit ein Banquier oder ein frürt Stäbte uno Ränder überid)wemmt. (5ott! womit verdient man es, Daß̃ man fo erfaben ift? Segt fofreib' aber."

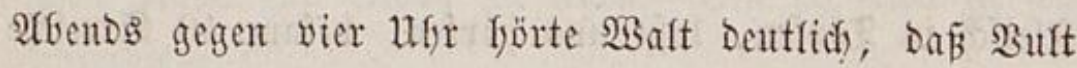
fu Floren jagte: "ef)' but uns betteft, fojones Sint, fo raufe

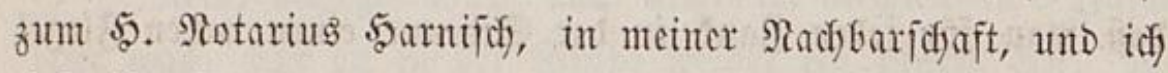

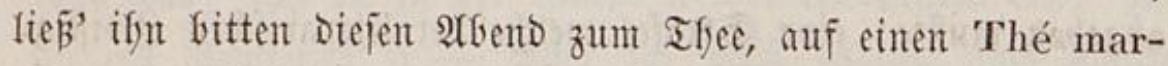
chant - uno fringe nur mir Ridjt, weil er Dann feines

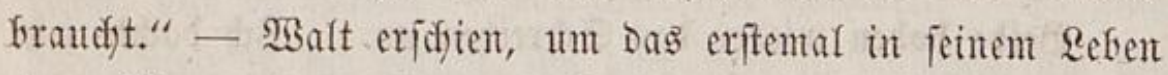
einen Thee moers als nach Saxirmitteln zut trinfen. Wult

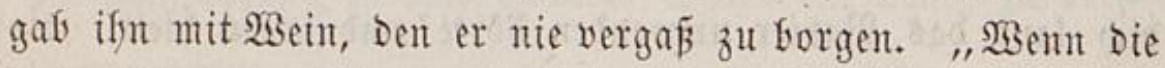
alten fidjon Den Afyorn mit $\mathfrak{B e i n}$ begollen, wie vief mefyr wir Den Sorbeer! - Waer einen 5oppelpoppel fidreibt, follte ofne= fin einen 5oppelpoppel trinfen, ia er follte beides vereinen,

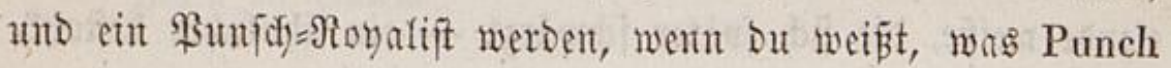




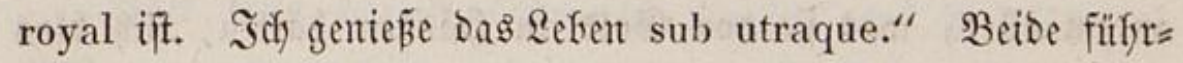
ten Darauf ifre guten Disfurje, wie Menidjen yflegen uno

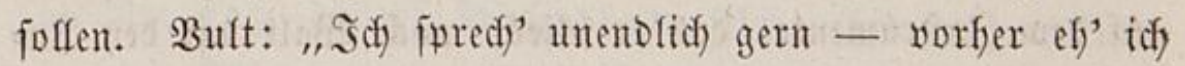

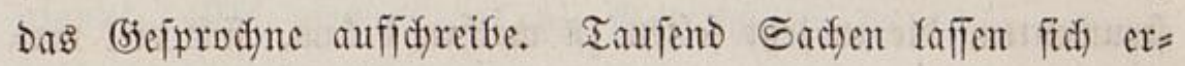
finden, wenn man feift und friegt. Dafer fommt's vieffeidft, Daß́ man auf $\mathfrak{A f a d e m i e n ~ f i d h ) ~ i n ~ a f f e ~ S B u ̈ r d e n ~ u n d ~ ( E x t a u b = ~}$ niffe, zu Yefren, nidyt wie an 5öfen fineinidymeichelt, fontern fineinzanft, D. h. DiBputirt, mozu Spredyen fo nötrig; z. $\mathfrak{B}$. fo bring' idf. Felber Diejen (Einfall oder Den vormittägigen vont Flegel fu Bapier." - Malt: "Darum werben Briefe als

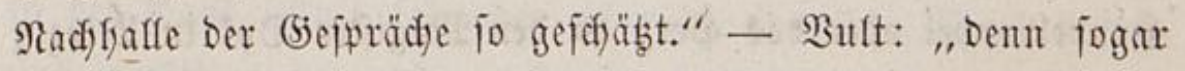
zum $\mathfrak{B f i l o j o p f i r e n}$ ift ein zweites Menidyengefidyt befülffidfer

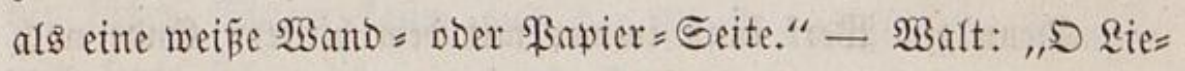
ber, wie hait ou Redyt! Dodh fam es nicht fo jefyr auf poetifue Darfeflungen waffen, als auf foerzhafte und wibgige und philofophifde; Dir filft Reden mefr, mir Sdyweigen." 3ult: "Der Binter ift überfaupt Die frudftbarfte Rettern= 3eit; Sdyneebaflen gefrieren zu Büderbalfen. Soingegen, wie reipet und flieget ein Menjid im $\mathfrak{L}_{\text {enz }}$ ! Şier wären Bilder Ieicht; aber Die Diterme le ift Der befte Beweis." - Waalt:

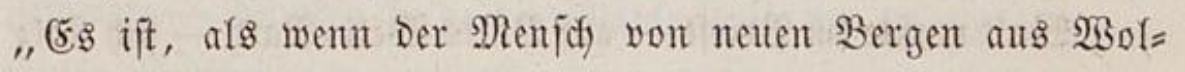
fen umidiflofien, ofne soimmel und ofne Erde, blos im Neer Des Sdnees treifeno - jo ganz allein - fein Sington und feine Farbe in Der Ratur - idf wollte etwas fagen: nämlidy

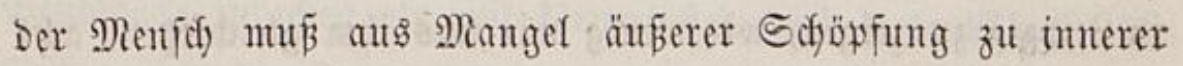
greifent."

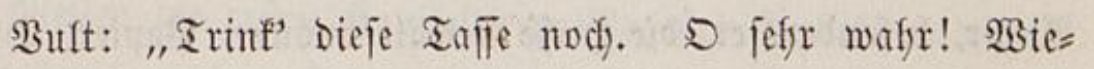
wol wir heute eben nidyt viel geidsrieben und idf gar nidjts."

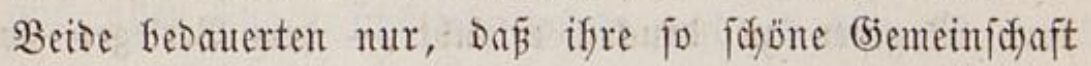
Der (5iuter Durd) Mangel an (bütern etwas geftöt mürde, 
indem affes, was fie yon (5old in sänden bätten, fich blos auf Die Goldofinger Daran einf(d)ränfe. Weber $\mathfrak{B}$ ult fonnte auf Dem Inftrumente, Das er blies, nody $\mathfrak{B a}$ alt mit Den $\mathfrak{I}=$ frumenten, bie er jef̧t felten zut madjen befam, fich vief ver=

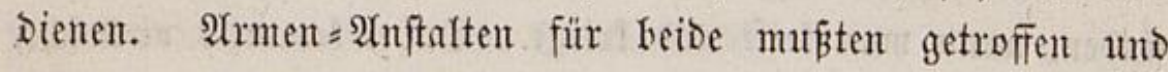
jeber Der Almojen=\$fleger Deß andern werden. Nodh beute, ia auf ber Stelle muspte ein Bauberidylag von unaffeflidfen Jolgen getfan werben; fie thaten ifn im 2 Beinfeuter mit vier Armen.

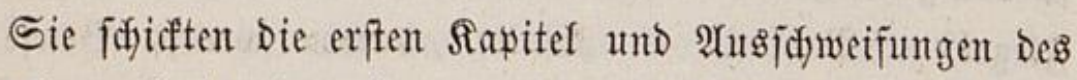
Soppelpoppel Doer Das berz an Den Magifter Dof in Leipzig zum Berlage.

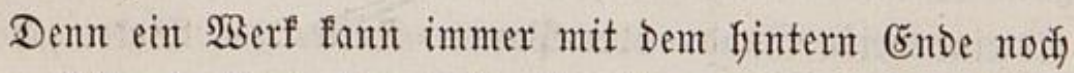
in Der Sdjnefenjodale des Sdjreibpultes wadjen, indé̉ Das

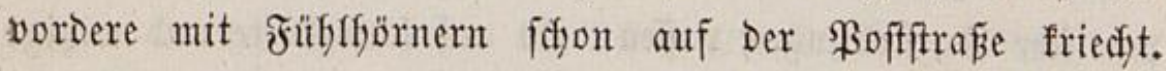

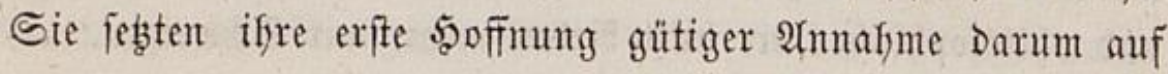
Den Magifter, weil fie glaubten, ein Bucthyänder, Der felfer ein (jelefyrter ift, habe Dod) immer mefr prüfenten (5ejdymad

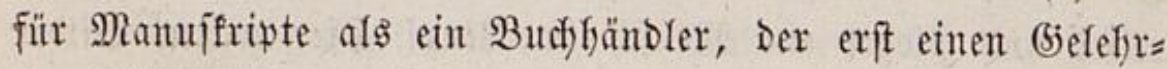
ten fuält, welcher wrïft.

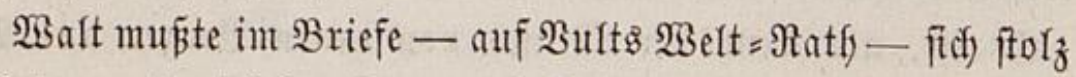
Befeffrben und viel begefren, und fith alle Rechte Der folgenten Auflagen vorbefralten. "Da Milton - jebzte er finzu - 12 (butineen für fein verlomes Paradies eimftrich: fo woflen wir, um in Leipzig zu zeigen, wie wenig wir uns iffm gleidffeb̧en, adyt uno vierzig begefren." - Der Notar erfaumte, Dẩ eit Autor, bejonders cr, Die grop̈e biewalt ausübe, \$apier, Drudf, Format und Stärfe Der 2 uffage - 3000 Eremplare murben Dem Magifer zu Drucfent erlaubt - Dem Berleger vorzu= foureithen. 
Bult trug Darauf felfer Die Rrotel auf bie fädfifiche

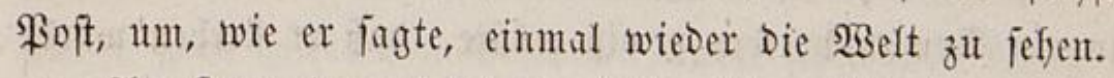

Am Tage Darauf jofufen beibe jefr. Ein junger âtor glaubt, afles was er auf bie $\mathfrak{B}_{0}$ ft fichift, fei fidon baburdy verlegt uno gebruteft, und fdjreibt Darum fleiß̈iger. Sein $\mathfrak{B}_{e}=$ judf, fein Fejt, fein Menfich, fein Brief färte fie. Bult hatte fein beld und 2 Galt war zum Sibling geborent. Didfter fauten, wie die afrifanifiden Böfer, ifje Brobfelder unter Mufif und nady Dem Tafte an. WBie oft fufr Balt über= ghücflid) vom Seflel auf und Durdy bie Stube mit Der feder in Der Fand (Bult faf) oben über Die fpanifode $\mathfrak{B a n t}$ finein und merft' es an) und ans Fenfter uno faf nichts uno founte Den füßen Sturm faum aus Der Bruft auf̧ \$apier bringen und jebste firf wieber nieder! Darauf fagt' er überfliésend: "శlöte immer, mein $\mathfrak{B u l t , ~ D u t ~ f t o ̈ r e f t ~ m i d ) ~ n i c h t ; ~ i d y ) ~ g e b e ~ g a r ~}$ nidft Darauf $\mathfrak{A}$ d)t, fondern veripüre mur im 2 ffgemeinen Das Ertönten vortheilfaft." - "Eagt mir liefer, Shr Sauz, von was idj jebst atsałldweifen habe in Euterem Rapitel, Damit wir beifanmen bleiben!" jagte $\mathfrak{B}$ ult.

Heber Dem Efien - bald auf $\mathfrak{B a l t s , ~ b a l o ~ a u f ~} \mathfrak{Z}$ ults 3immer - Defnten beide Die Maflzeit in Die Ränge, Die aug

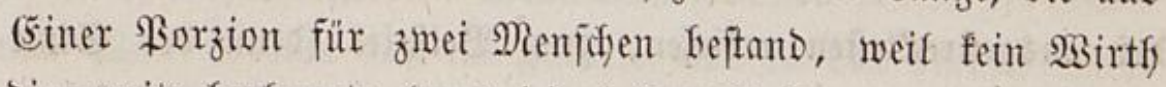
Die zweite ferforgte (was jedoch) Das Beijammenwobinen befto

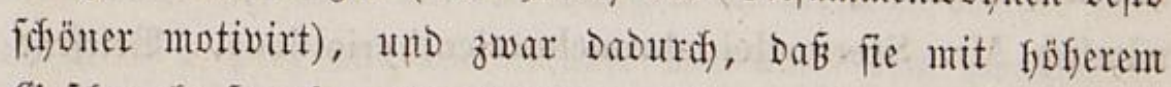
(5eidfmacfe fpradjen als mit förwerfidfem uno mefr 23 orte als Bifien üfer bie Bunge fradyten. Sie redfnetent aus, um wie viele Meilen Die erften Rapitel Dem Magifiter Dyf fơnon näfer wären, mit weldjem geuer Der 5opwelwowpel ifn Durdygreifent

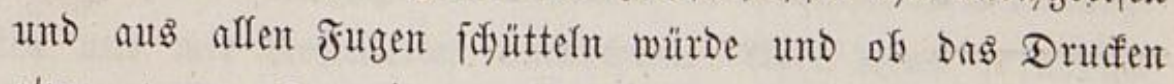
etwa, went es anginge, nicht fo fodnell fortginge, Daj mit Sean भaul's ausgew. Werte. XIV. 
Dem Sdyreiben faum nadjzufommen wäre. - Bult Gemerfte,

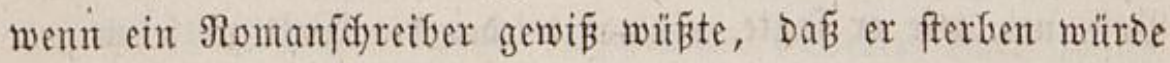
- 子. B. er bräd)te fich nur um - jo fönnt' er feltjame

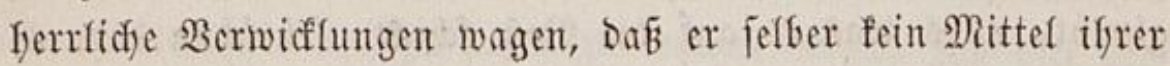
IUflöjung abfälye, aufer Durd) feine eigne; Denu jeber würbe, wenn er toot wäre, Die Durchondiftefte Entwicflung voraus=

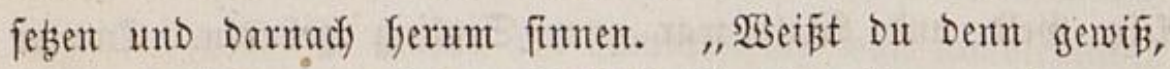
2Balt, Dấ Du am Leben bleibft? Sonit wäre mandjes zut madjen. - Snzwijdyen fely' idy jeb̧t it unjrer Stube berum und Denfe Daran, wie auffallent, falls wir nun beide burds unjern 5oppelpoppel uns unter (sfrenpforten uno in thefterb=

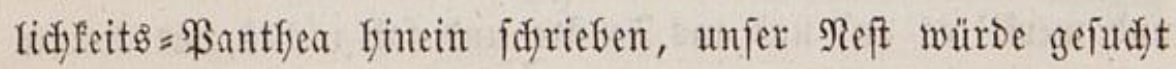
und bejudyt werben - jeben Bettel, Den Du an Die 2 Band fpufteft, whirbe man wie aus $\Re$ oufeau's Stube auf Der $\mathfrak{B}_{e}=$ ters = Injef abfraben und aborufen - Die Stadt felfer be=

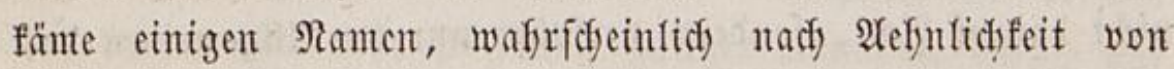
Ovidiopolis Den Ramen Harnischopolis. - $\mathfrak{B a g}$ mir aber

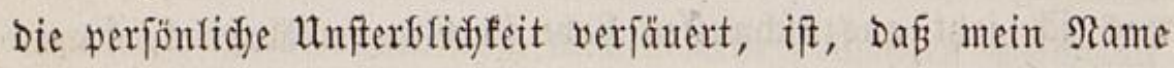
mur lange wäfrt, nidft $\operatorname{lang}^{*}$ ). $D$ wer es wiffert fünte

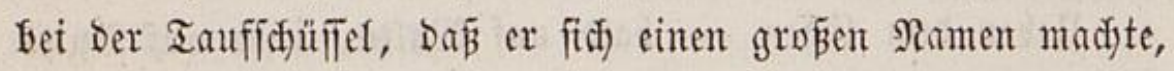
würbe fid ein foldfer Maun, wenn er fonft fiderzt, nidjt einen Der ausgeffrecfteften erfiejen, zum Beifpiel (Demn Der Sinu fat nichts zu jagen) Den Namen, Den fdon ein Musfel füfrt,

- nämlid) Mr. Sternocleidobronchocricothyrioideus. Belejente Damen fämen zu ifm und redeten ifyn an: 5 . Sterr scl und fömtent nicft weiter. Militairs thäten's nach und fagten: 5. Sternocleido! - Die Geliebte allein fudyte Den Nament ausmentig zu fönnen uno liebt' ifyn fo lange, als fie auss

*) Eange bezicht fidy auf 3eit, lang auf Raum. 
fprädfe: tfeuter M. Sternocleidobronchocricothyrioid! (5t wïrbe gern jitirt ron (belefrten, weil fojon fein Rame cine 3eile gilt vor Seb̧ern uno Räufern. - 2tpropos! SBarum (d)icft Denn Der Siefien = Erbe Baguogel nidjt Den erfen flor=

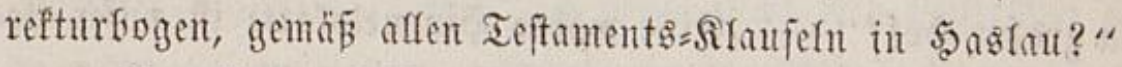

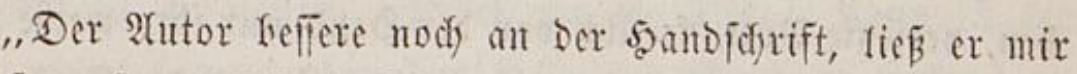
vorgeftern fagen," fagte 23 alt. - Darauf veridnauften fich beide in Der \&uft. WBie mandyen flüdytigen 3 ug Der föbern Stände fonnappte Der Rotar auf Der Strape im Borbetigefyen auf für feinen Roman. Die $\mathfrak{A}$ rt, wie cin 5 aglauter $50 f$ frova lier aus Dem $\mathfrak{B}$ agen fprang ober wie eine (5räfin ats Dem Jenf(ter faf), founte romantifiof niebergejofrieben werben uno (rin Mann für Taujend ftefen uno fallen! Dieje Uebertra=

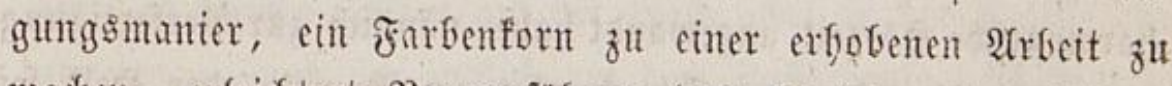
madyen, erfeidftert Bauternjöfnen Das Stubium Der böfern

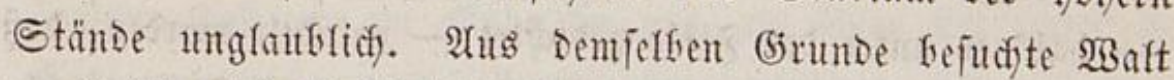
am liefiten bie 5offirdye und that bie 2 ugen auf.

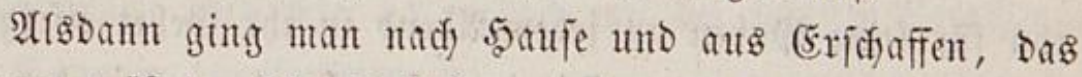
fo lange wäfrte, bis es finfter wurbe. Thu bie Dänmerung veridjoben fie - um Ridht zu eriparen - theils weitläuftigere (5epturäd)e, theils flöte. Wenn Bult fo blies finter Der $\mathfrak{Z}_{B}$ and uno $\mathfrak{B a l t}_{\text {fo }}$ Dort faí im Finfern und in ben blauten Ster= nenthimmel faf und an ben Morgen in Rofentyof ond dyte und

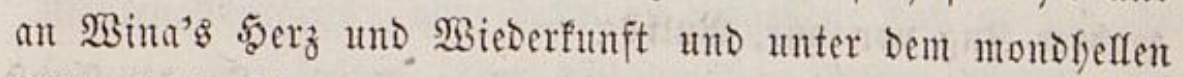
Flötenticjte fein flippenwoffes Leben eine romantijuse begeno wurbe: o fo fand er oft auf unt jebte fidf wieber fin, um Den Bruber Daburd im Blajen nidjt zu fëbren, Daß er ifjm fefannte, wie ifn jebzt bie Minuten in Brautfleibern umtanz= ten uno mit Rofenfetten umflöd)ten. Áber wenn er ausges blajen Gatte, umb nad) Der langen $\mathfrak{B}_{0}$ larbämmerung Ridjt fam: 


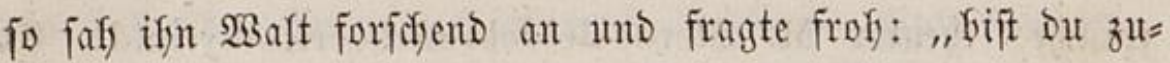
frieden, Bruber, mit Diejer füß̈en (Enge Des Rebens; und mit Den Srdfefter=?önen und innern 3auberbildern, Die wir heute viefleidyt eben fo reidy, nur ungeftörter, genofien fraben als irgento

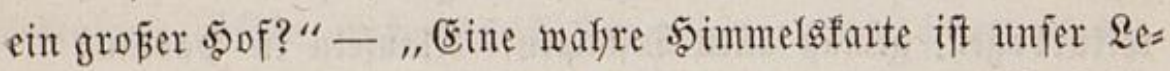

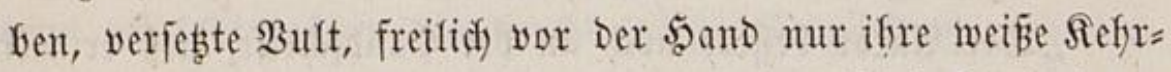
feite; Dod) einen Thaler, Den mir iemand auf Die Farte legte,

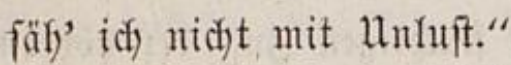

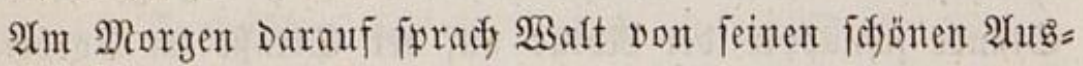
fichten auf Die flötende Nachtigaffen=Dämmerung. (Etwas müf)= fam wurbe Bult zu einer netten $\mathfrak{B}$ iederidjöpfung Des melo=

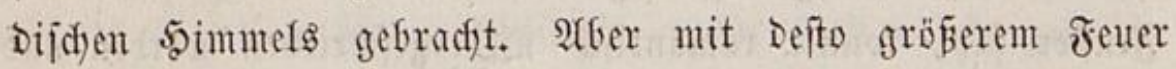
erzăhlte Darauf Der Notar, wie glücflici) er Die Dämmernde harmoniface 5örzeit angewanot fyabe, nämfich zur Berfertigung einer Replif und eines Strecfverjes im Roman; Der Seld fet - hab' er unter Der Flöte gebichtet - getadelt worden, Dañ er üfer Das 2 gort einer alten, franfen, Dummen Frau, weldhe ifyn für jeine (5aben an jebem atbento in ifyr biebet eifrig ein=

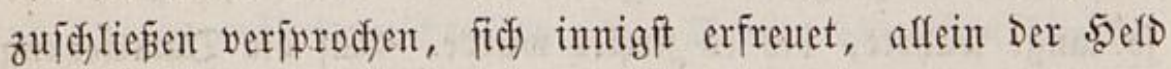

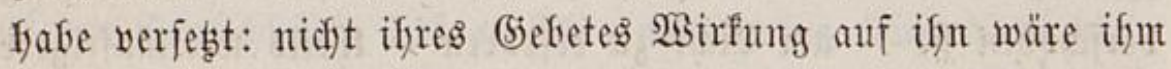
ctwas, fogar wenn Dieje gewiź wäre, fondern die auf fie jels

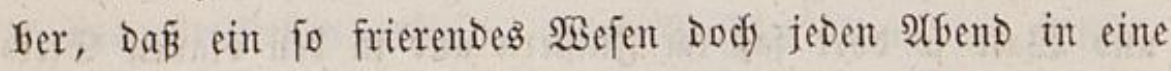
fơ)öne (Erffefung und Erwärmung gefange. "Sit Das fein wafjer 3 ug you mir, Bult?"

"(ङs ift ein wafrer von sir (jagte $\mathfrak{B u l t ) . ~ I n ~ D e r ~ S u m f t ~}$ wiro, wie yor Der Somne, nur Das 5ell warm, nidyt Die lebendigen Blumen." Balt verftano ifjn nicht; Dem oft fam es ifm yor, als finde Bult zuweilen fpäter Den Simn als Då 2 Bort.

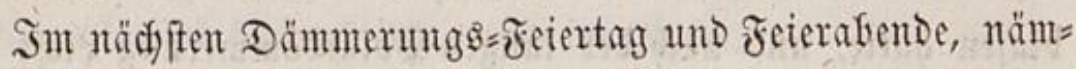




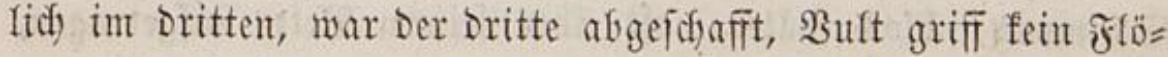
tenfoch), Glies feine Note. Afber Der Bruber nafm Den fünft= lerifden Ëigenfinn nicht übel, hielt ben Bruber für fo glüct= fidf als fich und wante nidfts ein gegen einen 23 edjel Der Dämmer = \$artien. "Salb' idy Denn nidyt eine \&uftröfre wie Du, io gut zu Lauten gebofret als Die flöte? Rann id Dir Dem nidyts jagen, ofne Das $\mathfrak{g}^{2}$ z ints Maul zu feefen? Disfuriren wir fieber beiderjeits," jagte $\mathfrak{B}$ ult.

In Den folgenten Dämmerungen fefrte biejer zur alten Sitte zurücf, finter Den Ratemenanzünoern Die (5a)̄en zu Durdfftreifen - ein âtenteuer mit einer Edyaupielerin zut beftefyen - Burgumber allein zu forgen (Waalten fielt er, jeit Diejer ifjn mit 8uder abjüpte, feines mefrr würoig) - mit Der Flöte in frembe Flöten auf Der (jafje ober in sie Siulifie cin= zutreten - und fich enofidy auf Dem Raffeebauje halb toot zut ärgern, Dak er am (Ende fo gut als einer fich unter die

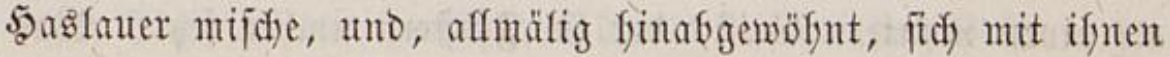
in (Bejprädye verfledste, Da er Dod) mit Der fefteften Beradjtung im Sommer angefommen jei.

WBalt blieb freudig zu 5auje; er fand in Den fleinfent

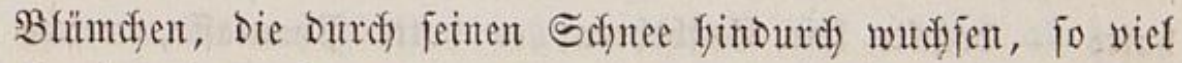

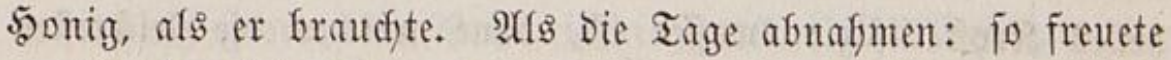

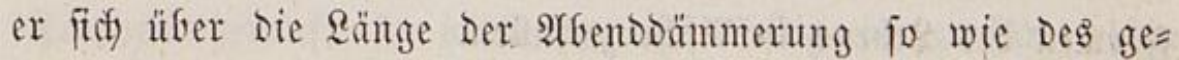
ftirnten Norgents; ofhe Dabei zou vergellen, Dấ er fid eben fo gut, mur fpäter, über Die 8 unafme freten mitroc. Der Mond war eigentlid) jein (shlüfeftern, fo Dấ er iffm in jedemt Nonate nidft viel weniger als 27 fidöne $\mathfrak{A}$ bente ober $\mathfrak{N o r g e n}$ Gerunterwarf; Denn beinafe 14 Tage (nur Die Bar erften ausgenommen) fount' er auf Deflen Wadfgtfum bauten; von Boffmond bis zum leb̧ten Biertel wurbe ofne Ertyfums 
Schimmer, flos päter, oft über feinem Bette aufgetragen, und Das leste Biertel gab Den Morgenftumben Siffer in Don Numb. Da einmal gerade in Der Dämmerung Baffmufif gegenüber war: io nafm er fidf fein Stücf $\mathfrak{B}$ interluffbar= feit beraus, fo gut wie einer. Die Mufif brang unfidyt=

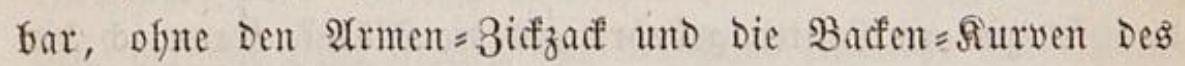
Drdfefters, mur entförpert mit feligen (jeiftern in fein Däm= merndes Stübchen. (Er fiellte fich) zum Ianjen an, und weil es ifun an Den fdyönfen an̈mzerinnen nidjt fefite - Da ganze 5arems und Romenidaften Darin waren und mefyrere Rojen= mäbdyen uno afles: - fo zog er bjöttimentron folchem (5) anz zum Tanzen nuf und mad)te mit ifnen - obwol leife, um

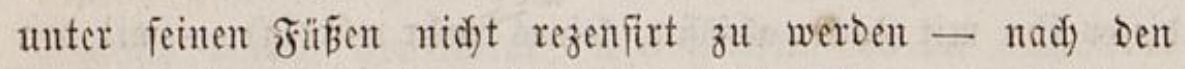
Fernen Taften, Die er begleitete, fo gut jeine \$as, feine Seiten=, feine Borpas zu 5opstänzen, zu (5ier=, zu Sijalltänzen,

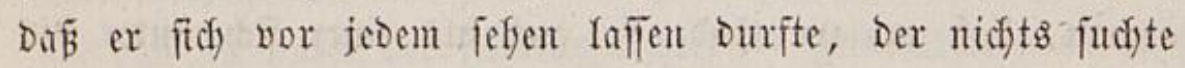
als einen muntern (5ieift, Der im Finfern umber febt. Was er in Der Seligfeit zu fideuen batte, war fros Bults plöb= lict)er Erintritt.

Sfnt - Der ofneffin nidjt gewofnt war, Daj er etwas batte - Drüfte fein Entfefrent, er hatte Phantafie, weldye helles Siryftallifazionsiwajer ift, ofne weldyes bie leidyteften Forment Des Rebens in 2lidje zerfalfent.

Dody wurbe feit simmel nidyt immer fo phantaftifis weit üfer bie Rüfte Der (Erde finaus gefoben, er wurbe auth) zumeilen fo real ferunter gebaut wie ein $\mathfrak{T}$ feater $=$ ober eit

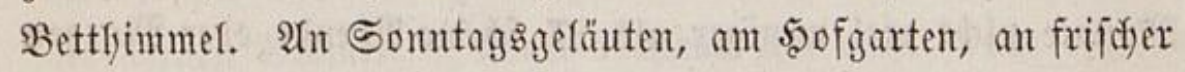
falter Ruft, an WBinterfonzerten (Die er unten auf Der (5)a fe fwazierento förte) batt' er fo viel $\mathfrak{A n t h e i l}$ als irgento eine \$er= fon mit Sdytïfer und Stern, Der im Innern gerade betide 


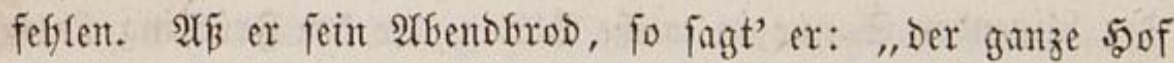

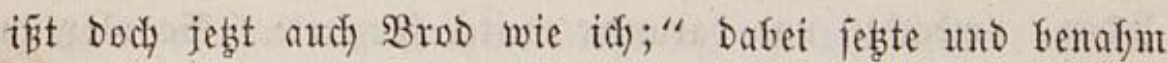
er fich zierlidy und artig, um gemiffermanen in guter (s)jefl=

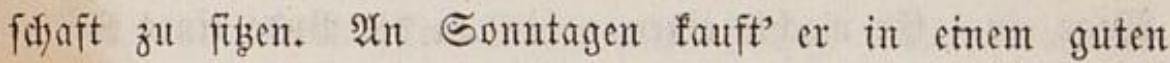

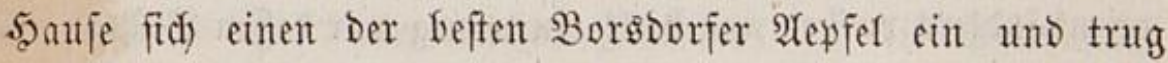
ifjn fidi) atbends in ber Dämmerung auf uno jagte: "ganz

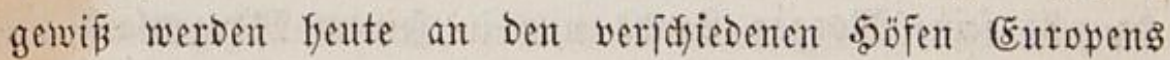

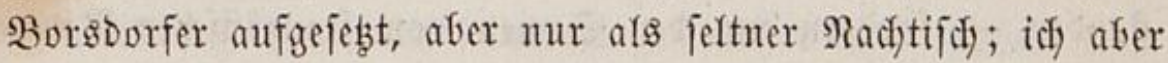
madye gar meinen 2 (bendtifa Daraus - mo wenn idf mefr Reiblicyes begefre, Du guter (jott, fo erfenne idy Deine (5üte

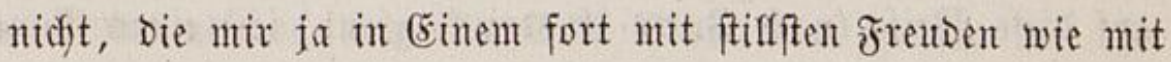
tiefen Suellen Die Geele überfüllt."

Im Durdyfidstigen Nebe feiner Prantafie fing fich jeber

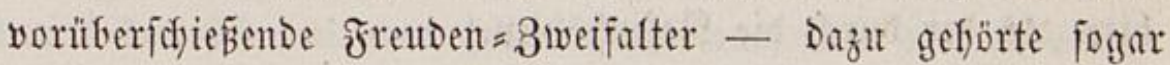
ein erwadjenter getber Sdymetterling im (5artenfjats - jeber Stern, Der frarf funfelte - itafiänifofe Blumen, Deren Deut= fdyen Ireibjherbent zwifhen Shawls er auf Der (5a) ale aufge=

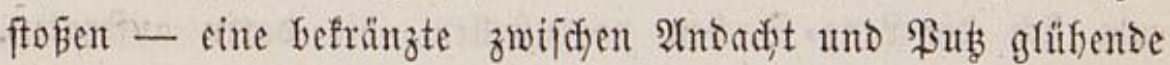
Braut - ein fönones Sino - cin Sanarienvogel in Der Bebergaffe, Der mitten int Deutichen 23 inter in Sunarieninjeln

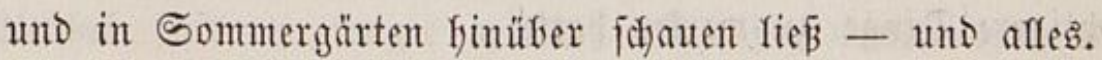

Flog Flora, bie Bettmeifterin, mit heffen Biefüngen bie Ireppen ferauf, fo förte er erf́te Sängerimnen für feinen Theil. -

(Einft an einem Marfttage fratt' er Galb Stafien mit cinem ganzen Friffling um fids. Der Tag fofien Dazu erlefen zu feryn. (ङs war ein felfr falter uno felfer $\mathfrak{B}$ internadjmittag, worin Diüfen in Den fodjefen Stralen fpielten, als er im 5ุof= garten - Den ber gute gürft jeden $\mathfrak{B}$ inter Dem $\mathfrak{B}$ brifum offnen lię̧ - Die filfernen Edyneffocfen Der Bäume unter 
Der Gribenden Goune in weipe Blüten, Die ben Früfling über= Yuben, umbad)te uno barunter weiter fpazierte. Eo plöblidy

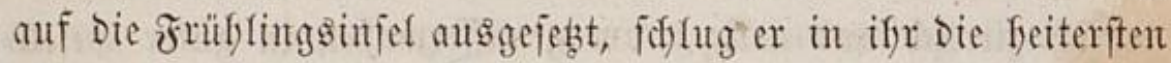
Wege ein. (Ex madyte einen nafen an Der Bude eines Sämes reienfänders vorbei uno hielt ein wenig vor deflen Bubentij(h), micht um cinte Düte zu faufen - wozu ifm ein Beet feflte,

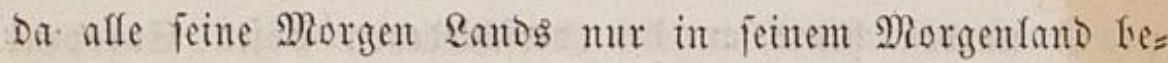
ftamben - fondern un Den Samen von frauzöfififen Rabie= fen, Maienrüben, bunten Feterbofnen, 3ufererbjen, Sawu= zimerfalat, gelfem Frinzenfopf zu Denfen uno zu riecten uno

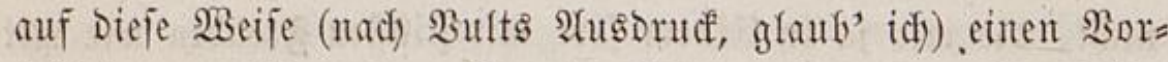
früfling zu formufen. In ber That gefft unter aflen Sin= nenwegen feiner fo offen und furz in Das feft zugefoutete (5ie= firm als̊ ber Durd) Die Rajenföhlen.

Darauf fyolte er fich feim Büderverfeifer vieles, was er von guten $\mathfrak{G e r f e n}$ über Sdjmetterlinge, Blumen = uno FelD= faut erwifichen fomte - uno the aufmerffam in Den 23 erfent, um fid Die $\mathcal{L}_{\mathrm{enz}}=$ Sadyen vorzuffelfen, Die Darin auftratent.

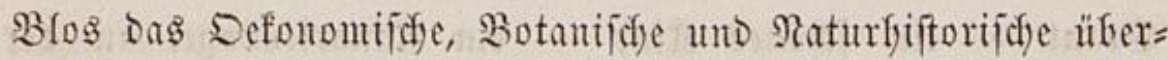
fyüfte er ofne fejondern Berftand und Esindrucf, weif er auf widftigere Dinge zu merfen hatte.

AlE Der Bruter fort war, ftand gerade die Atbentröthe

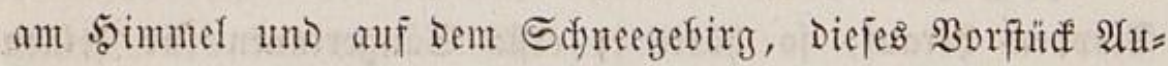

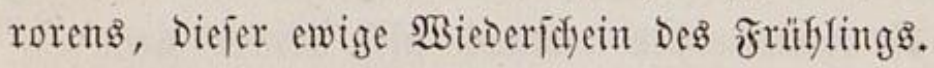

Heber Das 5aus fyerüber war fdon Das Nonosviertel

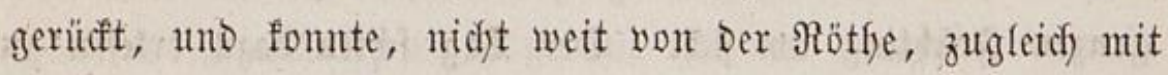
iffr in fein Stübchen fleine farben uno Stralen werfert. "Wenu nidft Der $\mathfrak{W}$ inter nur eine $\mathfrak{B}$ ofar $=$ Morgenrötfe Des Fritflings für Die Menfichen ift, fagt' er, intem er aufifant,

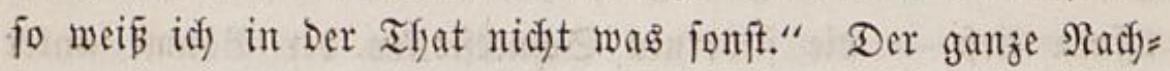




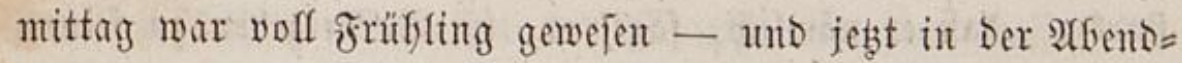
ftunde quoll gar ein Radytigallenfoldng wie aus einem äuß̌ern B(ütenffait in feinen imeen berüber. (5r แafm cinen JuDent=

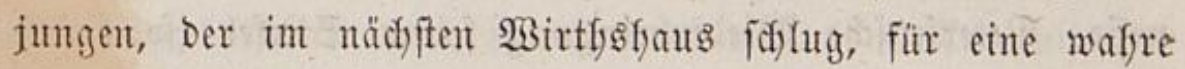

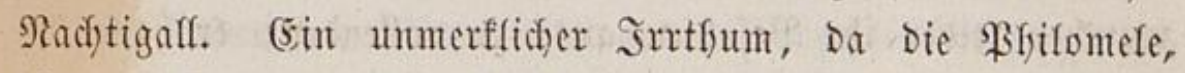
Die uns fingt, eigentfich) Dodf nirgents fibst und niftet als in miferer Bruft! Schnelf, wie von einem Bauberer, wurbent Die fteilen Felfenwände feiner 2 age umber mit Exphen und mit Blümdyen übergogen. Der Nond fam heffer ferein und SBalt ftand und ging mitten in jeinem leifen Gilanze träu= ment Getend, es war ifm, als fyöben und fielten ifn die geraben Stralen und als flabe er jeden gemeinen biegenftand im 3immer ober auf Der (5a)fe mit Feftapeten zu verfüffen,

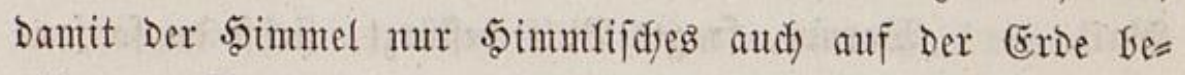
riifhre. "So war es gernde einft," fang er mefrmals, auf jenen Abend Deutent, wo er neben Wina's 3immer monto= fitf auf und ab ging. Ia er improvifitte fingend dent $\mathfrak{B}_{0}=$ Iymeter:

"Riebfit Dut midy," fragte Der Silngling Die (5eliebte jedent Morgen; aber fie jafy crröthet nieder und fidwieg. Sie wurde bleidfer und er fragte wieder, aber fie murbe rotf uno forwieg. CEinft als fie int Sterben war, fam er wieber und fragte, aber nur aus Edymerz: "liebfit Du midy nicht?" und fie jagte Sa und farb.

Er verjang fich immer tiefer in jein serz - 3eit unto Welt verichwand - er fwielte wie cine fterbende Ephemere füß in Den Gelfern Stralen Des Mondes und unter Monos=

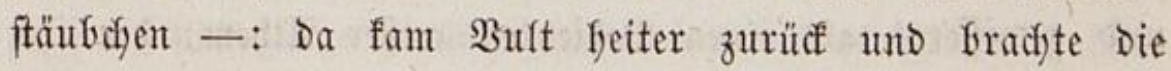
Rachridyt, Wina fei angefonmen, Decfte aber fogleidy Deren Wertly für ifn felber Durd) eine zweite luftige zu (uno ladjte 
ftarf): „Dấ er nämlidy, fagt' er, im Borbeigeben zu feinem Sdyufter gegangen, um ify zu fragen, ob er Dem jeit 14 Ia= gen feinen 15ten gefunden, um Die Rebabilitirung, $\mathfrak{B a l i n g e =}$ nefie, ßeterjenjide WBieberbringung feiner Stiefel (jo Drüde mandyer leiber ifrr Bejoffen aus) zu volfenden; er babe ify aber nidjt efjer als auf Dem Rücfwege gefunden, wo er auf= fallend ifm immer redits in bie Sdyattenjeite ansgebogen; fis or nady langem Bredigén gejeben, Dafi Der Mann die Stie= fel, weldye Der Bubtert Der Rajualrede waren, an Den Beinen bei fid babe und ferumtrage, um fie erif nod etwas abzu= treten, bevor er fie flicfe." "פBar Diejer Spaḱ, Dẹr nod) Dazu voll Unjpielungen ftect, nidyt po viel werth als bas befte Banr Stiefer jelber?" - "Sit er Dem fo fonderlich?" fagte Wart. - "Narum, fragte Bult beftürgt, fielyft bu fo fon= Derbar aug? Wareft Du traurig?" - "Jdh war felig, und

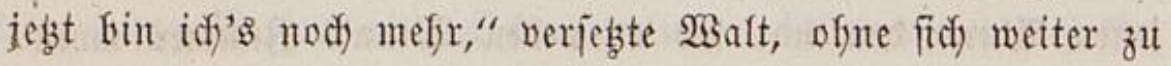
erflären. Die böbfte Entzüufung mad)t ernft wic ein Edymerz

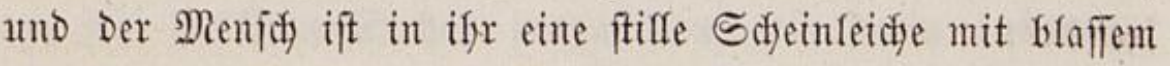
(5eficht, aber imnen volf überirdijd)er Träume.

No. 58. (5) $i$ f $t \mathfrak{f}$ tt $t \in \mathfrak{e}$.

(Erinnerungen.

Der Notarius erwartete ant Morgen nidfts geringeres und gewifferes als einen Bebienten auper atbem, Der ifnt cilig vor das Sifreibepult Des Bsenerals beftellte. Nidjts fam. Der Mittelmann glaubt, Die Dbermänner fefen Darum 
auf Den Güfern Sproflen Der Stantsleiter, um befler bie

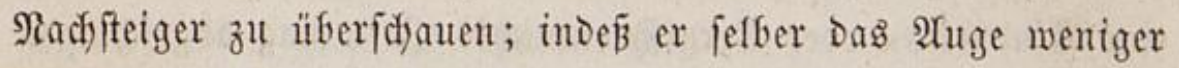
auf Den Siopf feines Radyfteigers alę auf Den şintern feines Borfteigers beftet; und fo affe auf uno ab. Die mittlern Stände haben Den föbern feine andere Bergefflidfeit fofuld zu geben als bie, weldye bie niesern wieber ifnen vorwerfen.

Die Dämmerung fonte $\mathfrak{B}$ ult foum crwarten, um ein

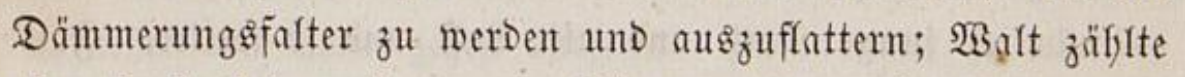
eben fo ftarf Darauf, um ein Dämmerungs $=$, ein $\Re a d y t=$ und ein Iagfalter zugleich) zu ferth, aber nur geiftig uno nur Dabeim.

Soimmel! er muro' es fo feffr! Denn als Bult ganz fwät und nidyt in befter Raume nad) Saauje fam, fant er $\mathfrak{B a}$ al= tent fingegen Darin, nämlich in befter - feurig idfreitent faft veriüngt, ia verfinolicht - fo Da er ifn fragte: "Dut

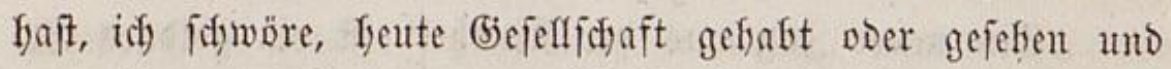

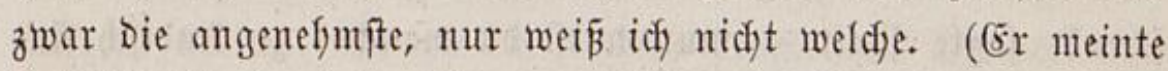
beimlidy Raphaela.) Doer hat Der Magifter Dyf gut ge= idjrieben?"

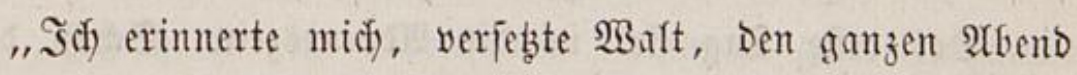
fort und fwar Der Sindfeit; Denu jonft fratt' id) nod) nichts."

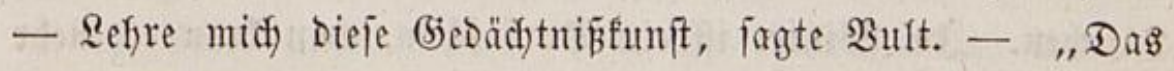

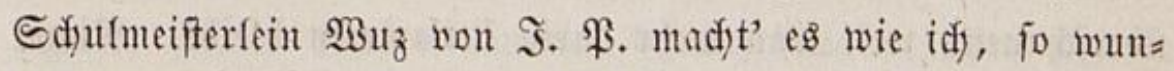
Derbar errätfy ein Didfter Dą (jefleimfte. Sch mödfte wol Tage fang über bie fleinen Frülflingsblümdfen Der erften $L_{e}=$ benszeit resen und fören. Sm Alter, wo man ofnefin ein

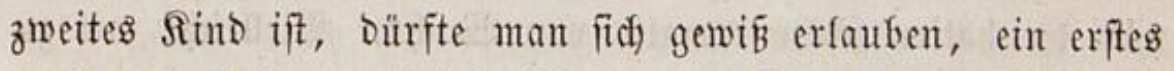

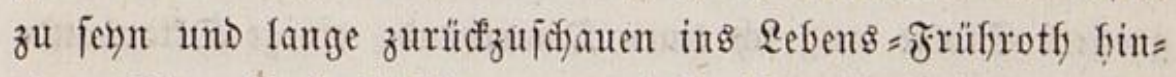
ein. Dir offenbar' idy's gern, Dấ idy mir böbere $23 e j e n$, 子. $\mathfrak{B}$. Engel, orbentlidf) wentiger jelig ants $\mathfrak{R a n g e l}$ an Sinto= 
Jeit Denfen fann, wiewol (5jott vielleidyt feinem $\mathfrak{B e j e n t}$ irgend

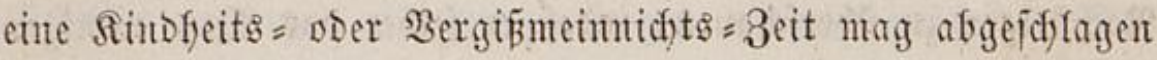
haben, Da jogar Jejus jelber ein Sind war bei jeiner Gicburt. Beffeft Denn nidft Das gute finderleben nur aus Ruft und 5ुoffuntg, Bruber, und Die Jrüfregen Der Tfränen fliegent Darüber mux flüdstig fin?"

"ซrüf)= Regen und alter Weiber Iänze und fo weiter - nämlich junge Notg uno alte $2 u f$ und fo weiter. Fall' id) nod) in Den Beitpunft Deiner versus memoriales?" jagte 刃ult.

„2Bafrlicf), ftets fyob id in Reipzig und fiex nur Iage Dazu beraus, wo Du nod) nidft mit Dem Mufifus entraus fent warit."

"So erimere Didf) Deines heutigen (Erimerns wieber bor mir, bat $\mathfrak{B u l t ; ~ - ~ i d f ) ~ f t e b e ~ D i r ~ m i t ~ n e u e n ~ 3 u ̈ g e n ~ b e i . " ~}$

"Šin neuter $3 \mathrm{ug}$ aus Der Rindfeit ift ein golones (Sies

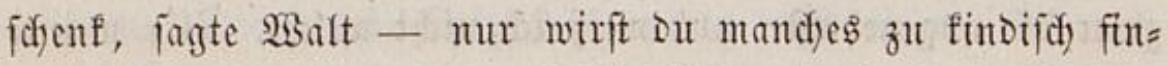
Den. (Rindifi) blos, jagte Bult.) Saf) nafym heute zmei Inge, nafye an fürzeiten und längiten.

Der crifte Tag fiel in Die âventezzeit. Sdyon Diejer Rame und Der andere, "Aloventsongel" umfliegt mid) wie ein Rüftben. Sm Sisinter ifit ein Dorf foön, man fann es mefrr Ḧterjobauen, weil man mebr Darin beifammen bleibt. Nimm nux Den Rontag. Edyon Den ganzen Eonntag freute idf midf auf Die Sifule am Montag. Sedes Rind munte um 7 ubr bei Gternenjoein mit jeinem Ridjtyen fommen; idj und Du fyatten foün bemalte von $\mathfrak{W a d}$ s. Siefleidyt mit zu gropem Gtolze trug id cinen Duartband, einige Dftabbände und ein Gedez=Werfisen unter Dem $\mathfrak{A}$ rm."

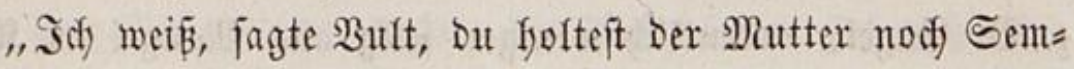




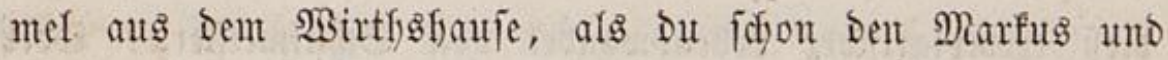
feiten Ddy fent griedifich exponirteft."

"Damn fing Die fiffone $2 B e l t$ Des Singens uno Refrents

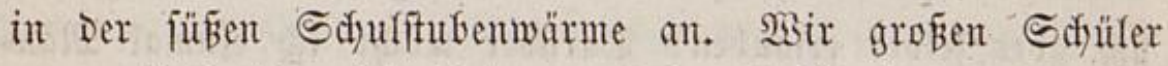
waren hod) über bie fleinen erhoben; Dafür fatten Die ÂAc=

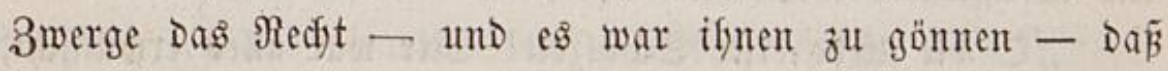
fie ben Fimbibaten faut anreben und ofme Anftand ein wenig aufitefen uno kerumgefen Durften.

Benn er un entweder die Epezialfarte auffintg, und

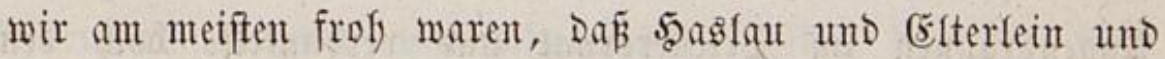
Die umliegenden Dorfidjaften Darauf ftanden - ober wemt er yon Den Sternen fprad) und fie bevölferte und idy voraus

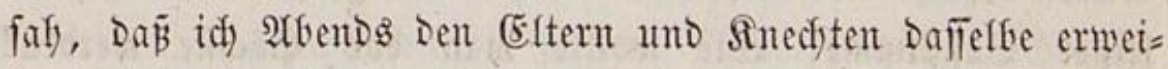
fen würde - oder went er uns laut vorlejen fieß̄: - "

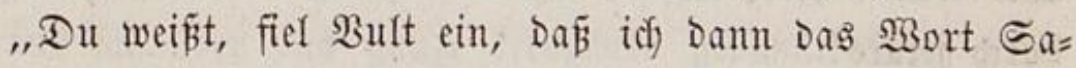
frament, er modste fagen, was er wollte, immer mit einem $\mathfrak{A l f}_{\text {zent }}$ herlas, als of ifi fluchte, Desgleidyen Donnerwetter.

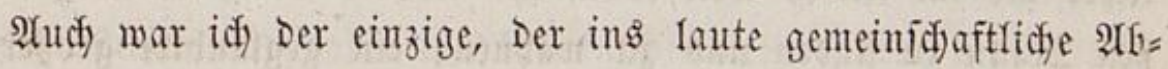
beten eine 2 rrt $3 / 8$ Taft z̆l bringen verjuchte."

"Sich) Gätte Dem arbeitfamen Manme fo gern Entzücfun= gen gegeben, wenn idh fie gefjabt fyätte. Sod betete oft ein Teijes Sater unfer, Damit bjott ifn einen Finfen, wenn er finter feinem Rloben lauerte, Darauf fangen Yieße; und Du

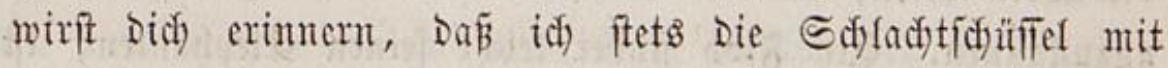
Fleific) (Du aber mur Den Suppentopf) ơ ifjm trug. WBie idf

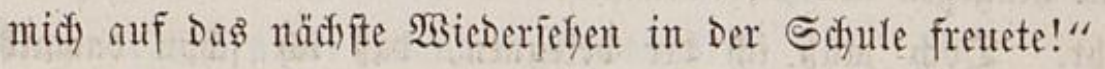

„, $\mathfrak{B e r}$ mid) hart gegen ben Sifulmeifter findet, fagte Sult, Dem balt' idf blos vor, Daß́ mir Der Gdjulmann cins mal cine angeraudde Bfeife abpfändete und fie in Derfelben

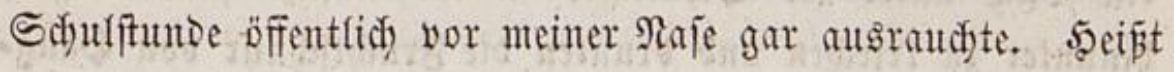


Dieß̄ eremplarifher Rebenswantel von Edhulmeiftern? Doer

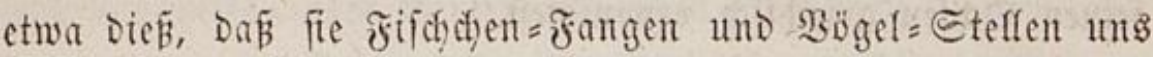

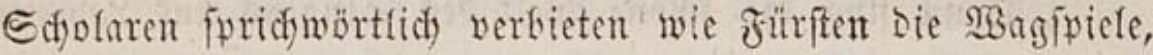
fich aber felber erlauten? Darïber mïd)t' id cinmal $\mathfrak{M a ̈ n}=$ ner in öffentlidfen Blättern fören." -

"D Die liebe erfte Edjufzeit! Mir war alles ermünfdyt,

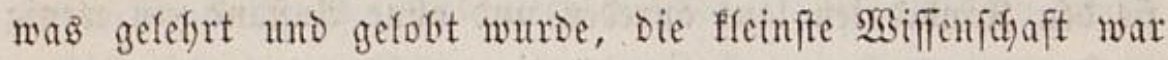

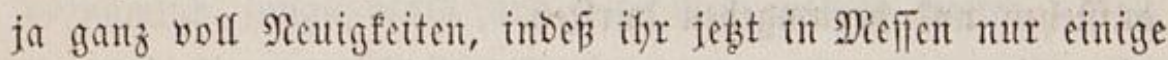
nadywadjen. Sam mu vollentos Der Sfarrer mit bet grofen Augenbraunen im Briefterornat und verounfelte Doch ben

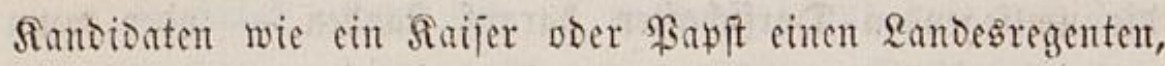

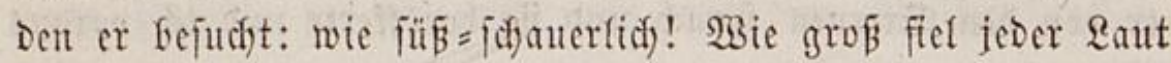
feiner Bafiftimme! Wite wollte man Das 5öbjfte werben! WBie wurde jebes Wort unfers Sdyomafers breifadj befiegelt Dur(f) jeines!

Sd) glaube, man ift fdyon Darum in Der Sindfeit glülơ = licher als im âter, weil es in ifyr leidfter wird, einent gros Ben $\mathfrak{R a n n}$ z̆l finden uno zu wäfnen; ein geglautbter grofier

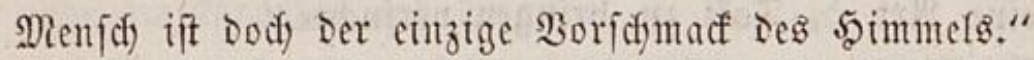

"Sn fofern, fagte Bult, möd)t' idj cin find jern, Glos um zu bewuntoen, weil man Damit fich fo gut fibelt als anberc. Sa id möchte als cin fötus mit Spintenarmen an bie $\mathfrak{B e l t}$ treten, um Die $\mathfrak{B e f m u t t e r}$ al\$ eine Sutno Qubovifi anzufaunen. (Ein floh finset leidft jeinen (Elewlyanten; ift man fingegen älter, fo ferwundert man am Ende feinen 5ุund

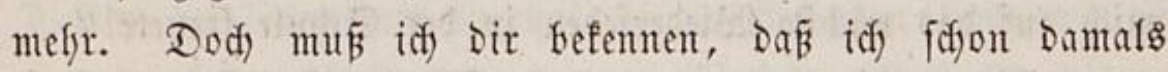
unferem fnurrenoen $\mathfrak{B}$ farrer belbföppel aus peiner fragen= (5) forie einige Stralen ausrupfte. Sah batte, wie gewöhnlid),

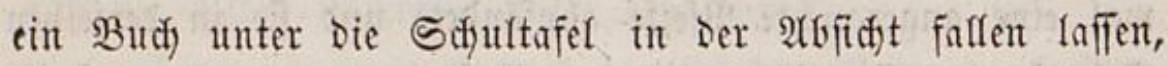
finunter zu fricd)en uno Drunten Die frudjtidynur von sängs 


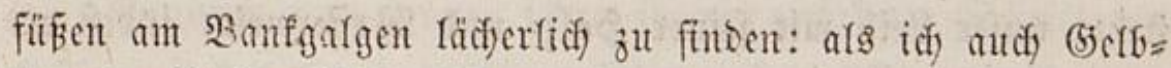
föppels Bodsenfitiefel auf Dem Boden antraf uno Durd) Den

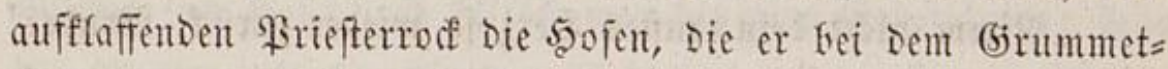
Afufladen angefabt, zu (jefid)t fefam - weg war jeine ganze oben Darauf gevelzte 2 Bürde - Der Menfí), wentigfens Der 2tyoftel, fit aus rinem Stüct geffeidet, or jei fein balber 2hofteltag, $23 a$ alt!"

"Bult, fift Du Dergleidyen nidyt faft in mandjer Bemer= fung? - Nut fam 11 Hhr beran, wo wir beide auf Den

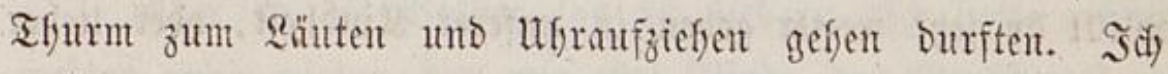

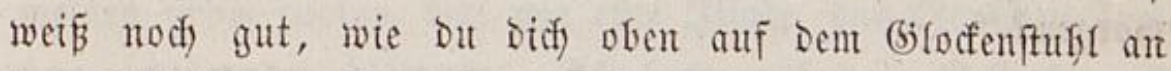
Dab Seil Der ausfdywanfenten (Slocfe fingit, um gejdwungen fu werber, obgleid) viele dir jagten, fie werfe Did) Durdi Das

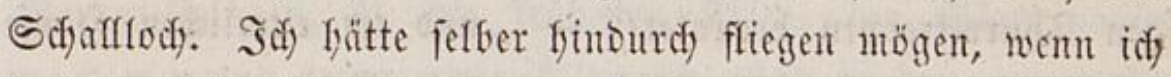
fo finaus jaf über bas ganze freuzweis gebafnte Dorf volf Yärmender Drefidtennen, und an bie Dunfle Bergitrane nadh Der Stadt, uno ülher Den weiten Sdyneeglanz auf alfen şügeln

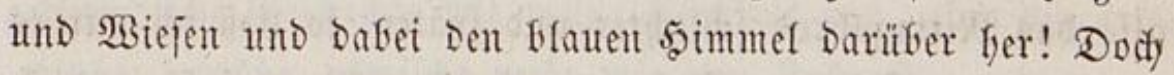
Damals war Der (Erde Der \$simmel nidjt jefor nötjig. - Şin=

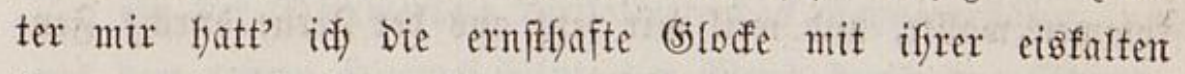
3unge und mit ifrem 5ammer, und iá) Dachte mir eg fojauer= lidy, wie fie einfam in ber froftigen Mittenad)t zu mir ins tiefe Salts und warme Bette binaf redent werde. Shr Sum=

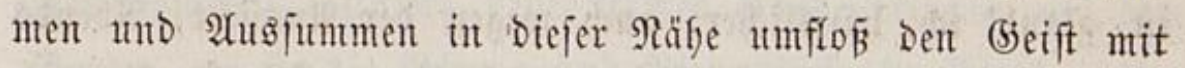
einem ftürmenten Neere, und afle brei Zeiten Dcs Refients fojienen Darin unter cinander fu wogent."

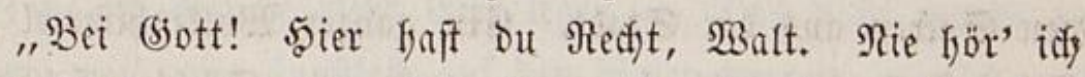
Diejes Tonbranjen ofme Sdyauder und ofne Den (Sedanfen,

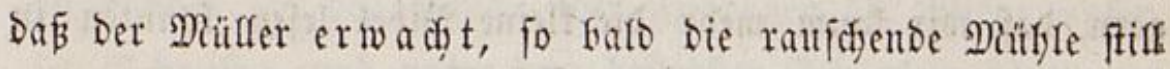




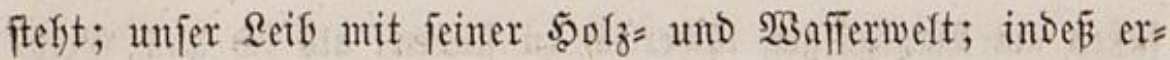

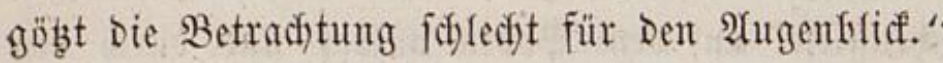

"Nimum nidyt Dein ermites 5ूerz fo wicder zurüaf, Bruter! Sollt' idy Dein (j) feidnnifí wieber mit einem beantworten, fo würo' id fagen, Diefe Stifle jei bie auf Dem (5ixfel Des bott= fyardsferges. 2tefes ift Dort ftumm, fein $\mathfrak{B}$ ogel uno fein Rüft= dyen zul fören, jener findet feinen 3 weig, Diejes fein Blatt; aber eine gewaltige $23 e l t$ liegt unter bir, und ber unendidfe 5̧immel (mit aflen übrigen 2 selten umfängt bid rings. Wiflt Du jebst weiter gefen in unjerer Sindheit, oder lieber morgen?"

"Sebst, Gejonters jebt. Der Rintheit werf' idf nidyts yor als zuweilen - Eittern. WBir ftiegen aljo beide bie lant= gen Shumtreppen herunter" - "uno im elterlidjen baufe wurben wir Durdi bie reinlid $=$ georonete Mittaggnelt erfreut an Der Stelle Der trüben Norgenftube; überall Somnenfidgen und $\mathfrak{A}$ uforonung. Da aber Der $\mathfrak{B a t e r}$ in Der Stast war und

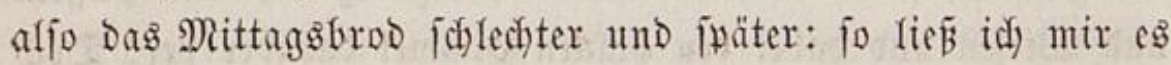
bis nady Der Sdyule auffeben, weil idy nidyt zu fpät in bieje fommen wollte, uno weil mir jekgt ans ber Fente Durdis Fens fter fijon Sameradent und Lefrer wieber neu erichienten.

In Der Gdyulftube grüßte man bie unveränderten Bänfe als net, weil man felfer verändert iff. (sin Sdfulnad)mittag

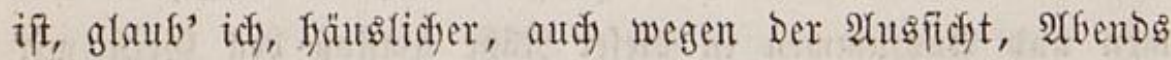

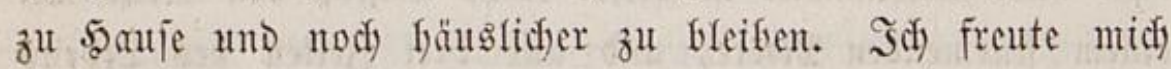

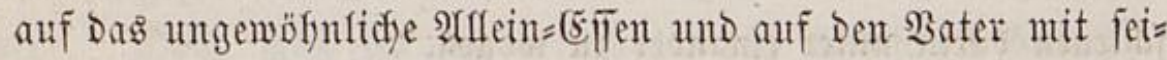
nen Sadjen aus Der Stadt. (Ein gauzer $\mathfrak{B}_{\text {olfenfinmel von }}$ Sdyneefloden wirbelte herunter, und wir Sdhüler fafen es gern, Daß́ wir faum mefr die fleine Sibel lejen founten in Der ofyefin Dunfeln trauliden Sdjulfube. 
Drauken nut jprang jeber in neu gefalfnen Gdjuee fefre

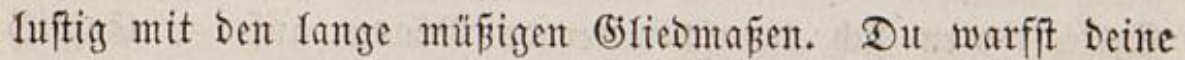
Bücher ins 5aus und bliebft weg bis zum (bebetläuten; Dent

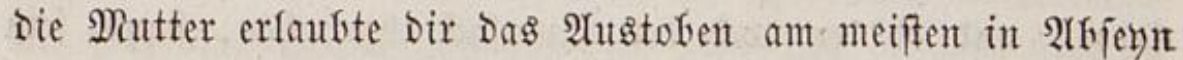
Des Baters. Sch folgte bir feltert. Der Şimmel meiß, warum idf ftets findificher, autsgelafiener, büpfenter, unbeholfen=effiger war, als Dut - idh madyte meine Sinds = ober Narrenftreidye allein, Du madyteft Deine als Befefylsfyafer frember mit."

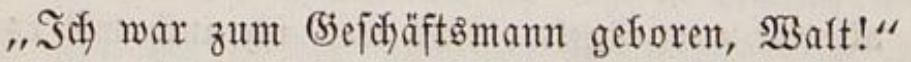

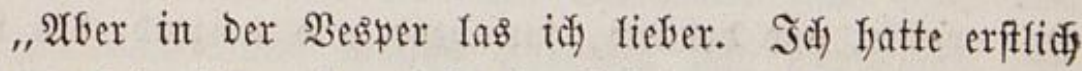
meinen orbis pictus, Der, wie eine Sliabe, Das Menfochen=?rei= ben auseinander blätterte. Shl hatte auf Dem (5iefimfe aud viele Befdreifungen, theils vom Norbpol, theils von alter Rorben=3eit, $z$. $\mathfrak{B}$. Die friffeften firiege der Sfandinavier It. $₹$. w., unt je grimmig =fälter idf affes in Den geograpfit $=$ folsen Büdfern fand oder je wilder in Den fifforifonen: Defto fäusficter und bequemer wurbe mir. Nody fommt mir bie altnorbifife bejofidyte wie meine Rinbfyeit vor, aber Die grie=

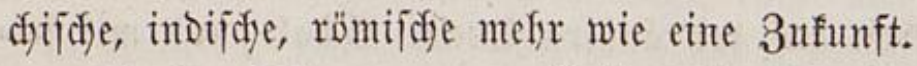

In Der Dämmerung verflatterte Das Sdneegeftzber, nnd aus Dem reinen Simmel Griţte Der Nond Durdy Das Bhumen= gebüfđ Der gefrierenten Fenfter - Sefll flang Drauken in Der fitrengen $2 u f t$ Das Xfbendläutent unter Den aufgebäumten Rautchfäulen - Unjere Seute famen Sände=reibend aus Demt (5arten, wo fie die Bäume und Bientenftöcfe in Stroly einge= fraut fatten - Die Salifner wurben in bie Stube getrieben, weif fie im Raudhe mefre (Eier Yegen - Das Rid)t murbe ges fpart, weil man ängftlich auf Den Bater forrete - Jd) und

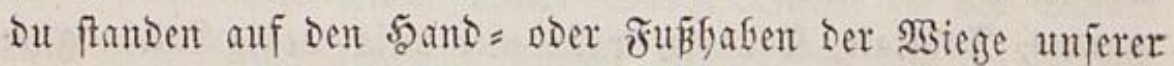
fer. Sdymefter, und unter Dent heftigften Sdymfeln Görten wir 


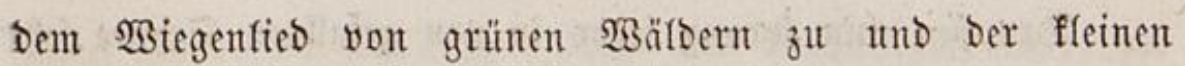
Secle thaten fich thauffimmernde Räume auf - Enolid) fifritt Der gevlagte Maun über ben Eteg, bereift und be: fabent, und eff er nod) Den Suerfact abgefjoben, ftand feit biffes Ridyt auf Dem Tija, fein bümnes. Weldye herrlidje Radjridyten, (Sjelder uno Sadyen fradyt' er mit uno feine eigne freube!"

"Wer bezweifelt jeine Entzücfung weniger als ids), Den er barin allemal auspringelte, blos weil id) aud mit entzülft fern wolfte, und Daburd), fpringento und tanjent, Den Rärm erregte, Den er in fiffler $\Omega_{u f}$ am meiften verfluchte; fo wie

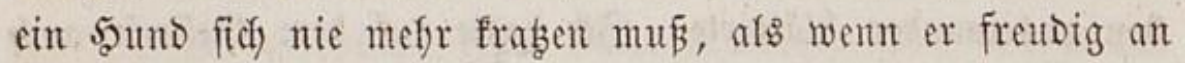
feinem bernt aufipringt."

"Sdjerze nidjt! Uno bedente, was or 1 ths mitfradite; (id) weiß es aber nidyt melyr - mir einen für mein (5ield ge= fauften Bogen Sonzeptpapier, wowon idy Damals nidyt Denfen fonnte, Daß̃ jo etwas breites, nettes nidyt mefyr fofte als zwei Bfentige. - Für die Sdywefter cin $2(b c=B$ ud ) mit (sold $=$ Budfftaben fojon auf Der äuñern Decfel= Schale und mit fri= fothen fautern Thier=Bitbern im Bergleid) gegen unje af: gegriffenen alten."

"Sd)ieß̄pufver, nls Digeftiopulver für Das Sdfwein, wo= yon bie wenigen Sörndyen, Die idf zufammenfefrte, mir Geffere Feuerwerfe auf einen Span befdeerten als ingend eintem $\Omega$ ï= nig ein Dreiß̧igjä̧riger frrieg." -

"Das befte war wol Der neue fintender. (5s war mir, als fielt' id bie 3ufunft in Der Şand, wie cinen Baum yoll

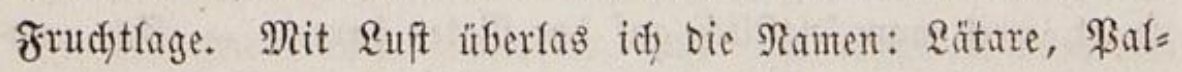
marum, Subilate, Santate, wobei mir mein wenig \&atein gute Dienfte tfat. Die Epipfanias waren mir verorießsfidy, bejon= 
Ders zu viele; fingegen ie mefrere Irinitatis=Sonntage fielen, Defto länger grüne, Dadht’ idf, Die frendenreiche Beit. \&ächer= Iidf fommt es mir vor, Dara, eben Da idj finten im Sinfender

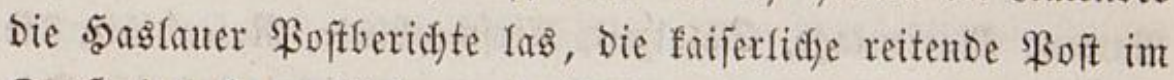
Dorfe ins Soon ftié, und idy Den guten Menjichen bewun= Derte und fredauterte, Der nun, laut Dem Beridfte, mitten im Binter affein nad) ganz $\mathfrak{B}$ ommern, Breuken, Bolent uno $\Re u \tilde{B}=$

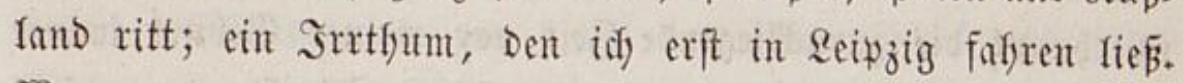
Bem nut Darauf Der Sandidat Sijomafer zum Effen fam 14no wir vom Bater mantife Sifforien mit \$ergnügen zunt zefontenumal förten - went Du nach) Dem (E)en auf einer Span = Bieige aus gewidfitem 3wirnfaden frabteft - und ids cinen glimmenten Sdyleupen= Span zu einem fenerrad um= fdiwang - und idf titto bu uno Der lange Sined)t, Der mir Damals, wie Den Sindern vielfeidst alle gewofnnte (s)fidfter,

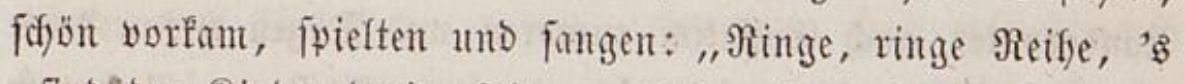
"finto Der Rinder Dreie, Sigen auf Dem 5ofberbuja), Sofreient

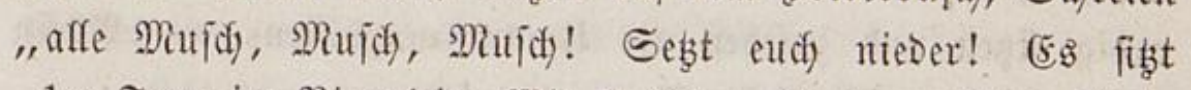
"'ne Frau im Ringelein, Mit 7 fleinen Rinbern. $\mathfrak{W a s}$ effen's "gern? Fijchelein. WBas trinfen's gern? Rotfen Wein. "Sekst eudif nieder!" - Imuig erfreutet las idj neulidy in (5räters Bragur Das einfältige Sinderding — Id) muß aber meinen Sabs ganz anders angefangen fraben." -

"Rummefyr ift ex gefdylofien. Das \&eben fängt, wie Das griedjiciche Drama, mit \$olfen an. Beginn', elf' Du erwachit, Deinen veriprodyenen Sommertag."

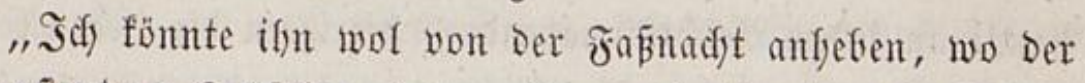
neu erftandene grilfying lauter Somenftralen in bie Sdyul= ftube voll fleiner gepubzter Tänzer ftreuet, fo Daß es in Den Seelen früfer briffte als in Den Grärten. Sdjon Der alte 


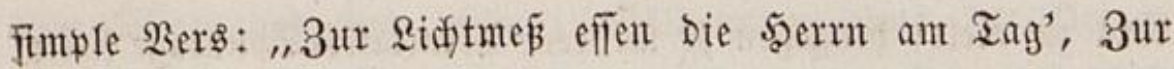

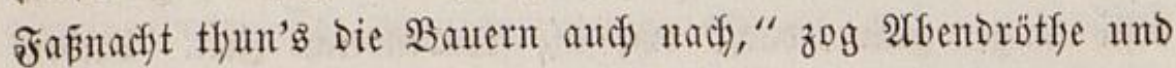

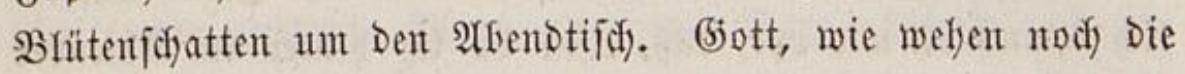

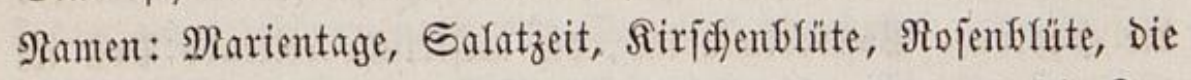
Bruft volf 3auberduft! - So Denf' id mir aud bie Su= gend meines Baters blos als einen umunterbrodyenen Gommer, Gejonders in Der Frembe; fo wie idi) meinen (5rof́bater und überfaupt Die gurücfliegende 3 eit vor meiner Beburt immer jung uno blüfend feffe. Da gab's fodsüe Menjojentage, jagt

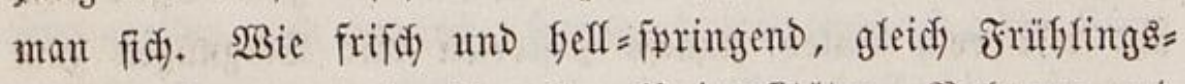
bäcfen, fommen mir bie alten Univerfitäten, Bologna und ßadua, yor mit ifren ungeme midh oft in biefe fincin!"

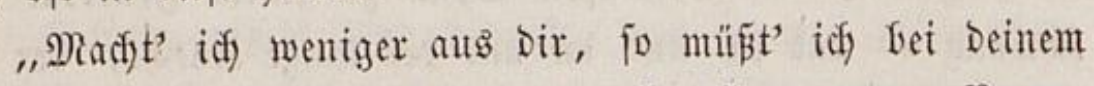
$\mathfrak{B}$ unf Ranbesvater, aud (5a)

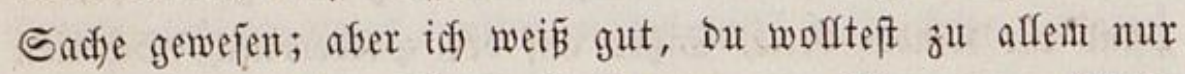
ruffig fibsen uno zufelyen als Rector magnificus. - Itfein gib num Deinen beutigen Sommertag!"

"(ธ夕) war Das h. Dreifaltigfeitsfét, und fwar Das jenter SBodje, worit bu auf und bavon gingeft. Sur vorfer laffe midi nod) bemerfen, Dẩ mir beine erwäfnten Studenten= Wörter theils neu flingen, theilg rof). Ân diejem h. Jefte mun, Das mit Redyt in Die fdoünfte Safyregzeit fällt, gingent,

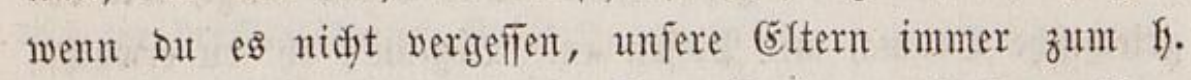
צtbendmafl. (5ierabe an jentem Sontabend - wie Denn über= f)aupt an jebem Beidftionnabend - bezeigten Die lieben EEItern fich nod) gütiger und gefpräd)iger gegen uns ßinder als fonft; (5iott aber fdjenfe ifjnen in Diejer Stunte Die Freitde, bie mir jebtat in ifrem 2tngedenfen Das 5erz Durdfwalft! Die Mutter 


\section{1}

Yié̉ vieles im Stall Durdi Rente bejorgen und betete aus bem

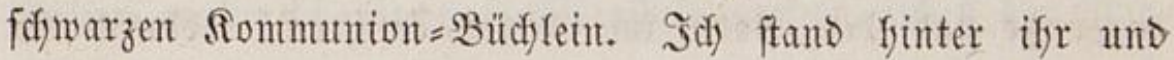
Getete unberwubst mit herunter, blos weil idf) Das Blatt um= fefyrte, wenn fie es herab fratte. Die Bauternftube war fo

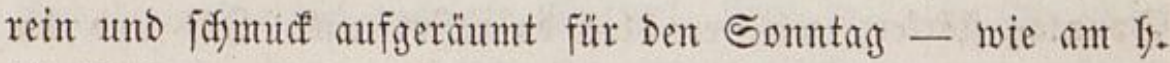
(5f)rifabend war es am Beidytabend - aber foüner und

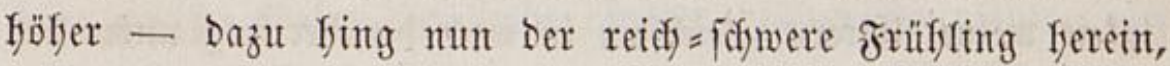
und Der Blütengerud fog Durdy Das ganze 5ants und jeden

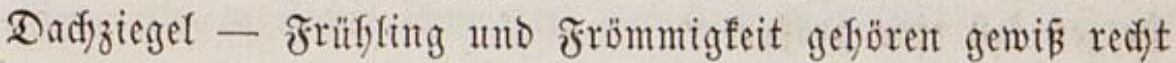

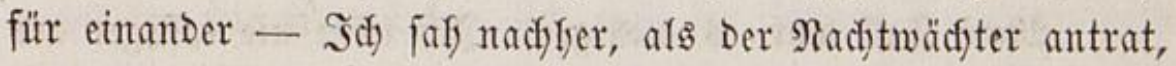
nod) ein wentig aus Dem Dadffenfter, voll Düfte uno Stente war ber simmel über Dem Dorfe - Die Benerafin ging fo fpät nod) mit iffrem Sinte aut Der 5anto auf Dem Sdylo $=$ wall fpazieren, und das ganze Dorf wuß̄te, Daß̃ fie morgen

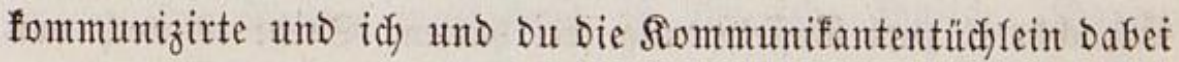

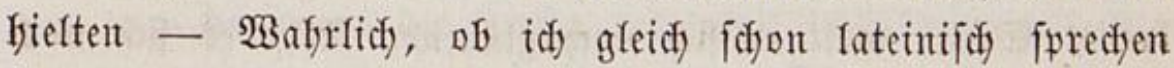
fonte, bie weírgefleidete Bieneralin fam mir als bie Mutter (5ottes vor, und Das Sind als iffr Sinto."

"Sat benn bie Generalin einen Soln?"

Balt fagte verlegent: "idid) ftellte mir nämlidy ifre $D \mathfrak{a}=$ malige Iodfter fo vor in ser Ferne. Sdh mödte jebt nods.

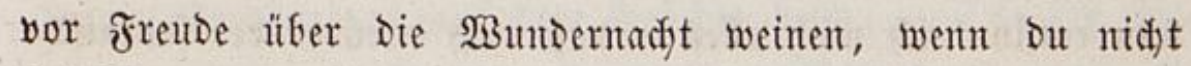
Iadteft ....."

"So weine zum Şenfer! Wer lacht Denn, Satan, went cinmal cin Menfid Die 2ufuridytigfeit in \$erjon ift?"

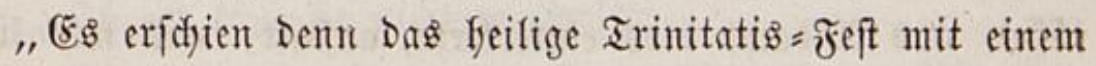
Glauen Morgen volf 2 ercfen und Birfentoüte; und als id aนs Dem Bodenfenfter Dieje Bläte über das ganze Dorf aus= gefpannt erblifte, murbe mir nidyt, wie fonft an fojönen $\mathfrak{T} a=$ gen, beflommen, fondern faft wie iaudjzent. Unten fano ids 
Die Mutter, Die fonft mur in Die Radjmittagsfirdye ging, fodon

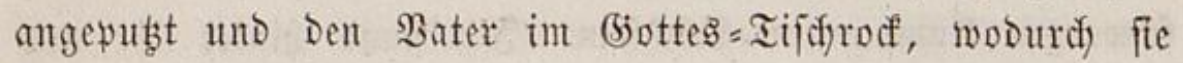
mir, zumal ba fie unjer Sonntags=23armbier nidyt mittranfen, fefre efrwürdig eridjienen. Den Bater fiebt' idf ofyefin am Somutag ftärfer, weil er blos da rafirt war. Sdy und Dut

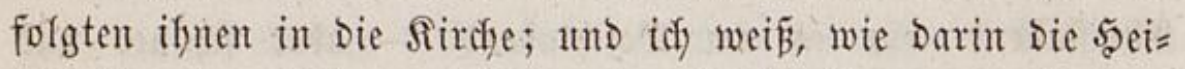
Yigfeit meiner (E) Itern gfeidffam in midy herïber zog unter Der ganzen Fredigt; eine frembe wirb in einem blutsverwanden 5erzen faft eine größ̈ere."

"Mein fall war es weniger. Sd lebte nie fuftiger als

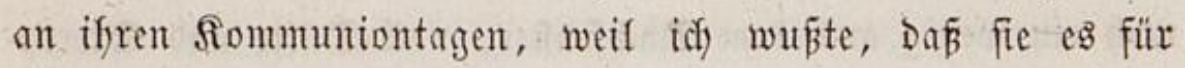
Sünde fielten, mid) früfer als vor Sonnenuntergang auşzt=

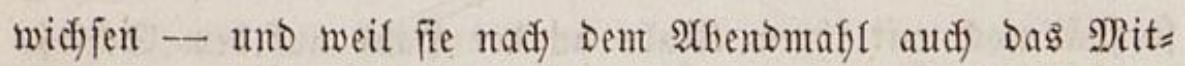
tagsmafyl bei Dem Pfarrer nafymen, uno wir folglidy Das Sdjachbrett zum Röffelfprung frei hatten. Steft es nodh vor Deiner Seele, malt es fich nody glüflento, färbt es fidf noch

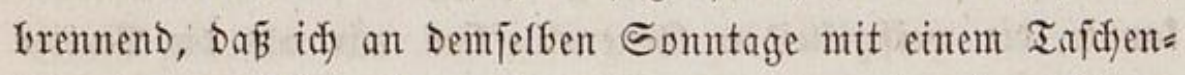
fpiegel vom Efyore herab Den Sonnenglanz wie einen Hara= Diešvogel burdh Die ganze Sitrdfe, uno fogar um Die zugebrüf=

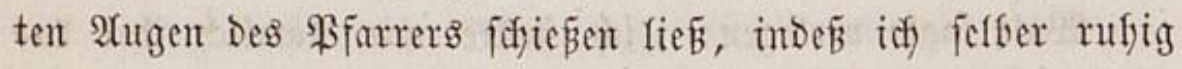
mit nadyfafy und nadyplirte? Uno gedenfit du nodj - Dent

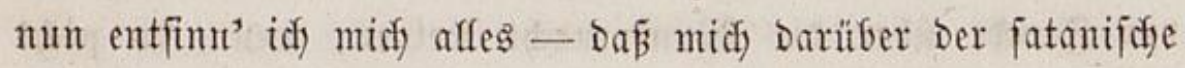
Sambibat erwifidte, uno ber Bater nady Der Rirdfe mid) nady Der peinlidyen Salsgerid)ts = Dromung von Rarl, Die (im Art. 113) (biefangenfid)aft mit Bejen = Streidjen Yeidft vertaufdent

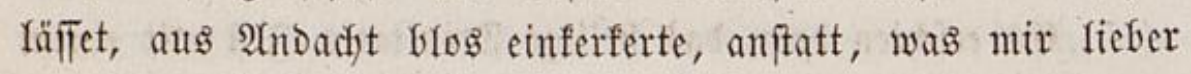
gewejen, midy balb toot zu folfagen?"

"Du fieltept aber Demnody in Der Rirche Das rechte Artar= tüchlein bei Der Solate unter Den Rommunifanten auf und if Das linfe beim Refdh. (ङs foll nie von mir vergeffen werben, 
wie Demütfig und rüfyrent mir unjer blaffer $\mathfrak{B}$ ater auf feinen

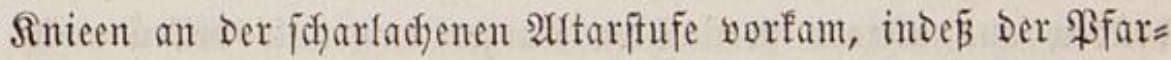
rer iffm fefre fidreiend Den goldnen fieldy vorfielt. 2(d) wie

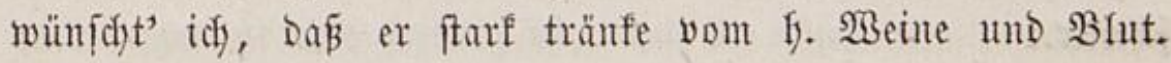
Und Dann Die tief geneigte Nutter! SBie war idif ifr unter Dem arinfen fo rein=gut! Die Sindfeit fennt nur unjouls Dige weífe Rojen Der Riebe, fpäter blüfen fie rötfer, uno yoll Sdyamröthe. Borfyer aber trat bie majeftätifiche lange (5)eneratin in ifrem fofwarzen und Dod) glänzenten Seidenge= wano an bie $\mathfrak{X}$ (tarftufe, fid) uno Die langen Augenwimpern fenfend wie vor einem (5ott, und bie ganze Sirdye flang mit ifyen Tönen Drein in Die andädytige (5iegenwart Diejer iDenlen Sgerzogin für 111 s alle im Dorf."

"Die Todyter foll iffr fo äfnulid) fefyen, Balt?"

"Die Mutter wenigftens ift iffr fefrr äfnlidy. Darauf

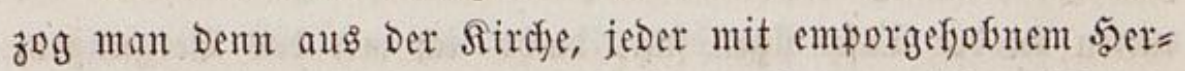
zen - Die Srgel fpielte in fefre holen Tönen, Die midy als Rind ftets in felle frembe baimmel boben - und Drauken batte fid Der blaue Aetfer ordentlidy tief ins Eonntaggoorf fineingelagert und vom Thurme wurbe Saudfzen in Dent Tag Jerab geblafen - Seber firrdgänger trug Die sूoffmung eines Iangen Freudentagg auf Dem (befichte heim - Die fich wie= gende facfirte Rutiche Der (Seneralin raflelte Durdy uns alfe Durd, nette, reide Bebienten jwrangen Gerab - Ueberfaupt wäre mur nadjher nidft Die Sadje mit Dir gemejen - -"

"3u oft fäue fie nidyt wieber!“

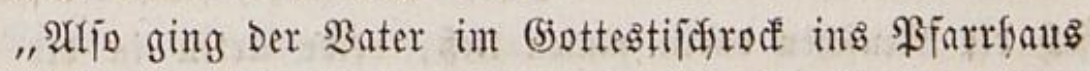
und finter ifm Die \$hutter. Und als idy, Da fie abgegeffen

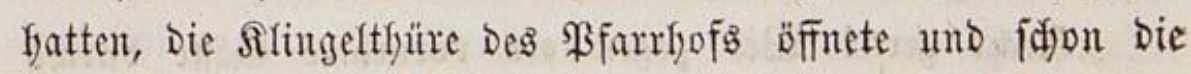
Irutfüfyner Deflelfen mit $\mathfrak{A} d$ fung faff:“ 


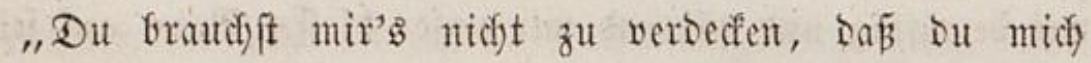
Drüben aus meiner berfludjten Sirzerfanmer losbitten woll=

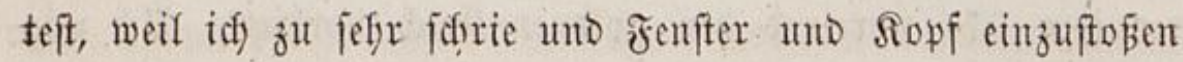
(i)wur."

"Die Bitte half wenig Geim Bater; viefleidft weil Der Sfarrer fagte, Du bätteft ifn zu fefr beleidigt und geblentet.

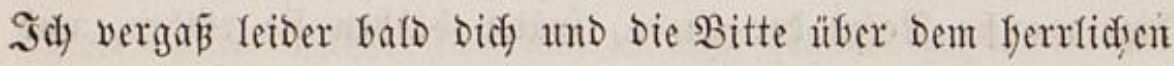
füBen $\mathfrak{B}$ ein, Den idj tranf. SUf Dem \&ande hat man zu we=

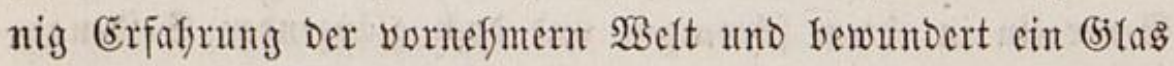

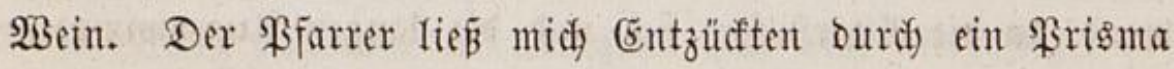
fdjauen und gleidjam jedes einzelne Stülf 2 elt - mit einer

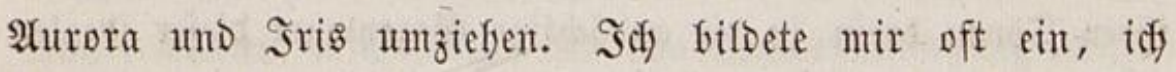
fömte wol, da ich) fo viel (sefüfll für Nalerei, fogar für ฐar= ben an Edyadfteln, 3widfeln, Biegelfeinen zeigte, faft mefrr zum Maler taugen, als idy Dädyte. Da idj meinen Water tief unten an Der Tafel fibert faff, Dadyt' idf mir Das Bergnügen, ify einft jeffr auszuzeidynen, fafls id) ctwas würde."

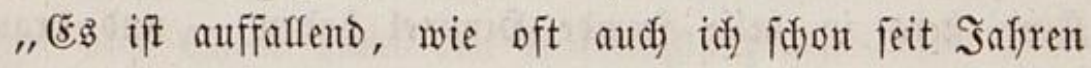
gejdyoren, midy meiner 5erfunft zu entfinnen, went id im Publifum bedeutend in bie 5äbe und Diffe müd) le, und midh weder Deiner nod) Der (E)ltern fu föämen. San fun faft nidgt frilf gentug anfangen, fid bejdeiden zu gewöfnen, weil man nidft weik, wie unendfid) vief man nod) wirb am (Ende. Siebe für garben, wovon du fpradjft, ift Darum nod feine für Zeidfunng; inzwifdyen fannft bu immer, wenn bie eine

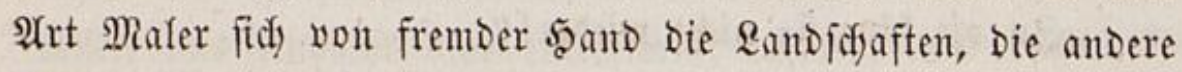

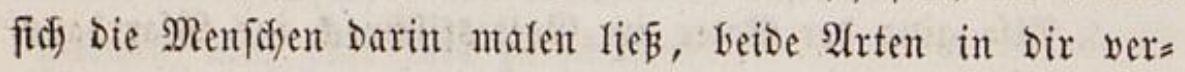
einen. Bergib Den Spap!"“

"Redft gern! WBir zogen als vornefime (5äfte burdjs Dorf nady Sauje, wo Der Dater bie Sdjarladjwefte anlegte 


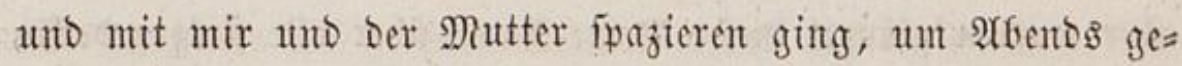

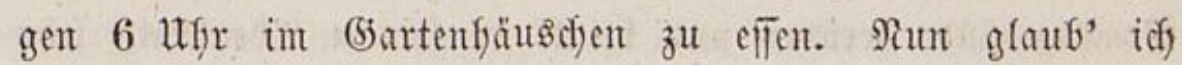

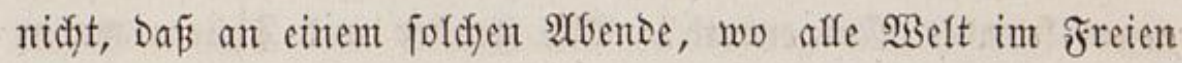
und angepubst und frendig iff, und bie (5ieneraliu und andere Bornefme mit roty jeionen Sonnentidymen fpazieren gefjen, irgent ein 5erz, wenn es zumal in eincm Bruber foflägt, es ertragen fann, Dab́ Du allein im Serfer haufeft."

"Saferment!" jagte Bult.

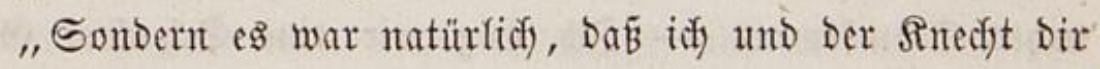
eiue Dadjleiter ants Jenfter febsten, Damit Du ferunter fömnteft

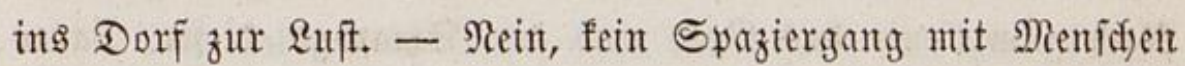
ift fo fibön als Der eines Rindes mit Den Eftern. WBir gin= gen Durdy Gobe grüne formfelder, worin idy bie Sdyefter

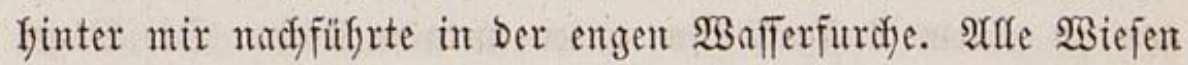

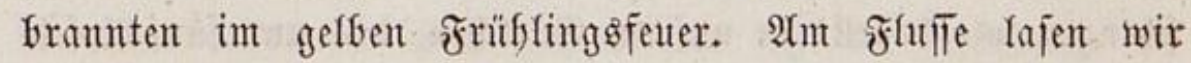
ausgejpulte Mujdyeln wegen ifres Sdyillerglanzes auf. Das

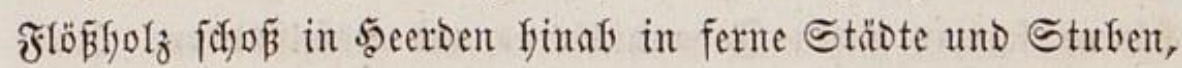
uno id) fyätte midy gern auf cin Sdyeit geifellt und wäre mit=

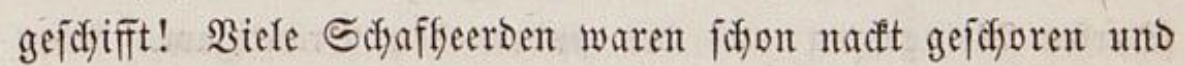

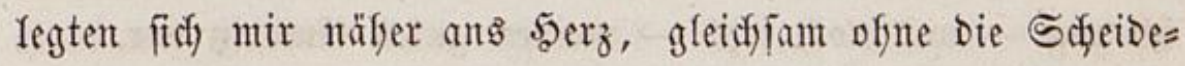

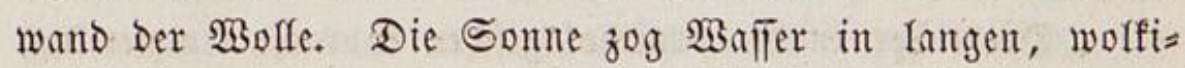
gen Etralen, aber mir fam eg vor, als jei bie Eroe mit (SIanzbändern an Die Somne gefangen und wiege fidf an ifjr.

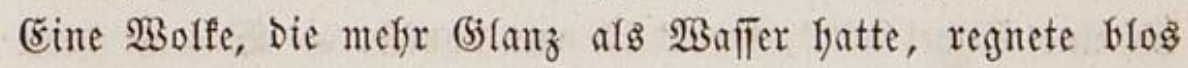
neben, nidyt auf uns; idh) begriff aber Damals gar nidjt, als

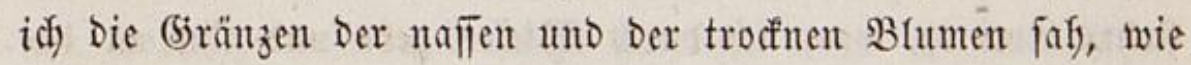
ein Regen nidht allezeit über Die ganze (řrde falle. Die Bäume neigten fich gegen einander, alg Die Wolfe tropfend Darüber

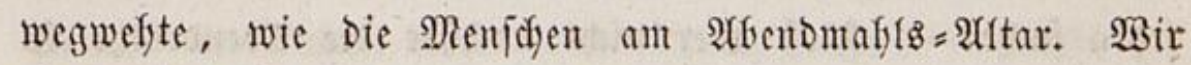
gingen ins Gartentgaus, Das innen uno auвen nur weiz iff; 
aber warum glänzet biejer fleine Name üleer alfe ftorz gebefte Fradjtgebäube berüber und blinft in feinem axbenorotf) fefr gegen frembes Niorgenroth? 2ufe fenfter und Ifüren waren aufgemadyt — Sonne und Mond fafjen zugleidf fincin Die rothweißen Aepfelfnospen wurben von iffen ftarren, ftrups

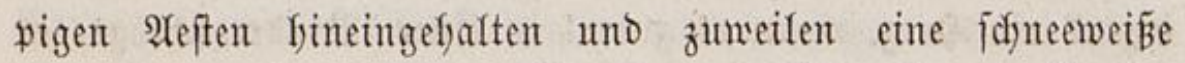
Aepfelflüte mit (o $\mathfrak{B u l t}$, id) gete Den $\mathfrak{A}$ pel für bie $\mathfrak{A}$ epfel= Glüte gern) - Die Bienen gaben Dem Bater Beidfen einę̧ nafen Sdywärments - Idh fintg mir eine Sdjadytel (5old: fäfer, für weldye idf Den 3 ucfer längit aufgeiparet fratte Nod) glänzt mir Das (jold und Der Smarago Diejer ßara= Dieşvögeldyen fienteden, in Deutfid)land meint' idf - 2 (uch) zog id) mir im (sarten Sijößlinge aus, um fie Dabeim anzupfan=

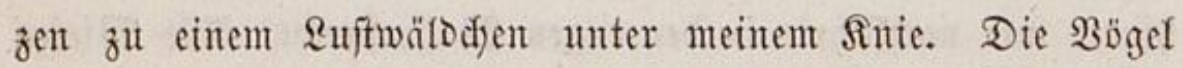
fdhlugen wie beftellt in unferm (3ärtdjen, Das nur fünf $\mathfrak{X}$ pfel= bäume uno zwei Riridbäume fratte uno mefrere Pflaumen= Fäume fammt guten Sofannisbeer = und 5ajelftauden. 3wet Finfen fidlugen, und Der Bater fagte, Der eine finge Den fdarfen $\mathfrak{B}$ eingefang und Der andere Den Bräutigam. AGer id) zog - uno nod) jeb̧t - meinen guten (Emfrib vor."

"Deutfict)ęr in Der ornitfologif(c)en Sprache (Emmerfing, "Boldammer, (5röning, Gelfling, Beelgerft, Emberiza citri"nella L." - , "weldher, wie Die E̋Itern fagten, fang: went

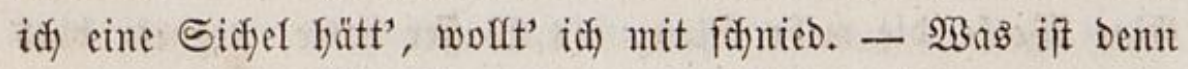
Das Dunfle im Nenjalen= Snnern, Daß id wirfid) Den ein=

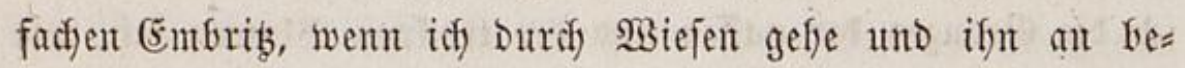

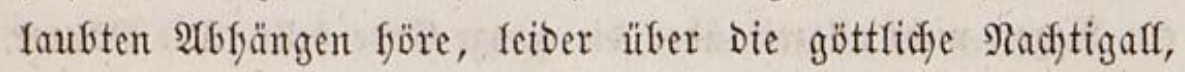
Die freifid) wentig rein Durdffüfrt, fondern beftig fwringt, zut

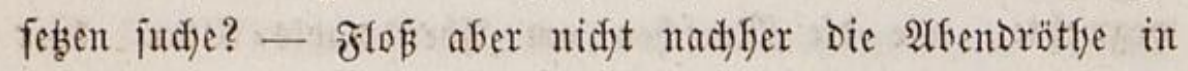
Dent ganzen Garten finein und färbte alle 3 weige? Ram fie 
mir nidft wie ein goloner Sonnentempel mit vielen Ifyüment und Wfeilern vor? Und gingen nicht auf Den $\mathfrak{B}$ ?olfenbergen Die Sterndyen wie Maienblümchen auf? - uno bie freite Eroe war ein $\mathfrak{B e f i f u h l}$ rofenrother Träume? Hno als wir fpät nadh Sauje wandelten, fingen nidyt in Den finftern

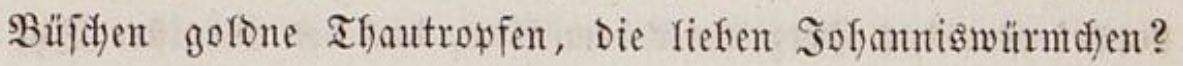
Und fandent wir nidyt im Dorfe ein ganz Gejonderes fefteflen, fogar bie fleinen ieflirten endicich im Sonntagswuls, und Dem $\mathfrak{B}$ irtfyghaufe feflte nidyts als Mufif, und auf Dem Sdylofie wurbe gejungen?"

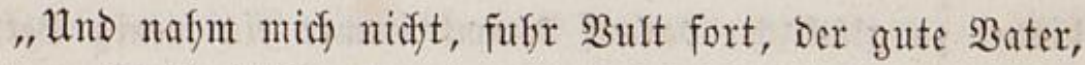
als er midh in Diejer freude als Theiffaber fand, leife bet Den 5 aaren mit nach 5auje und prügelte midy fo verfludyt? D Daß́ Dod) Der Teufel alle Erzieffungen folte, fo wie er fel= ber feine erfyalten! $\mathfrak{B e r}$ nimmt mir jebst Die Feftprïgel ab uno Den Rarzer? Du fammft Didy leidyt ferffellen und ent= finment und vergnügt auß̧er Dir fern und die Repetirufyr Der

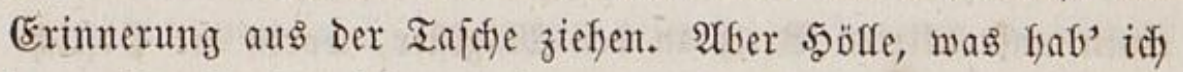
Denn fojmelzeno midi fut erinnern als an bie faupige Aurora eines aufgefyenden Edywanzfterns? D wie glüfflid), glüiflid fönnte man ein Sind machen! Dieß probire aber cinmal ciner bei einem greifen Sdyelm won 40 Jafjren! Esin einziger

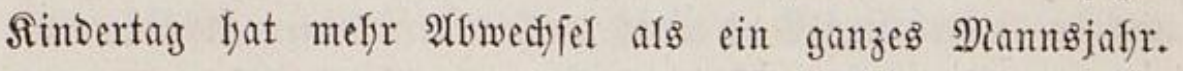
Sief' an, wie er midy, wenn das füf)ne Bild zu gebrauchen ift, aus einem zarten weiken Rinosgeficht fo zu einem brau= nen Sopfe geraudyt und erfibzt flat, wie einen \$ffeifenfopf! -

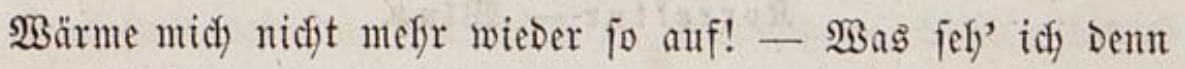

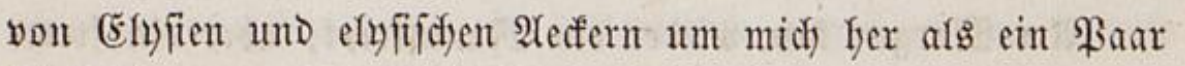
Sefiel? - unfern Bett = und Stubenforirm? - nidfts zu trinfen? - Didf guten Millionär blos voll immerer (bedäd), 


\section{8}

nißßmünzen? - uno einen förzernen Siłg Der Seligen? S id) mödyte... Sge Gerein mux! Biefleidyt bringt uns Dodh, Wart, ein 5immelsbürger eit oder ein $\mathfrak{B a r} 5$ simmelspforten uno (ร)mpräen."

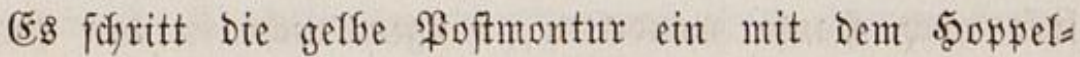
poppel ober Das \$acrz unter Dem $\mathfrak{X}$ rm, Das Der Magiffer Dyf mit Den Borten zurücfichiffte, er vertege zwar gern Rabener=

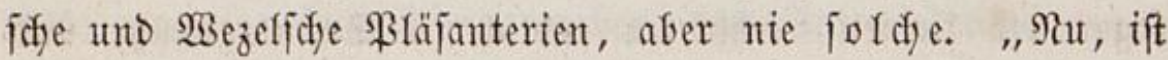
Das fein Somentiliff aus unjerm Frendenfimmel?" fragte

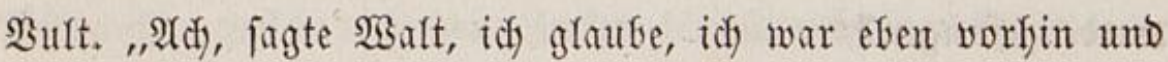
bisfer zu glüffidy; Darauf fommt immer ein wentg Betrïlb=

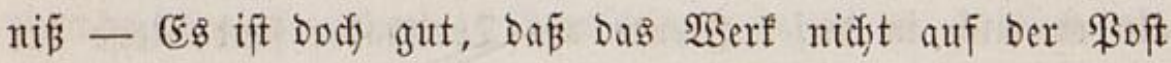
fin und fer verloren gegantgen." - „D bu weidhes - $50 l_{z}$ !

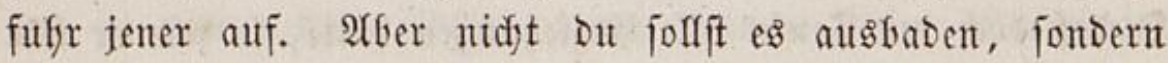
ber Magifter. Sal will ify wajdyen mit Seewajper, ob's gleid) nidyt meí̄ madjt."

(Er febzte fid auf Der Stefle nieder und fadrieb im (5rimm

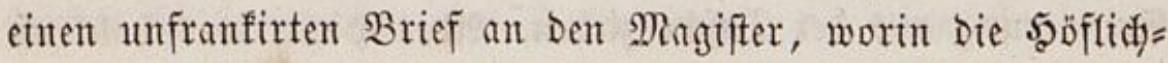
feit bes Briefityls fo gut als ganz fintan geję̧t war.

No. 59. $\Re \mathfrak{v} \pm \mathfrak{e} \mathfrak{n} \mathfrak{d} \mathfrak{n} \in \mathfrak{f}$ e.

Rorreftur - SBina.

Am Morgen fom wieder cin Manuff́tipt, aber ein frem=

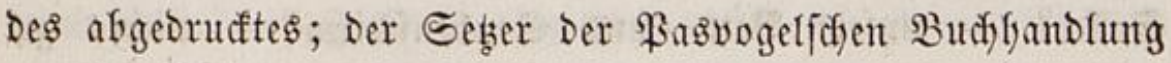
- für $\mathfrak{W}_{\text {alt }}$ war ein Seb̧er viel - bändigte den erften fior= 


\section{9}

refturbogen ein, Damit Der Univerjaferbe Der Rabelichen Ber= Ia Deflen Titel war: Das gelefyrte 5aglau alphabetifich georonet

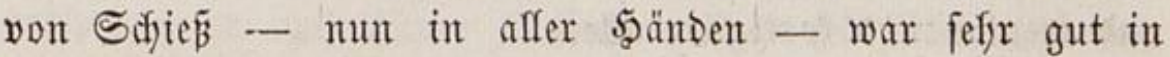
Deutifjer Spradje mit lateinifdyen Rettern gefdrrieben, nur aber

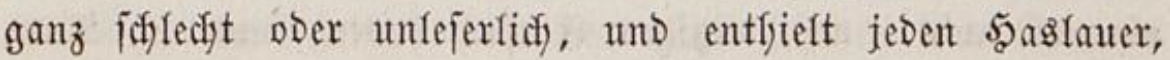
Der mefrr als eine Seite, näm(id) żvei, D. f. cin Blatt für Strape und Selt gemadjt, fammt einem furzen Nadftrag von Den Rambs=(belefirten, Die fodon als Sinder verfitorben. Wenn man zäfit, weldye Menge von Autoren zifenfdyer aus jei= nem gelefrten $\mathfrak{B}$ aireuth blog Dadurdi finaus fpert, Daß

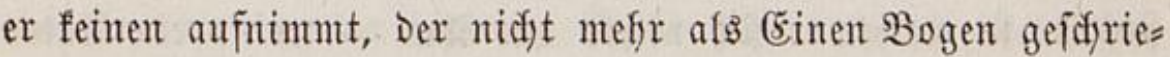
ben - jogar zwei reidhen nadh Der Borrebe nidgt hin, wenn's

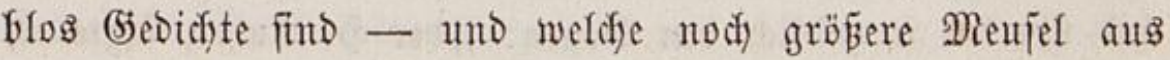

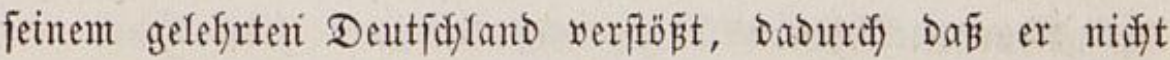

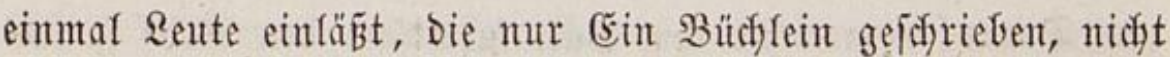
aber zwei: fo follte mol jeber wünjon, in sablat geforen zut fernt blos um in bas georucte gelefrte zu fommen, Da Sdjế

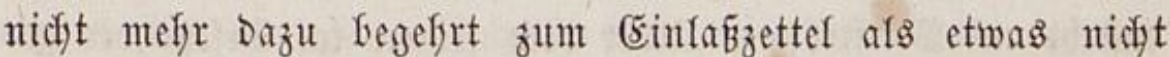
größeres, als Der Bettel ift, nur ein gebructes Blatt; Denu fici) mit nodf wenigerem in einen foldfen (5f)arons = Sabn, Der fets zur Uniferbfidfét Des (Ëbens entweder, oder Des Tarta= rus abfüfrt, einjochiffen wollen, bieß̄e ja Sdyriftifelfer einlaben, Die ganz und gar nidjts geidurieben.

Der Notar fing fofort Das forreftiren an - in Die Sorrefturzeidyen fratt' er fich längft cingeidyolien -; aber er

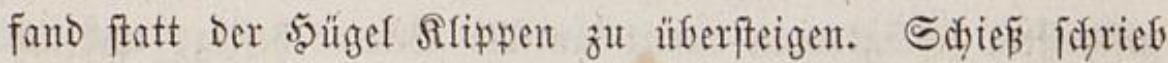
eine geleffrte 5and und eine ungelefrte zutgleidf; Der Sorref= turbogen war aus Titeln, Namen, Jafreszafilen und polchent Sachen gewebt, Die nirgents zufammentyängen als in (sott. 


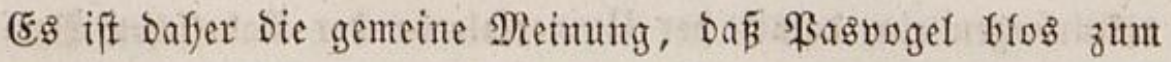
Druffe Des Rotars Den Druct Des $\mathfrak{B}$ erfes eingegangen. Bult wollte zwar beflern fyelfent, aber $\mathfrak{B a l t}$ fand frembe 5 zullfe gott= und treulos und forrigirte allein.

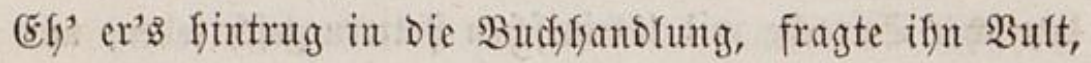
ob man nidyt einen wibigen (Einfall haben, und er, Bult,

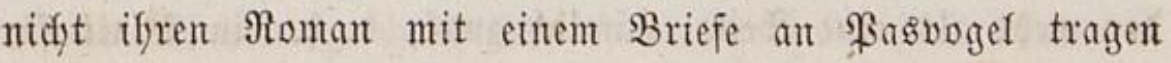
fönnte, worin er fich als Den Berfaffer auggäbe und fagte, Der Ëndes Unterfdjriebene ftefe Dem Rejer eben yor ber Raje. (5: gejd)af). Beide trafen zufällig einander im Budfladent.

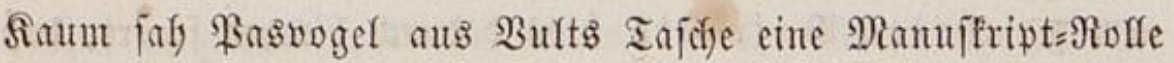
ftedjen: fo madyte er fich nidyts aus ifjm - weil's ein 2Autor

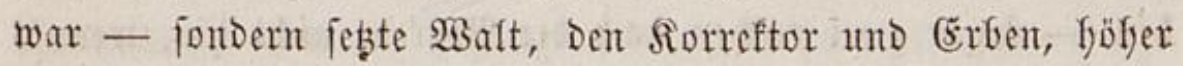
und überlas freundich Den Bogent: "Der 5 . 2 2 utor, fagte er, wird fidon nachjeffen."

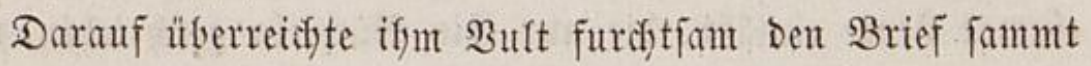
Roman unt jaf fegierig in jeine lejende Pryfitognomie, wie fie fich bei Der Stefle umiezzen würbe, wo Der Briefidrreiber Daftefyt als sriefträger. After Dem feinen im (bejebe Der ge= fefligen Stätigfeit rebenten Manme that Der $\Re i \hat{\beta}$ und 3 ưf wel) auf Der eleganten Saut und er fagte - nach Dem $\mathfrak{H e b e r =}$

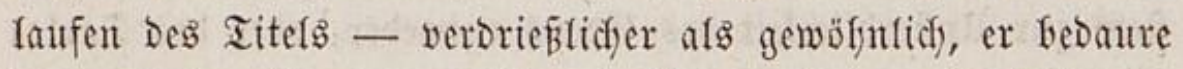
Daß er fodgon überladen jei uno fdjlage fleinere Budffänoler

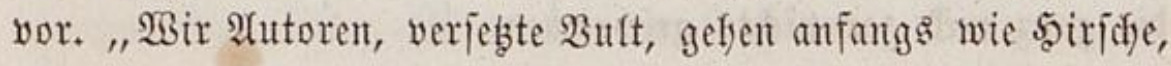
Denen Das zarte (jefyörn erf́t entipriepet, mit gejenftem מaapte;

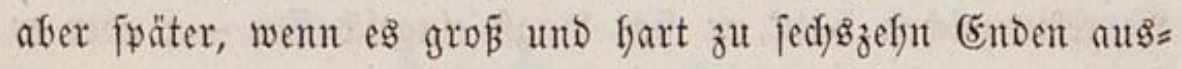

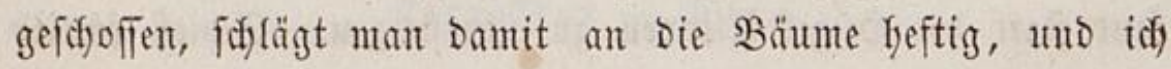

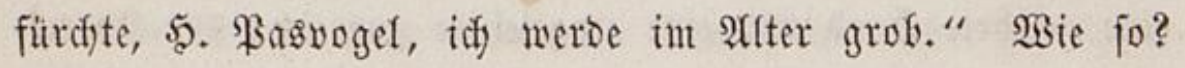
fagte biejer.

Bult that Darauf, als femt er $\mathfrak{B a l t e n}$ von weitem, und 
fagte: went er als Rabelidjer Errbe exfi Den erften Bogen übergeben, fo fochein' es faft, als wollten iffm bie Erben Das

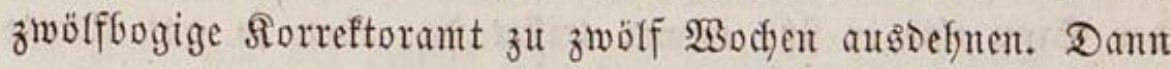
entiprang er nad) feiner bosfonften Sitte plöblidid, um Dem Feinde die Replif zu entwenden.

Beide verliefen Daffeim yor affen Dingen Dem Romane Flügel, weil bie 50 fintung immer fo lange zum Tobtliegenden

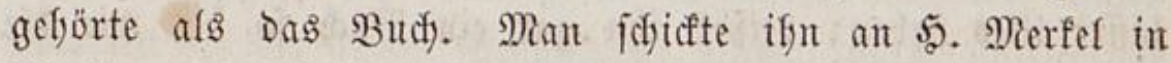
Berlin, Den Brief= uno Schriftifeller, Damit er Das Buch ci= nem ङelefrrten, 52. Rifolai, empfäfle und auffeftete.

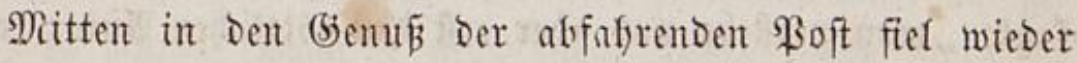
ein Staubregen; Der Ginfende Notar, Der befaunte Befdäfts= träger Der Erben, fam mit Dem erften forrefturlogen unt Schieß̃ens Re=Sorrefturent.

Balt hatte ein und zwanzig Drutfelyer ftefyen lafien.

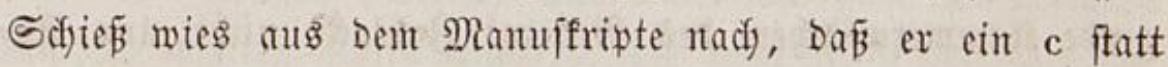
eines e - bann ein o ftatt eines $\mathrm{c}$ - ein $\int$ ftatt eines $\mathrm{s}$ ein $\int$ ftatt eines $f$ - ein Somma ftatt cines Semifolons eine 6 fratt ciner 9 - ein h fatt eines b - ein $\mathrm{n}$ f fatt eines u und umgefefret, Da eben beide umgefefirt waren -

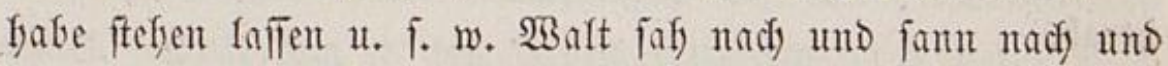
fprad) feufaend: "wol ift's nidyt anders!"

Arme Rorreftoren! wer fhat nod) eurer Mutter=Befifwes rungen und Rindegnothen in irgend einem Budje ermftraft ge=

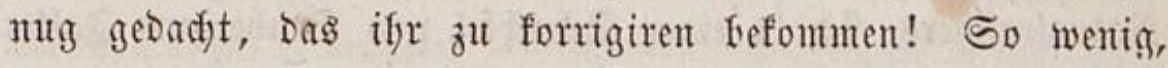

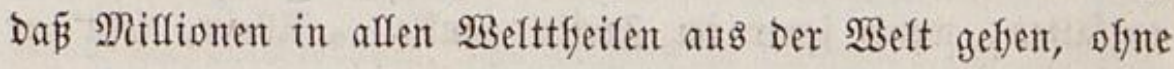
je erfafiren zut haben, was ein Sorreftor ausfteft, id meine nicht ctwa Dant, want er theils fungert, theils friert, theils nidyts fyat als fibende Rebensart, fondern Dann, want er ein Buch) gern lefen mödyte, Das er zmar vor fid) fieft (nod) Dazut 
gweimal, geidstieben unt gebrufft), aber forrigirent foll; bent

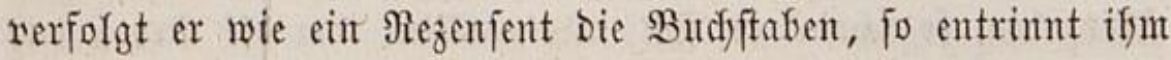
Der Sint und er fibt immer trifter ba; ebent fo gut fönnte einer fid) mit einer $\mathfrak{S B}_{\mathrm{f} f \mathrm{fe}}$, Durdy Deren Dunfftäubden er eine श्ulpe befeigt, Den Durft löjdyen.

Will er aber Sinn genteben, uno fid mit nadjheben: fo

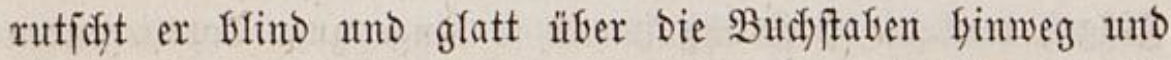

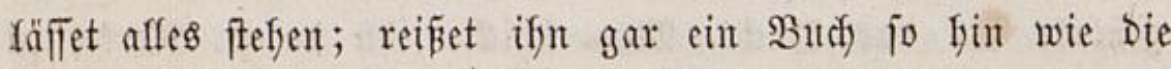

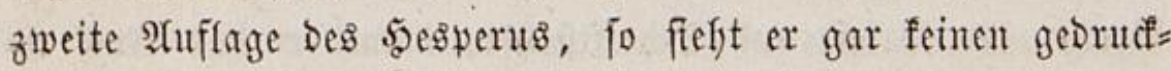
ten $\mathfrak{H}$ finn mefr, fondern nimment ifjn für gejdriebnen uno

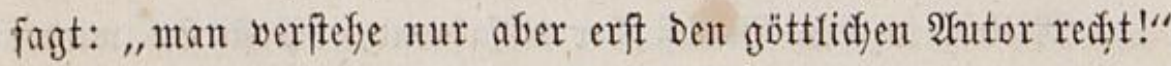
- Ia mird nidft jelber Der Rorreftor Diefer Rage blos aus Antfeil an Dem Antfyeil, Dent idy zeige, fo mandjes über= jefyen? -

Enolidy bradjte bas fidedyt fprechende und fodjön fins gente Rammermäbdyen Des (5eneral Zablocfi nidjt nur $\Re a=$ Whaten ein Briefoden ber Todjter, fonbern audj um eine Ireppe Göher 2 alten bie Frage Des Baters, of er nidjt bie fen ganzen Tag bei ifjum fdreiben fömnte? „D bott, ges

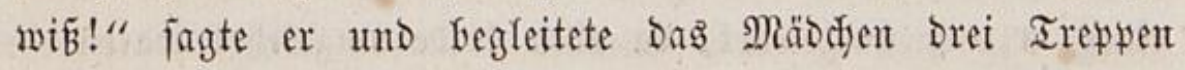
ferab.

Wult Yädjelte ifjn feltfam an und fagte: (Er fopire in mémoires érotiques mit und ofne Feber und jage $\mathfrak{M a b d h e n ; ~}$

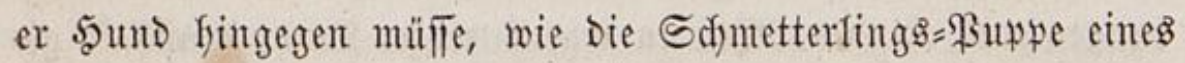
Raturforidyers, fidy in einer Sdjachtel won Stube zum Falter entfaften, went jener im greien gaufle. "ÎAflein, feçat' er Daz̧l, ein (3reifgeier, ein Bafflisf wie idy, hat fo gut jeinen Riebes=\$ipys, als cin ßyönix wie Du." - Walt wurbe fefr

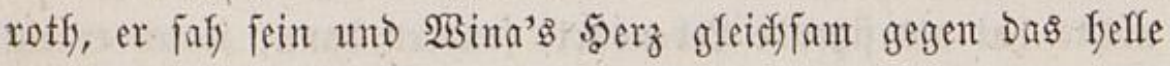
freie Iagsfidft geffalten. "Nu, mu, berfteige bidi mur um 
Drei Trepwen binauf, ober finab; indeß id babeim fyinter meiner arfabijuen Dorfwand ein Madrigal auf Den $\mathcal{S}_{d}$ melz Der $\mathfrak{A}$ uen uno Der 3äfne febze, uno Blumen uno sippen röthe. Das Mäbdjen gefiele mir felber, fie follte efher ein $\mathfrak{B a f l a f t =}$ als ein Rammermäbofyen jernn." Sefjr zornroth erwieberte

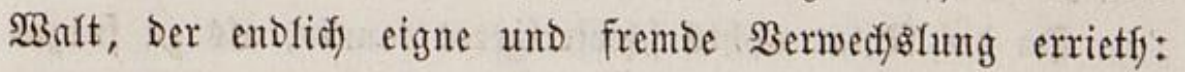
"Du thuft gar nidjt Redjt, Da Du weiṕt, wie mir Diejes Mäbdjen bei ber beften Singitimme einmal Durdy unzientidje Reden aufgefallen."

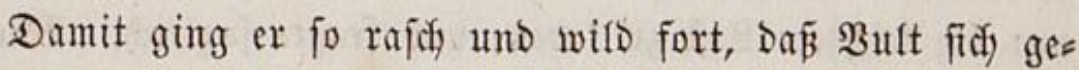
ftant, or würde, wenn er nidyt fidjon früfer Deflen \&iebe für

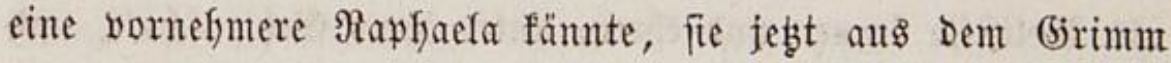

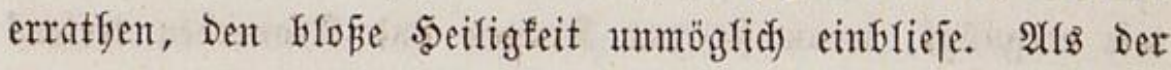
Notar in Den großen 3ablocfifden \$allaft, wovor unb worin viele leere $\mathfrak{S}_{\text {Bagen }}$ ftanden, und unter bie falte Dienerichaft fam: fo wirften Bults Sijerze, Die jeine Riebe entweder wie Sdjiefpulwer unter das Dady, doer wie Del in Den Refler

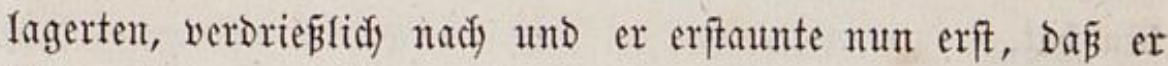
Bina liebe, und ifren Morgenblicf aufbenabre. Sein brhüf Glüfte als eine nafte $\mathfrak{B l u m e n f r o n e ~ a u f ~ e i n e m ~ e n t b l a ̈ t t e r t e n ~}$ Stiel. Spät fam cr nad) ieinem (Erimern an früfeftes $\mathfrak{B o r}=$ fordern in Das alte Sdyreibfüuldyen, und päter Der (5eneral.

"Innigft - jo fpam $23 a l t$, nafe an ifgn tretend die Unterrebung an, unt fire Dem andern nadh Den Biefeben Der

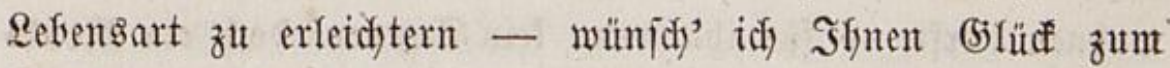

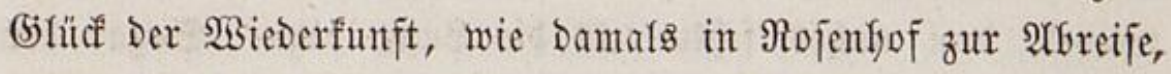
went Sie fidh Dicjer Rleinigfeit nod) entfinmen. Mïg’ Sghen Leipzig ein fortgejebter Spaziergang gewejen feyn!“ — „Sefjr verfunden! (fagte 3 abloffi) Sie verpflidjten midh, went Sie heute die bewuíten Briefe zu Ende fopiren und mir Sean Paul's ausgciv. Werte. XIV. 
Shren Tag weiben." - "Weldfen niḑt? - War $\mathfrak{S h r}$ brei= fad)es (5lüa - verzeifen Sie Die fecfe zrage - nidht, wie iđ fyoffe, Der Salyreszeit ungleid, ?" fragt' er.

"Jür bie jpäte Safrazeit mar Das Wetter gut genug," veriebste 3 ablociti.

Da Der Notar nidfts fdjwierigeres fante, als zu fragen - D. 1). im Dzean zu angeln - nidyts leichteres aber, als zu antworten, weil bie frage Die Antwort umfränzt: fo fielt er es für $\mathfrak{B f l i d j t}$ jebes Unterjpreiners, auf ben Sberipredjer mur bie leidftere $\Omega_{a f t}$ zu laben, und fragte fogleidf. WBie bes quem wohnen Dagegen $\mathfrak{M}$ änter, weldje gerabe Das $\mathfrak{B}$ Bderjpiel als Beltfitte fenten und effren, unter iffer (jefjirnfojale, uno wie vergnügt, went fie vor fronen und fronerben treten!

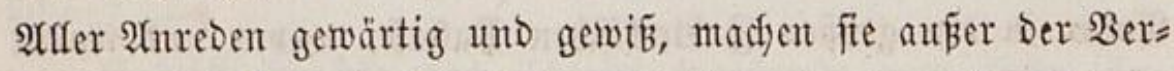
beugung nidjts uno feine eigne, fondern warten af. Sogar

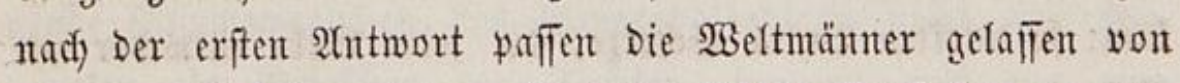
neuem, weil fein anberer als ber gefrönte Ropf fort zut wes ben fyat.

Der Notar madyte Sarauf feine Af(bifyriften von ben ver= liebten 8 ufodriften, aber feine Seele wofnte mit ifjren Füll= fäben nirgents als in Der Sdjneffe Des Solyrs, um jebem Laute Der verborgenen Rebensfeele nadjzufteflen. (Er fodrieb

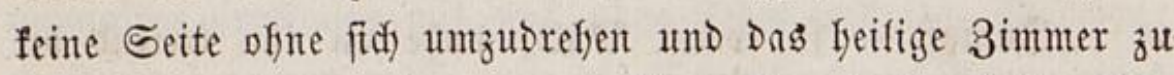
befdjauten - Das er einen ganzen Iag, aber als Den leżten, be= wofnen burfte - für ifn ment fein Sonnen= Dod) ein Nond $=$ tempel, Dem ridfte felfte als Die \&una dazu. Soggr Der blaue Streufand voll Goldand - Das blaumeífe Dintenfá und \$apier - Daz blaue Siegelfact - uno Die Blumenoüfte,

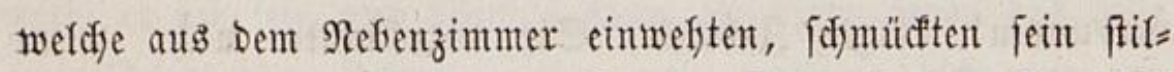
Yes $\mathfrak{A}$ etherfeft Der 5offinung. In Der Riebe ift Das Erntefeft 
Daв́ gerabe zufällig, went er eben in Den Epiegel faf, immer ein warmes (Errötffen Das ganze nieberbficfende Antlił über=

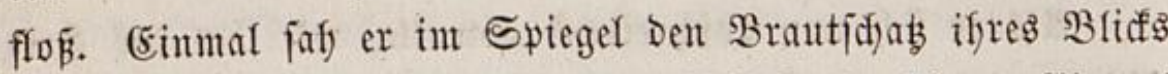
ausgelegt, fie zog feife wieder Den Sofjleier Daritber. Erinmal Da ifyr offres $\mathfrak{A}$ uge Darin wieber Dem jeinigen begegnete,

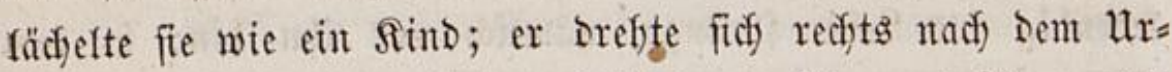

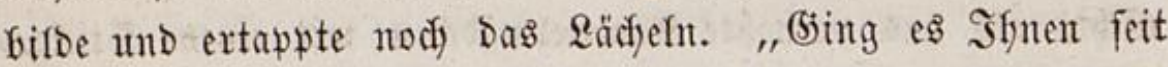
Rojentyof wohl, 52. Faarnijod?" jagte fie leije. "TBie einem Seligen, verjebste er, wie jeb̧t." (Er wollte wol etwas viel anderes feineres jagen; aber bie Biegenwart unterjabb fid Der Bergangenfyeit und teftirte in Deren Rament. Dodh gab er bie శrage zurüaf. "Id) lebte, fagte $\mathfrak{B}$ bina, mit meiner Mutter, Dieß̃ if genug; Leipzig und feine Ruftbarfeiten fen= nen Sie felber." - Diefe fennt freilidy ein Darbender Mijen=

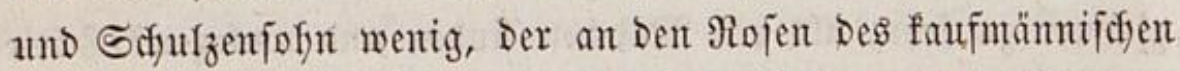
Rofentfals nidjt höfer aufflettert als bis zu Den Dornen, weil er jene nidyt einmal fo oft theift als ein Maurer=Meifter einen füriffichen Saal, zut weldyem Diejer ftets jo fange 3 utritt

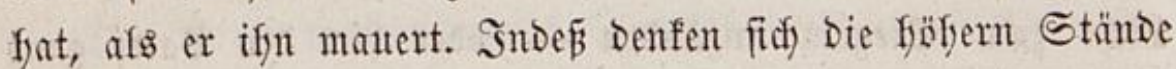
nidjt leidjter fjinab, zu sonorazioren bejonders - Dent von Sdyäfer=, D. F. Bauerfütten baben fie im franzöfific einge=

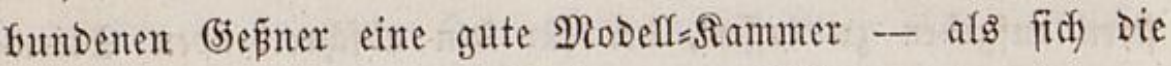
tiefern finauf. "(söttlich ift ba Der früfling, antwortete er,

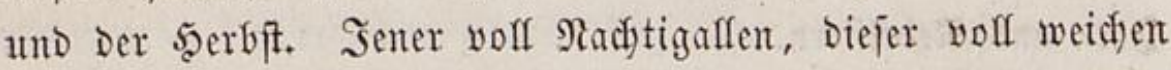
Duft; nur.geffen Der (5iegent Berge ab, weldye nad) meinem

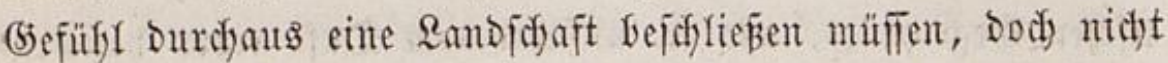
unterfrechen; Denn auf einem Berge felber ift nicht bie 2 and $=$ fod aft, fondern wieber ein fernfter Berg fojön und grob́. Die Reipziger bjegeno enget aljo ein, weil Die Bränze, ober

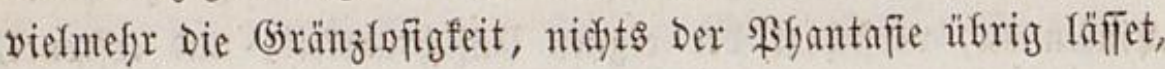


mas, fo viel idy gefört, nidyt einmal bas Meer thut, bas fich am Şorizont in Den Aetfers:5immel auflöfet." - "Sonder= bar, verjebte $\mathfrak{B}$ ina, heftimmt fier bie (5ewofnhyeit Des äunern

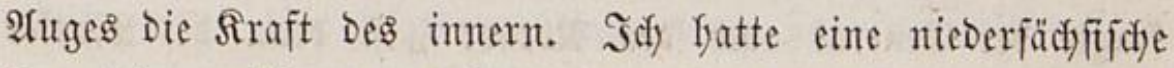
Freundin, weldie zum erfenmale von unjern Bergen eben fo befdränft wurbe, als wir von ifjen (stenen." Der Notarius war über ifre philofopfijge Spradffürze - Da überfoutpt Der $\mathfrak{M a n n}$ an Der fraut gerade fo fefjr jeinen Ropf bewun= Dert, al\& feine Bruft verdammt - fo betroffen, Dá̃ er nidjt wuste, was er fagen follte, fondern etwas anderes jagte. "Befuchten Sie zumeilen bie Babörter um Leipzig, " fragte

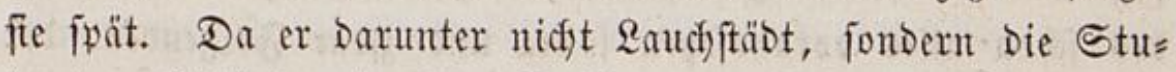
Denten = Babörter in Der \$leífe verfanto, uno eine joldje Frage von weiblichen Sippen zum yornefymen 3ynismus redfnete: fo umging or fie nad) Bermögen in Der Antwort: "Der Leipziger Magiftrat babe zu feiner 3 eit wegen mefrerer

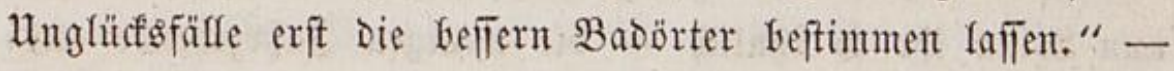

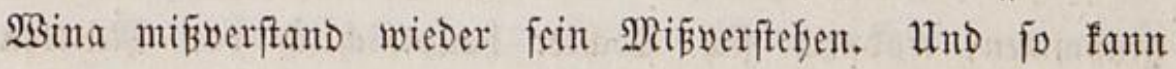
in Deutichland und faft auf ber (Erbe jeber, Der fich ber = fpridft, auf einen zäflen, Der fich verfört; fo wentge Ofiren, ob fie gleidy Dopwelt am fiopfe ftefen, gibt es für bie hie= figen Bungen und man findet nodi) fodwerer ein offenes als ein furzes.

Bloblich forang Der (jeneral wie mit entem veridfimmels ten bleidyen (beficht fyerein aus Dem Suberftïbdyen - mit

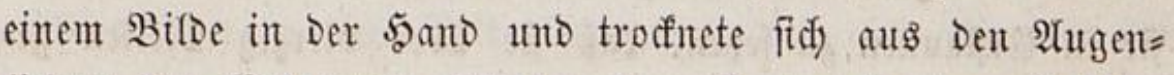
Yiedern Den Buber wie 3äfren ab. "Sage mir, wer ift äbn= licher, Die Putter poer Die Iodster? - Sn Der That redft brav retoudfirt!" Das (5emälde fteflte $\mathfrak{B}$ ina yor, wie fie zu einem ifyr äfnlidfen Tödfterdyen, Das nad) einem Sdymet= 
terling fing, ifre (befid)t ferab an bie fleine $\mathfrak{B a n g e}$ bengt, fefr mütterfidf = gleidfgültig, of fie vom finde über Dem Sdymetterfing überiefen werDe oder nicht. Jm Sumft $=$ geuter fragte Der (Seneral audf Den Notar: „ift Dem die Nutter

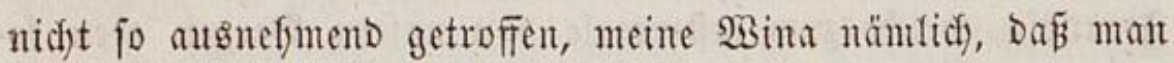
Die $\mathfrak{A}$ efnnlidfeit fogar im Sinde wieber findet? - Sprechen Sie als Dritter!" - $\mathfrak{B a l t}$ verlegen mit feiner Errötfung

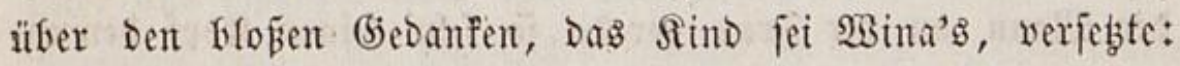

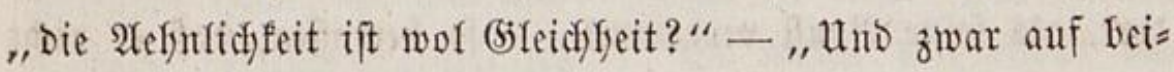
Den Seiten!" erwiederte 8ablofi, ofjne fefre Den Notar zu Faffen, Der nady Den gewöfynfidjen Borausjebsungen' Des Stan= Des fifon afles vorausjeben follte und zwar Jolgendes: Der (beneral wollte feiner loggetrenntent (jattin ein Denfmal jei= ner 3 ärte zumenden, einen Spiegel, Der nur fie abbilocte, nämlid) ein feftes $B$ illo; lyatt' aber leiber aus Rälte fie fonft nie fiben laflen, auper zulebst juriftifod. - 3um (s)lücfe war nun $\mathfrak{B i n a}$ ifr fo äfnulidy - bie wentigen Safrzefende aus=

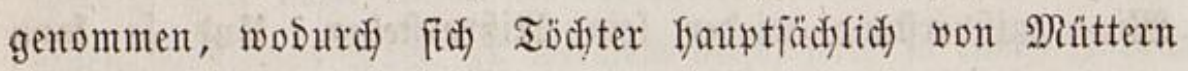

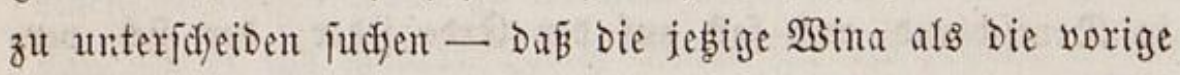
Mutter fut gefraudfen war, Der man nichts als bie vorige

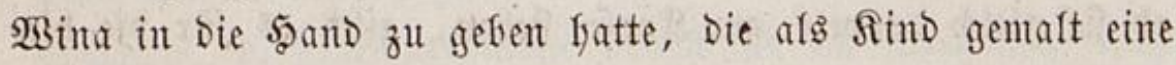
2urifet in Der Linfen fyält uno Darau einen weißen Schmet= terling mit Der Rechten jebst. Dieje zmeimal, als Bild und als Utrbild, angewante $\mathfrak{B}$ ina wollte Der Benteral feiner Jraut

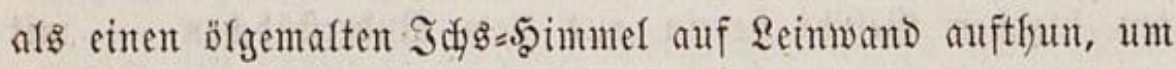
fie in Errftaunen z̆t feb̧en, Daß̃ fie über vierzig Neilen ges feाten - einem Maler.

ÁB Der Bater fort war, madyte $\mathfrak{B a f t}$ - nod tiefer it Erjtaunen uno unglauben gefebst - bie Bemerfung, fie fele sem fojönen Sinde ähntid, um nut feraugigezogen fut werden. 


\section{9}

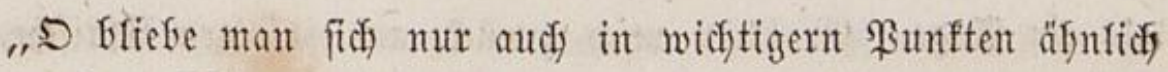

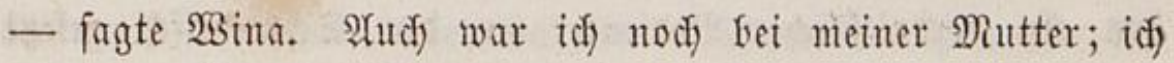
glaube, Sie poer Shr Brttoer lag Damals am Iage Deg Malens an Den Blattern blind; Denn fie ging mit mir in

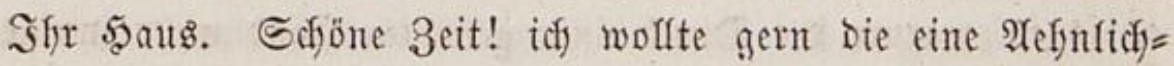
feit auf midi nefynen, fönnte idy Damit meiner Nutter bie smbere zurüuffüffren."

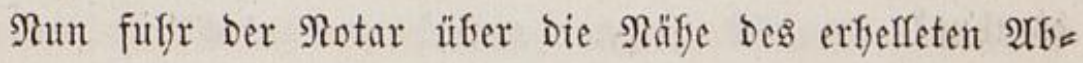
grunds, in Den er fyätte treten fönnen, rotf jurïaf, und fürd $=$ tete orbentlidy, bie Betife fafyre iffm nod wiber $2 B i f f e n$ aut

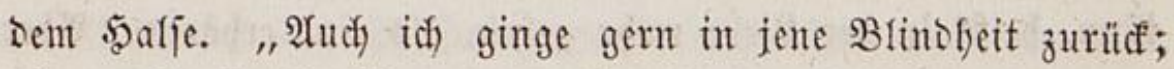
Die Racht ift Die Mutter Der (jötter uno (5öttimen!" fagte er und wollte erträglich auf bie $\mathfrak{A}$ (urifelfraut anppiefen. $\mathfrak{B}$ Bina verftano nidfts Davon als Den Ton und Blidf; und fo war es genug und gut gemtadist.

Man rief fie zum Effien. Da er glaubte, er werbe wie

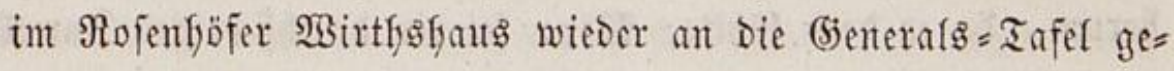
fogen: fo ftand or auf, um ifyr Den ârm zut rieten, fie fitifte aber fort; und er frano nafye am Rafymen und faf berab auf Das locfige 5aut, worin feine $\mathfrak{B}$ elt uno peine 3 ufunft molnte, Die fich in lauter Edyönfyeitent verbarg - Das ₹rudytgewinte Des Beiftes war vom Blumengewinte ber Beftalt foün ver= fü̈llt uno fojön veropppelt. Sie ftand auf. Sebt näferte er fid) mit Dem re(f)ten $\mathfrak{A}$ rme, um fie fort zu füfyren. "Id) werde - Fagte Wina fanft - nach Dem Ẽfen wieder fommen, uno Shrem Sergen cine Bitte bringen;" unt faff ifn mit Den groß̧en guten $\mathfrak{A}$ ugen unverlegen an, und gak, wie zur $\mathfrak{A n t}=$ wort auf feinen fragenten $\mathfrak{A} r \mathrm{nt}$, ifm ein wenig bic ablenfente Sand in jeine, unt fie zut brüfent. Mefre braudft' er nicht, Der Riebe ift einte 5 ant mefjr als ein $\mathfrak{A r m}$, wie ein Bliff melyt 


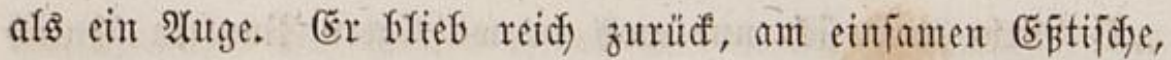

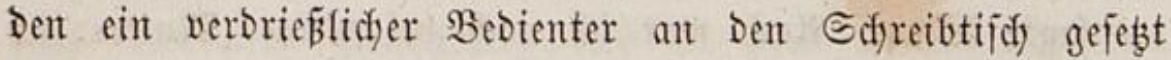
fyatte. Seine 5and war ifm wie gefeiligt Durdy Das $23 e j e n$, Das bisffer nur von feiner Geele berüfrt wurbe. WBer fann es jagen, warum der Drucf einer gefiebten sano mefre innige 3auberwärme in Die Seele fendet als jelber ein Suñ, went nidft etwa Die (rinfadjyeit, Unjoduld, Jeftigfeit Des Zeidjens es tfut?

Er ipeife an einer (5öttertafel - bie Belt $_{\text {war }}$ wer (5ötterfaal - Dem er fann $\mathfrak{B} B$ ina's nädjfter Bitte nad). (Fine thun, heif́t in Der Riebe mefir getsen, als eine erfören. Atber warum madjt bie Riebe Dent Dieje 2lusnafyme? $2 B a r u m$ gift es benn feine verflärte 2 selt, wo afle Menfdyenbitten fo viel gelten und geben, und wo Der (seber früfer Danft, als Der Empfänger?

Mit munderbaren (jefüflelt irrte er um $\mathfrak{B}$ ina's Bitte

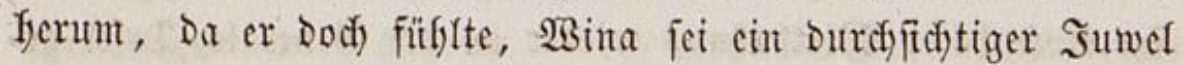
ofne $230 \ddot{l f} d y e n$ und Jedern. Denn Dieß ift eben bie Riebe, zu

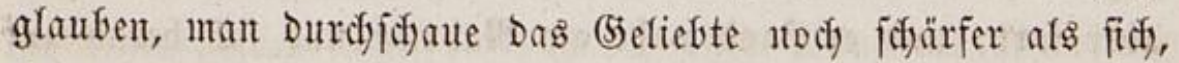
fo Dá̧ man Den Glauen 5immel Dadurd) erblicft, Durd) weld)en

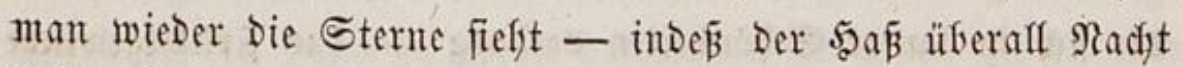
fiefst uno braudift uno fringt.

AlB er Die wenigen Stralen fübte, Die am Sterne Deß Stifts und Der Riebe aufgegangen waren oder gefticft: that

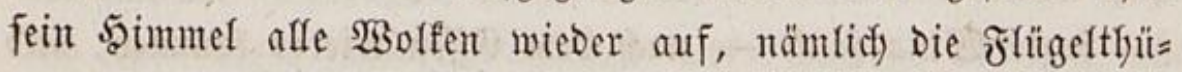
ren, uno $\mathfrak{B}$ ina erjofien uno fodien. (5r wollte fagen: idy bitte um Die $\mathfrak{B}$ itte; aber er frielt es für unzart, Das cite $B$ itte zu Mennen, waв 2 Bina eine genannt. So batt' er Den födyfent

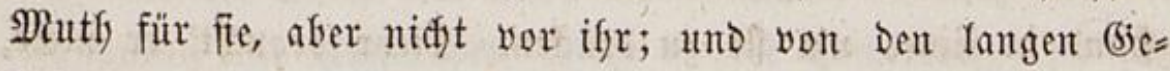

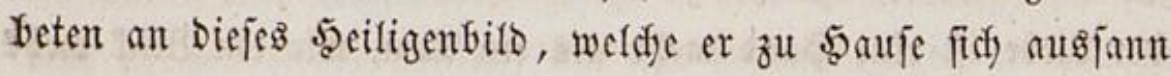


unt vornalym, bradjte er nidyts fum Bilbe felber auf jeinen Sinieen als: $\mathfrak{A}$ ment, oder $\mathfrak{S} a$, ja. "Sino Gie zumeiten bei

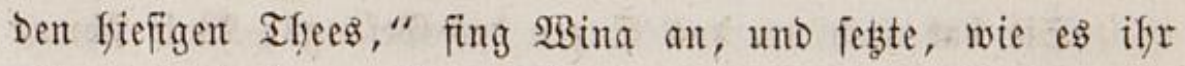
Stand thut, immer ifren Stand voraus. "Neufidy bei mir, bei bem vortrefflichen Flötenjpieler, Den Sie gewiß̈ berwun=

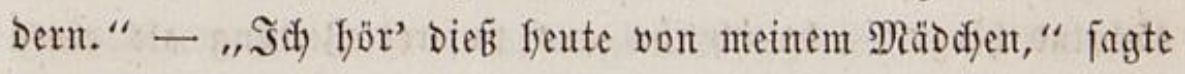
fie, meineno bie Nadyridyt Des Beifanmentwofnens; $2 B a l t$ aber

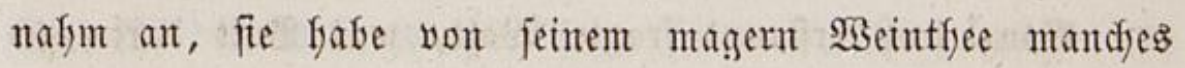
geffört.

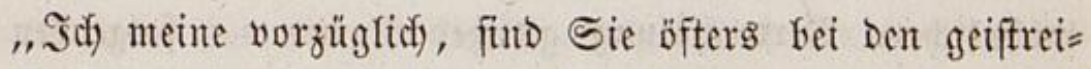
d)en Töbtern Des 5. 5oofagenten? (Eigentlid) red" idy) blos you meiner Freundin Raphaela." (Er füfrte - Dod) ofne Die

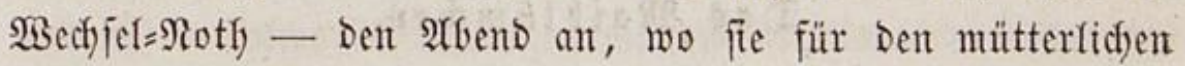
Geburtstag gefefien. "Wie ichön! jagte WBina. So ift fie ebent. Esinft als fie bei mir in Leipzig in eine fange firmt: feit fiel, Durfte iffer Mutter nidfts geforitebent werben, bis fie entweber genejen ober verjobieden fei. Um diejer Riebe

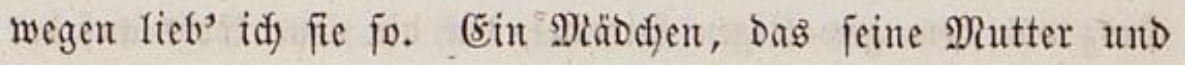
feine Sdjweftern nidyt fiebte - id) wei B nidyt, warum ober wie eb jonft nod) redyt lieben fömnte, nidyt einmal jeinen $\mathfrak{B} \mathfrak{a}=$ ter." - Walt wollt' ę gern äuperfit fein auf fie felber $z^{u}=$ rücfwentent unt madyte Dafer Die aflgemeine Bemerfung, Daß Töd)ter, Die ifjre Mutter fieben, Die beften und weiblidffen fint.

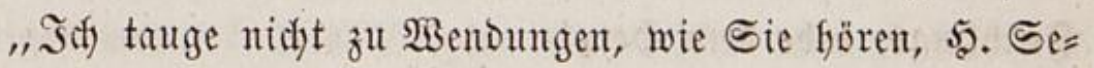
fretair. Empfangen Sie meine offne Bitte gutmütfig auf

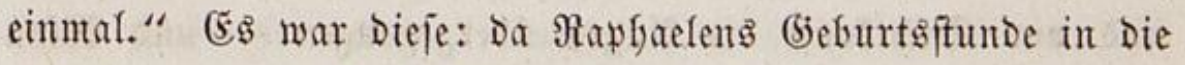
Radymitternadyt oder Norgenftunde Des Reujafres einfalle: fo wolle fie Durd) Den Beiftand (Engelbertents fie Durd) leijes $\mathfrak{A n}_{n}=$

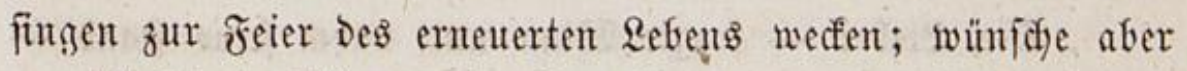
zur Dürftigen Stimme eine Begleitung, nämlidi Die Flöte, uno 


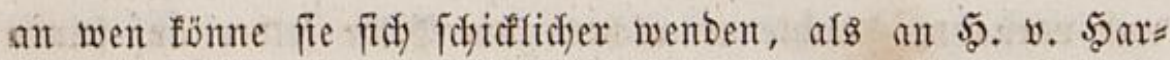
nifjo? - Walt jomur freubig, biejer blaje freubig bazu.

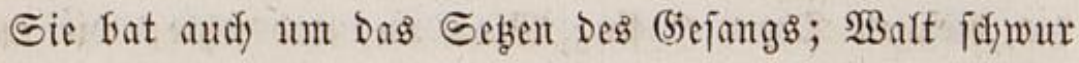

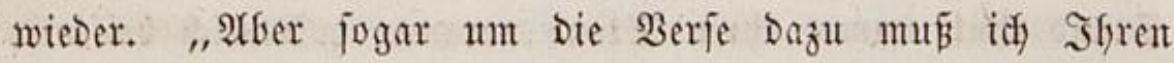

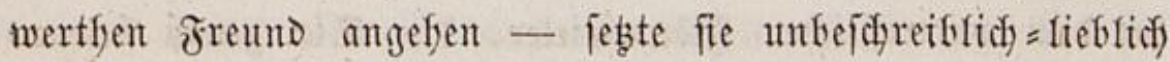
rädyelno finzu - Da ich iffn aus unjerer Beitung als einen weidyen Didfter Des şerzens fenure." -

(5anz froh erftaunt fragte $\mathfrak{B a l t ,}$ was Bult Darin ge= madyt. Sie fagt' ifjm - mit Der Den Riteratoren nod) ge=

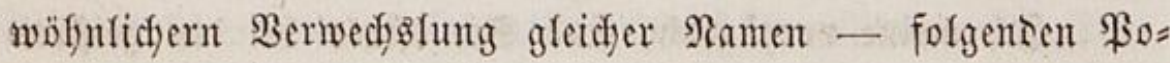
fymeter vout ifm felber fyer:

\section{Das Maibrümḍ̛en.}

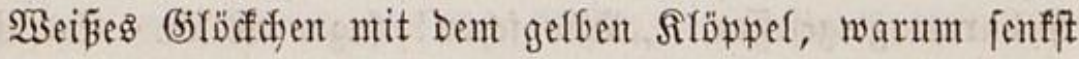
Dut Didy? Sit es Sdyam, weil Du hleid) wie Sdynee früfyer Die Eroce Durdjbridfft als bie grobent ftolzen Farbenflamment Der Iulpent und Der Rojen? - Doer fenfít du Dein weikes 5erz vor Dem gewaltigen \$immel, Der Die neue Eroe auf Der alten erjoffift, ober-vor Dem ftürmenten Mai? Doer willt bu gern Deinen Thautropfen wie eine Freuben $=$ Thyrane vergießen für Die junge fojöne Erotoe? - 3artes, weiß̄es Rnognenfrüm= Yein, hebe Dein Şerz! Iㄴ) will es füllen mit Blicfen Der Riebe, mit Ifyränen Der 2 sonue. D Edjönfte, Du erfte Ricbe des Jrütflings, hebe Dein 5̧erz!

Balten waren unter Dem 3ufjören vor Freute und Siebe und vor Didutfunft bie $\mathfrak{A}$ ugen übergegangen - und $\mathfrak{B}$ Bina fantte mit geweint, ofhe es zu merfen -; - Darauf fagt' er: "idi) Gabe wol sen Bers gemadyt." -

"Sie, Riefer - fringte $\mathfrak{B}$ ina und nafm feine sano -

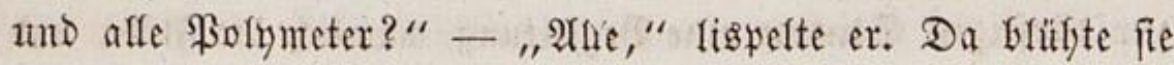


wie das Morgentoth, Das sie Sonte veripricht, unb er wie

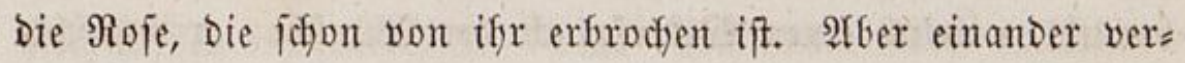
borgen finter ben frofyer nadfqueflenten Ifyränen glidyen fie

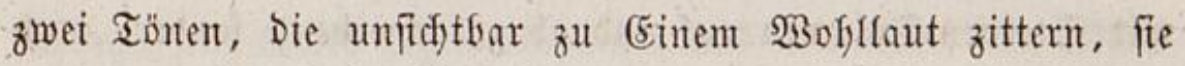
waren zwei gejenfte Paienbfüm(d)en, einanber Durd) frembes

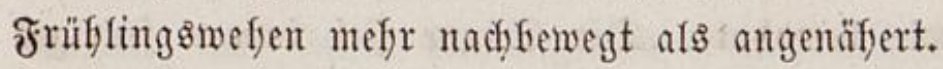

Jebst förte fie sen Baterstritt. "Uno Sie madjen Dent Text für Den (jeburtstag?" fagte fie. — „D! (verfebste er) — $\mathfrak{s}$, ja!" uno Durfte nidyt fort reden, weil Bablocfi eintrat unt mit Dem $\mathfrak{B a ̈ t e r}=$ und (5atten = Sofynaubent ifre Den arbeit=

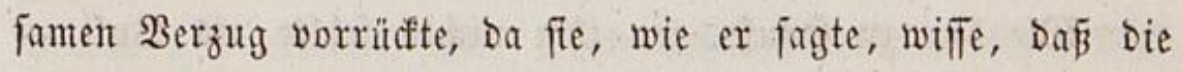
Reupeters - Dafin fufyr er mit ifrr - Bärgerfiche wärent, und ef) er foldye im Rleiniten manquire, fomm' er liefer bet Seinesgleidfen um Stunden zu jpät. Sie flof Dafin; er rief fie aber zurüf, um felber mit einem Sdylüfeldyen, fo grof

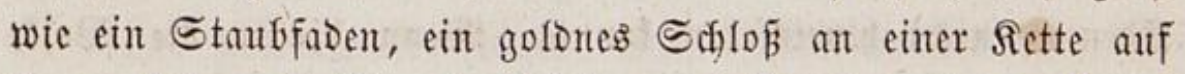

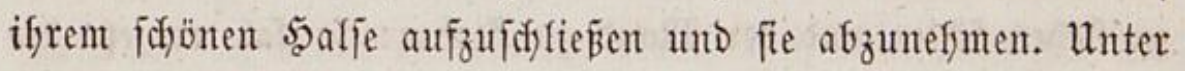

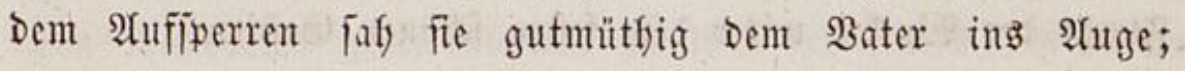
Dann warf fie fideidento Dem Notar einen flugblide woll 2 Belt= all $z^{\text {llt. }}$

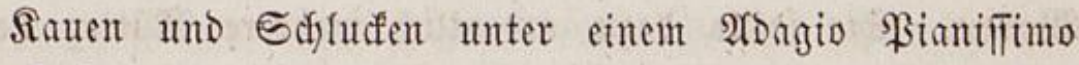
einer Iafelmufif bätte $\mathfrak{B a l t e n}$ nidht fo wiberftanden, als bie Antulfme von Ropirgebüfren, Dic ifm Der (5jeneral jeb̧t auf= nötfigen wollte. Das 2 Beigern bielt Diejer anfangs fitherzent

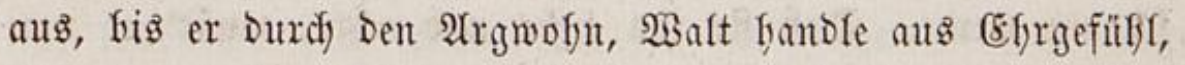
fein eignes fo beleidigt fand, Dañ er fo heftig fodwur, ifhn, wenn er nidht gefjordje, nie mefyr zu einem Rotariats = Inftru= ment ins Şaus zu la 5̧immelopforte nicht jelber zuzuriegeln.

Nun war er affein und zum reb̧tenmale als Siopift int 


\section{4}

Bimmer; und fratte, was ber Menfid) zum feinften (5) lüde

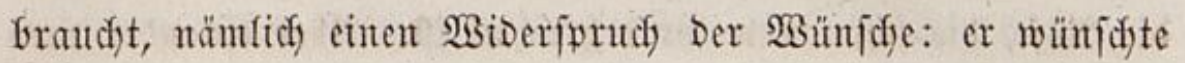

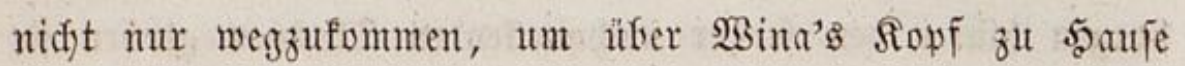
mit Sternen=Träumen auf uhd af zu fdjweben, fondern audy Da zu bleiben, Da er Das firönungs =3immer feines Selens zum lebstenmale bemofnte. Die Sonne fiel immer feuriger finein und vergolbete es zat ciner 3auberlaube im efyijifoen

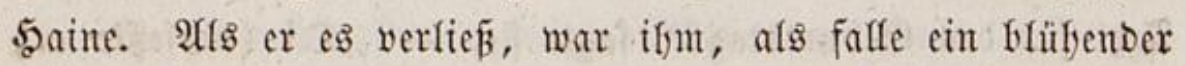
3weig herab, worauf bisher Die Radytigafl feiner Seele ge= jungert.

Wic lag zu saufe, wo ifm nidjts feflte alis Bult aber biefer faum - Das Reben und Der Traum im Reben wie vergoldetes (jewölf un ifn her! Iaujent Baradiejes = 8 weige fodlugen über ifm unfidytuar zujammen und Durdjogen ifn Yyeimfidy mit einem beraufdenten Bhüten = Dufte, in Deffen Eben er nidft Gineinfefen fonnte. Wenn bisfer die Bolfe fut ftelyen fajien uno Der Mond zu fliefyen: fo fafy er jebet bie

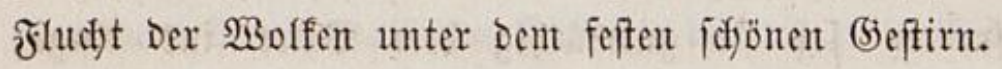

"'Renn fie nur redjt imnig liebt - Dadjt' er - gejebt audi), fie meinte midh nidht allein; Die sauptiache iff ifyre Wonne. Sie follte daz̧u orbentlid, mefrere Mütter Gaber, mefrere Bäter und unzählige Freundinnen!" (Er freute fith)

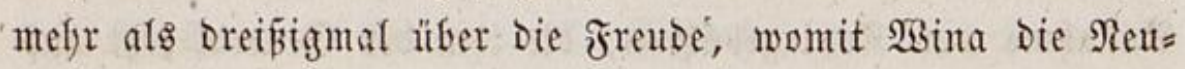

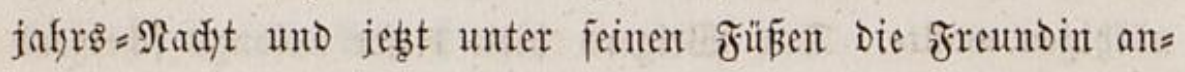

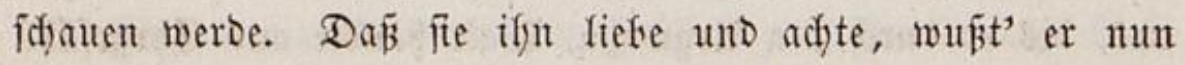
redyt; aber nicht wie ftarf; - Den födyfen (5rad iffer Riefe

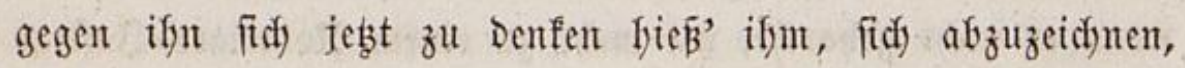
wie ifm fern würde, wenn man ifn auf Millionen $\mathfrak{B e l}_{\text {fifufen }}$ auf Die (Sitiffel=Sonne geleitete, um ifn, Den Notar, zum Gott ợ frönen. 


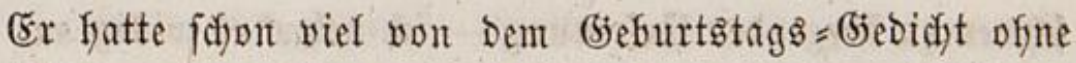

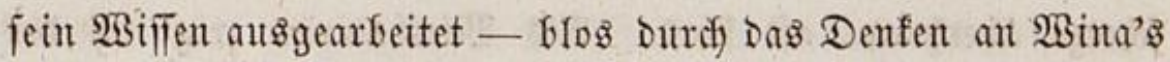

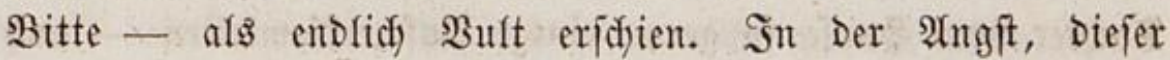
fodlage, aus Rälte gegen Raplyaela und Den Alder, Das Mufif= feft ab, wollt' er ifht etwas fünftlidy, wie in einem englijofent (5arten, auf feinen Sd)Iangenlinien und mit Mäandern vor Den Borfaflag wie vor ein Denfmal füfren, "Leider fojrieb id Geute Das lekgtemal beim (jeneral," frgt' er mit Der felig=

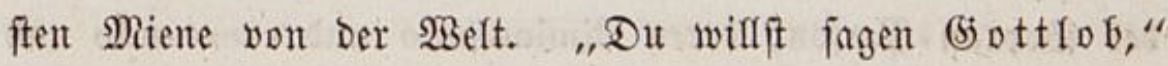
fagte $\mathfrak{B u l t}$. Balt ftolperte fifon vornen in Den Mäander

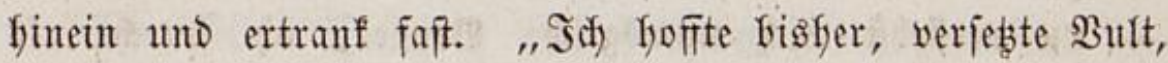

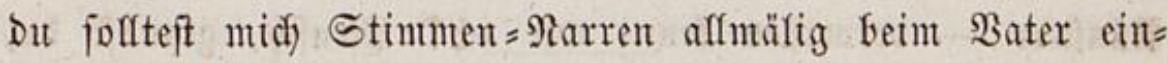
füfren, Dainit bie Iodjter fänge, wenn idf bliefe." - "Bei= Des, follug 2 alt heraus, faumft du ofne thn und midf jeb̧t faben, Dieß̄ bafs idy Dir jogar vorzuldylagen."

Der Frötenipieler fragte eftig. SBalt beftand aber Dar=

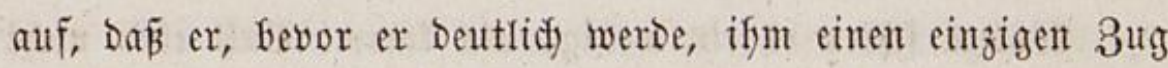
von Raphaelen gefen Dürfte; es war Der fojöne vom $\mathfrak{B}_{\mathrm{er}}=$ fotweigen Des Rranfierns.

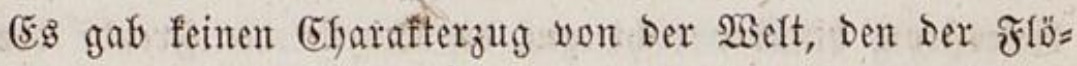
tempieler je mit einem fo abjtrebenden (befidste fid vorzeidfuen

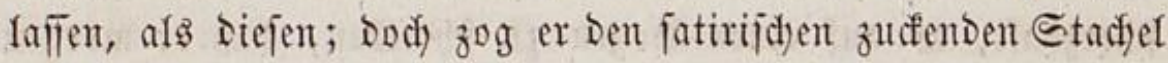

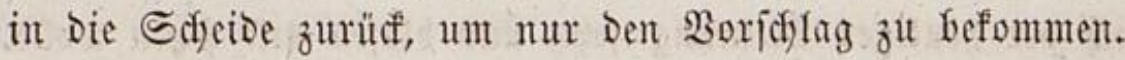

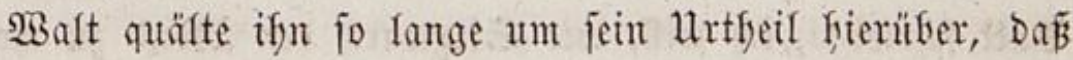

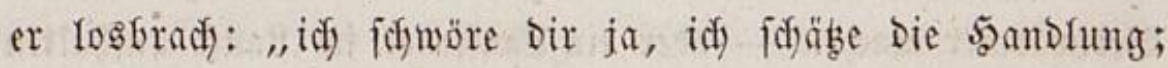
Der Teufel uno feine (5rofimutter fönnten nicht zärter ver= fafren; es if cine Redensart, id meine wir beide. Nun [pricif!" -

SBalt fod lug's vor.

"Du bift cin guter Menid - jugte $\mathfrak{B u l t}$ mit einer 


\section{6}

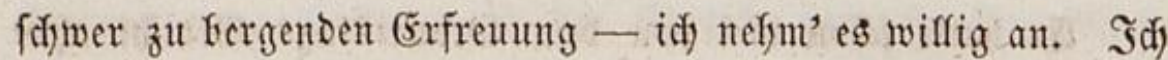

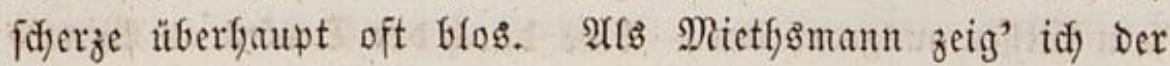

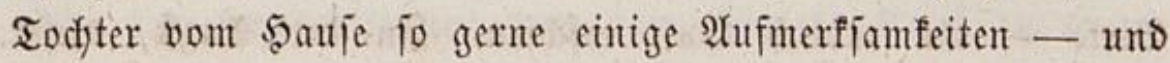

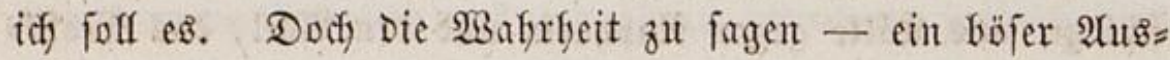
bruef, gleidyfam als habe man vorber feine gefagt - jo ftimmt midif) fier $\mathfrak{B}$ Bina mit iffer reinen roffenton Berlen = Stimme nod) mefrr. (5ott! Wie fann nidjt eine Singpartie gejelst wer= Den (bejonders von mir), wenn man Das cole Portamento Der Sopran = \$erjon, Deren diminuendo uno crescendo uno ifre fyerrlidfe Bereinigung won fiopf= uno $B \mathrm{ruft}=$ Stimme - Du verfteffif midy unmöglid, Bruder, idy fipreche als Rünfter - Dermaken ferunt wie id ? Menfid, glaubjt bu, DáB idf Damals, als ich) fie in (Elterlein förte, folvur, fie foll mit meinem $\mathfrak{B i f f e n ~ n i e ~ m e f r ~ a ̀ ~ s e c c o ~ f i n g e n ? ~ - ~ a ̀ ~ s e c c o , ~}$ Balt, heist nämlid allein; cin Bunfd = Moyalift wie id fommt freilidy audif leidft aufs Iroffite, aber anders."

Balten fofien es en wentg, als fomme Bult eben nidjt yom feften Lande fer. Beider afbend wurbe aber im feuer Der Riebe vergoldet. Seber glaubte, er jefje über Den \$ara= Diefesftrom binüber redyt gut bie Sulfe Der Frentie Des an= Dern won weitem raudjen und nebeln. WBalt zwang iffn fđjerzbaft, es auf einen Bogen zu fodreiben, Dá er morgen nody Der feutigen Meinung fern uno blajen unb peben wolfe. Bult idjrieb: „ich will, wie Siegwart, Den Mono zut meinem Bettwärmer madyen - ober ein \&auffeuter im 2 aufe auffalten - ja idh will bie exfte fefte Glacière von \$rübe fyeiratfen

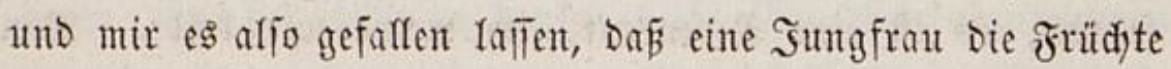
Der (5)tutzeit zu Esizzierratfen ausquetidt, z. B. zu Rofen= uno Aprifofeneis, zu Stachelbeereneis, zu 3itroneneis: wenn idj) nidyt bie befte glötenmufif pogleidy Mozartija jebse und 


\section{7}

Blaje zur 3autlerflöte, in Der Minute, wo Diefe mein Brutor gedichtet und aufgeidyrieben lyat; und idy entage jeber Exzeps=

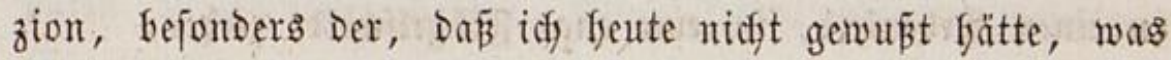
(id) morgen wollte."

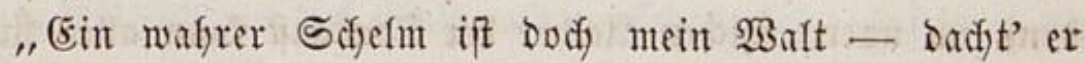
int Bette - würde ifn ein anderer wol in sauptpunfte fo Durdjiffauen wie idj? - Raum!"

\section{No. 60. S d)}

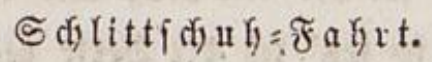

Der nächfte Iag bes Notars war aus 24 Morgenftunden gemadit, weil er über Das (jeburtatagstied für $\mathfrak{B}$ ina nad)= fant. Der zweite beftano aus eben jo vielen Mittagsftunden,

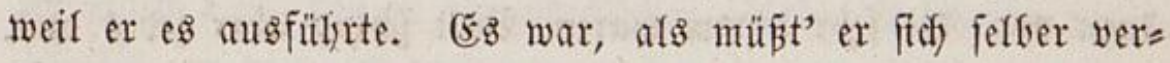

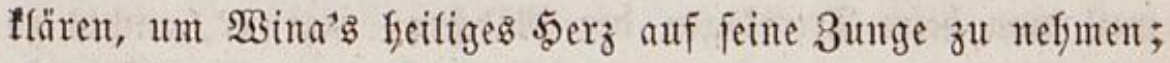
als mübt' er in Riebe zerrinnen, um iffere Riebe gegen bie Freundin in feiner Seele wie ein zweiter Regentogen neben Dem erften nadjzuglänzen. Da bie siebe fo gern int fremben Serzen lebt: fo wirb fie nody zärter, wenn fie in biejem wies Der für cin brittes fu leben lyat, wie Das zweite Escho leije über bie Milde bes erften fiegt. Dieß́ alles aber war nur leidftes Säen im Früffing, wo lauter nette Sänger am \$̧im= mel flogen; aber ant zweiten Inge fiel bie heipe Ernte ein -

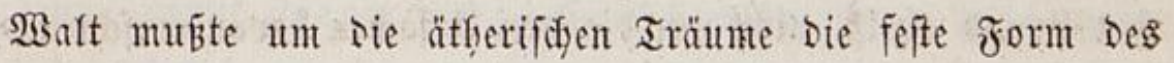
Badfens legen, nämlid) nidyt nur bie neute metrifoder Berbält= nij̄e, fonbern aud mufifalijuer, weil $\mathfrak{B u l t}$ oft ben beften 
(Gedanfen weder fing = nod firasfäbig fant. So mun jogar

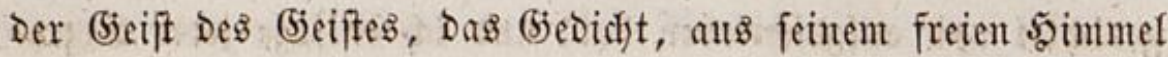
in einen (Erbenteib, in eine enge Flügelfocheide ziehen.

Bult fingegen fatte Ieid)t (bejang und Begleitung gejeb̧t;

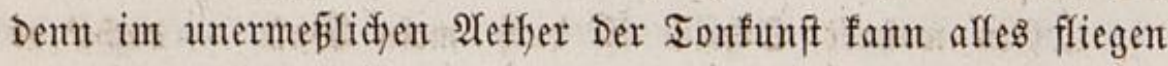
und freifen, Die fdywerfte (Erde, Das leidstefte Ridyt, ofjne zut begegnen und anzutopien.

Da Balt Gefanntfidf Das (jebid)t in feinem Roman ganz aborucfen lafien, nur mit wentigen, aber unwejentfichen $\mathfrak{A} b=$ änderungen in Den Steffen: $\mathfrak{B a d h}$ auf, (jefiebte, Der Morgen

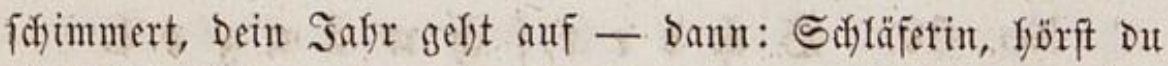
nidyt bie Riebe rufen und träumft Du, wer Didy liebt - und entidy: Dein Safrr fei bir ein Renz uno Dein Saerz im langent

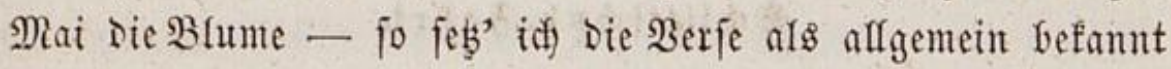
voraus.

Sebzt war blos bie Sdywierigfeit, SBinen Mufif uno Tertt

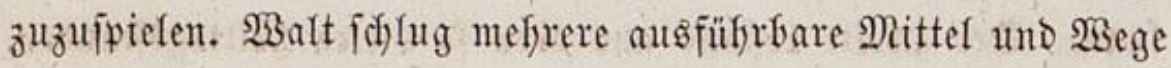
Daz̧u vor, bie feffr Dumm waren, Bult fojlug aber jedes aus, weil man beim Treibjagen Der Mäbd)en, fagt' er, nid)ts żl

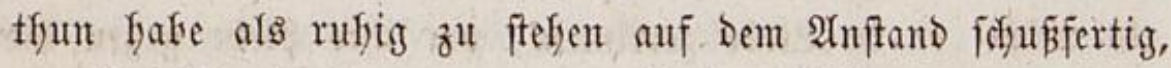

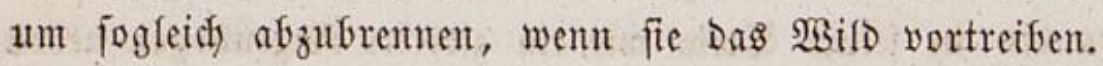

Inder wurde nidjts gebradyt; Binta verftand von den

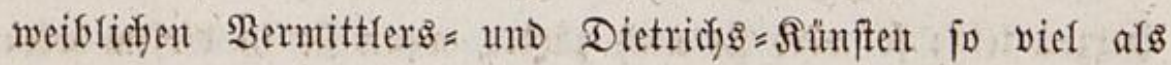
Walt. (Endidy eridfien eine hefle Dezember=Dämmerung int Barf, wo Der lange See (es war ein fodmaler Teidf) mit Demt Bejen rom Edyne gefäubert wurbe, uno wo fpäter, Da Der

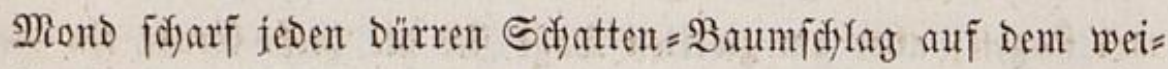

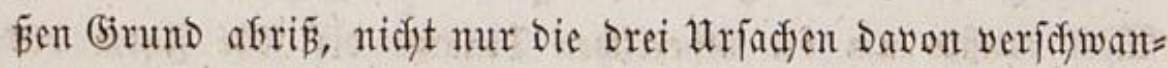

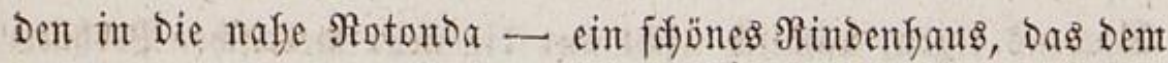

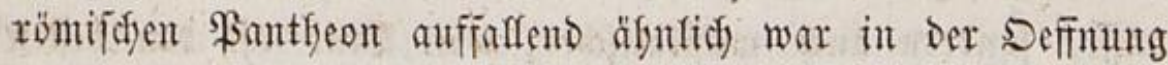


naci) oben - fondern aud fogleidy einander wieber fyerats=

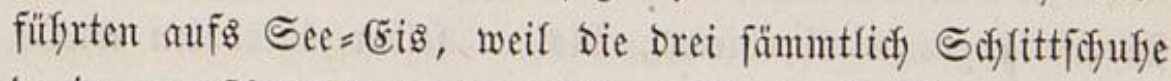
Darin angefdnallet fratten, SBina fowol als Raplyaela und Engelberta.

"(5öttlich) - rief 2 aalt, als er fafren fah - fliegen bie Beftalten wie SBelten Durcheinander, um cinander; weldye Edjwung = uno Edflangenfinien!" Ëben mad)te Engelferta, beide Arme maferija aufgefoben, herniffente singerwinfe. "Rauf mit Deinem Mufifblatt und jei Drunten ein $\mathfrak{R e n f}$ !) fagte $\mathfrak{B} u 1 t$ zu $\mathfrak{W a}$ alt. Sie wollen uns beim Teufel." -

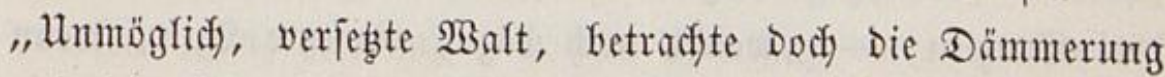
und Die 3ärte!" - "F̌rr ein \$aar Stiefel hat Doch Der Gee nod) Flab?" fragte $\mathfrak{B}$ ult finab und flatterte brei Ireps went fimunter, un einen Rabendiener ofne 2 Beiteres zum $\mathfrak{R a d}$ )=

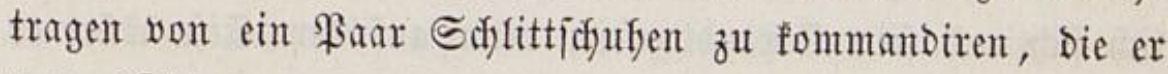
voraubiebze.

Walt ftecfte Das lyeilige Blatt woll Ion = und Didytfunit

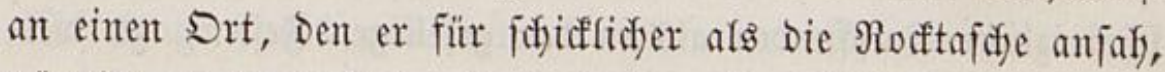

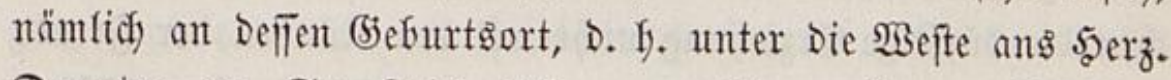
Drunten am See= Teidy fiế er an peinem lantgen Büffing Die Drei Danffagerimen vorüfer gleiten uno theifend Yoojen, weil er nidyt offenbaren fonnte, wie viel er jeder vom Rüfent= rogen abjonneide!

After weldye entwicfelnde Lebensfraft war mit $\mathfrak{B}$ ultent

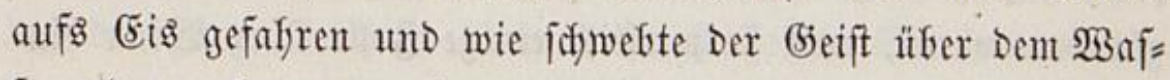
fer, Das gefroren war! - 3uerft bald Waina's Bart=, bald

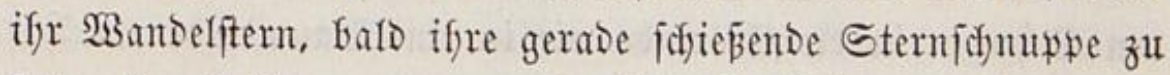
fern, Damit fing er an - fie Schadyfönigin zu Deffen gegen jede Rönigin, es fet als Räufer, als Epringer ober Tfurm -

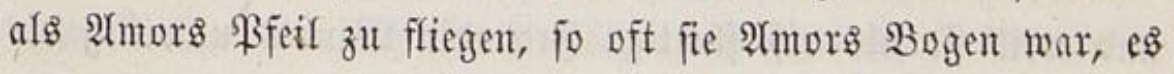

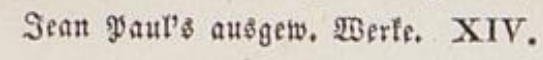


nidjt ful leiben, went fie filfyer fliegen wollte als er, fontorn fie fo lange fut itberbieten, bis er felfer überfoten murde uno Dann leidfter Den $\mathfrak{B e t t f l u g}$ mit einem Dopwelfiege fod ló Dieß́ war bie Runft, womit feine foföne von Der 2 Belt er= zogne (Geftalt iffren $2 B e r t$ entwifelte in leichter saltung und Wedfstung.

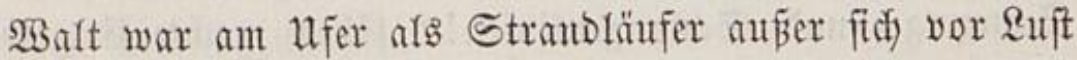

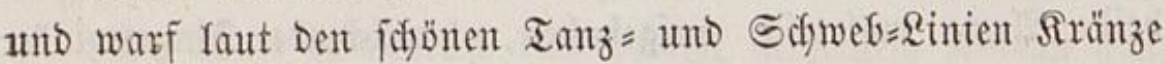
von (s)ewicht in fo ridftigen Runftwörtern zu, Dak man Gätte

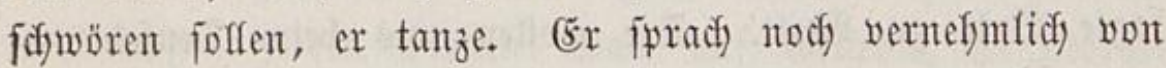

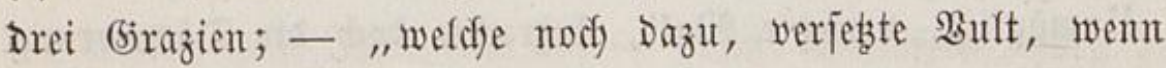
nidft um Die Benus, Dod) um Deren Mann, tanzen; und was

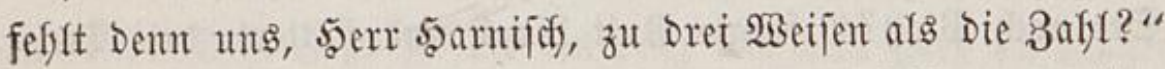
- Nur muß̄te Salt unter Dem Bemumbern Veflagen, näm= Iidf fidf uno jein Stranblaufen; Denn auf Demt (Eije wäre er nidjt viel leidfter zut Drefyen gewejen als ein Sirtegsifdiff. Biefleidyt wird Der Druf einer niebrigen Affifanmung nie fojmerglidfer empfunden als in Dent gefelligen Feften, fut wel=

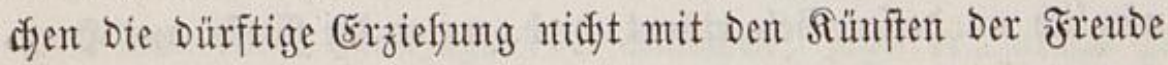

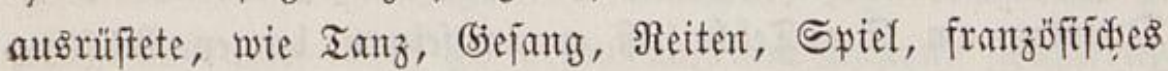
Eprecten fint.

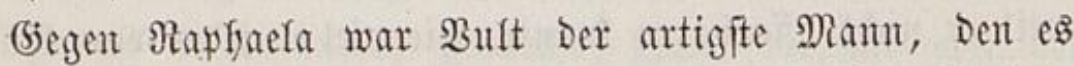
auf Dem Teidje gab, jagte ifyr \$öfflidffeitent über ibre für bie= fen Tanz gemadyte bieftalt - weldye iffm und iffr leidyt zut glauben waren, weil fie wirffid) einige 3 offe itber $\mathfrak{B}$ ina frin=

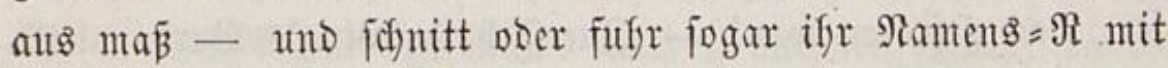
Den Sefuthen in bie Eisrinde wie in cine Baumrinde ein.

Sie nalym inter fein füfflidjes Hebermañ ofne eignes anf; viefleidft weif Das jeinige ben Siferz nidft genug verbarg und weil fie als eiferjüntige freundin $\mathfrak{W}_{\text {inta's }}$ unnillig bie 
5ant jaf), Die er fo offen nadj biejer ausfetrecte. (Er über= Güpfte ober überfulfre es. 3u Engelferta fagt' er: wir wollen

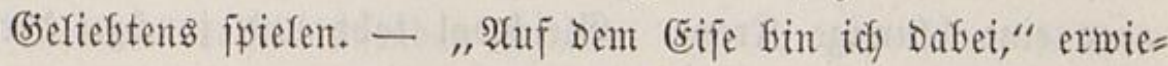
Derte fie; und fo necften beibe fid leidft uno rafid mit iffrem Rolfen = Sohein, er mit erel $=$ und weltmämijocher Recffeit, fie

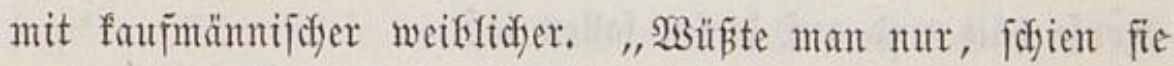
zut Denfen, of er mefjr ein feltiamer sanberedift wäre als ein türrifofer Sabbenichts; Dann wäre mefr zu tfun."

Jinfmal fatte fochon Walt an fein Mufifblatt gebadyt, um es einzufändigen, und es viermal vergellen, wenn $\mathfrak{B}$ ina wie feine ganze Bufunft um fein Ufer flog ober gar ifn mit cinem Shlumentifife bewarf, Dem er z̧u lange nadyträumte.

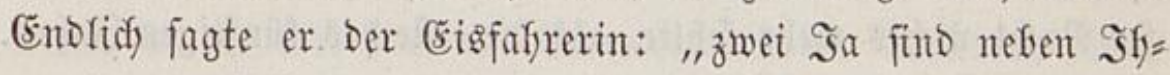
nen." - "Id) verftano Sie nidyt ganz," jagte fie lädyefno wieberfomment atto entglitt. Er ging ifr am $\mathfrak{H}$ fer ein wentg

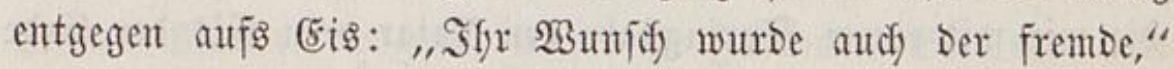
fagte er. "פBie ift's mit Der Flötenmufif?" fragte fie flielyeno.

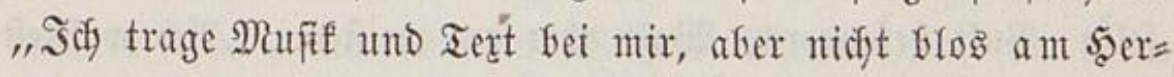
zen," antwortete er, als fie wieber ferfuffr. "WBie ferrlid)! " fagte fie umwertoent, und glänzte vor freulde.

Bult flog wic eiferiüdytig fragend fyer: Yyat fie Das Blatt? - "Sefjr fingedentet hab' idj Dreimal, verjebste 2 alt, aber wie natürficd fäfret fie nidyt unweiblid yor mir aus uno ftefft." - Jener zog feine flöte öffentlid wor uno jagte faut,

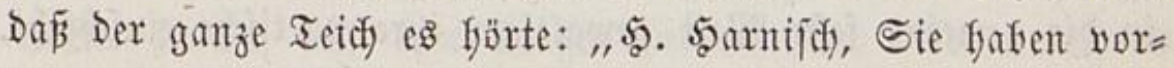
fin mein Mufifblatt eingeftedt? Sebst Glaj" idc." Diejer

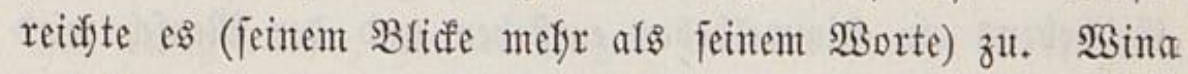
fan ferbei: ,fünten Sie, fagte Bult laut zut ifre, ę über= gebento, im Mondidecin nody lejen, was idh abjpiele?" Dab trautende Mäbdyen fafy ifyn lieblidy an und emptraft ins $\mathfrak{B}$ latt 


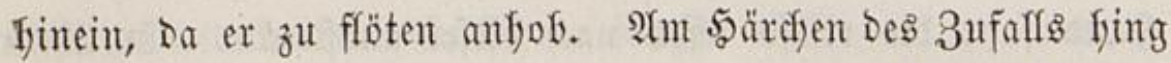
nun Der ganze Nenjafrs = Morgen fyerab, zwar fein Edfwert, aber eine blumige Sirone. (5leidfwol tolt und jauchjet ber

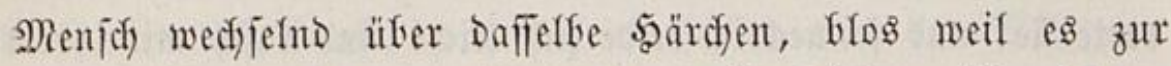
einen Beit ein Sijwert, zur andern cin Diadem über feinem Sopfe fält uno auf Diejen fallen läs̆t.

Bina las lange auf Dem Blatt Noten nady), bie er gar

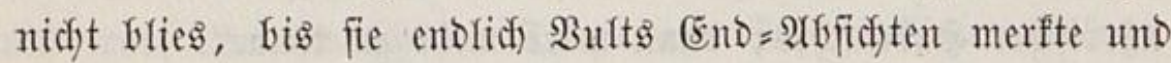
erfïllte. WBie flog fie Dann ber folote nady, um mit Bliffen

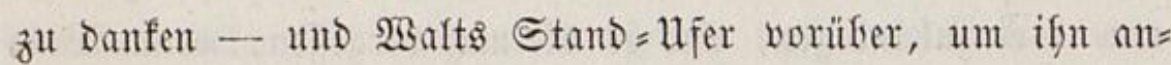
zufdyauen - und freubig über bie falte glădye, weil ifre

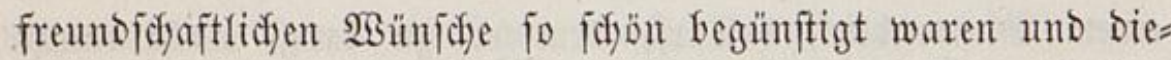

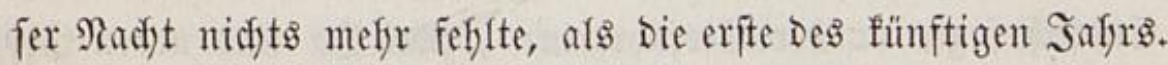
Welche crfreucte Blife warf fie auf ifre Freuntoin und zum Sternenfimmet! Dazu ging nun Die umlyer irrende flöte, Die wie mit einem Springftabe Den Rotar vom Eis Der Eroe ants Empyreums = (5is Des şimmels auflob. Atlles war zwar

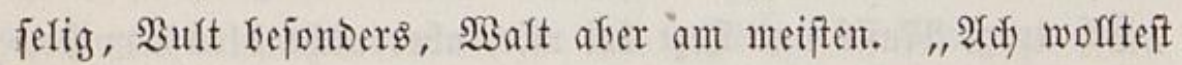
Du mir nidft - jagte $\mathfrak{B u f t}$ ferfafyreno mit vergnügtem (bes

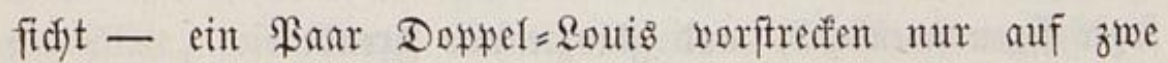

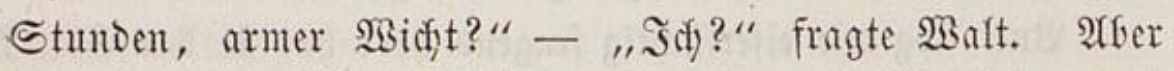
jener fufre uno blies fröblid) weiter, um als (shorfüfrer mit Sphärenmufifen Den fimmlifden Sïrpern auf Dem Eije yor unto nady zu fidweben. TBenn bie Ionfunft, weldye fidjon

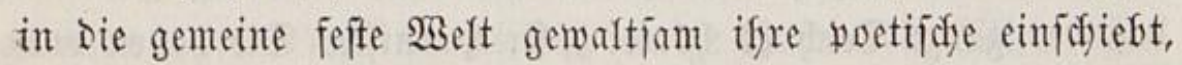
wollends eine offne bewegte findet: fo wird Darin fatt bes

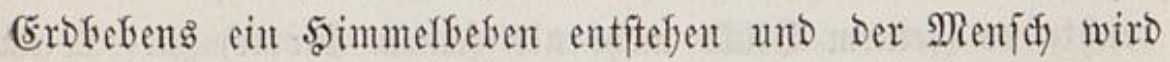
fern wie $\mathfrak{B a}$ alt, Der Das $\mathfrak{U}$ fer mit ftiflen Danfigebeten und laut= ten Frendenrufen umfief und jeine serzens=:2Belt, fo oft bie Stöte fie atsgejprodjen, immer yon neutem und verflärter 
erfduf. Er fanmelte alfe frembe Freuben wie warme Etralen in feiner fitfgefaltenen Seele zum Bremumufte. Den mit

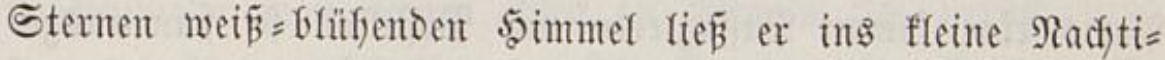
gaflenjpiel ferabfängen uno Der Mond muß̄te jeinen şeifigen=

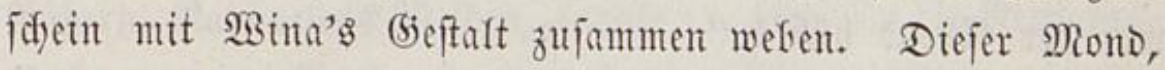
fagt' er fich, wird in ber Nadjmitternadyt Des Neujafyrs faft wieber fo am Simmel fefenen, und idf werbe nidft nur bie Flöte und meine (seonnfen, audd) Sfre Stimme Görent. Die Stene Des Morgens werben blinfen - unt idh werde erft unter biejer fünftigen Mufiff Denfen: , jo gró frätt' id

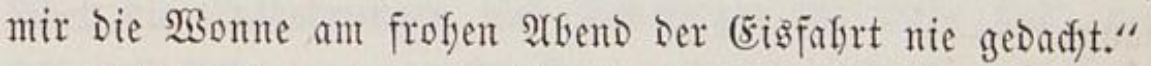

Selgt trat er immer weiter in Den Teidf finein, ober ftach weiter in bie See ober ins Eismecr, um Der beltebten näher zu begegner. Da fie ifn nun ein paarmal nafe umfreijete,

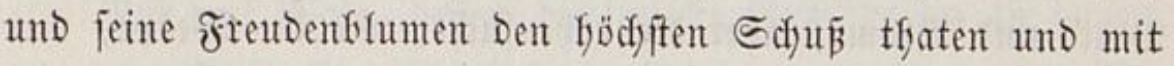
breiten Blättern wogten, mäfte fie 3ablocfi's Beoienter mit Der Radfridft ab: Der $\mathfrak{B a g e n}$ fei Da. Der ftolze Lafai er= innerte ifn wumberbar an $\mathfrak{B}$ inn's Stand, und an peine Rüfnlyeit.

Rad) Der Ffudft Der Drei nafm ifyn $\mathfrak{B} u(t$ am Srme aufs (Eis finein, und fagte: "jede Ruft ift eine Selffimörderin, und Damit gut. Afber gift es Denu ein fafferes \$aar arme

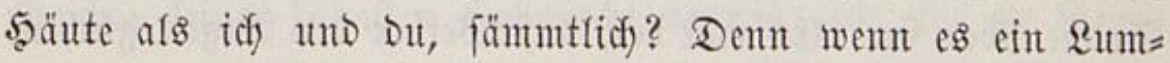

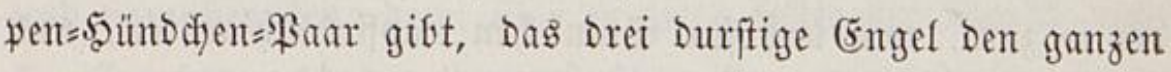

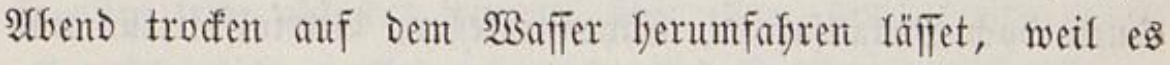
nicht fo viel in Der Iafdje, oder Droben in Der Stube zujam= men bringen fann, um Den Engeln uur Die fleinfte Erfrifochung

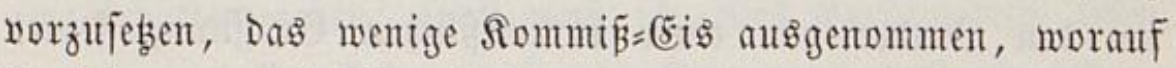
fie fuffren - : jo ift walyrlidy Das $\mathfrak{B a r}$ niemand als wir. Adf waren wir ben in Stande, wenn fie folfedfes $\mathfrak{B}$ etter 


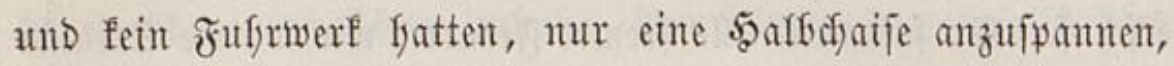
unD einen Flof Dazut anzuffirren, wie cinmal ein Finffter in

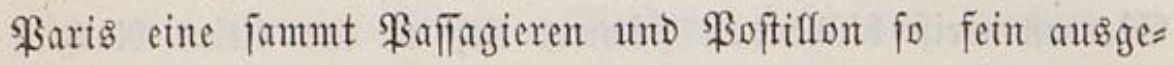

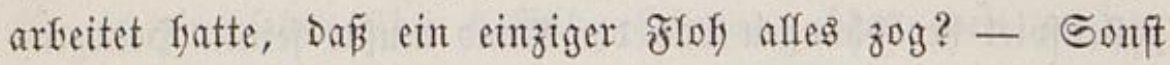

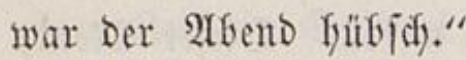

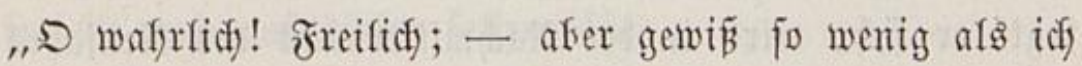
biejen âbeno an Yeibliche (jemülje Dadyte, fo wenig vieffeidyt Die gutent $\mathfrak{B} e$ en! Die Frout fyat einen Edjmerz, eine Frente; Der Mann hat Sdymerzen, Freuden. Sieh nady, Dieß trifit

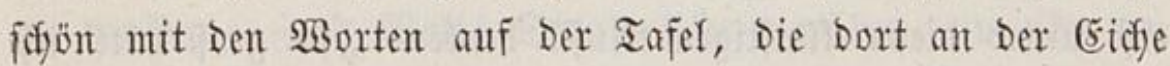
frägt." -

"Sine Rinde iff's," jagte Bult. "So fenn' idf, verjebzte Balt, immer bie (semädyje mur in Büdyern. - Darauf ftefyt: Die fojöne weiffiche Scele fudyt, wie bie Biene, nichts als

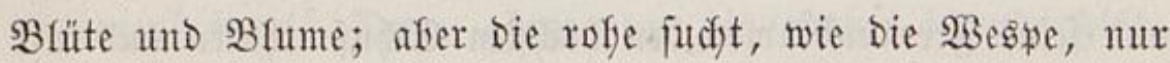
Æriudifte." ...

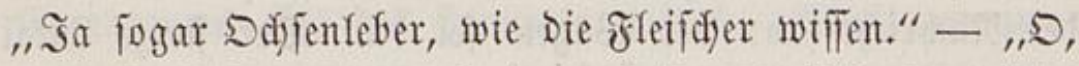
alle, fulfr 2 alt fort, waren beute fo frofy, und befonders über

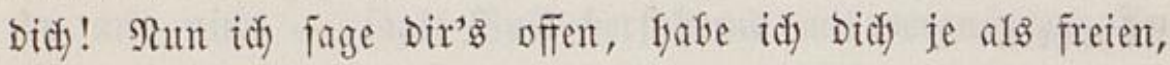
gewanten, filfnen, alles fojlidjtenten $\mathfrak{B}_{\text {eftmann }}$ erfannt, fo war's fyeute," jagte 23 alt und hob kefonders fein Benefyment gegen Rapfaela Yeraus. Wult bedanfte fich mit einem -

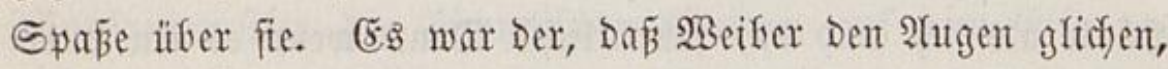
Die fo zart, rein und für Stäubdyen cmpfindfich wären, und Denen Dod) Metallafran, (Eayentepfeffer, Bitriolfpiritus uno andere angreifente $\mathfrak{A}$ ełmittel als beilung Dienten. Bon Beit

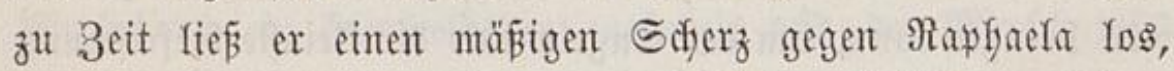

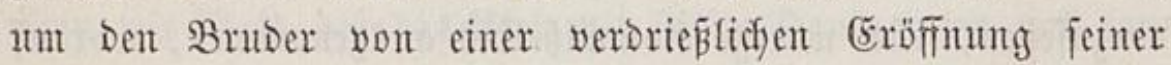

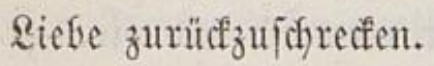

Aflmälig fanfen beibe fanft und ticf in bie Stifle iffres 


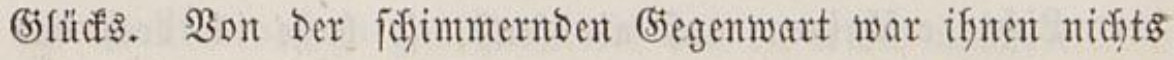
geblieben als oben ber şimmet, und unten bas serz. Der

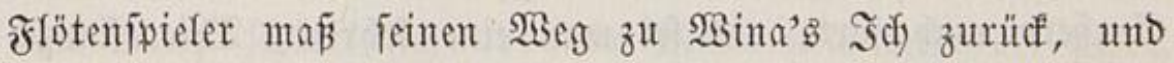

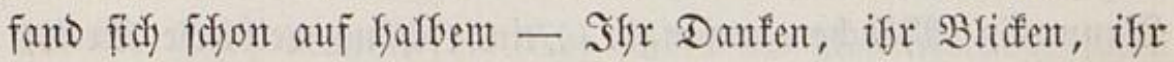

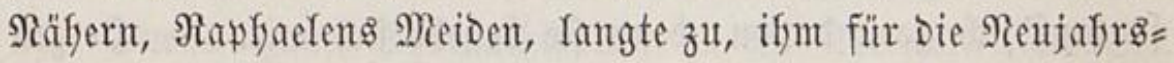
Nadjt, wo er alles burdy einen 3auberidjlag enticheident wollte,

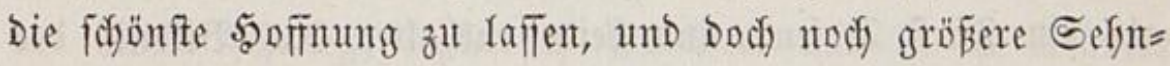
fucht. Afber gerabe dieje war iffm faft lieber und feltner als jene; er Danfte (5ott, wenn er fid nady irgent etwas unbe=

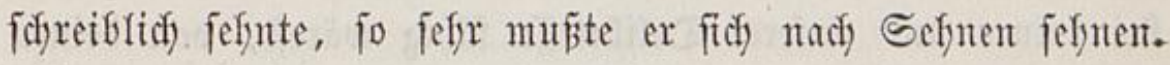
श्tber Die Entbefrungen und Sdymerzent Der Riebe find eben felber Errfülfungen und Freuten, tuto geben aroft, unt brats dyen feinen, fo wie Die Sonnenwolfen eben Das Reudfen Der Sonne erzengen und Die Erommolfent vertreifen.

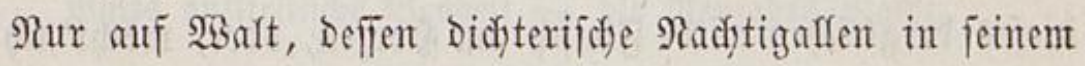
warmen Duft= (5Den betäubeno forlugen, madjten bie gött=

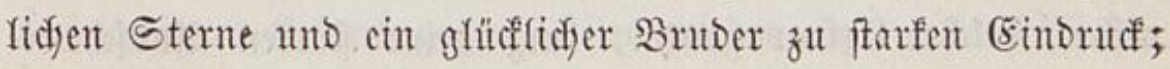

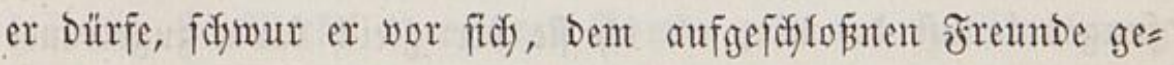
rabe bie Yeifigfte Serzens=Stätte, wo Winn's Denfimal it (5eftalt einer einzigen Şimmelsblume ftant, nidyt länger ver= Deffent und umfautien. Daber fojicfte er ofje meiteres 5amb= Druffe und Augen = Blicfe als Borfpiele Der fojambaften Beidfte feiner fulfnften Sefnjudft voraus, um ifn zu fragen uno vorzubereiten; Dann fing er an: ,follte Der Menfid) nidft fo offen feyn als Der 5̧immel über ifm, went biefer gernde

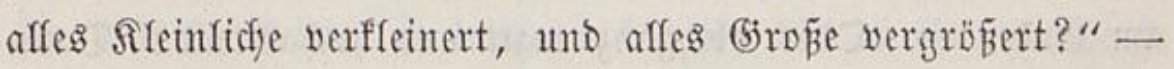

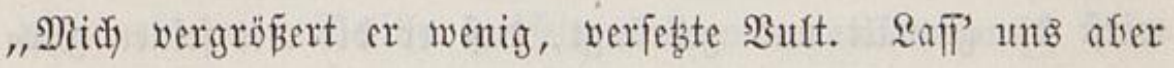
im Sifjatten gefen; fonit muß $i$ d) alfes vorbeigefend rejen, was da yon Empfindungen an bie Bäunte genagelt ift. Dent

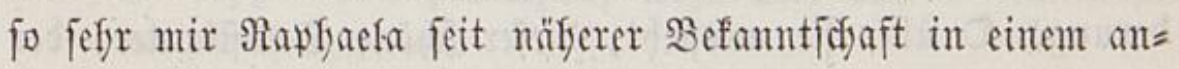




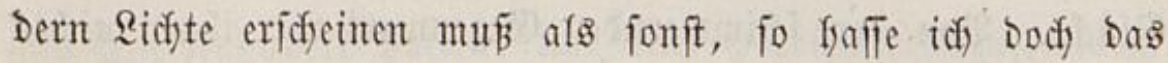

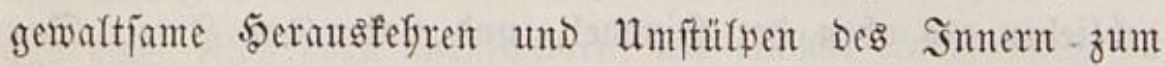
$\mathfrak{A}$ eupern nod) fort, als fei man eine fefrebare Tfyerpflanze. Went ein Mäbdyen anfängt: "eine fodjüe weiblidje Secle" fo lauf' ich gern Dabon; benn fie befiefte fich mit. - 5erzen fat ofneffin jebes fo viele aufzumadyen uno zu veridyenfen, als ein Fürft Dojen, und beide entfalten Das Bilonís Des (jebers, nifft des Empfängers. Heferfautpt! - Hnd fo fort! - atber idf berufe midy auf bidf felfer, of bu wol Gei beiner uno unferer Defiffatefie fäfig wäreft, yon Deinen

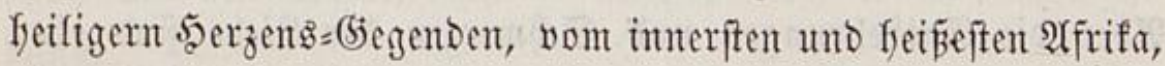
alles befaunt zut madyen und Rambfarten bavon zu ftechen. Ein anderes, Brutber, fund Epibgüfereien ber Riebe - blobe

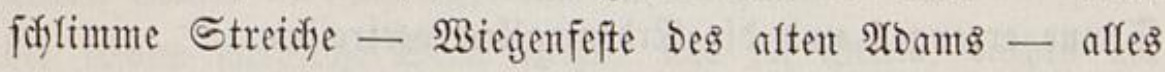

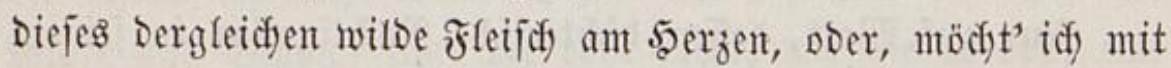
Den 2 erzten foredyen, foldje Ertravajata, poer mit Den Rano=

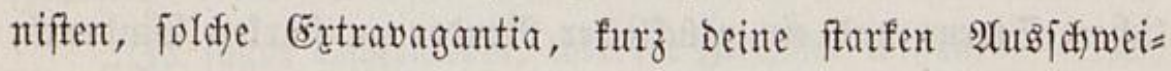
fungen fanmit bu mir, of idf fie Dir gleidf faum zugetraut fätte, ofne Sdyaden entblößen. Berliefte Riebe Gingegen bedenfe dię menigftens für fünftige fälle. Denn ber vor= treffliche Mant, Dem Dut etwa beine Flamme unt Deven (bies genftand befannt gemadift, weißs nidft redyt, Da er Dodf an Dei= nen frofen Empfindungen Den frofeiften $\mathfrak{A}$ ntfycil nefmen wifl, wie er bie ßerjon zu Gefandeln fabe. - Df ganz wie Du? Afber Dam fefite gar Der Unterichied, und Du fnurrteft wol ant Ěnde. - Doer of ganz matt und fodjadftend? Danut wirft du gequält und gebrängt, $\delta a \tilde{\beta}$ er bir mit jeinen gyp= fernen 2 utgen in Deine $n a \tilde{B}=$ Gremtenden fielyt. Der vortreff=

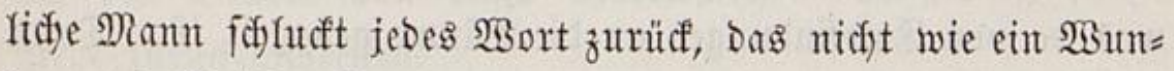

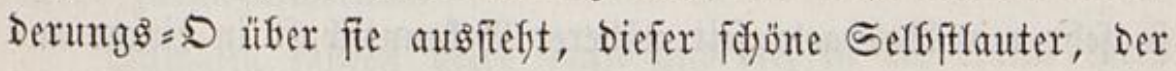


im Nunde efen jo gut Den Rreis als bie Rufle nadjpielt. Sfr beide ober ifre brei figt immer befangen neben einander. Der Mant föant fid bor Dem Mann ftets mefre Der Riefe,

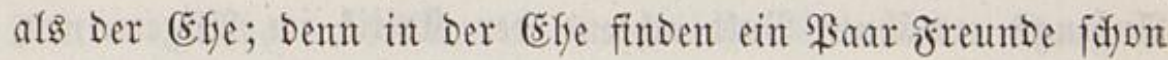
efjer etwas zum Sympatfifitren, z. B. Whedjel = Jammern über ifre $\mathfrak{B}$ eiber u. F. m."

Balt idjwieg, legte fich ins Bett und in bie Träume finein, und that bie Atugen zu, um afles zu feffen, was ifyn beglüifte.

No. 61. Sabrador=Blende von ber Jnjel St. Waul,

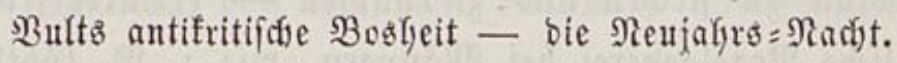

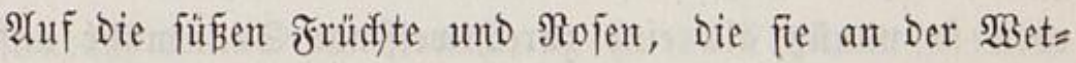
terjeite ifres Rebens zogen, Glies wieber ein raubes Rüftchen,

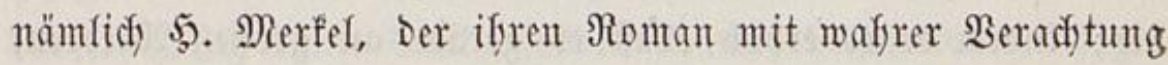

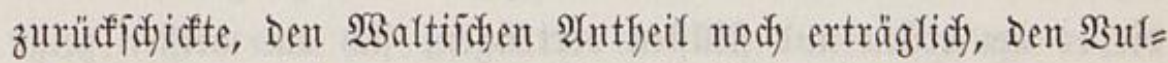
tifchen aber nicht mur abgefdymadt fand, fondern gar Dem

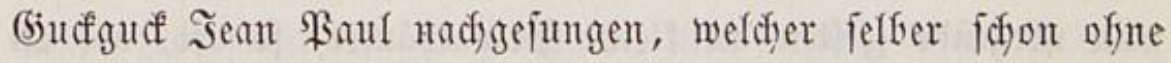
Die (3utfgucf

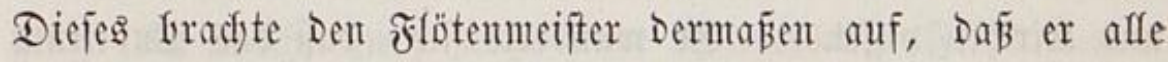

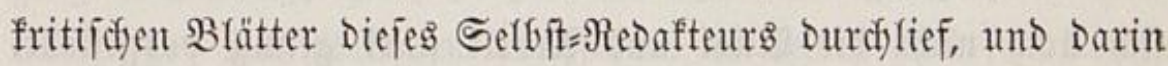

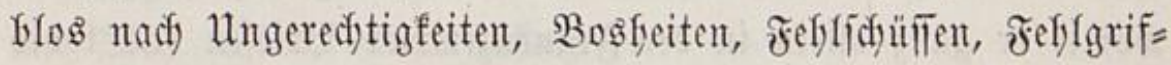
fen und fefiltritten fo lange nadjiagte, fis er ifm gerabe jo viele, als man Defifle in jeinem homme aux champs $\mathfrak{B} i e=$ Derfyolungen *) vorwarf, fum zweiten (Ëinriafen zufertigen

*) Im Appel aux principes, wozu nod) 558 - S(ntitfefen vo:geworfen werben. 


\section{8}

fonnte in cinem SBriefe, nämlidy fechsfyundert und orei unto vierzig.

Der ganze Brief war voll Ironie, nämlidy voll $\Omega_{0} b-$

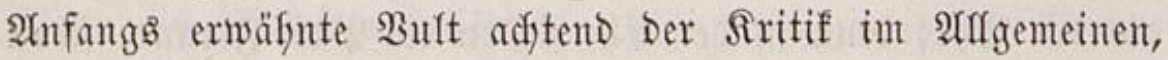
weldye er eine nötbige Budfthäusler = $\mathfrak{A}$ rbeit nennt, Da fie im

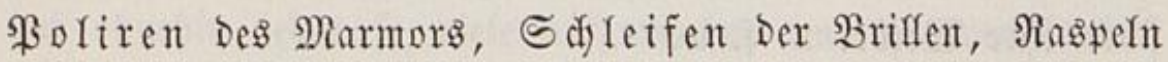
ber Эärbebälzer, tnd Şanfflopfen für Stridfe beftefse -

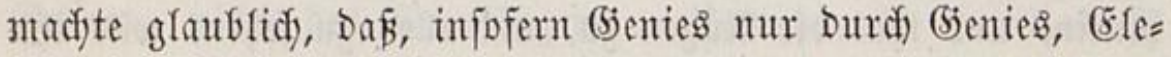
phanten mux Durd) (Elevfranten zu bändigen und zu zäfment

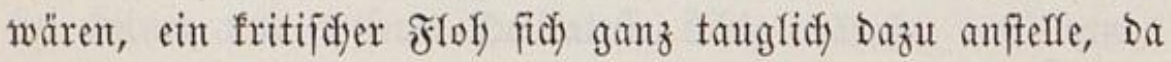
er fidf) won anderen (Eleplyanten weder in Der (seftalt, nod),

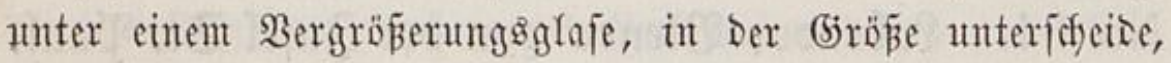

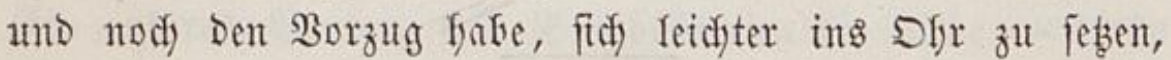

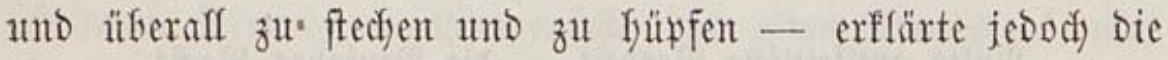

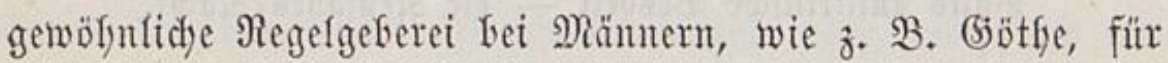
eben fo unnübs als eine zuredftweifende Sontuenufyr auf Der Sonne - rücte nun Serm Merfel nidjt ofne Bogfeit nä=

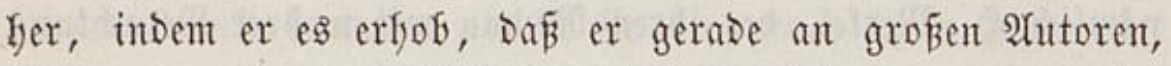
Die es am erften und ftilliten wertrügen, fid am meiften zeige

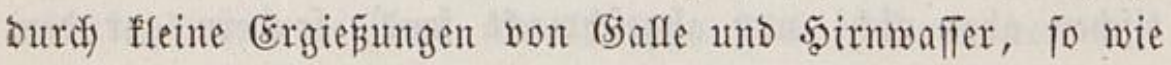
man nirgends (jelten an fleine Brivatyäujer) fo oft, als an

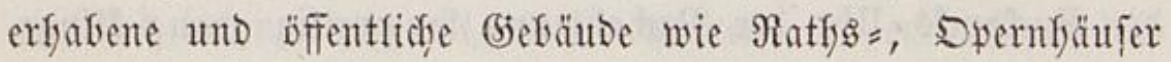

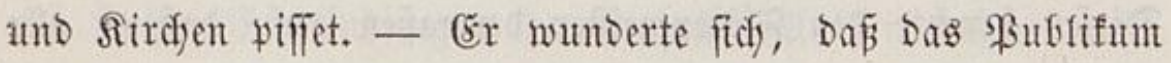
fidi) nody nidyt Die sual und arbeit ftarf genug vorgeftellt, womit er ganz allein in Den Franenzimmer = Briefen Das to te Mujenpferd aus Der Strape wegzufdlewpen frebte, eine Dar= ter, wowon ein $\mathfrak{B a j e n f i n e d y t ~ z u t ~ f w r e d i e n ~ w i ा l e , ~ b e r ~ m e f r e r e ~}$ Tage ganz aflein, weil jeber Borbeigebende fid zur şant= reidung auts Sorurtbeif für zu efrrlich balte, an einem ge= fallenen (5aule abtrage - nafm Davon (5elegentyeit, Deflen 


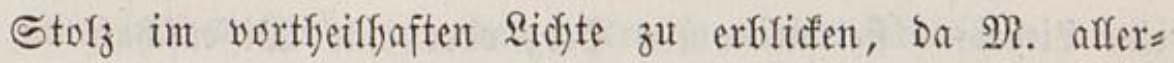

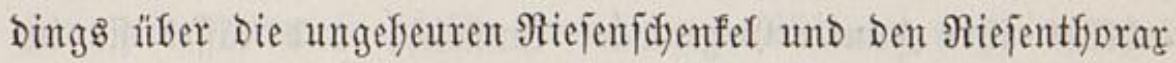
feines Sifnattens vergnügt erfaunen müfe, Den er auf bie Märfer $=$ Fläche projeftire bei Dem tiefen Stand Der Morgen= forme ber netuen 8eit. -

Da aber $\mathfrak{B u l t}_{\text {in }}$ Berfolge anfängt, angüglidid zut wer= Den, ja veradftend: jo fält fidid Der Berfaffer Durdy fein fia = belides aeftament und Durd, feine \&afrador = Blente von Der

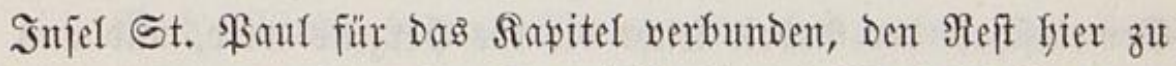
exzerpiren; um jo mefre, da nidyt cinmal Merfer felber das ganze Sd)reiben cingerüft ober beantwortet frat, Den idy hier iffentfici) zut bezeugen auffordere, of nidyt ber unterbrücfte

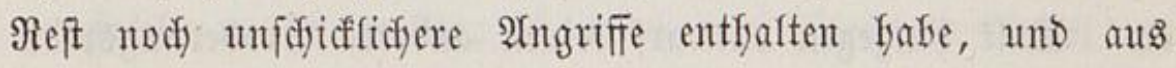
gleidyen (srïnden von ifm, wie von mir, unteridflagen mor= Den jei. -

Darauf wurbe Der Roman an $\mathfrak{5}$. v. Trattner in $\mathfrak{B}$ ien geforficft, weif man Dafin, fagte Bult, nur fralb franfirent Dürfe. "Id) Danfe (5ott, fobald id nur yoffen fant," fagte Walt. Die neue âtreit wurbe Der aften mit beigelegt. Der

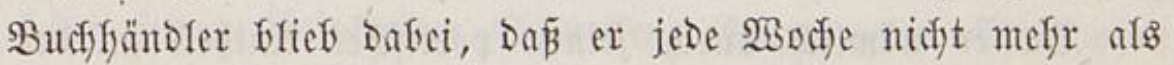
Einen Sorreftur = Bogen zufdjidte, und folglid) Diefes (Ertramt. Des Rorreftorats ungewöbnlich) ausdefnte. Der Rotarius be=

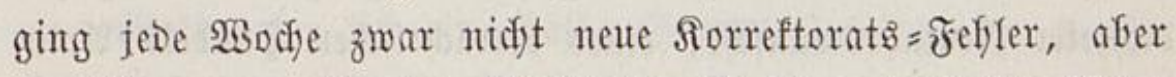

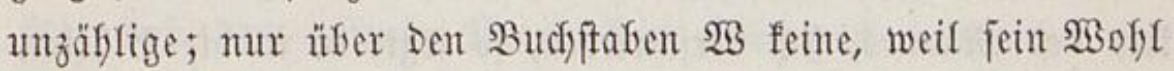
und $\mathfrak{B} e f$, 2 Bina, Damit anfing.

Todt = D̈De wäre Das Dowpel = Reben Der Brïber autgefar = Yen ofme Die Riebe, weldye Den Baugefangenten Der Notfy Die Yjödffen Ruftidylöfer erbauen läßjt, weld)es fo viel ift, als fie

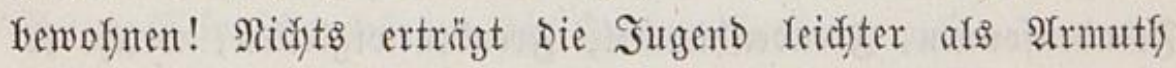

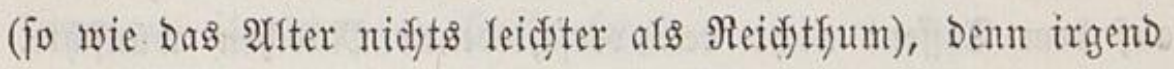




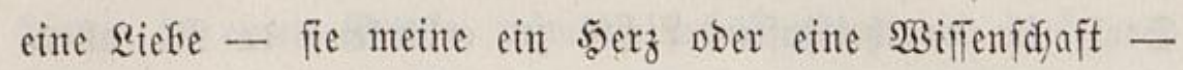
erfellet ifre Dunfle (begenwart fünftlidy, und räflet fie int funftlichent Inge fo freubig fern, als fei es ein walyer, wie Böget vor bem Radytlidjt fortidylagen, weil fie es für einent Iag ampelyen.

Bult war nun entidylōien, in Der Neujafres = Nadyt auf Wina's 5erz feine feindlidye Randung - mit ber flöte in Der 5amo - zu uradjen. 5ooffuungen fyatt' er - Da aus

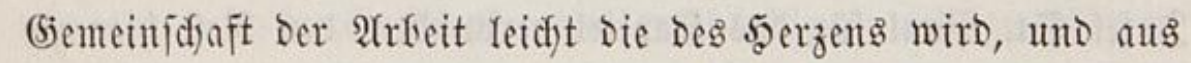
Dem Faftor Der Santelswittwe leidyt iffr Mann - genug: "wenn ein $\mathfrak{B a n r}$ Durd) Das $\mathfrak{A}$ ugfüfyen eines zweiftummigen Sabes nidjt cinfimmig werden: fo irr' id midf fefre," fagt' er. Walt fingegen entwarf feinen anderen Eroberungsplan als Den, $\mathfrak{B i n a}$ berftoffen anzufdjauen - vor Frente zu wei= nen - ja Geranzurücen mit fid - uno, wenn (5ott ifm Finferní, oder jonft (selegenfyeit bejocerte, im Saus unb

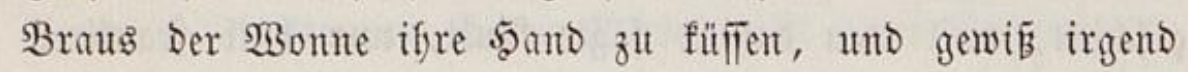
(5twas zu jagent. Bis bafin jagte er ifre nod) mefre, aber gebruft auf Iaffent uno feinftem ßapier.

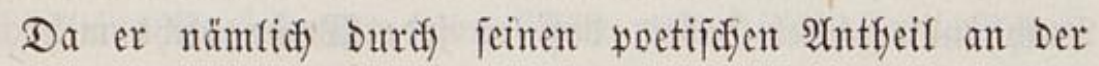

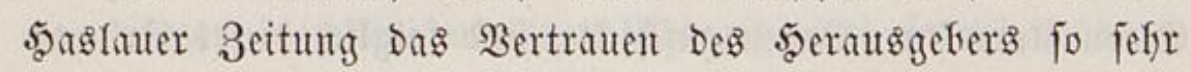
gewonten hatte, Dafi biejer von ifm bie ganze Rieferung ge=

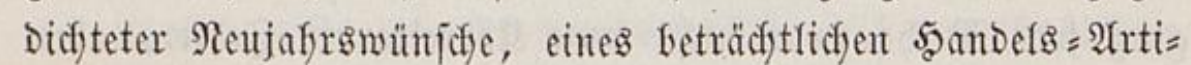
fels Des Mannes, fict veridurieben, fo regte er in Die Blätter, Die für $\mathfrak{R a ̈ b d j e n ~ v e r f a u f t ~ w u r b e n , ~ u n z a ̆ f l i g e ~ P G o ̈ n i x ~ = , ~ B a r a = ~}$

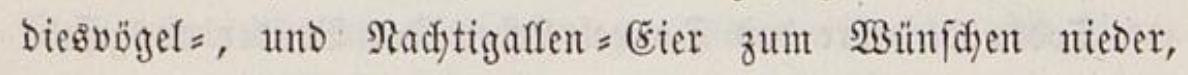

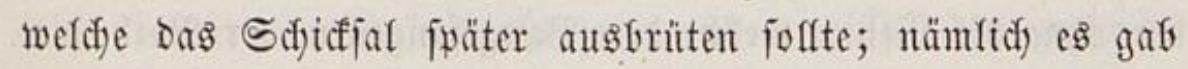
mit anderen 2 orten wenig grentenfränze, grentenmonde, Freutocnjonnen, Freutentimmel, Freubenewigfeiten, weldje er auf Dem Iaffent nidjt ben veridjiebenen Mäbdjen wünjote, 


\section{1}

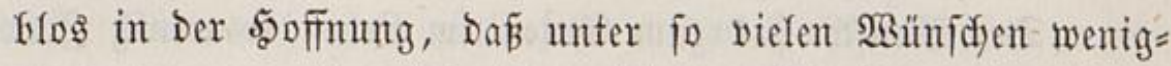
ftens einer von fo vielen freundinnen $\mathfrak{B}_{\text {inta's }}$ werbe gefauft werden, für Dieje. "D wol zefn! !" fagt' er.

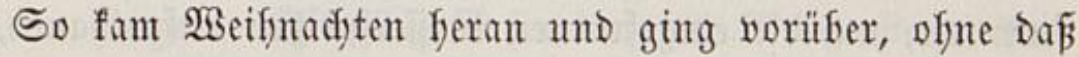

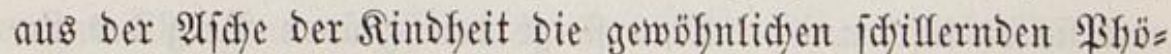
nize auffitiegen - Da bie Nenjafres = Nadft ifnen zu nafje

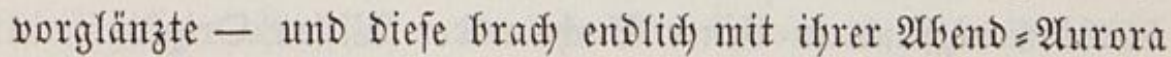
an, Die noch Dem alten Iafre gefjörte.

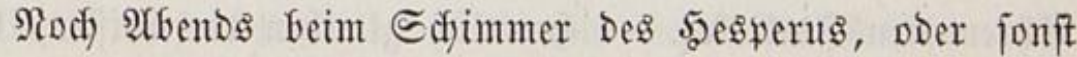

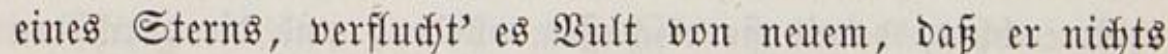
weiter batte, als bie fidonjpte (jelegenfyeit, aber fein (jelb, Radyts Den gafanteften $\mathfrak{R a n n}$ von $\mathfrak{B}$ elt bei Den Sungfrauen zut fpielen: "id wollte, idj wäre wie idjedjtere \$ufict mit Dem Bettelorben Der Reujafrsfafyer umfergeidifit, uno frätte menigftens nur fo viel erbettelt, um Den Reifjen zu machen," fagt' er. Sobald Engelferta ifn auf 4 Mrfr $M$ orgens in Die

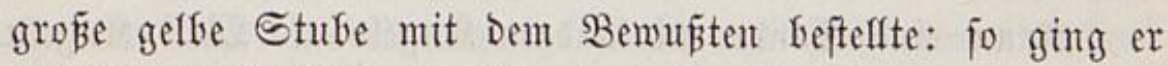

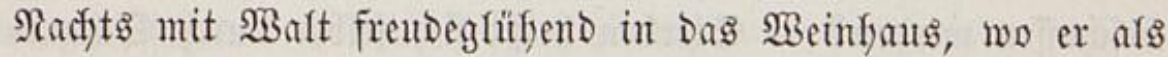

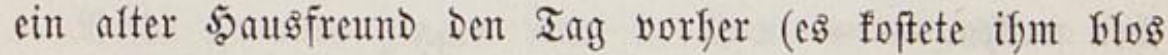
jeine feinen Beinfleider $=$ Sifnallen) (Shampagner $=$ Wein ofne

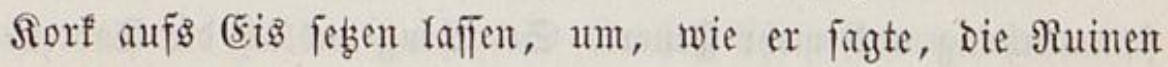
if)res 5ุunds = Rebens ein wenig auszutapeziren.

SBalt nafm fid eine fralbe Stunde Beit, um zu begrei= fen, Daß Dem offenen Weine fein $\mathfrak{B}$ eingeift verraudjet fei. Dann tranf - alfen Nadjridjten zufolge, Die man frat jeder; Dod, jo, Daß Feide einanter als yofitive und negative

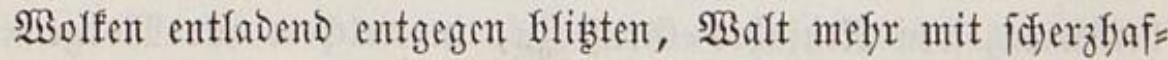
ten Einfäflen, Sult mit ernften. In einer Błumenteje au๖

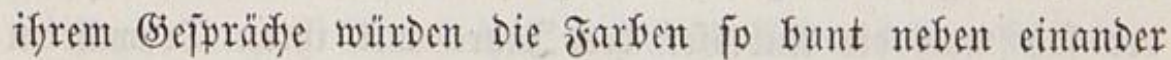
fommen, als fier zur Frobe folgt: 


\section{2}

"Der Menfol frat zum (buten im Seben fo wentg 3eit

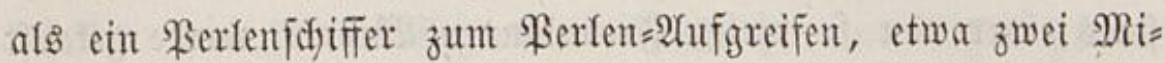
muten. - Mandje Staatseinridjtungen zünsen ein Sdjaden=

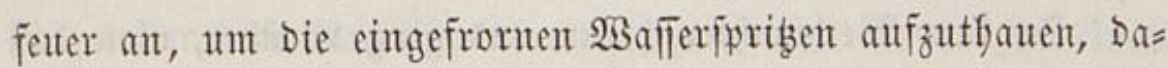
mit fie es löffifent. - Man feigt Den grünen Berg des $\mathcal{L}_{e}=$ Gens fintaf, um oben auf Dem Ëisberge zu ferben. - Seber bleibt wenigftens in Einer Sadje wiber $\mathfrak{B i f l}_{\mathrm{fen}}$ Driginal, in

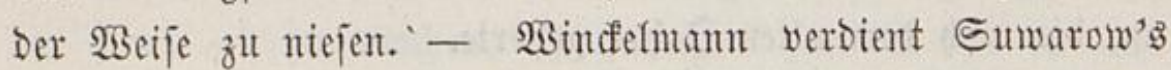
(Efrentamen Stafisfoi. - Seimlidy glauben bie meiften, Gott exiffire blos, Damit fie erichaffen murben; und bie burdl Dent Aetfer ausgeftrecfte $\mathfrak{B e l t e n}=$ Partie fei Die Erozunge iffres

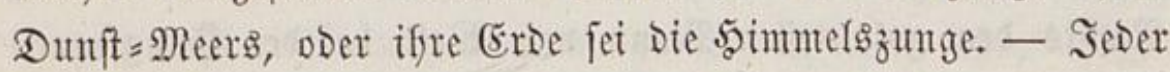
ift Dem 2 (ndoern zugleidy Sonne und Sonnenblume, er wirb gewentet, und wendet. -

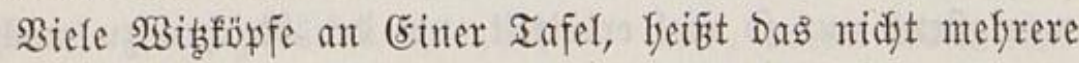

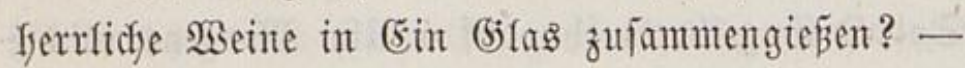

Sinn cine Sonte mit andern Rugefn als $\mathfrak{B e l t}=$ Sugeln

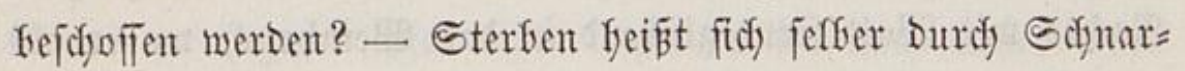
dyen wectert. - -

Uno fo weiter; Denn im Berfolge war viel wentiger $3 u=$

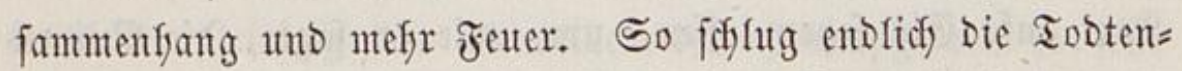
glocfe Des Jafres; und Der unfidytbare Reumond Des neuen

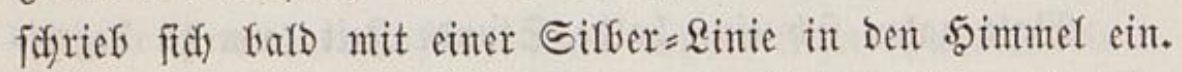

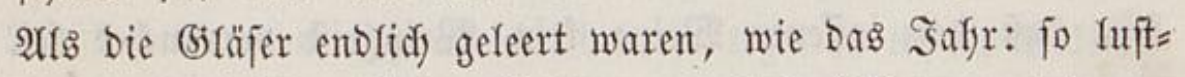
manbelten beide auf der (5ajle, wo es fo hell war, wie am Iage. Heberall riefen fidd Freunde, Die von Freutben=(jelagen

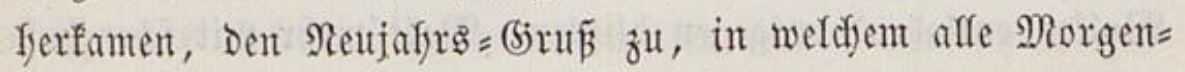

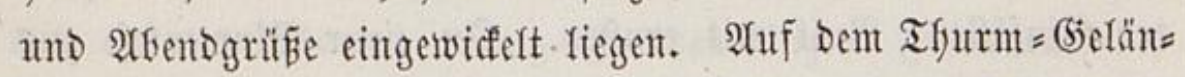
Der fah man bie $\mathfrak{A}$ bläjer Des Safyrs mit iffren Trommeten redyt Deutlid); Sagalt Dadyte fidy in ifye 50 bje finauf, uno in 
biejer fam es ifyt vor, als fefle er bas Safyr wie eine unges beure $\mathfrak{B o l f e}_{\mathrm{f}}$ voll wirbelnder Beftalten am borizont fyerauf= ziefyen; und Die Töne namten Die Beffalten fünftiger Stun= Dent beim Namen. Die Sterne ftanten als Morgenferne Des emigen Morgens am Simmel, Der feinen 2lbent und Morgen

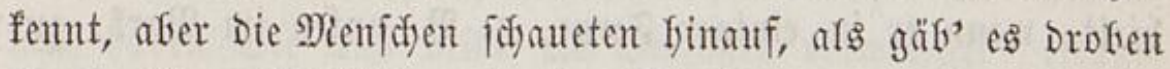

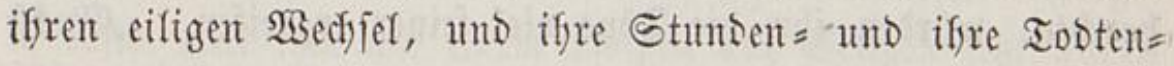
glocfen und Den Deutidfen Sanuar.

Unter biejen (befühlen (jottwalts ftand bie beliebte als

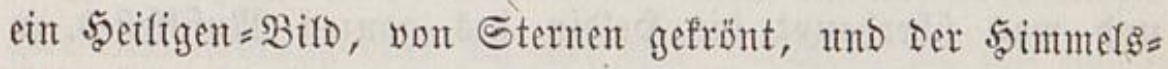
Sdyein zeigte ifre gropen Alugen beller, und ifre fanften $\Re_{0}=$ fenfipwent näfer. Richt wie jonft feelle ifym Das alte $\mathfrak{J a f h r}$, Das an Der (Sefurt Des neten farb, Das Bergefen Des $\mathcal{L}_{e}=$ bens Dar; Die Riebe verwandelt alles in (5)anz, Thränen und Gräber; uno yor ifr berüfyt Das Reben, wie die nieberge= fente Sonne auf Den norbifdsen Meeren ant langen Tage, nur mit Dem Rante bie Untergangg = Erbe und feigt Dann wieber morgendich Dent bimmelsbogen fintuf.

Beide freunde gingen $\mathfrak{A r m}$ in $\mathfrak{A}$ rm, endicidy Şand in 5ano, in Den Straß̄en umber. Waatts furze Ruftigfeit war Dem tiefern rüflen gewidgen. (Er faly fidf oft um, uno in Bults beficfst finein: "io muitien wir Gleiben in einem fort,

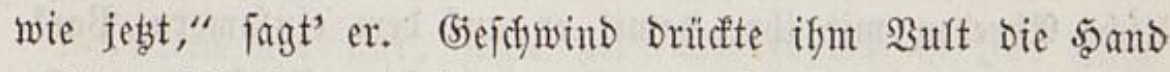

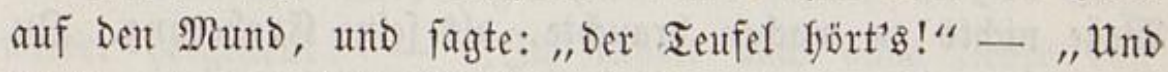
(5ott auch), verjebte 2 alt; und fügte Dann Yeife, rofentrotf, unb abgewanot finzut: "In foldfen Rächten follteft bu aud

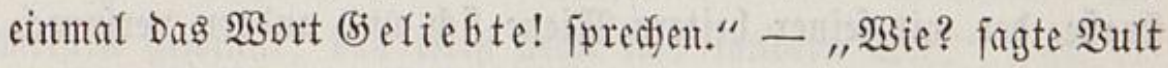
roth), Dießs wäre ja toll." -

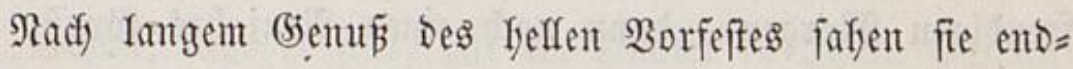

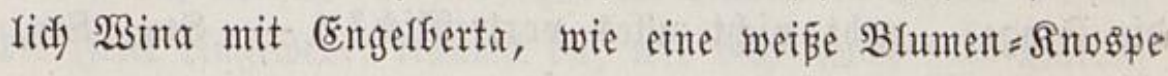




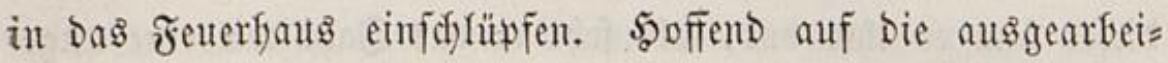
teten Plane jeiner Riebeg=(Erflärung, und fo glüclich) wie cin

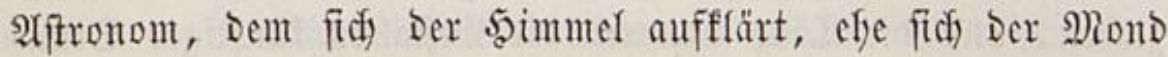
total verfinfert, fucdste $\mathfrak{B}$ ult jekst Die Shren Des Brubers in etwas yom Riebfaber= Theater wegzuffeflen, indem er ify vor= fielt, wemn er in einiger ferne, $\mathfrak{z}$. B. unten im $\mathfrak{B a r f}$, zu=

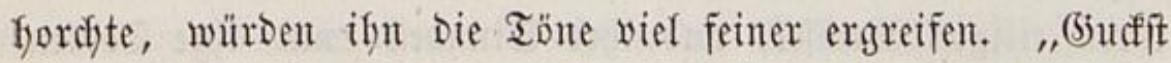

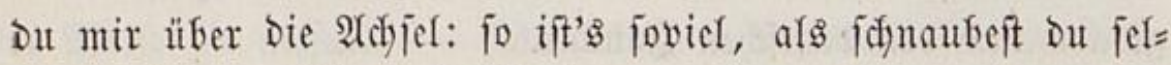
fer mit ints fötentod) finein, wobei wenig zut holen ift; und was ilferfant bie belbin Des ganzen Mufiffeftes zut einem Rager, Das zwei junge Mämer vor ifrem eignen im Bette nuficjlagen, jagt, braudedt Dodif aud Bedadyt, mein Walt!" - "Da es Dir jo lieb ift, fo wend id nidfte ein," fagte biejer, und ging in Den falten Barten, wo Der blent= Dende Salnee fo gut geftint war, als Der tiefe Alether.

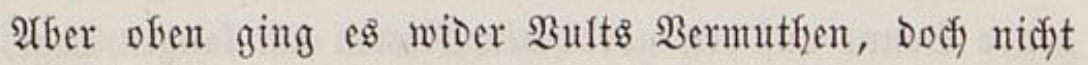

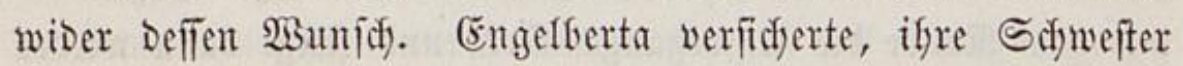
wirtbe, ba fie flöte und Stimme fo fenme, vom erfent $\mathfrak{2}_{1}=$ flang erwadien, und alles verberben. "So muñ bie Mufiff in grö̈̈ter Jerne anfangen, uno wachjend fid näfern." "(5)ut,

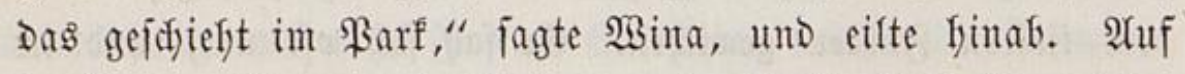
Der Ireppe, finter nafen Shren, nafm $\mathfrak{B u l t}$ eifigit afle mufifa=

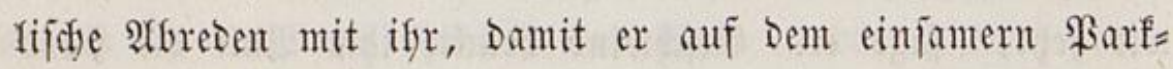
Wege nidjts zu madyen fraudjte, als feine Eroberumg. $3 u$

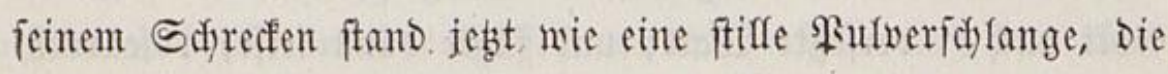
Glos auf Das Sogzünden martete, Ser Rotar auf Der saupt= fitrape, Der mit feiner Geitern Miene fidi und andern verjprady mitzugefyen, und alles zu begleiten. SBina gab ifjm einen

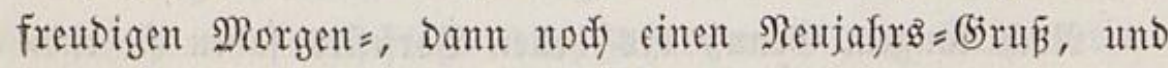
bie Frage, "gefft nicht afles vortrefflidf?" - Sta, Sta, 
Viator, fagte $\mathfrak{B u r t}$, und winfte ifm lyeftig rücfwärts, ftill zu fiegen - wab jener nadjoenfento vollzog, , weil id ja, Dad $t^{2}$,

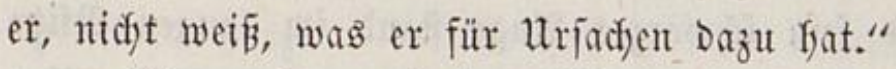

"Ein wafjer, inniger Meníd und Didjter," begann Bult. "Seine (jedidyte find fimmlifod," veriebste fie. "Den= nod) fraben Sie ung beide als Berfaj̄er verwedjelt? (fragt" er rafd, weil iffm wie einem (Ewigen uno Seligen ießgt nichts fefilte, als 3eit.) (Fin foldyer Srrtfum verbient nidft bie ge= ringite $\mathfrak{B} e r z e i f u n g$, fondern Danf. Eine andere, aber ridjti= gere Berwed)glung Denf' id) mir cher — (Wina faf ifn jof arf. in). Denn idf und er frafen ein $\mathfrak{B a a r}$ gegenjeitige 3 wiflings= (jefyeimniffe Des Rebens, Die idj niemand in Der 2 Belt entbeffe

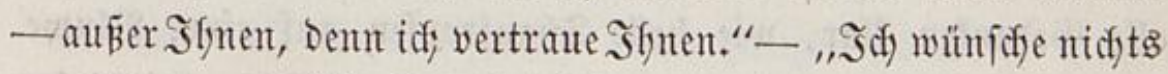

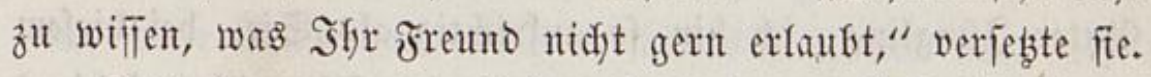

Sebzt fprang er, weil Das Erntbecfungs = (jejprädy viel zu lange 23 endungen nafm, und er vergefrlid auf langiamere Sd)ritte fant, um ifyr näfer z̆lt fommen, plöblidy yor eine Rinde, und las Davon folgende Iafelforrift von Raphaelen ab:

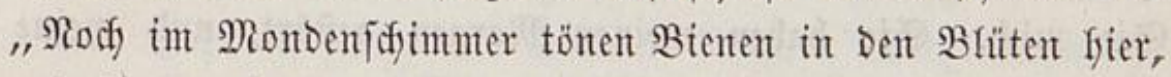

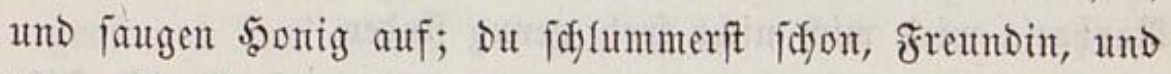
idf rulf' fier, und benf' an bidf, aber träumft du, wer Didi) liebt?"

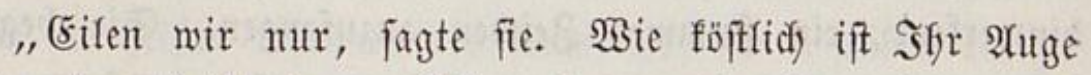
wieber bergefteflt!“ - „Id) nefyme audi alfes lieber von Amor an, Gejonders die (siftufeile, als die Binde; idj fah Sie ftets, verefrte Wina, wer babei von uns beiben am meiften gewinut, Das weiß nidjt idf, fondern Sie," fagte er mit feiner Miene.

"Shön, fuffr er fort, fyat ber Didfter in Jyren Gejang bie Beile eingewebt: träumft bu, wer bid lieft?" - Darauf

Sean भaul's aus̆getw. शEerte. XIV. 
Drefte er fich fyalf gegen fie, fang ifre leife bieje 3eife, bie er abfichtlid) zu biejem (bebraude fomponirt, ins treuferzige Ingefidyt, und fein fofwarzes $\mathfrak{A}$ uge ftand im langen Blib̧e Der Riebe. Da fie fodwieg uno ftärfer eifte: fo nafym er ifyre

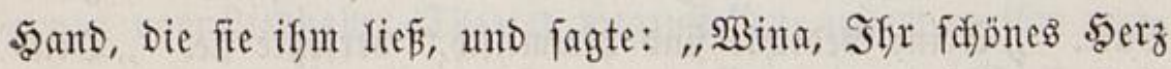
errätfy midy, Shnen wifl $i d$ anders, ja, wenn's nicht zut ftolz iff, äfntidfer eridfeinen als Der Menge. Sơ habe nidyts als mein 5erz und mein Leben; aber beibes fei Der Beften ge= weift." - "Dort, (5uter!" fagte fie reife, zog ifne eiliger an bie Stelle, wo fie fwielen mollten; Dann ftand fie fitfl,

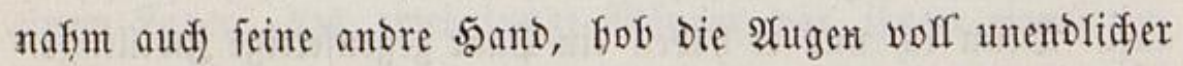
Siebe zut ifm entpor, uno auf iffrem reinen 2 Angeficht ftanden alle (sedanfen flar, wie helle Iffautropfen auf einer Bhume. "(Suter Süngling, id bin fo aufridytig als Sie, bei biejem

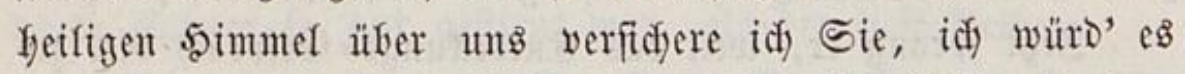
Shnen offen und frof geftefen, wenn idy Sie fiebte, in Dem

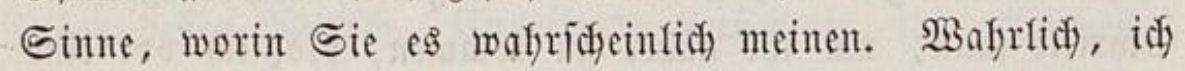
thä' es filfn aus Riebe gegen Sie. Sdjon jeb̧t fodmerzent Sie midj. Sie fraben meinen Morgen gefïbrt, und meine Rawlyaela wirb midf nidyt frof genug finden."

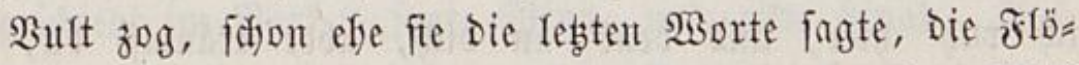
tenftüffe beraus, febste fie zufammen, und gab, mur einen Blicf finmerfent, ein ftummes 3eiden anzufangen. Sie begann mit erficfter Stimme, eine furze 3eit Darauf mefjr forte, aber Gald ordentlidf.

BBalt Durdfidnitt Den 5auptgang unten fin und ber,

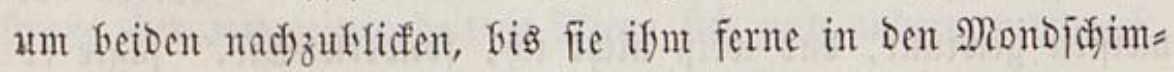
mer wie zergingen. (Endich) förte er Den munderbaren (5irufis (bejang an Die Shlafende, feine eigenen Worte, aub Der Dämnter $=$ Ferne, uno fein 5ूerz in eine fremoe Bruft verjebst, 
wie es ber armen Schläferin broben, an bie felber er bisher gerabe am wenigften geondyt, Die $\mathfrak{B}$ orte fagt: „erwadje frof,

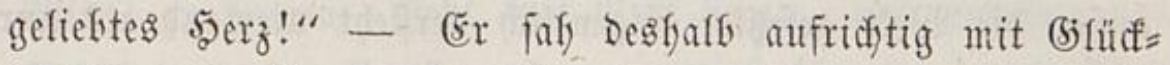

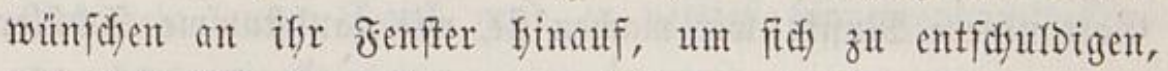
uno wünfdot' iffr alles, was Rebent uno Riebe Sdjöres zu

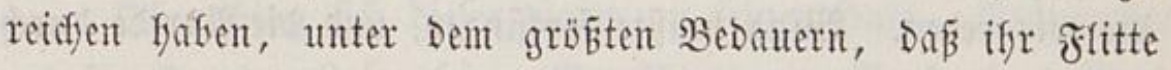

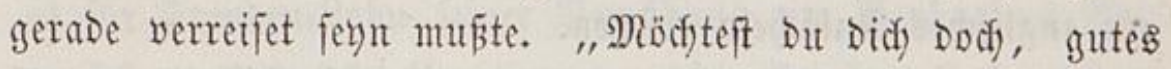
Mäbdyen, badft' er, täglidy für immer foüner falten, wär' audf nidjt ganz wafre! Uno Deine Mutter, Deine $\mathfrak{B}$ ina müfre audf) fo Denfen, um fidf fefre an Dir zu freuen!"

शtuf einmal fört' er Engelberta, Die ifm rietf), er möge, wenn er fidc) warm laufen wolle, lieber ins şaus finauf. Da ifn mun Diefe 2 Uufmerffamfeit eines 3eugen ftörte: fo ging er ins nafye Rindenffauts, wo er nidjts fafy, als über fid Das nädytliche Şimmelsblau, mit Dem fyereinftralenden Monde, und nidfts börte und in fidf ratte, als bie jüpen 2 sorte Der fer= nent zurten Rippen. (Er faf finter Der Rinde Die fajimmernde

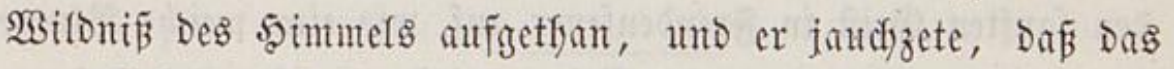
neue Safyr in jeiner mit Sternen bejesten Morgenfleidung fo groṕ und yoll baaben yor ify trat.

Nun fan $\mathfrak{B i n a}$, Die melodifhe $\mathfrak{B e c f e r i n}$ zum $\mathfrak{B}$ iegen= fefttage, immer näfer mit ftürferen Tönen, Bult finter iff,

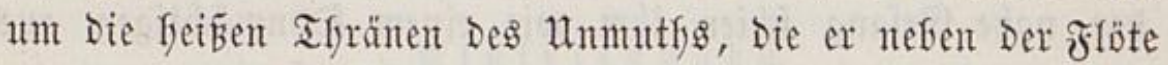

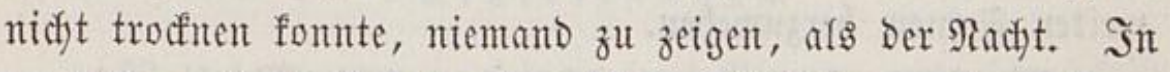
Der Räbe gab iffr Engelberta auf Das Edylafzimmer Der Sdywe= fter und $\mathfrak{B a}$ alts Rinden= Rotunda winfente 3 eidjen, welchen fie zut folgen glaubte, went fie fidf in Die Rotumba fingent verbarg, um da fich und iffr früflings = Ried yon ber erwa= djenten Freundin finden zu laffent.

Sie fand Den Notar mit Dem Auge auf Dem Monde, 
mit Dem breifte in Dem Glanten Ietfer - ifre näferen Töne und Bults fernere fratten ifn Geraujdyt, umb auper fich und auper Die Welt gejebst. (Eigentlid) verfteft niemant als nur (5ott unjere Mufif; wir madjen fie, wie taubftumme Edjüfer won seinede Worte, und vernefimen felfer bie Spradje nidft, Die wir reden. SBina muṕte fortfingen, und Die $\mathfrak{A}$ nrede Durdi

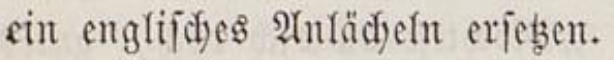

Da er gleidffalls nidste fagen burfte, fo lädyelte er audf

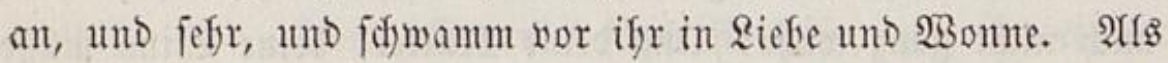
fie mun bie figöne melosifdje Beile fang: träumft bu, wer bidf riebt? und fie fo nafe an jeiner Bruft sie heimlichen Laute Derfelfen nadjprad): io fant er anf Die Sinie, umifient ob zum Beten ober zum Rieben, und faf auf zut ifre, weldye vom Mond wie cine obentyerabgefommene Madonna umfleidet wurbe mit Dem Radiglanze Des 5immels. Sie Yegte fanft die redfte 5anto auf feit weidjloctiges 5antpt; - er foob feine beident auf, und brücte fie an feine Stirn; - Die Berüfrung löpete Den janften (jeift in Freubenfeuer auf, wie eine meidje Blume in üppiger Sommernadyt Blibe wirft - Freutentffränen,

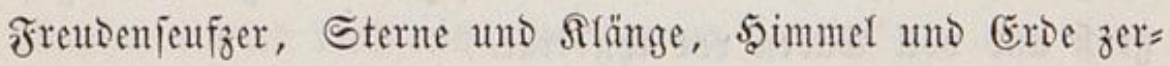
rannen in einander zu Einem 2letfermecre, er fielt, ofne zut wifien wie, ifre sinfe an fein podjendes berz georücft, und Der nabe befang fodien ifm wie cinem Shnmäd)tigen aus weiten gernen herzumefen.

Die Flöte ftand ganz nafe, Das leb̧te $\mathfrak{2}$ ort wurbe ge= fungen. WBina zog ifn fanft von Der Eride auf; er glaubte nod) inmer, es töne um ifyn. Da fam mit frentigem $\mathfrak{H}_{n}=$

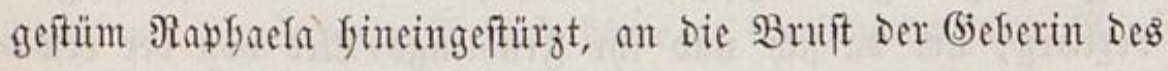
fidönfen Morgens. Wina erid)raf nidjt, aber (jottwalt fie gab Der Jreundin eine ganze freuntin. Sie fagte zut 
(5ottwalt, Der nidft foredjen fomute: wir fefjen uns arfentos mieder, am Montage? - Bei (5ott, antwortete er, ofjne Das Mittel zu fennert. Selgt trat Bult finzul, uno empfing von

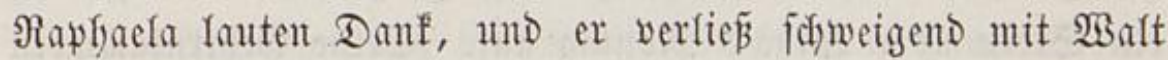
Den feltjamen barten.

Dben fing fid biejer warm an jeinen 5als. Sult nafm es für Freuden=Rofnt feiner Bemüffung um Raphaelens Mor=

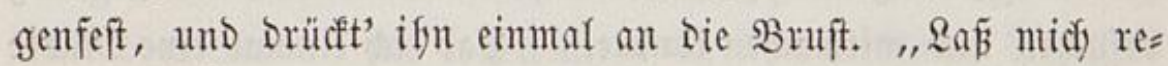

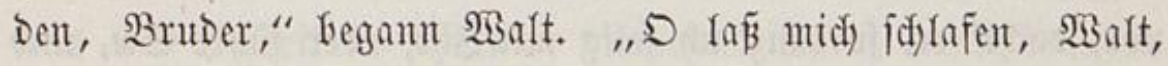
verfezte er - nur Sdjlaf Ger, aber redjten tiefen, Dunfefn, wo man von ₹imfterni recht berfer Schlaf nidyt für ein föfflicfjer weiter sandjee für

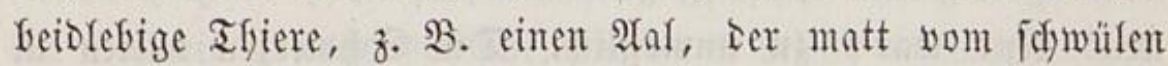
Rande fommt, unt Der nun im Rïlflen, Dunfeln, SBeiten

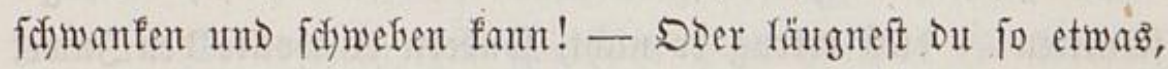
und mefrr?" — "Nun, fo gebe Dir (5ott Dod) Träume, und Die feligften, bie cin Edylaf mur fraben famm," fagte $\mathfrak{B a}_{\text {alt. }}$

No. 62. $\subseteq$ a ut ft $\mathfrak{e} i \mathrm{n}$.

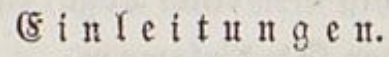

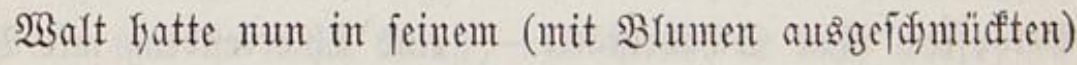
Sopf nidhts weiter als Den Montag, an weldyem er $\mathfrak{B}$ sina

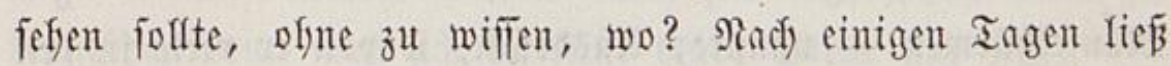
ifm Rapfaela Durdy Flora jagen, bie Redoute am Montage

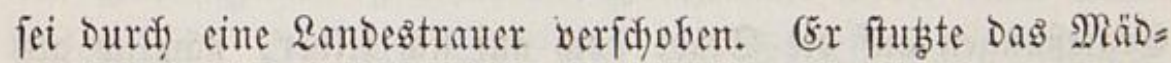
dyen an, uno jagte: "wie, ę̧ war cine Redoute?" 
Bult aber nadjfer anf Die $\mathfrak{A} d$ fer flopfte, und ammerfte, wafyr=

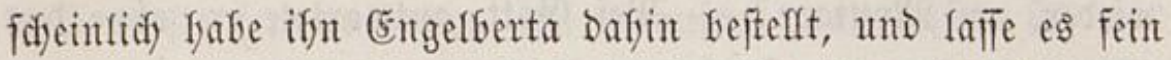
gemug burdi bie Sdjwejter jagen, fo ging iffm ein 2 iddst, ja

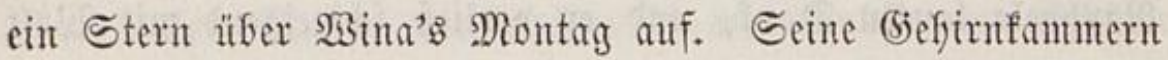
wurden 4 Masfenfäle; er joymur, jo lange fich abzufargen und follte er verfungern - bis er fo viel (5eld zufamment rätte, Daj er zum erftenmal in jeinem \&eben Den Larventanz bejuden uno mitmachen fönnte. "Sab

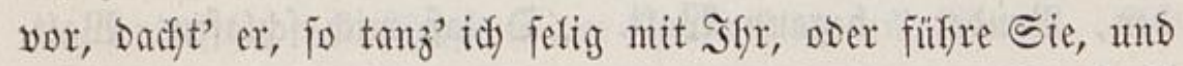
frage wafhrlich nichts Darnady, wie alles ausfieft." WBie fanft fätte es ify berilfyt uno gewärmt, wenn er feinen 3 wiflings:

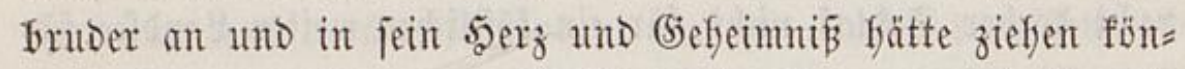
nen! Nur war's ful umtöglid. Die Schmerzen hatten it

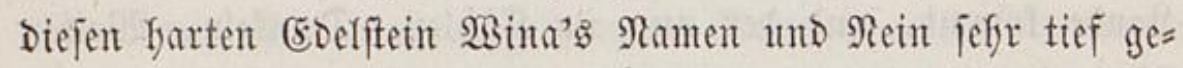
fónitten - Diép ertrug er nidft, fondern er wollte ben Suwel felber abuuben und abjheuern, Damit nidjts mefre Daran zut Tejen wäre; nidyt vor Riebe, jondern vor Ergrliebe, nidyt vor Sefnjudft, jondern vor Radjudft fyätte er fterben oder töbten föment. In biejem Bujtand war es jedem, Der fein Notartits war, fofwer, mit ifm auszufomment. Sor affen Dingen mi $\bar{\beta}=$ fiel ifm Die Räfe und Jerne, er verfludfte Ruartier und Stadt, jentes fein, Dieje geradezu, indem or fie eine Sfyafuppe

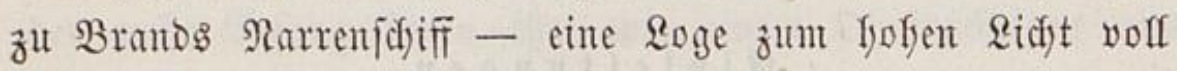

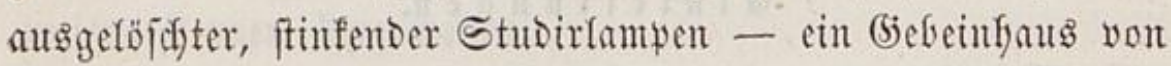
(5eföpften ofne Edyäbelifätte - eine Ifierrefitoenz mit Biely= marft und Ifiergärten, feinen Räferfabinetten und einigen Mäujetfürmen - nannte; $\mathfrak{A}$ แs̆orüde, wovon er viele in Den 5apwelpopwet poer Das berz Gineinnafm. Walt leitete Die Ergießungen auf Die Staot Dod) auf fit felber, nämlich als ob Der Bruber jagen wollte: "Deinetwegen fib' idf im Reft." 


\section{1}

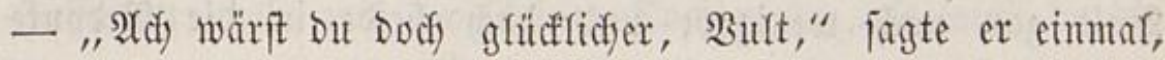

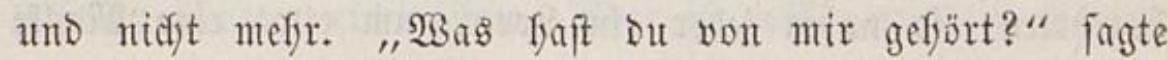
fornig Bult. "Nun eben Das borige," werfebte er, und nafym

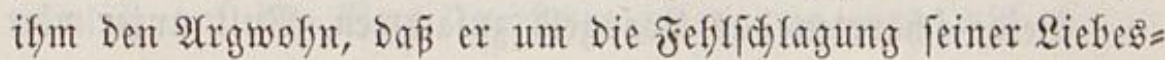
Erflärung wüßß̄te.

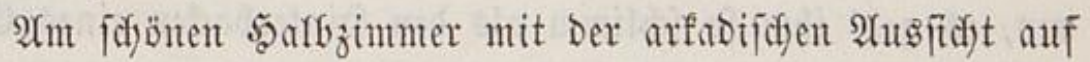

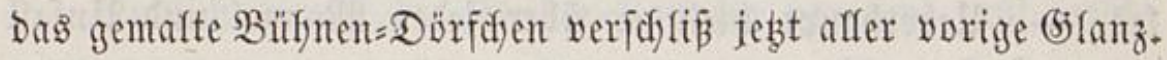
Bult Donuterte - als wäre $\mathfrak{B a l t}_{\text {ant }}$ Der Störutg Des $\mathfrak{F} l 0 ̈=$ tens und Scfreibens fduld - finter Der $23 a n$, went braupen

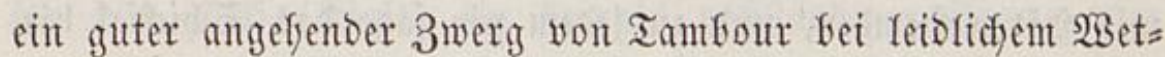
ter fidf auf Der Trommel uad) Bermögen übte und angriff; - oder went Der näfer wofntente fleifder von Beit zut Beit

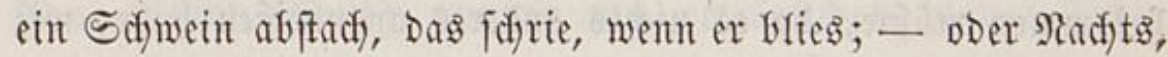

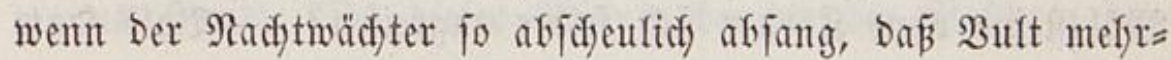
mals im Miondichein ifm über Den $\mathfrak{B a r f}$ finüfer bie ftärfften Sijimpf = und Drofmorte zujdreien mukte.

Die milde 2 ärme Des ewig liebenden Notars trieb uno bläfte feinen Sauterteig nur mefr auf; ,audf idy wäle an jeiner Stefle, jagte Bult, cin (5ottes=2amm und eine Mabonna

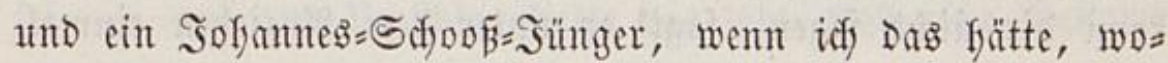
für er feine (5razie frält."

Der Notar aber Dadyte blos an Den Rarventanz und an Die Mittel Dazu. "D liebte nur mein Bruber irgend cine (5es liebte, wie leidjt und jelig wollten wir jern! WBir Drïften Dann alle uns an (Fine Bruft, uno weldide er aud liebte, es wäre meine bieliebite mit. - So ift's leidst, iffm alles zu vergeben, weun man fid an jeine trübe Stelle nur jebst!"

3ufällig verflogen fid in ifre Bimmer $\Omega_{0 o j e}$ einer Ritei=

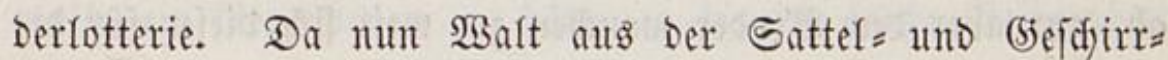
fammer Ser Magfen mandfes braudjte und nidjts fyatte, uno 
Bult gar nod) weniger; und Dod) beide in Die Reboute begefrten: io nafm jeder ein Soos, um etwa cine Masfe zu ziefren.

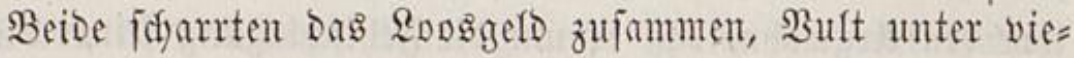

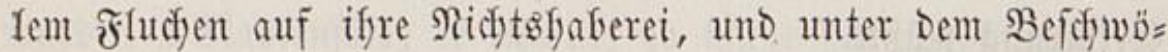

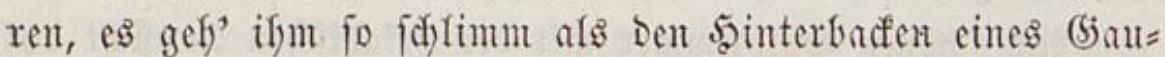
res. - Heberfant fielt er über jeden Mangel uno Hnfaff fange Sdjimpfredent gegen Das Reben, indem er jagte, auf Der

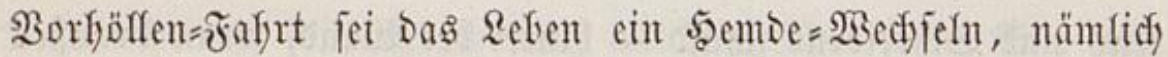

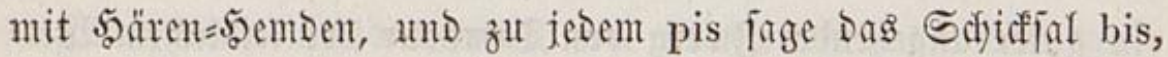

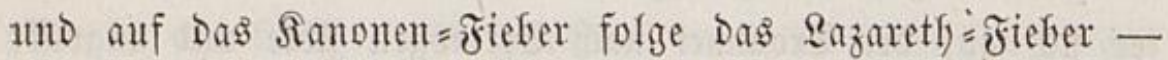

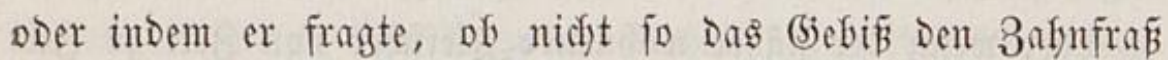
Gefommen müste, da es nidyts anderes anzubeínen fabe, wie Müfflfteine ofne Röner fid) jelfer angreifen? - Balo fagte er aud), Das Reben jei Durd) (Eis gut Darzufteflen - auf cinem (Eisferd babe man, auber falter Siludje und (befrornem, nody

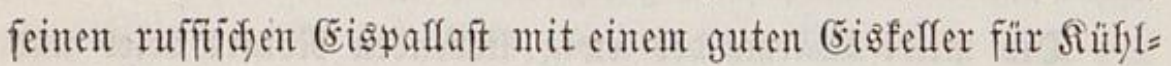

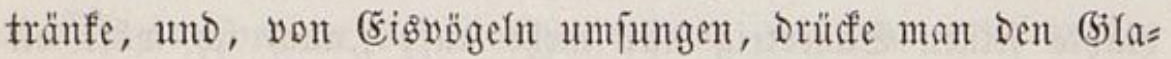

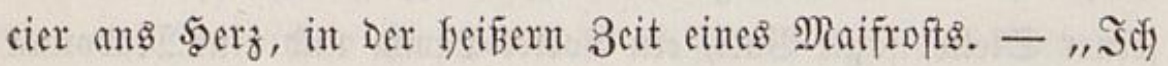

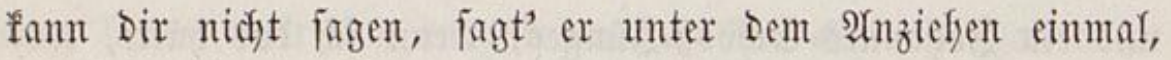
wie fefr id wün fodte, es wäre bei uns wie frei Den Dafjo= mets it Sber=(Suinea, wo niemand Strümpfe tragen Darf, กโs Der Rönig, uno es wäre jebst wie unter Rarl Dem VII. won granfreid, wo im ganzen Lano niemand 2 5eemben be=

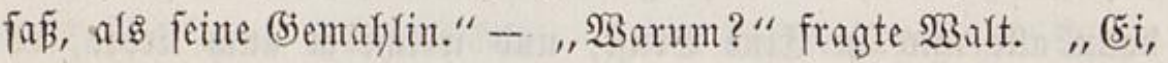
Dann fömenten wir uns redyt gut mit unjerm Stand entidut= Digen," verieste er.

Durdh Dieje Ergieß̄ungen füfrte er eine Nenge Berdruß ab, mur aber Dem Bruber mandfen z̆ll, weil fid Diejer für bie Suefle bielt. "IArmuth, antwortete $\mathfrak{B a l t , ~ i f t ~ b i e ~ M u t t e r ~ D e r ~}$ 
Sooffung; gefye mit Der fobnenen Tochter um, fo wirft Du bie

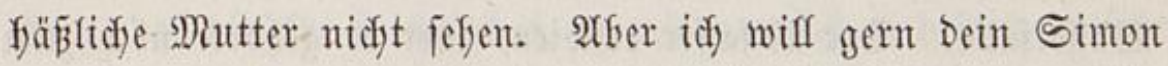
won 3yrene fern, Der Dir Das Areuz tragen filft." - "Bis nämlidy auf Den Berg, verjebste jenter, wo man midy Daran fajlägt." - Siebe fennt feine $\mathfrak{A}$ rmuth), weber eigne nod frembe.

(Endidy wurbe Die Rleiber $=$ Rotterie gezogen, auf weldhe betio fich blos Durch Ränge Der Beit Die größten 50 frinurgen

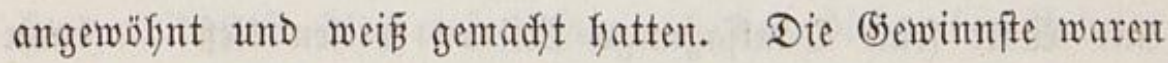

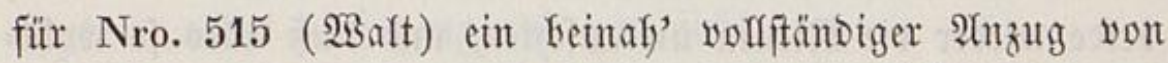

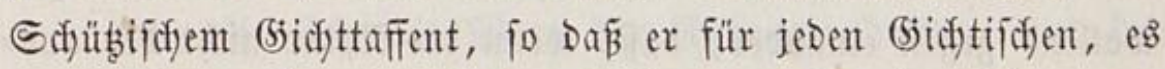
modyte ifn reipen, in weldyem bstiede es wollte, braudfbar war. Nro. 11000 (Bult) gewann ein erträglides blaues Jufles man!s=52emo. In Diefer Minute bradyte Der \$oftrote Den 5oppelpoppel wieder, Den fie an bie Budflyandlung Peter

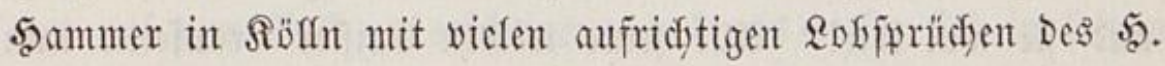
Sammers aflaufen lafjen - nadjoem vorfer leiber bas Mscpt. won 5 . von Trattner mit Der faflen (Entiofuldigung afgemies fent worben, er brucfe felten etwas, was nidjt fidon gebruct

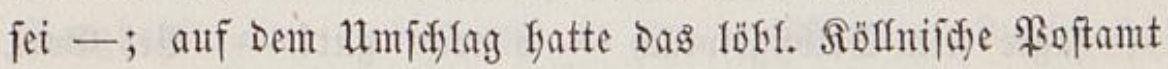
blos bemerft, es fei in ganz föfln feine \$eter sammeride Budfhandlung Diejes Namens zh exfragen, und Der Rame fei nur fingirt.

5ätte $\mathfrak{B u l t}$ je Die befte Beranlanjung gelfabt, über bie

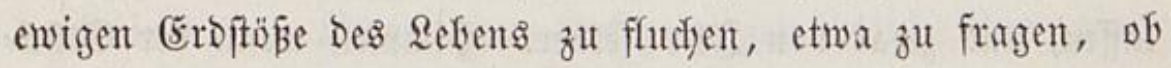

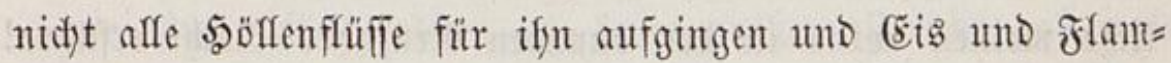

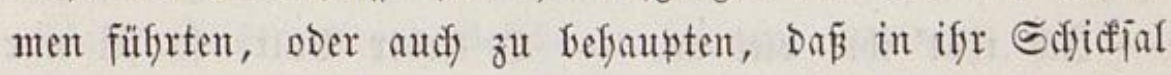
gerade jo gut ßoefie zu malen jei, als aũ eine seeujodreffen= molfe ein Regenlogent - bätte er je eine foldye (5elegentyeit geffabt, fo wäre es jebgt gewejen, wern er nidjt aus biejem 
Sdylagregen wäre ferauggefommen gar unter bie Traufe eines Walferfalls. Der Elfajier eridjien, aber er gefjörte nod) zum

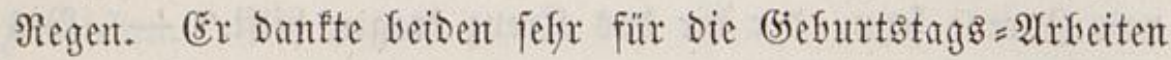
- nod) regnete $\mathrm{eBs}$ - Darauf aber, Da er mit feinem $\mathfrak{A} u f=$ trage von Raplyala herausrüfte, weldye $\mathfrak{B a l t e n}$ einen voll= ftänoigen Bergfafoit iffres Baters, Den er zumeifen in feinem

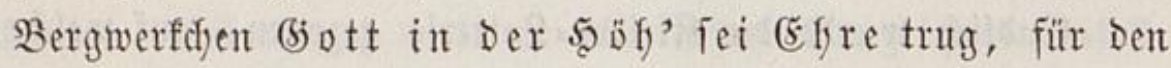

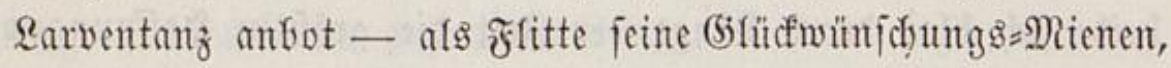

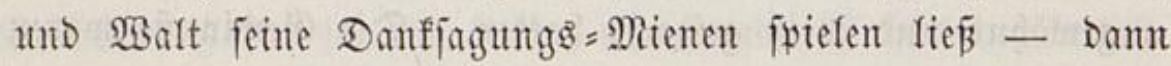

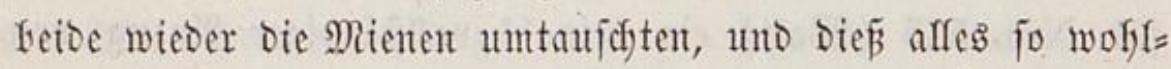
wollent gegen einander, Dấ, wenn Der Notar nidjt Der auts= gemadjtefte Spibsube Des feften Rmbes war, Raphnela burdy=

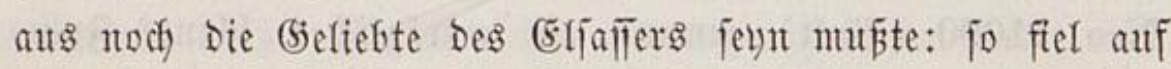
cimmal Der Iange Nebel und $\mathfrak{B u l t}$ in bie Traufe.

"(5ott verdamme, (Er liebt $\mathfrak{B i n a !}$ ( fagte Bult in ficd) und fie wol ifn!" afle feine wilden beifter braujeten nun wie Säuren auf - Dod) feft zugedect, anggenommen int

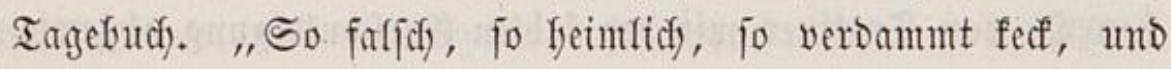
wie tolf emporftrebend Dadjt' idj mir Dody Den Narren nidft -- jagte jein Selbitgejpräcí - o recht gut! - Bet (5ott,

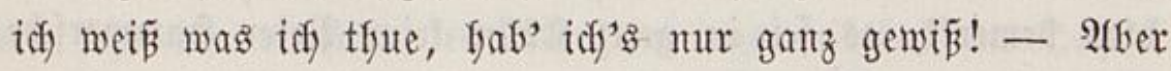
auf Demt Larventanz entlarv' idf); - Der Plan geft leidjt,

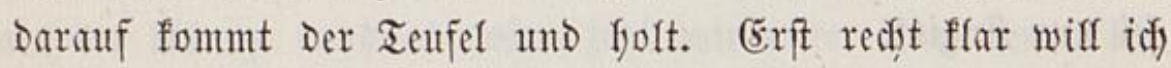
midy, zum Beweife meiner greundjoffaft gegen ifn, überzengen

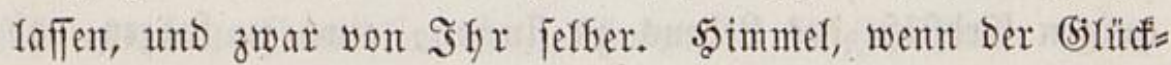
licfe meinen refus in Der Dummen Reujafjrs = Nadjt erfüfre! - Salj thät’ ifm viel an. - D lieber $\mathfrak{B u l t , ~ f o ~ f e i ~ m u r ~}$ Diefmal, eben Deswegen, Defto gezäfmerter und fitller, und bänoige Dein Sprect)= Bettg und beficht, blos bis morgen Nadyts!" 
Bults bisferige Fehlblicfe entidfulbigt leidjt bie Bemer= fung, Daß biejelbe Reidytigfeit, womit man fich einbildet, gefiebt

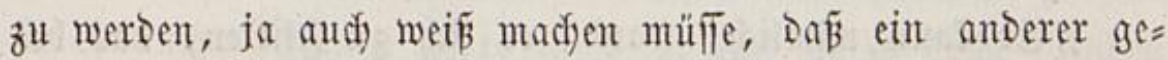

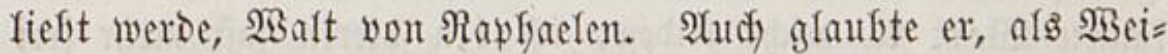

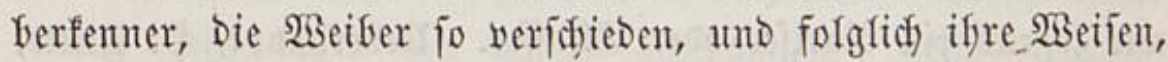
Die Riebe zut befennen, nod) mefr, Daß̃ er nur eine 2 seife an= nafm, worauf zu fuben fei, weldye aber nidyt Darin beftefle, Daß bie Frau ctwa an Den bals, oder an Daß berz falle,

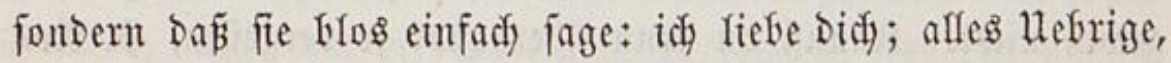

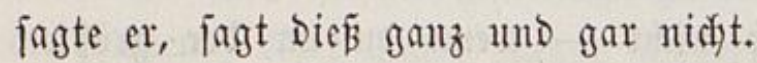

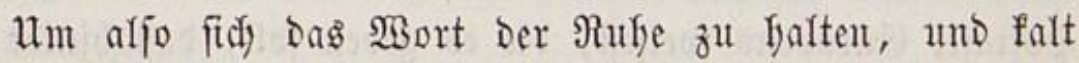

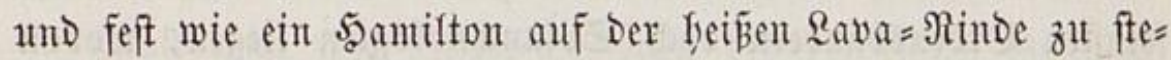
Yen, auf weldyer er fortrüfte: fo fprad) ex, wovon er wollte, uno beridytete Flitten, er und $\mathfrak{B a}$ alt Duzten fid) jebst. (Er rieth)

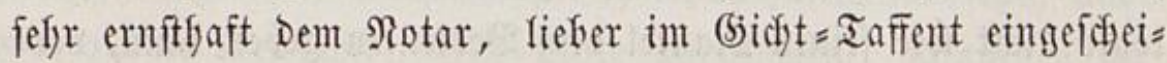
Det auf Dem $B$ alf zut erfoleinen; und als Diejer fids in jeinem uno Der Mittäuzerin Namen cfelte bor Der Sranfenffüfle: Glieb jener Dabei, er fefye fierin nidyts als cine ungewöfnlidye Masfe, Die ganz mertwartet jei. "Dodi) faffre meinetwegen in Den Bergfabit ein, und Damit in Den goldyaltigen \&uffichadjt;

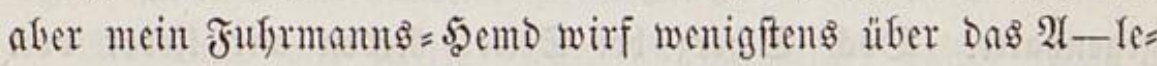

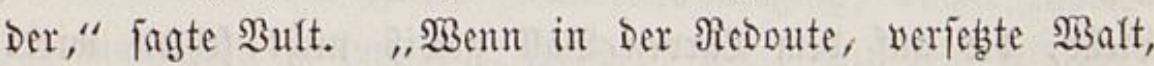
fici) Das Qeben und alle Stände unter einander und an einander mijosen: fo mögen zwei fid wol an (sinem Menjoyen finton und einen." "Berzeif) nur Das ganz gewöfnliche Bergmort" fagte Bult, für weldyen es feime gröfere freude gab, als Balten ins verlegne (jefidyt zut fidmen, wenn er von Culs de Paris [prady, weldye er anus cerebri Lutetiae namte (fo

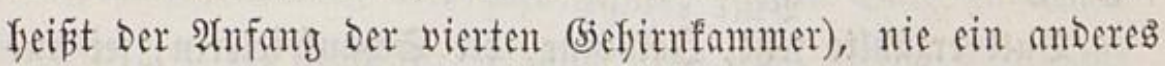
Wort zur Heferfebung erlas, als Das gebachte, fo fefr aud 


\section{6}

[dfon Dem fodwadjen Senter Der Dentichen Spradje Der grö̈̈te Reidjtfumt zumt $\mathfrak{B e c}$ jel vorliegt.

"Er faum näm(id), wantot' er fid zul fflitten, Das be=

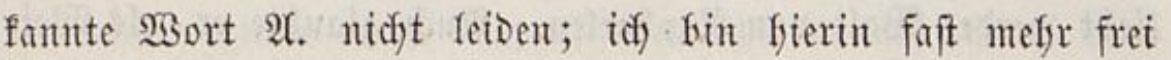
wie irgent ein \$arifer oder Elfaffer. Meberfaupt, מू. Flitte,

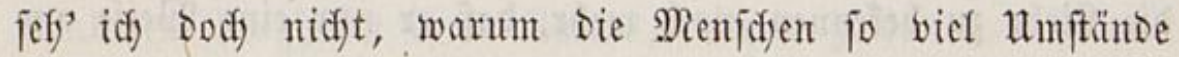
madjen, Sadjen auf Die Zunge zu bringen, zu weldyen bott felber mit jeiner jagen mußste: werbet. 3 ur Sünde jagte er's

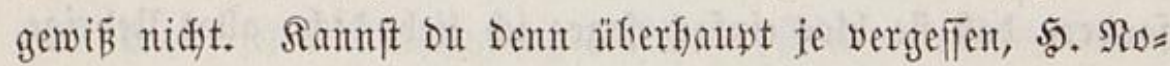
tar - mefyr frag' idf nidft - went bu an ber grö́pten

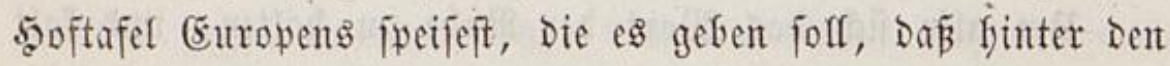
feinften Drdengbändern Dod) Splandyologien liegen, wovon jeder Die jeinige unter Die zierlidjfen Mienjofjen mitfringt, und fid) Damit vor Den feiligften şerzen, weil er Die Splanthno= logie nidft wie feinen Mantel Dem Bebienten geben faun, ver=

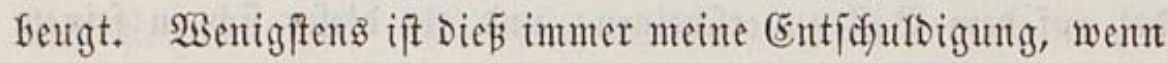
er midf fidsarf bornimmt, weil idf bie feber an ber innern unfid)tbaren Heberrocts=silappe affitreife, indem er immer ein= wirft, Die abgewante flädfe jefje Dodh wenigftents Der (beift; worruf idy ifym, wie gejagt, Den Rabel Der Menjogheit ent= gegenfalte. Dody Sdyerz bei Seite! Reben wir fieber von Rebe, Die auf Dem Larven=Ball gewi (Ëwige, glaul' $i$ id), Dauert lange, und länger als man glaubt - Denu idj wüpte nidjt, warum ein Riebfater bie feinige befownure, went er nidyt Damit veripräd)e, jein 5aerz fo lange

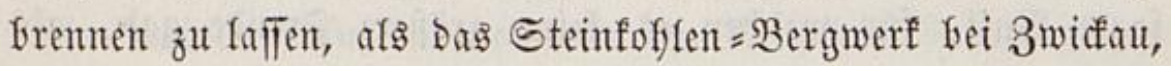
Das es̉ mun 1 Säfulum Durd thut." "Vive l'Amour!“ fagte Fritte.

Bult erzăhifte jebst, Infobine, bie Sdyaupielerin, fei an= gefommen: "fie wird auf Dem Balle audy ifre Rolfe fpielen, 


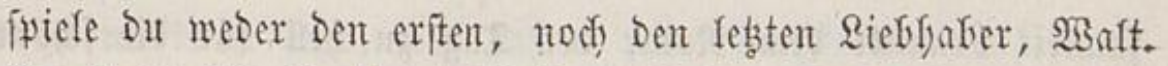

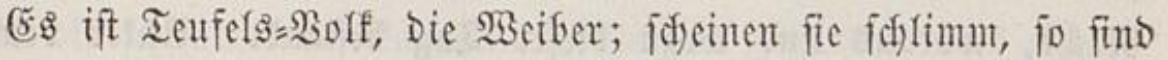

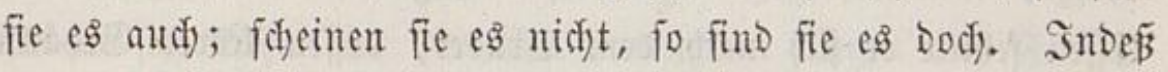
zief) id alfe Saforinen alfen \$rüben vor, weldye ifye fimmel= Glauen Rebe Durdi Den Netfer aufipamen." Waalt fragte, wie es Dent cine arme Sdyöne madjen folle, went Edyein unt Seyn nidhts bälfen. Afllerdings ift eine gewifle 3urüct=

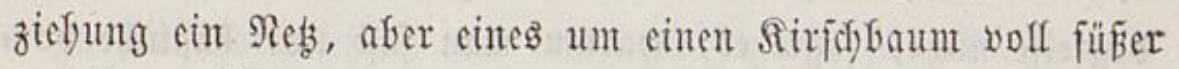
Fridute, nidjt um die Everlinge zu fangen, fondern unt fie

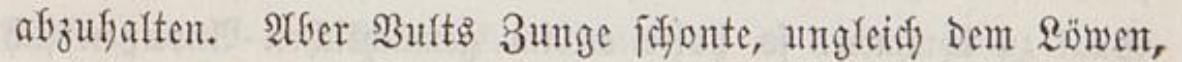
jelgt feine grant.

WBalt trug mit fiffem Beflagen Des vernumten Brutiors alfes gantz gern. Bor Bult hatte fid Die Rebenşeite in bie Radjtfeite gefefrt, Darum mufite er im Sodjatten falt jern, unb,

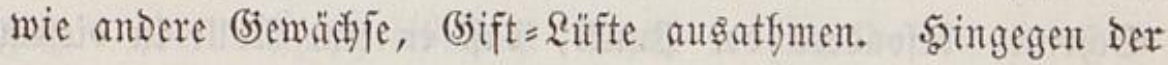

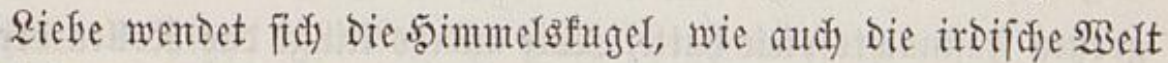
fich) Drefye, ftets mit aufgefjenden Sternen żt. WBit ein Sdjif= fer auf einem windfiffen Meer, fieft fie ofye alle Erde şim=

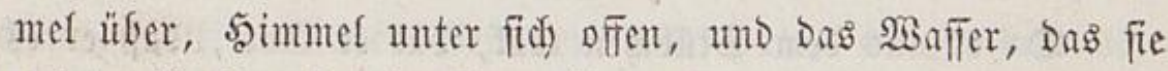
trägt, ift blog ber bunflere şimmel.

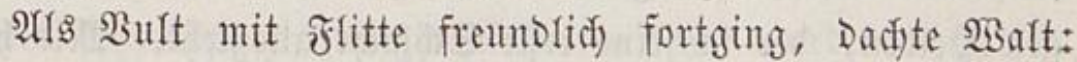

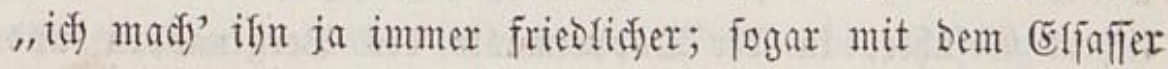

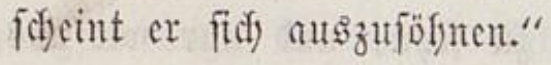

No. 63. $\mathfrak{I} \mathfrak{i} \ddagger \mathfrak{a} \mathfrak{n}=\mathfrak{S}$ d) $\mathfrak{b} \mathfrak{r} \mathfrak{l}$.

$\{a \mathfrak{x}$ e $n=\mathfrak{T} a \mathfrak{z}$.

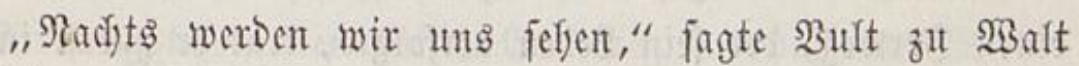
nm Morgen Der Reboute - und ging mit Diejem Borgrupe

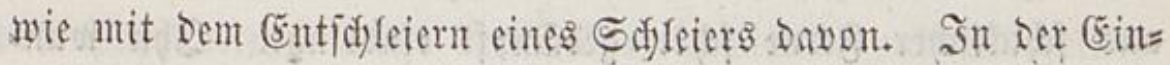


famfeit Gramnte Dem Rotar Der Iag zu helf für Die foböne Radjt, woraus und wozu biejer Ing beftand. Unter bem

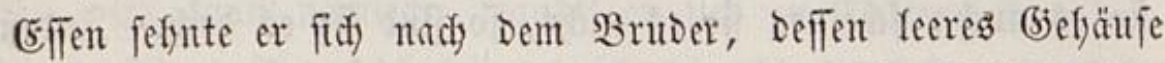
noch leerce wurbe, weif er ifn albends antreffen follte, ofne Dodif fut wiा̄en in welcher (jeftalt.

Walt ging in eine Rarvent $=$ Bube, und fudfte lange nady ciner Rarwe, weldye cinen $\mathfrak{A}$ pollo oder Supiter Darfefllte; er begreife nicht, fagte er, warum man faft nur fä̈̈liche vor= flefe. Da Bult ify gerathen, erft um 11 uhre in Den vollen Saal zu fommen: fo holte er im gemädylidfen 2 (npuben fid

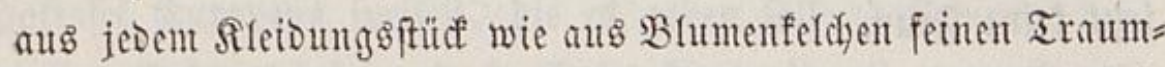
5onig. - Das 2Uffleiden gerade in Der 3eit Des 2 Uusflei= Dens, und Das affgemeine fwäte $\mathfrak{B a c h e n ~ u n d ~ S a ̈ r m e n ~ D e r ~ S t a b t ~}$ fo wie Des Saujes, fürbte ifm Die Radytwelt mit romuntichem

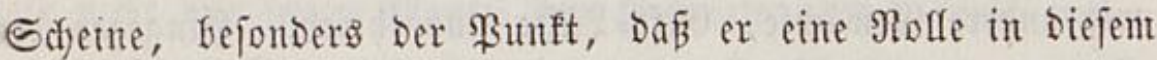
groben Faftuadjtsppiele fratte. SBie anders flingt Das Nollen Der Bangen, wesun man weiß, man fommt ifgnen nady, als went man

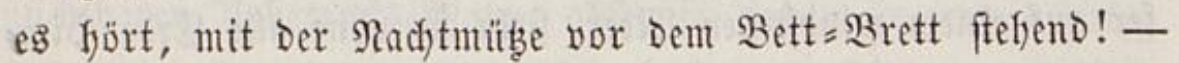

Da er aus Dem Stüfdyen trat, bat er (5ott, Dá̃ er es frof wieder finden möge; es war ifym wie einem rufymburfti= gen Sclden, Der in feine erfte Sdyladyt auszieft. Mit fyäus= Yichem (sefüfle, in Der Doppelmasfe Des Bergftrappen und

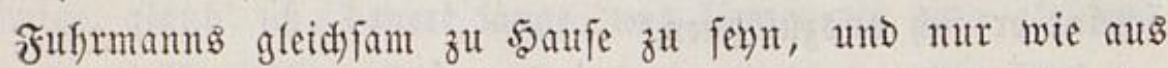
zwei Manfurdenfenfern zu gutêt, trug er fid) wie eine Sanfte üfor bie Gajfe, und formte es faum glauben, Daß́ er fo herrtich ungejefyen und zweigefyäufig mit affen Seelen = Rä= Dern überafl vorfeigeffe, wie cine $\mathfrak{u f r}$ in Der Tajde. Durdh einen Jrrweg, Der fein Reben verfolgte, trat er zuerft in Das \$unjoyzimmer ein, Das er für den Tanzfant fielt, worein Mufif

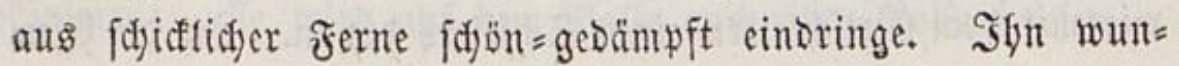


Derte nichts fo fefrr, als Daßs er feine Bergfapwe, einfafrento in bie fifimmernte Baumangfjoffle voll Figuren, nidjt afzog.

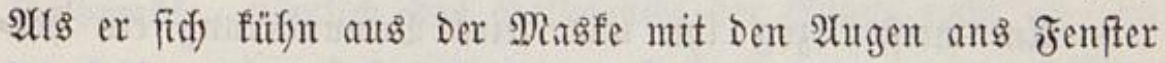
legte, fand er umferfechend nidft ofne Berwunderung viele

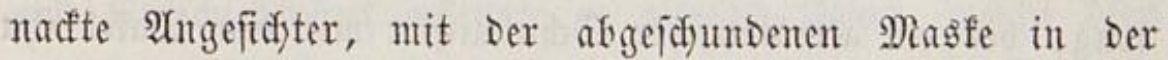
einen Sand, in ber andern mit einem (5iag. Das alfgemeine

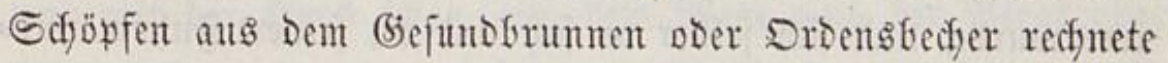

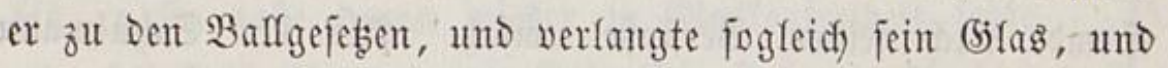

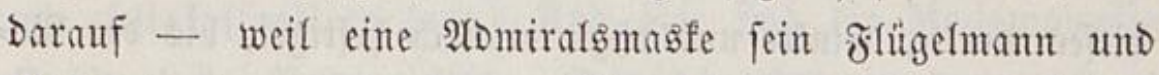
Nuffer war - nod cines. WBina jafy er nidyt, aud feinen Sdyein von Bult. (Eine Ritterin vom Drben Der Sflavimen Der Iugend ging gewant umfer, und faf ifm fefre in Die

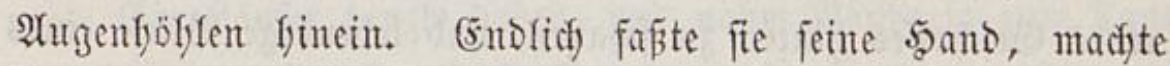
fie auf, uno zeidjnete ein 5 . Darein; Da er aber von biejer

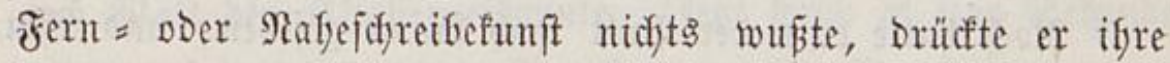
5and mäßig, anfatt foldie zu tefódreibert.

Endid) gerieth er, Da er Das fyercinftrömende Rebenzim= mer prüfen wollte, in ben wafren fidsalfenten, bremtenten Sanl, voll wallender beftalten und şüte, im 3auberraudy

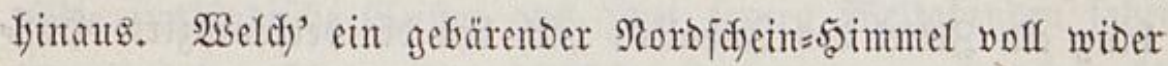
einamber fafrentoer ziffactiger (beftalten! (Er wurbe Didfterijad ertyoben, ba er, wie bei einer auferfefendent Erofuget am jüngffen Iage, $\mathfrak{B}$ ilde, alte $\Re$ itter, (5eiffliche, (5öttinnen, Moh)= ren, Suben, Nonnen, Tyroler und Soldaten Durdy einander faf. (Ex folgte lange einem Suben nad), Der mit heraugge= fdintittenen Edhulbforderungen aus Dem $\Re$. A2nzeiger befyangen war, und las ifn burdh, Dergleidyen einen mbern, welcher Die-Warnungstafelıt Des fürftl. (5artens, an paljende (5ilied= maken wertfeilt, um fatte. Bon einer ungefeuren $\mathfrak{B}$ erücfe voll \$apillotten, weldye Der $\mathfrak{T}$ räger afwicfelte uno austfeilte, 
Hafy er aud feine an, und fand nidyts barit, als einent ges meinen $\Omega_{0}$ bjprudi) auf jeine bezaubemben 2 tugent.

IAm meiften zog ifyn und feine Bemunderung ein fyer= untrutijyender Riejenfitefel an, Der fidh jelber anfatte und trug, bis ein altväterifcher Edyulmeifer mit Dem Bafel ifnt

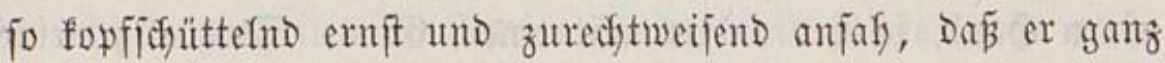
irre wurbe, und fidf felber an fich und an feinem fuffrmants=

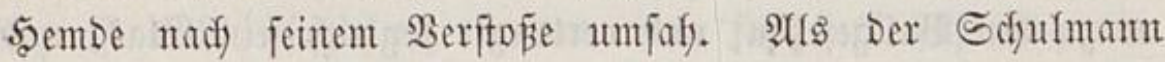
Diefes merfte, winfte und rügte er nodh Keftiger, fis Der $\mathfrak{N} 0$ tar, ber iffm eridjroffen in bie bräuenden 2 tugen gebficft, fich

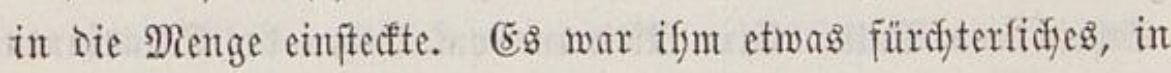
Die Dunfle unbefannte $\mathfrak{A}$ ugenföble wie in Die offne Nändung

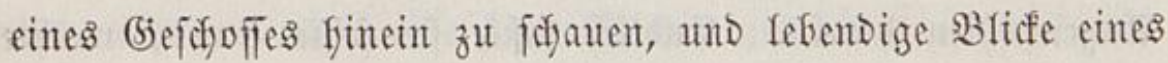
Untefaunten zut empangen.

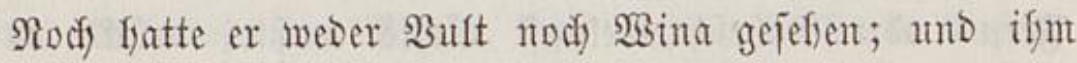
wurbe an (Ende fange, of er aud in biejem Meere fie wie Serten oder Snjeln finde.

2uf einumal ftellte fid cine Sungfraut mit einem Bhumen= franz auf Dem Sopfe yor ifn; aus Dem Munde Der Masfe fjing ein Bettel Des Snfalts: „idi) fin Die perfonifizirte 50 of = mung ober Spes, Die mit einem Błumenfranz auf Dem Siopfe, unto einer Rifie in Der redsten 5and abgebildet wird; mit Demt finfen $\mathfrak{A} r m$ ftïbst fie fidf auf einen $\mathfrak{A}$ nffer ober eine ftarfe Säule. ธ. Damms Nivthologie, neute $\mathfrak{A}$ fuflage von Levezov \$. 454." $23 a l t$, Der anfangs in jeber Sadhe mit Den Dümm= fent (5ebanfen geplagt war, wollte innerlid) auf $2 B$ ina rathen, wäre bie Beftalt nur feiner und wentger grố gewejen. Die

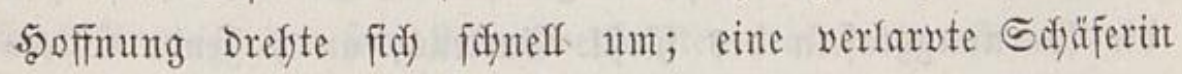
fan, uno cine einfache Nonne mit einer Salbmasfe und cinem

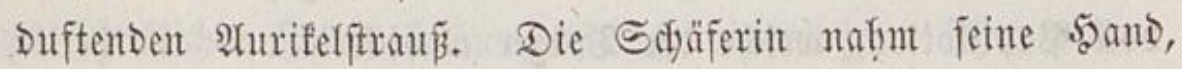
und fodrieb eit h finein; er Drincte bie ifrige nad feiner 
(5ewofnhleit, unb fofüttelte Den Sopf, weil er glaubte, fie babe fich) mit eintem h unterzeidynent wollen. Blöblidy fafy er bie 5alfmagfe, nämlidf Das 5alfgefidyt Der Nonne recht an, an Der feinten, aber fecfen Sinie Der Rojenfippen, und am Rimt

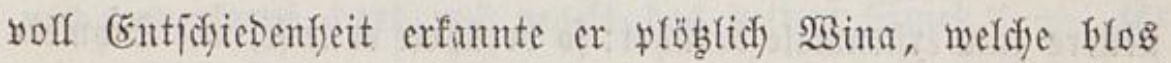
ants Dem Dunfel mit fanften $\mathscr{A}$ ugen= Stemen fricte. Er war mit Der 5and fdyon auf Dent $\mathfrak{B e g e}$ nady Ser Bergfappe, bis er fie nafie Daran wieder in Masfenfreifyeit febte. "D wie felig! (jagt' ex leife.) Uno Sie fino dic Mademoiselle Raphaela?" Beibe nictent. "S was begefyrt man Denn nody in foldher geiffertrunfenen 3 eit, went man fïa), verfüllt wic (bei= fter ofye Sörper, in elyfifident Feldern wieber erfennt."

Ëin Säufer tanzte Dafer, und nafm Rapfacla zum Tat= zen bayon: "Silïct auf, S. Bergfnappe!" fagt' er entfliegend,

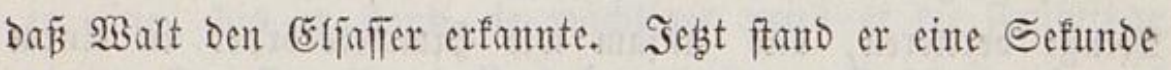
alfein ueben ber ruffigen Sungfrau - Die Menge war einen Augentidid lang feine Masfe. - Ret, reizent, Drang aus Der Salf = Rarve wie aus Der Blüten = Sujeide ciner gejenftent

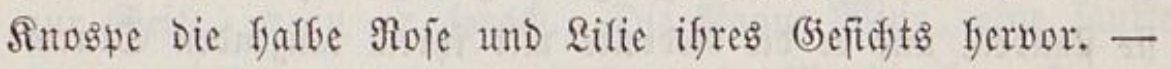

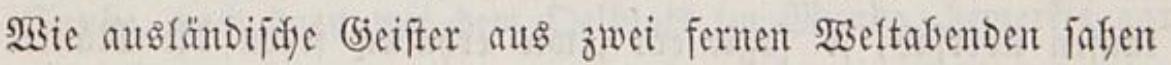
fie einanber finter ben Dunfeln Rarven an, gleidjfant bie Sterne in ciner Somnenfunferniz, und jebe Seele fafy bie aubre weit entfernt, uno mollte Darum Deutlidjer jeyn.

Da aber $\mathfrak{B a l t}$ in biejer Stellutg Niene madjte, als wollte er einige Subiläen Diefer föbunen Mimuten feiern uno erteben: fo fragte ifn $\mathfrak{B}$ ina, als Spes forjdyend bie Sflawin Der Tugend vorüberfüfrte, of er nic tanzte? Sogleid) wurbe er in ben $\mathfrak{T} a n z=$ Sturm geweht, fund half wefen, indent er tanzte wie Die Römer, Gei weldyen nad Böttiger Das mimifide Ianzen in nichts beftand als in Bewegung Der 5ände und

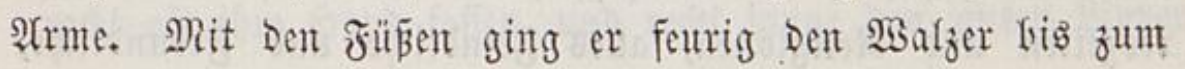


Raft=Zeiden Der 2 ange, wo ber fliegente Schwarm finters einanber fich anlegte als Stando =5eerde. Sntoé glaubt' ex, er flöge finter cinem mit Sommervögefn fliegenten Sommer.

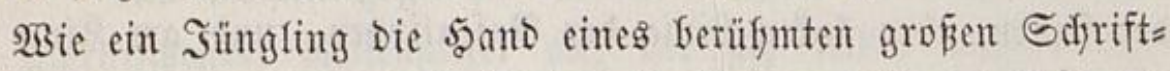
fteflers zum erftemmafe berüfrt: fo berübrte cr feije, wie Sdymet=

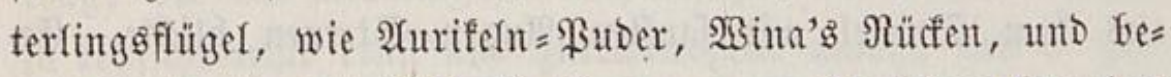

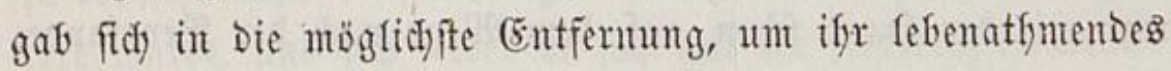
(5eficf)t auzujdautent. (5ibt es einen (Ente= Tanz, Der die Erute ift; gibt es ein Fenerrad Der liebenden Entzühtung: Bart, Der fufrmanu, yatte betbe. Da er aber feinen fun bemegen founte, ofute Die 3unge: fo war Der Tamziant mur fein größerer Redmerfuffy; und er fojilberte iffr unter Dem Tanz: "wie Da fogar Dor Sïrwer Mafif werde - wie Der Menfif fliege, und bas Rebent fefle - wie zwei Seelen bie Renge verlieren, und eimfant wie sjimmelsfürper in cintent

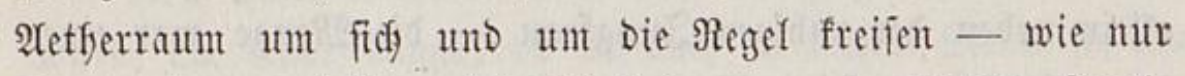
Scelen tanzen follten, bie fid liefen, un in biejem funft= Schein Harmonifider Bewegung Die geiftige abzulpiegefn." $\mathfrak{A}[\mathfrak{B}$ fie ftanden, und er Die Reboute mit ifrem tanzenden Sturn= laufen überjah, fo jagte er: "wie erfatien feffen sie Mäntel uno großen şüte Der Männer aus, gleichfam bie Felfenpartic neben Der weiblichen (5artenpartic! (Fin Bafl en masque ift

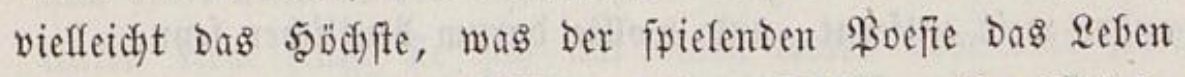
nachzufpielen vermag. Wie vor bem Didfter afle Stände unt Beiten gleidf fino, uno alles Xeurere mur Sleid ift, affes

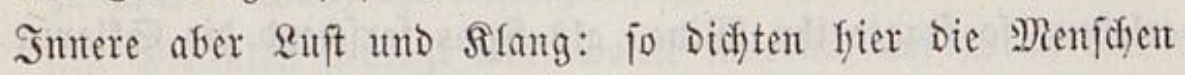
fiid) felfer uno das seben nad) - Die ältefte Tradht mo Sitte wambelt auferfanten neben junger - Der fermfte $W_{3 i l d e}$ Der feinfte wie der tofefte Stand, Das fpottende Berrfild,

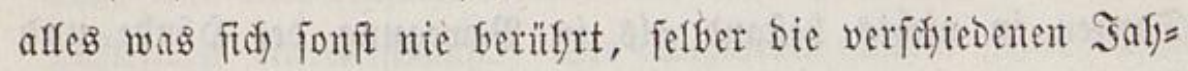
resjzeiten und Refigionen, afles Feindlidje uno Jreundidye, 
wiro in (Einen feidyten frofen Sireis geruntet uno Der Sireis wiro ferrlidy wie und bem Sylbenmá bewegt, nämfich it Der Nufif, Diejem Rmbe Der Seelen, wie die Masfen Das Lano Der Sïrper fint. Nur Ein $\mathfrak{B}$ efen fteft ermft, unbedecft uno unverfarwt Dort und regelt Das heitere Spiel." - Er meinte Den Redoutenmeifter, Den er mit cinem nacten fleinen

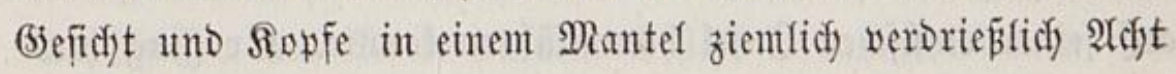
gebelt faf).

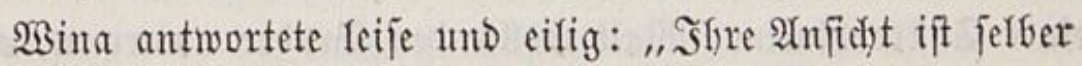

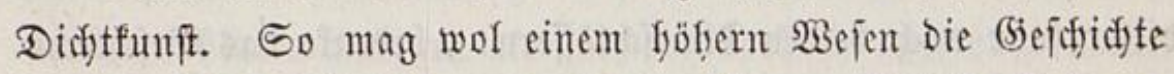

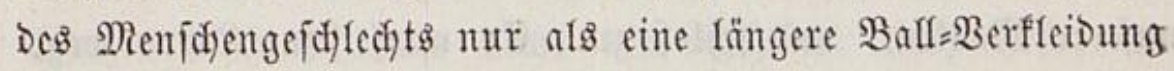
ericheincn." - "2Bir fint ein Feucrwerf, werfebzte $\mathfrak{B a l t}$ fơnefl, Das ein mäd)tiger (beift in verichiedenen Figuren $a \mathfrak{b}=$ brennt," unto fuffr in feinen effigen $\mathfrak{B a l}$ er finein. Se Yänger er ging, bis er ftand, je mädytiger wries er bie früfylinge,

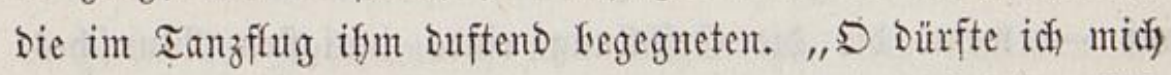

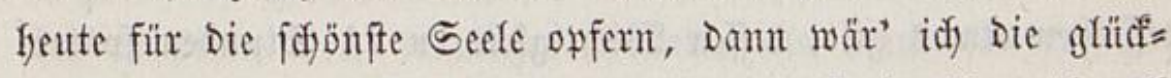
lichfte," fagt' er. Die 5ुoffrung (Spes) ftand ifm überalf zur Seite, wenn er fprady. Die Ronne $\mathbb{B}$ ina, eine fanfte Taube, nody Dazu mit Dem Delflatt im Numbe, bemerfte gar

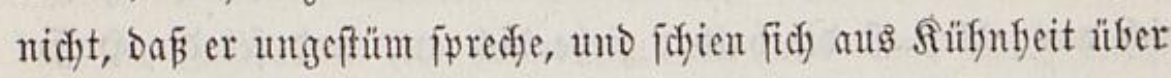

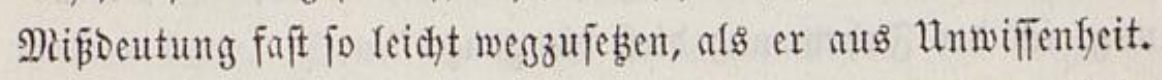

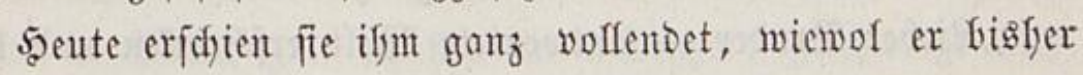
jescs lebztemal geglaubt flatte, ex üferfid)aue iffren ganzen wei= ten Wertf; wie Der Mond foron vorfer, eff er mit volfent. Sichte über uns hängt, unเ als cine vollenbete Edyeife auf= zugeffen fidsint.

Rad) Dem (Ende deß Deutiffen Imzes erjudyte or fie Da ifm ifre Radfficht alfmälig zu einer Effrenpforte feiner

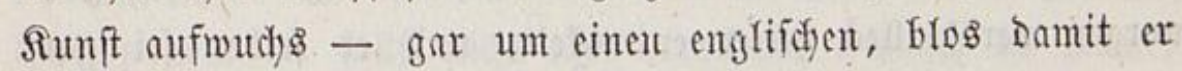
red)t oft iffre samb falfen, und redyt lange den guten sipwen. 


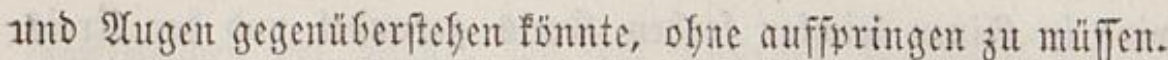
Sie jagte leije: Sa! -

Rody leijer fyört' er jeinen Ramen; binter ifyn fanto Spes unto fagte: "gefje gleidy Durdh Die grofe Saaftgüre, und

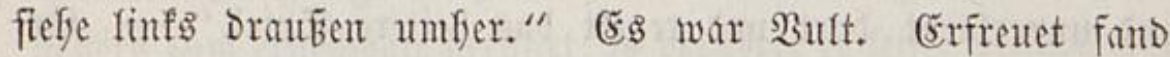
er unter Unbefamten jeinen lieben Befannten wieber, Den er auf jeiner eltyfifden Injel berumfüfren fonnte. (šr ging bin= aus; Spes ins fünfte Rabinet; Drauben winfte fie ifym aus einer Thüre fincin. WBaft wollte Den Bruber untarmen, aber

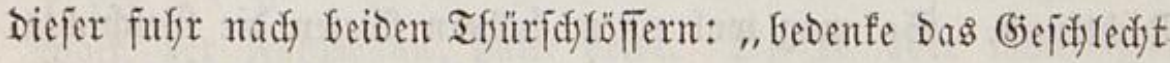

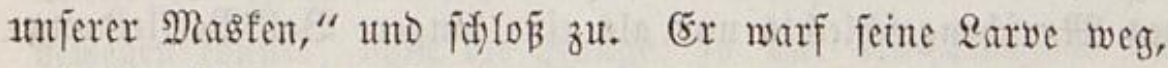

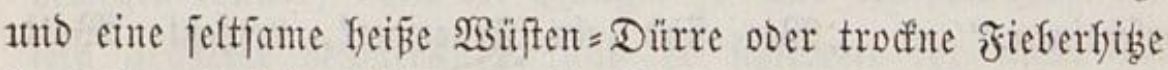
Gradi Durdy jeine Mienen und Borte. "Wenn Du ie Riebe für Deinen Bruber getragen - begam or mit trocfner Stimme, tnt nafm Den Firanz af, wno löjete Das 2 beiferfleid auf - went Dir Die Erfüllung eines innigiten Wbunjodyes

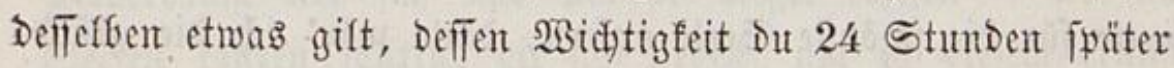
erfüfrif; - und ift eg Dir unter Deinen Jreuden nidjt gleids)= gültig, of er bie fleinften oder gröbten haben foll, furz went Du eine jeiner flefgentlidyften Bitten erfyören willit: fo ziebe

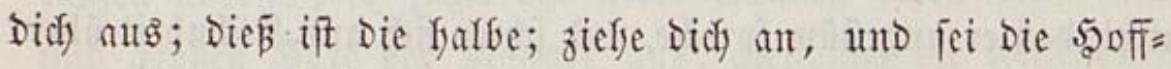

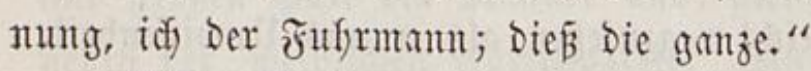

"Rteber Bruber - antwortete $\mathfrak{B a l t}$ erjodroden uno rié̃

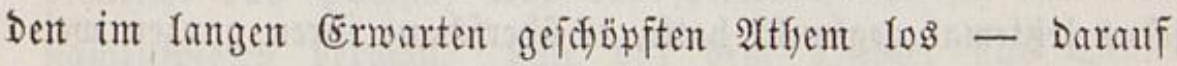
fann idy bir, wie fid) bon felbft verfeft, nur zur 2Antwort geben: mit Jreuben."

"So madje nur fifnelf," verjebste Bult, ofne zu Danfent. Walt febste finzu, fein feierfidfer Ton erjorede ifyn beinafje, audi) fall' er Den Bwed des Umtaujdys menig. Bult jagte, morgen werd' alles leiter entwidelt, uno er felber fei gar nidjt verbrieslich, fondern efjer zu fwapend. Anter Dem wed $)=$ 


\section{5}

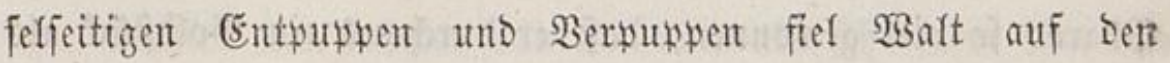
Sfrupel, of er aber ats Masfendame mit $23 i n a$, eitrer Dame, Den werfprodfenen (Engfijgen tanzen fönne: „D, idh frette midi fo jeffr Darauf, fagte er Dem Bruber, unter uns, es ift bie alfer= erfe 2ngloife, bie idf in meinem Reben tanze; aber auf mein

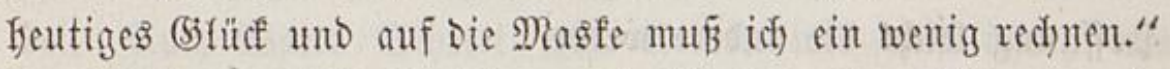
Da fhoflen auf Butts Dürrem (beficht Yefondige Mienen auf. "S5imutel, 5oulle, fagte er, eben fo leidjt nadif Dem Iafte wiff id) niefen, oder bie $\mathfrak{A}$ rme zurüđffiftecfent, uno meine Flûte traversière finten anlegent, als was Dut vorfaft, nadjtfun. Deine

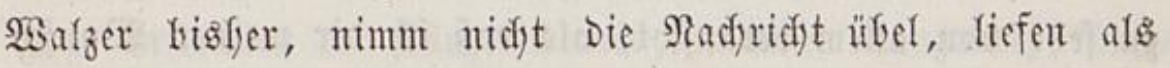

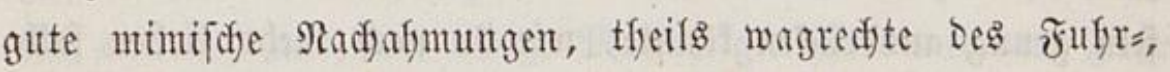
theifs fteifrechte Des Bergmanns im Saale Durdy, aber einen Engliffuen, Freund! und weldyen? (Ein teuflifofer, nidyt ein= mal ein irländijcher wirb's. Hno erwägft bu beine $\mathfrak{R i t =}$ täızerin, Die ja foljamrotly und leidjentbla eine Ritterin won trauriger (5iftalt, als Deine feiotragende Sreuzträgerin, jobalo ou nur ftocfit, plumpft, Drunterfäfrift

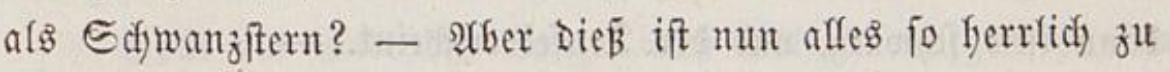

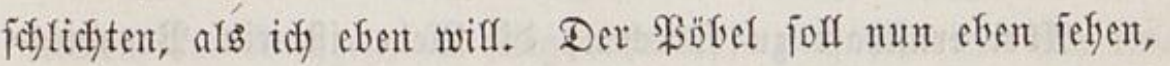

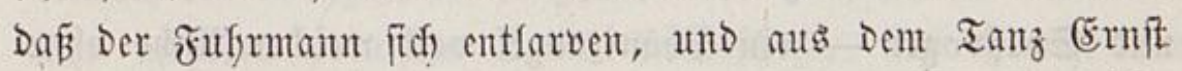
madjen funt. Dent idf tanze in Deiner Masfe bic Angloije. Sogar in Polen galt id) für einen Tänzer; gefduweige fier, wo nidyts von Bolen tant, als Der Bär."

Walt blieb einige Mimuten fiffl, Damn fagte er: "Die Dame, wowon idy meinte, ift $2 B$ ina 3 ablocit, ber idy Die Mithe Gisfer gemadyt fuben foll. Aber ba fie meiner Mabfe Den Ianz veriprodien, wie willft Du midy und ben $\mathfrak{B}$ Bedjel ent=

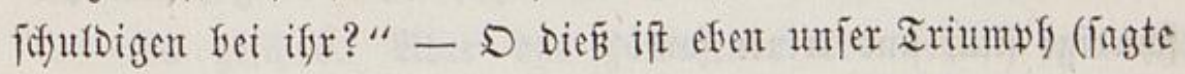

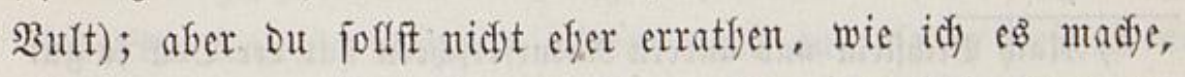
als morgen. - Darauf entbefte er iffm, er habe heute im 
Pharno fo riel gewonnen, Da Etüđfwerf zum Berftücfen von ifm annefmen müife, wäre es auch) nur, Damit er unter Den 3uidautern etwas zut thun fyabe, im Magenzimmer; Damit cmpfaffl er iflm, fich als Spes mit feiner weiblichen Masfe einzulnten, Da aus einer guten 5.offnung leidyt bie andere werde.

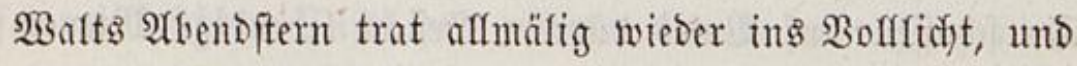

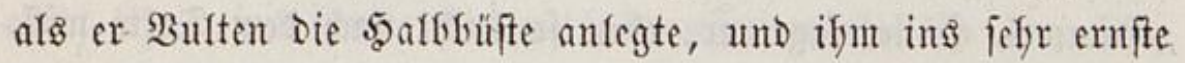

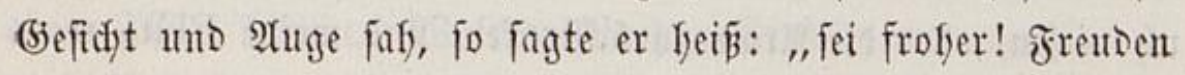

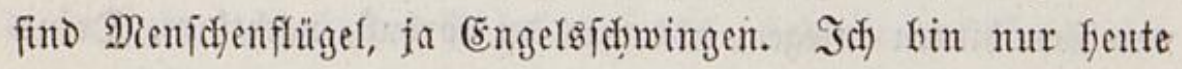

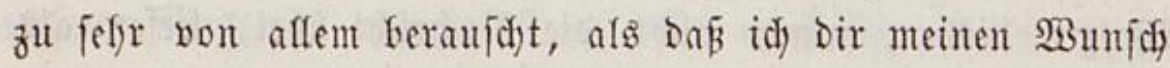
fein genug ausbrütefen fönnte, wie bu nod) mefr. Lieben folls teft, als midj." -

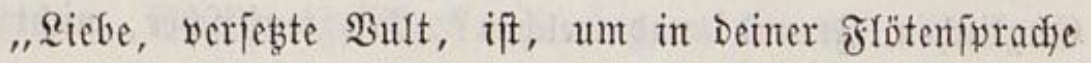
zu reden, ewig ein Sdjmerz, entweder ein füber, ober ein fit= terer, immer eine Racht, worin fein Stern aufgefht, ofne Daß einer finter meinem Rüfen untertaudyt - Freundidaft ift ein Iag, wo nidyts untergefft, als cinmal bie Somne; uno Dann ift's fópwarz, uno Der Teufet erfocint. -

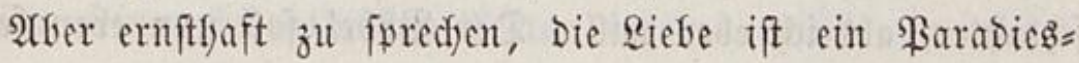

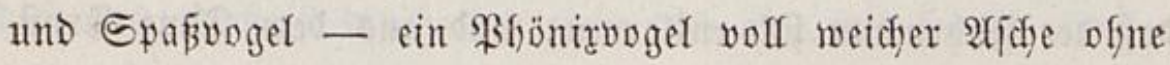

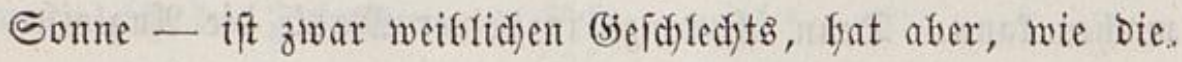
3iege, 5ärner und Bart, fo wie wieber Deren (Efyemann wafye Mild) hat.*) (Es ift beinalfe einertei, was einer üfer bie Siebe fagt ober einmirft; Denn alles ift wafr, fut gledder 3eit. - Siemit febe idy Dir Den slumenfranz auf, und ver= fleide bid) in Dns, was bu haft, bie Spes. (5ielye aber Durth meine Thüre in Den Saal, wie ich Durdh Deine - ficl) zut, fdifwcige ftill, uno trinfe fort!"

*; Ract) Mechitein und andern Raturforidsern hat ber Bodf fo gut

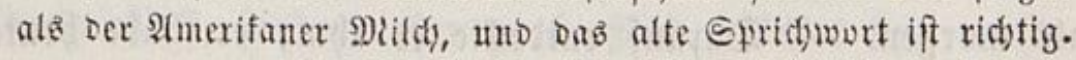


Walten fam's beim (Eintritt vor, alB fefe jeber iffm Den Earventaufd an, und fund (d)afte feinen Rern finter Der zwei= ten 5̧ülje leidyter aus, als fyinter ber erften. Einige $2 B$ eiber

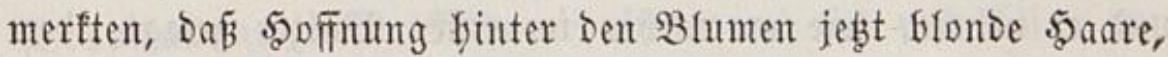
ftatt Der vorigen fojwarzen, trage, maken es aber Der \$erülfe bei. Xud $\mathfrak{B a l t s}$ Sdyritt war fleiner und weiblidger, wie fids's für

Afer bald vergaj er fid und Saral und alfes, Da ber Fuffrmant Bult ofne lumftände $\mathfrak{B}$ Bina, Die jeber fonnte, an Die regierende Spibe Des englifonen Ianzes fellte, uno nun

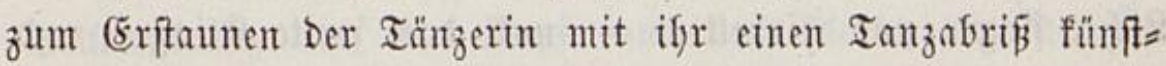

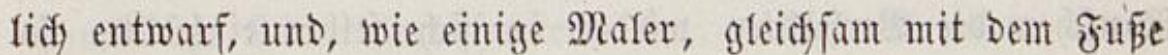
malte, mur mit größeren Deforaziongftridfen. WBina erftaunte,

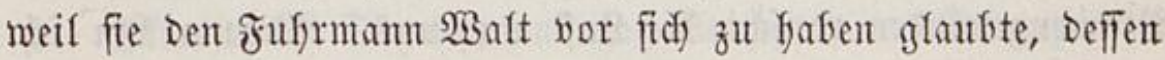
Stimme uno Stimmung Bult wider $\mathfrak{B a l t s}$ Borauseebung finter Der Larve walurfaft nadjpielte, Damit er nidjt etwa als Rügner befundent werbe, Der fidf für Den Notarius nur ausgebe.

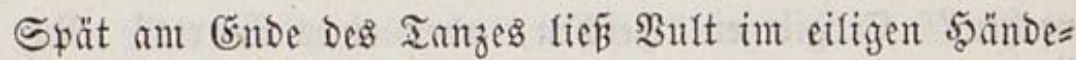
reidyen, im Rreuzen, im fliegenden $\mathfrak{A} u f=$ mo 2 fblciten fich im= mer mefrere polnifhe Saute entwifiden, nur saudse Der Sprache - mur irre aufs Meer verwelyte Sdymetterlinge einer fernen Snfel. WBie ein feltner Rerdiengejang int Radyjommer flang $\mathfrak{B i n e n}$ dieje Spradje herab. Freudenfeuer franuten

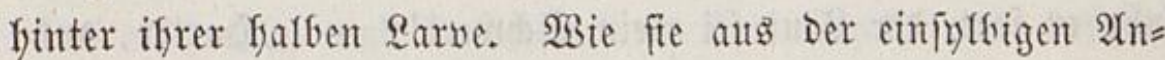
gloife in Den fpradffäfigen $\mathfrak{W a l}$ aer fidd Ginüberjefynte, weil fie ifym iffr (Exftaunen uno (Erfreuten gern anders, als mit frofent Bliden, fagent wollte, fafjen feine, die feine frofyen warent.

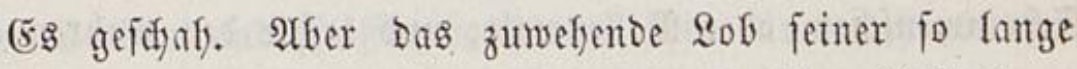
bebectten Talente blätterte wieder eines auf, feine Befdjeisen= freit. (Fr frabe, fagte er von fidf in ben beften Folonismen, 
To wentig 2 elt, fo viel Einfalt, wie wentig ansere Notarien,

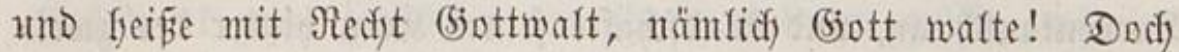
fein 5erz jet warm, feine Seele rein, jein Reben reije Didstend; anto er nefme, wie er vorfin im erfen 23 alzer gejagt, Den Earbentanz im Erdenfaal gern und frof, vom Ränderer und Edyäferballet an, fis zum $\mathfrak{B}$ affen= und Todtentanz.

Da jebst Der jweite Theil Der Mufiff in jene fefmpüdytige Heberfüfle, wie in tiefe $230 g e n$, einjant, welche gewalt famer,

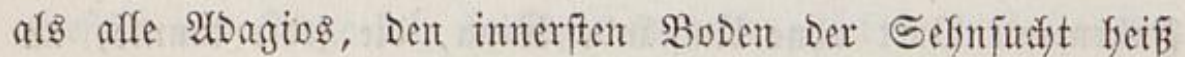
nus tiefem Meer auffebt - und da bie Menjchen und die Sidjte flogen und wirbelten - uno bas weite Rilingen uno

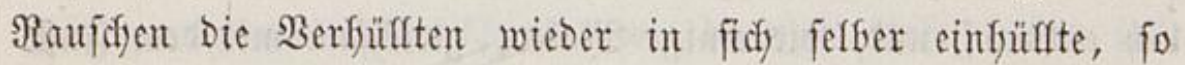

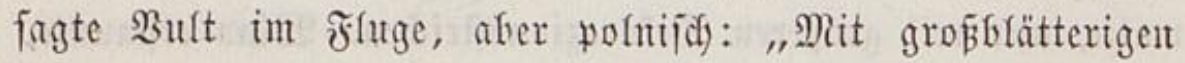

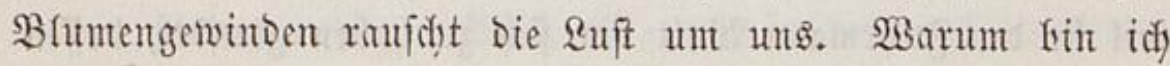
Der (Ëinzige fier, Der unaufförlid) ftirbt, weil er feinen soim= mel und feine (Erde fyat, Ronne? Denn du bift mir beides. Sal) wifl alles jagen, id, bin begeiftert zur Pein, wie zur Suft - willf Du cinen Gottverlapinen aus cinem Gottwalt madfen? S gib ein 3eidyen, aber eines 2 orts! Nur Der 3unge glaube id mein sood)geridyt; fie fei mein Sdywert, wenn fie fid bewegt, Nonue!"

"Gottwalt, jagte sinta ericjüttert, und jodwerer als er Dem Tanje folgent, wie fönte cine Menjdjenzunge Diép fern? - Alber Dürfen Sie midh fo quälen und fid ?" - „Nonne, fulfr er fort, Der Laut jei mein Edfwert!" - "sarter, ant= wortete fie mit leiperer Stimme, Sie foltern Yyärter zum Sd)wei= gen, als andere zum Reden."

Segt fratt' er alles: nämlidy iffr Riebes = Sa für jeinent Sdyeinmenfifen, oder Rollenwalt, und fadjte Den wafjren aus, Der als Rolle uno als $\mathfrak{B a b r b e i t}$ noch bloke Sूoffuntg fei uno fabe; allein jein erzürntes (s)emüth) bequemte fich mun zut 
feitem Sijattendanf, fondern fyartfumm tanzte er aus, und veridjwand problidid aus Dem fortjandjzenden Sireije.

Lange Yratte fich Spes mit Iauter Segnungen einer Doppelwonne in Der Rälye gefjalten, und fidi) und SBina zum

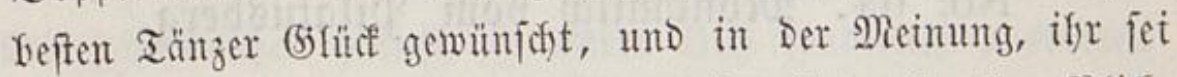
gejagt, was ifn abbilbe, lyatte er iffre fimmelsovollen Blife ganz auf fid frezogen. Bum unglüef fdjöpfte er cben im Trinfzimmer, als Der langweilige englifdje Tanz ausging, auf Deffen Ende er feine $\mathfrak{A}$ (nreden veridjoben - Bult fafwebte ebent in Der tauzentoen Riebes = Creflänutg, und Spes ftand mit Demt Błumenfranze auf Dem Ropfe und Dem Fllatterzettel Der Sn= fodrift am Rime leer=fyarremb Da, und mukte Dem fangent

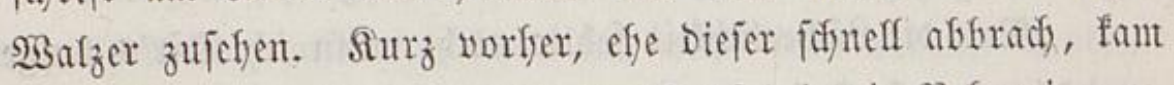
Dic Sflavin Der Iugent, und zog Epcjen it cin Nebenzimmer.

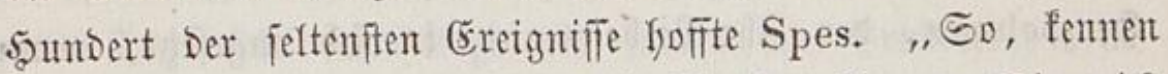
Sie midy nidft melyr?" fragte Die Magfe. Semnen Sie midf Denn? fragte Spes.

"Madyen Sie mur cinen Moment bie Alugen zu, fo bind" (id) Sfre Masfe ab, und meine sazu," fagte fie. Err that's. Sie fuifite ifn fodnell anf Den Mund, und ingte: Sie frabe

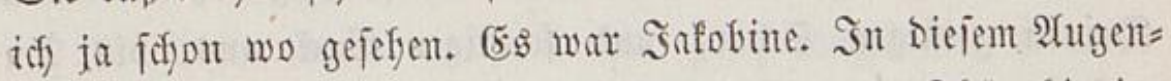
Glict trat Der (jeneral 3 ablocfi Durdh eine zweite Thür finein: "ei Safobine, fidon wieder bei ber 50 finutug," figte er, unto

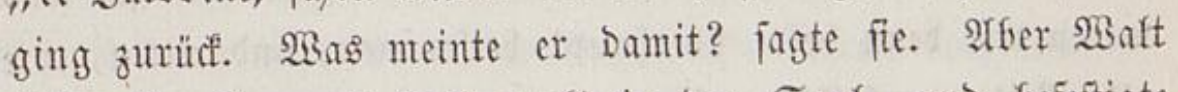
Yief eriforrofen und fralb nact in Den Saal, und befeftigte Darin mit einiger Müfye bie verforbobe Masfe wieder vor ben befränzten Siopf.

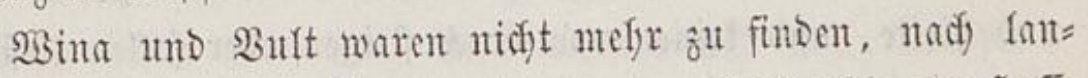

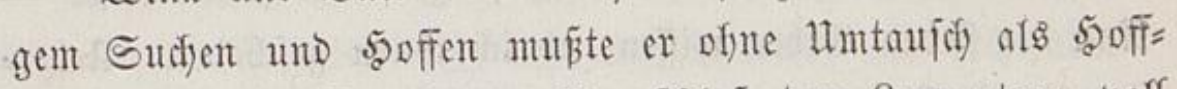

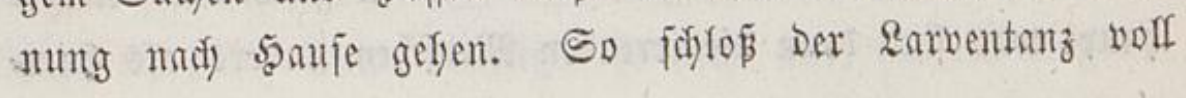


wifffürficher Berfüflungen endrich) mit unwiffëurlidfen von gröperer Edjwere.

\section{No. 64. Monomildy yom Silatusberg.}

$$
\text { Brief - Radtwanbler - Traum. }
$$

Bult war, jobald er $\mathfrak{B a}$ alts überfülyne Riebe gegen $\mathfrak{B}$ ina wno Deren Begünjigung, fo wie jeine eigne Rieberfage, fich

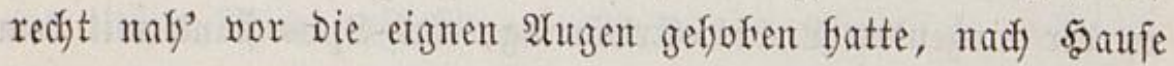
geeilt, mit einer Bruft, worin Die wilden $\mathfrak{B a}$ afer alfer Reiden= fojaften fraufen, un fogleidy an $2 B a l t$ fo zu fodreiben:

"Nour bie Rädferfichfeit fefilte nodh, wenn idf Dir's lange nerdächte, Dá Dein jogenanntes serz mun aud endicid Den Serzpolypen, Den Shr Riebe nennt, in fidt nugejelbt, went gleid) manches babei fo wentig bas Befte iff, als Dein fünft= Yiches Berftecten vor mir. Das aber nimmit Dut mir jebst nidjt übel, Daß̄ idi) zum Teufel gehe, und Didy allein Deinem

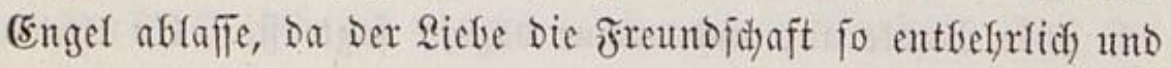

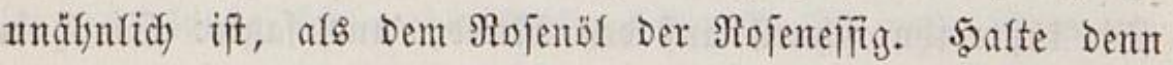
Deinen geiftigen Safar = und jonftigen Bod aus, ris Du auf grüncs $\Omega_{\text {and }}$ aușfteigft, uno auf Der Stelle genefeft, Die

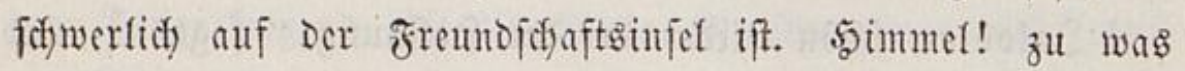
waren wir Dem beide überfaust beifammen, und ritten, wie alte $\Re$ itter, auf (Einem Trauer $=$ und Folter $=\Re$ ferd (equuleus),

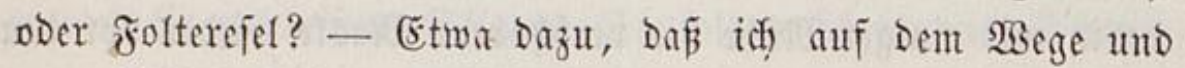
zum Beften Deiner (Erbjdyaft Didy uno Dein Bfero lenfte und fielte, unb feinen won (Endid fteigen oder faflen lię̧? Nun bie feben (Erben wifien, ob id) ifnen gejdydot. Meber= fyaupt was find Dem bie irrenten Menfinen anders ats 5im= 


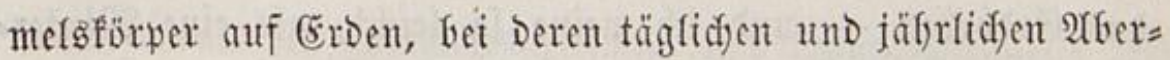
razionen und Nutazionen man nidfts madjen fann, als blos Den guten 3adh Dabei, näm(id) Die 3adifichen Tafeln Davon. (Eben fo frätteft $D$ u Did) aud jonft fintergangen, went $D u$ Dir gejodjmeidyelt fyätteft, idf würde Didy fonderlidy ausbilden und augprägen mit meinem Miunzfowf. Schl la fe Did), wie

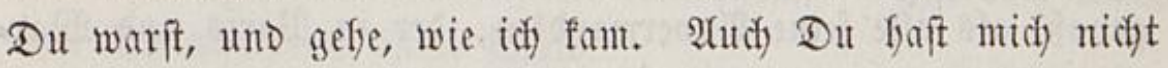

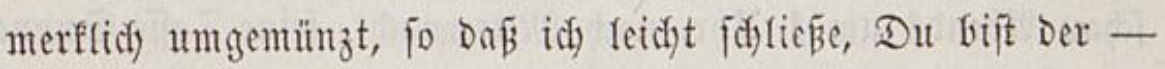
fo walfren - Meimung, es jei int (beifterreids), fo wie im Sïrperreich - man trage Das Fufymantsfembe fowol auf Redouten als auf chautfen - das Spurfafren verderbfich.

Norigen fin idy in Die freie $\mathfrak{B e l t}$ fjinauggezogen. Der

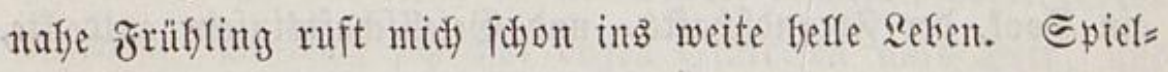
gelb, Das meine Edjulden bezafit, Yiegt bei; - mo fonit guten Iag. Fällt und flagt midh jemtand an, Bruber, jo ver=

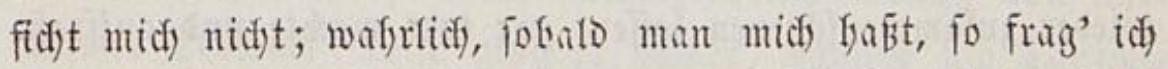
wenig Darnad), ob man midy un Drei Stufen ftärfer bajpe ober nicht; uno wie viele Menfdgen verbienen es Dent über=

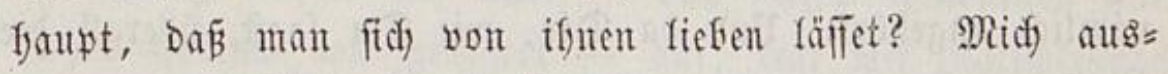
genomment nidjt zwet, und faum.

WBir Feide waren uns einander gantz aufgetfan, fo wie

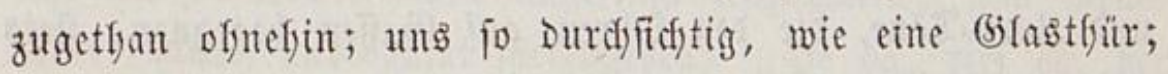

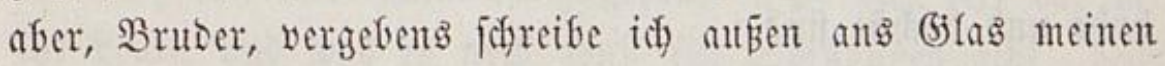
(5f)arafter mit lejertidgen (Sharafteren: Du famift Dodh innen, weil fie umgefefyrt erjojeinen, nidjts lejent und fefyen, nls bas umgefefrte. Hno jo befommt die ganze $\mathfrak{B e f t}$ faft inmer fefjr lesbare, aber umgefefrte Sdjrift zu lejen.

$\mathfrak{B}_{0}$ zu follen wir ben mit einander und von cinanter Blagen fyaten? Du, als refentor Didjter, als bichtenter Riebfyaber, bältft Deine funftigen fo leidjt aus, als ein Boget 
Das (Erobefen - und id) meine fo leidyt, als cine 2Binter: Iandidaft Den Saggel. 2Aber warum war idf fo Dumm, uno tranf täglidf eine flajche Burgunder meniger, ja dit zwei?

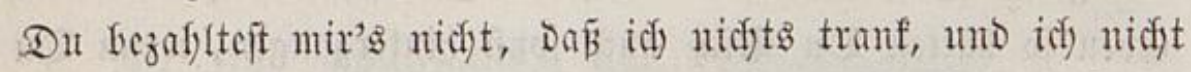
einmal, wenn id) etwas tranf. SDer glaubift Du, Dấ ein Maun, Der feine frlöte bläjet, Der mefyr Welt hat, fafj uno genoß́, als alle feine Anverwanten, Der in Faris und $\mathfrak{B a r}=$ forau Ahends um 1 urr, nady Mitternadyt, feine Iafie Suppe tranf, und feinen Röffel (Eis fpeifte, fo reidlyt fein Parts und

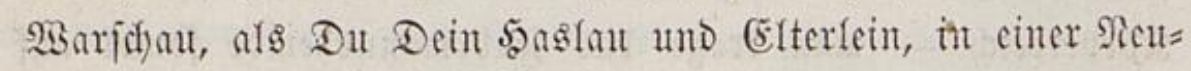
yeteridjen Namparoftube owfert, Die nicht eimmal Den Suabrat= infalt eines Syferaltars groß ift? Sdy afer glaube, id war cin (5oof, Der freundfd)afts = und (jejellichaftsinjeln entbecte, uno Darunter bie fibüne Infel D=2Baifi, weldje aber Den (šnt= Decfer und 2 Beftumfafrer zuleb̧t, als er Den Minitbaum wollte

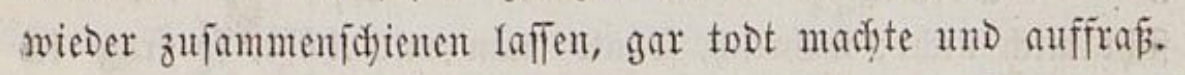

Sogar mene glöte ift Dir entbefrefids, da Du eimmat (mas Du wol vergetien) cine sobbe für eine flöte angejelyen,

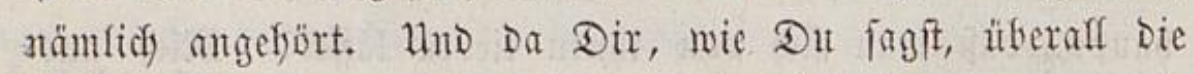
föchften Töne am meiffen gefaflen: fo wirft Du immer mujt=

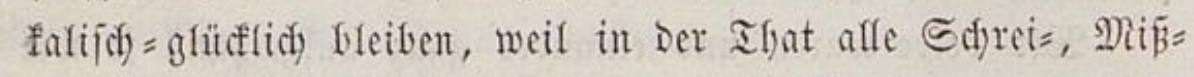
uno Born=?öne, bie ben Dhren auf Baffen hegegnen, ftets bolse uno böchite find.

Meine (jedanfen werfen fich fo wits umfer, wie (5ranit=

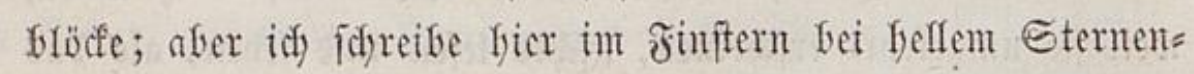

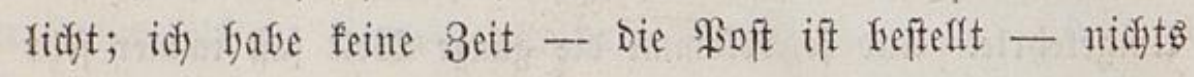
nod) eingewact; uno $D_{\text {ut }}$ folfit nidyt efjer won meinem the fidstbarmerden wifien, als nadh ifym. Mit Briefen, Die idf

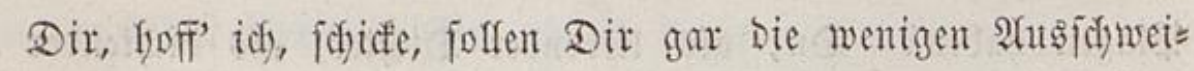
fungen zufoumen, Die umjerent 5oppefpoppel nodj feflem, 
werut er als feft zujammengeleimter und langgeid) wänzter $\mathfrak{B} a$ pierbrathe auffeteigen will in Leiyzig in Der 3abftwoct)e.

(5efrabe Didf wofy, Du bift nidyt zut ändern, idj nidyt fu befiern; fo wollen wir einamber bent in wedjjeljeitiger Suftweripeftive entlegen erblicfen, uno jeber von uns jage: "warum warft Du ein Rarr und fein $2 a m m$ ?" Hno Dod $\mathfrak{B a}$ alt, bift Du allein an alfem fochuld."

$\mathfrak{U}(\mathfrak{B}$ er eben in Das $\mathfrak{B a p i e r}$ nod) Den zweiten Infart, Då (jeld, gelegt fratte - und eilte, um nod vorfer fein Tage= butif), feine Noten und Notae und alles vorfer für bie $\mathfrak{B}_{0}$ ft zugefperret ful Kaben, bevor Der Bruber ericheine, förte er ifn fommen. (Er warf fich) vor Defien (Eintreten aufs Bett, uno fifnardfte als fuffrbergmann iffm entgegen. WBalt trat nafe ant $i f$, faly als Spes ins braunglüfyente (seficht volf ftür= mifider Iräume. Reife ging er umber, haudfte fich Ianzme= lobien vor, unt legte als aert Riebesworte unter.

3ulebist richtete fich Bult - von biejem windfiflen uno

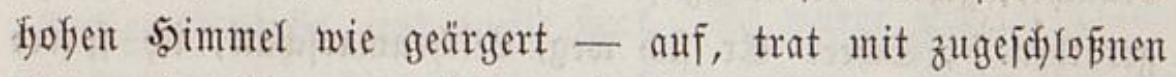
Atugen im Bimmer umber, und fieflte fich als Nadytwandrer an, um in foldyer Rolfe ungefragt cinzupacfen, und fobald jener folliefe, unbedautert fortzugefent. "Sge Da, rief er, fyer ifrr Reute, unb was es nod) fonft für Spibsuben gibt, helft wacfen, Beftien, und foleppen! (5reift mefyr zut, ifyr selfers= fyelfer! Soll idh Denu nidgt heute um 3 uhr nady Der Spibz= bubeninjel, und unten fteft fidon mein \$ferb gejattelt, wie?" Dabet $z \circ g$ er fich an. WBalt begleitete feine blinden Edyritte bewadyent. „A̛llerbings, Jreund, taugen bie Menjchen unt Die (5urfen niduts, jobalo fie reif find Das ift ia mein eigner

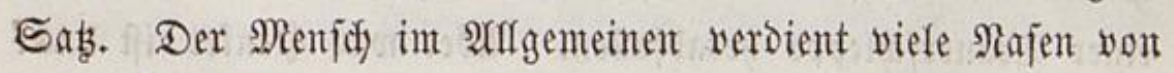
Sean yaul's auş getw. 2 certe. XIV. 


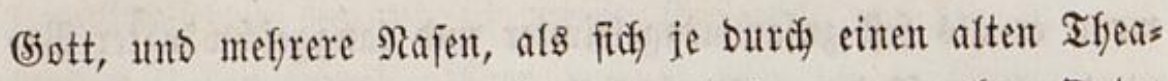
tervorfang gefteft fyaben, Den man Dafer an mandjen Drtent in $\mathfrak{B}$ led einfapte. Die (5rinto find freilidy nidyt jebem ges läufitg."

Sebst ging er in peinen 3immerveridslag und pacte, blint= zelno und fich oft yon $\mathfrak{B a l t}$ abfefrend, fein Tagebudi und

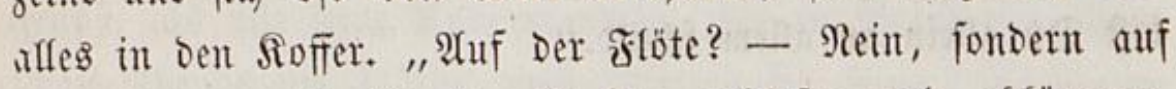
Dem Ramm will idg ifn fünftig anblajen und abfämmen. Sagen Sic mir nidyts von Riebe, 5. Reijemarjodyall, fie ift zu Dumm, eine hübjợe Antife, Die man Den ganzen Tag ergänzen mun - ein Sommentempel in 5ojentajuenformat - und Das Dumme Ding glaubt, cs rebe. Id) bab' es von ifs felfer. Der Menjáf fülyrt jogar (5ott yor einen $\mathfrak{B}$ ergröberungsjpiegel, fo unerjättfich und fo einfältig ift er - Stecht mich in Sutpfer, wie einen brittijden Rampfhafn, idf will eben ein $\mathfrak{M}_{0}=$

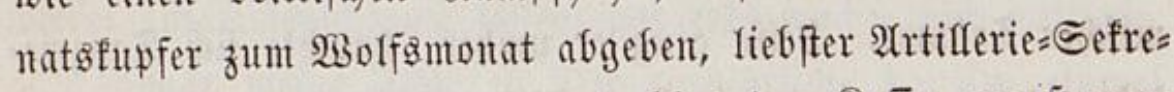

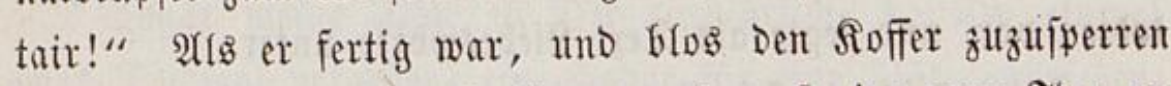
brauthte, fojien er nadjzufinten und auf eine neue Soee zut

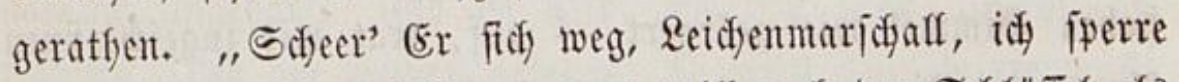
meinen Sarg fidyon jelfer zu, und will aud Den Sdytuffel als

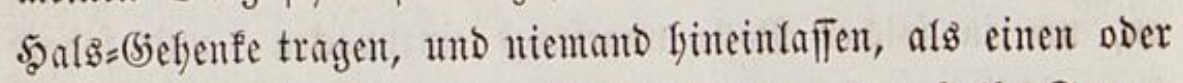
Den ambern guten Freund. Was die gautze und fralfe Trauter um mich antangt, fo foll fie niemanto aulegen, als ich. Nufiff wird als requiem wäfrent der Trauerzeit am wenigften ver= boten, aber idy beftefye auf eitem idfarfen Trauer = Reglemtent.

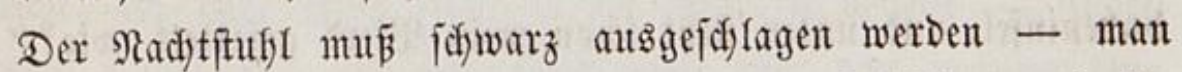
laple Das Rammergejofirr wie Den Degen ftahlblau anlaufen - jede Paus in meinent 5 ans foll in Sirepy gefen - meine Bapiflotten fömen Trauterifjeppen feyn, und ber 3 opf in

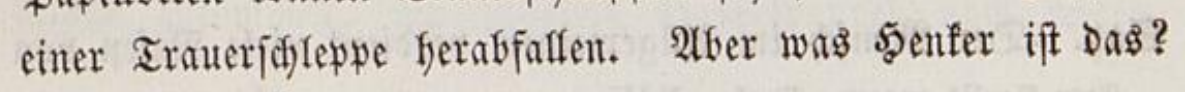


Dort feff' id ja leibfaftig, und eridheine mir cigenthändig. Saarte, wir wollen gleidy finden, wer von uns feiben wafren Du's Der wafre uno haltbarfte iff."

5̧ier veriebste er fidf uno Dem Notar zugleich einen bers bent Salag und erwadite Davon; erft, nadjoem er wie ver= Dubst fid von $\mathfrak{B a l t e n}$ lange auseinanderiekgen lafien, wo uno was er fei, wurbe er Dafin gefradyt, fich angefleibet aufs bett fut merfen. Indem beide einander eine Beit lang bewadjten, fielen beide in einen mafren Edylaf.

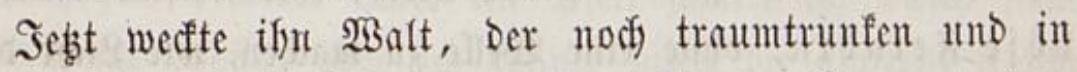
Geraujofter Bergeflenfyeit Der vorigen $S_{z}$ enen ifju ans Dem Bette folgenden Traum auforang:

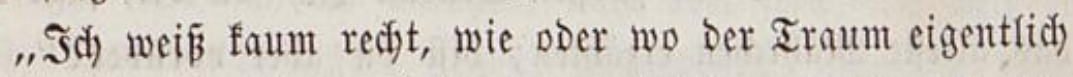

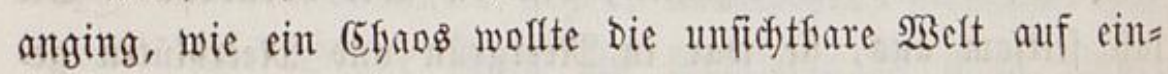
mal alles gebären, eine bieftalt feimte auf Der andern, alts

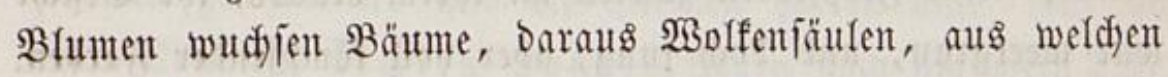
oben (sefichter und Blument bradjen. Daun fah idf ein wei= tes leeres Neer, auf ifm fofmamm blos Das fleine graue flefige $\mathfrak{B e l t}_{\mathrm{E}} \mathrm{E} i$, und zucte ftarf. alles genaunt, idf weí aber nidft von wem. Daun fuffe ein

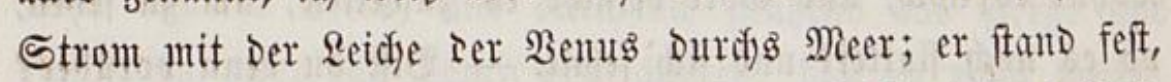
Das Meer fló wieder an ifm fin. Darauf fidnetete es Gelle Sterne finein, Der simmel wurbe leer, aber an Der Nittags= ftelfe Der Sonne entglomm eine Morgenröthe; Das Meer föfilte fich unter iffr aus, und thürmte in ungefyeuren bleienten

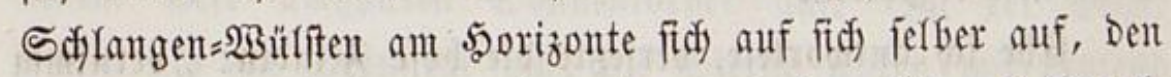

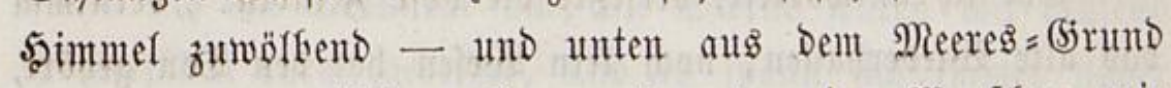
ftiegen aus unzälyligen Bergwerfen traurige Menjojen wie Tobte auf, und wurben geforent. (Eine biffe (5rutben= Nacht quoll iffnen nady. Afber ein Sturm foflug fidy auf Den Dampf, 
und zerquetiofte ifn zu einem Meer. (Sewaltig fuffr er auf

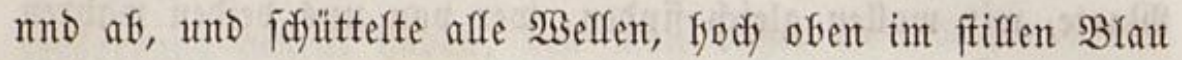
flog langjam eine goldene Biente leije fingend einem Stendyent zu, uno jog an Deflent weipen Blüten, uno rund un Den $50=$ rizont ftanden Thürme beiter mit leudjtenden Bemitterjpiben, fis wieber ungeheure 230 offen als reípende Thjere geftaltet ans fament unto am şimmel fraß̧et.

Da förte id einen Seufzer, alfes war veridjumben. Sä faf) nidyts als ein glattes ftifles Neer, aus biejem brady bie böfe feindin, ofne eine $\mathfrak{B e f l}_{\mathrm{f}}$ zu madyen, wie Ridht Durdy

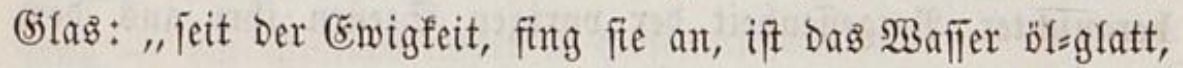
Das bedeutet efien Den grofen Sturm. Saj foll Dir, jagt man, Das ältefte Mäffrdyen erzäflen; bift bu aber vorüber?" Sie faf) feltjam aus, fie war in Neergrün und Neerblüten ges

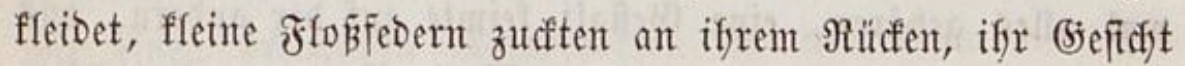
war meergrau, uno bod jung, aber yoll fämpfenter Farben. (Elye ich) antwortete, fubr bie böje Jeindin fort - „es war cinmal ein emiges Mäfrchen, alt, graut, taub, blind, und bas

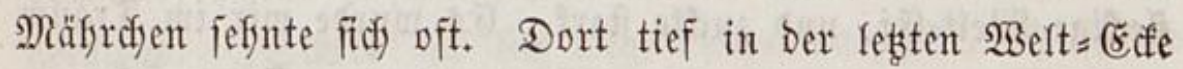
woljnt es nodj, und bott bejudyt es zumeifen, um zut jefjen, ob es nodi) flattert und fich lefjnt. -- Bift Du benu vorüber? So fidaue bie Ifiere am Hfer an!" - $\mathfrak{A}$ glatten Meere binauf lag ş volf reipenter Iffere, weldhe folliefen, aber im Schlafe fprachen, und einander einen uralten secißjgutger uno Bhutourf́t erzägltent.

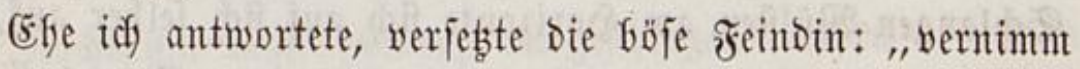
DaB alte Wieberfyallen; nodh fein $\mathfrak{W e j e n}_{\text {hat }}$ Den Ton gefört, Den es nadjpridft. WBenn aber einft Der 2 Bieberfall auffört, fo ift Die 3eit vorbet und bie Erwigfeit fommt zurücf, unto bringt bent Ion; fobald alfes jefre fitll ift, fo werb idy bie 
Drei Stummen fyören, ja Den Mrftummen, Der Das ältefte Mäbrctyen fich felber erzäblt; aber er ift, was er fich fagt. 5ölle, Dut eridfricfit wie ein Sterblicfer, bifit du benn nidjt vorüber, Ilyor?"

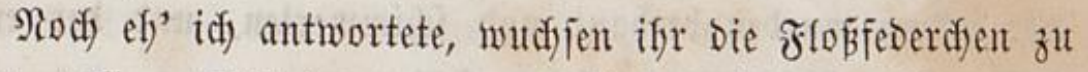
Yoben zadigen Edfwingen aus, womit fie mid) unverbient uno grimmig foflug; Da veridjwand afles, nur Das fojöne Tönen

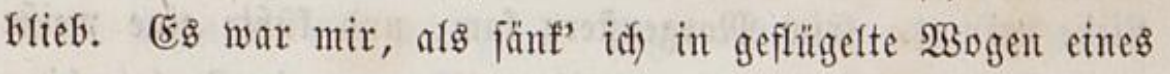
wolfentrofen Meeres. Wie ein $\mathfrak{B f e i l}$ fodnitt idj Durdy feine weltenfange $\mathfrak{B u ̈ f f f e}_{\text {; }}$ aber idy fonnte Durdf Die gläjerne Flädje

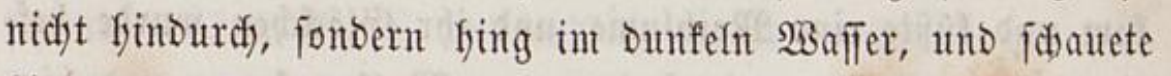

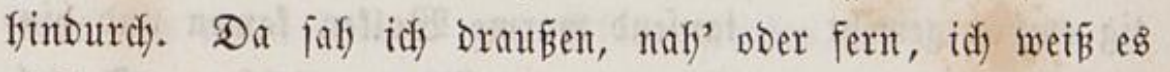
nidft, Das redite $\mathfrak{L}$ and fiegen, ausgedefynt, glänzento = bäm= merno. Die Sonne forient als Ephemere in ifrent eignen Stralen zu fpielen, uro Die Stralent fyörten auf. Nur Die leifen Tüne des redften 2 andes flogen nodj um mein Drr.

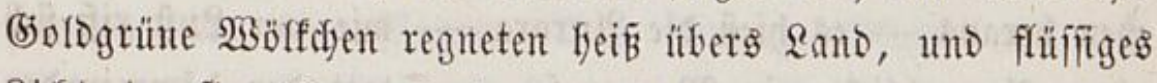
Sidyt tropfte überquellent aus Rofen = uno silien= Relchen. Ein Stral aus einem Thautropfent fofnitt herüber Durdh mein Dufferes Neer, und Durdjftady glüfend bas 5aerz, und

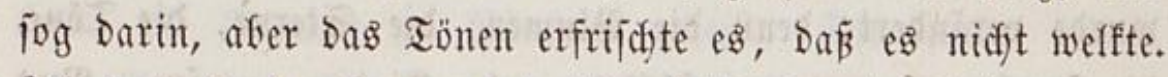
Sch fagte laut: es regnet Drüfen beipe Frententfränen; mur Die Riebe ift eine warme Ifräne, Der $\mathfrak{g a n}$ eine falte. - Tief

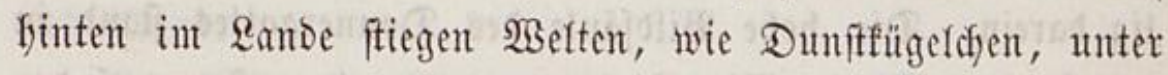
einem weit umfüflten Somnenförwer auf. Sit Der" Mitte Drefyte fid ein Spinnrad um, Die Sterne waren mit taujend Silberfäben baran gereifget, uno es pwant fid immer näber und enger vom foimmel hernieder. - $\mathfrak{A}$ einer Rilie fing ein Bienenfodwarm. (Ëine Roje jpielte mit einer Biente, beibe necften fidh mit ifren Stadgefn unb ifrem 5̧onig. Ëine 


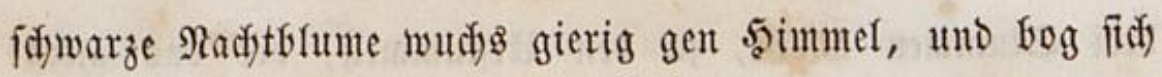
inmer heftiger hiber, je heller es wurbe; eine Spime lief

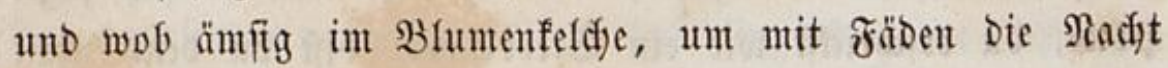

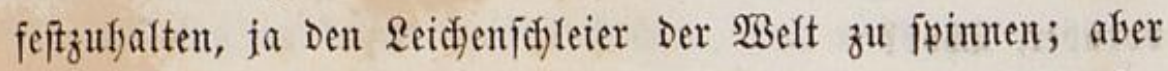
alle Fäbent wurben betfaut und fojimmerten, unto Der ewige

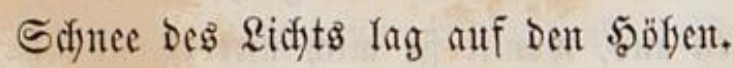

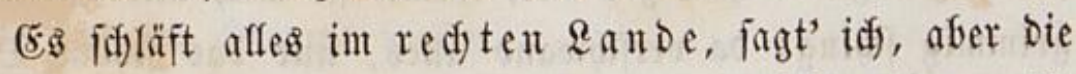

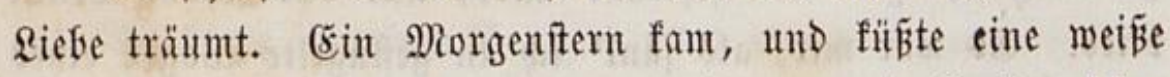
Rojenffospe, und blülyte mit iffr weiter - ein Bepfynr fing fich) fǖilento an einen (Eid)engipfel - einer Der leiféften Töne

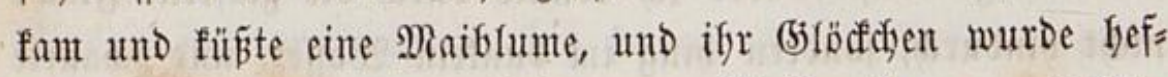
tig empor gewelyt - taujent warme $2 B o l f e n$ fament uno bins gent fid) briunftig an şimmel und (Erbe zugleid) - Turtels tauben wiegten fid Dufttunfen auf Radbtviolen, uno warfen girrento fich Die Rüife auf $\mathfrak{B l u m e n b l a ̈ t t e r n ~ z u t . ~}$

Auf cinmal quoll am 5ुimmel ein fidjarfbliz̧entes Stern=

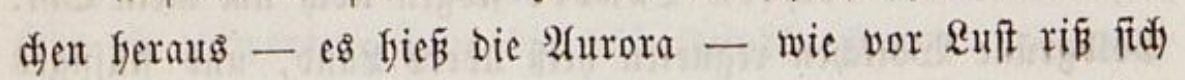
cinen Aُugenbliaf mein Meer auf. - Statt Der Dämmernden

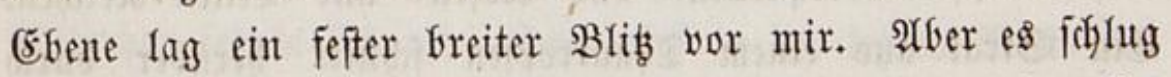
fiif) wieber zu, Das verdämmerte Land erwadite, und alfes wuroe verändert; Denn Die Blumen, Die Sterne, Die Töne, bie Tauben waren mur fidlummende Sinder gemejen. Nun unarmte jedes Rind ein Sinto, und Die $\mathfrak{A}$ urora flang unzäf)= lig Darein. Die hofe Bilojäule Dç Donnergottes fanto in Der $\mathfrak{L} a n d e s=$ Mitte. ( Stein=24rm, uno febste einen Sofjutterfing auf Den lebendigen ADJer, Der Den (5ott umfreijet. Dant flatterte Då̊ Rind wie leidftiuntig auf bie nädjpte $\mathfrak{B o l f e}$, und jah herab madh jeinem

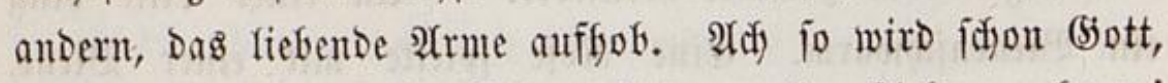
vor Dem wir ja affe Sinder fint, unjer Rieben nefmen! 
Darauf fpielten bie Rinber untereinanber "Riefents." "Sei meine rothe Tulpe," jagte Das eine, uno Das undere war fie, und Yieß fid an Die Bruft fecfent. "Sei mein liebes Sterndyent oben," und es war es und murbe - an die Bruft geftect. "Eei mein (jott" - "und Dit meiner," aber Dann verwandelten fidi) beibe nicht, fondern fahen fich lange an woll zut groper Riebe, unt verffyantent wie fterbend bafin. — "Bleibe bei mir, mein Rind, went Du von mir geffit," fagte Das bleibende; da wurde Das icheidente in Der Ferne ein fleines âtentoroth, Dam ein Abentiferndfen, Dam tiefer ins Land finein nur ein Mond = fojimmer ofne Nond, und endidy verlor es fid) ferner und ferner in einen fröten= ober $\mathfrak{B g}$ ilomelenton.

Aber Der Morgenröthe gegenüber ftand eine Morgen= röthe auf; immer fyerzerfebender raujdyten beide wie zwei (5yöre einander entgegen, mit Tönen ftatt garben, gleid)= fam als went unbefannte jelige $\mathfrak{B}_{\mathrm{B}}$ jen finter Der (Erbe ifre Frendentieder heraufingen. Die foywarze Blume mit Der Spime bog fich frampfifaft fis zum Sinifen nieber. 3 u einem Rilienfranze waren yom Rade bie Sterne vom simmet herabgefpomen, unt er mur fyelfelaut gemadyt. Der âfflantg Gatte Die Bhumen z̆ Bäumen gereift. Die Sinder waren

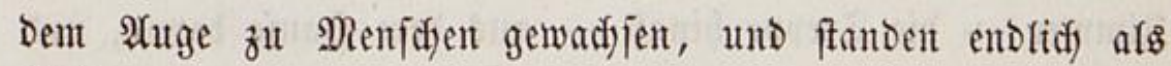
(5ötter und (5öttimten da, und fafen fefr ernft nady Morgen und Átent.

Die Sfyöre Der Morgentröthen fod hugen jekgt wie Donner einantoer entgegent, und jeder Soflag züntete einen gewaltigern an. 3wei Sonnen jollten aufifeigen, unter Dem Rlingen Des Morgents. Siefe, als fie fomment wollten, wurbe es Leijer,

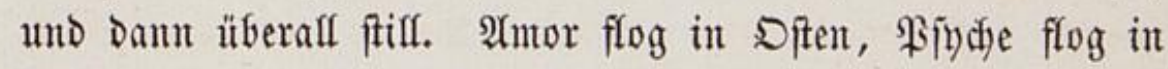
SBeften auf, und fie fanden fich oben mitten im simmel, und 
Die beiden Sonten gingen auf - es waren nur zwei leije Töne, zwei an einander ftertende und erwadjende; fie tönten biefleidyt: "Du und idf;" ziwei beifige, aber furdftbare faft aus Der tieffiten bruit uno Erwigfeit gezogne Raute, als fage fid) (5ott Dag erffe $230 r t$, uno antworte fid Das erife. Der Sterbliche Durfte fie nidft hören, ofme zu ferbent. Sod foflief in Den Sdjlaf finunter, Dody idjlaf = uno todestrunfen, war mir, als verfüfle uno vergifte midy Der Blumenouft eines yorbeifliegenden ßaradiefes - -

Da fand idj midy plöblidi am alten erften $\mathfrak{H}$ fer wieder, Die boje Feindin ftand wieder im $93 a$ afer; aber fie zitterte wie vor froft, uno zeigte ängitlid auf Ins glatte Neer finter ifr, mit Den $\mathfrak{B}$ orten: "Die Enigfeit ift yorbei, Der Sturm fommt, Dent Dab Meer wird geregt." Sd fah bin,

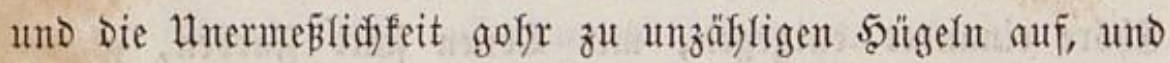
zum fimmelfofen Sturme; Dodf tief im Soorizont wallete finter Den Bacfen ein janftes Morgenfidst empor. Afer id erwacfte; - was jagft Du, Bruder, zu biejem fümftid $=$ fügenden Traume?"

"Du follft es jogleidy fören in Dein Bett finein," ver= jebte Bult, nafm Die Flöte, und ging, fie blajent, ans Dem 3immer - bie Treppe finab - aus Dem 5auje Davon, uno

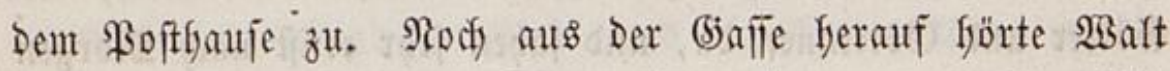
entzüuft bie entfliefyenden Töne reden, Denn er merfte nicht,

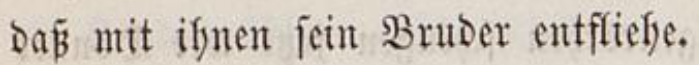




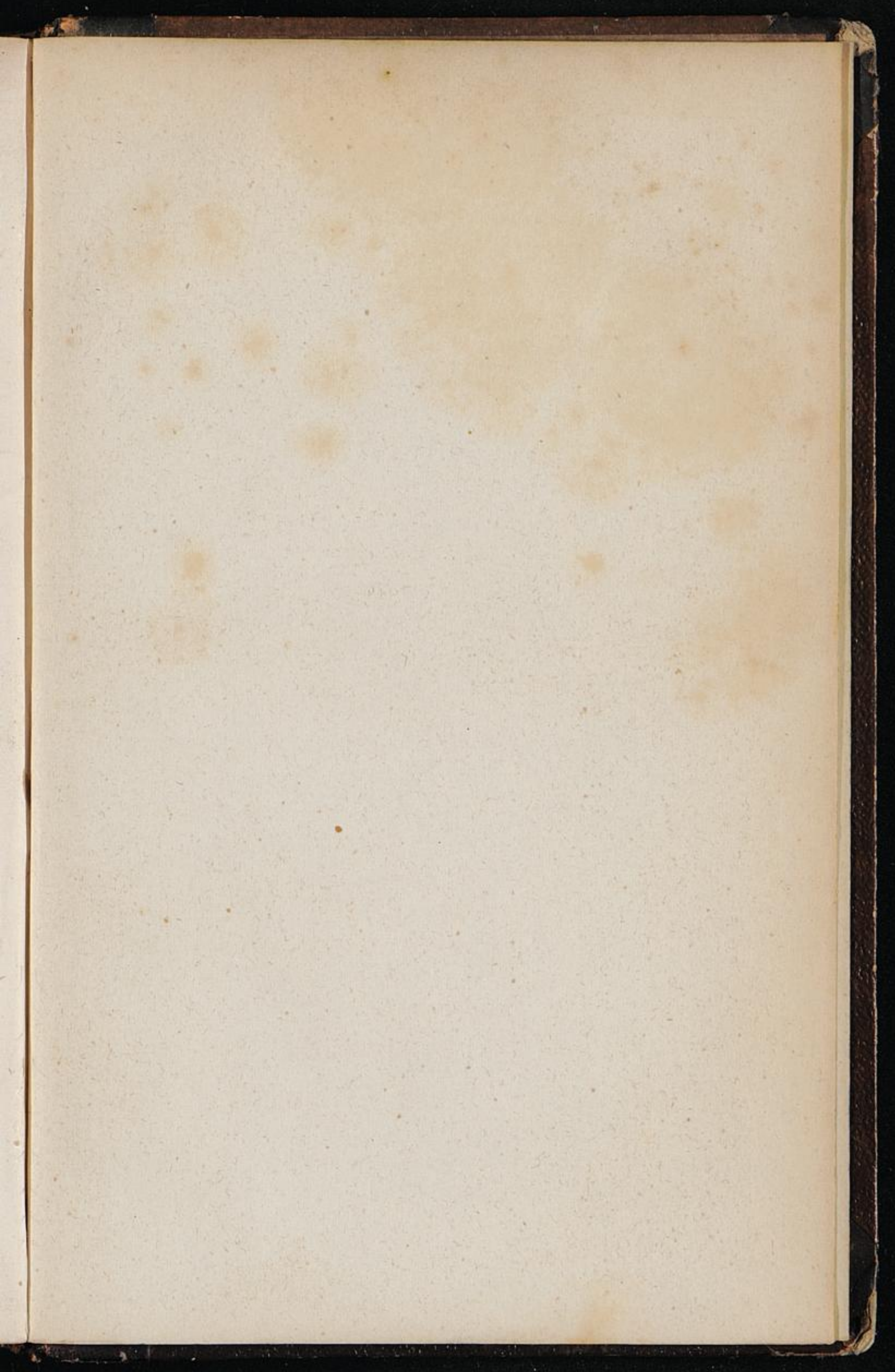




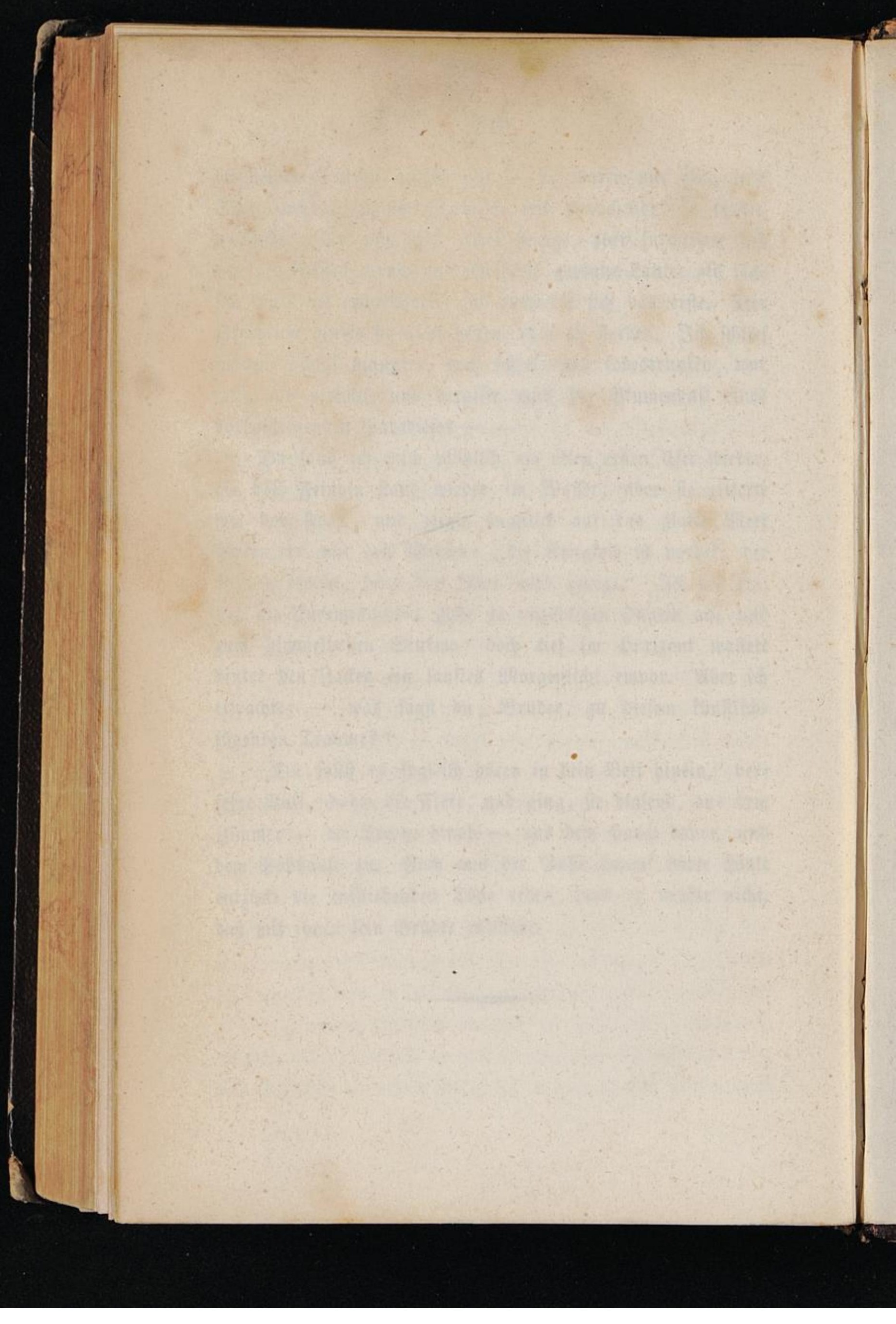




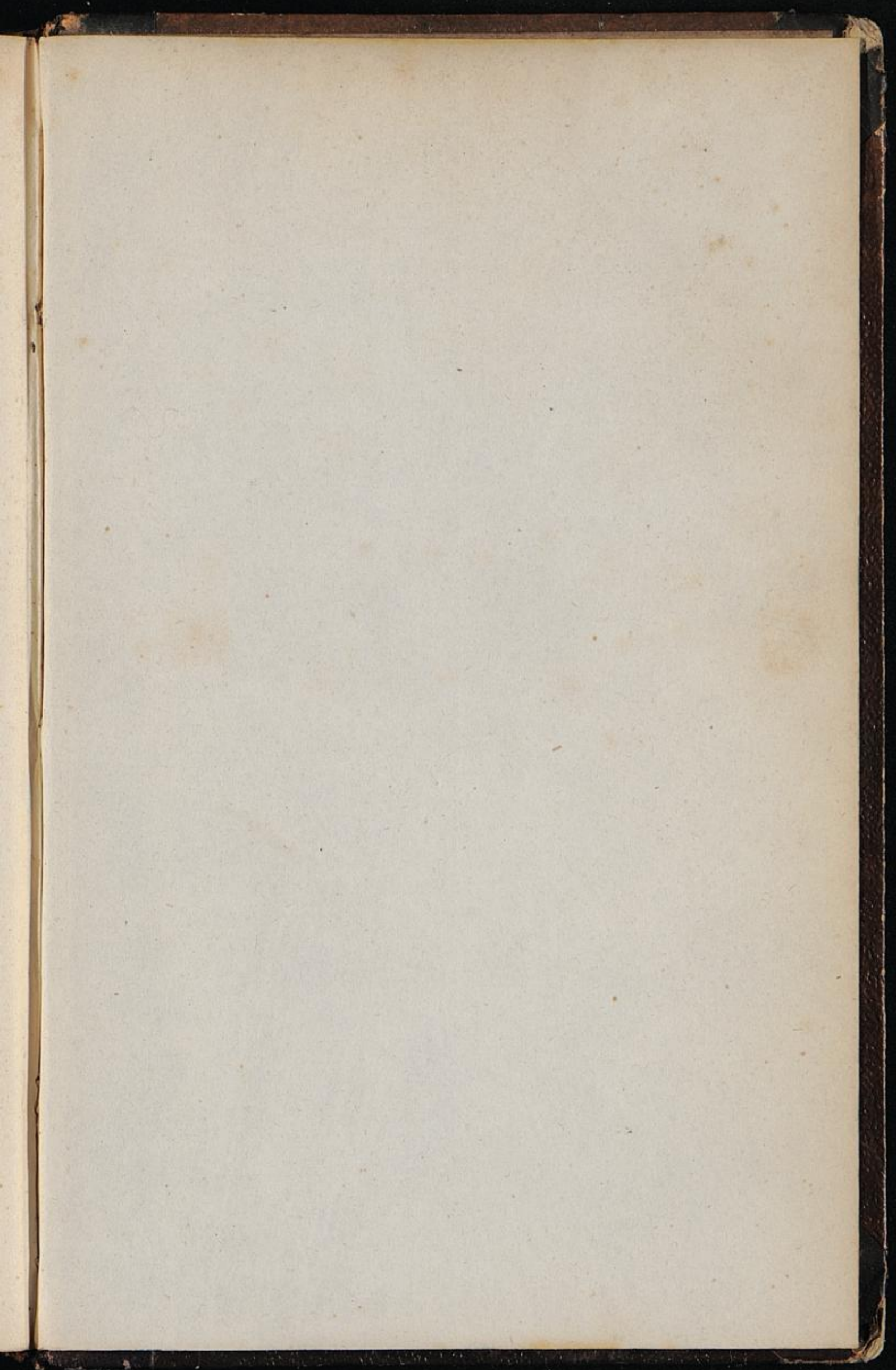




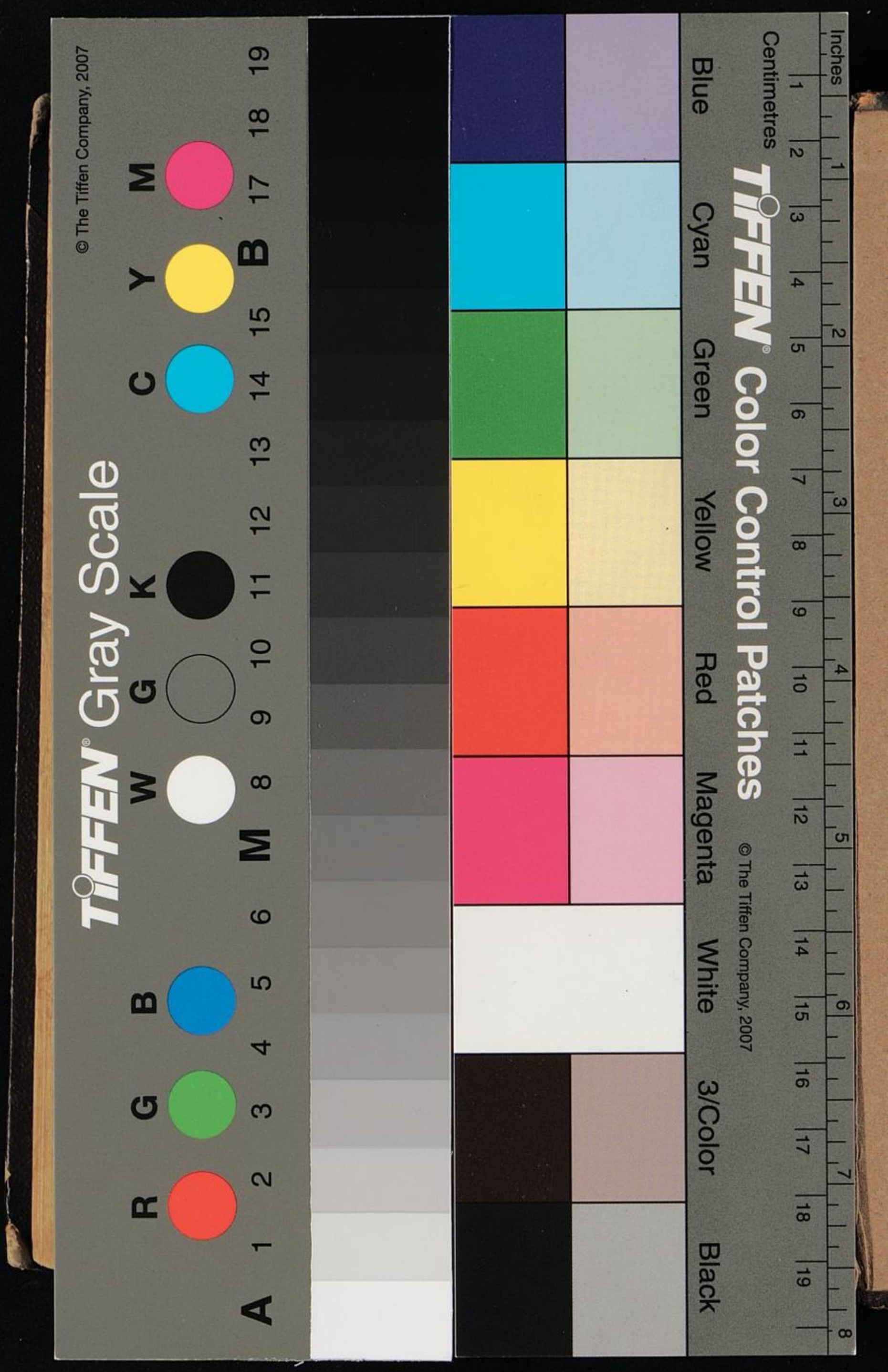




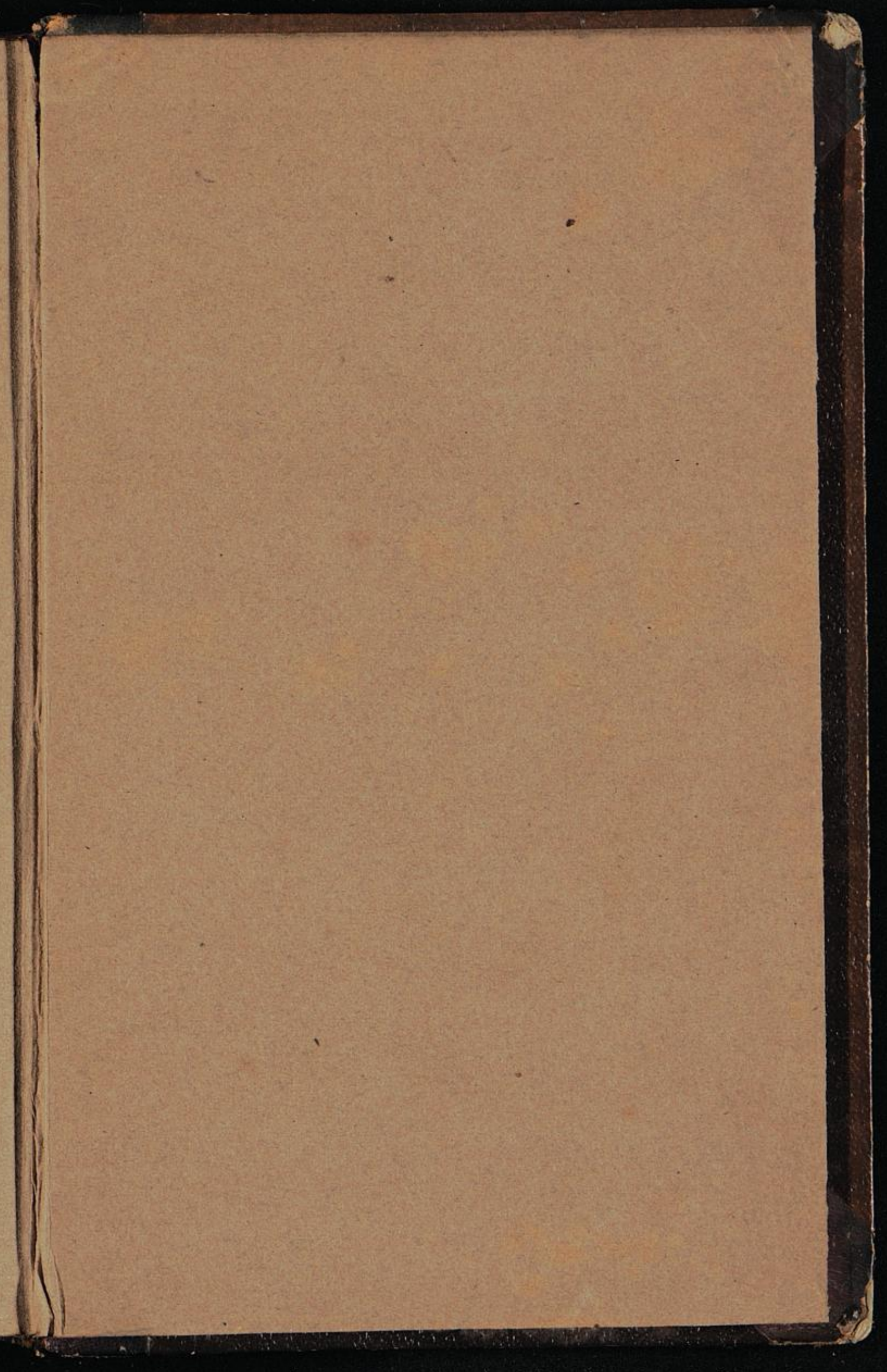




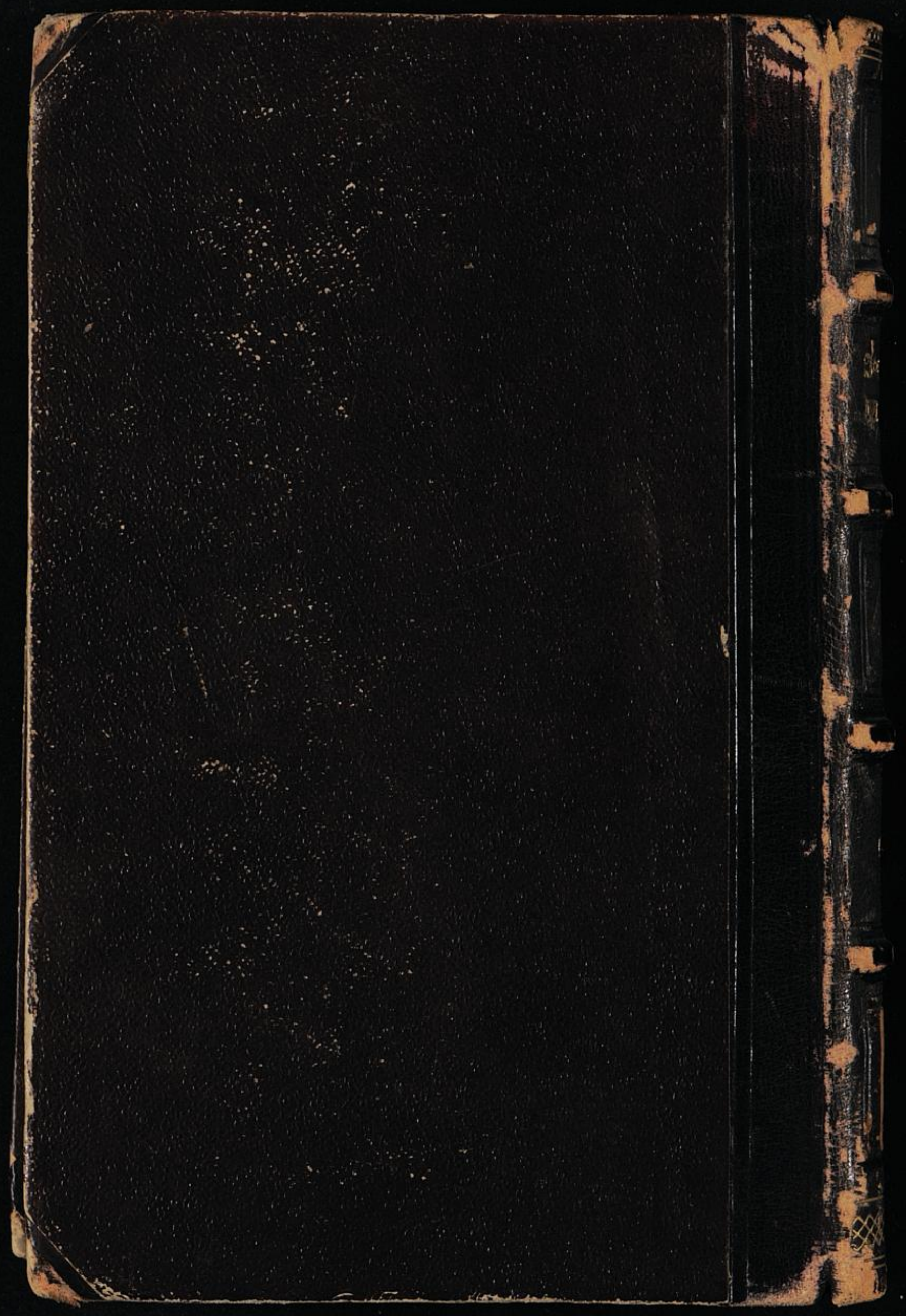

